\title{
SECURITIES AND EXCHANGE COMMISSION
}

\section{CFR PARTS 200, 201, 230, 240, 242, 249, and 270}

[Release No. 34-51808; File No. S7-10-04]

RIN 3235-AJ18

\section{REGULATION NMS}

AGENCY: Securities and Exchange Commission.

ACTION: $\quad$ Final rules and amendments to joint industry plans.

SUMMARY: The Securities and Exchange Commission (“Commission”) is adopting rules under Regulation NMS and two amendments to the joint industry plans for disseminating market information. In addition to redesignating the national market system rules previously adopted under Section 11A of the Securities Exchange Act of 1934 (“Exchange Act”), Regulation NMS includes new substantive rules that are designed to modernize and strengthen the regulatory structure of the U.S. equity markets. First, the "Order Protection Rule" requires trading centers to establish, maintain, and enforce written policies and procedures reasonably designed to prevent the execution of trades at prices inferior to protected quotations displayed by other trading centers, subject to an applicable exception. To be protected, a quotation must be immediately and automatically accessible. Second, the "Access Rule" requires fair and nondiscriminatory access to quotations, establishes a limit on access fees to harmonize the pricing of quotations across different trading centers, and requires each national securities exchange and national securities association to adopt, maintain, and enforce written rules that prohibit their members from engaging in a pattern or practice of displaying quotations that lock or cross automated quotations. Third, the "Sub-Penny Rule" prohibits market participants from accepting, ranking, or displaying orders, quotations, or indications of interest in a pricing 
increment smaller than a penny, except for orders, quotations, or indications of interest that are priced at less than $\$ 1.00$ per share. Finally, the Commission is adopting amendments to the "Market Data Rules" that update the requirements for consolidating, distributing, and displaying market information, as well as amendments to the joint industry plans for disseminating market information that modify the formulas for allocating plan revenues ("Allocation Amendment") and broaden participation in plan governance ("Governance Amendment").

DATES: $\quad$ Effective Date: August 29, 2005.

Compliance Dates: For specific phase-in dates for compliance with the final rules and amendments, see section VII of this release.

FOR FURTHER INFORMATION CONTACT: Order Protection Rule: Heather Seidel, Senior Special Counsel, at (202) 551-5608, Marc F. McKayle, Special Counsel, at (202) 5515633, David Hsu, Special Counsel, at (202) 551-5664, or Raymond Lombardo, Attorney, at (202) 551-5615; Access Rule: Heather Seidel, Senior Special Counsel, at (202) 551-5608, or David Liu, Attorney, at (202) 551-5645; Sub-Penny Rule: Michael Gaw, Senior Special Counsel, at (202) 551-5602; Market Data Rules, Allocation Amendment, and Governance Amendment: David Hsu, Special Counsel, at (202) 551-5664; Regulation NMS: Yvonne Fraticelli, Special Counsel, at (202) 551-5654; all of whom are in the Division of Market Regulation, Securities and Exchange Commission, 100 F Street, NE, Washington, DC 205496628.

\section{SUPPLEMENTARY INFORMATION:}

\section{Table of Contents}

I. Introduction

A. Summary of Rulemaking Process and Record

B. NMS Principles and Objectives

1. Competition Among Markets and Competition Among Orders 
2. Serving the Interests of Long-Term Investors and Listed Companies

C. Overview of Adopted Rules

1. Order Protection Rule

2. Access Rule

3. Sub-Penny Rule

4. Market Data Rules and Plans

II. Order Protection Rule

A. Response to Comments and Basis for Adopted Rule

1. Need for Intermarket Order Protection Rule

2. Limiting Protection to Automated and Accessible Quotations

3. Workable Implementation of Intermarket Trade-Through Protection

4. Elimination of Proposed Opt-Out Exception

5. Scope of Protected Quotations

6. Benefits and Implementation Costs of the Order Protection Rule

B. Description of Adopted Rule

1. Scope of Rule

2. Requirement of Reasonable Policies and Procedures

3. Exceptions

4. Duty of Best Execution

III. Access Rule

A. Response to Comments and Basis for Adopted Rule

1. Means of Access to Quotations

2. Limitation on Access Fees

3. Locking or Crossing Quotations

B. Description of Adopted Rule

1. Access to Quotations

2. Limitation on Access Fees

3. Locking or Crossing Quotations

4. Regulation ATS Fair Access

IV. Sub-Penny Rule

A. Background

B. Commission Proposal and Reproposal on Sub-Penny Quoting

C. Comments Received

1. Restriction Based on Price of the Quotation Not Price of the Stock

2. Quotations Below $\$ 1.00$

3. Revisiting the Penny Increment

4. Sub-Penny Trading

5. Acceptance of Sub-Penny Quotations

6. Application to Options Markets

7. One-to-One Negotiating Systems

8. Implementation of Rule 612 
V. Market Data Rules and Plan Amendments

A. Response to Comments and Basis for Adopted Rules

1. Alternative Data Dissemination Models

2. Level of Fees and Plan Governance

3. Revenue Allocation Formula

4. Distribution and Display of Data

B. Description of Adopted Rules and Amendments

1. Allocation Amendment

2. Governance Amendment

3. Consolidation, Distribution, and Display of Data

VI. Regulation NMS

A. Description of Regulation NMS

B. Rule 600 - NMS Security Designation and Definitions

1. NMS Security Designation - Transaction Reporting Requirements for

Equities and Listed Options

2. $\quad$ NMS Security and NMS Stock

3. Changes to Existing Definitions in the NMS Rules

4. Definitions in the Regulation NMS Rules Adopted Today

C. Changes to Other Rules

VII. Effective Date and Phased-In Compliance Dates

VIII. Paperwork Reduction Act

IX. Consideration of Costs and Benefits

X. Consideration of Burden on Competition, and Promotion of Efficiency, Competition and Capital Formation

XI. Regulatory Flexibility Act

XII. Response to Dissent

XIII. Statutory Authority

XIV. Text of Adopted Amendments to the CTA Plan, the CQ Plan, and the Nasdaq UTP Plan

XV. Text of Adopted Rules 


\section{Introduction}

The Commission is adopting Regulation NMS, a series of initiatives designed to modernize and strengthen the national market system ("NMS") for equity securities. ${ }^{1}$ These initiatives include:

(1) a new Order Protection Rule, ${ }^{2}$ which reinforces the fundamental principle of obtaining the best price for investors when such price is represented by automated quotations that are immediately accessible;

(2) a new Access Rule, which promotes fair and non-discriminatory access to quotations displayed by NMS trading centers through a private linkage approach;

(3) a new Sub-Penny Rule, which establishes a uniform quoting increment of no less than one penny for quotations in NMS stocks equal to or greater than $\$ 1.00$ per share to promote greater price transparency and consistency;

$1 \quad$ The Commission originally proposed Regulation NMS in February 2004. Securities Exchange Act Release No. 49325 (Feb. 26, 2004), 69 FR 11126 (Mar. 9, 2004) ("Proposing Release"). It issued a supplemental request for comment in May 2004. Securities Exchange Act Release No. 49749 (May 20, 2004), 69 FR 30142 (May 26, 2004) ("Supplemental Release"). On December 16, 2004, the Commission reproposed Regulation NMS in its entirety for public comment. Securities Exchange Act Release No. 50870 (Dec. 16, 2004), 69 FR 77424 (Dec. 27, 2004) ("Reproposing Release").

2 Although the Reproposing Release referred to Rule 611 as the "Trade-Through Rule," the reproposed Rule itself was named "Order Protection Rule." The term "Trade-Through Rule" was used in the Reproposing Release to avoid confusion, given that the term had been widely used in public debate. The term "Order Protection Rule," however, better captures the nature of the adopted Rule. For example, the term helps distinguish the existing trade-through provisions for exchange-listed stocks, which do not really protect orders. Limit order users want a fast, efficient execution of their orders, not a slow, costly "satisfaction" process that is provided by the existing trade-through provisions. See infra, note 30 and accompanying text. 
(4) amendments to the Market Data Rules and joint industry plans that allocate plan revenues to self-regulatory organizations ("SROs") for their contributions to public price discovery and promote wider and more efficient distribution of market data; and

(5) a reorganization of existing Exchange Act rules governing the NMS to promote greater clarity and understanding of the rules.

The Commission is adopting Regulation NMS in furtherance of its statutory responsibilities. In 1975, Congress directed the Commission, through enactment of Section 11A of the Exchange Act, to facilitate the establishment of a national market system to link together the multiple individual markets that trade securities. Congress intended the Commission to take advantage of opportunities created by new data processing and communications technologies to preserve and strengthen the securities markets. By incorporating such technologies, the NMS is designed to achieve the objectives of efficient, competitive, fair, and orderly markets that are in the public interest and protect investors. For three decades, the Commission has adhered to these guiding objectives in its regulation of the NMS, which are essential to meeting the investment needs of the public and reducing the cost of capital for listed companies. Over this period, the Commission has continued to revise and refine its NMS rules in light of changing market conditions.

Today, the NMS encompasses the stocks of more than 5000 listed companies, which collectively represent more than \$14 trillion in U.S. market capitalization. Consistent with Congressional intent, these stocks are traded simultaneously at a variety of different venues that participate in the NMS, including national securities exchanges, alternative trading systems ("ATSs"), and market-making securities dealers. The Commission believes that the NMS approach adopted by Congress is a primary reason that the U.S. equity markets are widely 
recognized as being the fairest, most efficient, and most competitive in the world. The rules that the Commission is now adopting represent an important and needed step forward in its continuing implementation of Congress's objectives for the NMS. By modernizing and strengthening the nation's regulatory structure, the rules are designed to assure that the equity markets will continue to serve the interests of investors, listed companies, and the public for years to come.

In recent years, the equity markets have experienced sweeping changes, ranging from new technologies to new types of markets to the initiation of trading in penny increments. The pressing need for NMS modernization to reflect these changes is inescapable. Thus, for the last five years, the Commission has undertaken a broad and systematic review to determine how best to keep the NMS up-to-date. This review has required the Commission to grapple with many difficult and contentious issues that have lingered unresolved for many years. We have devoted a great deal of effort to studying these issues, listening to the views of the public, and have carefully considered the comments contained in the record to craft rule proposals that would achieve the statutory objectives for the NMS.

Given the wide range of perspectives on market structure issues, it is perhaps inevitable that there would be differences of opinion on the Commission's policy choices. The time has arrived, however, when decisions must be made and contentious issues must be resolved so that the markets can move forward with certainty concerning their future regulatory environment and appropriately respond to fundamental economic and competitive forces. The Commission always seeks to achieve consensus, but trying to achieve consensus should not impede the achievement of the statutory objectives for the NMS and should not damage the competitiveness of the U.S. equity markets, both at home and internationally. We believe that further delay is not 
warranted and therefore have adopted final rules needed to modernize and strengthen the NMS.

The following discussion briefly summarizes the deliberate and open rulemaking process that the Commission has undertaken and the extensive record that supports the adoption of Regulation NMS, including the many empirical studies undertaken by the Commission staff.

\section{A. Summary of Rulemaking Process and Record}

The Commission has engaged in a thorough, deliberate, and open rulemaking process that has provided at every point an opportunity for public participation and debate. We have actively sought out the views of the public and securities industry participants. Even prior to formulating proposals, our review included multiple public hearings and roundtables, an advisory committee, three concept releases, the issuance of temporary exemptions intended in part to generate useful data on policy alternatives, and a constant dialogue with industry participants and investors. This process continued after the proposals were published for public comment. ${ }^{3}$ We held a public hearing on the proposals in April 2004 ("NMS Hearing") that included more than 30 panelists representing investors, individual markets, and market participants from a variety of different sectors of the securities industry. ${ }^{4}$ Because we believed that there were a number of important developments at the public hearing, we published a supplemental request for comment and extended the comment period on the proposals in May 2004 to give the public a full opportunity to respond to these developments. ${ }^{5}$ We then carefully considered the more than 700 comment letters submitted by the public, which encompassed a wide range of views.

3 Proposing Release, 69 FR at 11126.

$4 \quad$ A list of all panelists and full transcript of the NMS Hearing ("Hearing Tr."), as well as an archived video and audio webcast, are available on the Commission's Internet Web site (http://www.sec.gov).

$5 \quad$ Supplemental Release, 69 FR at 30142. 
The insights of the commenters, as well as those of the NMS Hearing panelists, contributed to significant refinements of the original proposals. In addition, the Commission staff prepared several studies of relevant trading data to help evaluate and respond to the views of commenters. Consequently, rather than immediately adopting rules, the Commission reproposed Regulation NMS in its entirety in December 2004 to afford the public an additional opportunity to review and comment on the details of the rules and on the staff studies. The Commission then received, and carefully considered, more than 1500 additional comments on the reproposal. ${ }^{6}$

This extensive rulemaking process has generated an equally extensive record, which is discussed at length throughout this release as it relates to each of the four substantive rulemaking initiatives. Indeed, substantial parts of the release are devoted to responding to the many public comments (particularly those opposing the proposals) and to discussing the estimated costs and benefits of the rules. This rulemaking raised difficult policy issues on which commenters submitted differing views. To move forward, the Commission necessarily has had to make policy decisions that not everyone will agree with.

The fact that each of the adopted rules provoked conflicting views from commenters should not, however, obscure the very substantial evidence in the record strongly supporting each of the four substantive rulemaking initiatives in Regulation NMS. Clearly, the Order Protection Rule was most controversial and attracted the most public comment and attention, yet

$6 \quad$ The Reproposing Release stated that the Commission would continue to consider all comments received on the Proposing Release and Supplemental Release, in addition to those on the Reproposing Release, in evaluating further rulemaking action. 69 FR at 77426. Accordingly, this release discusses comments received in response to all three previous releases. Comments on the Proposing Release and Supplemental Release are referred to as "[name of commenter] Letter." Comments on the Reproposing Release are referred to as "[name of commenter] Reproposal Letter." 
the breadth of support in the record for the Rule is compelling. Indeed, support for an intermarket price protection rule begins with the adoption by Congress in 1975 of the national market system itself. Both the House and Senate committees responsible for drafting Section 11A specifically considered and endorsed the Commission's authority to adopt a price protection rule as a means to achieve the statutory objectives for the NMS. ${ }^{7}$

Consistent with the drafters' views, a broad spectrum of commenters supported adoption of the Order Protection Rule for all NMS stocks, including investors, listed companies, individual markets, market participants, and academics. ${ }^{8}$ Many individual and institutional investors particularly supported the Commission's view that significant problems exist that require the Commission to modernize its regulations. They also suggested the need for strengthened intermarket price protection to further their interests, as did major groups representing investors, such as the Investment Company Institute (whose mutual fund members manage assets of $\$ 7.8$ trillion that account for more than $95 \%$ of all U.S. mutual fund assets), the Committee on Investment of Employee Benefit Assets (which represents 110 of the nation's largest corporate retirement funds managing \$1.1 trillion on behalf of 15 million plan participants and beneficiaries), the National Association of Investors Corporation (whose membership consists of investment clubs and individual investors with aggregate personal investments of approximately $\$ 116$ billion), and the Consumer Federation of America.

Moreover, the commenters' views on the need for an intermarket price protection rule were supported by the various empirical studies of trading data performed by Commission staff. These studies found, among other things, that an estimated 1 out of 40 trades for both NYSE and

7 See infra, notes 920-922 and accompanying text.

8 See infra, notes 56-59, 939-941, 957-960, and accompanying text. 
Nasdaq stocks are executed at prices inferior to the best displayed quotations, or approximately 98,000 trades per day in Nasdaq stocks alone. ${ }^{9}$ While the Commission believes that the total number of trade-throughs should not be the sole consideration in making its policy choices, the staff studies and analyses demonstrate that trade-through rates are significant and indicate the need for strengthened order protection for all NMS stocks.

Why did a broad spectrum of commenters, many of which have extensive experience and expertise regarding the inner workings of the equity markets, support the Order Protection Rule and its emphasis on the principle of best price? They based their support on two fundamental rationales, with which the Commission fully agrees. First, strengthened assurance that orders will be filled at the best prices will give investors, particularly retail investors, greater confidence that they will be treated fairly when they participate in the equity markets. Maintaining investor confidence is an essential element of well-functioning equity markets. Second, protection of the best displayed and accessible prices will promote deep and stable markets that minimize investor transaction costs. More than 84 million individual Americans participate, directly or indirectly, in the U.S. equity markets. ${ }^{10}$ The transaction costs associated with the prices at which their orders are executed represent a continual drain on their long-term savings. Although these costs are difficult to calculate precisely, they are very real and very substantial, with estimates ranging from $\$ 30$ billion to more than $\$ 100$ billion per year. ${ }^{11}$ Minimizing these investor costs to the greatest extent possible is the hallmark of efficient markets, which is a primary objective of the NMS. The Order Protection Rule is needed to help achieve this objective, thereby improving the

$9 \quad$ See infra, notes 66-69, 104, and accompanying text.

10 See infra, notes 25-26 and accompanying text.

11 See infra, note 990. 
long-term financial well-being of millions of investors and reducing the cost of capital for listed companies.

In sum, the rules adopted today are the culmination of a long and comprehensive rulemaking process. Reaching appropriate policy decisions in an area as complex as market structure requires an understanding of the relevant facts and of the often subtle ways in which the markets work, as well as the balancing of policy objectives that sometimes may not point in precisely the same direction. Based on the extensive record that we have developed over the course of the rulemaking process, the Commission firmly believes that Regulation NMS will protect investors, promote fair competition, and enhance market efficiency, and therefore fulfills its Exchange Act responsibility to facilitate the development of the NMS.

\section{B. NMS Principles and Objectives}

\section{Competition Among Markets and Competition Among Orders}

The NMS is premised on promoting fair competition among individual markets, while at the same time assuring that all of these markets are linked together, through facilities and rules, in a unified system that promotes interaction among the orders of buyers and sellers in a particular NMS stock. The NMS thereby incorporates two distinct types of competition competition among individual markets and competition among individual orders - that together contribute to efficient markets. Vigorous competition among markets promotes more efficient and innovative trading services, while integrated competition among orders promotes more efficient pricing of individual stocks for all types of orders, large and small. Together, they produce markets that offer the greatest benefits for investors and listed companies.

Accordingly, the Commission's primary challenge in facilitating the establishment of an NMS has been to maintain an appropriate balance between these two vital forms of competition. 
It particularly has sought to avoid the extremes of: (1) isolated markets that trade an NMS stock without regard to trading in other markets and thereby fragment the competition among buyers and sellers in that stock; and (2) a totally centralized system that loses the benefits of vigorous competition and innovation among individual markets. Achieving this objective and striking the proper balance clearly can be a difficult task. Since Congress mandated the establishment of an NMS in 1975, the Commission frequently has resisted suggestions that it adopt an approach focusing on a single form of competition that, while perhaps easier to administer, would forfeit the distinct, but equally vital, benefits associated with both competition among markets and competition among orders.

With respect to competition among markets, for example, the record of the last thirty years should give pause to those who believe that any market structure regulation is inherently inconsistent with vigorous market competition. Other countries with significant equity trading typically have a single, overwhelmingly dominant public market. ${ }^{12}$ The U.S., in contrast, is fortunate to have equity markets that are characterized by extremely vigorous competition among a variety of different types of markets. These include: (1) traditional exchanges with active trading floors, which even now are evolving to expand the range of choices that they offer investors for both automated and manual trading; (2) purely electronic markets, which offer both standard limit orders and conditional orders that are designed to facilitate complex trading strategies; (3) market-making securities dealers, which offer both automated execution of smaller orders and the commitment of capital to facilitate the execution of larger, institutional orders; (4) regional exchanges, many of which have adopted automated systems for executing smaller

12 These markets include the London Stock Exchange in the United Kingdom, the Tokyo Stock Exchange in Japan, Euronext in France, and the Deutsche Bourse in Germany. 
orders; and (5) automated matching systems that permit investors, particularly large institutions, to seek counter-parties to their trades anonymously and with minimal price impact.

In sum, while NMS regulation may channel specific types of market competition (e.g., by mandating the display to investors of consolidated prices and including the prices displayed internally by significant electronic markets), it has been remarkably successful in promoting market competition in its broader forms that are most important to investors and listed companies.

The difficulty, however, is that competition among multiple markets trading the same stocks can detract from the most vigorous competition among orders in an individual stock, thereby impeding efficient price discovery for orders of all sizes. The importance of competition among orders has long been recognized. Indeed, when Congress mandated the establishment of an NMS, it well stated this basic principle: "Investors must be assured that they are participants in a system which maximizes the opportunities for the most willing seller to meet the most willing buyer."13 To the extent that competition among orders is lessened, the quality of price

$13 \quad$ H.R. Rep. 94-123, 94th Cong., 1st Sess. 50 (1975). The quotation from the text of the House Report concludes a cogent description of the importance of maintaining the proper balance between competition among markets and competition among orders that is worth quoting in full:

Critics of this development [multiple trading of stocks] suggest that the markets are becoming dangerously fragmented. Others contend that the dilution of large market dominance is the result of healthy competitive forces which have done much to add to the liquidity and depth of the securities markets to the benefit of the investing public. The Committee shares the opinion that our markets will be strengthened by the infusion of marketmaker competition in listed securities with the concomitant increase in capital availability and diminution of risk which results from increased competition among specialists and marketmakers. Nonetheless, market fragmentation becomes of increasing concern in the absence of mechanisms designed to assure that public investors are able to obtain the best price for securities regardless of the type or physical location of the market upon which his transaction may be executed. Investors must be 
discovery for all sizes of orders can be compromised. Impaired price discovery could cause

market prices to deviate from fundamental values, reduce market depth and liquidity, ${ }^{14}$ and

create excessive short-term volatility that is harmful to long-term investors and listed companies.

More broadly, when market prices do not reflect fundamental values, resources will be

misallocated within the economy and economic efficiency - as well as market efficiency - will

be impaired.

\section{Serving the Interests of Long-Term Investors and Listed Companies}

In its extended review of market structure issues and in assessing how best to achieve an appropriate balance between competition among markets and competition among orders, the Commission has been guided by a firm belief that one of the most important goals of the equity markets is to minimize the transaction costs of long-term investors and thereby to reduce the cost of capital for listed companies. These functions are inherently related because the cost of capital

assured that they are participants in a system which maximizes the opportunities for the most willing seller to meet the most willing buyer.

Id.

14 The Proposing Release and Reproposing Release frequently emphasized the importance of promoting greater depth and liquidity. Some commenters appeared to equate depth and liquidity with other factors, such as trading volume and frequency of quotation updates. See, e.g., Letter from Edward J. Nicoll, Chief Executive Officer, Instinet Group Incorporated, to Jonathan G. Katz, Secretary, Commission, dated Jan. 26, 2005 ("Instinet Reproposal Letter") at 9; Letter from Marc E. Lackritz, President, Securities Industry Association, to Jonathan G. Katz, Secretary, Commission, dated Feb. 1, 2005 ("SIA Reproposal Letter") at 12. The Commission, however, uses the terms specifically to refer to the ability of investors to trade in large size at low cost and in general to a market's capacity to absorb order imbalances with minimized price impact. Depth is measured in terms of the volume of stock that can be readily traded at a particular price point. Liquidity is measured by the price movement experienced by investors when attempting to trade in large size. See infra, section II.A.6 (estimate of transaction costs for equity mutual funds). Although depth and liquidity are correlated with trading volume, they are not synonymous. For example, one stock might have less trading volume than another stock, but still have greater depth available at and close to the best quoted prices and lower transaction costs for large institutional investors. 
of listed companies is influenced by the transaction costs of those who are willing to accept the risk of holding corporate equity for an extended period. ${ }^{15}$

The Reproposing Release touched on this issue in the specific context of assessing the effect of the Order Protection Rule on the interests of professional traders in conducting extremely short-term trading strategies that can depend on millisecond differences in order response time from markets. Noting that any protection against trade-throughs could interfere to some extent with such short-term trading strategies, the release framed the Commission's policy choice as follows: "Should the overall efficiency of the NMS defer to the needs of professional traders, many of whom rarely intend to hold a position overnight? Or should the NMS serve the needs of longer-term investors, both large and small, that will benefit substantially from intermarket price protection?"16 The Reproposing Release emphasized that the NMS must meet the needs of longer-term investors, noting that any other outcome would be contrary to the Exchange Act and its objectives of promoting fair and efficient markets that serve the public interest. ${ }^{17}$

In response, some commenters disputed this focus on the interests of long-term investors in formulating Regulation NMS, one even questioning the Commission's statutory authority to do so. ${ }^{18}$ Others commenters appeared to share this view, as evidenced by their downplaying, or

15 Investors are more willing to own a stock if it can be readily traded in the secondary market with low transaction costs. The greater the willingness of investors to own a stock, the higher its price will be, thereby reducing the issuer's cost of capital. Reproposing Release, 69 FR at 77440.

17 Id.

18 Letter from Phylis M. Esposito, Executive Vice President, Chief Strategy Officer, Ameritrade, Inc., to Jonathan G. Katz, Secretary, Commission, dated Jan. 26, 2005 ("Ameritrade Reproposal Letter") at 9 (among other issues, questioning Commission's statutory authority); Letter from James A. Duncan, Chairman, and John C. Giesea, 
failing entirely to address, indications of a need for improvements in market quality that are important to long-term investors, such as minimizing short-term price volatility. ${ }^{19}$

Most of the time, the interests of short-term traders and long-term investors will not conflict. Short-term traders clearly provide valuable liquidity to the market. But when the interests of long-term investors and short-term traders diverge, few issues are more fundamentally important in formulating public policy for the U.S. equity markets than the choice between these interests. While achieving the right balance of competition among markets and competition among orders will always be a difficult task, there will be no possibility of accomplishing it if in the case of a conflict the Commission cannot choose whether the U.S. equity markets should meet the needs of long-term investors or short-term traders.

The objective of minimizing short-term price volatility offers an important example where the interests of long-term investors can diverge from those of short-term traders. Deep and liquid markets that minimize volatility are of most benefit to long-term investors. Such markets help reduce transaction costs by furthering the ability of investors to establish and unwind positions in a stock at prices that are as close to previously prevailing prices as possible. Indeed, the 1975 Senate Report on the NMS emphasized that one of the "paramount" objectives

President and CEO, Security Traders Association, to Jonathan G. Katz, Secretary, Commission, dated Jan. 19, 2005 ("STA Reproposal Letter") at 6; Letter from William A. Vance, Stephen Kay, and Kimberly Unger, The Security Traders Association of New York, Inc., dated Jan. 24, 2005 ("STANY Reproposal Letter") at 8 n. 18. Commission's assertion that the reproposed trade-through rule would increase fill rates or reduce transitory volatility on the Nasdaq market (or, for that matter, whether these are in fact 'weaknesses' that need to be addressed."). Short-term price volatility for Nasdaq stocks is discussed further in section II.A.1.b below. 
for the NMS is "the maintenance of stable and orderly markets with maximum capacity for absorbing trading imbalances without undue price movements."20

Excessively volatile markets, in contrast, can generate many opportunities for traders to earn short-term profits from rapid price swings. Short-term traders, in particular, typically possess the systems capabilities and expertise necessary to enter and exit the market rapidly to exploit such price swings. Moreover, short-term traders have great flexibility in terms of their choice of stocks, choice of initially establishing a long or short position, and time of entering and exiting the market. Long-term investors (both institutional and retail), in contrast, typically have an opinion on the long-term prospects for a company. They therefore want to buy or sell a particular stock at a particular time. These investors thus are inherently less able to exploit shortterm price swings and, indeed, their buying or selling interest often can initiate short-term price movements. ${ }^{21}$ Efficient markets with maximum liquidity and depth minimize such price movements and thereby afford long-term investors an opportunity to achieve their trading objectives with the lowest possible transaction costs.

The Commission recognizes that it is important to avoid false dichotomies between the interests of short-term traders and long-term investors, and that many difficult line-drawing issues potentially can arise in precisely defining the difference between the two terms. For

$20 \quad$ S. Rep. No. 94-75, 94th Cong., 1st Sess. 7 (1975).

21 Long-term investors, of course, also can be interested in fast executions. One of the primary effects of the Order Protection Rule adopted today will be to promote much greater speed of execution in the market for exchange-listed stocks. The difference in speed between automated and manual markets often is the difference between a 1-second response and a 15-second response - a disparity that clearly can be important to many investors. 
present purposes, however, these issues can be handled by simply noting that it makes little sense to refer to someone as "investing" in a company for a few seconds, minutes, or hours. ${ }^{22}$

Short-term traders and market intermediaries unquestionably provide needed liquidity to the equity markets and are essential to the welfare of investors. Consequently, much, if not most, of the time the interests of long-term investors and short-term traders in market quality issues such as speed and operational efficiency will coincide. Indeed, implementation of Regulation NMS likely will lead to a significant expansion of automated trading in exchange-listed stocks that both benefits all investors and opens up greater potential for electronic trading in such stocks than currently exists. But when the interests of long-term investors and short-term traders conflict in this context, the Commission believes that its clear responsibility is to uphold the interests of long-term investors.

Indeed, the core concern for the welfare of long-term investors who depend on equity investments to meet their financial goals was first expressed in the foundation documents of the Exchange Act itself. In language that remains remarkably relevant today, the 1934 congressional reports noted how the national public interest of the equity markets had grown as more and more Americans had begun to place their savings in equity investments, both directly and indirectly through investment intermediaries. ${ }^{23}$ Given this development, the reports emphasized that "stock

22 The concept of ownership for a significant time period is inherent in the meaning of word "invest." A dictionary definition of "investor," for example, is "one that seeks to commit funds for long-term profit with a minimum of risk." Webster's Third New International Dictionary of the English Language 1190 (Unabridged 1993).

H.R. Rep. No. 1383, 73rd Cong., 2d Sess. 3-4 (1934) ("It is estimated that more than $10,000,000$ individual men and women in the United States are the direct possessors of stocks and bonds; that over one-fifth of all the corporate stock outstanding in the country is held by individuals with net incomes of less than $\$ 5,000$ a year. Over 15,000,000 individuals held insurance policies, the value of which is dependent on the security holdings of insurance companies. Over 13,000,000 men and women have savings accounts in mutual savings banks and at least 25,000,000 have deposits in national and 
exchanges which handle the distribution and trading of a very substantial part of the entire national wealth ... cannot operate under the same traditions and practices as pre-war stock exchanges which handled substantially only the transactions of professional investors and speculators." 24

In the years since 1934, the priority placed by Congress on the interests of long-term investors has grown more and more significant. Today, more than 84 million individuals representing more than one-half of American households own equity securities. ${ }^{25}$ More than 70 million of these individuals participate indirectly in the equity markets through ownership of mutual fund shares. Most of them hold their investments, at least in part, in retirement plans. Indeed, nearly all view their equity investments as savings for the long-term, and their median

State banks and trust companies - which are in turn large holders of corporate stocks and bonds.").

Id. at 4. The Congressional emphasis on the interests of long-term investors versus shortterm traders also was expressed in the 1934 Report on Stock Exchange Practices prepared by investigators for the Senate Committee on Banking and Currency:

Transactions in securities on organized exchanges and over-the-counter markets are affected with the national public interest. . . . In former years transactions in securities were carried on by a relatively small portion of the American people. During the last decade, however, due largely to the development of the means of communication ... the entire Nation has become acutely sensitive to the activities on the securities exchanges. While only a fraction of the multitude who now own securities can be regarded as actively trading on the exchanges, the operations of these few profoundly affect the holdings of all.

S. Rep. No. 73-1455, 73rd Cong., 2d Sess. 5 (1934). America 17 (2002). 
length of ownership of equity mutual funds, both inside and outside retirement plans, is 10 years. ${ }^{26}$

In assessing the current state of the NMS and formulating its rule proposals, the Commission has focused on the interests of these millions of Americans who depend on the performance of their equity investments for such vital needs as retirement security and their children's college education. Their investment returns are reduced by transaction costs of all types, including the explicit costs of commissions and mutual fund fees. But the largely hidden costs associated with the prices at which trades are executed often can dwarf the explicit costs of trading. For example, the implicit transaction costs associated with the price impact of trades and liquidity search costs of mutual funds and other institutional investors is estimated at more than $\$ 30$ billion per year. ${ }^{27}$ Such hidden costs eat away at the long-term returns of millions of individual mutual fund shareholders and pension plan participants. One of the primary objectives of the NMS is to help reduce such costs by improving market liquidity and depth. The best way to promote market depth and liquidity is to encourage vigorous competition among orders. As a result, the Commission cannot merely focus on one type of competition competition among markets to provide trading services - at the expense of competition among orders. The interests of U.S. long-term investors and listed companies require that the NMS continue to promote both types of competition.

\section{Overview of Adopted Rules}

\section{Order Protection Rule}

See infra, section II.A.6. 
The Order Protection Rule (Rule 611 under Regulation NMS) establishes intermarket protection against trade-throughs for all NMS stocks. A trade-through occurs when one trading center executes an order at a price that is inferior to the price of a protected quotation, often representing an investor limit order, displayed by another trading center. ${ }^{28}$ Many commenters on the proposals, particularly large institutional investors, strongly supported the need for enhanced protection of limit orders against trade-throughs. ${ }^{29}$ They emphasized that limit orders are the building blocks of public price discovery and efficient markets. They stated that a uniform rule for all NMS stocks, by enhancing protection of displayed prices, would encourage greater use of limit orders and contribute to increased market liquidity and depth. The Commission agrees that strengthened protection of displayed limit orders would help reward market participants for displaying their trading interest and thereby promote fairer and more vigorous competition among orders seeking to supply liquidity. Moreover, strong intermarket price protection offers greater assurance, on an order-by-order basis, that investors who submit market orders will receive the best readily available prices for their trades. The Commission therefore has adopted the Order Protection Rule to strengthen the protection of displayed and automatically accessible quotations in NMS stocks.

The Order Protection Rule takes a substantially different approach than the trade-through provisions currently set forth in the Intermarket Trading System ("ITS") Plan, ${ }^{30}$ which apply only

28 The nature and scope of quotations that will be protected under the Order Protection Rule are discussed in detail in sections II.A.2 and II.B.1 below.

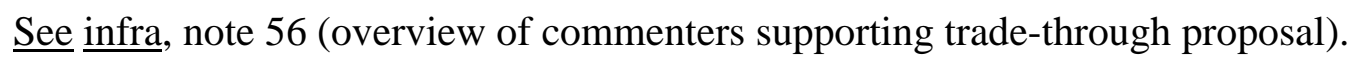

30 The full title of the ITS Plan is "Plan for the Purpose of Creating and Operating an Intermarket Communications Linkage Pursuant to Section 11A(c)(3)(B) of the Securities Exchange Act of 1934." The ITS Plan was initially approved by the Commission in 1978. Securities Exchange Act Release No. 14661 (Apr. 14, 1978), 43 FR 17419 (Apr. $24,1978)$. All national securities exchanges that trade exchange-listed stocks and the 
to exchange-listed stocks. The ITS provisions are not promulgated by the Commission, but rather are rules of the markets participating in the ITS Plan. These rules were drafted decades ago and do not distinguish between manual and automated quotations. Moreover, they state that markets "should avoid" trade-throughs and provide an after-the-fact complaint procedure pursuant to which, if a trade-through occurs, the aggrieved market may seek satisfaction from the market that traded through. Finally, the ITS provisions have significant gaps in their coverage, particularly for off-exchange positioners of large, block transactions (10,000 shares or greater), that have weakened their protection of limit orders.

In contrast, the adopted Order Protection Rule protects only quotations that are immediately accessible through automatic execution. It thereby addresses a serious weakness in the ITS provisions, which were drafted for a world of floor-based markets and fail to reflect the disparate speed of response between manual and automated quotations. By requiring order routers to wait for a response from a manual market, the ITS trade-through provisions can cause an order to miss both the best price of a manual quotation and slightly inferior prices at automated markets that would have been immediately accessible. The Order Protection Rule eliminates this potential inefficiency by protecting only automated quotations. It also promotes equal regulation and fair competition among markets by eliminating any potential advantage that the ITS trade-through provisions may have given manual markets over automated markets.

In addition, the Order Protection Rule incorporates an approach to trade-throughs that is stricter and more comprehensive than the ITS provisions. First, it requires trading centers to

NASD are participants in the ITS Plan. It requires each participant to provide electronic access to its displayed best bid or offer to other participants and provides an electronic mechanism for routing orders, called commitments to trade, to access those displayed prices. The participants also agreed to avoid trade-throughs and locked markets and to adopt rules addressing such practices. 
establish, maintain, and enforce written policies and procedures that are reasonably designed to prevent trade-throughs, or, if relying on one of the rule's exceptions, that are reasonably designed to assure compliance with the exception. To assure effective compliance, such policies and procedures will need to incorporate objective standards that are coded into a trading center's automated systems. Moreover, a trading center is required to regularly surveil to ascertain the effectiveness of its policies and procedures and to take prompt action to remedy deficiencies. Second, the Order Protection Rule eliminates very significant gaps in the coverage of the ITS provisions that have undermined the extent to which they protect limit orders and promote fair and orderly trading. In particular, the ITS provisions do not cover the transactions of brokerdealers acting as off-exchange block positioners in exchange-listed stocks. They also exclude trade-throughs of 100-share quotations, thereby allowing some limit orders of small investors to be bypassed. The Order Protection Rule closes both of these gaps in coverage.

The definition of "protected bid" or "protected offer" in paragraph (b)(57) of adopted Rule 600 controls the scope of quotations that are protected by the Order Protection Rule. The Commission is adopting the reproposed "Market BBO Alternative" that protects only the best bids and offers ("BBOs") of the nine self-regulatory organizations ("SROs") and The Nasdaq Stock Market, Inc. ("Nasdaq") whose members currently trade NMS stocks. As discussed further in section II.A.5 below, the Commission has decided not to adopt the reproposed "Voluntary Depth Alternative." In particular, it believes that the Market BBO Alternative: (1) strikes an appropriate balance between competition among markets and competition among orders; and (2) will be less difficult and costly to implement than the Voluntary Depth Alternative. 
The rule text of the original proposal included a general "opt-out" exception that would have allowed market participants to disregard displayed quotations. While the opt-out proposal was intended to provide flexibility to market participants, such an exception would have left a gap in protection of the best displayed prices and thereby reduced the proposal's potential benefits for investors. The elimination of any protection for manual quotations is the principal reason that this broad exception is no longer necessary in the Order Protection Rule as adopted. In addition, the Rule adds a number of tailored exceptions that carve out those situations in which many investors may otherwise have felt they legitimately needed to opt-out of a displayed quotation. These exceptions are more consistent with the principle of protecting the best price than a general opt-out exception would have been. The additional exceptions also will help assure that the Order Protection Rule is workable for high-volume stocks. Examples of these exceptions include intermarket sweep orders, quotations displayed by markets that fail to meet the response requirements for automated quotations, and flickering quotations with multiple prices displayed in a single second. ${ }^{31}$

Some commenters questioned the need to extend the Order Protection Rule to Nasdaq stocks. ${ }^{32}$ These commenters generally emphasized the much improved efficiency of trading in Nasdaq stocks in recent years. They particularly were concerned that extension of intermarket price protection to Nasdaq stocks, at least in the absence of a general opt-out exception, would interfere with current trading methods.

The Commission believes, however, that intermarket price protection will benefit investors and strengthen the NMS in both exchange-listed and Nasdaq stocks. It will contribute

31 Flickering quotations are discussed further in section II.A.3 below.

32 See infra, notes 61-62 and accompanying text. 
to the maintenance of fair and orderly markets and, thereby, promote investor confidence in the markets. As discussed below, ${ }^{33}$ trade-through rates are significant in both Nasdaq and exchangelisted stocks. For example, an estimated 1 of every 40 trades in both Nasdaq and NYSE stocks represents a significant trade-through of a displayed quotation. For many active Nasdaq stocks, approximately 1 of every 11 shares traded is a significant trade-through. The execution of trades at prices inferior to those offered by displayed and accessible limit orders is inconsistent with basic notions of fairness and orderliness, particularly for investors, both large and small, who post limit orders and see those orders routinely traded through. These trade-throughs can undermine incentives to display limit orders. Moreover, many of the investors whose market orders are executed at inferior prices may not, in fact, be aware they received an inferior price from their broker and executing market. In sum, the Commission believes that a rule establishing price protection on an order-by-order basis for all NMS stocks is needed to protect the interests of investors, promote the display of limit orders, and thereby improve the efficiency of the NMS as a whole.

\section{Access Rule}

The Access Rule (Rule 610 under Regulation NMS) sets forth new standards governing access to quotations in NMS stocks. As emphasized by many commenters on the proposals, ${ }^{34}$ protecting the best displayed prices against trade-throughs would be futile if broker-dealers and trading centers were unable to access those prices fairly and efficiently. Accordingly, Rule 610 is designed to promote access to quotations in three ways. First, it enables the use of private

33 See infra, section II.A.1.a.ii.

$34 \quad$ See infra, section III.A.1. 
linkages offered by a variety of connectivity providers, ${ }^{35}$ rather than mandating a collective linkage facility such as ITS, to facilitate the necessary access to quotations. The lower cost and increased flexibility of connectivity in recent years has made private linkages a feasible alternative to hard linkages, absent barriers to access. Using private linkages, market participants may obtain indirect access to quotations displayed by a particular trading center through the members, subscribers, or customers of that trading center. To promote this type of indirect access, Rule 610 prohibits a trading center from imposing unfairly discriminatory terms that would prevent or inhibit the access of any person through members, subscribers, or customers of such trading center.

Second, Rule 610 generally limits the fees that any trading center can charge (or allow to be charged) for accessing its protected quotations to no more than $\$ 0.003$ per share. ${ }^{36}$ The purpose of the fee limitation is to ensure the fairness and accuracy of displayed quotations by establishing an outer limit on the cost of accessing such quotations. For example, if the price of a protected offer to sell an NMS stock is displayed at $\$ 10.00$, the total cost to access the offer and buy the stock will be $\$ 10.00$, plus a fee of no more than $\$ 0.003$. The adopted rule thereby assures order routers that displayed prices are, within a limited range, true prices.

The adopted fee limitation substantially simplifies the originally-proposed limitation on fees, which, in general, would have limited the fees of individual market participants to $\$ 0.001$ per share, with an accumulated cap of $\$ 0.002$ per share. Perhaps more than any other single

35 Private linkages are discussed further in section III.A.1 below.

36 If the price of a protected quotation is less than $\$ 1.00$, the fee cannot exceed $0.3 \%$ of the quotation price. The rule as adopted also applies the fee limitation to quotations other than protected quotations that are the BBOs of an SRO or Nasdaq. See infra, section III.A.2. 
issue, the proposed limitation on access fees splintered the commenters. ${ }^{37}$ Some supported the proposal as a worthwhile compromise on an extremely difficult issue. They believed that it would level the playing field in terms of who could charge fees, as well as give greater certainty to market participants that quoted prices will, essentially, be true prices. Others were strongly opposed to any limitation on fees, believing that competition alone would be sufficient to address high fees that distort quoted prices. Still others were equally adamant that all access fees of electronic communications networks ("ECNs") charged to non-subscribers should be prohibited entirely, although they did not see a problem with fees charged to a market's members or subscribers. Although consensus could not be achieved on any particular approach, commenters expressed a strong desire for resolution of a difficult issue that has caused discord within the securities industry for many years.

The Commission believes that a single, uniform fee limitation of $\$ 0.003$ per share is the fairest and most appropriate resolution of the access fee issue. First, it will not seriously interfere with current business practices, as trading centers have very few fees on their books of more than $\$ 0.003$ per share or earn substantial revenues from such fees. ${ }^{38}$ Second, the uniform fee limitation promotes equal regulation of different types of trading centers, where previously some had been permitted to charge fees and some had not. Finally and most importantly, the fee limitation of Rule 610 is necessary to support the integrity of the price protection requirement established by the adopted Order Protection Rule. In the absence of a fee limitation, some "outlier" trading centers might take advantage of the requirement to protect displayed quotations by charging exorbitant fees to those required to access the outlier's quotations. Rule 610's fee

37 The comments on access fees are addressed in section III.A.2 below.

38 See infra, section III.A.2. 
limitation precludes the initiation of this business practice, which would compromise the fairness and efficiency of the NMS.

Finally, Rule 610 requires SROs to establish, maintain, and enforce written rules that, among other things, prohibit their members from engaging in a pattern or practice of displaying quotations that lock or cross the protected quotations of other trading centers. Trading centers will be allowed, however, to display automated quotations that lock or cross the manual quotations of other trading centers. The Access Rule thereby reflects the disparity in speed of response between automated and manual quotations, while also promoting fair and orderly markets by establishing that the first protected quotation at a price, whether it be a bid or an offer, is entitled to an execution at that price instead of being locked or crossed by a quotation on the other side of the market.

\section{Sub-Penny Rule}

The Sub-Penny Rule (adopted Rule 612 under Regulation NMS) prohibits market participants from displaying, ranking, or accepting quotations in NMS stocks that are priced in an increment of less than $\$ 0.01$, unless the price of the quotation is less than $\$ 1.00$. If the price of the quotation is less than $\$ 1.00$, the minimum increment is $\$ 0.0001$. A strong consensus of commenters supported the sub-penny proposal as a means to promote greater price transparency and consistency, as well as to protect displayed limit orders. ${ }^{39}$ In particular, Rule 612 addresses the practice of "stepping ahead" of displayed limit orders by trivial amounts. It therefore should further encourage the display of limit orders and improve the depth and liquidity of trading in NMS stocks.

\section{Market Data Rules and Plans}


The adopted amendments to the Market Data Rules (adopted Rules 601 and 603 under Regulation NMS) and joint industry plans ("Plans") ${ }^{40}$ are designed to promote the wide availability of market data and to allocate revenues to SROs that produce the most useful data for investors. They will strengthen the existing market data system, which provides investors in the U.S. equity markets with real-time access to the best quotations and most recent trades in the thousands of NMS stocks throughout the trading day. For each stock, quotations and trades are continuously collected from many different trading centers and then disseminated to the public in a consolidated stream of data. As a result, investors of all types have access to a reliable source of information for the best prices in NMS stocks. When Congress mandated the creation of the NMS in 1975, it noted that the systems for disseminating consolidated market data would "form the heart of the national market system."41 Accordingly, one of the Commission's most important responsibilities is to preserve the integrity and affordability of the consolidated data stream.

The adopted amendments promote this objective in several different respects. First, they update the formulas for allocating revenues generated by market data fees to the various SRO participants in the Plans. The current Plan formulas are seriously flawed by an excessive focus on the number of trades, no matter how small the size, reported by an SRO. They thereby create

$40 \quad$ The three joint-industry plans are (1) the CTA Plan, which is operated by the Consolidated Tape Association and disseminates transaction information for exchangelisted securities, (2) the CQ Plan, which disseminates consolidated quotation information for exchange-listed securities, and (3) the Nasdaq UTP Plan, which disseminates consolidated transaction and quotation information for Nasdaq-listed securities. The CTA Plan and CQ Plan are available at www.nysedata.com. The Nasdaq UTP Plan is available at www.utpdata.com. H.R. Rep. No. 94-229, 94th Cong., 1st Sess. 93 (1975). 
an incentive for distortive behavior, such as wash sales and trade shredding, ${ }^{42}$ and fail to reflect an SRO's contribution to the best displayed quotations in NMS stocks. The adopted formula corrects these flaws. It also is much less complex than the original proposal, primarily because, consistent with the approach of the Order Protection Rule and Access Rule, the new formula eliminates any allocation of revenues for manual quotations. It therefore will promote an allocation of revenues to the various SROs that more closely reflects the usefulness to investors of each SRO's market information.

The adopted amendments also are intended to improve the transparency and effective operation of the Plans by broadening participation in Plan governance. They require the creation of advisory committees composed of non-SRO representatives. Such committees will give interested parties an opportunity to be heard on Plan business, prior to any decision by the Plan operating committees. Finally, the amendments promote the wide availability of market data by authorizing markets to distribute their own data independently (while still providing their best quotations and trades for consolidated dissemination through the Plans) and streamlining outdated requirements for the display of market data to investors.

Many commenters on the market data proposals expressed frustration with the current operation of the Plans. ${ }^{43}$ These commenters generally fell into two groups. One group, primarily made up of individual markets that receive market data fees, believed that the current model of consolidation should be discarded in favor of a new model, such as a "multiple consolidator" model under which each SRO would sell its own data separately. The other group, primarily made up of securities industry participants that pay market data fees, believed that the current

42 Trade shredding, or the splitting of large trades into a series of 100-share trades, is discussed further in section V.A.3 below.

43 Comments on the market data proposals are discussed in section V.A below. 
level of fees is too high. This group asserted that, prior to modifying the allocation of market data revenues, the Commission should address the level of fees that generated those revenues. ${ }^{44}$ The Commission has considered these concerns at length in the recent past. As was noted in the Proposing Release, ${ }^{45}$ a drawback of the current market data model, which requires all SROs to participate jointly in disseminating data through a single consolidator, is that it affords little opportunity for market forces to determine the overall level of fees or the allocation of those fees to the individual SROs. Prior to publishing the proposals, therefore, the Commission undertook an extended review of the various alternatives for disseminating market data to the public in an effort to identify a better model. These alternatives were discussed at length in the Proposing Release, but each has serious weaknesses. The Commission particularly is concerned that the integrity and reliability of the consolidated data stream must not be compromised by any changes to the market data structure.

For example, although allowing each SRO to sell its data separately to multiple consolidators may appear at first glance to subject the level of fees to competitive forces, this conclusion does not withstand closer scrutiny. If the benefits of a fully consolidated data stream are to be preserved, each consolidator would need to purchase the data of each SRO to assure that the consolidator's data stream in fact included the best quotations and most recent trade report in an NMS stock. Payment of every SRO's fees would effectively be mandatory, thereby affording little room for competitive forces to influence the level of fees.

$44 \quad$ Some commenters mistakenly believed that the level of market data fees had been left unreviewed for many years. In fact, the Commission comprehensively reviewed market data fees in 1999, which led to a 75\% reduction in fees paid by retail investors for market data. See infra, note 574.

45 Proposing Release, 69 FR at 11177. 
The Commission also has considered the suggestion of many in the second group of commenters that market data fees should be cut back to encompass only the costs of the Plans to collect and disseminate market data. Under this approach, the individual SROs would no longer be allowed to fund any portion of their operational and regulatory functions through market data fees. ${ }^{46}$ Yet, as discussed in the Commission's 1999 concept release on market data, ${ }^{47}$ nearly the entire burden of collecting and producing market data is borne by the individual markets, not by the Plans. If, for example, an SRO's systems fail on a high-volume trading day and it can no longer provide its data to the Plans, investors will suffer the consequences of a flawed data stream, regardless of whether the Plan is able to continue operating.

If the Commission were to limit market data fees to cover only Plan costs, SRO funding would have been cut by $\$ 393.7$ million in $2004 .^{48}$ Given the potential harm if vital SRO functions are not adequately funded, the Commission believes that the level of market data fees is most appropriately addressed in a context that looks at SRO funding as a whole. It therefore has requested comment on this issue in its recent concept release on SRO structure. ${ }^{49}$ In

$46 \quad$ The U.S. equity markets are not alone in their reliance on market information revenues as a significant source of funding. All of the other major world equity markets currently derive large amounts of revenues from selling market information. See infra, note 587 and accompanying text.

47 Securities Exchange Act Release No. 42208 (Dec. 9, 1999), 64 FR 70613 (Dec. 17, 1999) ("Market Information Release").

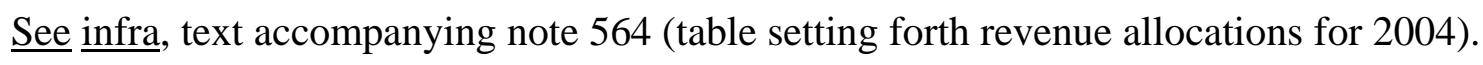
Securities Exchange Act Release No. 50700 (Nov. 18, 2004), 69 FR 71256 (Dec. 8, 2004) ("SRO Structure Release"). 
addition, the recently proposed rules to improve SRO transparency would, if adopted, assist the public in assessing the level and use of market data fees by the various SROs. ${ }^{50}$

In sum, there is inherent tension between assuring consolidated price transparency for investors, which is a fundamental objective of the Exchange Act, ${ }^{51}$ and expanding the extent to which market forces determine market data fees and SRO revenues. Each alternative model for data dissemination has its particular strengths and weaknesses. The great strength of the current model, however, is that it benefits investors, particularly retail investors, by helping them to assess quoted prices at the time they place an order and to evaluate the best execution of their orders against such prices by obtaining data from a single source that is highly reliable and comprehensive. In the absence of full confidence that this benefit would be retained if a different model were adopted, the Commission has decided to adopt such immediate steps as are necessary to improve the operation of the current model.

\section{Order Protection Rule}

The Commission is adopting Rule 611 under Regulation NMS to establish protection against trade-throughs for all NMS stocks. Rule 611(a)(1) requires a trading center (which includes national securities exchanges, exchange specialists, ATSs, OTC market makers, and block positioners $)^{52}$ to establish, maintain, and enforce written policies and procedures that are reasonably designed to prevent trade-throughs on that trading center of protected quotations and,

$50 \quad$ Securities Exchange Act Release No. 50699 (Nov. 18, 2004), 69 FR 71126 (Dec. 8, 2004) ("SRO Transparency Release").

51 Section $11 \mathrm{~A}(\mathrm{a})(1)(\mathrm{C})(\mathrm{iii})$ of the Exchange Act.

52 An "OTC market maker" in a stock is defined in Rule 600(b)(52) of Regulation NMS as, in general, a dealer that holds itself out as willing to buy and sell the stock, otherwise than on a national securities exchange, in amounts of less than block size (less than 10,000 shares). A block positioner in a stock, in contrast, limits its activity in the stock to transactions of 10,000 shares or greater. 
if relying on an exception, that are reasonably designed to assure compliance with the terms of the exception. Rule 611(a)(2) requires a trading center to regularly surveil to ascertain the effectiveness of its policies and procedures and to take prompt action to remedy deficiencies. To qualify for protection, a quotation must be automated. Rule 600(b)(3) defines an automated quotation as one that, among other things, is displayed and immediately accessible through automatic execution. Thus, Rule 611 does not require market participants to route orders to access manual quotations, which generally entail a much slower speed of response than automated quotations.

Rule 611(b) sets forth a variety of exceptions to make intermarket price protection as efficient and workable as possible. These include an intermarket sweep exception, which allows market participants to access multiple price levels simultaneously at different trading centers - a particularly important function now that trading in penny increments has dispersed liquidity across multiple price levels. The intermarket sweep exception enables trading centers that receive sweep orders to execute those orders immediately, without waiting for better-priced quotations in other markets to be updated. In addition, Rule 611 provides exceptions for the quotations of trading centers experiencing, among other things, a material delay in providing a response to incoming orders and for flickering quotations with prices that have been displayed for less than one second. Both exceptions serve to limit the application of Rule 611 to quotations that are truly automated and accessible.

By strengthening price protection in the NMS for quotations that can be accessed fairly and efficiently, Rule 611 is designed to promote market efficiency and further the interests of 
both investors who submit displayed limit orders and investors who submit marketable orders. ${ }^{53}$ Price protection encourages the display of limit orders by increasing the likelihood that they will receive an execution in a timely manner and helping preserve investors' expectations that their orders will be executed when they represent the best displayed quotation. Limit orders typically establish the best prices for an NMS stock. Greater use of limit orders will increase price discovery and market depth and liquidity, thereby improving the quality of execution for the large orders of institutional investors. Moreover, strong intermarket price protection offers greater assurance, on an order-by-order basis, to investors who submit market orders that their orders in fact will be executed at the best readily available prices, which can be difficult for investors, particularly retail investors, to monitor. Investors generally can know the best quoted prices at the time they place an order by referring to the consolidated quotation stream for a stock. In the interval between order submission and order execution, however, quoted prices can change. If the order execution price provided by a market differs from the best quoted price at order submission, it can be particularly difficult for retail investors to assess whether the difference was attributable to changing quoted prices or to an inferior execution by the market. The Order Protection Rule will help assure, on an order-by-order basis, that markets effect trades at the best available prices. Finally, market orders need only be routed to markets displaying quotations that are truly accessible. Accordingly, as discussed in detail below, the Commission

$53 \quad$ For ease of reference in this release, the term "limit order" generally will refer to a nonmarketable order and the term "marketable order" will refer to both market orders and marketable limit orders. A non-marketable limit order has a limit price that prevents its immediate execution at current market prices. Because these orders cannot be executed immediately, they generally are publicly displayed to attract contra side interest at the price. In contrast, a "marketable limit order" has a limit price that potentially allows its immediate execution at current market prices. As discussed further below, marketable limit orders often cannot be filled at current market prices because of insufficient liquidity and depth at the market price. See infra, text accompanying notes 121-123, 134136. 
finds that the Order Protection Rule is necessary and appropriate in the public interest, for the protection of investors, and otherwise in furtherance of the purposes of the Exchange Act.

\section{A. Response to Comments and Basis for Adopted Rule}

Rule 611 as adopted reflects a number of changes to the rule as originally proposed. As discussed below, the Commission has made these changes in response to substantial public comment on the proposed rule and on the issues arising out of the NMS Hearing that were addressed in the Supplemental Release. In addition, the adopted rule includes a new exception for certain "stopped orders" in response to the suggestions of commenters on the reproposal. The public submitted more than 2200 comments addressing the trade-through proposal and reproposal..$^{54}$ Although the comments covered a very wide range of matters, they particularly focused on the following issues:

(1) whether an intermarket trade-through rule is needed to promote fair and efficient equity markets, particularly for Nasdaq stocks which have not been subject to the current ITS trade-through provisions;

(2) whether only automated and immediately accessible quotations should be given trade-through protection and, if so, what is the best approach for defining such quotations;

(3) whether intermarket protection against trade-throughs can be implemented in a workable manner, particularly for high-volume stocks;

(4) whether the exception in the original proposal allowing a general opt-out of protected quotations is necessary or appropriate, particularly if manual quotations are excluded from trade-through protection;

$54 \quad$ The Commission has considered the views of all commenters in formulating Rule 611 as adopted, as well as the other rules and amendments adopted today. 
(5) whether the scope of quotations entitled to trade-through protection should extend beyond the best bids and offers of the various markets; and

(6) whether the benefits of an intermarket trade-through rule would justify its cost of implementation.

In the following sections, the Commission responds to comments on the trade-through proposal and reproposal and discusses the basis for its adoption of Rule 611.

\section{Need for Intermarket Order Protection Rule}

Commenters were divided on the central issue of whether intermarket protection of displayed quotations is needed to promote the fairest and most efficient markets for investors. ${ }^{55}$ Many commenters strongly supported the adoption of a uniform rule for all NMS stocks to promote best execution of market orders, to protect the best displayed prices, and to encourage the public display of limit orders. ${ }^{56}$ They stressed that limit orders are the cornerstone of

$55 \quad$ Nearly all commenters, both those supporting and opposing the need for an intermarket trade-through rule, agreed that the current ITS trade-through provisions are seriously outdated and in need of reform. They particularly focused on the problems created by affording equal protection against trade-throughs to both automated and manual quotations. See supra, section II.A.2. Adopted Rule 611 responds to these problems by protecting only automated quotations.

Approximately 1689 commenters on the proposal and reproposal favored a uniform trade-through rule without an opt-out exception. These commenters included: (1) several mutual fund companies and the Investment Company Institute; (2) the Consumer Federation of America and the National Association of Individual Investors Corporation; (3) the floor-based exchanges and their members; (4) approximately 107 listed companies; (5) a variety of securities industry participants; and (6) approximately 42 members of Congress. Of the commenters supporting the reproposal, approximately 452 utilized "Letter Type G" (noting the existence of two alternative proposals and urging "support for the Regulation NMS proposal without the CLOB" alternative), 70 utilized "Letter Type H" ("we support the 'top of the book' proposal that has been discussed for the past year as part of the Regulation NMS discussion"), 204 utilized "Letter Type I" ("I believe a better approach would be the SEC's proposed alternative to the CLOB, to protect the best price in each market center"), 548 utilized "Letter Type J" ("Of the two alternatives laid out in the rule as re-proposed on December 15, 2004, protecting the best bid and offer in each market center preserves both types of competition in a way that 
efficient, liquid markets and should be afforded as much protection as possible. ${ }^{57}$ They noted, for example, that limit orders typically establish the "market" for a stock. ${ }^{58}$ In the absence of limit orders setting the current market price, there would be no benchmark for the submission and execution of marketable orders. Focusing solely on best execution of marketable orders (and the interests of orders that take displayed liquidity), therefore, would miss a critical part of the equation for promoting the most efficient markets (i.e., the best execution of orders that supply displayed liquidity and thereby provide the most transparent form of price discovery).

Commenters supporting the need for an intermarket trade-through rule also believed that it

benefits all securities industry participants."), 28 utilized "Letter Type K" ("One alternative is that of protecting the "best bid and offer" in each market center. This concept enhances competition, allows for price negotiation, encourages innovation, and treats all market participants fairly and equally."), and 109 utilized "Letter Type L" (noting the existence of two alternative proposals and urging support for "the Regulation NMS proposal without the CLOB" alternative). Each of the letter types is posted on the Commission's Internet Web site (http://www.sec.gov/rules/proposed.shtml). Those commenters that only expressed opposition to the Voluntary Depth Alternative were not included in the foregoing summary. In addition, many commenters supported an opt-out exception to a trade-through rule, but varied in the extent to which they made clear whether they supported a trade-through rule in general. These commenters are not included in the foregoing summary, but are included in note 232 below addressing supporters of an opt-out exception.

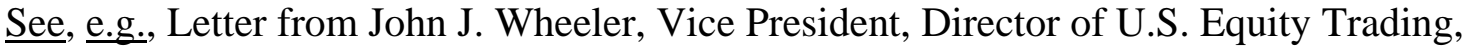
American Century Investment Management Inc., to Jonathan G. Katz, Secretary, Commission, dated June 30, 2004 ("American Century Letter") at 2; Letter from Matt D. Lyons, Capital Research and Management Company, to Jonathan G. Katz, Secretary, Commission, dated June 28, 2004 ("Capital Research Letter") at 2; Letter from Ari Burstein, Associate Counsel, Investment Company Institute, to Jonathan G. Katz, Secretary, Commission, dated Jan. 26, 2005 ("ICI Reproposal Letter") at 2; Letter from Henry H. Hopkins, Vice President and Chief Legal Counsel, and Andrew M. Brooks, Vice President and Head of Equity Trading, T. Rowe Price Associates, Inc., to Jonathan G. Katz, Commission, dated Jan. 27, 2005 ("T. Rowe Price Reproposal Letter") at 2; Letter from George U. Sauter, Managing Director, The Vanguard Group, Inc., to Jonathan G. Katz, Secretary, Commission, dated Jan. 27, 2005 ("Vanguard Reproposal Letter") at 2.

Id. 
would increase investor confidence by helping to eliminate the impression of unfairness when an investor's order executes at a price that is worse than the best displayed quotation, or when a trade occurs at a price that is inferior to the investor's displayed order. ${ }^{59}$

Other commenters, in contrast, opposed any intermarket trade-through rule. ${ }^{60}$ These commenters did not believe that such a rule is necessary to promote the protection of limit orders, the best execution of market orders, or efficient markets in general. They asserted that, given public availability of each market's quotations and ready access by all market participants to such quotations, competition among markets, a broker's existing duty of best execution, and economic self-interest would be sufficient to protect limit orders and produce the most fair and efficient markets. They therefore believed that any trade-through rule would be unnecessary and costly. These commenters also were concerned that any trade-through rule could interfere with the ability of competitive forces to produce efficient markets, particularly for Nasdaq stocks.

Commenters on the original proposal who were opposed to any trade-through rule also expressed their view that there is a lack of empirical evidence justifying the need for intermarket protection against trade-throughs. They noted, for example, that trading in Nasdaq stocks has never been subject to a trade-through rule, while trading in exchange-listed stocks, particularly

$59 \quad$ See, e.g., Letter from Barbara Roper, Director of Investor Protection, Consumer Federation of America, to Jonathan G. Katz, Secretary, Commission, dated June 17, 2004 ("Consumer Federation Letter") at 2; Letter from Ari Burstein, Associate Counsel, Investment Company Institute, to Jonathan G. Katz, Secretary, Commission, dated June 30, 2004 ("ICI Letter") at 7.

60 Approximately 448 commenters on the proposal and reproposal opposed a trade-through rule. Approximately 179 of these commenters utilized "Letter Type C," which primarily supported an opt-out exception to the proposed rule, but also suggested that having no trade-through rule would be simpler. Letter Type $C$ is posted on the Commission's Internet Web site (http://www.sec.gov/rules/proposed.shtml). The remaining commenters included securities industry participants, particularly electronic markets and their participants, a variety of local political and community groups and individuals, and 34 members of Congress. 
NYSE stocks, has been subject to the ITS trade-through provisions. Given the difference in regulatory requirements between Nasdaq and NYSE stocks, many commenters relied on two factual contentions to show that a trade-through rule is not needed: (1) fewer trade-throughs occur in Nasdaq stocks than NYSE stocks; ${ }^{61}$ and (2) trading in Nasdaq stocks currently is more efficient than trading in NYSE stocks. ${ }^{62}$ Based on these factual contentions, opposing commenters concluded that a trade-through rule is not necessary to promote efficiency or to protect the best displayed prices.

The Commission has carefully evaluated the views of these commenters on both the original proposal and the reproposal. In addition, Commission staff has prepared several studies of trading in Nasdaq and NYSE stocks to help assess and respond to commenters' claims. The studies and the Commission's conclusions are discussed in detail below. In general, however, the

See, e.g., Letter from Kim Bang, President \& Chief Executive Officer, Bloomberg Tradebook LLC, to Jonathan G. Katz, Secretary, Commission, dated June 30, 2004 ("Bloomberg Tradebook Letter") at 10; Letter from Eric D. Roiter, Senior Vice President \& General Counsel, Fidelity Management and Research Company, to Jonathan G. Katz, Secretary, Commission, dated June 22, 2004 ("Fidelity Letter I") at 11; Letter from Suhas Daftuar, Managing Director, Hudson River Trading, to Jonathan G. Katz, Secretary, Commission, dated August 13, 2004 ("Hudson River Trading Letter") at 1; Letter from Edward J. Nicoll, Chief Executive Officer, Instinet Group Incorporated, to Jonathan G. Katz, Secretary, Commission, dated June 30, 2004 ("Instinet Letter") at 14; Letter from Edward S. Knight, The Nasdaq Stock Market, Inc., to Jonathan G. Katz, Secretary, Commission, dated July 2, 2004 ("Nasdaq Letter II") at 6 and Attachment III.

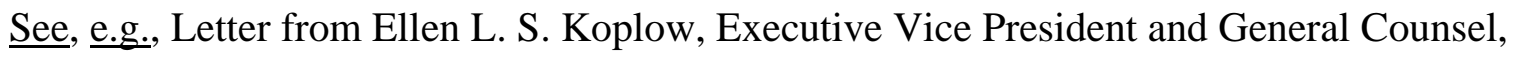
Ameritrade Holding Corporation, to Jonathan G. Katz, Secretary, Commission, dated June 30, 2004 ("Ameritrade Letter I"), Appendix at 10; Letter from William O'Brien, Chief Operating Officer, Brut LLC, to Jonathan G. Katz, Secretary, Commission, dated July 29, 2004 ("Brut Letter") at 10; Fidelity Letter I at 11; Instinet Letter at 3, 9 and Exhibit A; Nasdaq Letter II at 6 and Attachment II; Letter from Bruce N. Lehmann \& Joel Hasbrouck, Organizers, Reg NMS Study Group, to Jonathan G. Katz, Secretary, Commission (no date) ("NMS Study Group Letter") at 4; Letter from David Colker, Chief Executive Officer \& President, National Stock Exchange, to Jonathan G. Katz, Secretary, Commission, dated June 29, 2004 ("NSX Letter") at 3; Letter from Huw Jenkins, Managing Director, Head of Equities for the Americas, UBS Securities LLC, to Jonathan G. Katz, Secretary, Commission, dated June 30, 2004 ("UBS Letter") at 4. 
Commission has found that current trade-through rates are not lower for Nasdaq stocks than NYSE stocks, despite the fact that nearly all quotations for Nasdaq stocks are automated, rather than divided between manual and automated as they are for exchange-listed stocks. Moreover, the majority of the trade-throughs that currently occur in NYSE stocks fall within gaps in the coverage of the existing ITS trade-through rules that will be closed by the Order Protection Rule. Consequently, the Commission believes that the Order Protection Rule, by establishing effective intermarket protection against trade-throughs, will materially reduce the trade-through rates in both the market for Nasdaq stocks and the market for exchange-listed stocks.

In addition, the commenters' claim that the Order Protection Rule is not needed because trading in Nasdaq stocks, which currently does not have any trade-through rule, is more efficient than trading in NYSE stocks, which has the ITS trade-through provisions, also is not supported by the relevant data. ${ }^{63}$ This conclusion is particularly evident when market efficiency is examined from the perspective of the transaction costs of long-term investors, as opposed to short-term traders. The data reveals that the markets for Nasdaq and NYSE stocks each have their particular strengths and weaknesses. In assessing the need for the Order Protection Rule, the Commission has focused primarily on whether effective intermarket protection against tradethroughs will materially contribute to a fairer and more efficient market for investors in Nasdaq stocks, given their particular trading characteristics, and in exchange-listed stocks, given their particular trading characteristics. Thus, the critical issue is whether each of the markets would be improved by adoption of the Order Protection Rule, not whether one or the other currently is, on some absolute level, superior to the other. The Commission believes that effective intermarket protection against trade-throughs will produce substantial benefits for investors in 
both markets and, therefore, has adopted the Order Protection Rule for both Nasdaq and exchange-listed stocks.

\section{a. Trade-Through Rates in Nasdaq and NYSE Stocks}

The first principal factual contention of commenters on the original proposal who were opposed to a trade-through rule is premised on the claim that there are fewer trade-throughs in Nasdaq stocks, which are not covered by any trade-through rule, than in NYSE stocks, which are covered by the ITS trade-through provisions. ${ }^{64}$ One commenter asserted that, outside the exchange-listed markets, competition alone had been sufficient to create a "no-trade through zone." ${ }^{65}$ To respond to these commenters, the Commissions staff reviewed public quotation and trade data to estimate the incidence of trade-throughs for Nasdaq and NYSE stocks. ${ }^{66}$ It found that the overall trade-through rates for Nasdaq stocks and NYSE stocks were, respectively, 7.9\% and $7.2 \%$ of the total volume of traded shares. ${ }^{67}$ When considered as a percentage of number of

$64 \quad$ See, e.g., Bloomberg Tradebook Letter at 10; Fidelity Letter I at 11; Hudson River Trading Letter at 1; Instinet Letter at 14; Nasdaq Letter II at 6 and Attachment III.

Letter from Kevin J. P. O’Hara, Chief Administrative Officer \& General Counsel, Archipelago Holdings, Inc., to Jonathan G. Katz, Secretary, Commission, dated September 24, 2004 ("ArcaEx Letter") at 3.

Memorandum to File, from Office of Economic Analysis, dated December 15, 2004 (analysis of trade-throughs in Nasdaq and NYSE issues) ("Trade-Through Study"). The Trade-Through Study has been placed in Public File No. S7-10-04 and is available for inspection on the Commission's Internet Web site (http://www.sec.gov). To eliminate false trade-throughs, the staff calculated trade-through rates using a 3-second window - a reference price must have been displayed one second before a trade and still have been displayed one second after a trade. In addition, the staff eliminated quotations displayed by the American Stock Exchange LLC ("Amex") from the analysis of Nasdaq stocks because they were manual quotations. Finally, the staff used the time of execution of a trade, if one was given, rather than time of the trade report itself. This methodology was designed to address manual trades, such as block trades, that might not be reported for several seconds after the trade was effected manually.

Trade-Through Study, Tables 4, 11. The 7.9\% and 7.2\% figures include the entire size of trades that were executed at prices inferior to displayed quotations. 
trades, the overall trade-through rate for both Nasdaq and NYSE stocks was 2.5\%. When considered as the size of traded-through quotations as a percentage of total share volume, the overall rates for Nasdaq and NYSE stocks were, respectively, $1.9 \%$ and $1.2 \%{ }^{68}$ In addition, the staff study found that the amount of the trade-throughs was significant -2.3 cents per share on average for Nasdaq stocks and 2.2 cents per share for NYSE stocks. ${ }^{69}$

The staff study also revealed that a large volume of block transactions $(10,000$ shares or greater) trade through displayed quotations. Block transactions represent approximately 50\% of total trade-through volume for both Nasdaq and NYSE stocks. ${ }^{70}$ Importantly, many block transactions currently are not subject to the ITS trade-through provisions that apply to exchangelisted stocks. Broker-dealers that act solely as block positioners are not covered by the ITS trade-through provisions if they print their trades in the over-the-counter ("OTC") market. In addition to not covering the trades of block positioners, the ITS trade-through provisions include an exception for 100-share quotations. They therefore often may fail to protect the small orders of retail investors. When block trade-throughs and trade-throughs of 100-share quotations are eliminated, the overall trade-through rate for NYSE stocks is reduced from $7.2 \%$ to approximately $2.3 \%$ of total share volume. ${ }^{71}$ The two gaps in ITS coverage therefore account for most of the trade-through volume in NYSE stocks. The Order Protection Rule, by closing these gaps in protection against trade-throughs, will establish much stronger price protection than the ITS provisions.

$68 \quad \underline{\text { Id. }}$ at 2 . The $1.9 \%$ and $1.2 \%$ figures include only the total displayed size of quotations that were traded through by trades executed at prices inferior to the displayed quotations. Id., Tables 3, 10.

$70 \quad$ Id., Tables 4, 11.

$71 \quad$ Id., Table 11. 
Commenters opposed to the trade-through reproposal offered a number of criticisms of the staff study. Such criticisms generally fall into two categories: (1) possible reasons why the staff study might have overestimated trade-through rates, particularly for Nasdaq stocks; and (2) even assuming the estimated trade-through rates were accurate, arguments for why such rates do not support a conclusion that the Order Protection Rule is needed or will benefit the markets, particularly for Nasdaq stocks. These criticisms are evaluated below.

\section{i. Accuracy of Estimated Trade-Through Rates}

Several commenters asserted that the staff study overestimated trade-through rates because it failed to consider the existence of reserve size and sweep orders in the Nasdaq market, which could have caused "false positive" trade throughs. ${ }^{72}$ In theory, order routers could intend to sweep the market of all superior quotations before trading at an inferior price, but if they did not effectively sweep both displayed size and reserve size, the superior quotations would not change and the staff study would report a false indication of a trade-through when the trade in another market occurred at an inferior price. In practice, however, those who truly intend to sweep the best prices are quite capable of routing orders to execute against both displayed and estimated reserve size, thereby precluding the possibility of a false positive trade-through. Indeed, although commenters asserted that the staff study failed to consider the existence of reserve size for Nasdaq stocks, the validity of their own argument is premised on the failure of sophisticated market participants to consider the existence of reserve size when routing sweep orders.

Letter from Kim Bang, Bloomberg L.P., to Jonathan Katz, Secretary, dated Jan. 25, 2005 ("Bloomberg Reproposal Letter") at 6; Letter from Edward S. Knight, The Nasdaq Stock Market, Inc., to Jonathan G. Katz, Secretary, dated Jan. 26, 2005 ("Nasdaq Reproposal Letter"), Exhibit A at 4; Letter from Daniel Coleman, Managing Director and Head of Equities for the Americas, UBS Securities LLC ("UBS Reproposal Letter") at 4. 
It currently is impossible to determine from publicly available trade and quotation data whether the initiator of a trade-through in one market has simultaneously attempted to sweep better-priced quotations in other markets. ${ }^{73}$ The data can reveal, however, the extent to which false-positive indications of a trade-through were even a possibility by examining trading volume at the traded-through market. If the accumulated volume of trades in that market did not equal or exceed the displayed size of a traded-through quotation, it shows that a sweep order, even one attempting to execute only against displayed size, could not have been routed to the market that was traded-through. Commission staff therefore has supplemented its trade-through study to check this possibility and to help the Commission assess and respond to commenters' criticisms. It found that this possibility rarely occurs - a finding that fully supports an inference that market participants are capable of effectively sweeping the best prices, both displayed and reserve, when

73 After implementation of Rule 611, such orders generally will be marked as intermarket sweep orders pursuant to the exceptions set forth in Rule 611(b)(5) and (6). As discussed in note 317 below, the Commission intends to request that the NMS trade reporting plans consider collecting and disseminating special modifiers for all trades that are executed pursuant to an exception from Rule 611. Such modifiers would greatly enhance transparency and minimize the potential for false appearances of violations of Rule 611. 
they intend to do so. ${ }^{74}$ Thus, it is very unlikely that the existence of reserve size and sweep orders caused a significant number of false positive trade-throughs in Nasdaq stocks. ${ }^{75}$

One commenter asserted that the staff study was flawed because its sample trading days involved unusual trading activity. ${ }^{76}$ Commission staff chose the sample trading days, however, only after affirming that they were representative of normal trading. To respond to this commenter's claim, Commission staff reaffirmed that all four days were well within the norms

74 Memorandum to File, from Office of Economic Analysis, dated April 6, 2005, at 1 (supplemental trade-through analysis - reserve size analysis, sample day activity analysis, and analysis of quote depth) ("Supplemental Trade-Through Study"). For example, the Supplemental Trade-Through Study found that, when the trade-through statistics are adjusted to reflect possible instances in which sweep orders could have failed to execute against reserve size, the estimated trade-through rates for Nasdaq stocks declined slightly from $2.5 \%$ of total trades to $2.3 \%$ of total trades, and from $7.9 \%$ of total share volume to $7.7 \%$ of total share volume. These small reductions do not support the assertion of commenters that market participants systematically fail to take out reserve size when routing sweep orders. Rather, the reductions are much more consistent with the random distribution of trade volume that would be expected to occur in the traded-through markets from time to time.

ArcaEx noted that it was common practice in the market for exchange-listed stocks to send commitments to trade through the ITS to avoid trading through quotations in other markets. Letter from Kevin J. P. O'Hara, Chief Administrative Officer and General Counsel, Archipelago Holdings, Inc., to Jonathan G. Katz, Secretary, Commission, dated Jan. 26, 2005 ("ArcaEx Reproposal Letter"), Annex A at 1. Given the slowness with which ITS commitments to trade often are processed and manual quotations are updated, ArcaEx suggested that trade-through rates for exchange-listed stocks might be overestimated. The Commission agrees that this criticism may well be valid to some extent. Thus, the trade-through rates for NYSE stocks in the staff study may be overstated for ArcaEx and other markets trading exchange-listed stocks. The occurrence of apparent trade-throughs in exchange-listed stocks caused by manual quotations under the current ITS provisions is addressed in the Order Protection Rule by protecting only automated quotations. 
for trading volume and price volatility. ${ }^{77}$ In addition, the trade-through rates remained quite stable across the four days (e.g., ranging only from $2.3 \%$ to $2.6 \%$ for Nasdaq stocks). ${ }^{78}$

Two commenters asserted that, even if the staff study's estimate of trade-through rates was correct for the trading days chosen in the Fall of 2003, such rates are now outdated for Nasdaq stocks because of structural changes in the market. ${ }^{79}$ In particular, they cited the merger of the Island and Instinet ECNs and Nasdaq's acquisition of the BRUT ECN. Nasdaq also presented statistics indicating that the trade-through rates for Nasdaq stocks in some trading centers had dropped from the Fall of 2003 to the Fall of 2004. The staff study used data from the Fall of 2003, however, because it was prior to the Commission's proposal of a trade-through rule and its public announcement that the staff was reviewing trade-through rates. While the conduct of market participants may have changed in certain respects when they were a focus of regulatory attention, the Commission cannot be assured that such behavior would continue if the Commission did not adopt the proposed regulatory action to address trade-throughs.

Indeed, Nasdaq's own data illustrates this possibility. ${ }^{80}$ Although Nasdaq asserts that the reduction in trade-through rates from 2003 to 2004 is a result of fewer independently operating ECNs, its data undercuts this explanation. For example, Nasdaq's data shows that the tradethrough rate at internalizing securities dealers dropped from 3.2\% in 2003 to $1.4 \%$ in $2004{ }^{81}$ It is unlikely that ECN consolidation could have caused such a major reduction in trade-through

$77 \quad$ Supplemental Trade-Through Study at 3.

78 Id.

79 Bloomberg Reproposal Letter at 5; Nasdaq Reproposal Letter, Exhibit 1 at 3-4.

$80 \quad$ Nasdaq Reproposal Letter, Exhibit 1 at 4.

81 Id. 
rates at securities dealers when they execute their customer orders internally. ${ }^{82}$ The great majority of internalized trades are the small trades of retail investors. The fact that, in 2003, nearly 1 of 30 of these millions of trades appears to have been executed at a price inferior to an automated and accessible quotation is troubling. Given that one of the primary benefits of the Order Protection Rule is to backstop a broker's duty of best execution on an order-by-order basis, Nasdaq's data appears to indicate a continuing need for regulatory action to reinforce the fundamental principle of best price for all NMS stocks.

Nasdaq also criticized the staff study for failing to address whether large block trades "intentionally avoid interacting with the posted quotes." ${ }^{83}$ Far from demonstrating a flaw in the staff study, however, the fact that large trades intentionally avoid interacting with displayed quotations was one of the primary reasons identified in the Reproposing Release supporting the need for intermarket order protection. ${ }^{84}$ The opportunity for displayed limit orders to begin interacting with this substantial volume of block trades is likely to be one of the most significant incentives for increased display of limit orders after implementation of the Order Protection Rule. Moreover, the Order Protection Rule will promote a more level playing field for retail investors that currently see their smaller displayed orders bypassed by block trades.

Two commenters did not believe the staff study should have included trades larger than quoted size, asserting that "[e]ven in a hard CLOB environment, orders larger than the inside

$82 \quad$ Nasdaq also mentions "less developed" matching systems as contributing to the high rate of trade-throughs in Fall 2003, but does not identify any major technology advances from Fall 2003 to Fall 2004 that would have enabled the reduction in trade-through rates at internalizing securities dealers. $\underline{\text { Id. }}$ at 4.

83 Nasdaq Reproposal Letter, Exhibit 1 at 4. See also UBS Reproposal Letter at 4 (describing numbers in staff study as "inflated" because they included institutional block trades).

$69 \mathrm{FR}$ at 77434. 
quote would still 'trade through' the inside quote in effect at the time the order was received." ${ }^{185}$ These commenters do not appear to have understood the methodology of the staff study or the operation of a central limit order book ("CLOB"). As discussed above, large trades would not have been identified as trade-throughs in the staff study if orders simultaneously had been routed to sweep displayed quotations with superior prices. To exclude such trades from its analysis, the study used a three-second quotation window in which the lowest best bid or the highest best offer during the three-second period must be traded-through before a trade was identified as a tradethrough. The 3-second quotation window particularly was designed to allow sufficient time for quotations to update to reflect the arrival of sweep orders (just as in a CLOB environment, the execution of a large order simultaneously would eliminate all superior-priced quotations). In sum, large orders would trade with, rather than trade through, the superior-priced displayed quotations, thereby leaving only quotations that did not have superior prices to the trade price. Such large orders therefore would not have been identified as trade-throughs in the staff study. Commenters also criticized the staff study for allegedly failing to consider the effect of locked or crossed quotations for Nasdaq stocks. ${ }^{86}$ By using a 3-second quotation window, however, the staff study excluded any trade-throughs that would have been caused by short

85 Letter from James J. Angel, Associate Professor of Finance, Georgetown University, to Jonathan G. Katz, Secretary, Commission, dated Jan. 25, 2005 ("Angel Reproposal Letter") at 3; Letter from Eric D. Roiter, Senior Vice President and General Counsel, Fidelity Management \& Research Company, to Jonathan G. Katz, Secretary, Commission, dated Jan. 26, 2005 ("Fidelity Reproposal Letter") at 7. These commenters also criticized the staff study for including average-price trades, even when the individual pieces of such trades may have been executed at or within the relevant quotations. The staff study, however, addressed this issue by excluding any trade reported as an averageprice trade, along with all other trades that included a non-blank condition code (primarily out-of-sequence trades, late trades, and previous reference price trades). Trade-Through Study at 9.

$86 \quad$ Bloomberg Reproposal Letter at 5; Nasdaq Reproposal Letter, Exhibit 1 at 5. 
periods of locking or crossing quotations. The staff analysis appropriately did not exclude longer periods of locked quotations. Indeed, locked quotations do not qualify for an exception from the Order Protection Rule - both the best bid and best offer are readily accessible at the same price and should not be traded through. Quotations rarely are crossed for three seconds and therefore are unlikely to have caused a material number of false trade-throughs. ${ }^{87}$

Finally, commenters asserted a variety of arguments relating to timing latencies in the quotation and trade data that might have caused the staff study to include false trade-throughs, including delayed trade reports, flickering quotations, stale quotations, manual quotations, and poor clock synchronization. ${ }^{88}$ The staff study, however, used a variety of means to minimize the effect of these factors on the data, as well as to check for the extent to which timing latencies might affect its results. The goal of the staff study was to obtain a reasonable estimate of the true trade-through rates for Nasdaq and NYSE stocks. It is important to recognize that, in designing a methodology to achieve this goal, the more conservative the methodology used to eliminate potentially false indications of trade-throughs, the greater the number of true trade-throughs that are likely to be eliminated. Thus, a methodology designed simply to assure the elimination of every conceivable false indication of a trade-through would not have been useful to the Commission in assessing its policy options because it would have severely underestimated true trade-through rates. The staff study's conservative methodology was designed to produce reasonable estimates of true trade-through rates, but still is more likely to have resulted in an understatement of trade-through rates than an overstatement, particularly for Nasdaq stocks.

$87 \quad \underline{\text { See, }}$ e.g., Nasdaq Reproposal Letter, Exhibit 1 at 5 n. 14 ("rare" for market to be crossed for the entirety of the three-second window). Letter at 7; Nasdaq Reproposal Letter, Exhibit 1 at 5; UBS Reproposal Letter at 4. 
Nasdaq stocks are traded primarily on automated markets, and the data for such stocks therefore should be less affected by timing latencies than the data for NYSE stocks, which is produced by both automated and manual markets.

For example, the staff study used a three-second quotation window for both Nasdaq and NYSE stocks to minimize the effect of possible timing lags between trade data and quotation data. Given that in Fall 2003 the overwhelming proportion of trades in Nasdaq stocks were executions of automated orders against automated quotations, with automated reporting of trades to the relevant Plan processor, three seconds is a conservative time frame to assess overall tradethrough rates. But even when the quotation window is extended to an overly conservative eight seconds and thereby clearly excludes a large number of true trade-throughs, trade-through rates remain significant $-1.7 \%$ of trades and $6.8 \%$ of share volume in Nasdaq stocks. ${ }^{89}$

In addition, the trade execution time derived from audit trail data for Nasdaq stocks, rather than trade report time, was used when it was supplied and whenever the two times differed to minimize timing latencies in the data caused by delayed reporting. Separate times derived from audit trail data are not reported for NYSE stocks, and delayed trade reports therefore could have contributed to false reports of trade-throughs in NYSE stocks. Similarly, for Nasdaq stocks, the quotations of Amex - the only market that displays manual quotations - were excluded from the staff study. Because the NYSE currently displays primarily manual quotations in NYSE stocks, while other markets display automated quotations, the difficulties of integrating data from manual and automated markets could have caused false indications of trade-throughs for NYSE stocks. ${ }^{90}$ The occurrence of false indications of trade-throughs caused

89 Trade-Through Study, Table 1.

90 See infra, section II.A.2 (discussion of need to limit coverage of Order Protection Rule to automated quotations). 
by manual quotations in exchange-listed stocks is addressed in the Order Protection Rule by protecting only automated quotations that are immediately accessible and immediately updated.

Fidelity incorrectly believed that the staff study failed to use the time of trade execution derived from audit trail data when analyzing trade-through rates in Nasdaq stocks. ${ }^{91}$ Fidelity also attached to its comment letter a paper prepared by two academics, Robert Battalio and Robert Jennings, which included a variety of criticisms of the staff study and the Reproposing Release in general ("Battalio/Jennings Paper"). ${ }^{92}$ Among other things, the Battalio/Jennings Paper cited an academic paper which, for trading in Nasdaq stocks in 1996 and 1997, found significant delays between the time of trade execution reflected in proprietary trading center data and the time of trade report in public data disseminated by Nasdaq as Plan processor. ${ }^{93}$ The authors of the Battalio/Jennings Paper, however, did not account for significant improvements in the quality of trade data for Nasdaq stocks since 1997. In particular, the NASD developed and implemented a new order audit trail system ("OATS"). ${ }^{94}$ As summarized in a 1998 NASD Notice to Members, OATS specifically was designed, among other things, to address the discrepancies between proprietary trade data and trade data reported to Nasdaq's Automated Confirmation Transaction Service ("ACT") :

$91 \quad$ Letter from Eric D. Roiter, Senior Vice President and General Counsel, Fidelity Management \& Research Company, to Jonathan G. Katz, Secretary, Commission, dated Mar. 28, 2005 ("Fidelity Reproposal Letter II") at 2.

92 Robert Battalio and Robert Jennings, Analysis of the Re-Proposing Release of Reg NMS and the OEA's Trade-Through Study (Mar. 28, 2005) (attached to Fidelity Reproposal Letter II). Other claims made in the Battalio/Jennings Paper are addressed below at notes 151-158, 296 and accompanying text.

93 Battalio/Jennings Paper at 12-13. For example, the academic study of 1996-1997 Nasdaq data found that $65 \%$ of trades were reported with delays of more than 8 seconds.

See, e.g., NASD Notice to Members 98-82 (Oct. 1998) at 1. 
OATS is designed to provide NASD Regulation, Inc. (NASD Regulation) with the ability to reconstruct markets promptly, conduct efficient surveillance, and enforce NASD and SEC rules. The SEC has directed that OATS must provide an accurate, time-sequenced record of orders and transactions from the receipt of an order through its execution. To accomplish this, NASD Regulation will combine information submitted to OATS with transaction data reported by members through ACT and quotation information disseminated by Nasdaq. ... The ACT trade data and the OATS order information will be used to construct an integrated audit trail. Under the amended rules, all trade reports for OATS-eligible securities entered into Nasdaq's ACT system will be required to have a time of execution expressed in hours, minutes, and seconds. ${ }^{95}$

To obtain the most accurate analysis of trade-through rates in Nasdaq stocks, the staff study used the audit trail record of the time of trade execution, rather than the time of trade report, whenever it was supplied and whenever the two times differed. ${ }^{96}$ The Battalio/Jennings Paper therefore was mistaken when it stated that "[w]ith the data OEA chose to use, we simply cannot conclude anything about actual trade-through rates" and when it "urge[d] the OEA to revise their methodology and conduct a trade-through analysis using audit-trail data." ${ }^{97}$ The staff study did indeed use audit trail data when available for Nasdaq stocks and therefore provides a reasonable basis for estimating true trade-through rates for Nasdaq stocks.

As noted above, however, the data for exchange-listed stocks may be more affected by timing latencies because it is generated by both automated and manual markets. The tradethrough rates estimated in the staff study therefore may somewhat overstate the true trade-rates for NYSE stocks. Given that the ITS trade-through provisions currently apply to exchange-listed

95

96 97

$\underline{\text { Id. }}$.

Trade-Through Study at 8 ("Trade data from the Nastraq file was used for the analysis of Nasdaq stocks. This file contains the executed price, share volume, trade report time, trade execution time, and an indicator of non-regular or unusual trade reporting or settlement conditions. The Nastraq trade file was selected over the TAQ trade file, as the latter does not have trade execution time, only trade report time.").

Battalio/Jennings Paper at 20. 
stocks, however, the Commission does not believe that the possibility that true trade-through rates potentially are lower than estimated in the staff study detracts from the strong policy reasons to maintain and strengthen trade-through protection for exchange-listed stocks. Rather, eliminating any trade-through protection for exchange-listed stocks could lead to rates that are as high, or higher, than were conservatively estimated for Nasdaq stocks, which have not been subject to any trade-through restrictions.

Moreover, the evidence from the staff study itself indicates that the concerns about delayed trade reporting discussed at length in the Battalio/Jennings Paper with respect to historical data have largely been resolved. For example, if delayed trade reporting were truly a serious problem that caused the staff study to be flawed, one would expect to see significant rates of trade-throughs by a single trading center's trades of its own quotations - the two data feeds would be out of synchronization with each other because trades were reported slower than quotation updates. In fact, however, the staff study found very low trade-through rates for single trading centers of their own quotations. ${ }^{98}$ The primary exception is for trades reported on Nasdaq that trade through Nasdaq quotations, but Nasdaq, unlike the other major markets, does not consist of a single trading center. Rather, it includes the NASDAQ Market Center, several ECNs, and many market makers that trade, to a great extent, separately. Thus, the trade-through rates for Nasdaq reflect true trade-throughs among different trading centers, not false tradethroughs of a single trading center of its own quotations.

Finally, problems with clock synchronization at the various trading centers are unlikely to have materially detracted from the accuracy of the staff study. The great majority of time stamps

$98 \quad$ See, e.g., Trade-Through Study, Table 5 (a rounded 0.0\% of CSE trades are tradethroughs of CSE quotations in Nasdaq stocks; a rounded $0.0 \%$ of PCX trades are tradethroughs of PCX quotations in Nasdaq stocks), and Table 12 (0.2\% of NYSE trades are trade-throughs of NYSE quotations in NYSE stocks). 
were assigned to quotations and trades as the data was received by a single entity - Nasdaq as the

Plan processor for Nasdaq stocks and SIAC as the Plan processor for NYSE stocks. ${ }^{99}$ One commenter, however, asserted that the two Plan processors themselves had major clock synchronization problems between quotation data and trade data. ${ }^{100}$ If this were in fact the case, the staff study likely would have found a high rate of trade-throughs by a single market of its own quotations, because the Plan processor's time stamps for the market's quotations would have been out of synchronization with its time stamps for the market's trades. As noted in the preceding paragraph, the staff study found few trade-throughs by a single market of its own quotations, thereby indicating that the Plan processors' quotation data and trade data are not materially out of synchronization.

\section{ii. Significance of Trade-Through Rates}

99 As discussed above, the staff study used the time of trade execution assigned by individual trading centers in their audit trail data for Nasdaq stocks when this time was available and differed from the time of trade report. The staff study noted that this occurred for approximately $5-10 \%$ of Nasdaq trades. Trade-Through Study at 8 n. 8 . As a result, problems with synchronization of clocks at the various Nasdaq trading centers (which must be synchronized within three seconds of the standard set by the National Institute of Standards and Technology) could have affected the time stamps for these trades. Nevertheless, the fact that trade-through rates remain significant for both Nasdaq stocks and exchange-listed stocks even when the quotation window is extended to a full eight seconds (thereby eliminating many true trade-throughs as well as false tradethroughs caused by unsynchronized time stamps) indicates that the staff study's estimates of trade-through rates were not materially affected by potential clock synchronization problems. Moreover, the trades most likely to be reported with different trade execution times than trade report times are large, manually-executed block trades reported by dealers. These are the very types of trades that commenters admitted often deliberately bypass displayed quotations. See, e.g., Fidelity Reproposal Letter at 3; Nasdaq Reproposal Letter, Exhibit 1 at 4. Angel Reproposal Letter at 3. 
Some commenters questioned whether the trade-through rates found by the staff study were significant enough to warrant adoption of the trade-through reproposal. ${ }^{101}$ They believed, for example, that the rates were low, particularly when considered as a percentage of total trades (2.5\% for both Nasdaq and NYSE stocks) and as the percentage of total share volume represented by the total displayed size of quotations that were traded through (1.9\% and 1.2\%, respectively, for Nasdaq and NYSE stocks). ${ }^{102}$ They therefore asserted that the rates did not demonstrate a serious problem or a need for regulatory action to address trade-throughs.

The Commission does not agree that the trade-through rates found in the staff study are insignificant, nor does it believe that the total number of trade-throughs is the sole consideration in evaluating the need for the Order Protection Rule. A valid assessment of their significance and the need for intermarket protection against trade-throughs must be made in light of the Exchange Act objectives for the NMS that would be furthered by the Order Protection Rule, including: (1) to promote best execution of customer market orders; (2) to promote fair and orderly treatment of customer limit orders; and (3) by strengthening protection of limit orders, to promote greater depth and liquidity for NMS stocks and thereby minimize investor transaction costs. The staff study examined trade-through rates from a variety of different perspectives, including percentage of trades, percentage of total share volume, percentage of share volume of trades of less than 10,000 shares, and percentage of total share volume of traded-through

101 ArcaEx Reproposal Letter at 6; Fidelity Reproposal Letter at 8; Instinet Reproposal Letter at 6 n. 6; Nasdaq Reproposal Letter, Exhibit 1 at 4; UBS Reproposal Letter at 4.

102 The $1.9 \%$ and $1.2 \%$ figures include only the total displayed size of quotations that were traded through by trades executed at prices inferior to the displayed quotations. 
quotations. ${ }^{103}$ In evaluating the need for the Order Protection Rule, the different measures vary in their relevance depending on the particular objective under consideration.

For example, the percentage of total trades that receive inferior prices is a particularly important measure when assessing the need to promote best execution of customer market orders. The staff study found that 1 of every 40 trades (2.5\%) for both Nasdaq and NYSE stocks have an execution price that is inferior to the best displayed price, or approximately 98,000 trades per day in Nasdaq stocks alone. ${ }^{104}$ As discussed above, ${ }^{105}$ investors (and particularly retail investors) often may have difficulty monitoring whether their orders receive the best available prices, given the rapid movement of quotations in many NMS stocks. The Commission believes that furthering the interests of these investors in obtaining best execution on an order-by-order basis is a vitally important objective that warrants adoption of the Order Protection Rule.

The percentage of total trades that receive inferior prices also is quite relevant when assessing the need to promote fair and orderly treatment of limit orders for NMS stocks. Many of the limit orders that are bypassed are small orders that often will have been submitted by retail investors. One of the strengths of the U.S. equity markets and the NMS is that the trading interests of all types and sizes of investors are integrated, to the greatest extent possible, into a unified market system. Such integration ultimately works to benefit both retail and institutional investors. Retail investors will participate directly in the U.S. equity markets, however, only to the extent they perceive that their orders will be treated fairly and efficiently. The perception of

103 See, e.g., Trade-Through Study at 1-2 and Tables 1, 4, 6, 7-8, 11, 13.

104 Id., Tables 1, 8. In October 2004, there were 3.9 million average daily trades reported in Nasdaq stocks. Source: http://www.nasdaqtrader.com. The average trade-through rate of $2.5 \%$ for Nasdaq stocks yields average daily trade-throughs of approximately 98,000.

105 Supra, note 53 and accompanying text. 
unfairness created when a retail investor has displayed an order representing the best price for an NMS, yet sees that price bypassed by 1 in 40 trades, is a matter of a great concern to the Commission. The Order Protection Rule is needed to maintain the confidence of all types of investors that their orders will be treated fairly and efficiently in the NMS.

The third principal objective for the Order Protection Rule is to promote greater depth and liquidity for NMS stocks and thereby minimize investor transaction costs. Depth and liquidity will be increased only to the extent that limit order users are given greater incentives than currently exist to display a larger percentage of their trading interest. The potential upside in terms of greater incentives for display is most appropriately measured in terms of the share volume of trades that currently do not interact with displayed orders. It is this volume of trading interest that will begin interacting with displayed orders after implementation of the Order Protection Rule.

The share volume of trade-throughs, rather than the number of trade-throughs, is most useful for assessing the effect of the Order Protection Rule on depth and liquidity because very small trades represent such a large percentage of trades in today's markets, but a small percentage of share volume. For example, the staff study found that, for Nasdaq stocks, 100-share trades represented $32.7 \%$ of the number of trade-throughs, but only $0.8 \%$ of the share volume of tradethroughs. ${ }^{106}$ Thus, the number of trade-throughs is useful for assessing the number of investors, particularly retail investors, affected by trade-throughs, while the share volume of trade-throughs is useful for assessing the extent to which depth and liquidity are affected by trade-throughs. For example, $41.1 \%$ of the share volume of trade-throughs in Nasdaq stocks is attributable to trades

$106 \quad$ Trade-Through Study, Table 6. 
of greater than 1000 shares that bypass quotations of greater than 1000 shares. ${ }^{107}$ Addressing the failure of this substantial volume of trading interest to interact with significant displayed quotations is a primary objective of the Order Protection Rule.

In contrast, the share volume of quotations that currently are traded through grossly underestimates the potential for increased incentives to display because it reflects only the current size of displayed quotations in the absence of strong price protection. As a result, the share volume of quotations that currently are traded through is a symptom of the problem that the Order Protection Rule is designed to address - a shortage of quoted depth - rather than an indication of the benefits that the Order Protection Rule will achieve. For example, when many Nasdaq stocks can trade millions of shares per day, but have average displayed size of less than 2000 shares at the NBBO, it will be nearly impossible for trade-throughs of displayed size to account for a large percentage of total share volume - there simply is not enough displayed depth. ${ }^{108}$ Small displayed depth is evidence of a market problem, not market quality.

Every trade-through transaction in today's markets potentially sends a message to limit order users that their displayed quotations can be and are ignored by other market participants. The cumulative effect of such messages over time as trade-throughs routinely occur each trading day should not be underestimated. When the total share volume of trade-through transactions that do not interact with displayed quotations reaches $9 \%$ or more for many of the most actively

Id.

108 See Supplemental Study at 4. Commission staff examined the average displayed depth in Nasdaq stocks to help evaluate commenters' claims concerning the current level of depth and liquidity for such stocks. The Supplemental Study measured the total depth displayed at the NBBO in Nasdaq stocks as follows: an average of 1,833 shares, a median of 581 shares, 384 shares at the 25th percentile, and 987 shares at the 75th percentile. 
traded Nasdaq stocks, ${ }^{109}$ this message is unlikely to be missed by those who watched their quotations being traded through. Certainly, the routine practice of trading through displayed size is most unlikely to prompt market participants to display even greater size.

Thus, the Commission believes that the percentage of share volume in a stock that trades through displayed and accessible quotations is a useful measure for assessing the potential increase in incentives for display of limit orders after implementation of the Order Protection Rule. In particular, the dual measurements of percentage of share volume of traded-through quotations (an overall 1.9\% for Nasdaq stocks) and the percentage of share volume of trades that bypass displayed quotations (an overall 7.9\% for Nasdaq stocks) likely represent the lower and upper bounds for a potential improvement in depth and liquidity after implementation of the Order Protection Rule.

Commenters opposing the trade-through reproposal questioned whether protection against trade-throughs would lead to any increase in the use of limit orders, particularly given the many reasons militating against display (e.g., displayed limit orders give a free option to all other market participants to trade at the limit order price). ${ }^{110}$ The Commission is aware of a variety of reasons that currently deter market participants from displaying their trading interest in full. Indeed, it is the existence of these negative factors, combined with a shortage of positive incentives for display, that have contributed to the relatively small displayed depth at the best prices that characterizes the market for many NMS stocks today. A large investor interested in buying 50,000 shares of a stock is unlikely to suddenly decide to display all of its trading interest simply because its order is given trade-through protection. The objective for the Order

$109 \quad$ See Trade-Through Study, Tables 4 and 11.

$110 \quad$ See, e.g., Instinet Reproposal Letter at 6 and n. 6; UBS Reproposal Letter at 3. 
Protection Rule is more modest. The Rule is designed to increase the perceived benefits of order display, against which the negatives are balanced. As a result, the market participant that currently displays only 500 shares of its 50,000-share trading interest might be willing to display 1000 shares. The collective effect of many market participants reaching the same conclusion would be a material increase in the total displayed depth in the market, thereby improving the transparency of price discovery and reducing investor transaction costs.

Moreover, because of the enormous volume of trading in NMS stocks, even a small percentage improvement in depth and liquidity could lead to very significant dollar benefits for investors in the form of reduced transaction costs. As discussed in section II.A.6 below, for example, the annual implicit transaction costs of large institutional investors are estimated at more than $\$ 30$ billion in 2003. ${ }^{111}$ As a result, even a small percentage reduction in these costs because of improved depth and liquidity would result in very substantial annual savings for millions of mutual fund and pension fund investors. The Commission therefore believes that the estimated trade-through rates in the staff study support the need for enhanced protection of limit orders as a means to promote greater depth and liquidity in NMS stocks.

\section{b. Efficiency of Trading in Nasdaq and NYSE Stocks}

A few commenters on the original proposal submitted empirical data to support their

claim that trading in Nasdaq stocks currently is more efficient than trading in NYSE stocks. ${ }^{112}$

111 Implicit transaction costs are associated with the prices at which trades are executed, in contrast with explicit transaction costs such as commissions. Implicit costs include the adverse price movements experienced by institutional investors when searching for the liquidity and executing the orders necessary to trade in large size. See infra, notes 146, 300-305, 990, and accompanying text.

112 Instinet Letter, Exhibit A; Nasdaq Letter II, Attachment II. One commenter on the reproposal referred the Commission to an academic study of trading in Nasdaq and NYSE stocks, asserting that its conclusion was that "bid-ask spreads were shown to be narrower and liquidity shown to be greater in Nasdaq stocks." STANY Reproposal 
Specifically, they submitted tables asserting that effective spreads in Nasdaq stocks in the S\&P 500 are significantly narrower than effective spreads in NYSE stocks in the S\&P 500. ${ }^{113}$ To help assess and respond to the views of commenters on market efficiency, the Commission staff analyzed Rule 11Ac1-5 reports and other trading data to evaluate the markets for Nasdaq and NYSE stocks. ${ }^{114}$

In its comment on the reproposal, Nasdaq argued that the staff studies contained flaws in their methodologies. ${ }^{115}$ With respect to the S\&P Index Study, Nasdaq stated that the execution quality statistics were drawn from an atypical month and that the methodology for analyzing effective spreads favored higher-priced NYSE stocks over lower-priced Nasdaq stocks. The

Letter at 8. The referred study was Lehn, Patro, and Shastri, Information Shocks and Stock Market Liquidity: A Comparison of the New York Stock Exchange and Nasdaq (presented at the American Enterprise Institute on June 10, 2004) (available at www.aei.com). The commenter misinterpreted, however, the results of the study. The study found that "during both the calm and stress periods, quoted and effective bid-ask spreads are significantly lower for NYSE versus Nasdaq stocks, a result generally consistent with the existing literature." Id. at 2. Finally, the Mercatus Center referenced several statistical studies in its comment letter and concluded that the findings of such studies are mixed. Letter from Susan E. Dudley, Director, Regulatory Studies Program, Mercatus Center, George Mason University, to Jonathan G. Katz, Secretary, Commission, dated May 24, 2004 ("Mercatus Center Letter") at 3.

113 Nasdaq and Instinet based their tables on statistics derived from the reports ("Dash 5 Reports") on order execution quality made public by markets pursuant to Exchange Act Rule 11Ac1-5 (redesignated as Rule 605 under Regulation NMS). Their source for these reports is Market Systems, Inc. ("MSI"), a private vendor that collects the reports of all markets each month and includes them in a searchable database. MSI also is the source of the Dash 5 Reports used in the staff analyses.

114 Memorandum to File, from Office of Economic Analysis, dated December 15, 2004 (comparative analysis of execution quality for NYSE and NASDAQ stocks based on a matched sample of stocks) ("Matched Pairs Study"); Memorandum to File, from Division of Market Regulation, dated December 15, 2004 (comparative analysis of Rule 11Ac1-5 statistics by S\&P Index) ("S\&P Index Study"). The Matched Pair Study and S\&P Index Study are in Public File No. S7-10-04 and are available for inspection on the Commission's Internet Web site (http://www.sec.gov). Nasdaq Reproposal Letter, Exhibit 1 at 1. 
S\&P Index Study presented statistics from January 2004, however, because this was the month selected by Nasdaq in the comment letter that it submitted on the proposal in July 2004. Moreover, the general statistics reported by Nasdaq for later months do not appear to differ materially from those for January $2004 .{ }^{116}$ In addition, the S\&P Index Study analyzed investor transaction costs in terms of a percentage of investment rather cents per share because, as discussed below, the percentage of investment methodology most reflects economic reality for investors. ${ }^{117}$

With respect to the Matched Pairs Study, Nasdaq asserted that it largely examined small stocks. Nasdaq noted, for example, that more than $25 \%$ of the stocks included in the Matched Pairs Study were not eligible for NYSE listing and that only $10 \%$ of the stocks were included in the Nasdaq-100 Index. The purpose of the Matched Pairs Study, however, was to compare execution quality in Nasdaq and NYSE across a broad range of stocks, not solely for large stocks or those that were eligible for NYSE listing. Although 25\% of the stocks may not have been eligible for NYSE listing, the staff analysis used matching criteria more directly designed to produce an "apples-to-apples" comparison - market capitalization, price, average daily dollar volume (adjusted downward by 30\% for Nasdaq stocks to reflect trade reporting practices in such stocks), and relative price range. The Commission therefore believes that the staff studies provide a valid basis to compare trading in Nasdaq stocks and NYSE stocks.

116 See, e.g., id., Exhibit 1 at 15 (table showing that blended effective spread statistics in terms of cents-per-share for both market orders and marketable limit orders generally declined throughout 2004 for both Nasdaq and NYSE stocks).

117 To the extent Nasdaq has more low-priced stocks than the NYSE, the Dash 5 statistics favor Nasdaq in the larger order size categories because of "bracket creep" - i.e., it typically will be easier to execute a 2000 share order in a $\$ 5$ stock ( $\$ 10,000$ total volume) than to execute a 2000 share order in a $\$ 40$ stock ( $\$ 80,000$ total volume), assuming the stocks are otherwise comparable. 
The staff studies indicate that the execution quality statistics submitted by commenters on the original proposal are flawed. The claimed large and systematic disparities between Nasdaq and NYSE effective spreads disappear when an analysis of execution quality more appropriately controls for differences in stocks, order types, and order sizes. ${ }^{118}$ The staff studies reveal that both the market for Nasdaq stocks and the market for NYSE stocks have significant strengths. But, as discussed below, both markets also have weaknesses that could be reduced by strengthened protection against trade-throughs.

First, the effective spread analyses submitted by commenters do not, in a number of respects, reflect appropriately the comparative transaction costs in Nasdaq and NYSE stocks. ${ }^{119}$ They were presented in terms of "cents-per-share" and therefore failed to control for the varying level of stock prices between Nasdaq stocks and NYSE stocks in the S\&P 500. Lower priced stocks naturally will tend to have lower spreads in terms of cents-per-share than higher priced stocks, even when such cents-per-share spreads constitute a larger percentage of stock price and therefore represent transaction costs for investors that consume a larger percentage of their investment. By using cents-per-share statistics, commenters did not adjust for the fact that the average prices of Nasdaq stocks are significantly lower than the average prices of NYSE stocks.

118 Matched Pairs Study, Tables 4-10; S\&P Index Study, Tables 2-9.

119 The effective spread is a useful measure of transaction costs for market orders, particularly for small order sizes, because it reflects the prices actually received by investors when compared to the best quotes at the time a market received an order. Consequently, unlike the quoted spread, the effective spread reflects any cost to investors caused by movement in prices during a delay between receipt of an order and execution of an order. In other words, the effective spread penalizes slow markets for failing to execute trades at their quoted prices at the time they received an order. It therefore provides an appropriate criterion with which to compare execution quality between automated and manual markets for comparable stocks, order types, and order sizes. As discussed below, however, effective spread statistics do not capture transaction costs that are attributable to low fill rates - the failure to obtain an execution - for marketable limit orders. 
For example, the average price of Nasdaq stocks in the S\&P 500 in January 2004 was $\$ 34.14$, while the average price of NYSE stocks was $\$ 41.32 .{ }^{120}$

The effective spread analyses submitted by commenters also were weakened by their failure to address the much lower fill rates of orders in Nasdaq stocks than orders in NYSE stocks. The commenters submitted "blended" statistics that encompassed both market orders and marketable limit orders. The effective spread statistics for these order types are not comparable, however, because market orders do not have a limit price that precludes their execution at prices inferior to the prevailing market price at time of order receipt. In contrast, the limit price of marketable limit orders often precludes an execution, particularly when there is a lack of liquidity and depth at the prevailing market price. For example, the fill rates for marketable limit orders in Nasdaq stocks generally are less than $75 \%$, and often fall below $50 \%$ for larger order sizes. ${ }^{121}$

Accordingly, investors must accept trade-offs when deciding whether to submit market orders or marketable limit orders (particularly when the limit price equals the current market price). Use of a limit price generally assures a narrower spread by precluding an execution at an inferior price. By precluding an execution, however, the limit price may cause the investor to "miss the market" if prices move away (for example, if prices rise when an investor is attempting to buy). Effective spreads for marketable limit orders therefore represent transaction costs that are conditional on execution, while effective spreads for market orders much more completely reflect the entire implicit transaction cost for a particular order. Market orders represent only approximately $14 \%$ of the blended flow of market and marketable limit orders in Nasdaq stocks

$120 \quad$ S\&P Index Study, Table 1.

$121 \quad$ Matched Pairs Study, Table 10; S\&P Index Study, Tables 7, 9. 
(reflecting the fact that ECNs now dominate Nasdaq order flow and limit orders represent the vast majority of ECN order flow). ${ }^{122}$ In contrast, market orders represent approximately $36 \%$ of the blended order flow in NYSE stocks. ${ }^{123}$ Accordingly, the effective spread statistics for marketable limit orders, and particularly for orders in Nasdaq stocks, must be considered in conjunction with the fill rate for such orders - while a narrow spread is good, the benefits are greatly limited if investors are unable to obtain an execution at that spread. The analyses presented by the commenters, however, did not address the respective fill rates for Nasdaq stocks and NYSE stocks or reflect the inherent differences in measuring the transaction costs of market orders and marketable limit orders.

The analyses prepared by Commission staff are designed to provide appropriate evaluations of comments on the efficiency of trading in Nasdaq and NYSE stocks. In particular, they are more finely tuned to evaluate trading for different types of stocks with varying trading volume, different types of orders, and different sizes of orders. These analyses indicate that the markets for Nasdaq and NYSE stocks each have weaknesses that an intermarket price protection rule could help address. By "weakness," the Commission simply means that there appears to be considerable room for improvement. For example, the effective spread statistics for large, electronically-received market orders in NYSE stocks show significant "slippage" - the amount by which orders are executed at prices inferior to the national best bid or offer ("NBBO") at the time of order receipt. ${ }^{124}$ Slippage often results in effective spreads for large orders that are many times wider than the effective spreads for small orders in the same NYSE stocks. By protecting

122 Most market orders in Nasdaq stocks are executed by market-making dealers pursuant to agreement with their correspondent or affiliated brokers.

$123 \quad$ Matched Pairs Study at 1.

124 Matched Pairs Study, Tables 4, 7; S\&P Index Study, Tables 2, 4, 6, 8. 
automated quotations, the Order Protection Rule should enhance the depth and liquidity available for large, electronic orders in NYSE stocks and thereby improve their execution quality.

For Nasdaq stocks, the Rule 11Ac1-5 statistics reveal very low fill rates for larger sizes of marketable limit orders (e.g., 2000 shares or more), which generally fall below 50\% for most Nasdaq stocks. Contrary to the assertion of some commenters, ${ }^{125}$ certainty of execution for large marketable limit orders clearly is not a strength of the current market for Nasdaq stocks. Certainty of a fast response is a strength, but much of the time the response to large orders will be a "no fill" at any given trading center. ${ }^{126}$

Two commenters on the reproposal disputed whether low fill rates for marketable limit orders in Nasdaq stocks indicate any weakness that needed to be addressed. ${ }^{127}$ Instinet, for example, believed that "the Commission is misplaced in its contention that low fill rates in Nasdaq stocks are a weakness of that market," and that they are a phenomenon "intrinsic to electronic markets in which market participants are free to cancel and replace orders." ${ }^{128}$ Instinet

125 See, e.g., Instinet Reproposal Letter at 7; Nasdaq Letter II at 6. In addition to effective spread statistics, Instinet submitted statistics indicating that combined market and marketable limit orders in Nasdaq stocks were more likely to be executed at or inside the NBBO than such orders in NYSE stocks. Instinet Letter, Table I-C. These statistics, however, only reflect orders that in fact receive an execution - not the large volume of orders in Nasdaq stocks that fail to receive any execution at all. Some commenters asserted that the large number of limit orders in Nasdaq stocks indicates that sufficient incentives exist for the placement of limit orders in such stocks.

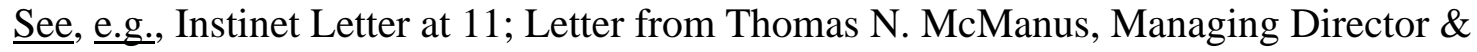
Counsel, Morgan Stanley \& Co. Incorporated, to Jonathan G. Katz, Secretary, Commission, dated August 19, 2004 ("Morgan Stanley Letter") at 14. Strengthened intermarket trade-through protection, however, is designed to improve the quality of limit orders in a stock, particularly their displayed size, and thereby promote greater depth and liquidity. This goal is not achieved, for example, by a large number of limit orders with small sizes and high cancellation rates. Instinet Reproposal Letter at 6-7; Nasdaq Reproposal Letter at 5.

128 Instinet Reproposal Letter at 6-7. 
also noted that many market centers in Nasdaq stocks have significant reserve size in addition to displayed size and that market participants commonly routed oversized marketable limit orders to attempt to interact with reserve size. ${ }^{129}$ Similarly, Nasdaq stated that the staff studies "erroneously conclude that differential fill rates for large marketable limit orders in Nasdaqlisted and NYSE-listed stocks are evidence of a defect in Nasdaq's market structure," and that they failed "to consider a widely used order routing technique of intentionally sending oversized orders at displayed quotes searching (also known as "pinging") for reserves within the many limit order books trading Nasdaq-listed securities." ${ }^{130}$ Nasdaq also asserted that marketable limit orders are "exceedingly popular in electronic venues where they have effectively supplanted market orders as the order of choice in accessing availability liquidity at the current price."131

The Commission continues to believe that fill rates for large marketable limit orders are a useful measure of order execution quality for Nasdaq stocks. They are especially useful because they measure the availability of both displayed and undisplayed liquidity, whereas simply measuring displayed size would understate the total liquidity readily available for Nasdaq stocks. Indeed, the existence of "pinging" orders searching for reserve size in Nasdaq stocks at electronic markets is widely known. Such oversized orders (i.e., orders with sizes greater than displayed size) could as aptly be labeled "liquidity search" orders as "pinging" orders. Given the relatively

129 Instinet Reproposal Letter at 7. Instinet also asserted that low fill rates for large marketable limit orders might be attributable to the frequent locking of markets in lowpriced stocks. In fact, however, the Dash 5 fill rates for large orders in low-priced stocks generally are higher than those for high-priced stocks, likely because the dollar value of such orders is low (i.e., 5000 shares of a $\$ 5$ stock $(\$ 25,000)$ generally will be easier to trade than 5000 shares of a $\$ 50$ stock $(\$ 250,000)$ ). See infra, text accompanying notes 141-142 (average fill rates for large orders in low-priced stocks in Nasdaq-100 Index are much higher than fill rates for most other stocks in Index).

$130 \quad$ Nasdaq Reproposal Letter at 5.

$131 \quad$ Id., Exhibit 1 at 8. 
small displayed size in nearly all Nasdaq stocks (i.e., significantly less than 2000 shares), ${ }^{132}$ orders with sizes of 2000 to 4999 shares and 5000 to 9999 shares (the two largest Dash 5 size categories) generally will exceed the displayed size. Thus, low fill rates demonstrate that the total displayed and reserve liquidity available for Nasdaq stocks at any particular trading center typically is small compared to the demand for liquidity at the inside prices. Moreover, increased displayed liquidity - a principal goal of the Order Protection Rule - would promote market efficiency by reducing the uncertainty and costs associated with the need for market participants to "ping" electronic markets for liquidity that is held in reserve.

The Reproposing Release did not suggest, however, that the differential fill rates for large marketable limit orders in Nasdaq and NYSE stocks were useful in comparing the liquidity and depth available in each market. Instead, the Reproposing Release focused on the most relevant Dash 5 statistic for each market, given its particular trading characteristics. As noted above, the significant amount of "slippage" in the execution of electronically-received large market orders in NYSE stocks suggest that improved incentives for display of automated trading interest will help improve execution quality for NYSE stocks. Notably, Instinet and Nasdaq agreed that slippage rates for automated market orders represented a problem in the market for NYSE stocks. ${ }^{133}$ Because market participants generally choose not to submit market orders to electronic markets in Nasdaq stocks, however, the fill rates for marketable limit orders are a more relevant Dash 5 statistic to assess depth and liquidity in Nasdaq stocks.

132 Supplemental Trade-Through Study at 5. In Fall 2003, only 273 Nasdaq stocks had average displayed size at the NBBO of 2000 or greater shares, 213 of which were lowpriced stocks (prices of less than $\$ 10$ per share).

133 Instinet Reproposal Letter at 6 ("we ourselves make a point of a high level of slippage as being an issue in the NYSE market"); Nasdaq Letter II, Attachment II (table comparing market order shares traded outside the quote for Nasdaq and NYSE stocks). 
Accordingly, the Commission's concern with fill rates for larger orders in Nasdaq stocks is not that they are lower than those for NYSE stocks, but that they are very low in absolute terms - often falling well below 50\%. ${ }^{134}$ Moreover, the larger order sizes typically account for a small percentage of executed shares compared to the executed shares of smaller order sizes. ${ }^{135}$ When considered in conjunction with one another, the low fill rates and small percentage of executed shares indicate substantial room for improvement in depth and liquidity in many Nasdaq stocks. An important objective for Regulation NMS as a whole is to facilitate more efficient trading in larger sizes, an objective that has become much more important to large investors since decimalization. ${ }^{136}$ An improvement in fill rates for larger sized orders (or an increase in their percentage of executed shares) would evidence progress toward this objective.

Fill rates for marketable limit orders, however, offer only indirect evidence of the total transaction costs incurred by investors. They indicate that no execution was obtained for an investor order at a particular trading center, but do not indicate how the investor subsequently fared in obtaining an execution. As discussed above, there are significant trade-offs between marketable limit orders and market orders. The use of a restrictive limit price at the NBBO

$134 \quad$ See, e.g., Matched Pairs Study, Table 10.

135 See, e.g., Matched Pairs Study, Table 3. Nasdaq also asserted that the difference in share volume of Dash 5 marketable limit orders for Nasdaq stocks versus NYSE stocks indicated the superiority of Nasdaq execution quality for marketable limit orders. The difference in marketable limit order share volume in Nasdaq and NYSE stocks, however, is attributable to structural differences between the two markets. For example, many large orders in NYSE stocks are handled manually by brokers on the NYSE floor and therefore are not included in the Dash 5 statistics, which only encompass electronic orders. In addition, a greater volume of market orders are executed in NYSE stocks than in Nasdaq stocks. Matched Pairs Study, Table 3. As discussed below, the need for a restrictive limit price to prevent outside-the-quote executions likely is an additional reason that Nasdaq market participants choose to use marketable limit orders rather than market orders. See infra, notes 138-139 and accompanying text. See Reproposing Release, 69 FR at 77425. 
precludes any slippage in execution price, but also may cause an investor to miss the market if prices subsequently move away from the order (i.e., rise when an investor is attempting to buy or fall when an investor is attempting to sell). To evaluate the total transaction costs associated with an order that goes unfilled or receives a partial fill, it is necessary to know the price at which the investor ultimately obtained an execution for its full order.

To help the Commission evaluate and respond to commenters' criticisms and, in particular, to supplement its analysis of fill rates as a measure of depth and liquidity for Nasdaq stocks and to evaluate the extent to which missed fills may lead to higher investor transaction costs, Commission staff also examined execution quality statistics for marketable limit orders in Nasdaq-100 Index stocks that are executed outside the best quotes at the Inet ATS and the NASDAQ Market Center. ${ }^{137}$ By definition, such orders have been placed with liberal limit prices that give more flexibility for executions away from the NBBO than orders with limit prices that are restrictively set at the NBBO. Accordingly, the slippage rates for such orders give another indication of available liquidity for Nasdaq-100 stocks.

The statistics for outside-the-quote executions in marketable limit orders buttress a conclusion that there is significant room for improved depth and liquidity in Nasdaq stocks. For

137 Memorandum to File, from Division of Market Regulation, dated April 6, 2005 (analysis of Rule 11Ac1-5 statistics for Nasdaq-100 Index) ("Nasdaq-100 Index Supplemental Study"). The Nasdaq100 Index Supplemental Study has been placed in Public File No. S7-10-04 and is available for inspection on the Commission's Internet Web site (http://www.sec.gov). The staff examined Nasdaq-100 stocks in response to Nasdaq's suggestion that they are most appropriate for evaluating execution quality in the market for Nasdaq stocks. See Nasdaq Reproposal Letter, Exhibit 1 at 1, 11. The statistics are from December 2004 and are equal-stock weighted to give a more representative view of trading across all stocks, rather than a view concentrated on a few stocks that are much more actively traded than the others. 
example, the Inet ATS did not fill $83.0 \%$ of its large marketable limit orders. ${ }^{138}$ Of the orders it executed, $19.5 \%$ of shares were executed outside the quote by an average of 2.7 cents. Thus, while the overall quoted and effective spreads for executed shares for large orders were, respectively, 1.6 cents and 2.5 cents, the spread for outside the quote executions was 7.0 cents 438\% wider than the narrow quoted spread. The statistics for the NASDAQ Market Center are similar. It did not fill $68.4 \%$ of its large marketable limit orders. ${ }^{139}$ Of the orders it executed, $14.7 \%$ were executed outside the quote by an average of 2.3 cents. The overall quoted and effective spreads for large orders were, respectively, 1.6 cents and 2.5 cents, compared to 6.2 cents for outside the quote executions - 388\% wider than the narrow quoted spread. The outside-the-quote spreads provide the best available indication of execution quality that otherwise would have been obtained at the time orders were placed for the $83.0 \%$ and $68.4 \%$ of shares that were not filled due to their restrictive limit price. The outside-the-quote spreads also are relevant in assessing the reasons why market participants most often use marketable limit orders with limit prices at the NBBO rather than market orders when trading Nasdaq stocks.

In addition, the supplemental staff study separately examined fill rates and executed share volume for types of Nasdaq-100 stocks where liquidity for orders with large share sizes can reasonably be expected to be highest. ${ }^{140}$ These stock groupings were selected primarily to assess whether low fill rates for large marketable limit orders are an inherent part of the structure of the market for Nasdaq stocks. Specifically, the supplemental staff study calculated fill rates and

$138 \quad$ Nasdaq-100 Index Supplemental Study, Table 1 (orders with sizes of 5000 to 9999 shares).

139 Nasdaq-100 Index Supplemental Study, Table 5 (orders with sizes of 5000 to 9999 shares).

140 Nasdaq-100 Index Supplemental Study, Tables 2-3, 6-7. 
executed share volume for the three Nasdaq stocks with the largest capitalization - Microsoft, Intel, and Cisco. These three stocks are widely recognized among all Nasdaq stocks as having markets with significant depth and liquidity. In addition, the supplemental staff study examined the seven Nasdaq-100 stocks with share prices of less than $\$ 10$ per share. Liquidity for orders with large share sizes in these stocks can be expected to be higher than for stocks with higher prices because the dollar sizes are much smaller (e.g., a 5000 share order in a $\$ 5$ stock totals $\$ 25,000$, whereas a 5000 share order in a $\$ 30$ stock totals $\$ 150,000$ ). In terms of economic reality, therefore, large orders in a low-priced stock generally are easier to execute than large orders in a higher-priced stock, assuming the stocks are otherwise comparable. Finally, the supplemental staff study separately examined the other 90 stocks in the Nasdaq-100 Index (i.e., stocks with prices of at least $\$ 10$ per share other than Microsoft, Intel, and Cisco).

The supplemental staff study reveals that low fill rates for large marketable limit orders are not an inherent feature of the market for Nasdaq stocks. For example, the NASDAQ Market Center fill rates for large orders are $76.7 \%$ for the three large-cap stocks, $70.1 \%$ for the lowpriced stocks, and $27.1 \%$ for the other 90 stocks in the Nasdaq-100 Index. ${ }^{141}$ Similarly, the Inet ATS fill rates for large orders are 58.5\% for the three large-cap stocks, $55.0 \%$ for low-priced stocks, and $12.6 \%$ for the other 90 stocks in the Nasdaq-100 Index. ${ }^{142}$

The order execution quality measures included in Dash 5 reports do not, of course, reflect all types of investor transaction costs. They generally focus on the execution price of individual orders in comparison with the best quoted prices at the time orders are received. As a result, they do not capture transaction costs that are associated with the short-term movement of quoted

\footnotetext{
$141 \quad$ Nasdaq-100 Index Supplemental Study, Tables, 6-8.

142 Nasdaq-100 Index Supplemental Study, Tables 2-4.
} 
prices. To further assist the Commission in evaluating the views of commenters, Commission staff has analyzed price volatility for trading in Nasdaq and NYSE stocks. ${ }^{143}$ This analysis particularly focuses on transitory volatility - short-term fluctuations away from the fundamental or "true" value of a stock. Transitory volatility should be distinguished from fundamental volatility - price fluctuations associated with factors independent of market structure, such as earnings changes and other economic determinants of stock prices. The staff analysis found that on average both intraday volatility and transitory volatility are higher for Nasdaq stocks than for NYSE stocks. ${ }^{144}$ Excessive transitory volatility indicates a shortage of depth and liquidity that otherwise would minimize the effect of short-term order imbalances. Such volatility may provide benefits in the form of profitable trading opportunities for short-term traders or market makers, but these benefits come at the expense of other investors, who would be buying at artificially high or selling at artificially low prices. Retail investors, in particular, tend to be relatively uninformed concerning short-term price movements and are apt to bear the brunt of the

143 Memorandum to File, from Office of Economic Analysis, dated December 15, 2004 (analysis of volatility for stocks switching from NASDAQ to NYSE) ("Volatility Study"). The Volatility Study has been placed in Public File No. S7-10-04 and is available for inspection on the Commission's Internet Web site (http://www.sec.gov).

144 Volatility Study at 1. Nasdaq raised a number of objections to the Volatility Study in its comment on the reproposal. Nasdaq Reproposal Letter, Exhibit 1 at 16-19. To help the Commission evaluate these objections, Commission staff performed supplemental analysis to reflect Nasdaq's concerns and to provide a fuller description of volatility for Nasdaq and NYSE stocks. The results of the additional analysis confirm the basic conclusions reached in the original analysis - the stocks that switched from Nasdaq listing to NYSE listing during the sample period experienced a decrease in total volatility and in transitory volatility. Memorandum to File, from Office of Economic Analysis, dated April 6, 2005 (additional analysis of volatility for stocks switching from NASDAQ to NYSE) ("Supplemental Volatility Study"). The Supplemental Volatility Study has been placed in Public File No. S7-10-04 and is available for inspection on the Commission's Internet Web site (http://www.sec.gov). 
trading costs associated with excessive transitory volatility. ${ }^{145}$ The Order Protection Rule, by promoting greater depth and liquidity, is designed to help reduce excessive transitory volatility in Nasdaq stocks.

Finally, an important measure of depth and liquidity for NMS stocks is the transaction costs actually incurred by institutional investors when they trade in large size. These costs are not readily available for public view because their measurement requires access to a large volume of private order and execution data of institutional investors. One of the leading authorities on institutional transaction costs uses an extensive database of such data obtained from its clients to calculate their transaction costs. It recently published calculations of average transaction costs for Nasdaq and NYSE stocks during the fourth quarter of 2003 as, respectively, 83 basis points and 55 basis points. ${ }^{146}$ Given the significant differences in the overall nature of Nasdaq and NYSE stocks, these figures cannot be used to assess the relative efficiency of the two markets. The figures for both, however, suggest room for improved depth and liquidity, particularly when compared with the average quoted spreads in NMS stocks, which generally are less, and often much less, than 10 basis points for large capitalization stocks that dominate trading volume. ${ }^{147}$

145 See infra, section I.A.2 (discussion of Exchange Act emphasis on minimizing volatility to protect interests of investors).

146 Wayne H. Wagner, Faster!, 1 FIXGlobal 54, 55 (3rd Quarter 2004) (estimate of Plexus Group, Inc.). Explicit transaction costs such as commissions represent only a small part of total transaction costs calculated by Plexus (e.g., 12 basis points for large capitalization stocks). The remaining implicit transaction costs are attributable to the impact of the trade on market price as it interacts with other buyers and sellers, delay or liquidity search costs that occur when portions of the trade are held back for fear of upsetting the supply/demand balance, and opportunity costs that arise when the trade is abandoned before all desired shares have been acquired. $\underline{\text { Id. }}$.

See, e.g., Matched Pairs Study, Tables 3, 8. 


\section{c. Need for Intermarket Rule to Achieve Effective Protection Against Trade-Throughs}

As discussed in the preceding section, the relevant data, as well as the policy choices the Commission has articulated above, supports the need for strengthened protection against tradethroughs in both Nasdaq and exchange-listed stocks. Some commenters argued, however, that competitive forces alone would achieve the fairest and most efficient markets. ${ }^{148}$ In particular, they asserted that reliance on efficient access to markets and brokers' duty of best execution would be sufficient without the need for an intermarket rule against trade-throughs. This argument, however, fails to take into account two structural problems - principal/agent conflicts of interest and "free-riding” on displayed prices.

Agency conflicts may occur when brokers have incentives to act otherwise than in the best interest of their customers. For example, brokers may have strong financial and other interests in routing orders to a particular market, which may or may not be displaying the best price for a stock. Moreover, the Commission has not interpreted a broker's duty of best execution for retail orders as requiring that a separate best execution analysis be made on an order-by-order basis. ${ }^{149}$ Nevertheless, retail investors generally expect that their small orders will be executed at the best displayed prices. They may have difficulty monitoring whether their individual orders miss the best displayed prices at the time they are executed and evaluating the

148 See, e.g., ArcaEx Reproposal Letter at 5; STA Reproposal Letter at 3; STANY Reproposal Letter at 2.

149 See, e.g., Securities Exchange Act Release No. 37619A (Sept. 6, 1996), 61 FR 48290, 48323 n. 362 ("Order Handling Rules Release") ("Commission has recognized that it may be impractical, both in terms of time and expense, for a broker that handles a large volume of orders to determine individually where to route each order it received."). See also $\underline{\text { infra, }}$, section II.B.4 (discussion of duty of best execution). 
quality of service provided by their brokers. ${ }^{150}$ Given the large number of trades that fail to obtain the best displayed prices (e.g., approximately 1 in 40 trades for both Nasdaq and NYSE stocks), the Commission is concerned that many of the investors that ultimately received the inferior price in these trades may not be aware that their orders did not, in fact, obtain the best price. The Order Protection Rule will backstop a broker's duty of best execution on an order-byorder basis by prohibiting the practice of executing orders at inferior prices, absent an applicable exception.

Just as importantly, even when market participants act in their own economic selfinterest, or brokers act in the best interests of their customers, they may deliberately choose, for various reasons, to bypass (i.e., not protect) limit orders with the best displayed prices. For example, an institution may be willing to accept a dealer's execution of a particular block order at a price outside the NBBO, thereby transferring the risk of any further price impact to the dealer. Market participants that execute orders at inferior prices without protecting displayed limit orders are effectively "free-riding” on the price discovery provided by those limit orders. Displayed limit orders benefit all market participants by establishing the best prices, but, when bypassed, do not themselves receive a benefit, in the form of an execution, for providing this public good. This economic externality, in turn, creates a disincentive for investors to display limit orders and ultimately could negatively affect price discovery and market depth and liquidity.

Fidelity's comment letters on the reproposal questioned whether large trades that bypass displayed quotations should be considered as free-riding on the price discovery provided by

$150 \quad$ See supra, note 53 and accompanying text (discussion of difficulty for investors to monitor whether their order execution prices equal the best quoted prices at the time of order execution). 
displayed limit orders. ${ }^{151}$ It emphasized that the price-formation process reflects information stemming from all trading interest and that institutional trading interest is an important part of the process. As evidence, it noted that almost one-third of reported volume on the NYSE in 2004 was of block size, typically representing undisplayed institutional trading interest.

Institutional trading interest, both displayed and undisplayed, undoubtedly is an important part of the price discovery process. Notably, the large volume of block trades currently executed on the NYSE is subject both to the NYSE's order interaction rules and the ITS trade-through rules. Accordingly, NYSE block trades cannot be considered as free-riding on displayed limit orders, in contrast to block trades reported by block positioners in the OTC market that currently do not interact with (and thereby are free-riding on) displayed liquidity and are not covered by the ITS provisions.

Moreover, the Order Protection Rule does not require that all institutional trading interest be displayed. Rather, the Rule strengthens the incentive for the voluntary display of a greater proportion of latent trading interest by assuring that, when such interest is displayed, it is protected against most trade-throughs. In these circumstances, institutions will choose to display when they determine it is in their own interests, not because it is mandated by Commission rule. Greater displayed size will improve the quality and transparency of price discovery for all market participants.

Fidelity also asserted that "an institutional investor, seeking to acquire or dispose a large block of stock will be put to a distinct and unfair advantage if it is deprived of the ability to negotiate, at one time and at a specified price, an all-in price for its block trade with a dealer." ${ }^{152}$

$151 \quad$ Fidelity Reproposal Letter at 5; Fidelity Reproposal Letter II at 2. $\underline{\text { See }} \underline{\text { also }}$ Battalio/Jennings Paper at 2.

$152 \quad$ Fidelity Reproposal Letter at 3. 
Similarly, the Battalio/Jennings Paper suggests that, for large marketable limit orders of institutions, "it might be better to ignore a penny quote for a few hundred shares in order to get a large order done quickly rather than try to chase the small quote and risk losing the ability to fill the size desired." 153 These contentions do not recognize that the Order Protection Rule does not, in fact, preclude institutions from negotiating "all-in" prices for their trades with dealers or immediately routing orders to access larger-sized depth-of-book quotations. Rather, the Rule simply requires a dealer, at the same time as executing a large institutional order at an all-in price, to route an intermarket sweep order to execute against the displayed size of protected quotations with superior prices to the institution's trade price. Similarly, the Rule allows an institution to simultaneously route intermarket sweep orders to execute against both small-sized quotations at the best prices and larger-sized depth-of-book quotations. The Rule therefore does not require institutions to parcel out their block orders in a series of transactions over time.

Fidelity and the Battalio/Jennings Paper also incorrectly asserted that the Commission's concern about free-riding on displayed quotations related only to the limit orders of retail investors, citing a number of academic studies indicating that institutional trades and quotations are important contributors to price discovery. ${ }^{154}$ In fact, however, the Reproposing Release did not distinguish between the limit orders of retail investors and those of institutions when discussing the problem of free-riding. ${ }^{155}$ Rather, the Order Protection Rule is designed to

153 Battalio/Jennings Paper at 29.

154 Battalio/Jennings Paper at 4 n. 1, 30-36; Fidelity Reproposal Letter II at 2.

155 See, e.g., Reproposing Release, 69 FR at 77434 ("Displayed limit orders benefit all market participants by establishing the best prices, but, when bypassed, do not themselves receive a benefit, in the form of an execution, for providing this public good. This economic externality, in turn, creates a disincentive for investors to display limit orders, particularly limit orders of any substantial size.") (emphasis added). In contrast, the Commission's concern specifically for the limit orders of retail investors relates 
promote displayed liquidity from all sources, and institutional limit orders clearly are a significant source of such liquidity. Indeed, the Battalio/Jennings Paper itself notes that "institutions dominate price discovery via quoting" and that "the preponderance of quote-based discovery for NYSE-listed securities takes place at the NYSE" where "institutions dominate trading." ${ }^{156}$ Many institutional investors and the NYSE are strong supporters of strengthened limit order protection for all NMS stocks. ${ }^{157}$ For example, the ICI, whose members manage assets that account for more than 95\% of assets of all U.S. mutual funds, stated that it "strongly supports the establishment of a marketwide trade-through rule.... [S]uch a rule represents a significant step in providing protection for limit orders. By affirming the principle of price priority, a trade-through rule should encourage the display of limit orders, which in turn would improve the price discovery process and contribute to increased market depth and liquidity."158

primarily to the perception of unfairness created when retail orders are ignored by other market participants. Although some of these orders may subsequently be executed or cancelled, the retail investors that submitted orders with the best prices have not received the appropriate reward for their use of an aggressive limit price - a prompt, efficient execution consistent with the principle of price priority. Moreover, the orders that ultimately never receive an execution are also likely to be the very orders that would have been most profitable for the investor (e.g., when the order was to buy a stock and the stock's price climbed after the trade-through occurred). To meet the Exchange Act's objectives for the NMS, investors of all types should have confidence that their orders will be handled in a fair and orderly fashion. Battalio/Jennings Paper at 35.

157 See, e.g., American Century Letter at 2; Capital Research Letter at 2; ICI Reproposal Letter at 2; NYSE Reproposal Letter at 3; T. Rowe Price Reproposal Letter at 2; Vanguard Reproposal Letter at 2.

ICI Reproposal Letter at 2. 
Another commenter asserted that the reproposal overly emphasized the importance of displayed limit orders in the price discovery process. ${ }^{159}$ It stated that the interaction of displayed limit orders with marketable orders is only one aspect of price discovery, which is "a dynamic process that operates in the context of other transactions that have recently been made, current quotes, and a richer tapestry of the expressed and latent interest of a broader array of market participants." ${ }^{160}$ The Commission generally concurs with this characterization of the price discovery process, but believes that displayed limit orders are a critically important element of efficient price discovery that deserve greater protection against trade-throughs. Publicly displayed and automated limit orders are the most transparent and accessible source of liquidity in the equity markets. Moreover, displayed limit orders provide price discovery on a going forward basis - they indicate the prices at which trades can be effected in the future. Trade reports, in contrast, look backward at the prices of trades that already have occurred, which may or may not be still be available.

There are, of course, other sources of liquidity, including: (1) reserve size (limit orders with undisplayed size); (2) "not held" institutional orders that are worked by floor brokers on an exchange; (3) automated matching networks that allow large buyers and sellers to meet directly and anonymously; and (4) securities dealers that are willing to commit capital to facilitate

159 Letter from Stewart P. Greene, Chief Counsel, Securities Law, to Jonathan G. Katz, Secretary, Commission, dated Jan. 26, 2005 ("TIAA-CREF Reproposal Letter"), Attachment at 15-16. This commenter also asserted that the reproposal failed to appreciate the importance of "quantity discovery," in addition to price discovery. Id. at 9. As evidenced by the repeated concern expressed in both the proposal and reproposal for improving market depth and liquidity, the Commission considers the term "price discovery" to encompass both the inside prices for a stock and the quantity of stock that can be traded at and away from the inside prices. It believes, however, that displayed limit orders are a vital source of price discovery in all of its forms. Id. at 16 . 
customer orders. Displayed limit orders, however, give anyone the ability to trade when they want to trade on a first-come, first-served basis. They thereby act as a vital reference point for all other sources of liquidity. Specifically, reserve size, undisplayed floor interest, automated matching, and dealer capital commitments all are facilitated by displayed information concerning the price and size of stock that is available for immediate trading in the public markets.

As demonstrated by the current rate of trade-throughs of the best quotations in Nasdaq and NYSE stocks, the problems of agent/principal conflicts and the free-riding externality often can lead to executions at prices that are inferior to displayed quotations, meaning that limit orders are being bypassed. The frequent bypassing of limit orders can cause fewer limit orders to be placed. The Commission therefore believes that the Order Protection Rule is needed to encourage greater use of limit orders. The more limit orders available at better prices and greater size, the more liquidity available to fill incoming marketable orders. Moreover, greater displayed liquidity will at least lower the search costs associated with trying to find liquidity. Increased liquidity, in turn, could lead market participants to interact more often with displayed orders, which would lead to greater use of limit orders, and thus begin the cycle again. We expect that the end result will be an NMS that more fully meets the needs of a broad spectrum of investors.

\section{Limiting Protection to Automated and Accessible Quotations}

The original trade-through proposal sought to strengthen protection against tradethroughs, while also addressing problems posed by the inherent differences in quotations displayed by automated markets (which are immediately accessible) and quotations displayed by manual markets (which are not), by distinguishing between automated and non-automated markets with respect to trade-through protection. The proposal included an exception that would 
have allowed automated markets to trade through manual markets, but only up to certain amounts that varied depending upon the price of the security. Under the proposal, a market would have been classified as "manual" if it did not provide for an immediate automated response to all incoming orders attempting to access its displayed quotations. ${ }^{161}$

At the NMS Hearing, a significant portion of the discussion of the trade-through proposal addressed issues relating to quotations of automated and manual markets. Representatives of two floor-based exchanges announced their intent to establish "hybrid" trading facilities that would offer automatic execution of orders seeking to interact with their displayed quotations, while at the same time maintaining a traditional floor. ${ }^{162}$ These representatives acknowledged the difficulties posed in developing an efficient hybrid market, but emphasized that they were committed to developing such facilities and that such facilities were likely to become operational prior to any implementation of Regulation NMS.

Other panelists at the NMS Hearing strongly believed that manual quotations should not receive any protection against trade-throughs and that the proposed trade-through amounts should be eliminated. ${ }^{163}$ They noted, however, that existing order routing technologies are capable of identifying, on a quote-by-quote basis, indications from a market that a particular quotation is not immediately and automatically accessible (i.e., is a manual quotation). Using this functionality, a trade-through rule could classify individual quotations as automated or manual, rather than classifying an entire market as manual solely because it displayed manual quotations on occasion.

161 Proposing Release, $69 \mathrm{FR}$ at 11140.

162 Hearing Tr. at 90-92, 94-97, 120.

163 Hearing Tr. at 57-58, 67, 142-143, 157-158. 
To give the public a full opportunity to comment on these issues, the Supplemental Release described the developments at the NMS Hearing and requested comment on whether a trade-through rule should protect only automated quotations and whether the rule should adopt a "quote-by-quote" approach to identifying protected quotations. ${ }^{164}$ The Supplemental Release also requested comment on the requirements for an automated quotation, including whether the rule should impose a maximum response time, such as one second, on the total time for a market to respond to an order in an automated manner. Comment also was requested on mechanisms for enforcing compliance with the automated quotation requirements.

Nearly all commenters on the original proposal believed that only automated quotations should receive protection against trade-throughs and that therefore the proposed limitation on trade-through amounts for manual markets should be eliminated. ${ }^{165}$ In response to these commenters, the Commission modified the proposed Rule in the Reproposing Release to protect only those quotations that are immediately and automatically accessible. As noted above in Section II.A.1, a substantial number of commenters supported the reproposed Order Protection Rule, with some commenters specifically supporting limiting trade-through protection to automated and immediately accessible quotations. ${ }^{166}$

164 Supplemental Release, 69 FR at 30142-30144.

165 See, e.g., Ameritrade Letter I at 8; Letter from Lou Klobuchar Jr., President and Chief Brokerage Officer, E*TRADE Financial Corporation, to Jonathan G. Katz, Secretary, Commission, dated June 30, 2004 ("E*Trade Letter") at 6; ICI Letter at 12; Nasdaq Letter II at 9, 14; Letter from Marc Lackritz, President, Securities Industry Association, to Jonathan G. Katz, Secretary, Commission, dated June 30, 2004 ("SIA Letter") at 15.

166 See, e.g., Letter from George W. Mann, Jr., General Counsel, Boston Stock Exchange, Inc., to Jonathan G. Katz, Secretary, Commission, dated January 26, 2005 ("BSE Reproposal Letter”) at 5; Letter from David Baker, Global Head of Cash Trading and Global Head of Portfolio Trading, Deutsche Bank Securities Inc., to Jonathan G. Katz, Secretary, Commission, dated February 3, 2005 ("Deutsche Bank Reproposal Letter”) at 2; ICI Reproposal Letter at 3, n. 6; Letter from James T. Brett, Managing Director, J.P. 
The Commission agrees with commenters that providing protection to manual quotations, even limited to trade-throughs beyond a certain amount, potentially would lead to undue delays in the routing of investor orders, thereby not justifying the benefits of price protection. The Commission therefore is adopting, as reproposed, an approach that excludes manual quotations from trade-through protection. Under the Order Protection Rule as adopted, investors will have the choice of whether to access a manual quotation and wait for a response or to access an automated quotation with an inferior price and obtain an immediate response. Moreover, those who route limit orders will be able to control whether their orders are protected by evaluating the extent to which various trading centers display automated versus manual quotations.

Commenters expressed differing views, however, on the appropriate standards for automated quotations and on the standards that should govern "hybrid" markets - those that display both automated and manual quotations. These issues are discussed below.

\section{a. Standards for Automated Quotations}

Nearly all commenters addressing the issue believed that only quotations that are truly firm and fully accessible should qualify as "automated."167 To achieve this goal, they suggested

Morgan Securities Inc., to Jonathan G. Katz, Secretary, Commission, dated January 28, 2005 (“JP Morgan Reproposal Letter”) at 3-4; Letter from Bernard L. Madoff and Peter B, Madoff, Bernard L. Madoff Investment Securities L.L.C., to Jonathan G. Katz, Secretary, Commission, dated February 3, 2005 ("Madoff Reproposal Letter") at 1; Letter from David Humphreville, President, The Specialist Association of the New York Stock Exchange, to Jonathan G. Katz, Secretary, Commission, dated January 26, 2005 (“Specialist Assoc. Reproposal Letter”) at 2-3.

167 See, e.g., Letter from John J. Wheeler, Vice President, Director of U.S. Equity Trading, American Century Investment Management Inc., to Jonathan G. Katz, Secretary, Commission, dated June 30, 2004 ("American Century Letter") at 3; Letter from C. Thomas Richardson, Citigroup Global Markets, Inc., to Jonathan G. Katz, Secretary, Commission, dated July 20, 2004 ("Citigroup Letter") at 6-7; Letter from Gary Cohn, Managing Director, Goldman, Sachs \& Co., to Jonathan G. Katz, Secretary, Commission, dated July 19, 2004 ("Goldman Sachs Letter") at 4-5; ICI Letter at 13; Morgan Stanley Letter at 7; SIA Letter at 6. 
that, at a minimum, the market displaying an automated quotation should be required to provide a functionality for an incoming order to receive an immediate and automated (i.e., without human intervention) execution up to the full displayed size of the quotation. In addition, they believed the market should be required to provide an immediate and automated response to the sender of the order indicating whether the order had been executed (in full or in part) and an immediate and automated updating of the quotation. A number of commenters advocated requiring a specific time standard for distinguishing between manual and automated quotations, ranging from one second down to 250 milliseconds. ${ }^{168}$ Other commenters did not believe the definition of automated quotation should require a specific time standard, generally because setting a specific standard might discourage innovation and become a "ceiling” on market performance. $^{169}$

168 See, e.g., Ameritrade Letter I at 6; Bloomberg Tradebook Letter at 13; Letter from Kenneth R. Leibler, Chairman, Boston Stock Exchange, Inc., to Jonathan G. Katz, Secretary, Commission, dated June 30, 2004 ("BSE Letter") at 7; Consumer Federation Letter at 3; Letter from David A. Herron, Chief Executive Officer, Chicago Stock Exchange, to Jonathan G. Katz, Secretary, Commission, dated June 30, 2004 ("CHX Letter") at 7-8; Letter from C. Thomas Richardson, Citigroup Global Markets, Inc., to Jonathan G. Katz, Secretary, Commission, dated July 20, 2004 (“Citigroup Letter”) at 7; Letter from Gary Cohn, Managing Director, Goldman, Sachs \& Co., to Jonathan G. Katz, Secretary, Commission, dated July 20, 2004 (“Goldman Sachs Letter”) at 4; ICI Letter at 3, 10; Nasdaq Letter II at 3, 13; Letter from John Martello, Managing Director, Tower Research Capital LLC, to Jonathan G. Katz, Secretary, Commission, dated June 30, 2004 ("Tower Research Letter") at 5.

169 See, e.g., American Century Letter at 3; Letter from Salvatore F. Sodano, Chairman \& Chief Executive Officer, American Stock Exchange LLC, to Jonathan G. Katz, Secretary, Commission, dated June 30, 2004 ("Amex Letter"), Exhibit A at 6; Letter from Matt D. Lyons, Capital Research and Management Company, to Jonathan G. Katz, Secretary, Commission, dated June 28, 2004 ("Capital Research Letter") at 2; Fidelity Letter I at 8; Letter from John H. Bluher, Executive Vice President \& General Counsel, Knight Trading Group, to William H. Donaldson, Chairman, Commission, dated July 2, 2004 ("Knight Letter II") at 5; Letter from James T. Brett, J.P. Morgan Securities Inc., to Jonathan G. Katz, Secretary, Commission, dated July 8, 2004 ("JP Morgan Letter") at 3; Morgan Stanley Letter at 7; Letter from Darla C. Stuckey, Corporate Secretary, New York Stock Exchange, Inc., to Jonathan G. Katz, Secretary, Commission, dated July 2, 
The Commission included in the Reproposing Release a definition of automated quotation that incorporated the three elements suggested by commenters: ${ }^{170}$ (1) acting on an incoming order; (2) responding to the sender of the order; and (3) updating the quotation. The proposed definition of automated quotation did not set forth a specific time standard for responding to an incoming order. As noted above, a significant number of commenters on the Reproposing Release supported the reproposed Order Protection Rule, ${ }^{171}$ with a few commenters specifically supporting the definition of automated quotation. ${ }^{172}$ As discussed in detail below, the Commission has adopted the definition of automated quotation as proposed.

In particular, Rule 600(b)(3) requires that the trading center displaying an automated quotation must provide an "immediate-or-cancel" ("IOC") functionality for an incoming order to execute immediately and automatically against the quotation up to its full size, and for any unexecuted portion of such incoming order to be cancelled immediately and automatically

2004 ("NYSE Letter"), Attachment at 3; Letter from David Humphreville, President, The Specialist Association, to Jonathan G. Katz, Secretary, Commission, dated June 30, 2004 ("Specialist Assoc. Letter") at 8; Letter from Lisa M. Utasi, President, et al., The Security Traders Association of New York, Inc., to Jonathan G. Katz, Secretary, Commission, dated June 30, 2004 ("STANY Letter") at 4; Letter from George U. Sauter, Managing Director, The Vanguard Group, Inc., to Jonathan G. Katz, Secretary, Commission, dated July 14, 2004 ("Vanguard Letter") at 4.

170 See, e.g., Letter from Kevin J. P. O’Hara, Chief Administrative Officer and General Counsel, Archipelago Holdings, Inc., to Jonathan G. Katz, Secretary, Commission, dated September 24, 2004 (“Archipelago Letter”) at 7; Brut Letter at 7; Letter from Lisa M. Utasi, President, et al., The Security Traders Association of New York, Inc., to Jonathan G. Katz, Secretary, Commission, dated June 30, 2004 (“STANY Letter”) at 4; Letter from George U. Sauter, Managing Director, The Vanguard Group, to Jonathan G. Katz, Secretary, Commission, dated July 14, 2004 ("Vanguard Letter") at 4.

171 See supra section II.A.1.

172 Letter from Adam Cooper, Senior Managing Director and General Counsel, Citadel Investment Group, L.L.C., to Jonathan G. Katz, Secretary, Commission, dated July 9, 2004 (“Citadel Reproposal Letter”) at 3; ICI Reproposal Letter at 3, n. 6; SIA Reproposal Letter at 4-5. 
without being routed elsewhere. The trading center also must immediately and automatically respond to the sender of an IOC order. To qualify as "automatic," no human discretion in determining any action taken with respect to an order may be exercised after the time an order is received. Trading centers are required to offer this IOC functionality only to market participants that request immediate action and response by submitting an IOC order. Market participants therefore have the choice of whether to require an immediate response from the trading center, or to allow the market to take further action on the order (such as by routing the order elsewhere, seeking additional liquidity for the order, or displaying the order). Finally, trading centers are required to immediately and automatically update their automated quotations to reflect any change to their material terms (such as a change in price, displayed size, or "automated" status).

The definition of automated quotation as adopted does not set forth a specific time standard for responding to an incoming order. The Commission agrees with commenters that the

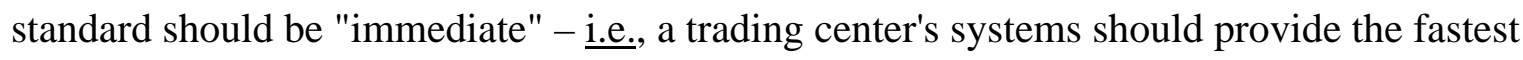
response possible without any programmed delay. Nevertheless, the Commission also is concerned that trading centers with well-functioning systems should not be unnecessarily slowed down waiting for responses from a trading center that is experiencing a systems problem. Consequently, rather than specifying a specific time standard that may become obsolete as systems improve over time, Rule 611(b)(1) addresses the problem of slow trading centers by providing an exception for quotations displayed by trading centers that are experiencing, among other things, a material delay in responding to incoming orders. Given current industry conditions, the Commission believes that repeatedly failing to respond within one second after 
receipt of an order would constitute a material delay. ${ }^{173}$ Accordingly, a trading center would act reasonably in the current technological environment if it bypassed the quotations of another trading center that had repeatedly failed to respond to orders within a one-second time frame (after adjusting for any potential delays in transmission not attributable to the other trading center). ${ }^{174}$ This "self-help" remedy, discussed further in sections II.A.3 and II.B.3 below, will give trading centers needed flexibility to deal with another trading center that is experiencing systems problems, rather than forcing smoothly-functioning trading centers to slow down for a problem trading center.

\section{b. Standards for Automated Trading Centers}

The original trade-through proposal would have classified a market as manual if it did not provide automated access to all orders seeking access to its displayed quotations. Many commenters responded positively to the concept of allowing hybrid markets to display both automated and manual quotations that was raised at the NMS Hearing and discussed in the Supplemental Release. Most national securities exchanges believed that focusing on whether individual quotations are automated or manual would permit hybrid markets to function, thereby expanding the range of trading choices for investors. ${ }^{175}$ For example, Amex stated that hybrid

173 Cf. Ameritrade Letter I at 6 (one second response time is appropriate); Letter from David A. Herron, Chief Executive Officer, The Chicago Stock Exchange, to Jonathan G. Katz, Secretary, Commission, dated June 30, 2004 (“CHX Letter”) at 8 (receive, execute, and report back within one second); Citigroup Letter at 7 (turnaround time of no more than one second); Goldman Sachs Letter at 4 (orders executed or cancelled within not more than one second).

174 As discussed further in section II.B.3 below, a trading center utilizing the material delay exception will be required to establish specific objective parameters for its use of the exception in its required policies and procedures.

175 See, e.g., Amex Letter at 5; Letter from William J. Brodsky, Chairman \& Chief Executive Officer, Chicago Board Options Exchange, Inc., to Jonathan G. Katz, 
markets would offer investors the choice to utilize auction markets when advantageous for them to do so, while at the same time offering automatic execution to those investors desiring speed and certainty of a fast response. ${ }^{176}$ A majority of other commenters also believed that the application of any trade-through rule should depend on whether a particular quotation is automated. ${ }^{177}$ They believed that such a rule would achieve the benefits of encouraging limit orders and improving market depth and liquidity, while avoiding indirectly mandating a particular market structure.

Although generally supportive of the concept of hybrid markets, several commenters on the original proposal expressed concern about how the "quote-by-quote" approach to protected quotations would operate in practice. ${ }^{178}$ The ICI noted that "[w]e are concerned that if it is left completely up to an individual market's discretion when a quote is 'automated' or manual, that market could base its decision on what is in the best interests of that market and its members, as opposed to the best interests of investors and other market participants." ${ }^{179}$ These commenters suggested that the Commission should provide clear guidelines as to when and how a market

Secretary, Commission, dated July 1, 2004 ("CBOE Letter") at 3; CHX Letter at 7; NYSE Letter at 4.

176 Amex Letter, Appendix A at 4-5.

177 See, e.g., Letter from Joseph M. Velli, Senior Executive Vice President, The Bank of New York, to Jonathan G. Katz, Secretary, Commission, dated June 30, 2004 ("BNY Letter") at 2; Letter from Lou Klobuchar Jr., President and Chief Brokerage Officer, E*Trade Financial Corporation, to Jonathan G. Katz, Secretary, Commission, dated June 30, 2004 (“E*Trade Letter”) at 6; ICI Letter at 13; Morgan Stanley Letter at 6.

$178 \quad$ See, e.g., Citigroup Letter at 6; ICI Letter at 13; Morgan Stanley Letter at 7; Nasdaq Letter II at 13-14; Vanguard Letter at 5.

ICI Letter at 13. 
could switch its quotations from automated to manual, and vice versa, so as to prevent abuse by the market.

After considering the views of commenters, the Commission included in the reproposed Rule certain requirements for a trading center to qualify as an "automated trading center," one of which requires that a trading center adopt reasonable standards limiting when its quotations change from automated quotations to manual quotations (and vice versa) to specifically defined circumstances that promote fair and efficient access to its automated quotations and that are consistent with the maintenance of fair and orderly markets. The reproposed Rule also provided that only a trading center that met all of the requirements could display protected quotations. Although a substantial number of commenters supported the reproposed Rule, ${ }^{180}$ a few commenters continued to express concern with the ability of a trading center to switch from automated to manual quotations. ${ }^{181}$

The Commission recognizes the concerns of commenters regarding the ability of a trading center to change from automated to manual quotation mode, but believes that the requirements necessary to qualify as an automated trading center will sufficiently mitigate this concern. Any standards established by an SRO trading center to govern when its quotations

180 See supra section II.A.1.

181 See Ameritrade Reproposal Letter at 7 (questioning whether certain aspects of NYSE's hybrid proposal are "consistent with the requirement that an automated trading center has "adopted reasonable standards limiting when its quotations change from automated quotations to manual quotations, and vice versa"'); Letter from Alistair Brown, Managing Director, Lime Brokerage LLC, to Jonathan G. Katz, Secretary, Commission, dated January 26, 2005 ("Lime Brokerage Reproposal Letter") at 1 (expressing concerns regarding the operation of NYSE's hybrid proposal in conjunction with the Order Protection Rule); Letter from J. Greg Mills, Managing Director, Head of Global Equity Trading, RBC Capital Markets Corporation, to Jonathan G. Katz, Secretary, Commission, dated January 26, 2005 (“RBC Capital Markets Reproposal Letter”) at 8-9 (requesting that the Commission establish and define standards as to when a hybrid market can switch from automated to manual quotations). 
change from automated to manual will be subject to public notice and comment and Commission approval pursuant to the rule filing process of Section 19(b) of the Exchange Act. If a non-SRO trading center intends to display both automated and non-automated quotations, it will be subject to the oversight of the SRO through whose facilities its quotations are displayed with respect to the reasonableness of its procedures, as well as Commission oversight.

The Commission therefore is adopting the definition of automated trading center as reproposed. The adopted approach offers flexibility for a hybrid market to display both automated and manual quotations, but only when such a market meets basic standards that promote fair and efficient access by the public to the market's automated quotations. This approach is designed to allow markets to offer a variety of trading choices to investors, but without requiring other markets and market participants to route orders to a hybrid market with quotations that are not truly accessible.

To qualify as an automated trading center, the trading center must have implemented such systems, procedures, and rules as are necessary to render it capable of displaying quotations that meet the action, response, and updating requirements set forth in the definition of an automated quotation. ${ }^{182}$ Further, the trading center must identify all quotations other than automated quotations as manual quotations, and must immediately identify its quotations as manual quotations whenever it has reason to believe that it is not capable of displaying automated quotations. ${ }^{183}$ These requirements will enable other trading centers readily to determine whether a particular quotation displayed by a hybrid trading center is protected by the

182 Rule 600(b)(4)(i). The Commission is modifying this requirement from the reproposal to include the term "procedures," to clarify that non-SRO trading centers have procedures, not rules. Rule 600(b)(4)(ii) and (iii). 
Order Protection Rule. Finally, an automated trading center must adopt reasonable standards limiting when its quotations change from automated quotations to manual quotations, and vice versa, to specifically defined circumstances that promote fair and efficient access to its automated quotations and are consistent with the maintenance of fair and orderly markets. ${ }^{184}$

These requirements are designed to promote efficient interaction between a hybrid market and other trading centers. The requirement that automated quotations cannot be switched on and off except in specifically defined circumstances is particularly intended to assure that hybrid markets do not give their members, or anyone else, overbroad discretion to control the automated or manual status of the trading center's quotations, which potentially could disadvantage market participants that must protect these quotations. Changes from automated to manual quotations, and vice versa, must be subject to specific, enforceable limitations as to the timing of switches. For a trading center to qualify as entitled to display any protected quotations, the public in general must have fair and efficient access to a trading center's quotations.

Some commenters on the Reproposing Release expressed a concern about the scope of the exception for single-priced reopenings in Rule 611(b)(3), particularly in the context of a trading center switching back and forth from automated quotation to manual quotation mode. ${ }^{185}$ They asserted that the applicability of the exception to the recommencement of trading after a non-regulatory trading halt in one market (such as a trading halt due to an intra-day order imbalance) could lead to disruptive trading activity and provide an unfair competitive advantage for the trading center that halted trading. They believed this could create a significant loophole

$184 \quad$ Rule 600(b)(4)(iv).

185 See Letter from C. Thomas Richardson, Citigroup Global Markets, Inc., to Jonathan G. Katz, Secretary, Commission, dated January 26, 2005 (“Citigroup Reproposal Letter") at 8; Nasdaq Reproposal Letter at 6-7; SIA Reproposal Letter at 20-21. 
in the protections provided by the Rule. For instance, one commenter expressed concern that a trading center could halt trading and reopen solely to enable it to trade-through other trading centers. ${ }^{186}$ Another commenter expressed concern regarding the interplay of the proposed exception and the operation of the NYSE's proposed hybrid trading system, stating that it is unclear what would be considered a reopening under NYSE's proposal, particularly with respect to when a liquidity refreshment point is reached or when the quotation is gapped. ${ }^{187}$ Two commenters suggested that the exception apply only to reopenings after regulatory trading halts. ${ }^{188}$

The Commission recognizes the commenters' concern, but emphasizes that the exception will not permit a trading center to declare a trading halt merely to be able to circumvent the operation of the Order Protection Rule upon reopening. The exception applies only to singlepriced reopenings and therefore requires that a trading center conduct, pursuant to its rules or written procedures, a formalized and transparent process for executing orders during reopening after a trading halt that involves the queuing and ultimate execution of multiple orders at a single equilibrium price. ${ }^{189}$ In addition, the trading center must have formally declared a trading halt pursuant to its rules or written procedures. Thus, the exception would not include a situation

186 Citigroup Reproposal Letter at 8.

187 Nasdaq Reproposal Letter at 6. See also infra, note 190.

188 Nasdaq Reproposal Letter at 7; SIA Reproposal Letter at 21 (agreeing that the exception should apply to regulatory halts).

189 See section III.D.3 of the Proposing Release for a discussion of the practical need for an exception for single-priced openings and reopenings. $69 \mathrm{FR}$ at 11142. 
where a trading center merely spread its quotations or switched back to automated quotation mode from manual quotation mode. ${ }^{190}$

\section{Workable Implementation of Intermarket Trade-Through Protection}

Several commenters expressed concern that the original proposed trade-through rule could not be implemented in a workable manner, particularly for high-volume stocks. ${ }^{191}$ Morgan Stanley, for example, asserted that an inefficient trading center might have inferior systems that would delay routed orders and potentially diminish their quality of execution. ${ }^{192}$ Instinet emphasized that protecting a market's quotations "confers enormous power on a market. .. Such power can and will be abused either directly (e.g., by quoting slower than executing orders) or indirectly (e.g., not investing in more than minimum system capacity or redundancy)."193 Hudson River Trading noted that markets sometimes experience temporary systems problems and questioned how a trade-through rule would address these scenarios. ${ }^{194}$ Nasdaq observed that

190 Under NYSE's hybrid proposal, the turning off of automatic execution, for example, for a gap-quoting situation, the triggering of a liquidity refreshment point, or the reporting of a block transaction, would not in and of itself halt trading and thus trigger a reopening pursuant to paragraph (b)(3) of Rule 611.

191 See, e.g., Hudson River Trading Letter at 3; Instinet Letter at 18-19; Morgan Stanley Letter at 11-12; Letter from Edward S. Knight, The Nasdaq Stock Market, Inc., to Jonathan G. Katz, Secretary, Commission, dated September 29, 2004 ("Nasdaq Letter III") at 3.

$192 \quad$ Morgan Stanley Letter at 12.

193 Instinet Letter at 17.

194 Hudson River Trading Letter at 3. This commenter also raised a number of specific questions concerning the operation of an intermarket trade-through rule. To address these detailed order sequencing and response scenarios, trading centers will be able to adopt policies and procedures that reasonably resolve the practical difficulties of handling fast-arriving orders in a fair and orderly fashion. For example, if a trading center routed orders to another market to access the full displayed size of its protected quotations under the Order Protection Rule, the routing trading center will be allowed to continue trading without regard to that market's quotations until it has received a response from such 
quotations in many Nasdaq stocks are updated more than two times per second. It said that these frequent changes could lead to many false indications of trade-throughs and that eliminating these "false positives" would greatly reduce the percentage of transactions subject to a tradethrough rule. ${ }^{195}$ Finally, many commenters noted that market participants need the ability to sweep multiple price levels simultaneously at different trading centers. They emphasized that a trade-through rule should accommodate this trading strategy by freeing each trading center to execute orders immediately without waiting for other trading centers to update their better priced quotations. $^{196}$

The Commission agreed with these commenters that intermarket protection against tradethroughs must be workable and implemented in a way that promotes fair and orderly markets, and therefore amended the original proposal in the reproposal to better achieve this objective in a variety of ways. As discussed below, commenters were generally supportive of the measures included in the reproposal as providing necessary flexibility, although several commenters made specific recommendations as to how to improve the operation of the exceptions. In response to these comments, the Commission has made additional modifications to the Order Protection Rule that, in conjunction with the reproposed measures, will further promote its workability. First and most importantly, as included in the reproposal and as adopted today, only automated trading centers, as defined in Rule 600(b)(4), that are capable of providing immediate

market. With respect to concern that traders will not be able to control the routing of their own orders if markets are required to route out to other markets, a trader's use of the IOC functionality specified in Rule 600(b)(3) will preclude the first market from routing to other markets.

$195 \quad$ Nasdaq Letter III at 3-4.

196 See, e.g., Brut Letter at 10; Citigroup Letter at 10; E*Trade Letter at 8; Goldman Sachs Letter at 7. 
responses to incoming orders are eligible to have their quotations protected. Moreover, an automated trading center is required to identify its quotations as manual (and therefore not protected) whenever it has reason to believe that it is not capable of providing immediate responses to orders. ${ }^{197}$ Thus, a trading center that experiences a systems problem, whether because of a flood of orders or otherwise, must immediately identify its quotations as manual.

The Commission will monitor and enforce the adopted requirements for automated trading centers and automated quotations. Nevertheless, it concurs with commenters' concerns that well-functioning trading centers should not be dependent on the willingness and capacity of other markets to meet, and the Commission's ability to enforce, these automation requirements. The adopted Order Protection Rule therefore provides a "self-help" remedy that will allow trading centers to bypass the quotations of a trading center that fails to meet the immediate response requirement. Rule 611(b)(1) sets forth an exception that applies to quotations displayed by trading centers that are experiencing a failure, material delay, or malfunction of its systems or equipment. To implement this exception consistent with the requirements of Rule 611(a), trading centers will have to adopt policies and procedures reasonably designed to comply with the self-help remedy. Such policies and procedures will need to set forth specific objective parameters for dealing with problem trading centers and for monitoring compliance with the selfhelp remedy, consistent with Rule 611. Given current industry capabilities, the Commission believes that trading centers should be entitled to bypass another trading center's quotations if it repeatedly fails to respond within one second to incoming orders attempting to access its protected quotations. Accordingly, trading centers will have the necessary flexibility to respond to problems at another trading center as they occur during the trading day.

$197 \quad$ Rule 600(b)(4)(iii). 
Most commenters that addressed the self-help exception supported the exception as providing necessary flexibility to trading centers to avoid inaccessible quotations. ${ }^{198}$ Some commenters, however, objected to a statement in the Reproposing Release that a trading center must attempt to contact the non-responsive trading center to resolve a problem prior to disregarding its quotations. ${ }^{199}$ They believed that such a requirement would not be practicable or workable, especially during real-time trading. ${ }^{200}$ One commenter recommended that, instead of requiring notice as a "condition precedent," the Commission require the trading center electing the self-help exception to contact the slow or non-responding trading center immediately after it elects self-help. ${ }^{201}$

The Commission agrees with the concerns of the commenters that a prior notice requirement may not be practicable or workable in real-time, and that a trading center should be allowed simply to notify the non-responding trading center immediately after (or at the same time as) electing self-help pursuant to objective standards consistent with Rule 611 that are contained in its policies and procedures. An electing trading center must also assess, however, whether the cause of a problem lies with its own systems and, if so, take immediate steps to resolve the problem appropriately.

Another commenter suggested that third-party vendors that provide connectivity among trading centers should be allowed to determine when a trading center has failed to meet the

\footnotetext{
198 See, e.g., BSE Reproposal Letter at 5; Citigroup Reproposal Letter at 7; ICI Reproposal Letter at 6, n. 10; Nasdaq Reproposal Letter at 7; SIA Reproposal Letter at 19.

199 Citigroup Reproposal Letter at 7; Nasdaq Reproposal Letter at 7-8; SIA Reproposal Letter at 19.

200 Citigroup Reproposal Letter at 7; Nasdaq Reproposal Letter at 7-8.

$201 \quad$ Nasdaq Reproposal Letter at 7.
} 
immediate response requirement. ${ }^{202}$ The Commission agrees that a third-party vendor could perform such a function, but, as with use of the intermarket sweep order exception, the responsibility for compliance with the exception remains with the relevant trading center that uses the services of the third-party vendor. Thus, a trading center is responsible for compliance with the requirements of the exception, including the obligation to establish, maintain, and enforce written policies and procedures and to surveil for their effectiveness, regardless of whether it routes orders using its own systems or a third-party vendor's systems.

Some commenters believed that the trading center experiencing a problem should have primary responsibility for notifying other trading centers and market participants when such problems occur and when they are resolved. ${ }^{203}$ The definition of automated market center in both the reproposed and adopted rule directly imposes this responsibility on the trading center experiencing difficulties. ${ }^{204}$ It requires such a trading center immediately to identify its quotations as manual whenever it has reason to believe that it is not capable of displaying automated quotations. The trading center must continue to identify its quotations as manual until it no longer has reason to believe that there will be a problem with its quotations. A trading center that continues to identify its quotations as automated when it has reason to believe otherwise would make a material misstatement to other trading centers, investors, and the public.

One commenter believed that, in the absence of an opt-out, the material delay exception was too narrowly drawn, and that market participants should be allowed to avoid trading with

202 Letter from Richard A. Kornhammer, Chairman and Chief Executive Officer, Lava Trading Inc., to Jonathan G. Katz, Secretary, Commission, dated January 26, 2005 (“Lava Reproposal Letter”) at 3.

203 SIA Reproposal Letter at 19-20; STANY Reproposal Letter at 12.

204 Rule 600(b)(4)(iii). 
trading centers for any objective, reasonable basis as they do today in the context of fiduciary and best execution obligations, and not just for slow response times. ${ }^{205}$ The Commission does not believe that the scope of the exception should be expanded to give a trading center the ability to avoid another trading center for reasons not related to reliable and efficient accessibility because to do so would be inconsistent with the objectives of the Rule. The exception in paragraph (b)(1) of Rule 611, however, covers any failure or malfunction of a trading center's systems or equipment, as well as any material delay. The Commission believes that there may be certain limited instances where repeated, critical system problems, even those that do not necessarily cause a delayed response time during trading (such as systems problems that repeatedly result in the breaking of trades), would justify use of the exception by other trading centers until the problem trading center has provided reasonable assurance to all other trading centers that the problems have been corrected. ${ }^{206}$

In many active NMS stocks, the price of a trading center's best displayed quotations can change multiple times in a single second ("flickering quotations"). These rapid changes can create the impression that a quotation was traded-through, when in fact the trade was effected nearly simultaneously with display of the quotation. ${ }^{207}$ To address the problem of flickering

205 Letter from Thomas N. McManus, Managing Director and Counsel, Morgan Stanley \& Co. Incorporated, to Jonathan G. Katz, Secretary, Commission, dated February 7, 2005 (“Morgan Stanley Reproposal Letter”) at 11-12.

206 During the implementation period for the Order Protection Rule, the Commission staff will be available to provide guidance to trading centers as they develop objective standards to implement this exception consistent with Rule 611. A number of commenters on the original proposal were concerned about flickering quotations and recommended an exemption to address the problem. CHX Letter at 7 , n.19; E*Trade Letter at 9; JP Morgan Letter at 3; Letter from Richard A. Korhammer, Chairman \& Chief Executive Officer, Lava Trading Inc., to Jonathan G. Katz, Secretary, Commission (no date) ("Lava Trading Letter") at 5; Letter from Marc Lackritz, President, Securities Industry Association, to Jonathan G. Katz, Secretary, Commission, dated June 
quotations, the Commission included in the reproposal a proposed exception from Rule 611 that would allow trading centers a one-second "window" prior to a transaction for trading centers to evaluate the quotations at another trading center. Specifically, the Commission proposed that pursuant to Rule 611(b)(8) trading centers would be entitled to trade at any price equal to or better than the least aggressive best bid or best offer, as applicable, displayed by the other trading center during that one-second window. For example, if the best bid price displayed by another trading center has flickered between $\$ 10.00$ and $\$ 10.01$ during the one-second window, the trading center that received the order could execute a trade at $\$ 10.00$ without violating Rule 611. Most of the commenters that addressed this exception supported it. ${ }^{208}$ The SIA noted that the exception would provide "much-needed practical relief." ${ }^{209}$ Several commenters, however, raised issues regarding the time frame for the exception, with some supporting a longer window $^{210}$ and some questioning whether it was necessary to establish a specific time frame in the rule, rather than through interpretive guidance. ${ }^{211}$ One commenter opposed the exception because it believed that it would create an arbitrage opportunity that could be taken advantage of

30, 2004 (“SIA Letter”) at 10; Letter from Mary McDermott-Holland, Chairman \& John C. Giesea, President, Security Traders Association, to Jonathan G. Katz, Secretary, Commission, dated June 30, 2004 ("STA Letter") at 5.

208 BSE Reproposal Letter at 5; ICI Reproposal Letter at 6, n. 10; JP Morgan Reproposal Letter at 4; Letter from Michael J. Lynch, Managing Director, Merrill Lynch, Pierce, Fenner \& Smith Incorporated, to Jonathan G. Katz, Secretary, Commission, dated February 4, 2005 ("Merrill Lynch Reproposal Letter") at 7; SIA Reproposal Letter at 3, 18.

SIA Reproposal Letter at 18.

210 Letter from Bruce C. Turner, Managing Director, CIBC World Markets Corp., to Jonathan G. Katz, Secretary, Commission, dated February 4, 2005 (“CIBC Reproposal Letter") at 3 (supporting a 3 second window); SIA Reproposal Letter at 18 (questioning whether the proposed one second window is too narrow).

211 Merrill Lynch Reproposal Letter at 7; SIA Reproposal Letter at 18-19. 
by computerized market participants. ${ }^{212}$ Another commenter expressed concern that the exception would enable trading centers to execute trades internally and route orders using the worst quotation during the one second window. ${ }^{213}$

After reviewing the response from commenters, the Commission is adopting the exception as proposed. Allowing a one-second "window" prior to a transaction for trading centers to evaluate the quotations at another trading center will ease implementation of and compliance with the Order Protection Rule by giving trading centers added flexibility to deal with the practical difficulties of protecting quotations displayed by other trading centers, without significantly reducing the benefits of the Rule. ${ }^{214}$ It appears that many of the potential implementation difficulties with respect to high-volume stocks are related to the problem of dealing with sub-second time increments. The Commission generally does not believe that the benefits would justify the costs imposed on trading centers of attempting to implement an intermarket price priority rule at the level of sub-second time increments. Accordingly, Rule 611

212 Letter from Meyer S. Frucher, Chairman and Chief Executive Officer, Philadelphia Stock Exchange, Inc., to Jonathan G. Katz, Secretary, Commission, dated January 31, 2005 (“Phlx Reproposal Letter”) at 3.

$213 \quad$ Nasdaq Reproposal Letter at 8. As emphasized in section II.B.4 below, Rule 611 is designed to facilitate intermarket trade-through protection only. It does not lessen the best execution responsibilities of broker-dealers. In making a best execution determination, for example, a broker-dealer can not rely on the Rule's exception for flickering quotations to justify ignoring a recently displayed, better-priced quotation when experience shows that the quotation is likely to be accessible.

214 Even with the one-second exception for flickering quotations, Rule 611 will address a large number of trade-throughs that currently occur in the equity markets. The substantial trade-through rates discussed in section II.A.1 above were calculated using a 3 -second window. Rule 611 will address all of these trade-throughs, assuming no other exception is applicable. 
has been formulated to relieve trading centers of this burden. ${ }^{215}$ The Commission does not believe, however, that it is necessary to allow more than a one second window, given the realities of today's trading environment and the frequency with which many quotations update. ${ }^{216}$ The Commission also is concerned that allowing for a greater than one second window would permit the execution of many trade-throughs that could have been reasonably prevented. The Commission also notes that opportunities for arbitrage between trading centers displaying different prices for the same NMS stock would exist irrespective of whether the Commission adopted an order protection rule, and does not believe that the adoption of the flickering quotation exception to the Rule increases these arbitrage opportunities.

The Commission also included in the reproposal paragraphs (b)(5) and (b)(6) of Rule 611 that provided exceptions for intermarket sweep orders that respond to the need of market participants to access multiple price levels simultaneously at different trading centers. Commenters that addressed this exception overwhelmingly supported it. ${ }^{217}$ Citadel, for instance, stated that the intermarket sweep exception is crucial, addresses most of its concerns about the

215 Several commenters raised questions concerning "clock drift" and time lags between different data sources. See, e.g., Hudson River Trading Letter at 2; Letter from Edward S. Knight, The Nasdaq Stock Market, Inc., to Jonathan G. Katz, Secretary, Commission, dated September 29, 2004 (“Nasdaq Letter III") at 4. These implementation issues are most appropriately addressed in the context of a trading center's reasonable policies and procedures. Clearly, one essential procedure will be implementation of clock synchronization practices that meet or exceed industry standards. In addition, a trading center's compliance with the Order Protection Rule will be assessed based on the times that orders and quotations are received, and trades are executed, at that trading center.

216 Specifically, given the advanced trading and routing technology available today, a onesecond window should significantly ease the compliance burden of trading centers for stocks with many quotation updates.

217 See, e.g., BSE Reproposal Letter at 5; Citadel Reproposal Letter at 1, 2; ICI Reproposal Letter at 5; JP Morgan Reproposal Letter at 4; Merrill Lynch Reproposal Letter at 3; SIA Reproposal Letter at 3. 
Commission's initial trade-through proposal, and would have many benefits. ${ }^{218}$ The ICI believed that the exception would allow institutional investors to continue to execute large-sized orders in an efficient manner. ${ }^{219}$ As discussed below, the Commission is adopting this exception as reproposed.

An intermarket sweep order is defined in Rule 600(b)(30) as a limit order that meets the following requirements: (1) the limit order is identified as an intermarket sweep order when routed to a trading center; and (2) simultaneously with the routing of the limit order, one or more additional limit orders are routed to execute against all better-priced protected quotations displayed by other trading centers up to their displayed size. These additional orders also must be marked as intermarket sweep orders to inform the receiving trading center that they can be immediately executed without regard to protected quotations in other markets. Paragraph (b)(5) allows a trading center to execute immediately any order identified as an intermarket sweep order, without regard for better-priced protected quotations displayed at one or more other trading centers. The exception is fully consistent with the principle of protecting the best displayed prices because it is premised on the condition that the trading center or broker-dealer responsible for routing the order will have attempted to access all better-priced protected quotations up to their displayed size. ${ }^{220}$ Consequently, there is no reason why the trading center that receives an intermarket sweep order while displaying an inferior-priced quotation should be required to delay an execution of the order.

218 Citadel Reproposal Letter at 1, 2.

$219 \quad$ ICI Reproposal Letter at 5.

220 Reserve size, in contrast, is not displayed. Trading centers and broker-dealers therefore will not be required to route orders to access reserve size. 
Paragraph (b)(6) authorizes a trading center itself to route intermarket sweep orders and thereby enable immediate execution of a transaction at a price inferior to a protected quotation at another trading center. For example, paragraph (b)(6) can be used by a dealer that wishes immediately to execute a block transaction at a price three cents away from the NBBO, as long as the dealer simultaneously routed orders to access all better-priced protected quotations. By facilitating intermarket sweep orders of all kinds, Rule 611 as adopted will allow a much wider range of beneficial trading strategies than as originally proposed. In addition, the intermarket sweep exception will help prevent an "indefinite loop" scenario in which waves of orders otherwise might be required to chase the same quotations from trading center to trading center, one price level at a time. ${ }^{221}$

Several commenters suggested that the Commission provide an exception from the Rule for very actively-traded and highly liquid NMS stocks. ${ }^{222}$ They argued that the trading of these stocks already is highly efficient and does not raise the concerns that the Commission is trying to address through the proposed Order Protection Rule, and that imposing the Rule on the trading of these stocks would not improve efficiency or protect limit orders in any meaningful way. They also believed that providing such an exception would make the Rule more workable, particularly for NMS stocks with rapid quotation updates, thus easing compliance and surveillance costs of

221 The indefinite loop scenario also is addressed by: (1) the self-help remedy in Rule 611(b)(1) for trading centers to deal with slow response times; and (2) the requirement that trading centers immediately stop displaying automated (and therefore protected) quotations when they can no longer meet the immediate response requirement for automated quotations.

222 CIBC Reproposal Letter at 1; Citigroup Reproposal Letter at 2-3 (advocating granting the exception on a pilot basis); Letter from Richard M. Whiting, Executive Director and General Counsel, Financial Services Roundtable, to Jonathan G. Katz, Secretary, Commission, dated February 4, 2005 (“FSR Reproposal Letter”) at 4; Merrill Lynch Reproposal Letter at 7; SIA Reproposal Letter at 2, 12-14 (advocating granting the exception on a pilot basis). 
the Rule. Some of these commenters suggested defining liquidity and active trading by reference to the frequency of quotation updates. ${ }^{223}$

The Commission recognizes that commenters have raised a serious concern regarding implementation of the Order Protection Rule, particularly for many Nasdaq stocks that are very actively traded and whose trading is spread across many different individual trading centers. An exemption for active stocks, however, would be particularly inconsistent with the investor protection objectives of the Order Protection Rule because these also are the stocks that have the highest level of investor participation. For example, the need for a trade-through rule to backstop a broker's duty of best execution by assuring that retail investors receive the best available price on an order-by-order basis is perhaps most acute with respect to the most active NMS stocks.

One of the Commission's goals throughout its review of market structure issues has been to formulate rules for the national market system that adequately reflect current technologies and trading practices and that promote equal regulation of stocks and markets. This goal does not reflect a mere desire for uniformity, but is identified in the Exchange Act as a vital component of a truly national market system. ${ }^{224}$ Active stocks obviously are a vital part of the national market system. It should not be that the orders of ordinary investors are protected by a Commission rule for some NMS stocks, but that caveat emptor still prevails for others.

A number of provisions in the Order Protection Rule are specifically designed to address the legitimate concern that the Rule must be workable for active stocks. These include the

223 CIBC Reproposal Letter at 1; Citigroup Reproposal Letter at 3; SIA Reproposal Letter at 12. The Commission notes that the existence of rapid quotation updates does not necessarily mean that a security is actively traded or highly liquid. 
flickering quotation exception, the intermarket sweep order exception, and the self-help exception. The Commission is committed to working closely with trading centers and the securities industry in general to make these exceptions as practical and useful as possible, consistent with the price protection objectives of the Rule and the technology currently available. In addition, the operative provision of the Order Protection Rule requires each trading center to establish, maintain, and enforce policies and procedures that are reasonably designed to prevent trade-throughs on that trading center of protected quotations and to comply with the Rule's exceptions. Implementation of intermarket trade-through protection is likely to present the greatest challenge for agency markets trading active stocks that handle a large volume of buy and sell orders and must assure that such orders interact in an orderly and efficient manner in compliance with all applicable priority rules. The requirements to have procedures reasonably designed to prevent trade-throughs will mitigate this challenge. In this regard, the Commission is encouraged that several trading centers executing the largest number of agency orders currently exhibit the lowest rates of trade-throughs. ${ }^{225}$

\section{Elimination of Proposed Opt-Out Exception}

The rule text of the original proposal included a broad exception for persons to opt-out of the best displayed prices if they provided informed consent. The Proposing Release indicated that the exception was particularly intended to allow investors to bypass manual markets, to execute block transactions without moving the market price, and to help discipline markets that provided slow executions or inadequate access to their quotations. ${ }^{226}$ The Commission also noted, however, that an opt-out exception would be inconsistent with the principle of price

$225 \quad$ See Trade-Through Study, Tables 2, 9.

$226 \quad$ Proposing Release, $69 \mathrm{FR}$ at 11138. 
protection and, if used frequently, could undermine investor confidence that their orders will receive the best available price. It therefore requested comment on an automated execution alternative to the opt-out exception, under which all markets would be required to provide an automated response to electronic orders. At the subsequent NMS Hearing, some panelists questioned whether, assuming only truly accessible and automated quotations were protected, there was a valid reason for opting-out of such a quotation. ${ }^{227}$ To address this issue, the Commission requested comment in the Supplemental Release on whether the proposed opt-out exception would be necessary if manual quotations were excluded from trade-through protection.

Many commenters on the original proposal opposed a general opt-out exception. ${ }^{228}$ They believed that it would be inconsistent with the principle of price protection and undermine the very benefits the trade-through rule is designed to provide. American Century, for example, asserted that the Commission should focus on the limit order investors who have "opted-in" to the NMS, rather than on those that wish to opt-out. ${ }^{229}$ Vanguard noted that an opt-out exception might serve a short-term desire to obtain an immediate execution, but "without recognizing the second order effect of potentially significantly reducing liquidity in the long term."230 Similarly, the ICI stated that "while our members may be best served on a particular trade by 'opting-out' from executing against the best price placed in another market, we believe that in the long term, all investors will benefit by having a market structure where all limit orders are protected and

$227 \quad$ Hearing Tr. at 32, 58, 65, 74, 80, 84-85, 154.

228 See supra note 56 (overview of commenters supporting a strong trade-through rule without an opt-out exception).

229 American Century Letter at 4.

230 Vanguard Letter at 5. 
investors are provided with an incentive to place those orders in the markets." ${ }^{231}$ All of the foregoing views were conditioned on an assumption that only accessible, automated quotations would be protected by a trade-through rule.

Many other commenters, in contrast, supported the proposed opt-out exception. ${ }^{232}$ Aside from concerns that a trade-through rule would be unworkable without an opt-out exception, which were discussed in the preceding section, the primary concerns of these commenters were that, without an opt-out exception, a trade-through rule would: (1) dampen competition among markets, particularly with respect to factors other than price; and (2) restrict the freedom of choice for market participants to route marketable orders to trading centers that are most appropriate for their particular trading objectives and to achieve best execution. The Commission formulated the reproposed Order Protection Rule to respond to these concerns, while still preserving the benefits of intermarket price protection.

In response to the Reproposing Release, many commenters supported the reproposed Order Protection Rule, ${ }^{233}$ with some specifically addressing, and supporting, the elimination of the opt-out exception. ${ }^{234}$ For example, the ICI noted its strong support of the decision to

$231 \quad$ ICI Letter at 14 (emphasis in original).

232 Approximately 371 commenters supported an opt-out exception. Approximately 211 of these commenters opposed a trade-through rule and endorsed an opt-out to remediate what they viewed as its adverse effects. Of these 211 commenters, 179 commenters utilized Form Letter C. The remaining commenters supporting an opt-out exception included a variety of securities industry participants and 22 members of Congress.

See supra, section II.A.1.

234 Letter from Barbara Roper, Director of Investor Protection, Consumer Federation of America, to Jonathan G. Katz, Secretary, Commission, dated January 24, 2005 ("CFA Reproposal Letter”) at 1; ICI Reproposal Letter at 5, n. 8; Letter from Kenneth S. Janke, Chairman, National Association of Investors Corporation, to Jonathan G. Katz, Secretary, Commission, dated January 14, 2005 (“NAIC Reproposal Letter”) at 2. 
eliminate the opt-out exception, agreeing that the elimination of protection for manual quotations makes such an exception unnecessary. ${ }^{235}$ Other commenters continued to express the concern that a trade-through rule without an opt-out exception would impede intermarket competition and innovation and restrict the ability of investors and market intermediaries to choose how best to execute their or their customers' orders to achieve best execution. ${ }^{236}$ For the reasons discussed more fully below, after carefully considering the views of all commenters, the Commission has determined to adopt the Order Protection Rule as reproposed, without an opt-out exception.

\section{a. Preserving Competition Among Markets}

Many commenters believed that an opt-out exception was necessary to promote competition among trading centers, particularly competition based on factors other than price, such as speed of response. For example, 179 commenters on the original proposal submitted letters stating that, in the absence of an opt-out exception, "Reg. NMS will freeze market development and, over the long term, could hurt investors." ${ }^{237}$ Morgan Stanley asserted that allowing market participants to opt-out "would reward markets that provide faster and surer executions, and conversely, would penalize those markets that are materially slower or are displaying smaller quote sizes by ignoring those quotes." ${ }^{\text {238 }}$ Although agreeing that changes

235 ICI Reproposal Letter at 5, n. 8.

236 See, e.g., Letter from Daniel M. Clifton, Executive Director, American Shareholder Association, to Jonathan G. Katz, Secretary, Commission, dated January 26, 2005 (“ASA Reproposal Letter") at 2; Fidelity Reproposal Letter at 3-6; Instinet Reproposal Letter at 5; Morgan Stanley Reproposal Letter at 2, 5-6; Nasdaq Reproposal Letter at 3-4; RBC Capital Markets Reproposal Letter at 3-5. Comments discussing concerns that a tradethrough rule would be unworkable without an opt-out exception are discussed in the preceding section.

$237 \quad$ Letter Type C.

238 Morgan Stanley Letter at 11-12. 
made to the reproposal in the absence of an opt-out exception generally would strengthen any Order Protection Rule, Morgan Stanley continued to be concerned that, without an opt-out exception, the Order Protection Rule may not provide a sufficient amount of flexibility to market participants that encounter a minimally competitive or outright non-compliant trading center. ${ }^{239}$ Instinet believed that, without an opt-out exception, a trade-through rule "would virtually eliminate intermarket competition by forcing operational and technological uniformity on each marketplace, negating price competition, system performance, or any other differentiating feature that a market may develop."240 In its comments on the Reproposing Release, Instinet continued to oppose an Order Protection Rule without an opt-out exception, stating that it does not believe that the exclusion of manual quotations from protection and the proposed "tailored exceptions" are adequate substitutes for an opt-out exception. ${ }^{241}$

The Commission recognizes the vital importance of preserving vigorous competition among markets, but continues to believe that commenters have overstated the risk that such competition will be eliminated by adoption of an order protection rule without a general opt-out exception. The Commission believes that markets likely will have strong incentives to continue to compete and innovate to attract both marketable orders and limit orders. Market participants and intermediaries responsible for routing marketable orders, consistent with their desire to achieve the best price and their duty of best execution, will continue to rank trading centers

239 Morgan Stanley Reproposal Letter at 6.

$240 \quad$ Instinet Letter at 19.

241 Instinet Reproposal Letter at 5. Other commenters on the Reproposing Release also continued to express a concern about the impact the reproposed Rule would have on competition and innovation. See, e.g., JP Morgan Reproposal Letter at 7-8; RBC Capital Reproposal Letter at 3-4; Letter from Jeffrey T. Brown, Senior Vice President, Charles Schwab \& Co., Inc., to Jonathan G. Katz, Secretary, Commission, dated February 1, 2005 (“Schwab Reproposal Letter”) at 2. 
according to the total range of services provided by those markets. Such services include cost, speed of response, sweep functionality, and a wide variety of complex order types. ${ }^{242}$ The most competitive trading center will be the first choice for routing marketable orders, thereby enhancing the likelihood of execution for limit orders routed to that trading center. Because likelihood of execution is of such great importance to limit orders, routers of limit orders will be attracted to this preferred trading center. More limit orders will enhance the depth and liquidity offered by the preferred trading center, thereby increasing its attractiveness for marketable orders, and beginning the cycle all over again. Importantly, Rule 611 will not require that limit orders be routed to any particular market. Consequently, competitive forces will be fully operative to discipline markets that offer poor services to limit orders, such as limiting the extent to which limit orders can be cancelled in changing market conditions or providing slow speed of cancellation.

Conversely, trading centers that offer poor services, such as a slower speed of response, likely will rank near the bottom in order-routing preference of most market participants and intermediaries. Whenever the least-preferred trading center is merely posting the same price as other trading centers, orders will be routed to other trading centers. As a result, limit orders displayed on the least preferred trading center will be least likely to be executed in general. Moreover, such limit orders will be the least likely to be executed when prices move in favor of the limit orders, and the most likely to be executed only when prices are moving against the limit order, adding the cost of "adverse selection" to the cost of a low likelihood of execution. In sum, the lowest ranked trading center in order-routing preference, with or without intermarket price

242 One commenter expressed the view that market participants would continue to compete on a total range of services even with an Order Protection Rule without an opt-out and with depth-of-book protection. Vanguard Reproposal Letter at 4. 
protection, will suffer the consequences of offering a poor range of services to the routers of marketable orders. ${ }^{243}$ The Commission therefore does not believe that the absence of an opt-out exception would freeze market development or eliminate competition among markets.

Commenters have, however, identified a troubling potential for intermarket price protection to lessen the competitive discipline that market participants now can impose on inefficient trading centers in Nasdaq stocks. The Order Protection Rule generally requires that trading centers match the best quoted prices, cancel orders without an execution, or route orders to the trading centers quoting the best prices. This is good for investors generally, but may not be if the quoting market is inefficient. For example, a trading center may have poor systems that do not process orders quickly and reliably. Or a low-volume trading center may not be nearly as accessible as a high-volume trading center.

Currently, consistent with their best execution and other agency responsibilities, participants in the market for Nasdaq stocks can choose not to deal with any trading center that they believe provides unsatisfactory services. Under the Order Protection Rule, market participants can limit their involvement with any trading center to routing IOC orders to access only the best bid or best offer of the trading center. Nevertheless, even this limited involvement potentially could lessen the competitive discipline that otherwise would be imposed on an inefficient trading center. The Commission therefore believes that this potentially serious effect

243 As discussed below in section III.A.2, a competitive problem could arise if a least preferred market was allowed to charge exorbitant fees to access its protected quotations, and then pass most of the fee on as rebates to liquidity providers to offset adverse selection costs. To address the problem of such an "outlier" market, Rule 610(c) sets forth a uniform fee limitation for accessing protected quotations, as well as manual quotations that are the best bid or best offer of an exchange, The NASDAQ Market Center, or the ADF. 
must be addressed at multiple levels in addition to the specific exceptions included in the Rule that were discussed above.

First, trading centers themselves have a legal obligation to meet their responsibilities under the Exchange Act to provide venues for trading that is orderly and efficient. ${ }^{244}$ Through registration and other requirements, the Exchange Act regulatory regime is designed to preclude entities that are not capable of meeting high standards of conduct from doing business with the public. This critically important function would be undermined by a trading center that displayed quotations in the consolidated data stream, but could not, because of poor systems or otherwise, provide efficient access to market participants and efficient handling of their orders. In addition, a trading center would violate its Exchange Act responsibilities if it failed to comply fully with the requirements set forth in Rule 600(b)(3) and (4) for automated quotations and automated trading centers. In particular, an automated trading center must implement such systems, procedures, and rules as are necessary to render it capable of meeting the requirements for automated quotations and must immediately identify its quotations as manual whenever it has reason to believe that it is not capable of displaying automated quotations. These requirements place an affirmative and vitally important legal duty on trading centers to identify their quotations as manual at the first sign of a problem, not after a problem has fully manifested itself and thereby caused a rippling effect at other trading centers that damages investors and the public interest.

Second, those responsible for the regulatory function at SROs have an affirmative responsibility to examine for and enforce all Exchange Act requirements and the SRO rules that

244 See, e.g., Exchange Act Sections 6(b)(1) and 6(b)(5); Exchange Act Section 15; Exchange Act Sections 15A(b)(2) and 15A(b)(6); Exchange Act Section 11A(a)(1)(C); Regulation ATS. 
apply to the trading centers that fall within their regulatory authority. One of the key policy justifications for a self-regulatory system is that industry regulators have close proximity to, and significant expertise concerning, their particular trading centers. In addition, industry regulators typically have greater flexibility to address problems than governmental authorities. Implementation of the Order Protection Rule will heighten the importance of effective selfregulation. Those responsible for the market operation functions of an SRO may have business incentives that militate against dealing with potential problems in an effective and forthright manner. Regulatory personnel are expected to be independent of such business concerns and have an affirmative responsibility to prevent improper factors from interfering with an SRO's full compliance with regulatory requirements.

Finally, the Commission itself plays a critical role in the Exchange Act regulatory regime. Effective implementation of the Order Protection Rule also will depend on the Commission taking any action that is necessary and appropriate to address trading centers that fail to meet fully their regulatory requirements. The Commission and its staff must continue to monitor the markets closely for signs of problems and listen to the concerns of market participants as they arise, especially with regard to the new requirements imposed by the Order Protection Rule. Quick and effective action will be needed to assure that all responsible parties do not feel that inattention to problems is an acceptable course of action.

\section{b. Promoting the Interests of Both Marketable Orders and Limit Orders}

Many commenters that supported an opt-out exception believed that an ability to opt-out of the best displayed prices was necessary to promote full freedom of choice in the routing of marketable orders, and particularly to allow factors other than quoted prices to be considered. For example, 179 commenters on the original proposal submitted a letter stating that "[i]nvestors 
are driven by price, but prices that are inaccessible either because of lagging execution time within a market or insufficient liquidity at the best price point impact the overall costs associated with trading securities in today's markets. The Trade Through rule may harm investors by restricting their ability to achieve best execution, and investors deserve the opportunity to make choices." ${ }^{245}$ Similarly, Fidelity asserted that "as a fiduciary to the mutual funds under our management, we should be free to reach our own informed judgment regarding the market center where our funds' trades are to be executed, particularly when delay may open the way for exchange floor members and others to exploit an informational advantage that arises not from their greater investment or trading acumen but merely from their privileged presence on the physical trading floor."246 Fidelity continues to support an opt-out exception, stating in response to the Reproposing Release that there is a substantial risk that an institutional investor, seeking to trade a large block of stock, will be put to a "distinct and unfair" disadvantage if it cannot negotiate an all-in price for a block trade with a dealer. ${ }^{247}$

The Commission agrees that the interests of investors in choosing the trading center to which to route marketable orders are vitally important, but believes that advocates of the opt-out exception have failed to consider the interests of all investors - both those who submit marketable orders and those who submit limit orders. A fair and efficient NMS must serve the interests of both types of investors. Moreover, their interests are inextricably linked together.

$245 \quad$ Letter Type C.

$246 \quad$ Fidelity Letter I at 6-7.

247 Fidelity Reproposal Letter at 3. Other commenters continued to express a concern that the reproposed Order Protection Rule would limit the ability of investors and market intermediaries to choose how to best execute orders, and, by focusing exclusively on price, would interfere with the ability of institutional investors to achieve best execution. See, e.g., JP Morgan Reproposal Letter at 4-5; Morgan Stanley Reproposal Letter at 5; RBC Capital Reproposal Letter at 4-5; UBS Reproposal Letter at 2. 
Displayed limit orders are the primary source of public price discovery. They typically set quoted spreads, supply liquidity, and in general establish the public "market" for a stock. The quality of execution for marketable orders, which, in turn, trade with displayed liquidity, depends to a great extent on the quality of markets established by limit orders (i.e., the narrowness of quoted spreads and the available liquidity at various price levels).

Limit orders, however, make the first move - when submitted, they must be displayed rather than executed, and therefore offer a "free option" for other market participants to trade a stock by submitting marketable orders and taking the liquidity supplied by limit orders. Consequently, the fate of limit orders - whether or when they receive an execution - is dependent on the choices made by those who route marketable orders. Much of the time, the interests of marketable orders in obtaining the best available price are aligned with those of limit orders that are displaying the best available price. But, as shown by the significant trade-through rates discussed in section II.A.1 above (even for automated quotations in Nasdaq stocks), the interests of marketable orders and limit orders are not always aligned.

One important example of where the interests of limit orders and marketable orders often diverge is large, block trades. Several commenters noted that they often are willing to bypass the best quoted prices if they can obtain an immediate execution of large orders at a fixed price that is several cents away from the best prices. ${ }^{248}$ Yet these block trades often will be priced based on the displayed quotations in a stock. They thereby demonstrate the "free-riding" economic externality that, as discussed in section II.A.1 above, is one of the factors at the heart of the need for intermarket price protection. To achieve the full benefits of intermarket price protection, all investors should be governed by a uniform rule that encompasses their individual trades. For any

$248 \quad$ See, e.g., Fidelity Letter I at 9; Morgan Stanley Letter at 12. 
particular trade, an investor may believe that the best course of action is to bypass displayed quotations in favor of executing larger size immediately. The Commission believes, however, that the long-term strength of the NMS as a whole is best promoted by fostering greater depth and liquidity, and it follows from this that the Commission should examine the extent to which it can encourage the limit orders that provide this depth and liquidity to the market at the best prices. Allowing individual market participants to pick and choose when to respect displayed quotations could undercut the fundamental reason for displaying the liquidity in the first place.

Consequently, the Commission is adopting the Order Protection Rule as reproposed without an opt-out exception because such an exception could severely detract from the benefits of intermarket order protection. Instead, Rule 611 addresses the concerns of those who otherwise may have felt they needed to opt-out of protected quotations in a more targeted manner. In particular, the Rule incorporates an approach that seeks to serve the interests of both marketable orders and limit orders by appropriately balancing these interests in the contexts where they may diverge. In this way, the Order Protection Rule is designed to promote the fairness and efficiency of the NMS for all investors.

First and most importantly, Rule 611 protects only immediately accessible quotations that are available through automatic execution. It does not require investors submitting marketable orders to access "maybe" quotations that, after arrival of the order, are subject to human intervention and thereby create the potential for other market participants to determine whether to honor the quotation. Moreover, as discussed in section II.A.2 above, Rule 611 includes a variety of provisions designed to assure that marketable orders must be routed only to wellfunctioning trading centers displaying executable quotations. 
Second, Rule 611 has been formulated to promote the interests of investors seeking immediate execution of specific order types that reduce their total trading costs, particularly for larger orders. Although the Rule does not provide a general exception for block orders, it addresses the legitimate interest of investors in obtaining an immediate execution in large size (and thereby minimizing price impact). The intermarket sweep order exception will allow broker-dealers to continue to facilitate the execution of block orders. ${ }^{249}$ The entire size of a large order can be executed immediately at any price, so long as the broker-dealer routes orders seeking to execute against the full displayed size of better-priced protected quotations. The size of the order therefore need not be parceled out over time in smaller orders that might tip the market about pending orders. By both allowing immediate execution of the large order and protecting better-priced quotations, Rule 611 is designed to appropriately balance the interests for investors on both sides of the market. ${ }^{250}$

249 Cf. ICI Reproposal Letter at 5 (stating its belief that the intermarket sweep exception would allow institutional investors to continue to execute large-sized orders in an efficient manner).

250 One commenter requested that the Commission consider the practical aspects of executing and reporting large block transactions in compliance with the Rule. For instance, if a dealer agreed to execute a large institutional investor order at three cents outside the market and sent intermarket sweep orders to execute against protected quotations at the same time that it executed and reported the trade, practical issues could arise as to how the dealer could pass through to the investor any better-priced executions of the sweep orders without canceling and correcting the reported block trade. Morgan Stanley Reproposal Letter at 7-9. The Commission agrees that compliance with Rule 611 should not interfere with the ability of a dealer to provide its customers the benefit of better executions and should not cause confusion with respect to the accurate reporting of transactions. As the commenter noted, the practical issues for reporting block trades could be resolved in a variety of ways. The Commission will work with the industry during the implementation period to achieve the most appropriate resolution. 
In the Reproposing Release, the Commission stated that it preliminarily did not believe that "stopped" orders should be excepted from Rule $611,{ }^{251}$ and requested comment on the extent to which the proposed rule language appropriately designated those transactions that should be excepted because they are consistent with the price protection objectives of Rule $611 .^{252}$ Several commenters on the Reproposing Release recommended that the Commission except the execution of stopped orders from the operation of Rule $611 .^{253}$ They believed that, because dealers executing stopped orders provide a source of liquidity that does not otherwise exist in the market at the time the order is stopped, the use of stopped orders represents a common and valuable form of capital commitment by dealers that inures to the benefit of investors. They were concerned that, in the absence of an exception for stopped orders, dealers may be unwilling to commit capital in this manner, or, at a minimum, may charge investors a greater risk premium for the capital commitment.

The Commission agrees that stopped orders can provide a valuable tool for the execution of institutional orders, but is concerned that a broad exception for all stopped orders would undermine the price protection objectives of Rule 611. Several commenters recognized this

251 For purposes of this discussion and Rule 611, a stopped order is an order for which a trading center has guaranteed, at the time of order receipt, an execution at a price no worse than a specified price (referred to in this discussion as the "stop” price).

252 Reproposing Release, 69 FR at 77440 n. 149.

253 See, e.g., Letter from Bruce Lisman, Bear, Stearns \& Co., to Jonathan G. Katz, Secretary, Commission, dated January 27, 2005 ("Bear Stearns Reproposal Letter”) at 2-3; Citigroup Reproposal Letter at 7-8; Morgan Stanley Reproposal Letter at 9-10; SIA Reproposal Letter at 16-18; UBS Reproposal Letter at 6. But see Goldman Sachs Letter at 7-8, n.14; Letter from Mary Yeager, Assistant Secretary, New York Stock Exchange, Inc., to Jonathan G. Katz, Secretary, Commission, dated January 12, 2005 ("NYSE Reproposal Letter I”), Detailed Comments at 3 n. 13. 
concern and suggested criteria for a stopped order exception that would limit the possibility of abuse. $^{254}$ For instance, UBS suggested limiting the applicability of the exception to instances where the stop price is "in the money" when elected (‥e., below the current best bid for buy stops and above the current best offer for sell stops). In these circumstances, the dealer is required to commit capital at a disadvantageous price that would be exacerbated if the dealer also had to satisfy protected quotations at the time it executed the stopped order. ${ }^{255}$ The SIA also suggested that a stopped order guarantee subject to the exception only be available to a non-broker-dealer or a broker-dealer for the benefit of a non-broker-dealer customer and that the customer must agree to the stopped price on an order-by-order basis. ${ }^{256}$

In response to these comments, the Commission has adopted a separate exception for the execution of stopped orders in Rule 611(b)(9). The exception is narrowly drawn to prevent abuse, while also facilitating the continued use of stopped orders by institutional customers. As suggested by the commenters, the exception will apply to the execution of so-called “underwater” stops. Specifically, the exception applies to the execution by a trading center of a stopped order when the price of the execution of the order was, for a stopped buy order, lower than the national best bid in the stock at the time of execution or, for a stopped sell order, higher than the national best offer in the stock at the time of execution. To qualify for the exception, the

254 Bear Stearns Reproposal Letter at 3; Morgan Stanley Reproposal Letter at 10; SIA Reproposal Letter at 17-18; UBS Reproposal Letter at 6.

255 UBS Reproposal Letter at 6. See also SIA Reproposal Letter at 17 (recommending that the exception only be available if the customer that received the stop guarantee is on the advantaged side and the dealer that gave the guarantee is on the disadvantaged side). 
stopped order must be for the account of a customer and the customer must have agreed to the stop price on an order-by-order basis. ${ }^{257}$

In addition, as proposed in the Reproposing Release, paragraph (b)(7) of Rule 611 sets forth an exception that would allow the execution of volume-weighted average price ("VWAP") orders, as well as other types of orders that are not priced with reference to the quoted price of a stock at the time of execution and for which the material terms were not reasonably available at the time the commitment to execute the order was made. This exception will serve the interests of marketable orders and is consistent with the principle of protecting the best displayed quotations.

Several commenters suggested that Rule 611 should include exceptions for additional types of transactions, such as those involving an equity security and a related derivative (for instance, a stock-option transaction), risk arbitrage strategies, and convertible or merger arbitrage. ${ }^{258}$ These commenters noted that the economics of these transactions are based on the relationship between the prices of a security and the related derivative (or between two related securities), and the execution of one trade is contingent upon the execution of the other trade. Thus, the parties to these transactions are less concerned with the price of the individual transactions than with the spread between the individual transaction prices. They believed that the economics of these transactions would be distorted, and additional risk would be introduced,

257 Rule 611(b)(9)(i), (ii), and (iii). "Customer" is defined in Rule 600(b)(16) as any person that is not a broker or dealer.

258 Bear Stearns Reproposal Letter at 3-4; Citigroup Reproposal Letter at 7; Morgan Stanley Reproposal Letter at 10; SIA Reproposal Letter at 16. 
if the dealer or an investor was forced to comply with the Order Protection Rule with respect to the execution of one or both sides of the transaction. ${ }^{259}$

The Commission has given a great deal of consideration to the comments favoring a general exception from Rule 611 for broad categories of transactions, variously described as "contingency" transactions, "arbitrage" transactions, "spread" transactions, and transactions priced with reference to derivatives. Any exception for such a broad category of transactions, however, potentially could unduly detract from the price protection objectives of the Rule. For example, one of the well-known benefits of arbitrage transactions in general is that they promote more efficient pricing of securities in the public markets. Excluding all such transactions from interacting with public quotations potentially could lessen the price discovery benefits of arbitrage. Accordingly, the Commission has determined that the most appropriate process to handle suggestions that specific types of transactions should be excluded from the coverage of Rule 611 is through its exemptive procedure set forth in paragraph (d) of the Rule. The extended implementation period for Regulation NMS will provide a full opportunity for the public to request specific exemptions that they believe are necessary or appropriate in the public interest and consistent with the protection of investors. Of course, the Commission also will consider exemptive requests once Regulation NMS has been implemented.

Even given all the exceptions set forth in Rule 611, however, the Commission recognizes that the existence of intermarket price protection without an opt-out exception may interfere to some extent with the extremely short-term trading strategies of some market participants. Some of these strategies can be affected by a delay in order-routing or execution of as little as 3/10ths of one second. Given the current NMS structure with multiple competing markets, any

259 See, e.g., Morgan Stanley Reproposal Letter at 10. 
protection of displayed quotations in one market could affect the implementation of short-term trading strategies in another market. This conflict between protecting the best displayed prices and facilitating short-term trading strategies raises a fundamental policy question - when such a conflict exists, should the overall efficiency of the NMS defer to the needs of short-term traders, many of whom rarely intend to hold a position overnight? Or should the NMS serve the needs of longer-term investors, both large and small, that will benefit substantially from intermarket price protection?

The Commission believes that two of the most important public policy functions of the secondary equity markets are to minimize trading costs for long-term investors and to reduce the cost of capital for listed companies. These functions are inherently connected, because the cost of capital of listed companies is influenced by the transaction costs of those who are willing to accept the investment risk of holding corporate stock for an extended period. To the extent that the interests of short-term traders and market intermediaries in a broad opt-out exception conflict with those of investors, the Commission believes that the interests of long-term investors are entitled to take precedence. ${ }^{260}$ In this way, the NMS will fulfill its Exchange Act objectives to promote fair and efficient equity markets for investors and to serve the public interest.

\section{Scope of Protected Quotations}

The original trade-through proposal would have protected all quotations disseminated by a Plan processor in the consolidated quote stream. Currently, the scope of these quotations depends on the regulatory status of an SRO. Under Exchange Act Rule 11Ac1-1 ("Quote Rule") (redesignated as Rule 602), exchange SROs are required to provide only their best bids and offers ("BBOs") in a stock. In contrast, a national securities association, which currently

See supra, section I.B.2. 
encompasses Nasdaq's trading facilities and the NASD's ADF, must provide BBOs of its individual members. Consequently, the original proposal would have protected only a single BBO of an exchange and not any additional quotations in its depth of book ("DOB"). For Nasdaq facilities and the ADF, however, the proposal would have protected member BBOs at multiple price levels. The Proposing Release requested comment on whether only a single BBO for Nasdaq and the ADF should be protected. ${ }^{261}$

Commenters expressed concern that the proposed rule text would protect the BBOs of individual market makers and ATSs in Nasdaq's facilities and the ADF, but only a single BBO of exchange SROs. ${ }^{262}$ The Specialist Association, for example, believed that it would be unfair to offer greater protection to the quotations of members of an association SRO than to those of an exchange SRO. ${ }^{263}$ Morgan Stanley stated that to "equalize the protections available to all market participants, we believe the Commission should treat SuperMontage as a single market for purposes of the trade-through rule, instead of treating each individual Nasdaq market maker as a separate quoting market participant." ${ }^{264}$

The Commission agrees with these commenters that Rule 611 should not mandate a regulatory disparity between the quotations displayed through exchange SROs and those displayed through Nasdaq facilities and the ADF. Potentially, Nasdaq and the ADF could attract a significant number of limit orders if they were able to offer order protection that was not available at exchange SROs. This result would not be consistent with the Exchange Act goals of

$261 \quad$ Proposing Release, $69 \mathrm{FR}$ at 11136.

262 See, e.g., Goldman Sachs Letter at 6; Morgan Stanley Letter at 8; NYSE Letter, Attachment at 4; Specialist Assoc. Letter at 3.

$263 \quad$ Specialist Assoc. Letter at 3.

$264 \quad$ Morgan Stanley Letter at 8. 
fair competition among markets and the equal regulation of markets. ${ }^{265}$ The Commission therefore modified the definition of "protected bid" and "protected offer" in the reproposal to encompass the BBOs of an exchange, Nasdaq, and the ADF. In this way, exchange markets would be treated comparably with Nasdaq and the ADF.

The Proposing Release also addressed the issue of extending trade-through protection to DOB quotations, but questioned whether protecting all DOB quotations would be feasible at this time. ${ }^{266}$ Comment specifically was requested, however, on whether protection should be extended beyond the BBOs of SROs if individual markets voluntarily provided DOB quotations through the facilities of an effective national market system plan. ${ }^{267}$ At the subsequent NMS Hearing, a panelist specifically endorsed the policy and feasibility of extending trade-through protection to DOB quotations, as long as such quotations were automated and accessible: "Automatically executable quotes, whether they are on the top of the book or up and down the book, should be protected by the trade-through rule, and manual quotes should not be. This is a simple and technically easy idea to implement...."268

Most of the subset of comment letters on the original proposal that specifically addressed the DOB issue supported the approach of extending trade-through protection to all limit orders displayed in the NMS, not merely the BBOs of the various markets. ${ }^{269}$ The Consumer

265 Exchange Act Sections 11A(a)(1)(C)(ii) and 11A(c)(1)(F).

266 Proposing Release, 69 FR at 11136.

267 Id.

268 Hearing Tr. at 57 (testimony of Thomas Peterffy, Chairman, Interactive Brokers Group).

269 American Century Letter at 2; Ameritrade Letter I at 4; BNY Letter at 2; Capital Research Letter at 2; Consumer Federation Letter at 2; Goldman Sachs Letter at 6; ICI Letter at 8. See also ArcaEx Letter at 7 (supported trade-through protection for exchange-listed stocks only, but for entire depth-of-book). But see Letter from Samuel F. 
Federation of America, for example, stated that "such an approach would result in better price transparency and help to address complaints that decimal pricing has reduced price transparency because of the relatively thin volume of trading interest displayed in the best bid and offer." 270 The ICI noted that protecting all displayed limit orders might not be feasible at this time, but urged the Commission to examine the issue further. ${ }^{271}$

The Commission recognized, however, that other commenters may have chosen not to address the alternative of protecting voluntary DOB quotations because it was not included in the proposed rule text. In the Reproposing Release, therefore, the Commission proposed rule text for two alternatives: (1) the Market $\mathrm{BBO}$ Alternative that would protect only the $\mathrm{BBOs}$ of the exchange SROs, Nasdaq, and the ADF; or (2) the Voluntary Depth Alternative that, in addition to protecting $\mathrm{BBOs}$, would protect the $\mathrm{DOB}$ quotations that markets voluntarily disseminate in the consolidated quotations stream. The Commission requested comment on which of the two alternatives would most further the Exchange Act objectives for the NMS in a practical and workable manner. In particular, comment was requested on whether extending trade-through protection to DOB quotations would significantly increase the benefits of the Order Protection Rule, and on the effect that adoption of the Voluntary Depth Alternative would have on

Lek, Chief Executive Officer, Lek Securities Corporation, to Jonathan G. Katz, Secretary, Commission, dated May 24, 2004 ("Lek Securities Letter") at 7; Letter from David Humphreville, President, the Specialist Association of the New York Stock Exchange, to Jonathan G. Katz, Secretary, Commission, dated June 30, 2004 ("Specialist Assoc. Letter") at 3.

$270 \quad$ Consumer Federation Letter at 2.

$271 \quad$ ICI Letter at 8. 
competition among markets. The Commission also requested comment on whether the

Voluntary Depth Alternative could be implemented in a practical and cost-effective manner. ${ }^{272}$

A large majority of commenters that supported the reproposed Order Protection Rule supported the Market BBO Alternative. ${ }^{273}$ Many commenters believed that the Market BBO

Alternative achieves the appropriate balance between the need to promote competition among

See Section II.A.5 in the Reproposing Release for a detailed discussion of the request for comment on the Market BBO Alternative and the Voluntary Depth Alternative.

273 Approximately 1,556 commenters expressed support for the Market BBO Alternative, of which approximately 1,411 were form letters. See, e.g., Letter from Brendan R. Dowd and Zdrojeski, Co-Presidents, Alliance of Floor Brokers, to Jonathan G. Katz, Secretary, Commission, dated January 20, 2005 (“Alliance of Floor Brokers Reproposal Letter”) at 1; Letter from Neal L. Wolkoff, Acting Chief Executive Officer, American Stock Exchange, LLC, to Jonathan G. Katz, Secretary, Commission, dated January 27, 2005 (“Amex Reproposal Letter”) at 2; Bear Stearns Reproposal Letter at 1 (if properly modified); Letter from Minder Cheng, Managing Director, CIO, US Active Equities, Global Head of Equity and Currency Trading, Barclays Global Investors, N.A., to Jonathan G. Katz, Secretary, Commission, dated January 26, 2005 ("BGI Reproposal Letter”) at 2; Letter from Joseph M. Velli, Senior Executive Vice President, The Bank of New York, to Jonathan G. Katz, Secretary, Commission, dated January 26, 2005 ("BNY Reproposal Letter”) at 2; BSE Reproposal Letter at 2; Letter from David A. Herron, Chief Executive Officer, The Chicago Stock Exchange, to Jonathan G. Katz, Secretary, Commission, dated January 26, 2005 (“CHX Reproposal Letter”) at 2; Letter from Kimberly G. Walker, Chairman, Committee on Investment of Employee Benefit Assets, to Jonathan G. Katz, Secretary, Commission, dated January 25, 2005 ("CIEBA Reproposal Letter”) at 2; Deutsche Bank Reproposal Letter at 2; Form Letters G, H, I, J, and K; Letter from D. Keith Ross, Jr., Chief Executive Officer, Getco, LLC, to Jonathan G. Katz, Secretary, Commission, dated January 26, 2005 (“Getco Reproposal Letter”) at 2; Letter from Thomas Peterffy, Chairman, and David M. Battan, Vice President, The Interactive Brokers Group, to Jonathan G. Katz, Secretary, Commission, dated January 24, 2005 (“Interactive Brokers Group Reproposal Letter”) at 1; NAIC Reproposal Letter at 2; Letter from John M. Schaible, President, NexTrade Holdings, Inc., to Jonathan G. Katz, Secretary, Commission, dated December 22, 2004 (“Nextrade Reproposal Letter”) at 3; NYSE Reproposal Letter I at 1-3; Letter from Kenneth J. Polcari, President, et al., Organization of Independent Floor Brokers, to Jonathan G. Katz, Secretary, Commission, dated January 12, 2005 (“Organization of Independent Floor Brokers Reproposal Letter”) at 2; Phlx Reproposal Letter at 1; Letter from Richard A. Rosenblatt, CEO, and Joseph C. Gawronski, COO, Rosenblatt Securities Inc., to Jonathan G. Katz, Secretary, Commission, dated January 26, 2005 ("Rosenblatt Securities Reproposal Letter”) at 2; Specialist Association Reproposal Letter at 2; T. Rowe Price Reproposal Letter at 2. 
orders and to preserve competition among markets, ${ }^{274}$ but that the Voluntary Depth Alternative, by focusing too exclusively on competition among orders, would unduly restrict competition among markets. ${ }^{275}$ Many commenters also believed that implementing the Voluntary Depth Alternative would be significantly more difficult and costly than implementing the Market BBO Alternative. $^{276}$

The Commission has determined to adopt the Market BBO Alternative. The Commission believes that providing enhanced protection for the best bids and offers of each exchange, Nasdaq, and the ADF will represent a major step toward achieving the objectives of intermarket price protection, but with fewer of the costs and drawbacks associated with the Voluntary Depth Alternative. In particular, the Market BBO Alternative will promote best execution for retail investors on an order-by-order basis, given that most retail investors justifiably expect that their orders will be executed at the NBBO. In addition, implementation of the Market BBO Alternative will not require an expansion of the data disseminated through the Plans. The Plans

$274 \quad$ See, e.g., Amex Reproposal Letter at 3; BGI Reproposal Letter at 2; BNY Reproposal Letter at 2-3; Form Letter J; Specialist Association Reproposal Letter at 3.

275 See, e.g., Alliance of Floor Brokers Reproposal Letter at 2; Amex Reproposal Letter at 3; Bear Stearns Reproposal Letter at 2; BNY Reproposal Letter at 2-3; BSE Reproposal Letter at 6; CHX Reproposal Letter at 3; CIEBA Reproposal Letter at 2; Deutsche Bank Reproposal Letter at 2; Getco Reproposal Letter at 1-2; Interactive Brokers Reproposal Letter at 3; NAIC Reproposal Letter at 1-2; NYSE Reproposal Letter I at 2; Organization of Independent Floor Brokers Reproposal Letter at 2; Rosenblatt Securities Reproposal Letter at 2; Specialist Association Reproposal Letter at 5.

$276 \quad$ See, e.g., Amex Reproposal Letter at 3; BNY Reproposal Letter, at 3; BSE Reproposal Letter at 7; CHX Reproposal Letter at 2; Letter from W. Leo McBlain, Chairman, and Thomas J. Jordan, Executive Director, Financial Information Forum, to Jonathan G. Katz, Secretary, Commission, dated January 26, 2005 (“FIF Reproposal Letter”) at 2-3; Getco Reproposal Letter at 1; Interactive Brokers Group Reproposal Letter at 1; Nextrade Reproposal Letter at 3; NYSE Reproposal Letter I, Detailed Comments at 8; Phlx Reproposal Letter at 2; Specialist Association Reproposal Letter at 4. 
currently disseminate the BBOs of each SRO, but do not disseminate the depth of book of all SROs.

The Commission does not agree with commenters that the Voluntary Depth Alternative would be a CLOB, virtual or otherwise. ${ }^{277}$ The essential characteristic of a CLOB is strict price/time priority. To achieve time priority, all orders must be funneled through a single trading facility so that they can be ranked by time. Such a facility would greatly reduce the opportunity for markets to compete by offering a variety of different trading services. Price priority alone, however, would not cause nearly as significant an impact on competition among markets because it allows price-matching by competing markets. Thus, while a CLOB requires centralization of essentially all orders, price priority (whether the Market BBO Alternative or the Voluntary Depth Alternative) merely requires the routing of a much smaller subset of orders that otherwise would be executed at inferior prices.

A number of commenters believed that enhanced order interaction with quotations beyond the best bids and offers of the various SROs would likely result even if the Commission adopted the Market BBO Alternative. ${ }^{278}$ Given the existence of highly sophisticated order

277 Many of these commenters expressed the view that implementation of the Voluntary Depth Alternative effectively would amount to a virtual CLOB. See, e.g., Alliance of Floor Brokers Reproposal Letter at 2; BGI Reproposal Letter at 3; BNY Reproposal Letter at 2-3; CHX Reproposal Letter at 2-3; Letter from Congressman Peter T. King et al., to Jonathan G. Katz, Secretary, Commission, dated January 25, 2005 ("Congressman King et al. Reproposal Letter”) at 1; Letter from Congressman Edward R. Royce and Congressman George Radanovich to Jonathan G. Katz, Secretary, Commission, dated January 25, 2005 (“Congressmen Royce \& Radanovich Reproposal Letter”); Letter from Congresswoman Lydia M. Velazquez to Jonathan G. Katz, Secretary, Commission, dated January 25, 2005 (“Congresswoman Velazquez Letter") at 1; NAIC Reproposal Letter at 1; NYC Comptroller Reproposal Letter; NYSE Reproposal Letter at 2; Organization of Independent Floor Brokers Reproposal Letter at 1; Form Letters G, H, I, J, K, and L.

278 See, e.g., Bear Stearns Reproposal Letter at 2; BNY Reproposal Letter at 2; Interactive Brokers Reproposal Letter at 4. 
routing technology and the requirement to route orders to access the best bids and offers under the Market BBO Alternative, these commenters asserted that competition and best execution responsibilities would lead market participants to voluntarily access depth-of-book quotations in addition to quotations at the top-of-book. The Commission believes that such a competitiondriven outcome would benefit investors and the markets in general.

Another group of commenters advocated protecting only the NBBO. ${ }^{279}$ They believed that NBBO protection would be a more measured first step forward that would strengthen existing price protection while helping to mitigate implementation problems and potential unintended consequences with either the Market BBO or Voluntary Depth Alternative. ${ }^{280}$ The Commission does not support the NBBO approach. The marginal benefits to be gained from protecting only the NBBO would not justify the costs of implementing the approach. In addition, protecting only the NBBO would be a step backwards from the scope of the existing ITS trade-through rule, which covers the best bids and offers of each exchange and the NASD. The Commission also is concerned that an order protection rule that protected only the NBBO would be excessively vulnerable to gaming behavior, because a market participant could post a 100-share order improving the NBBO and then execute a much larger order away from the NBBO while protecting only the 100-share quotation. This result would not be consistent with the purposes of the Order Protection Rule.

279 CIBC Reproposal Letter at 1 (joining positions taken by SIA in its letter); Citigroup Reproposal Letter at 6 (arguing that to the extent a trade-through rule is necessary, it prefers protecting the NBBO, with an exception for most liquid securities preferred); FSR Reproposal Letter at 4; JP Morgan Reproposal Letter at 3 (stating that if Commission does not provide large order exception then NBBO preferred); Lava Reproposal Letter at 1,3 (not supporting or opposing the reproposed Order Protection Rule but indicating NBBO would facilitate adoption and ease implementation concerns); Merrill Lynch Reproposal Letter at 3; SIA Reproposal Letter at 5-12; STANY Reproposal Letter at 10. See, e.g., SIA Reproposal Letter at 5-12. 


\section{Benefits and Implementation Costs of the Order Protection Rule}

Commenters were concerned about the cost of implementing the original trade-through

proposal. Some argued that, in general, implementing the proposed rule would be too expensive and would outweigh any perceived benefits of the rule. ${ }^{281}$ Commenters also were concerned about the cost of specific requirements in the proposed rule, particularly the procedural requirements associated with the proposed opt-out exception (e.g.g. obtaining informed consent from customers and disclosing the NBBO to customers). ${ }^{282}$

Some of the commenters based their concerns about implementation costs on the estimated costs included in the Proposing Release for purposes of the Paperwork Reduction Act of 1995 ("PRA"). ${ }^{283}$ In the Reproposing Release, the Commission revised its estimate of the PRA costs associated with the proposed rule to reflect the streamlined requirements of Rule 611 as reproposed, and to reflect a further refinement of the estimated number of trading centers subject to the rule. ${ }^{284}$ In particular, Rule 611 as reproposed did not contain an opt-out exception, and thus costs associated with the proposed exception, which represented a large portion of the

281 See, e.g., Bloomberg Tradebook Letter at 14; Fidelity Letter I at 12; Instinet Letter at 14, 15; Nasdaq Letter II at 2; Letter from Junius W. Peake, Monfort Distinguished Professor of Finance, Kenneth W. Monfort College of Business, University of Northern Colorado, dated April 23, 2004 ("Peake Letter I") at 2; NMS Study Group Letter at 4; Letter from Richard A. Rosenblatt, Chief Executive Officer, \& Joseph C. Gawronski, Chief Operating Officer, Rosenblatt Securities Inc., to William H. Donaldson, Chairman, Commission, dated June 23, 2004 ("Rosenblatt Securities Letter II") at 4; STANY Letter at 3; UBS Letter at 8.

282 See, e.g., Ameritrade Letter I at 8; Brut Letter at 12; Citigroup Letter at 8-9; E*TRADE Letter at 7; Letter from W. Leo McBlain, Chairman, \& Thomas J. Jordan, Executive Director, Financial Information Forum, to Jonathan G. Katz, Secretary, Commission, dated July 9, 2004 ("Financial Information Forum Letter") at 2; JP Morgan Letter at 4; SIA Letter at 12-14.

44 U.S.C. 3501 et seq.

284 The PRA analysis is forth in section VIII.A below. 
overall estimated costs described in the Proposing Release, were no longer applicable. ${ }^{285}$ In total, eliminating the opt-out procedural requirements alone reduced the estimate of costs in the Proposing Release by \$294 million in start-up costs and \$207 million in annual costs. In the Reproposing Release, the Commission also refined its estimate of the number of broker-dealers that would be required to establish, maintain, and enforce written policies and procedures designed to prevent trade-throughs pursuant to the reproposed Rule from 6,788 registered broker-dealers to approximately 600 broker-dealers. ${ }^{286}$

Taken together, these changes substantially reduced the estimated costs associated with implementation of and ongoing compliance with reproposed Rule 611. As discussed further in section VIII.A below, the estimated PRA costs associated with reproposed Rule 611 were \$17.8 million in start-up costs and \$3.5 million in annual costs. In addition, as discussed further in section IX.A.2 below, the estimated implementation costs in the Reproposing Release for necessary systems modifications were $\$ 126$ million in start-up costs and \$18.4 million in annual

285 Specifically, the estimated costs of providing investors with disclosure necessary to obtain informed consent to opt-outs and retaining records relating to such disclosures were \$100 million in start-up costs and \$59 million annually. Further, the estimated costs of the proposed requirement for broker-dealers to provide every customer that opted out with the NBBO at the time of execution were \$194 million in start-up costs and almost \$148 million annually.

286 In the Proposing Release, the Commission estimated that potentially all of the 6,768 registered broker-dealers would be subject to this requirement, but acknowledged that it believed the figure was likely overly-inclusive because it might include registered brokerdealers that do not effect transactions in NMS stocks. As noted in the Reproposing Release, after further consideration, the Commission believes that this number indeed greatly overestimated the number of registered broker-dealers that would be subject to the rule, given that most of those broker-dealers do not engage in the business of executing orders internally. The estimated number therefore was reduced to approximately 600 broker-dealers in the Reproposing Release. No comments were received on this estimate. The estimate is described further in section VIII.A below. 
costs. Accordingly, the total estimated costs in the Reproposing Release were \$143.8 million in start-up costs and \$21.9 million in annual costs.

Although a number of commenters generally expressed the view that there would be significant costs associated with implementing and complying with the reproposed Rule, they did not discuss the specific estimated cost figures included in the Reproposing Release or include their own estimates. ${ }^{287}$ Many commenters expressed concerns with the costs associated with implementing the Voluntary Depth Alternative, believing that the costs of implementing the Voluntary Depth Alternative would be substantially greater than the Market BBO Alternative. ${ }^{288}$ As discussed above in Section II.A.5, the Commission is adopting the Market BBO Alternative and not the Voluntary Depth Alternative. The Commission does not believe that the inclusion of a stopped order exception will materially impact the estimated costs included in the Reproposing Release. ${ }^{289}$ The Commission continues to estimate implementation costs for the Order Protection Rule as adopted of approximately \$143.8 million and annual costs of approximately $\$ 21.9$ million. $^{290}$

287 See, e.g., CIBC Reproposal Letter at 4; Letter from Thomas M. Joyce, CEO \& President, Knight Trading Group, Inc., to Jonathan G. Katz, Secretary, Commission, dated January 25, 2005 (“Knight Securities Reproposal Letter” “Knight Reproposal Letter”) at 5 (expressing the view that the costs of either the Market BBO or Voluntary Depth Alternative outweigh the nominal benefits of the Rule); Merrill Lynch Reproposal Letter at 5; Nasdaq Reproposal Letter at 2; SIA Reproposal Letter at 11.

288 Amex Reproposal Letter at 3; Letter from Steve Swanson, CEO \& President, Automated Trading Desk, LLC, to Jonathan G. Katz, Secretary, Commission, dated January 26, 2005 (“ATD Reproposal Letter”) at 4; BNY Reproposal Letter at 3; CHX Reproposal Letter at 2; NYSE Reproposal Letter I, Detailed Comments at 8; RBC Capital Markets Reproposal Letter at 6; STANY Reproposal Letter at 9.

289 The estimated cost figures included the Reproposing Release did not include additional costs that would be associated with the Voluntary Depth Alternative. See section IX.A.2 of the Reproposing Release.

See infra sections VIII.A and IX.A.2. 
In assessing the implementation costs of the Order Protection Rule, it is important to recognize that much, if not all, of the connectivity among trading centers necessary to implement intermarket price protection has already been put in place. Trading centers for exchange-listed securities already are connected through the ITS. The Commission understands that, at least as an interim solution, ITS facilities and rules can be modified relatively easily and at low cost to provide the current ITS participants a means of complying with the provisions of Rule 611. With respect to Nasdaq stocks, connectivity among many trading centers already is established through private linkages. Routing out to other trading centers when necessary to obtain the best prices for Nasdaq stocks is an integral part of the business plan of many trading centers, even when not affirmatively required by best execution responsibilities or by Commission rule. Moreover, a variety of private vendors currently offer connectivity to NMS trading centers for both exchange-listed and Nasdaq stocks.

The Commission believes that the benefits of strengthening price protection for exchange-listed stocks (e.g., by eliminating the gaps in ITS coverage of block positioners and 100-share quotes) and introducing price protection for Nasdaq stocks will be substantial, although the total amount is difficult to quantify. One objective, though quite conservative, estimate of benefits is the dollar amount of quotations that annually are traded through. The Commission staff's analysis of trade-through rates indicates that over 12 billion shares of displayed quotations in Nasdaq and NYSE stocks were traded through in 2003, by an average amount of 2.3 cents for Nasdaq stocks and 2.2 cents for NYSE stocks. ${ }^{291}$ These traded-through quotations represent approximately \$209 million in Nasdaq stocks and \$112 million in NYSE stocks, for a total of \$321 million in bypassed limit orders and inferior prices for investors in

291 Trade-Through Study at 3, 5. 
2003 that could have been addressed by strong trade-through protection. ${ }^{292}$ The Commission believes that this $\$ 321$ million estimated annual benefit, particularly when combined with the benefits of enhanced investor confidence in the fairness and orderliness of the equity markets, justifies the one-time costs of implementation and ongoing annual costs of the Order Protection Rule.

Two commenters on the reproposal asserted that the dollar amount of traded-through quotations overstated the benefits of order protection because "trading is for the most part a zerosum game." ${ }^{293}$ They believed that trades executed at inferior prices were random noise that sometimes benefited and sometimes disadvantaged a particular investor, stating that "[i]t is only if one class of investors systematically loses out to another class as a result of trade-throughs that there is a problem." ${ }^{294}$

The Commission does not agree that trades executed at inferior prices should be considered merely a transfer of benefits from one group of investors to another equally-situated group of investors. There are at least three parties affected by every trade-through transaction: (1) the party that received an inferior price; (2) the party whose superior-priced limit order was traded-through; and (3) the contra party to the trade-through transaction that received an advantageous price. The redistributions of welfare resulting from trade-through transactions cannot reasonably be expected to occur randomly across these parties. Customers of brokers that are doing a poor job of routing orders are more likely to be harmed than customers of brokers

$292 \quad$ Id. at 3.

293 Angel Reproposal Letter at 4; Fidelity Reproposal Letter at 8.

$294 \quad$ Angel Reproposal Letter at 4. 
that are doing a better job. ${ }^{295}$ Investors who generally submit limit orders at the best prices are more likely to be harmed than customers who generally submit less aggressively-priced limit orders.

Thus, trade-through transactions can result in direct harm to two parties, as well as more general harm to the efficiency of the markets by dampening the incentive for aggressive quoting. Moreover, even when the party receiving an inferior price does so willingly (such as when an institution accepts a block trade at a price away from the inside quotation), ${ }^{296}$ the party whose quotation was traded through and the efficiency of the markets still are harmed. Finally, many trade-throughs are dealer internalized trades, where the party receiving the advantageous price is not an investor but a market intermediary, and therefore such trades cannot be considered a transfer of benefits from one group of investors to another equally-situated group of investors. This transfer of benefits from investors to market intermediaries cannot be dismissed as mere "random noise."

295 As discussed above, it can be difficult for retail investors in particular to monitor whether their orders in fact received the best available price at the time of order execution. See supra, note 53 and accompanying text.

296 Fidelity and the Battalio/Jennings Paper asserted that the staff study should not have included block trades in its estimate of the benefits of strengthened trade-through protection. Fidelity Reproposal Letter II at 1; Battalio/Jennings Paper at 2. The Commission does not agree. First, the amount that block trades contributed to the \$321 million estimate is very small. Block trades represented only $1.9 \%$ of total tradethroughs in Nasdaq stocks and $1.1 \%$ of total trade-throughs in NYSE stocks. TradeThrough Study, Tables 6, 13. Most importantly, the staff study used the lesser of the size of the traded-through quotation and the size of the trade-through transaction when calculating the $\$ 321$ million. Id. at 3. Thus, if a 10,000 share transaction traded through a 100-share quotation, only 100 shares counted toward the estimation of benefits. The Battalio/Jennings Paper incorrectly asserted that the staff study did not use this conservative approach. Battalio/Jennings Paper at 2. Finally, block trades are appropriately included in the estimation of benefits because their failure to interact with significant displayed quotations is one of the most serious problems with respect to the protection of limit orders that the Order Protection Rule is designed to address. supra, section II.A.1.c. 
In addition, economic theory predicts that, in an auction market, buyers who place the highest value on a stock will bid most aggressively. ${ }^{297}$ If an incoming market order is allocated to an investor who is not bidding the best price, this re-allocation is neither zero-sum nor random. It systematically reallocates trades away from those investors for whom the welfare gains would be largest. The argument also can be framed in terms of an investor's preferences with respect to the tradeoff between price and execution speed. Among those investors who trade using limit orders, we would expect more aggressive limit orders to be submitted by those investors who place more value on speed or certainty of execution and relatively less value on price. Conversely, we would expect investors who place a lower value on speed and certainty of execution and a higher value on price to submit less aggressive limit orders. When an incoming market order is executed against a limit order with an inferior price, the result is: (1) a faster execution for an investor who does not place as much value on speed of execution; and (2) a lost execution or slower execution for the investor who places a higher value on prompt execution. This is not a zero-sum redistribution.

Moreover, the \$321 million estimate is a conservative measure of the total benefits of the Order Protection Rule. It does not attempt to measure any gains from trading associated with investors' private values, beyond those expressed in their limit order prices. The Order Protection Rule can be expected to generate other categories of benefits that are not quantified in the $\$ 321$ million estimate, such as the benefits that can be expected to result from increased use of limit orders, increased depth, and increased order interaction.

Thus, the Commission believes that the $\$ 321$ million estimate of benefits is conservative because it is based solely on the size of displayed quotations in the absence of strong price

297 See, e.g., B. Hollifield, R. Miller and P. Sandas, "Empirical Analysis of Limit Order Markets,” 71 Review of Economic Studies 1027-1063 and n. 4 (2004). 
protection. In essence, it measures the problem - a shortage of quoted depth - that the Order Protection Rule is designed to address, rather than the benefits that it could achieve. Every tradethrough transaction potentially sends a message to market participants that their displayed quotations can be and are ignored by other market participants. When the total share volume of trade-through transactions that do not interact with displayed quotations reaches $9 \%$ and above for hundreds of the most actively traded NMS stocks, ${ }^{298}$ this message is unlikely to be missed by those who watched their quotations being traded through. Certainly, the common practice of trading through displayed size is most unlikely to prompt market participants to display even greater size.

A primary objective of the Order Protection Rule is to increase displayed depth and liquidity in the NMS and thereby reduce transaction costs for a wide spectrum of investors, particularly institutional investors that must trade in large sizes. Precisely estimating the extent to which strengthened price protection will improve market depth and liquidity, and thereby lower the transaction costs of investors, is very difficult. The difficulty of estimation should not hide from view, however, the enormous potential benefits for investors of improving the depth and efficiency of the NMS. Because of the huge dollar amount of trading volume in NMS stocks - more than $\$ 17$ trillion in $2003^{299}$ - even the most incremental improvement in market depth and liquidity could generate a dollar amount of benefits that annually would dwarf the one-time start-up costs of implementing trade-through protection.

One approach to evaluating the potential benefits of the Order Protection Rule is to examine a category of investors that stand to benefit a great deal from improved depth and

$298 \quad$ See Trade-Through Study, Tables 4.

299 World Federation of Exchanges, Annual Report (2003), at 86. 
liquidity for NMS stocks - the shareholders in U.S. equity mutual funds. In 2003, the total assets of such funds were $\$ 3.68$ trillion. ${ }^{300}$ The average portfolio turnover rate for equity funds was 55\%, meaning that their total purchases and sales of securities amounted to approximately $\$ 4.048$ trillion. ${ }^{301}$ A leading authority on the trading costs of institutional investors has estimated that in the second quarter of 2003 the average price impact experienced by investment managers ranged from 17.4 basis points for giant-capitalization stocks, 21.4 basis points for largecapitalization stocks, and up to 35.4 basis points for micro-capitalization stocks. ${ }^{302}$ In addition, it estimated the cost attributable to adverse price movements while searching for liquidity for institutional orders, which often are too large simply to be presented to the market. Its estimate of these liquidity search costs ranged from 13 basis points for giant capitalization stocks, 23 basis points for large capitalization stocks, and up to 119 basis points for micro-capitalization stocks.

To obtain a conservative estimate of price impact costs and liquidity search costs incurred across all stocks, the total market impact and liquidity search costs for giant capitalization stocks (30.4 basis points) and the total market impact and liquidity search costs for large capitalization stocks ( 44.4 basis points) are averaged together to yield a figure of 37.4 basis points. ${ }^{303}$ The much higher market impact and liquidity search costs of midcap, smallcap, and microcap stocks

$300 \quad$ Investment Company Institute, Mutual Fund Fact Book (2004), at 55.

301 Id. at 64. Portfolio turnover is reported as the lesser of portfolio sales or purchases divided by average net assets. Because price impact occurs for both purchases and sales, the turnover rate must be doubled, then multiplied by total fund assets, to estimate the total value of trading that would be affected by an improvement in depth and liquidity.

302 Plexus Group, Inc., Commentary 80, "Trading Truths: How Mis-Measurement of Trading Costs Is Leading Investors Astray," (April 2004), at 2-3.

303 Cf. supra, note 146 and accompanying text (Plexus estimate of average transaction costs, including commissions, during the fourth quarter of 2003 for Nasdaq and NYSE stocks as, respectively, 83 basis points and 55 basis points; commissions average 12 basis points for large capitalization stocks). 
are not included. Using this estimate of 37.4 basis points, the shareholders in U.S. equity mutual funds incurred implicit transaction costs of \$15.1 billion in 2003. Based on a hypothetical assumption that, in light of the current share volume of trade-through transactions that does not interact with displayed liquidity, intermarket trade-through protection could improve depth and liquidity for NMS stocks by 5\% (or an average reduction of 1.87 basis points in price impact and liquidity search costs for large investors), the savings in transaction costs for U.S equity funds alone, and the improved returns for their millions of individual shareholders, would have amounted to approximately \$755 million in 2003.

Of course, the benefits of improved depth and liquidity for the equity holdings of other types of investors, including pension funds, insurance companies, and individuals, are not incorporated in the foregoing calculations. In 2003, these other types of investors held 78\% of the value of publicly traded U.S. equity outstanding, with equity mutual funds holding the remaining 22\%. ${ }^{304}$ For example, pension funds alone held $\$ 9$ trillion in assets in 2003, of which an estimated $\$ 4.9$ trillion was held in equity investments other than mutual funds. ${ }^{305}$ Thus, the implicit transaction costs incurred by institutional investors each year is likely at least double the $\$ 15.1$ billion estimated for equity mutual funds, for a total of more than $\$ 30$ billion. Assuming that these other types of investors experienced a reduction in transaction costs that equaled the reduction of trading costs for equity mutual funds, the assumed 5\% improvement in market depth and liquidity could yield total transaction cost savings for all investors of over \$1.5 billion Mutual Fund Factbook, supra note 300, at 59.

305 Id. at 91 (employer-sponsored pension market held estimated $\$ 9.0$ trillion in assets in 2003, \$7.7 trillion of which were not represented by mutual fund assets); Milliman, Inc., Pension Fund Survey (available at www.milliman.com) (consulting firm's survey of 2003 annual reports for 100 of largest U.S. corporations found that the median equity allocation for pension fund assets was 65\%). 
annually. Such savings would improve the investment returns of equity ownership, thereby promoting the retirement and other long-term financial interests of individual investors and reducing the cost of capital for listed companies.

\section{B. Description of Adopted Rule}

Rule 611 can be divided into three elements: (1) the provisions that establish the scope of the Rule's coverage, most of which are set forth in the definitions of Rule 600(b); (2) the operative requirements of paragraph (a) of Rule 611, which, among other things, mandate the adoption and enforcement of written policies and procedures that are reasonably designed to prevent trade throughs on that trading center of protected quotations and, if relying on an exception, that are reasonably designed to assure compliance with the terms of the exception; and (3) the exceptions set forth in paragraph (b) of Rule 611. These elements are discussed below, followed by a section emphasizing that a broker's duty of best execution is not lessened by the adoption of Rule 611.

\section{Scope of Rule}

The scope of Rule 611 is largely determined by a series of definitions set forth in Rule 600(b). In general, the Rule addresses trade-throughs of protected quotations in NMS stocks by trading centers. A "trading center" is defined in Rule 600(b)(78) as a national securities

exchange or national securities association that operates an SRO trading facility, ${ }^{306}$ an ATS, ${ }^{307}$ an

$306 \quad$ An "SRO trading facility" is defined in Rule 600(b)(72) as a facility operated by or on behalf of an SRO that executes orders in a security or presents orders to members for execution.

307 An "alternative trading system" is defined in Rule 600(b)(2) with a cross reference to Regulation ATS. 
exchange market maker, ${ }^{308}$ an OTC market maker, ${ }^{309}$ or any other broker or dealer that executes orders internally by trading as principal or crossing orders as agent. This last phrase is intended particularly to cover block positioners. An "NMS stock" is defined in paragraphs (b)(47) and (b)(46) of Rule 600 as a security, other than an option, for which transaction reports are collected, processed and made available pursuant to an effective national market system plan. This definition effectively covers stocks listed on a national securities exchange and stocks included in either the National Market or SmallCap tiers of Nasdaq. It does not include stocks quoted on the OTC Bulletin Board or elsewhere in the OTC market.

The term "trade-through" is defined in Rule 600(b)(77) as the purchase or sale of an NMS stock during regular trading hours, ${ }^{310}$ either as principal or agent, at a price that is lower than a protected bid or higher than a protected offer. Rule 600(b)(57), which defines a "protected bid" or "protected offer,"311 includes three main elements: (1) an automated quotation; (2) displayed by an automated trading center; and (3) that is the best bid or best offer of an exchange, The NASDAQ Stock Market, or an association other than The NASDAQ Stock Market (currently, the best bid or offer of the NASD's ADF). ${ }^{312}$

As discussed above, an "automated quotation" is defined in Rule 600(b)(3) as a quotation displayed by a trading center that: (1) permits an incoming order to be marked as immediate-or-

308 An "exchange market maker" is defined in Rule 600(b)(24).

309 An "OTC market maker" is defined in Rule 600(b)(52).

310 The term "regular trading hours" is defined in Rule 600(b)(64) as the time between 9:30 a.m. and 4:00 p.m. Eastern time, unless otherwise specified.

311 Protected bid and protected offer are collectively defined as a "protected quotation" in Rule 600(b)(58).

312 See section II.A.5 above for a discussion of the Commission's determination to adopt the Market BBO Alternative with respect to the scope of protected quotations. 
cancel; (2) immediately and automatically executes an order marked as immediate-or-cancel

against the displayed quotation up to its full size ${ }^{313}$ (3) immediately and automatically cancels any unexecuted portion of an order marked as immediate-or-cancel without routing the order elsewhere; (4) immediately and automatically transmits a response to the sender of an order marked as immediate-or-cancel indicating the action taken with respect to such order; and (5) immediately and automatically displays information that updates the displayed quotation to reflect any change to its material terms.

Consequently, a quotation will not qualify as "automated" if any human intervention after the time an order is received is allowed to determine the action taken with respect to the quotation. The term "immediate" precludes any coding of automated systems or other type of intentional device that would delay the action taken with respect to a quotation. Although a

313 The requirement that an automated quotation be accessible up to its full size does not mean that a trading center must automate all of its available trading interest. For example, trading centers will be permitted to operate hybrid markets with different order types and rules for automated trading and manual trading. Rather, the "full size" term in the definition of automated quotation requires that, once a trading center offers an automated execution of a particular displayed quotation and thereby obtains protection under Rule 611, such quotation must be immediately and automatically accessible up to its full size, which will include both the displayed and reserve size of the quotation. Given that to comply with Rule 611, market participants need to be able to access the displayed size of protected quotations at all trading centers (even when the displayed size of the quotation may be less than the size of the market participant's total trading interest), the Commission believes trading centers must provide fair and efficient access

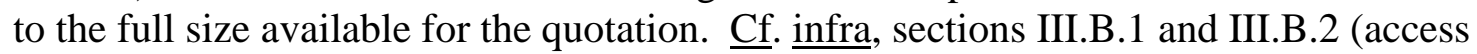
standard and fee limitation of Rule 610 apply to both displayed and reserve size of displayed quotations). This requirement, which is applicable to trading centers that display automated quotations, does not mean that market participants are required to route orders in an attempt to execute against the reserve size of a protected quotation. Rather, Rule 611 operates as follows. In the first instance, the Rule protects prices - a trading center cannot execute a transaction at a price inferior to the price of a protected quotation, absent an exception. One of the most commonly used exceptions to the Rule is likely to be the intermarket sweep order exception, which applies to sweep orders that are routed to execute against the full displayed size of better-priced protected quotations.

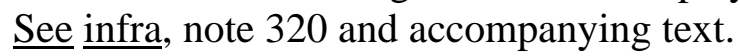


trading center must provide an IOC/no-routing functionality for incoming orders, it also can offer additional functionalities. Among the changes to material terms that require an immediate update to a quotation are price, displayed size, and automated/manual indicator. Any quotation that does not meet the requirements for an automated quotation is defined in Rule 600(b)(37) as a "manual quotation."

As discussed above, an "automated trading center" is defined in Rule 600(b)(4) as a trading center that: (1) has implemented such systems, procedures, and rules as are necessary to render it capable of displaying quotations that meet the requirements for an automated quotation set forth in paragraph (b)(3) of this section; (2) identifies all quotations other than automated quotations as manual quotations; (3) immediately identifies its quotations as manual quotations whenever it has reason to believe that it is not capable of displaying automated quotations; and (4) has adopted reasonable standards limiting when its quotations change from automated quotations to manual quotations, and vice versa, to specifically defined circumstances that promote fair and efficient access to its automated quotations and are consistent with the maintenance of fair and orderly markets. The requirement of reasonable standards for switching the automated/manual status of quotations is designed to preclude practices that would cause confusion among market participants concerning the status of a trading center's quotations or that would inappropriately advantage the members or customers of a trading center at the expense of the public.

The third element of the definition of "protected bid" and "protected offer" identifies which automated quotations are protected under the Order Protection Rule. Specifically, Rule 600(b)(57) provides that an automated quotation displayed by an automated trading center that is the $\mathrm{BBO}$ of an exchange SRO, the BBO of Nasdaq, or the BBO of the NASD (i.e., the ADF) 
qualifies as a protected quotation. Thus, only a single, accessible best bid and best offer for each of the exchange SROs, Nasdaq, and the NASD is protected under the Order Protection Rule. A best bid and best offer must be accessible by routing an order to a single market destination (i.e., currently, either to a single exchange execution system, a single Nasdaq execution system, or a single ADF participant).

\section{Requirement of Reasonable Policies and Procedures}

Paragraph (a)(1) of Rule 611 requires a trading center to establish, maintain, and enforce written policies and procedures that are reasonably designed to prevent trade-throughs on that trading center of protected quotations in NMS stocks that do not fall within an exception set forth in paragraph (b) of Rule 611 and, if relying on such an exception, that are reasonably designed to assure compliance with the terms of the exception. ${ }^{314}$ In addition, paragraph (a)(2) of Rule 611 requires a trading center to regularly surveil to ascertain the effectiveness of the policies and procedures required by paragraph (a)(1) and to take prompt action to remedy deficiencies in such policies and procedures.

As discussed in the Proposing Release, the Commission believes it would be inappropriate to implement a complete prohibition against any trade-throughs, particularly given the realities of intermarket trading and order-routing in many high-volume NMS stocks, ${ }^{315}$ and has not adopted such an approach. In this trading environment, despite reasonable attempts to

314 The Commission has modified the language of Rule 611(a)(1) to make clear that a trading center's policies and procedures must only be reasonably designed to prevent trade-throughs on its own trading center of protected quotations in NMS stocks that do not fall within an exception set forth in paragraph (b) of Rule 611 and, if relying on such an exception, that are reasonably designed to assure compliance with the terms of the exception.

315 Proposing Release, 69 FR at 11137 (noting the problem of "false positive" trade-throughs caused by rapidly changing quotations, even when a trading center took reasonable precautions to prevent trade-throughs). 
prevent them, false positive or accidental trade-throughs may result from timing discrepancies resulting from technology limitations, latencies in the delivery and receipt of quotation updates, and data discrepancies. The requirement of written policies and procedures, as well as the responsibility assigned to trading centers to regularly surveil to ascertain the effectiveness of their procedures and take prompt remedial steps, is designed to achieve the objective of eliminating all trade-throughs that reasonably can be prevented, while also recognizing the inherent difficulties of eliminating trade-through transactions that, despite a trading center's reasonable efforts, may occur.

In the Reproposing Release, the Commission requested comment on whether this approach would be sufficient to address enforceability concerns. Several commenters expressed a concern about the significant burden that would be placed on market participants to prove compliance and defend each execution that appears to be a trade-through (‥e., they could be presumed to have violated the Rule unless they can prove they did not), particularly in light of the significant number of false positives that are likely to result. ${ }^{316}$ The Commission recognizes this concern and intends to work closely with industry participants during the implementation period for the Order Protection Rule to provide useful and practical guidance for trading centers on the policies and procedures needed to comply with the Rule.

At a minimum, a trading center's policies and procedures must enable the trading center (and persons responsible for transacting on its market, such as specialists) to monitor, on a realtime basis, the protected quotations displayed by other trading centers so as to determine the prices at which the trading center can and cannot execute trades. In addition, a trading center's

$316 \quad$ Morgan Stanley Reproposal Letter at 15; Letter from David Cummings, Chief Executive Officer, Tradebot Systems, Inc., to Jonathan G. Katz, Secretary, Commission, dated January 26, 2005 (“Tradebot Reproposal Letter”) at 1; UBS Reproposal Letter at 5 (expressing the view that the Rule would be unenforceable). 
policies and procedures must establish objective standards and parameters governing its use of the exceptions set forth in Rule 611(b). A trading center's automated order-handling and trading systems must be programmed in accordance with these policies and procedures. Finally, the trading center must take such steps as are necessary to enable it to enforce its policies and procedures effectively. For example, trading centers will need to establish procedures such as regular exception reports to evaluate their trading and order-routing practices. Such reports will need to be examined to affirm that a trading center's policies and procedures have been followed by its personnel and properly coded into its automated systems and, if not, to promptly identify the reasons and take remedial action.

Of course, surveillance is an important component of a trading center's satisfaction of its legal obligations. In the context of Rule 611, paragraph (a)(2) of the Rule reinforces the ongoing maintenance and enforcement requirements of paragraph (a)(1) of the Rule by explicitly assigning an affirmative responsibility to trading centers to surveil to ascertain the effectiveness of their policies and procedures. Trading centers cannot merely establish policies and procedures that may be reasonable when created and assume that such policies and procedures continue to satisfy the requirements of Rule 611. Rather, trading centers must regularly assess the continuing effectiveness of their procedures and take prompt action when needed to remedy deficiencies. In particular, trading centers must engage in regular and periodic surveillance to determine whether trade-throughs are occurring without an applicable exception and whether they have failed to implement and maintain policies and procedures that would have reasonably prevented such trade-throughs.

As a further means to bolster compliance with the Order Protection Rule, the Commission has instructed its staff to develop for our consideration and for notice and comment 
a rule proposal that would require trading centers to publicly disclose standardized and comparable statistics on the incidence of trade-through transactions that do not fall within an exception to the Rule. Such industry-wide statistics would promote greater public accountability by trading centers for the quality of their policies and procedures. The statistics also would be helpful for trading centers, as well as regulatory authorities, in assessing the reasonableness and effectiveness of the policies and procedures adopted by various trading centers. In particular, a trading center that generated a materially higher rate of trade-throughs than other comparable trading centers would need to closely evaluate the types of policies and procedures used by the other trading centers as a means to upgrade its own policies and procedures. On the other hand, the fact that many trading centers generated comparable rates of trade-throughs would not shield them from a violation of the Order Protection Rule if a material number of the trade-through transactions could reasonably have been prevented by the use of particular policies and procedures. In general, the Commission preliminarily believes that comparable, industry-wide statistics on trade-throughs would provide a valuable resource to identify the most effective policies and procedures and to promote their use by all relevant trading centers.

\section{Exceptions}

Rule 611(b) sets forth a variety of exceptions addressing transactions that may fall within the definition of a trade-through, but which are not subject to the operative requirements of the Rule. The exceptions primarily are designed to achieve workable intermarket price protection and to facilitate certain trading strategies and order types that are useful to investors, but also are consistent with the principle of price protection. ${ }^{317}$

317 Several commenters recommended that the consolidated tape should identify trades that were executed and reported pursuant to an exception to the Rule. See, e.g., Citigroup Reproposal Letter at 7; SIA Reproposal Letter at 17. The Commission agrees that 
Paragraph (b)(1) excepts a transaction if the trading center displaying the protected quotation that was traded through was experiencing a failure, material delay, or malfunction of its systems or equipment when the trade-through occurred. As discussed in section II.A.3 above, the exception for a "material delay" gives trading centers a self-help remedy if another trading center repeatedly fails to provide an immediate response (within one second) to incoming orders attempting to access its quotes. The trading center receiving an order can only be held responsible for its own turnaround time (i.e., from the time it first received an order to the time it transmits a response to the order). Accordingly, the routing trading center will be required to develop policies and procedures that allow for any potential delays in transmission not attributable to the receiving trading center. The exception in paragraph (b)(1) also covers any failure or malfunction of a trading center's systems or equipment, as well as any material delay. Trading centers will need to establish specific objective parameters governing their use of the "self-help" exemption as part of their reasonable policies and procedures. For example, a single failure to respond within one second generally will not justify future bypassing of another trading center's quotations. Many failures to respond within one second in a short time period, in contrast, clearly will warrant use of the exception. A trading center making use of the exception must notify the non-responding trading center immediately after (or at the same time as) electing

increased transparency would be greatly beneficial. Such identification would give market participants and investors timely notice that a trade qualified for an exception and was not a true trade-through. The Commission therefore intends to request that the market data Plans explore the feasibility of identifying trade-through exceptions. It also intends to initiate a discussion with the Plans on shortening the current 90-second time frame for reporting trades in light of current technology and trading practices. Reporting trades in substantially less than 90 seconds would reduce the number of trades that are reported out of sequence, thus improving the accuracy and reliability of the consolidated trade stream and helping to reduce the false appearance of trade-throughs. 
this exception pursuant to reasonable and objective standards contained in its policies and procedures. $^{318}$

Paragraph (b)(8) of Rule 611 sets forth an exception for flickering quotations. It excepts a transaction if the trading center displaying the protected quotation that was traded through had displayed, within one second prior to execution of the trade-through, a best bid or best offer, as applicable, for the NMS stock with a price that was equal or inferior to the price of the tradethrough transaction. This exception thereby provides a "window" to address false indications of trade-throughs that in actuality are attributable to rapidly moving quotations. It also potentially will reduce the number of instances in which a trading center must alter its normal trading procedures and route orders to other trading centers to comply with Rule 611. The exception is thereby intended to promote more workable intermarket price protection.

Paragraphs (b)(5) and (b)(6) of Rule 611 set forth exceptions for intermarket sweep orders. An intermarket sweep order is defined in Rule 600(b)(30) as a limit order ${ }^{319}$ that meets the following requirements: (1) when routed to a trading center, the limit order is identified as an intermarket sweep order; and (2) simultaneously with the routing of the limit order identified as an intermarket sweep order, one or more additional limit orders, as necessary, are routed to execute against the full displayed size of all protected quotations with a superior price. These additional limit orders must be marked as intermarket sweep orders to allow the receiving market center to execute the order immediately without regard to better-priced quotations displayed at

318 For instance, a trading center may wish to use electronic mail to make this notification.

319 Such a limit order would be "marketable" because it would be immediately subject to execution at current displayed prices. Consequently, "limit order" is used differently in this context than elsewhere in this release, where it is used to refer to non-marketable orders that generally will be displayed, in contrast to marketable orders that generally will not be displayed. See supra, note 53 (description of marketable limit orders and nonmarketable limit orders). 
other trading centers (by definition, each of the additional limit orders would meet the requirements for an intermarket sweep order).

Paragraph (b)(5) allows a trading center immediately to execute any order identified as an intermarket sweep order. It therefore need not delay its execution for the updating of the betterpriced quotations at other trading centers to which orders were routed simultaneously with the intermarket sweep order. Paragraph (b)(6) allows a trading center itself to route intermarket sweep orders and thereby clear the way for immediate internal executions at the trading center. This exception particularly will facilitate the immediate execution of block orders by dealers on behalf of their institutional clients. Specifically, if a dealer wishes to execute internally a customer order at a price that would trade through one or more protected quotations on other trading centers, the dealer will be able to do so if it simultaneously routes one or more intermarket sweep orders to execute against the full displayed size of each such better-priced protected quotations. If there is only one better-priced protected quotation, then the dealer is only required to route an intermarket sweep order to execute against that protected quotation.

Paragraph (c) of Rule 611 requires that the trading center, broker, or dealer responsible for the routing of an intermarket sweep order take reasonable steps to establish that orders are properly routed in an attempt to execute against all applicable protected quotations. A trading center, broker, or dealer is required to satisfy this requirement regardless whether it routes the order through its own systems or sponsors a customer's access through a third-party vendor's systems.

To illustrate the operation of the intermarket sweep order exception, assume that a broker-dealer's customer wished to sell a large amount of an NMS stock. Trading Center A is displaying the national best bid of 500 shares at $\$ 10.00$, along with quotations in its proprietary 
depth-of-book data feed of 1500 shares at $\$ 9.99$, and 5000 shares at $\$ 9.97$. The customer decides to sweep all liquidity on Trading Center A down to \$9.97. Assume also that Trading Center B is displaying a protected bid of 2000 shares at \$9.99, Trading Center C is displaying a protected bid of 400 shares at $\$ 9.98$, and Trading Center D is displaying a protected bid of 200 shares at $\$ 9.97$. The broker-dealer could execute this trade for its customer, subject to its best execution responsibilities, by simultaneously routing the following orders: (1) an intermarket sweep order to Trading Center A with a limit price of \$9.97 and a size of 7000 shares; (2) an intermarket sweep order to Trading Center B with a limit price of \$9.99 and a size of 2000 shares; and (3) an intermarket sweep order to Trading Center C with a limit price of $\$ 9.98$ and a size of 400 shares. All of these orders would meet the requirements of Rule 600(b)(30) because the necessary orders simultaneously were routed to execute against the displayed size of all better-priced protected quotations. Trading Centers A, B, and C all could execute their orders immediately without regard to the protected quotations displayed at other trading centers. No order would need to be routed to Trading Center $\mathrm{D}$ because the price of its bid was not superior to the most inferior limit price of the order routed to Trading Center A. Assuming the customer obtained a fill for each of its orders at the displayed prices and sizes, ${ }^{320}$ it would have been able to obtain an immediate execution of a 9400-share trade by sweeping through four price levels at

$320 \quad$ An intermarket sweep order could go unfilled because the protected quotation at a trading center was accessed or withdrawn prior to the trading center's receipt of the intermarket sweep order. In addition, the existence of undisplayed orders or reserve size at some trading centers could result in an execution at better prices than may have been indicated by the displayed prices and sizes. The router of an intermarket sweep order would only be responsible, however, for routing orders in accordance with the displayed price and size of protected quotations. Whether the orders actually execute against the protected quotations, or go unfilled because the quotations have been previously executed or withdrawn, is not within the responsibility or control of the router of the intermarket sweep order. 
Trading Center A, while also honoring the protected quotations at two other trading centers. ${ }^{321}$ The trade therefore would have both upheld the principle of price protection and served the customer's legitimate interest in obtaining an immediate execution of large size.

The exception in paragraph (b)(7) of Rule 611 will facilitate other types of orders that often are useful to investors - benchmark orders. It excepts the execution of an order at a price that was not based, directly or indirectly, on the quoted price of an NMS stock at the time of execution and for which the material terms were not reasonably determinable at the time the commitment to execute the order was made. A common example of a benchmark order is a VWAP order. Assume a broker-dealer's customer decides to buy a stock at 9:00 a.m. before the markets open for normal trading. The customer submits, and the broker-dealer accepts, an order to buy 100,000 shares at the volume-weighted average price of the stock from opening until 1:00 p.m. At 1:00 p.m., the national best offer in the stock is $\$ 20.00$, but the relevant volumeweighted average price (in a rising market) is $\$ 19.90$. The broker-dealer would be able to rely on the benchmark order exception to execute the order at $\$ 19.90$ at 1:00 p.m., without regard to better-priced protected quotations at other trading centers. Of course, any transactions effected by the broker-dealer during the course of the day to obtain sufficient stock to fill the benchmark order would remain subject to Rule 611. The benchmark exception also would encompass the execution of an order that is benchmarked to a market's single-priced opening, as the Commission would not interpret such an opening price to be the "quoted price" of the NMS stock at the time of execution.

321 If a trading center has routed intermarket sweep orders to access the full displayed size of protected quotations under the Order Protection Rule, it will be allowed to continue trading without regard to a particular trading center's quotations until it has received a response from such trading center. See supra, note 194. 
Paragraph (b)(9) of Rule 611 provides an exception for the execution of certain stopped orders. ${ }^{322}$ Specifically, the exception applies to the execution by a trading center of a stopped order where the price of the execution of the order was, for a stopped buy order, lower than the national best bid at the time of execution or, for a stopped sell order, higher than the national best offer at the time of execution. ${ }^{323}$ To illustrate the operation of this requirement, assume that a dealer's customer wished to buy a large amount of an NMS stock. Assume further that the dealer has agreed to guarantee execution of the order at an average price no worse than $\$ 10.12$ (the stop price), and that the national best bid and offer for the stock at the time was 10.05 to 10.07 . If the dealer buys on behalf of the customer until half of the order is completed and has averaged 10.10 to that point, but the national best bid and offer for the stock is then 10.15 to 10.17 , the dealer would be obligated to execute the remainder of the order by selling to the customer at 10.14 to average 10.12 for the entire order. The exception in paragraph (b)(9) of Rule 611 permits the dealer to execute the remainder at 10.14 without being obligated to route to all protected bids at 10.15. In addition, to qualify for the exception, the stopped order must be for the account of a customer $^{324}$ and the customer must have agreed to the "stop" price on an order-by-order basis. ${ }^{325}$ The Commission notes that any individual transactions executed by the dealer in the market for the customer must be executed in compliance with Rule 611.

322 $\quad$ See section II.A.4.b and notes 251 to 257 and accompanying text above for a discussion of this exception.

323 Rule 611(b)(9)(iii).

324 Rule 611(b)(9)(i). Customer is defined in Rule 600(b)(16) as any person that is not a broker or dealer.

325 Rule 611(b)(9)(ii). 
Finally, paragraph (b) of Rule 611 includes a variety of other exceptions: (1) transactions other than "regular way" contracts; ${ }^{326}$ (2) single-price opening, reopening, or closing transactions; ${ }^{327}$ and (3) transactions executed at a time when protected quotations were crossed. $^{328}$ The crossed quotation exception would not apply when a protected quotation crosses a non-protected (e.g., manual) quotation. ${ }^{329}$ The exception for single-priced reopenings will only apply to single-priced reopening transactions after a trading halt conducted pursuant to a trading center rule. To qualify, the reopening process must be transparent and provide for the queuing and ultimate execution of multiple orders at a single equilibrium price. ${ }^{330}$

\section{Duty of Best Execution}

Several commenters on the original proposal who supported excluding manual quotations from trade-through protection also suggested that manual quotations should be excluded from the NBBO that is calculated and disseminated by Plan processors. ${ }^{331}$ Under this approach, market participants could disregard manual quotations for purposes of assessing the best execution of customer orders and calculating execution quality statistics under Rule 11Ac1-5 (redesignated as Rule 605 of Regulation NMS). The Reproposing Release did not propose to eliminate manual

326 Rule 611(b)(2). "Regular way” refers to bids, offers, and transactions that embody the standard terms and conditions of a market. Thus, this exception applies to a transaction that was executed other than pursuant to standardized terms and conditions, for instance a transaction that has extended settlement terms.

Rule 611(b)(3).

$328 \quad$ Rule 611(b)(4).

329 Id.

330 See supra, section II.A.2.b for a discussion of this exception.

331 See, e.g., Citigroup Letter at 3, 6; Goldman Sachs Letter at 5-6; Morgan Stanley Letter at 2-3, 7; SIA Letter at 13. 
quotations from the NBBO and emphasized that adoption of Rule 611 would not lessen a brokerdealer's duty of best execution. ${ }^{332}$ Noting the common business practice of market makers to use the NBBO to price investors orders (particularly retail orders), the Reproposing Release expressed concern that eliminating manual quotations from the NBBO potentially would widen the spreads in many stocks, even though the quotations often may in fact represent the best indication of the current market price of the stock.

In response to the Reproposing Release, some commenters continued to assert that manual quotations should be excluded from the NBBO. ${ }^{333}$ They believed that that it would be inconsistent and unreasonable to distinguish between automated and manual quotations for purposes of trade-through protection, market data revenue, access fees, and requirements regarding locked and crossed markets, but not to remove such quotations from the calculation of the NBBO. ${ }^{334}$ They argued that including manual quotations in the benchmark against which a broker-dealer's best execution responsibility is judged provides an unfair standard of comparison, particularly to the extent manual quotations are not accessible. ${ }^{335}$ Several commenters requested that, at a minimum, the Commission clarify a broker-dealer's duty of best

$332 \quad$ Reproposing Release, 69 FR at 77447.

333 See, e.g., Ameritrade Reproposal Letter at 7; ATD Reproposal Letter at 7; Citigroup Reproposal Letter at 8; Knight Reproposal Letter at 6; Madoff Reproposal Letter at 2-3; Morgan Stanley Reproposal Letter at 12; SIA Reproposal Letter at 3, 14-15; STANY Reproposal Letter at 10-11; UBS Reproposal Letter at 6.

$334 \quad$ See, e.g., ATD Reproposal Letter at 6; Citigroup Reproposal Letter at 8; Madoff Reproposal Letter at 4.

335 See, e.g., Citigroup Reproposal Letter at 8; Knight Reproposal Letter at 6; STANY Reproposal Letter at 11. 
execution with respect to manual quotations. ${ }^{336}$ Another commenter suggested that manual quotations be removed from the NBBO when the manual market is not the primary market. ${ }^{337}$

The Commission continues to be concerned that eliminating all manual quotations from the NBBO would exclude not only inaccessible manual quotations, but also manual quotations that truly establish the best available price for a stock, particularly for those stocks with relatively small trading volume in which a manual market has a dominant share of trading. Such a result could lead to decreased execution quality for investors in these stocks by allowing broker-dealers to ignore the best available quotations when executing customer orders. The Commission therefore is not at this time excluding manual quotations from the NBBO or from the benchmark used for calculating execution quality statistics under Rule 605.

The Commission continues to emphasize that adoption of Rule 611 in no way lessens a broker-dealer's duty of best execution. A broker-dealer has a legal duty to seek to obtain best execution of customer orders. ${ }^{338}$ According to the Report of the Special Study of Securities Markets, "[t]he integrity of the industry can be maintained only if the fundamental principle that a customer should at all times get the best available price which can reasonably be obtained for him is followed." ${ }^{339}$ A broker-dealer’s duty of best execution derives from common law agency

336 Ameritrade Reproposal Letter at 7-8; Merrill Lynch Reproposal Letter at 8; SIA Reproposal Letter at 15.

$337 \quad$ ATD Reproposal Letter at 7.

338 See, e.g., Newton v. Merrill, Lynch, Pierce, Fenner \& Smith, Inc., 135 F.3d 266, 269-70, 274 (3d Cir.), cert. denied, 525 U.S. 811 (1998); Certain Market Making Activities on Nasdaq, Securities Exchange Act Release No. 40900 (Jan. 11, 1999) (settled case) (citing Sinclair v. SEC, 444 F.2d 399 (2d Cir. 1971); Arleen Hughes, 27 SEC 629, 636 (1948), aff'd sub nom. Hughes v. SEC, 174 F.2d 969 (D.C. Cir. 1949)). See also Order Execution Obligations, Securities Exchange Act Release No. 37619A (Sept. 6, 1996), 61 FR 48290 (Sept. 12, 1996) (“Order Handling Rules Release”).

339 H.R. Doc. No. 95, $88^{\text {th }}$ Cong., $1^{\text {st }}$ Sess. Pt. II, 624 (1963). 
principles and fiduciary obligations, and is incorporated in SRO rules and, through judicial and Commission decisions, the antifraud provisions of the federal securities laws. ${ }^{340}$

The duty of best execution requires broker-dealers to execute customers' trades at the most favorable terms reasonably available under the circumstances, i.e., at the best reasonably available price. ${ }^{341}$ The Commission has not viewed the duty of best execution as inconsistent with the automated routing of orders or requiring automated routing on an order-by-order basis to the market with the best quoted price at the time. Rather, the duty of best execution requires broker-dealers to periodically assess the quality of competing markets to assure that order flow is directed to the markets providing the most beneficial terms for their customer orders. ${ }^{342}$ Broker-

340 Order Handling Rules Release, $61 \mathrm{FR}$ at 48322. See also Newton, $135 \mathrm{~F} .3 \mathrm{~d}$ at 270. Failure to satisfy the duty of best execution can constitute fraud because a broker-dealer, in agreeing to execute a customer's order, makes an implied representation that it will execute it in a manner that maximizes the customer's economic gain in the transaction. See Newton, 135 F.3d at 273 ("[T] understanding that the client is engaging in the trade - and retaining the services of the broker as his agent - solely for the purpose of maximizing his own economic benefit, and that the broker receives her compensation because she assists the client in reaching that goal.”); Marc N. Geman, Securities Exchange Act Release No. 43963 (Feb. 14, 2001) (citing Newton, but concluding that respondent fulfilled his duty of best execution). See also Payment for Order Flow, Securities Exchange Act Release No. 34902 (Oct. 27, 1994), 59 FR 55006, 55009 (Nov. 2, 1994) ("Payment for Order Flow Final Rules”). If the broker-dealer intends not to act in a manner that maximizes the customer's benefit when he accepts the order and does not disclose this to the customer, the broker-dealer's implied representation is false. See Newton, 135 F.3d at 273-274.

341 Newton, 135 F.3d at 270. Newton also noted certain factors relevant to best execution order size, trading characteristics of the security, speed of execution, clearing costs, and the cost and difficulty of executing an order in a particular market. Id. at $270 \mathrm{n} .2$ (citing Payment for Order Flow, Exchange Act Release No. 33026 (Oct. 6, 1993), 58 FR 52934, 52937-38 (Oct. 13, 1993) (Proposed Rules)). See In re E.F. Hutton \& Co. ("Manning”), Securities Exchange Act Release No. 25887 (July 6, 1988). See also Payment for Order Flow Final Rules, 59 FR at 55008-55009.

342 Order Handling Rules Release, $61 \mathrm{FR}$ at 48322-48333 ("In conducting the requisite evaluation of its internal order handling procedures, a broker-dealer must regularly and rigorously examine execution quality likely to be obtained from different markets or market makers trading a security.”). See also Newton, 135 F.3d at 271; Market 2000: An 
dealers must examine their procedures for seeking to obtain best execution in light of market and technology changes and modify those practices if necessary to enable their customers to obtain the best reasonably available prices. ${ }^{343}$ In doing so, broker-dealers must take into account price improvement opportunities, and whether different markets may be more suitable for different types of orders or particular securities. ${ }^{344}$

The protection against trade-throughs required of trading centers by Rule 611 undergirds the broker-dealer's duty of best execution, by helping ensure that customer orders are not executed at prices inferior to the best protected quotations. Nonetheless, the Order Protection Rule does not supplant or diminish the broker-dealer's responsibility for achieving best execution, including its duty to evaluate the execution quality of markets to which it routes customer orders, regardless of the exceptions set forth in the Rule.

At the same time, however, the Commission recognizes the validity of concerns expressed by commenters with respect to the need for guidance concerning their best execution responsibilities after implementation of Regulation NMS. As they do today, broker-dealers will

Examination of Current Equity Market Developments V-4 (SEC Division of Market Regulation January 1994) ("Without specific instructions from a customer, however, a broker-dealer should periodically assess the quality of competing markets to ensure that its order flow is directed to markets providing the most advantageous terms for the customer's order.”); Payment for Order Flow Final Rules, 59 FR at 55009.

Order Handling Rules, 61 FR at 48323.

344 Order Handling Rules, $61 \mathrm{FR}$ at 48323. For example, in connection with orders that are to be executed at a market opening price, "[b]roker-dealers are subject to a best execution duty in executing customer orders at the opening, and should take into account the alternative methods in determining how to obtain best execution for their customer orders.” Disclosure of Order Execution and Routing Practices, Securities Exchange Act Release No. 43590 (Nov.17, 2000), 65 FR 75414, 75422 (Dec. 1, 2000) (adopting new Exchange Act Rules 11Ac1-5 and 11Ac1-6 and noting that alternative methods offered by some Nasdaq market centers for pre-open orders included the mid-point of the spread or at the bid or offer). 
continue to be able to assess the level of accessibility and availability of manual quotations in making their best execution determinations. In particular, when the market for a stock is dominated by trading centers that display automated quotations, and a trading center that is not a dominant market for the stock displays manual quotations, a broker-dealer reasonably could determine, as part of its regular and rigorous review of execution quality, to bypass such a market with manual quotations in the particular stock if its prior experience demonstrated that attempting to access the market would not be in its customers' best interest. In making its assessment the broker-dealer would be entitled to consider both the likelihood of receiving an execution at displayed prices and the potential cost to its customers of failed attempts. The Commission also emphasizes that any trading center posting quotations, whether automated or manual, in the public quotation stream has a responsibility to be firm for its quotations pursuant to Rule 602.

\section{Access Rule}

For the NMS to fulfill its statutory objectives, fair and efficient access to each of the individual markets that participate in the NMS is essential. One of the statutory NMS objectives, for example, is to assure the practicability of brokers executing investors' orders in the best market. ${ }^{345}$ Another is to assure the efficient execution of securities transactions. ${ }^{346}$ Clearly, neither of these objectives can be achieved if brokers cannot fairly and efficiently route orders to execute against the best quotations for a stock, wherever such quotations are displayed in the NMS. In 1975, Congress determined that the "linking of all markets" for NMS stocks through communications and data processing facilities would "foster efficiency; enhance competition; 
increase the information available to brokers, dealers, and investors; facilitate the offsetting of investors' orders; and contribute to the best execution of investors' orders." ${ }^{347}$ Since 1975, there have been dramatic improvements in communications and processing technologies. Rule 610 is intended to capitalize on these improvements and thereby enhance the "linking of all markets" for the future NMS.

All SROs that trade exchange-listed stocks currently are linked through ITS, a collective intermarket linkage facility. ITS provides a means of access to exchanges and Nasdaq by permitting each market to send a "commitment to trade" through the system, with receiving markets generally having up to 30 seconds to respond. ${ }^{348}$ ITS also provides access to quotations of participants without fees and establishes uniform rules to govern quoting practices. ${ }^{349}$ Although ITS promotes access among participants that is uniform and free, it also is often slow and limited. Moreover, it is governed by a unanimous vote requirement that has at times impeded innovation in the system or its set of rules.

In contrast, there is no collective intermarket linkage system for Nasdaq stocks. Instead, access is achieved primarily through private linkages among individual trading centers. This approach has demonstrated its benefits among electronic markets; it is flexible and can readily incorporate technological advances as they occur. There is no intermarket system, however, that offers free access to quotations in Nasdaq stocks. Nor are the trading centers for Nasdaq stocks subject to uniform intermarket standards governing their quoting and trading practices. The fees for access to ECN quotations in Nasdaq stocks, as well as the absence of standards for quotations

347 Section 11A(a)(1)(D) of the Exchange Act.

348 ITS Plan, Section 6(b)(i).

349 ITS Plan, Sections 6(b), 8(d), and 11(b). 
that lock and cross markets, have been the source of disputes among participants in the market for Nasdaq stocks for many years. Moreover, access problems have arisen with respect to small market centers operating outside of an SRO trading facility and markets like the Amex that engage in manual trading of Nasdaq stocks. Access problems also have arisen with respect to intentional barriers to access, especially involving fees.

Rule 610 reflects the Commission's determination that fair and efficient access to markets can be achieved without a collective intermarket linkage facility such as ITS, if baseline intermarket access rules are established. ${ }^{350}$ The rule adopts a private linkage approach for all NMS stocks with modifications to address the most serious problems that have arisen with this approach in the trading of Nasdaq stocks. Rule 610 addresses three subject areas: (1) means of access to quotations; (2) fees for access to protected quotations and any other quotations that are the best bid or best offer of an exchange, The NASDAQ Market Center, or the NASD's ADF; and (3) locking and crossing quotations. ${ }^{351}$ In response to comments on the reproposal, the Commission is modifying the fee limitation to apply to any quotation at the best bid or offer as well as protected quotations. ${ }^{352}$ In addition, the Commission is modifying the fair access requirements of Regulation ATS to extend their application to ATSs with 5\% of trading volume in a security. ${ }^{353}$

350 With the implementation of Rule 610, the Commission believes that SROs can withdraw from the ITS Plan, assuming they have otherwise arranged to meet their access responsibilities.

351 The Commission has modified the language of Rule 610(d) to require that an exchange or association "establish, maintain, and enforce" rules relating to certain locking and crossing activity, and to clarify that such rules must be written, to conform the language to the operative language of Rule 611(a)(1). See infra note 455 and accompanying text. See infra, section III.A.2.

353 The modification of Regulation ATS is discussed in section III.B.4 below. 


\section{A. Response to Comments and Basis for Adopted Rule 1. Means of Access to Quotations}

Paragraphs (a) and (b) of Rule 610 address means of access to quotations. Among the variety of services offered by equity markets, access to displayed quotations, particularly the best quotations of a trading center, is vital for the smooth functioning of intermarket trading. Brokers responsible for routing their customers' orders, as well as investors that make their own orderrouting decisions, clearly must have fair and efficient access to the best displayed quotations of all trading centers to achieve best execution of those orders. In addition, trading centers themselves must have the ability to execute orders against the displayed quotations of other trading centers. Indeed, the very concept of intermarket protection against trade-throughs is premised on the ability of trading centers to trade with, rather than trade through, the protected quotations displayed by other trading centers.

Access to quotations, sometimes referred to as "order execution access," ${ }^{354}$ should be distinguished from broader access to all of the different types of services offered by markets, such as the right to display limit orders or to submit complex order types. To obtain the full range of their services, markets generally require that an individual or firm become a member or subscriber of the market. This type of access, or "membership access," subsumes access to quotations and is governed by particular regulatory requirements. Sections 6(b)(2) and 15A(b)(3) of the Exchange Act, for example, provide for fair access to membership in SROs. Similarly, Rule 301(b)(5) of Regulation ATS prohibits certain high volume ATSs from denying

$354 \quad$ See Rule 301(b)(3) of Regulation ATS (order display and execution access requirements). 
fair access to their services. ${ }^{355}$ Rules 610(a) and (b), in contrast, only address the responsibilities of trading centers to provide order execution access to their quotations.

Rules 610(a) and (b) further the goal of fair and efficient access to quotations primarily by prohibiting trading centers from unfairly discriminating against non-members or nonsubscribers that attempt to access their quotations through a member or subscriber of the trading center. Market participants can either become members or subscribers of a trading center to obtain direct access to its quotations, or they can obtain indirect access by "piggybacking" on the direct access of members or subscribers. These forms of access are widely used today in the market for Nasdaq stocks (as well as to a lesser extent in the market for exchange-listed stocks). Instead of every market participant establishing separate linkages with every trading center, many different private firms have entered the business of linking with a wide range of trading centers and then offering their customers access to those trading centers through the private firms' linkages. Competitive forces determine the types and costs of these private linkages. Most commenters supported this private linkage approach for access to quotations. ${ }^{356}$ They noted the success of private linkages among electronic markets for Nasdaq stocks and contrasted the speed and usefulness of those linkages with the ITS linkage for exchange-listed stocks. Morgan Stanley stated that "[p]rivate linkages are much easier to establish and operate and can be constructed directly between [order execution facilities] or through market

355 As discussed in section III.B.4 below, the Commission is amending the fair access requirements of Regulation ATS to extend their application to ATSs with 5\% of trading volume in a security.

356 See, e.g., Citigroup Letter at 12; Consumer Federation Letter at 4; Goldman Sachs Letter at 4; ICI Letter at 16-17; Morgan Stanley Letter at 17; Nasdaq Letter II at 20; NYSE Letter, Attachment at 6; Letter from Carrie E. Dwyer, General Counsel \& Executive Vice President, Charles Schwab \& Co., Inc., to Jonathan G. Katz, Secretary, Commission, dated June 30, 2004 ("Schwab Letter") at 17; SIA Letter at 16; UBS Letter at 8. 
intermediaries. The smooth operation of the market for Nasdaq stocks today clearly demonstrates the power of private linkages." ${ }^{357}$ The NYSE concluded that "[i]n the market for listed stocks, we believe that proposed Regulation NMS will provide the framework for alternatives to ITS for intermarket access." ${ }^{358}$ The SIA stated that "[p]rivate linkages, as opposed to ITS-type linkages, will provide the flexibility -- technologically and otherwise -- that is vital to the continued development of the markets. ${ }^{359}$ Bloomberg expressed the belief that private linkages have proven to be effective in the market for Nasdaq securities and "can readily, quickly and inexpensively be adapted for use in exchange-listed securities," and even believed that ITS can be abandoned. ${ }^{360}$

A few commenters opposed the proposed private linkages approach. ${ }^{361}$ Some questioned whether multiple private linkages could match the efficiency of a single, uniform intermarket linkage, although they generally emphasized that the current ITS linkage needed to be enhanced. The Alliance of Floor Brokers, for example, suggested that problems with the ITS linkage, such as its slow speed and lack of structural flexibility, "should be addressed before it is determined to replace it with some, as yet unspecified, routing methodology or mechanism." ${ }^{362}$ While agreeing that private linkages could promote access if they were not the sole means of communications

\footnotetext{
$357 \quad$ Morgan Stanley Letter at 17.

$358 \quad$ NYSE Letter, Attachment at 7.

$359 \quad$ SIA Reproposal Letter at 21.

$360 \quad$ Bloomberg Reproposal Letter at 7-8.

361 See, e.g., Letter from Brendan R. Dowd, Daniel W. Tandy \& Ronald Zdrojeski, Alliance of Floor Brokers, to Jonathan G. Katz, Secretary, Commission, dated June 24, 2004 ("Alliance of Floor Brokers Letter") at 2; Ameritrade Letter I, Appendix at 11; BSE Letter at 7; CHX Letter at 13; E*Trade Letter at 9.

362 Alliance of Floor Brokers Letter at 2.
} 
between trading facilities and trading centers, and that ITS' "archaic technology and restrictive membership provisions actively limit access," NexTrade contended that private linkages, if used to replace existing and universal industry links, could reduce total access. ${ }^{363}$ STANY believed that the Commission vastly underestimated the access issues represented by the proposal, and raised a number of concerns regarding the costs and feasibility of implementing the private linkage approach, including issues relating to software, hardware, maintenance, and protocols. ${ }^{364}$

The Commission has carefully considered the views of all the commenters. The Commission agrees with the commenters that stated that private linkages currently work well in the market for Nasdaq securities. ${ }^{365}$ The Commission believes that the benefits of private linkages, including their flexibility to meet the needs of different market participants and the scope they allow for competitive forces to determine linkages, justifies reliance on this model rather than a single intermarket linkage. Recognizing, however, that the adoption of the Order Protection Rule increases the importance of efficient access to each trading center, particularly with respect to access to ADF participants, the requirements in the Rule are designed to mitigate concerns about the cost of access to ADF participants, as discussed below. In addition, the Commission believes, given the significant number and variety of entities that currently provide access services and the competitive nature of the market for these services, that competition will be sufficient to provide routing services for any trading center that chooses to utilize an outside vendor rather than incur costs associated with building its own linkages. One ECN, for example,

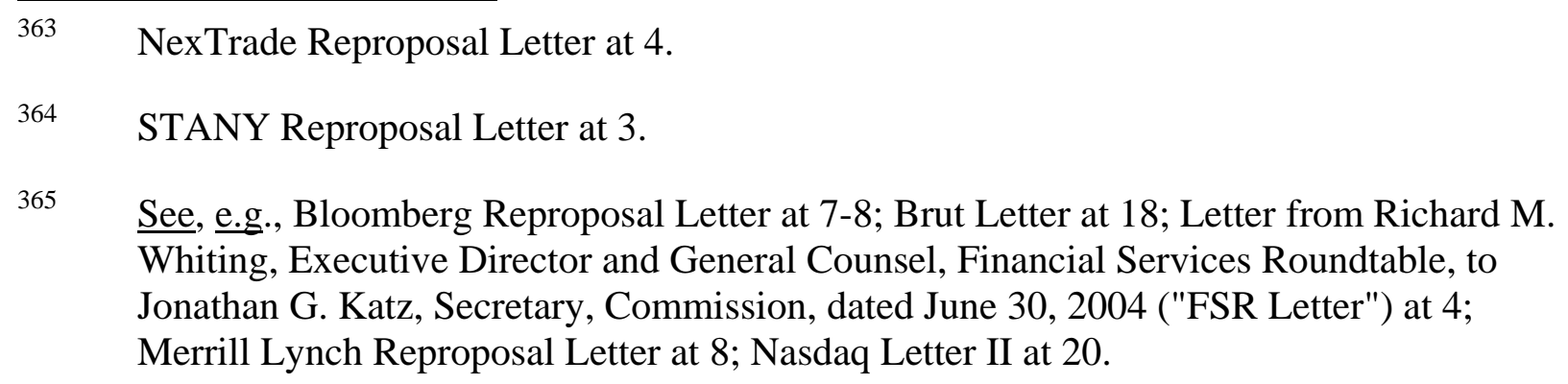

365 See, e.g., Bloomberg Reproposal Letter at 7-8; Brut Letter at 18; Letter from Richard M. Whiting, Executive Director and General Counsel, Financial Services Roundtable, to Jonathan G. Katz, Secretary, Commission, dated June 30, 2004 ("FSR Letter") at 4; Merrill Lynch Reproposal Letter at 8; Nasdaq Letter II at 20. 
can be accessed through five extranets and at least 21 other access providers, as well as through direct connections. $^{366}$

Several commenters, including some that otherwise supported the proposal, expressed concern about particular problems that might arise under a private linkage approach. ${ }^{367}$ Some were concerned that requiring non-discriminatory access to markets might undermine the value of SRO membership. CHX stated that "[b]y requiring the Exchange to grant non-members access to the full capabilities of its order execution systems, the Commission's fair access proposal would inappropriately require the Exchange's members to help fund the costs of operating a market that could be routinely used by non-members. It would severely undercut the value of membership and enable non-members to free-ride on the fees paid by members." 368 Amex stated that "to the extent that the proposed rule undermines our right to differentiate between members (who pay fees and have duties and responsibilities to the Exchange) and nonmembers in our charges, it could effectively remove any incentive for Amex membership."369

The Commission does not believe that the private linkage approach adopted today will seriously undermine the value of membership in SROs that offer valuable services to their members. First, the fact that markets will not be allowed to impose unfairly discriminatory terms on non-members who obtain indirect access to quotations through members does not mean that non-members will obtain free access to quotations. Members who provide piggyback access to

366 See www.nasdaqtrader.com/trader/ebrut/ourofferings/connectivity.shtm.

367 Alliance of Floor Brokers Letter at 10; Amex Letter, Exhibit A at 25-26; BSE Letter at 12; CHX Letter at 14; Citigroup Letter at 12; Letter from Edith H. Hallahan, First Vice President, Deputy General Counsel, Philadelphia Stock Exchange, to Jonathan G. Katz, Secretary, Commission, dated August 10, 2004 ("Phlx Letter") at 2; STANY Letter at 9. CHX Letter at 14.

$369 \quad$ Amex Letter, Exhibit A at 26. 
non-members will be providing a useful service and presumably will charge a fee for such service. The fee will be subject to competitive forces and likely will reflect the costs of SRO membership, plus some element of profit to the SRO's members. As a result, non-members that frequently make use of indirect access are likely to contribute indirectly to the costs of membership in the SRO market. Moreover, the unfair discrimination standard of Rule 610(a) will apply only to access to quotations, not to the full panoply of services that markets generally provide only to their members. These other services will be subject to the more general fair access provisions applicable to SROs and large ECNs, as well as the statutory provisions that govern SRO rules.

On the other hand, any attempt by an SRO to charge differential fees based on the nonmember status of the person obtaining indirect access to quotations, such as whether it is a competing market maker, would violate the anti-discrimination standard of Rule 610. As noted above, fair and efficient access to quotes is essential to the functioning of the NMS. To comply with the Order Protection Rule and their duty of best execution, trading centers often may be required to access the quotations of other trading centers. If a trading center charged discriminatory fees to non-members, including competitors, accessing its quotations, this would interfere with the functioning of the private linkage approach and detract from its usefulness to trading centers in meeting their regulatory responsibilities.

Other types of differential fees, however, would not violate the anti-discrimination standard of Rule 610. Fees with volume-based discounts or fees that are reasonably based on the cost of providing a particular service will be permitted, so long as they do not vary based on the non-member status of a person obtaining indirect access to quotations. For example, a member 
providing indirect access could be given a volume discount on the full amount of its volume, including the volume accounted for by persons obtaining indirect access to quotations.

Another specific concern expressed by commenters about the private linkage approach was the cost and difficulty of building efficient linkages to trading centers with a small amount of trading volume that do not make their quotations accessible through an SRO trading facility. ${ }^{370}$ Such concerns arise at present with respect to the ADF, a display-only quotation facility operated by the NASD, because quotations displayed by ADF participants can only be reached by obtaining direct access to that trading center. As a result, the greater the number of ADF participants, the greater the number of separate connectivity points that market participants will need to access to comply with the Order Protection Rule and to meet their best execution responsibilities. The Commission's original proposal would have required such trading centers to provide access only to SROs and other ADF participants. At the NMS Hearing, several panelists expressed concern that this requirement would be inadequate to assure sufficient access, which prompted the Commission to request comment on the matter in its Supplemental Release. ${ }^{371}$ It noted that panelists at the NMS Hearing had suggested that relatively inactive ATSs and market makers should be required to publish their quotations in an SRO trading facility, at least until their share of trading reached a point where the cost of direct connections to those markets would not be out of proportion to their volume of trading. Alternatively, the Supplemental Release requested comment on whether an SRO without a trading facility, of which the NASD is currently the only one, should be required to ensure that any ATS or market

370 Amex Letter at 8; Brut Letter at 19; Citigroup Letter at 13; E*Trade Letter at 9; Nasdaq Letter II at 22; SIA Letter at 16; Specialist Assoc. Letter at 12; STA Letter at 4; STANY Letter at 10; UBS Letter at 9.

371 Hearing Tr. at 135, 138-140; Supplemental Release, 69 FR at 30146. 
maker is directly connected to most market participants before publishing its quotations in a display-only facility.

Several commenters on the original proposal supported the approach of requiring lowvolume trading centers to make their quotations available through an SRO trading center. ${ }^{372}$ Brut, for example, stated that the presence of such low-volume trading centers "requires vast industry investments to establish private connectivity (or utilize vendors) to access these markets - no matter how small or potentially how fleeting - to satisfy best execution obligations and avoid market disruption. The effort and investment to establish such connectivity is disproportionate to the liquidity on such market." ${ }^{373}$ Brut further noted that it had sought to avoid such ADF trading centers in the past, but that the extension of trade-through protection to Nasdaq stocks would eliminate this option.

The SIA also believed that "reliance solely on the SEC's proposed market access rules would fail to address access issues related to smaller markets. ... If the SEC obligates market participants to trade with [a smaller ADF market maker or ATS] by promulgating a tradethrough rule, we are concerned about the firms' burden of creating many private linkages to many small ATSs that may charge exorbitant fees for the necessary access." ${ }^{374}$ SIA members were divided, however, on the best means to resolve the issue. Some favored requiring smaller trading centers to make their quotes accessible through an SRO trading facility. Other SIA

372 See, e.g., Brut Letter at 13; Citigroup Letter at 13; SIA Letter at 17 (some firms).

373 Brut Letter at 13.

$374 \quad$ SIA Letter at 16. 
members, as well as other commenters, recommended requiring all trading centers to make their best quotations available through a public intermarket linkage facility. ${ }^{375}$

One commenter, in contrast, believed that access to trading centers quoting on the ADF should be addressed by requiring the NASD to add an order execution functionality to ADF. NexTrade stated that the ADF was created to make participation in Nasdaq's SuperMontage facility voluntary. It believed that "the Commission should re-evaluate whether or not 'private sector' solutions for SROs without an execution mechanism are sufficient for the investment community to satisfy its various obligations under the Act." 376

After considering the various views of commenters on the original proposal, in the Reproposing Release the Commission proposed to require ADF participants to bear the costs of providing the necessary connectivity that would facilitate efficient access to their quotations. ${ }^{377}$ Specifically, under reproposed Rule 610(b)(1) those ATSs and market makers that choose to display quotations in the ADF would bear the responsibility of providing a level and cost of access to their quotations that is substantially equivalent to the level and cost of access to quotations displayed by SRO trading facilities.

A large number of commenters on the reproposal supported the proposed requirements in Rule 610(b)(1). ${ }^{378}$ The SIA, for example, stated that this requirement would likely address most

$375 \quad$ See, e.g., Ameritrade Letter I, Appendix at 11; E*Trade Letter at 9; SIA Letter at 17.

376 Letter from John M. Schaible, President, NexTrade Holdings, Inc., to Jonathan G. Katz, Secretary, Commission, dated July 29, 2004 ("NexTrade Letter") at 14.

See Section III.A.1 of the Reproposing Release for a discussion of the comments.

378 See, e.g., CIBC Reproposal Letter at 1; JP Morgan Reproposal Letter at 2; Letter from Paul W. Lerro to Jonathan G. Katz, Secretary, Commission, dated January 22, 2005 ("Lerro Reproposal Letter") at 14; Merrill Lynch Reproposal Letter at 9; Nasdaq Reproposal Letter at 18 (although advocating requiring trading facilities with less than a five percent share volume to make their quotations available through an SRO trading 
of its previously stated concerns about ATSs and market makers that choose to make their quotations accessible only through the ADF. ${ }^{379}$ One commenter noted that it thought the approach was fair and appropriate. ${ }^{380}$

At the same time, some commenters (both those supporting and those opposing the reproposed access standards) continued to voice their concerns about the potential need to develop, and the costs of developing, connections to numerous small trading centers in the ADF. ${ }^{381}$ For instance, one commenter, noting that the ADF is not a single market and that the expense of access increases proportionally by the number of markets that must be accessed, stated that the cost of accessing more than one or two additional markets would be prohibitive for most of its members. ${ }^{382}$ Several commenters believed that non-SRO trading centers should make their quotations available through the automatic execution facilities of an SRO, thereby requiring other market participants to only have to maintain access to six or seven markets, rather than potentially dozens. ${ }^{383}$ In contrast, one commenter that is an ADF participant continued to express its concerns with the proposed access requirements, stating its belief that the proposal to require ADF participants to establish the necessary connectivity that would facilitate efficient

facility, thought that the Commission's proposal was the "next best approach"); SIA Reproposal Letter at 3, 21; UBS Reproposal Letter at 1; Vanguard Reproposal Letter at 5.

$379 \quad$ SIA Reproposal Letter at 3.

380 Citigroup Reproposal Letter at 4.

381 See, e.g., Merrill Lynch Reproposal Letter at 9; SIA Reproposal Letter at 21; STANY Reproposal Letter at 3-4.

382 STANY Reproposal Letter at 3.

383 See, e.g., Knight Reproposal Letter at 5; Nasdaq Reproposal Letter at 17-18 (expressing the view that trading facilities with less than a five percent volume shares should be required to make their quotations available through an SRO trading facility); STA Reproposal Letter at 6; Type N Reproposal Letter at 1. 
access to their quotations would create a cost barrier that discriminates against smaller firms in the $\mathrm{ADF} .{ }^{384}$

The Commission has decided to adopt Rule 610(b)(1) as reproposed, but does not believe that its adopted access approach discriminates against smaller firms or creates a barrier to access for innovative new market entrants. Rather, smaller firms and new entrants have a range of alternatives from which to choose that will allow them to avoid incurring any costs to meet the connectivity requirements of Rule 610(b)(1) if they wish to do so. This approach is fully consistent with Congressional policy set forth in the Regulatory Flexibility Act, which directs the Commission to consider significant alternatives to regulations that accomplish the stated objectives of the Exchange Act and minimize the economic impact on small entities. ${ }^{385}$

Small ATSs are exempt from participation in the consolidated quotation system and, therefore, from the connectivity requirements of Rule 610. Under Rule 301(b)(3) of Regulation ATS, an ATS is required to display its quotations in the consolidated quotation stream only in those securities for which its trading volume reaches $5 \%$ of total trading volume. Consequently, smaller ATSs are not required to provide their quotations to any SRO (whether an SRO trading facility or the NASD's ADF) and thereby trigger the access requirements of Rule 610. Moreover, potential new entrants with innovative trading mechanisms can commence business without having to incur any costs associated with participation in the consolidated quotation system.

$384 \quad$ NexTrade Reproposal Letter at 4-6.

3855 U.S.C. 603(c). In the Reproposing Release, the Commission noted that only two of the approximately 600 broker-dealers (including ATSs) that would be subject to Rule 610 are considered small (total capital of less than \$500,000) for purposes of the Regulatory Flexibility Act. $69 \mathrm{FR}$ at 77492 . The adopted access approach provides alternatives that will benefit a wider range of smaller ATSs than the two that are considered small entities. 
Some smaller ATSs, however, may wish to participate voluntarily in the consolidated quotation system. Such participation can benefit smaller firms and promote competition among markets by enabling smaller firms to obtain wide distribution of their quotations among all market participants. ${ }^{386}$ Here, too, such firms will have alternatives that would not obligate them to comply with the connectivity requirements of Rule 610(b)(1). ATSs and market makers that wish to trade NMS stocks can choose from a number of options for quoting and trading. They can become a member of a national securities exchange and quote and trade through the exchange's trading facilities. They can participate in The NASDAQ Market Center and quote and trade through that facility. By choosing either of these options, an ATS or market maker would not create a new connectivity point that all other market participants must reach and would not be subject to Rule 610(b)(1). Some firms, however, may not want to participate in an SRO trading facility. These ATSs and market makers can quote and trade in the OTC market. The existence of the NASD's ADF makes this third choice possible by providing a facility for displaying quotations and reporting transactions in the consolidated data stream.

The NASD is not, however, statutorily required to provide an order execution functionality in the ADF. As a national securities association, the NASD is subject to different regulatory requirements than a national securities exchange. It is responsible for regulating the OTC market (i.e., trading by broker-dealers otherwise than on a national securities exchange). Section 15A(b)(11) of the Exchange Act requires an association to have rules governing the form and content of quotations relating to securities sold otherwise than on a national securities exchange that are published by a member of the association. Such rules must be designed to

386 See infra, note 566 (the Commission's Advisory Committee on Market Information recommended retention of the consolidated display requirement because, among other things, it "may promote market competition by assuring that information from newer or smaller exchanges is widely distributed."). 
produce fair and informative quotations and to promote orderly procedures for collecting, distributing, and publishing quotations. The Exchange Act does not expressly require an association to establish a facility for executing orders against the quotations of its members, although it could choose to do so.

The Commission believes that market makers and ECNs should continue to have the option of operating in the OTC market, rather than on an exchange or The NASDAQ Market Center. As noted in the Commission's order approving Nasdaq's SuperMontage trading facility, this ability to operate in the ADF is an important competitive alternative to Nasdaq or exchange affiliation. ${ }^{387}$ Therefore, the Commission has determined not to require small trading centers to make their quotations accessible through an SRO trading facility.

Instead, Rule 610(b)(1) requires all trading centers that choose to display quotations in an SRO display-only quotation facility to provide a level and cost of access to such quotations that is substantially equivalent to the level and cost of access to quotations displayed by SRO trading facilities. Rule 610(b) therefore may cause trading centers that display quotations in the ADF to incur additional costs to enhance the level of access to their quotations and to lower the cost of connectivity for market participants seeking to access their quotations. The extent to which these trading centers in fact incur additional costs to comply with the adopted access standards will be largely within the control of the trading center itself. As noted above, ATSs and market makers that wish to trade NMS stocks can choose from a number of options for quoting and trading, including quoting and trading in the OTC market. As a result, the additional connectivity requirements of Rule 610(b) will be triggered only by a trading center that displays its quotations

See Securities Exchange Act Release No. 43863 (Jan. 19, 2001), 66 FR 8020 (Jan. 26, 2001). 
in the consolidated data stream and chooses not to provide access to those quotations through an SRO trading facility.

Currently, nine SROs operate trading facilities in NMS stocks. Market participants throughout the securities industry generally have established connectivity to these nine points of access to quotations in NMS stocks. By choosing to display quotations in the ADF, a trading center effectively could require the entire industry to establish connectivity to an additional point of access. Potentially, many trading centers could choose to display quotations in the ADF, thereby significantly increasing the overall costs of connectivity in the NMS. Such an inefficient outcome would become much more likely if an ADF trading center were not required to assume responsibility for the additional costs associated with its decision to display quotations outside of an established SRO trading facility.

Although the Exchange Act envisions an individual broker-dealer having the option of trading in the OTC market, ${ }^{388}$ it does not mandate that the securities industry in general must subsidize the costs of accessing a broker-dealer's quotations in the OTC market if the NASD chooses not to provide connectivity. The Commission believes that it is reasonable and appropriate to require those ATSs and market makers that choose to display quotations in the ADF to bear the responsibility of providing a level and cost of access to their quotations that is substantially equivalent to the level and cost of access to quotations displayed by SRO trading facilities. Under Rule 610(b)(1), therefore, ADF participants will be required to bear the costs of the necessary connectivity to facilitate efficient access to their quotations. This standard will help ensure that additional connectivity burdens are not imposed on the securities industry each

388 See Sections 11A(c)(3)(A) and (4) of the Exchange Act, 15 U.S.C 78k-1(c)(3)(A) and (4). 
time that an additional ADF participant necessitates a new connectivity point by choosing to begin displaying quotations in the consolidated quotation stream.

To clarify the intent of this requirement, the Commission emphasizes that a "substantially equivalent" cost of access will not be evaluated in terms of absolute dollar costs of access and therefore does not necessarily allow an ATS or market maker quoting in the ADF to charge the same fees or impose the same costs that an SRO trading facility charges or imposes. Rather, the standard in Rule 610(b)(1) compares the costs to an ADF participant's relative degree of trading volume. $^{389}$ Consequently, the cost of access to an ADF participant must be substantially equivalent to the cost of access to SRO trading facilities on a per transaction basis. For example, a $\$ 1000$ port fee charged by an ECN participating in the ADF that trades one million shares a day would not be substantially equivalent to a $\$ 1000$ port fee charged by an SRO trading facility trading 100 million shares a day.

As discussed above, the Commission recognizes that trading centers subject to Rule 610(b)(1) may incur costs associated with providing access to their quotations in compliance with the Rule, although the costs will vary depending upon the manner in which each trading center determines to provide such access. As noted in the Commission's order approving the pilot program for the ADF, the reduction in communications line costs in recent years and the advent of competing access providers offer the potential for multiple competitive means of access to the various trading centers that trade NMS stocks. ${ }^{390}$ To meet their regulatory

389 Cf. NexTrade Reproposal Letter at 6. See Section III.A.1 of the Reproposing Release and supra notes 370 to 375 discussing the concerns of commenters and panelists at the NMS Hearings regarding access to relatively inactive ATSs and market makers with a small amount of trading volume.

390 Securities Exchange Act Release No. 46249 (July 24, 2002), 67 FR 49822 (July 31, 2002). 
requirements, ADF participants will have the option of establishing and, when necessary, paying for connections to industry access providers that have extensive connections to a wide array of market participants through a variety of direct access options and private networks. The option of participation in existing market infrastructure and systems should reduce a trading center's cost of compliance.

Two commenters raised concerns about reliance on third party private vendors to provide access, since they may not be regulated by the Commission and thus could deny access to a trading center they viewed as a competitor, or because utilizing their services to link to other trading centers is outside the control of a trading center. ${ }^{391}$ The Commission believes that the requirement in Rule 610(b)(1) that ADF participants provide a substantially equivalent level of access will preclude the ADF participant from providing access only through a narrow range of private access providers. The range of access providers must be sufficient to provide access substantially equivalent to SRO trading facilities. In these circumstances, and given the significant number and variety of entities that currently provide access services and the competitive nature of the market for these services, the Commission believes that competition will be sufficient to provide services for any trading center choosing to utilize an outside vendor. $^{392}$

One commenter emphasized the importance of the NASD carefully assessing and monitoring the extent to which ADF participants meet the access standards of Rule 610(b). ${ }^{393}$ The Commission agrees that effective NASD oversight of ADF participants' compliance with the

$391 \quad$ NexTrade Reproposal Letter at 6; STANY Reproposal Letter at 4.

392 For example, as noted above, one ECN can be accessed through five extranets and at least 21 other access providers, as well as through direct connections. 
Rule is critical to the viability of the access standards adopted today, given that these participants are not accessible through an SRO trading facility. As the self-regulatory authority responsible for the OTC market, the NASD must act as the "gatekeeper" for the ADF, and, as such, will need to closely assess the extent to which ADF participants meet the access standards of Rule 610 . Prior to implementation of Rule 610, the NASD will need to make an affirmative determination that existing ADF participants are in compliance with the requirements of the Rule. ${ }^{394}$ If an ADF participant is not complying with these access standards, the NASD would have a responsibility to stop publishing the participant's quotations until the participant comes into compliance. ${ }^{395}$ The Commission also believes that, in light of these new access standards, the addition of a new ADF participant would constitute a change in a material aspect of the operation of the NASD's facilities, and thus require the filing of a proposed rule change pursuant to Section 19(b) of the Exchange Act that would be subject to public notice and comment. ${ }^{396}$ Alternatively, the NASD could choose to provide a communications facility that would link all of the ADF participants to each other and that would provide a single point of access to market participants attempting to access an ADF participant. ${ }^{397}$

\section{Limitation on Access Fees}

394 See Section 15A of the Exchange Act, 15 U.S.C. 78ㅁ-3.

395 Id.

396 See Rule 19b-4(b)(1) under the Exchange Act, 17 CFR 240.19b-4(b)(1).

397 The Commission does not believe that NASD, solely by providing such a communications facility, would fall within the definition of SRO trading facility, which applies to an SRO that operates a facility that executes orders in a security or presents orders to members for execution. 
A number of ECN trading centers charge fees to incoming orders that execute against their displayed quotations. ${ }^{398}$ These ECNs typically pass a substantial portion of the access fee on to limit order customers as rebates for supplying the accessed liquidity (‥e., submitting nonmarketable limit orders). For Nasdaq stocks, ECNs have charged access fees directly to their subscribers, but also have charged access fees to non-subscribers when their quotations have been displayed and executed through Nasdaq facilities. Market makers have not been permitted to charge any fee for counterparties accessing their quotations under the Quote Rule. Other types of trading centers, including exchange SROs, may charge fees that are triggered when incoming orders access their displayed quotations. These fees have only been charged to their members, because only members have the right to route orders to an exchange other than through ITS. For exchange-listed stocks, however, the ITS has provided free intermarket access to quotations in other markets for its participants.

The trade-through protection and linkage requirements adopted today will significantly alter the conditions that have shaped access fee practices in the past. For exchange-listed stocks, Rule 610 adopts a private linkage approach that relies on access through members and subscribers rather than through a public intermarket linkage system. For access outside of ITS, markets will pay, directly or indirectly, the fees charged by other markets to their members and subscribers. For Nasdaq stocks, the Order Protection Rule will, for the first time, establish price protection, so market participants will no longer have the option of bypassing the quotations of trading centers with access fees that they view as too high.

The benefits of strengthened price protection and more efficient linkages could be compromised if trading centers are able to charge substantial fees for accessing their quotations.

398 A full description of the current framework for access fees is provided in the Proposing Release. $69 \mathrm{FR}$ at 11156. 
Moreover, the wider the disparity in the level of access fees among different market centers, the less useful and accurate are the prices of quotations displayed for NMS stocks. For example, if two trading centers displayed quotations to sell an NMS stock for $\$ 10.00$ per share, one offer could be accessible for a total price of $\$ 10.00$ plus a $\$ 0.009$ fee, while the second trading center might not charge any access fee. What appeared in the consolidated data stream to be identical quotations would in fact be far from identical.

To address the potential distortions caused by substantial, disparate fees, the original access proposal included a limitation on fees. Trading centers would have been limited to a fee of no more than $\$ 0.001$ per share. Liquidity providers also would have been limited to a fee of no more than $\$ 0.001$ per share for attributable quotations, but could not have charged any fee for non-attributable quotations. In addition, the proposal established an accumulated fee limitation of no more than $\$ 0.002$ per share for any transaction. At the NMS Hearing, panelists sharply disagreed about access fees, with some panelists arguing that agency markets must be allowed to charge access fees for their services, and other panelists arguing that access fees distort quotation prices and should be banned. ${ }^{399}$ In the Supplemental Release, therefore, the Commission requested comment on all aspects of the proposed fee limitations, including whether it should adopt a single accumulated fee limitation that would apply to all types of market centers, and, if so, whether the proposed $\$ 0.002$ per share was an appropriate amount, or whether the amount should be higher or lower. ${ }^{400}$

Commenters on the original proposal were splintered on the issue of access fees. A number supported the Commission's proposal as a worthwhile compromise resolution on an

$399 \quad$ See, e.g., Hearing Tr. at 166, 168.

$400 \quad$ Supplemental Release, 69 FR at 30147. 
extremely difficult issue. $^{401}$ They believed that the proposal would level the playing field in terms of who could charge fees, and provide some measure of certainty to market participants that the quoted price will be, essentially, the price they will pay. Other commenters were strongly opposed to any limitation on fees, believing that competition alone would sufficiently address the high fees that distort quoted prices. ${ }^{402}$ One asserted that "[c]ompetitive forces have satisfactorily dealt with the issue of outlier ECNs. . [M]arket participants have put them at the bottom of their order routing tables, which means that orders placed on these ECNs would be the last to be executed at any price level, a position that no market participant wants to be in." ${ }^{403}$ In contrast, some commenters argued that all access fees charged to non-members and nonsubscribers should be prohibited, but believed that the proposed fee limitations should not apply to SRO transaction fees, particularly those that are filed with the Commission for approval. ${ }^{404}$ Finally, a few commenters questioned the Commission's authority to set limitations on access fees. ${ }^{405}$

$401 \quad$ See, e.g., BNY Letter at 4; Letter from Kenneth Griffin, President \& Chief Executive Officer, Citadel Investment Group, L.L.C., to Jonathan G. Katz, Secretary, Commission, dated July 9, 2004 ("Citadel Letter") at 9; Citigroup Letter at 14; E*Trade Letter at 10; Nasdaq Letter II at 3; SIA Letter (some members) at 18.

402 See, e.g., Brut Letter at 12; Instinet Letter at 24; SIA Letter (some firms) at 18.

$403 \quad$ Instinet Letter at 27.

$404 \quad$ See, e.g., Amex Letter at 7-8; Goldman Sachs Letter at 5; Knight Letter II at 2; NYSE Letter at 5; STA Letter at 6 .

405 See, e.g., Instinet Letter at 24; Letter from Roderick Covlin, Executive Vice President, TrackECN, to William H. Donaldson, Chairman, Commission, dated May 10, 2004 ("TrackECN Letter") at 1. 
After considering the many divergent views of the commenters on the original proposal, the Commission reproposed a flat $\$ 0.003$ per share access fee cap. ${ }^{406}$ Commenters on the reproposal also held varying views with regard to the proposal to limit access fees to $\$ 0.003$ per share. One group of commenters supported the reproposal's simplified approach to access fees. ${ }^{407}$ For example, one commenter stated that the reproposal is a reasonable alternative to either banning access fees outright or permitting access fees with relatively high price caps. ${ }^{408}$ Another group of commenters opposed the Commission's access fee limitation, ${ }^{409}$ with some opposing any effort to limit fees through regulatory means ${ }^{410}$ and others believing that all

406 For the relatively small number of NMS stocks priced under $\$ 1.00$, fees will be limited to $0.3 \%$ of the quotation price per share to prevent fees from constituting an excessive percentage of share price.

407 See, e.g., BNY Reproposal Letter at 1,3; Deutsche Bank Reproposal Letter at 3; FSR Reproposal Letter at 4 (some members supported the proposal, which they believed would provide certainty for all market participants, while other members believed that access fees should be banned entirely); JP Morgan Reproposal Letter at 2; SIA Reproposal Letter at 3 (members were split). Nasdaq, although questioning the inflexibility of the fee limitation, stated that the fee limits were an inevitable consequence of the trade-through proposal, needed because markets and market participants could otherwise take advantage of the power granted to them. Nasdaq Reproposal Letter at 19.

Deutsche Bank Reproposal Letter at 3.

409 See Ameritrade Reproposal Letter at 10; ArcaEx Reproposal Letter at 9-10; BGI Reproposal Letter at 3; Bloomberg Reproposal Letter at 1, 8; BSE Reproposal Letter at 2; CHX Reproposal Letter at 4; Letter from Lawrence E. Harris, Fred V. Keenan Chair in Finance, Department of Finance and Business Economics, Marshall School of Business, University of Southern California, to Jonathan G. Katz, Secretary, Commission, dated February 5, 2005 ("Harris Reproposal Letter") at 4-5; Instinet Reproposal Letter at 10; Merrill Lynch Reproposal Letter at 3, 9; Morgan Stanley Reproposal Letter at 12-13; NexTrade Reproposal Letter at 7-8; Phlx Reproposal Letter at 4-5.

410 See, e.g., ArcaEx Reproposal Letter at 10; BGI Reproposal Letter at 3; BSE Reproposal Letter at 2; CHX Reproposal Letter at 4; Phlx Reproposal Letter at 4-5. 
access fees should be prohibited. ${ }^{411}$ Many of those against imposing any fee limitation believed that competition was the best means for determining prices, ${ }^{412}$ although at least one commenter acknowledged a trade-through rule could change this competitive dynamic. ${ }^{413}$ One commenter questioned the Commission's statutory authority to impose an access fee cap. ${ }^{414}$

Some of the commenters that supported a total ban on access fees nonetheless supported the Commission's efforts to limit fees, if the Commission were to permit access fees. ${ }^{415}$ Some commenters, although opposed to a fee limitation, thought that the reproposal improved on the original proposal. ${ }^{416}$ One commenter stated that the reproposal improved on the original fee limitation proposal by eliminating the attribution requirement, reducing the potential for unintended consequences, and simplifying its administration. ${ }^{417}$

Although acknowledging the many difficult issues associated with access fees, the Commission remains concerned that these issues must be resolved to promote a fair and efficient

$411 \quad$ See, e.g., Bloomberg Reproposal Letter at 8; Harris Reproposal Letter at 4-5; Merrill Lynch Reproposal Letter at 3.

412 Ameritrade Reproposal Letter at 10; ArcaEx Reproposal Letter at 10; CHX Reproposal Letter at 4; Instinet Reproposal Letter at 10.

413 Nasdaq Reproposal Letter at 19.

414 Instinet Reproposal Letter at 10.

415 See, e.g.. Citigroup Reproposal Letter at 4 (although advocating that the access fee limitation should be set at $\$ 0.001$, or the original proposal's tiered cap of \$0.002); Knight Trading Group Reproposal Letter at 6; STA Reproposal Letter at 4 (supporting the $\$ 0.003$ per share cap in the absence of complete prohibition on fees); STANY Reproposal Letter at 5 (supporting the $\$ 0.003$ per share cap in the absence of complete elimination of non-subscriber fees).

416 Bloomberg Reproposal Letter at 8 (supporting abolishment of all access fees, but praising the Reproposal's simplified approach); Instinet Reproposal Letter at 3, 10-11.

417 Instinet Reproposal Letter at 3, 10-11. 
NMS, particularly under the regulatory structure adopted today. As the SIA noted in its discussion of access fees, its members continue to be united in their desire for a market-wide resolution of the access fee issue, although divided on the optimum solution. ${ }^{418}$

After considering the continuing divergent views of commenters, the Commission believes that a flat limitation on access fees to $\$ 0.003$ per share is the fairest and most appropriate solution to what has been a longstanding and contentious issue. ${ }^{419}$ The limitation is intended to achieve several objectives. First, Rule 610(c) promotes the NMS objective of equal regulation of markets and broker-dealers by applying equally to all types of trading centers and all types of market participants. ${ }^{420}$ As noted above, although ECNs and other types of trading centers, including SROs, may currently charge access fees, market makers have not been permitted to charge any fee for counterparties accessing their quotations. The Commission believes, however, that it is consistent with the Quote Rule for market makers to charge fees for access to their quotations, so long as such fees meet the requirements of Rule 610(c). In particular, market makers will be permitted to charge fees for executions of orders against their quotations, irrespective of whether the order executions are effected on an SRO trading facility or directly by the market maker.

Second, the adopted fee limitation is designed to preclude individual trading centers from raising their fees substantially in an attempt to take improper advantage of strengthened protection against trade-throughs and the adoption of a private linkage regime. In particular, the

\footnotetext{
$418 \quad$ SIA Reproposal Letter at 3.
}

419 For the relatively small number of NMS stocks priced under $\$ 1.00$, fees will be limited to $0.3 \%$ of the quotation price per share to prevent fees from constituting an excessive percentage of share price.

420 Section $11 \mathrm{~A}(\mathrm{c})(1)(\mathrm{F})$ of the Exchange Act. 
fee limitation is necessary to address "outlier" trading centers that otherwise might charge high fees to other market participants required to access their quotations by the Order Protection Rule. It also precludes a trading center from charging high fees selectively to competitors, practices that have occurred in the market for Nasdaq stocks. In the absence of a fee limitation, the adoption of the Order Protection Rule and private linkages could significantly boost the viability of the outlier business model. Outlier markets might well try to take advantage of intermarket price protection by acting essentially as a toll booth between price levels. The high fee market likely will be the last market to which orders would be routed, but prices could not move to the next level until someone routed an order to take out the displayed price at the outlier market. Therefore, the outlier market might see little downside to charging exceptionally high fees, such as $\$ 0.009$, even if it is last in priority. While markets would have significant incentives to compete to be near the top in order-routing priority, ${ }^{421}$ there might be little incentive to avoid being the least-preferred market if fees were not limited.

The \$0.003 cap will limit the outlier business model. It will place all markets on a level playing field in terms of the fees they can charge and the rebates they can pass on to liquidity providers. Some markets might choose to charge lower fees, thereby increasing their ranking in the preferences of order routers. Others might charge the full $\$ 0.003$ and rebate a substantial proportion to liquidity providers. Competition will determine which strategy is most successful.

Moreover, the fee limitation is necessary to achieve the purposes of the Exchange Act. Access fees tend to be highest when markets use them to fund substantial rebates to liquidity providers, rather than merely to compensate for agency services. If outlier markets are allowed to charge high fees and pass most of them through as rebates, the published quotations of such

$421 \quad$ See supra, section II.A.4.a (discussion of competitive implications of trade-through protection). 
markets would not reliably indicate the true price that is actually available to investors or that would be realized by liquidity providers. Section $11 \mathrm{~A}(\mathrm{c})(1)(\mathrm{B})$ of the Exchange Act authorizes the Commission to adopt rules assuring the fairness and usefulness of quotation information. For quotations to be fair and useful, there must be some limit on the extent to which the true price for those who access quotations can vary from the displayed price. Consequently, the $\$ 0.003$ fee limitation will further the statutory purposes of the NMS by harmonizing quotation practices and precluding the distortive effects of exorbitant fees. Moreover, the fee limitation is necessary to further the statutory purpose of enabling broker-dealers to route orders in a manner consistent with the operation of the NMS. ${ }^{422}$ To protect limit orders, orders must be routed to those markets displaying the best-priced quotations. This purpose would be thwarted if market participants were allowed to charge exorbitant fees that distort quoted prices.

The Commission notes the $\$ 0.003$ fee limitation is consistent with current business practices, as very few trading centers currently charge fees that exceed this amount. ${ }^{423}$ It appears that only two ECNs currently charges fees that exceed $\$ 0.003$, charging $\$ 0.005$ for access through the ADF. These ECNs currently do not account for a large percentage of trading volume. In addition, while a few SROs have large fees on their books for transactions in ETFs that exceed a certain size (e.g., 2100 shares), it is unlikely that these fees generate a large amount of revenues.

422 Section $11 \mathrm{~A}(\mathrm{c})(1)(\mathrm{E})$ of the Exchange Act authorizes the Commission to adopt rules assuring that broker-dealers transmit orders for NMS stocks in a manner consistent with the establishment and operation of a national market system.

423 Cf. Instinet Letter at 38 ("there is no basis for adopting any limitation other than at the prevailing \$0.003 per share level, which was arrived at through open competition among ATSs, ECNs, and SRO markets in the Nasdaq market") and Instinet Reproposal Letter at 11 ("as for an appropriate amount for such an accumulated fee limitation, the Reproposal sets the cap at the prevailing $\$ 0.003$ per share level for stocks priced above $\$ 1.00$, which was arrived at through open competition among marketplaces"). 
Accordingly, the adopted fee limitation will not impair the agency market business model. The Commission recognizes that agency trading centers perform valuable agency services in bringing buyers and sellers together, and that their business model historically has relied, at least in part, on charging fees for execution of orders against their displayed quotations. Under current conditions, the Commission believes that prohibiting access fees entirely would unduly harm this business model.

Several commenters believed that, because best execution responsibilities may require a broker-dealer to access non-protected quotations, the Commission should extend the access fee cap to all quotations, not just protected quotations. ${ }^{424}$ One commenter argued that the potential contribution of manual quotations to a market center's execution quality could require market participants to access those quotations to fulfill their duty of best execution, even though they are not protected by Rule $611 .^{425}$ Thus, the commenter suggested that the access fee limitation should apply to all quotations, including manual quotations, so as not to disincent market participants from attempting to access those quotations. ${ }^{426}$

The Commission agrees that the access fee limitation should apply to manual quotations that are best bids and offers to the same extent it applies to protected quotations, to preclude any incentive for trading centers to display manual quotations as a means to charge a higher access fee. In addition, the Commission recognizes that at present a trading center's execution quality

424 Ameritrade Reproposal Letter at 10 (only if fee limitation is adopted); Citigroup Reproposal Letter at 4; Madoff Reproposal Letter at 5 (also stating that extending the fee limitation to all quotations will ensure that all quotations are treated fairly); Merrill Lynch Reproposal Letter at 9; SIA Reproposal Letter at 22; STANY Reproposal Letter at 2, 5 .

$425 \quad$ Madoff Reproposal Letter at 5.

426 Id. 
statistics will be evaluated against the NBBO, whether that quotation is a manual or automated quotation. The Commission therefore has modified the proposed fee limitation in Rule 610(c) to apply to any quotation that is the best bid or best offer of an exchange, the ADF, or The NASDAQ Market Center, in addition to any protected quotations as defined in Rule $600(b)(57) .^{427}$

The Commission is not, however, extending the fee cap to all quotations displayed by a trading center. Thus, the fee cap will not apply to depth-of-book quotations, or to any other services offered by markets. By applying only to the best bid and offer of an exchange, the ADF, or The NASDAQ Market Center, the limitation is narrowly drafted to have minimal impact on competition and individual business models while furthering the objectives of the Exchange Act by preserving the fairness and usefulness of quotations, as discussed above. It will provide the necessary support for proper functioning of the Order Protection Rule and private linkages, while leaving trading centers otherwise free to set fees subject only to other applicable standards (e.g., prohibiting unfair discrimination).

Two commenters expressed a concern with the ability to determine after-the-fact whether a quotation against which an incoming order executed was subject to an access fee cap, given that under the Rule a market participant could be charged different fees based on whether or not a quotation was protected. ${ }^{428}$ In particular, one commenter raised the issue in the context of a sweep order that could hit non-protected quotations, and advocated applying the access fee limit to all sweep orders. ${ }^{429}$ The Commission acknowledges these concerns, but notes that market

427 In addition, the Commission notes that the access standards in Rule 610(a) and (b) apply to all quotations, not just automated quotations.

428 Bloomberg Reproposal Letter at 8, n. 6; SIA Reproposal Letter at 22.

429 Bloomberg Reproposal Letter at 8, n. 6. 
participants will be able to control the extent to which their orders interact with protected and non-protected quotations. First, under the Order Protection Rule, the definition of intermarket sweep order requires market participants to route orders to interact only with protected quotations. The objective can be achieved by routing an IOC, marketable limit order with a limit price that equals the price of the protected quotation. The extent to which they route to nonprotected quotations will be subject to the full range of competitive forces, including the fees that trading centers choose to charge for access to non-protected quotations.

The Commission recognizes, however, the concern that a market participant could intend to interact only with a protected quotation but in fact execute against a non-protected quotation. For example, at the time a market participant routes an order to a trading center, it may be attempting to execute against only that trading center's best bid or offer, which will be subject to the fee cap under adopted Rule 610(c) (for instance, by sending an intermarket sweep order with a limit price equal to the price of the protected quotation). By the time the order arrives at the trading center, the incoming order may, if a better priced bid or offer has been displayed at the trading center for a size smaller than the size of the incoming order, execute against both the new best bid or offer and the quotation that previously was the trading center's best bid or offer. To meet the requirements of Rule 610(c), however, a trading center must ensure that it never charges a fee in excess of the cap for executions of an order against its quotations that are subject to the fee cap. The operation of this limitation will be based on quotations as they are displayed in the consolidated quotation stream. Thus, the trading center is responsible for ensuring that any time lag between prices in its internal systems and its quotations in the consolidated quotation system do not cause fees to be charged that violate the limitation of Rule 610(c). Compliance with this requirement obviously will not be a problem for trading centers that do not 
charge any fees in excess of the cap. Given the often rapid updating of quotations in NMS stocks, however, the Commission does not believe a trading center that charges fees above the cap for quotations that are not subject to the fee cap could comply with the Rule unless it provides a functionality that enables market participants to assure that they will never inadvertently be charged a fee in excess of the cap. For example, such a trading center could provide a "top-of-book only" or "limited-fee only" order functionality. By using this functionality, market participants themselves could assure that they were never required to pay a fee in excess of the levels set forth in Rule 610(c).

In restricting the fee cap to the top-of-book, we are attempting to reduce the regulatory impact to the minimum extent necessary to effect the statutory purposes. We intend to monitor the operation of these rules to assess whether in practice, distinguishing which quotations are subject to the cap is so difficult, and accessing non-protected quotations is so essential, that broader coverage of the rule is necessary.

\section{Locking or Crossing Quotations}

The original access proposal provided that the SROs must establish and enforce rules:

(1) requiring their members reasonably to avoid posting quotations that lock or cross the quotations of other markets; (2) enabling the reconciliation of locked or crossed markets; and (3) prohibiting their members from engaging in a pattern or practice of locking or crossing quotations. In light of the discussion at the NMS Hearing concerning automated quotations and automated markets, ${ }^{430}$ the Supplemental Release requested comment on whether market participants should be allowed to submit automated quotations that lock or cross manual 
quotations. ${ }^{431}$ In the Reproposing Release, the Commission reproposed restrictions on the practice of displaying locking or crossing quotations, but, consistent with its approach in the reproposed Order Protection Rule, modified the proposal to allow automated quotations to lock or cross manual quotations. Rule 610(d) as reproposed thereby addressed the concern that manual quotations may not be fully accessible and recognized that allowing automated quotations to lock or cross manual quotations may provide useful market information.

Most of the commenters who addressed the issue supported the proposed restrictions on locking and crossing quotations. ${ }^{432}$ They generally agreed that the practice of displaying quotations that lock or cross previously displayed quotations is inconsistent with fair and orderly markets and detracts from market efficiency. One noted, for example, that locked and crossed markets "can be a sign of an inefficient market structure" and "may create confusion for investors, as it is unclear under such circumstances what is the true trading interest in a stock."433 Another commenter stated that "[p]ricing rationality is disrupted by locked and crossed markets, and efforts should be taken to reduce the incidence of such disruptions." ${ }^{434}$ Some commenters asserted that locked markets often occur when a market participant deliberately posts a locking quotation to avoid paying a fee to access the quotation of another market and to receive a

$431 \quad$ Supplemental Release, 69 FR at 30147.

432 Amex Letter, Exhibit A at 27-28; Letter from Steve Swanson, Chief Executive Officer \& President, Automated Trading Desk, LLC, to Jonathan G. Katz, Secretary, Commission, dated June 30, 2004 ("ATD Letter") at 3; Brut Letter at 17; BSE Letter at 13; Citigroup Letter at 14; E*Trade Letter at 10; ICI Letter at 18; JP Morgan Letter at 6; Nasdaq Letter II at 23-24; NYSE Letter, Attachment at 9; SIA Letter at 19-20; STA Letter at 6; STANY Letter at 8; UBS Letter at 9-10.

$433 \quad$ ICI Letter at 18.

$434 \quad$ Deutsche Bank Reproposal Letter at 3. 
liquidity rebate for an execution against its own displayed quotation. ${ }^{435}$ Nasdaq submitted data regarding the frequency of locked and crossed markets. During a one-week period in March 2004, it found that markets for Nasdaq stocks were locked or crossed an average of 509,018 times each day, with an average of 194,638 of the locks and crosses lasting more than 1 second and an average duration of all locks and crosses of 3.1 seconds. ${ }^{436}$ Nasdaq stocks currently are not subject to provisions discouraging intermarket locking or crossing quotations such as those contained in the ITS Plan.

Several commenters specifically supported the modification to allow automated quotations to lock or cross manual quotations. ${ }^{437}$ One commenter stated that market participants should not be forced to seek out slow, uncertain executions before being permitted to offer liquidity at prices they find acceptable. ${ }^{438}$

435 Amex Letter, Exhibit A at 27-28; ATD Reproposal Letter at 5; ICI Letter at 18; Nasdaq Letter II at 23.

$436 \quad$ Nasdaq Letter II at 23. One commenter pointed to this data as support for not prohibiting locked and crossed markets, since 314,380 of the 509,018 locks or crosses lasted less than one second, even without a rule. Letter from Edward J. Joyce, President and Chief Operating Officer, Chicago Board Options Exchange, Incorporated, to Jonathan G. Katz, Secretary, Commission, dated February 14, 2005 ("CBOE Reproposal Letter") at 7.

437 Citigroup Reproposal Letter at 4; Nasdaq Reproposal Letter at 18; SIA Reproposal Letter at 23.

$438 \quad$ Nasdaq Reproposal Letter at 18. 
A few commenters opposed restricting the practice of locking or crossing quotations. ${ }^{439}$ They generally believed that the proposal would impair market transparency and efficiency, such as by prohibiting the display of information as to the true level of trading interest or information that a particular market's quotations may be inaccessible. One commenter identified a number of causes, apart from access fees and liquidity rebates, which could lead to locked and crossed markets. ${ }^{440}$ These included determinations by market participants that quotations displayed by a locked or crossed market are not truly accessible, decisions by market participants that the potential disadvantages of routing away outweigh the potential advantages (e.g., loss of execution priority on the market place currently displaying the order), and decisions by market participants to exclusively use a particular market to run a trading strategy, even at the risk of missing some trading opportunities. One commenter stated that providing an exception from the restrictions for manual quotations would do little to mitigate the negative impact of the restrictions on market transparency and efficiency. ${ }^{441}$

The Commission recognizes that Rule 610(d), by restricting locked markets with respect to automated quotations, can prohibit the display of an order that would otherwise have been displayed and reduced the quoted spread to zero. However, although locked markets do occur a certain percentage of the time, they do not occur all the time, even in extremely active stocks,

439 CBOE Reproposal Letter at 1-4; Letter from Linda Lerner, General Counsel, Domestic Securities, Inc., to Jonathan G. Katz, Secretary, Commission, dated September 9, 2004 ("Domestic Securities Letter") at 2-3; Hudson River Trading Letter at 5-6; Instinet Reproposal Letter at 3,11; Letter from Michael J. Simon, Senior Vice President \& Secretary, International Securities Exchange, Inc., to Jonathan G. Katz, Secretary, Commission, dated June 30, 2004 ("ISE Letter") at 7-8; Tower Research Letter at 6-8; Tradebot Reproposal Letter at 1.

440 Instinet Letter at 39.

441 Instinet Reproposal Letter at 3. 
and thus the average effective spread in these stocks typically is between one-half cent and one cent (one cent being the minimum price increment for all but a very few stocks). Thus, the Commission believes that any widening of average effective spreads caused solely by the adopted rule will be limited to the difference between a sub-penny and penny spread. In addition, a locked market currently may not actually represent two market participants willing to buy and sell at the same price. Often, the locking market participant is not truly willing to trade at the displayed locking price, but instead chooses to lock rather than execute against the alreadydisplayed quotation to receive a liquidity rebate. ${ }^{442}$

The Commission agrees with commenters supporting the proposal that an automated quotation is entitled to protection from locking or crossing quotations. When two market participants are willing to trade at the same quoted price, giving priority to the first-displayed automated quotation will encourage posting of quotations and contribute to fair and orderly markets. The basic principle underlying the NMS is to promote fair competition among markets, but within a system that also promotes interaction between all of the buyers and sellers in a particular NMS stock. Allowing market participants simply to ignore accessible quotations in other markets and routinely display locking and crossing quotations is inconsistent with this principle. The Rule will, however, not prohibit automated quotations from locking or crossing manual quotations, thereby permitting market participants to reflect information regarding the inaccessibility of a particular trading center's quotations.

Two commenters requested that the Commission include an exception to the locked and crossed requirements for system malfunctions and material delays, and one commenter requested that the Commission include an exception for flickering quotations, similar to the exceptions

442 See supra, note 435. See also AFB Comment Letter at 9; Schwab Comment Letter at 17. 
proposed for the Order Protection Rule. ${ }^{43}$ The SIA also requested that the Commission further clarify the operation of the "ship and post" procedures. ${ }^{444}$ The Commission believes that it would be reasonable for the SROs to include in their rules implemented pursuant to Rule 610(d) exceptions equivalent to those included in the Order Protection Rule. ${ }^{445}$ The Commission intends to work closely with the SROs and other industry participants during the implementation period for Regulation NMS to achieve reasonable industry-wide standards for SRO rules relating to locked and crossed markets. In addition, such rules must be filed for Commission approval, thereby providing an opportunity for public notice and comment.

\section{B. Description of Adopted Rule}

Paragraphs (a) and (b) of Rule 610 address access to all quotations displayed by an SRO trading facility or by an SRO display-only facility. Paragraph (c) addresses the fees charged for access to protected quotations, and paragraph (d) addresses locking and crossing quotations. The Commission also is extending the scope of the fair access requirements of Regulation ATS as proposed and reproposed.

\section{Access to Quotations}

443 Nasdaq Reproposal Letter at 18; SIA Reproposal Letter at 23.

$444 \quad$ SIA Reproposal Letter at 23.

445 Specifically, such exceptions would be included within SRO rules adopted pursuant to Rule 610(d) that require their members to reasonably avoid displaying quotations that lock or cross a protected quotation or displaying manual quotations that lock or cross any quotation in an NMS stock. The Commission notes that it has modified the language of Rule 610(d)(3) from the reproposal to clarify that, if an SRO's rules (as approved by the Commission) provide for reasonable exceptions to the locking and crossing requirements of Rule 610(d), the prohibition on its members engaging in a pattern or practice of displaying quotations that lock or cross any protected quotation in an NMS stock, or of displaying manual quotations that lock or cross any quotation in an NMS stock disseminated pursuant to an effective national market system plan, will not apply to the display of quotations that lock or cross any protected or other quotation as permitted by an applicable exception. 


\section{a. Quotations of SRO Trading Facilities}

Paragraph (a) of Rule 610 applies to quotations of an SRO trading facility. In Rule 600(b)(72), an SRO trading facility is defined as a facility operated by or on behalf of a national securities exchange or a national securities association that executes orders in securities or presents orders to members for execution. ${ }^{446}$ This definition therefore encompasses the trading facilities of each of the exchanges, as well as The NASDAQ Market Center. The term "quotation" is defined in Rule 600(b)(62) as a bid or an offer, and "bid" or "offer" is defined in Rule 600(b)(8) as the bid price or the offer price communicated by a member of a national securities exchange or national securities association to any broker or dealer or to any customer. Rule 610(a) therefore applies to the entire depth of book of displayed orders of an SRO trading facility, including reserve size as well as displayed size at each price.

Rule 610(a) prohibits an SRO from imposing unfairly discriminatory terms that prevent or inhibit any person from obtaining efficient access through a member of the SRO to the quotations in an NMS stock displayed by the SRO trading facility. This anti-discrimination standard is designed to give non-members indirect access to quotations through members. It is premised on fair and efficient access of SRO members themselves to the quotations of the SRO's trading facility. SRO member access currently is addressed by a series of provisions of the Exchange Act. Sections (6)(b)(4) and 15A(b)(5) provide that the rules of an exchange or association provide for the equitable allocation of reasonable dues, fees, and other charges among its members and other persons using its facilities, while Sections 6(b)(5) and 15A(b)(6) provide in part that its rules not be designed to permit unfair discrimination between customers,

446 The Commission has modified the definition of SRO trading facility in Rule 600(b)(72) to include the phrase "or on behalf of" after "operated by" to make clear that the term includes an SRO trading facility for which an exchange or association has contracted out the operation to a third party. 
brokers, or dealers. In addition, Sections 6(b)(1) and 15A(b)(2) of the Exchange Act require that an exchange or association must have the capacity to be able to carry out the purposes of the Exchange Act. Sections 6(b)(5) and 15A(b)(6) also require an exchange or association to have rules designed to remove impediments to and perfect the mechanism of a free and open market and a national market system. Section $11 \mathrm{~A}(\mathrm{a})(1)(\mathrm{C})$ provides that two of the objectives of a national market system are to assure the economically efficient execution of securities transactions and the practicability of brokers executing investors' orders in the best market. To achieve these objectives, an SRO's members - broker-dealers that have the right to trade directly on an SRO facility - must themselves have fair and efficient access to the quotations displayed on such facility.

Rule 610(a) builds on this existing access structure by prohibiting unfair discrimination that prevents or inhibits non-members from piggybacking on the access of members. In the absence of mandatory public linkages directly between markets, the ability to obtain indirect access is necessary to assure that non-members can readily access quotations to meet the requirements of the Order Protection Rule and to fulfill their duty of best execution. In general, any SRO rule or practice that treats orders less favorably based on the identity of the ultimate party submitting the order through an SRO member could violate Rule 610(a). Thus, for example, charging differential fees or reducing an order's priority based on the identity of a member's customer would be inconsistent with Rule 610(a).

Given the critical importance of indirect access to the private linkage approach incorporated in Rule 610(a), the Commission intends to review the current extent to which SRO members have fair and efficient access to quotations in NMS stocks that are displayed on an SRO trading facility (which term does not include the NASD's ADF, as discussed below). In 
this regard, we emphasize that the SROs with trading facilities cannot meet the access requirements of the Exchange Act simply by assuming direct access is available to trading centers that participate in the SRO trading facilities. Thus, if a trading center displays quotations on an SRO trading facility, but also provides direct access to such quotations, that SRO could not rely on the level of direct access to the non-SRO trading center to meet its Exchange Act responsibilities. An SRO trading facility must itself provide fair and efficient access to the quotations that are displayed as quotations of such SRO. Stated another way, an SRO trading facility cannot be used simply as a conduit for the display of quotations that cannot be accessed fairly and efficiently through the SRO trading facility itself. Accordingly, each SRO's facilities will be reviewed to determine whether they are able to meet the enhanced need for access under the adopted regulatory structure.

\section{b. Quotations of SRO Display-Only Facility}

Paragraph (b) of Rule 610 applies to all quotations displayed by an SRO display-only facility. The term "SRO display-only facility" is defined in Rule 600(b)(71) as a facility operated by or on behalf of a national securities exchange or national securities association that displays quotations in securities, but does not execute orders against such quotations or present 
orders to members for execution. ${ }^{447}$ For quotations in NMS stocks, this definition currently encompasses only the NASD's ADF. ${ }^{448}$

Paragraph (b)(1) of Rule 610 requires any trading center that displays quotations in NMS stocks through an SRO display-only facility to provide a level and cost of access to such quotations that is substantially equivalent to the level and cost of access to quotations displayed by SRO trading facilities. The phrase "level and cost of access" would encompass both (1) the policies, procedures, and standards that govern access to quotations of the trading center, and (2) the connectivity through which market participants can obtain access and the cost of such connectivity. As discussed in section III.A.1 above, trading centers that choose to display quotations in an SRO display-only facility will be required to bear the responsibility of establishing the necessary connections to afford fair and efficient access to their quotations. The nature and cost of these connections for market participants seeking to access the trading center's quotations would need to be substantially equivalent to the nature and cost of connections to

$447 \quad$ The term "SRO trading facility" is defined in Rule 600(b)(72) to mean a facility operated by or on behalf of a national securities exchange or a national securities association that executes orders in a security or presents orders to members for execution. The Commission has included the phrase "to members" after the phrase "or present orders" in the definition of "SRO display-only facility" in Rule 600(b)(71) as adopted to conform it to the definition of SRO trading facility. The Commission also has modified the definition of SRO display-only facility to include the phrase "or on behalf of" after "operated by" to make clear that the term includes an SRO trading facility for which an exchange or association has contracted out the operation to a third party.

448 The Commission notes that Rule 610(b)(1) applies to all quotations displayed on an SRO display-only facility, even if the trading center also displays quotations in an SRO trading facility. To preclude the consolidated data stream from giving a misleading indication of available liquidity, separate quotations displayed on an SRO trading facility and an SRO display-only facility must each be fully accessible. 
SRO trading facilities. ${ }^{449}$ In recent years, a variety of different types of entities have entered the business of providing connections for brokers and market participants to different trading centers. The Commission anticipates that ADF participants will take advantage of linking to these service providers to establish the necessary connectivity.

The NASD, as the self-regulatory authority responsible for enforcing compliance by ADF participants with the requirements of the Exchange Act, will need to evaluate the connectivity of ADF participants to determine whether it meets the requirements of Rule 610(b)(1). Prior to implementation of Rule 610, the NASD will need to make an affirmative determination that existing ADF participants are in compliance with the requirements of the Rule. ${ }^{450}$ If an ADF participant is not complying with these access standards, the NASD would have a responsibility to stop publishing the participant's quotations until the participant comes into compliance. ${ }^{451}$ The Commission also believes that the addition of a new ADF participant would constitute a material aspect of the operation of the NASD's facilities, and thus require the filing of a proposed rule change pursuant to Section 19(b) of the Exchange Act that would be subject to public notice and comment. ${ }^{452}$

Paragraph (b)(2) of Rule 610 prohibits any trading center that displays quotations through an SRO display-only facility from imposing unfairly discriminatory terms that prevent or inhibit any person from obtaining efficient access to such quotations through a member, subscriber, or

449 As stated above in section III.A.1, this requirement does not apply on an absolute basis, but instead applies on a per-transaction basis to reflect the costs relative to the ADF participant's trading volume.

450 See Section 15A of the Exchange Act, 15 U.S.C. 78ㅁ-3.

$451 \quad \underline{\text { Id. }}$.

452 See Rule 19b-4(b)(1) under the Exchange Act, 17 CFR 240.19b-4(b)(1). 
customer of the trading center. This prohibition parallels the prohibition in Rule 610(a) that applies to the quotations of SRO trading facilities. ${ }^{453}$ Thus, a trading center's differential treatment of orders based on the identity of the party ultimately submitting an order through a member, subscriber, or customer of such trading center generally is inconsistent with this Rule.

\section{Limitation on Access Fees}

Rule 610(c) limits the fees that can be charged for access to protected quotations and manual quotations at the best bid and offer. It provides that a trading center shall not impose, nor permit to be imposed, any fee or fees for the execution of an order against a protected quotation of the trading center or against any other quotation of the trading center that is the best bid or best offer of a national securities exchange, the best bid or best offer of The Nasdaq Stock Market, Inc., or the best bid or best offer of a national securities association other than the best bid or best offer of The Nasdaq Stock Market, Inc. in an NMS stock ("BBO quotations") that exceed or accumulate to more than $\$ 0.003$ per share or, for its protected quotations and BBO quotations with a price of less than $\$ 1.00$, that exceed or accumulate to more than $0.3 \%$ of the quotation price per share. Thus, the scope of Rule 610(c) is limited to the price of the best bid and offer, whether automated or manual, of each exchange, The NASDAQ Market Center, and the ADF. When triggered, the fee limitation of Rule 610(c) will apply to any order execution at the displayed price of the protected quotation or the BBO quotation. It therefore would encompass executions against both the displayed size and any reserve size at the price of those quotations.

Rule 610(c) encompasses a wide variety of fees currently charged by trading centers, including both the fees commonly known as access fees charged by ECNs and the transaction

$453 \quad$ Moreover, as with paragraph (a) of Rule 610, paragraph (b) applies to both the displayed and reserve size of the displayed quotations of an SRO display-only facility. 
fees charged by SROs. So long as the fees are based on the execution of an order against a protected quotation or a BBO quotation, the restriction of Rule 610(c) will apply. Conversely, fees not triggered by the execution of orders against protected quotations or BBO quotations (e.g., certain periodic fees such as monthly or annual fees) generally will not be included.

In addition, Rule 610(c) encompasses any fee charged directly by a trading center, as well as any fee charged by market participants that display quotations through the trading center's facilities. Nothing in Rule 610(c) will preclude an SRO or other trading center from taking action to limit fees beyond what is required by the Rule, and trading centers will have flexibility in establishing their fee schedules to comply with Rule 610(c). In particular, trading centers could impose a limit on the fees that market participants are permitted to charge for quotations that are accessed through a trading center's facilities. For example, Nasdaq has adopted such a limit for quotations displayed by The NASDAQ Market Center. ${ }^{454}$

The Commission believes that it is consistent with the Quote Rule for market makers to charge fees for access to their quotations, so long as such fees meet the requirements of Rule 610(c). In particular, market makers will be permitted to charge fees for executions of orders against their quotations irrespective of whether the order executions are effected on an SRO trading facility or directly by the market maker.

\section{Locking or Crossing Quotations}

Rule 610(d) restricts locking or crossing quotations, but recognizes that locked and crossed markets can occur accidentally, especially given the differing speeds with which trading centers update their quotations. It requires that each national securities exchange and national

$454 \quad$ NASD Rule 4623(b)(6). 
securities association establish, maintain, and enforce written rules that: ${ }^{455}$ (1) require its members to reasonably avoid displaying quotations that lock or cross any protected quotation in an NMS stock, or of displaying manual quotations that lock or cross any quotation in an NMS stock disseminated pursuant to an effective national market system plan; (2) are reasonably designed to assure the reconciliation of locked or crossed quotations in an NMS stock; and (3) prohibit its members from engaging in a pattern or practice of displaying quotations that lock or cross any protected quotation in an NMS stock, or of displaying manual quotations that lock or cross any quotation in an NMS stock disseminated pursuant to an effective national market system plan, other than displaying quotations that lock or cross any protected or other quotation as permitted by an exception contained in the SRO's rules established pursuant to (1). Of course, the SRO's locking and crossing rules should apply only to its own quoting facility.

Rule 610(d) distinguishes between protected (and therefore automated) ${ }^{456}$ quotations and manual quotations. Protected quotations can not be intentionally crossed or locked by any other quotations. Manual quotations, in contrast, can be locked or crossed by automated quotations, but can not themselves intentionally lock or cross any other quotations included in the consolidated data stream, whether automated or manual. Recognizing that quotations may on occasion accidentally lock or cross other quotations, Rule 610(d) requires members to "reasonably avoid" locking and crossing and prohibits a "pattern or practice" of locking or crossing quotations where this can reasonably be avoided. SRO rules can include so-called "ship and post" procedures that require a market participant to attempt to execute against a relevant

455 The Commission has modified the language of adopted Rule 610(d) to require that an exchange or association "establish, maintain, and enforce" such rules, and to clarify that such rules must be written, to conform the language to the operative language of Rule 611(a)(1).

456 Under Rule 600(b)(57), only automated quotations can qualify as protected quotations. 
displayed quotation while posting a quotation that could lock or cross such a quotation. Finally, Rule 610(d)(2) requires that each SRO's rules be reasonably designed to enable the reconciliation of locked or crossed quotations in an NMS stock. Such rules must require the market participant responsible for displaying the locking or crossing quotation to take reasonable action to resolve the locked or crossed market. ${ }^{457}$

\section{Regulation ATS Fair Access}

The "fair access" standards of Rule 301(b)(5) of Regulation ATS ${ }^{458}$ require a covered ATS, among other things, to: (1) establish written standards for granting access on its system; and (2) not unreasonably prohibit or limit any person in respect to services offered by the ATS by applying its access standards in an unfair or discriminatory manner. As originally proposed and reproposed, the Commission is amending this section of Regulation ATS to lower the threshold that triggers the Regulation ATS fair access requirements from $20 \%$ of the average daily volume in a security to $5 \% .{ }^{459}$ Under the access approach adopted today, the fairness and efficiency of private linkages will assume heightened importance. A critical component of

457 The Commission notes that the requirement in Rule 610(d)(1) that an SRO establish, maintain, and enforce rules that require its members reasonably to avoid engaging in certain activity relating to locking and crossing of displayed quotations may appear to be similar to the language contained in Section 8(d)(i) of the existing ITS Plan that "[t]he Participants also agree that "locked markets" in System securities should be avoided." The Commission emphasizes, however, that the intent and meaning of Rule 610(d) is more strict and comprehensive than the ITS Plan provision. In particular, as noted above, Rule 610(d) requires SROs to restrict their members' ability to engage in locking and crossing activity. The Commission therefore believes that most existing SRO rules established to implement the locked and crossed provision of the ITS Plan likely would not be sufficient to comply with Rule 610(d).

$458 \quad 17$ CFR 242.301(b)(5).

459 The Regulation ATS fair access requirements are triggered on a security-by-security basis for equity securities. See Securities Exchange Act Release No. 40760 (Dec. 8, 1998), 63 FR 70844, 70873 (Dec. 22, 1998). 
private linkages is the ability of interested market participants to become members or subscribers of a trading center, particularly those trading centers with significant trading volume. As discussed in section III.A.1 above, market participants then may use their membership or subscribership access as a means for others to obtain indirect access by piggybacking on the direct access of members or subscribers. The Commission therefore believes that it is appropriate to lower the fair access threshold of Regulation ATS. ${ }^{460}$ Lowering the threshold for paragraph (b)(5) of Rule 301 also makes its coverage consistent with the 5\% threshold triggering the order display and execution access requirements of Rule 301(b)(3). As a result, each ATS required to disseminate its quotations in the consolidated data stream also will be prohibited from unreasonably limiting market participants from becoming a subscriber or customer. Aside from lowering the threshold, the substantive requirements of Rule 301(b)(5) are left unchanged.

One commenter, Liquidnet, argued that the fair access standards of Regulation ATS should not apply to systems that display orders only to one other system subscriber, such as through a negotiation feature. ${ }^{461}$ Among other things, Liquidnet maintained that the fair access requirement should not apply to it because, in essence, it is an institutional block trading desk

$460 \quad$ One commenter opposed the proposal to lower the threshold for Regulation ATS fair access, primarily because it largely acts as an agency broker that routes orders to other venues. Bloomberg Tradebook Letter at 7. The Commission believes that ATSs, which by definition have chosen to offer market functions beyond mere agency routing, would appropriately be subject to regulatory requirements that reflect such functions. Commenters on the Proposing and Reproposing Releases supported the proposal to lower the fair access threshold. See, e.g. Amex Letter at 28-29; Citigroup Reproposal Letter at 3; E*TRADE Letter at 10; ICI Letter at 4; Instinet Reproposal Letter at 3,12; Morgan Stanley Letter at 17-18; Merrill Lynch Reproposal Letter at 9; Nasdaq Reproposal Letter at 17; Specialist Assoc. Letter at 11; UBS Letter at 9.

461 See letter to Jonathan G. Katz, Secretary, Commission, from Seth Merrin, Chief Executive Officer, Liquidnet Inc., dated January 26, 2005 ("Liquidnet Reproposal Letter") at 3. 
that does not publish quotations. ${ }^{462}$ By its terms, Rule 301(b)(5) of Regulation ATS will apply to Liquidnet. However, the Commission believes that some form of exemptive relief under Section 36 of the Exchange Act may be appropriate to maintain the fair access threshold at $20 \%$ for an ATS, such as Liquidnet, that, among other things, limits its business to institutional block trading and does not disseminate quotations. The Commission intends to consider this matter further during the implementation period for Regulation NMS.

\section{Sub-Penny Rule}

The Commission today is adopting Rule 612 under the Exchange Act ${ }^{463}$ which will govern sub-penny quoting of NMS stocks. Rule 612 imposes new requirements on any bid, offer, order, or indication of interest that is displayed, ranked, or accepted by a national securities exchange, national securities association, ATS, vendor, or broker-dealer. The Commission is adopting Rule 612 as it was reproposed in December 2004 with only a few minor amendments for clarity.

\section{A. Background}

In June 2000, the Commission issued an order directing NASD and the national securities exchanges to act jointly in developing a plan to convert their quotations in equity securities and options from fractions to decimals. ${ }^{464}$ The June 2000 Order stated that the plan could fix the

\footnotetext{
462 See id.

$463 \quad 17$ CFR 242.612.

464 See Securities Exchange Act Release No. 42194 (June 8, 2000), 65 FR 38010 (June 19, 2000) ("June 2000 Order"). On January 28, 2000, the Commission had ordered NASD and the exchanges to facilitate an orderly transition to decimal pricing in the securities markets. See Securities Exchange Act Release No. 42360 (Jan. 28, 2000), 65 FR 5003 (Feb. 2, 2000) ("January 2000 Order"). In that order, the Commission set a timetable for NASD and the exchanges to begin trading some equity securities, and options on those securities, in decimals by July 3, 2000, and to begin trading all equities and options by January 3, 2001. See January 2000 Order, 65 FR at 5005. In April 2000, the
} 
minimum price variation ("MPV") during the phase-in period, provided the MPV was no greater than $\$ 0.05$ and no less than $\$ 0.01$ for any equity security. ${ }^{465}$ The June 2000 Order also required NASD and the exchanges to provide the Commission with studies analyzing how decimal conversion had affected systems capacity, liquidity, and trading behavior, including an analysis of whether there should be a uniform MPV. ${ }^{466}$ The Commission stated that, if NASD or an exchange wished to move to quoting stocks in an increment less than $\$ 0.01$, its study should include a full analysis of the potential impact on the market requesting the change and on the markets as a whole. ${ }^{467}$ Furthermore, the Commission required each SRO to propose a rule change under Section 19(b) of the Exchange Act ${ }^{468}$ to establish its individual choice of MPV for securities traded on its market. ${ }^{469}$ NASD and the exchanges complied with these requirements, and in August 2002 the Commission approved rule changes from all of these SROs to establish an MPV of $\$ 0.01$ for equity securities. ${ }^{470}$

Commission issued another order staying the original deadlines for decimalization. See Securities Exchange Act Release No. 42685 (Apr. 13, 2000), 65 FR 21046 (Apr. 19, 2000).

465 See June 2000 Order, 65 FR at 38013. The June 2000 Order also required that at least some equity securities be quoted in minimum increments of $\$ 0.01$. See $\underline{\text { id. }}$

466 See id.

$467 \quad$ See $\underline{\text { id. }}$

$468 \quad 15$ U.S.C. 78 s(b).

469 See June 2000 Order, 65 FR at 38013.

$470 \quad$ See Securities Exchange Act Release No. 46280 (July 29, 2002), 67 FR 50739 (Aug. 5, 2002) ("August 2002 Order") (approving SR-Amex-2002-02, SR-BSE-2002-02, SR-CBOE-2002-02, SR-CHX-2002-06, SR-CSE-2002-02, SR-ISE-2002-06, SR-NASD-2002-08, SR-NYSE-2002-12, SR-PCX-2002-04, and SR-Phlx-2002-05). 
Between the June 2000 Order and the August 2002 Order, the Commission issued a Concept Release seeking public comment on the potential impact of sub-penny pricing, ${ }^{471}$ including its effect on: (1) price clarity (e.g., the potential to cause ephemeral or "flickering" quotations); (2) market depth (i.e., the number of shares available at a given price); (3) compliance with the Order Handling Rules and other price-dependent rules; and (4) the operations and capacity of automated systems. ${ }^{472}$ The Commission received 33 comments on the Concept Release. ${ }^{473}$ The majority of commenters opposed sub-penny pricing. Some stated that the negative effects of decimal trading would be exacerbated by further reducing the MPV, without meaningfully reducing spreads or securing other benefits for the markets or investors. ${ }^{474}$ These commenters recommended that all securities have an MPV of at least a penny. ${ }^{475} \mathrm{~A}$ smaller number of commenters believed that the forces of competition, rather than regulation by the Commission or Congress, should determine the MPV. ${ }^{476}$ These commenters suggested that a smaller MPV could improve market efficiency and provide investors with greater opportunity for price improvement. They argued generally that the problems accompanying decimals could be resolved through technology enhancements, rather than through regulation.

471 Securities Exchange Act Release No. 44568 (July 18, 2001), 66 FR 38390 (July 24, 2001) ("Concept Release").

472 See 66 FR at 38391-95.

473 For a list of the commenters, see Proposing Release, 69 FR at 11165.

474 See id.

475 However, some commenters that opposed sub-penny quoting thought that trading in subpennies should be permitted. See $\underline{\text { id. }}$

$476 \quad$ See id. at 11165-66. 
In August 2003, Nasdaq submitted a proposed rule change to the Commission to adopt an MPV of $\$ 0.001$ for Nasdaq-listed securities. ${ }^{477}$ Nasdaq stated that, unless and until a uniform MPV were established, it felt compelled to implement an MPV of $\$ 0.001$ to remain competitive with ECNs that permit their subscribers to quote in sub-pennies. At the same time, Nasdaq filed a petition for Commission action urging the Commission "to adopt a uniform rule requiring market participants to quote and trade Nasdaq securities in a consistent monetary increment ... with the exception of average price trades." ${ }^{478}$

\section{B. Commission Proposal and Reproposal on Sub-Penny Quoting}

In February 2004, the Commission proposed new Rule 612 that would govern sub-penny quoting as part of the overall Regulation NMS proposal. In the initial Proposing Release, the Commission summarized the conversion of the U.S. securities markets from fractional to decimalized trading and stated its view that, on balance, the benefits of decimalization have justified the costs. The Commission cautioned, however, that if the MPV were to decrease beyond a certain level, the potential costs to investors and the markets could at some point surpass any potential benefits. ${ }^{479}$ To address this concern, Rule 612 as proposed would have prohibited any national securities exchange, national securities association, ATS, vendor, or broker-dealer from displaying, ranking, or accepting from any person a bid, offer, order, or indication of interest in an NMS stock priced in an increment less than $\$ 0.01$ per share. This restriction would not have applied to any NMS stock the share price of which is below $\$ 1.00$.

$477 \quad$ See SR-NASD-2003-121. Nasdaq has since withdrawn this proposal.

478 Letter to Jonathan G. Katz, Secretary, Commission, from Edward S. Knight, Executive Vice President, Nasdaq, dated August 4, 2003 ("Nasdaq Petition").

$479 \quad$ See Proposing Release, 69 FR at 11165. 
The proposed rule was designed to limit the ability of a market participant to gain execution priority over a competing limit order by stepping ahead by an economically insignificant amount. In issuing the sub-penny proposal, the Commission cited research performed by OEA showing a high incidence of sub-penny trades that cluster around the $\$ 0.001$ and $\$ 0.009$ price points. The OEA study concluded that this phenomenon resulted from market participants attempting to step ahead of competing limit orders for the smallest economic increment possible. $^{480}$

In the Proposing Release, the Commission pointed to a variety of additional problems caused by sub-penny quoting, including the following:

- If investors' limit orders lose execution priority for a nominal amount, investors may over time decline to use them, thus depriving the markets of liquidity.

- When market participants can gain execution priority for an infinitesimally small amount, important customer protection rules such as exchange priority rules and NASD's Manning rule ${ }^{481}$ could be rendered meaningless. Without these protections, professional traders would have more opportunity to take advantage

$480 \quad$ See $69 \mathrm{FR}$ at $11169-70$.

481 See NASD IM-2110-2 (generally requiring that a member firm that accepts and holds an unexecuted limit order from its customer in a Nasdaq security and that continues to trade the subject security for its own market-making account at prices that would satisfy the customer's limit order, without executing that limit order, shall be deemed to have acted in a manner inconsistent with just and equitable principles of trade). The impetus for this rule was a case brought by a customer of an NASD member firm, William Manning, who alleged that the firm had accepted his limit order, failed to execute it, and violated its fiduciary duty to him by trading ahead of the order. In the Manning decision, In re E.F. Hutton \& Co., Exchange Act Release No. 25887 (July 6, 1988), the Commission affirmed NASD's finding that a member firm, upon acceptance of a customer's limit order, undertakes a fiduciary duty to its customer and cannot trade for its own account at prices more favorable than the customer's order. 
of non-professionals, which could result in the latter either losing executions or receiving executions at inferior prices.

- $\quad$ Flickering quotations that can result from widespread sub-penny pricing could make it more difficult for broker-dealers to satisfy their best execution obligations and other regulatory responsibilities. The best execution obligation requires a broker-dealer to seek for its customer's transaction the most favorable terms reasonably available under the circumstances. ${ }^{482}$ This standard is premised on the practical ability of the broker-dealer to determine whether a displayed price is reasonably obtainable under the circumstances.

- $\quad$ Widespread sub-penny quoting could decrease market depth (i.e., the number of shares available at the NBBO) and lead to higher transaction costs, particularly for institutional investors (such as pension funds and mutual funds) that are more likely to place large orders. These higher transaction costs would likely be passed on to retail investors whose assets are managed by the institutions.

- $\quad$ Decreasing depth at the inside also could cause such institutions to rely more on execution alternatives away from the exchanges and Nasdaq that are designed to help larger investors find matches for large blocks of securities. Such a trend could increase fragmentation of the securities markets.

In the Reproposing Release, the sub-penny rule was fundamentally unchanged although the Commission made certain minor modifications in response to the comments received on the (Sept. 12, 1996) (adopting the Commission's Order Handling Rules). A broker-dealer's duty of best execution derives from common law agency principles and fiduciary obligations and is incorporated in SRO rules and, through judicial and Commission decisions, the antifraud provisions of the federal securities laws. See $\underline{\text { id. }}$ 
Proposing Release. These modifications in reproposed Rule 612 would have: (1) based the subpenny restriction on the price of the quotation rather than the price of the NMS stock itself; and (2) limited a quotation priced less than $\$ 1.00$ per share to four decimal places.

\section{Comments Received}

The Commission sought comment on all aspects of reproposed Rule 612. Of the total comments that the Commission received in response to the Reproposing Release, approximately 33 commenters addressed the sub-penny rule. The majority of these commenters supported a restriction on sub-penny quoting. ${ }^{483}$ One commenter argued that sub-penny quoting would too easily permit market professionals to step ahead of competing limit orders by an economically insignificant amount. ${ }^{484}$ Another commenter stated that "[t]oday, SROs are held to minimum quoting increments, while other market centers are not, and this arbitrage should be

See Ameritrade Reproposal Letter at 10; Angel Reproposal Letter at 6; Archipelago Reproposal Letter at 15; ATD Letter at 4; Barclays Global Investors Reproposal Letter at 4; Bennett Letter at 1; BSE Reproposal Letter at 2; Citigroup Reproposal Letter at 8-9; DBSI Reproposal Letter at 3; Financial Information Forum Reproposal Letter at 3; Financial Services Roundtable Reproposal Letter at 5; GETCO Reproposal Letter at 1; Harris Letter at 3-4; JPMSI Reproposal Letter at 2; Knight Reproposal Letter at 6; Lerro Reproposal Letter, Appendix A, at 1; Merrill Lynch Reproposal Letter at 9-10; Nasdaq Reproposal Letter at 20; e-mail from Chris Sexton to William H. Donaldson, Chairman, Commission, dated January 31, 2005; SIIA/FISD Reproposal Letter at 4-5; STA Reproposal Letter at 7-8; STANY Reproposal Letter at 2; T. Rowe Price Reproposal Letter at 3; UBS Reproposal Letter at 1 . See also Morgan Stanley Reproposal Letter at 13 (suggesting that "a reasonable compromise" would be to allow sub-penny quotations for the sole purpose of reflecting an access fee but to prohibit them in all other circumstances); SIA Reproposal Letter at 23 (supporting reproposed Rule 612 while noting that a minority of SIA members believe that Commission rulemaking in this area is not necessary).

484 See Knight Reproposal Letter at 6. This comment echoed similar comments in response to the initial Proposing Release. See, e.g., Ameritrade Letter at 10; Archipelago Letter at 14; ATD Letter at 3; Bloomberg Tradebook Letter at 2; Citadel Letter at 9; Citigroup Letter at 14; ICI Letter at 7-8; Tullo Letter at 8. 
eliminated." ${ }^{485}$ A third commenter offered a similar perspective, stating that the sub-penny prohibition "will prevent renegade systems from allowing a minority of traders to exploit the majority" that do not offer sub-penny quoting. ${ }^{486}$

Three commenters argued that, in the absence of a general prohibition on sub-penny quoting, market data systems would be severely taxed. ${ }^{487}$ One commenter - a trade organization that addresses issues relating to market data and securities processing automation - doubted "whether the impact of sub-penny quoting and trading on rising infrastructure costs is adequately offset by market quality benefits to investors and market participants." ${ }^{\text {"88 }}$ A second commenter stated that an industry-wide shift to sub-penny quoting would "forc[e] the industry into another round of substantial capital investments to accommodate the quote traffic." ${ }^{\text {"89 }}$ A third commenter echoed that view, stating that the new rule "will protect industry systems from significant data traffic that has little benefit to investors or to the industry." ${ }^{490}$

\footnotetext{
485 Archipelago Reproposal Letter at 15.

$486 \quad$ Harris Letter at 4.

$487 \quad$ See Financial Information Forum Reproposal Letter at 3; Knight Reproposal Letter at 6; SIIA/FISD Reproposal Letter at 5 . These comments echoed similar comments on the initial Proposing Release. See Financial Information Forum Letter at 2-3; Financial Services Roundtable Letter at 6; Knight Letter at 7; Lehman Brothers Letter at 5; Reuters Letter at 4.

488 SIIA/FISD Reproposal Letter at 5.

$489 \quad$ Knight Reproposal Letter at 6.

$490 \quad$ Financial Information Forum Reproposal Letter at 3.
} 
A few commenters on the Reproposing Release opposed Rule $612,{ }^{491}$ as did a minority of commenters on the initial Proposing Release. ${ }^{492}$ Some commenters argued that quoting in subpennies should be permitted because it increases liquidity, lowers trading costs, and promotes efficient pricing in the equity markets. ${ }^{493}$ Two commenters believed that government intervention was not appropriate, as market forces should address this issue. ${ }^{494}$ Alternatively, one commenter who objected to reproposed Rule 612 argued that "[t]he appropriate MPV in the equities market is at least [a] nickel or some reasonable, tiered alternative." ${ }^{495}$

One commenter on the Reproposing Release - INET, an ECN that currently offers its users the ability to quote certain NMS stocks in sub-pennies - argued generally that "the various

491 See letter from Alex Goor, President, INET ATS, Inc. to Jonathan G. Katz, Secretary, Commission, dated January 26, 2005 ("INET Reproposal Letter"); Instinet Reproposal Letter at 17-18; Malureanu E-mail (no page numbers); NexTrade Reproposal Letter at 12.

492 See Brut Letter at 24; Domestic Securities Summary of Intended Testimony (no page numbers); GETCO Letter (no page numbers); memorandum to File No. S7-10-04 from Susan M Ameel, Counsel to Commissioner Atkins, dated August 20, 2004 (meeting with Hudson River Trading) (no page numbers); Instinet Letter at 50; King Letter at 1; Mercatus Center Letter at 7; NexTrade Letter at 9-10; Reg NMS Study Group Letter at 9; Tower Research Letter at 8; Vie Securities Letter at 3. In addition, one commenter submitted a study on sub-penny pricing shortly before the Commission approved the Reproposing Release for publication. See also e-mail from Dr. Bidisha Chakrabarty, Assistant Professor, John Cook School of Business, Saint Louis University, to marketreg@sec.gov, dated December 1, 2004, enclosing two articles, "Can sub-penny pricing reduce trading costs?" ("Chakrabarty and Chung Study") and "One tick fits all? A study of the Island and Instinet ECN merger" ("Chakrabarty and Tripathi Study"). While not explicitly opposing the sub-penny proposal, the studies argued that a general prohibition on sub-penny quoting would keep spreads artificially high for many securities.

493 See Hudson River Trading Testimony (no page numbers); GETCO Letter (no page numbers).

$494 \quad$ See Instinet Letter at 50; Tower Research Summary of Intended Testimony (no page numbers).

$495 \quad$ NexTrade Reproposal Letter at 12. 
marketplaces ... are better positioned than regulators to evaluate the most appropriate trading increment." ${ }^{496}$ In addition, INET maintained that the existing penny MPV exacerbates larger market structure problems, such as internalization and payment for order flow, ${ }^{497}$ stating that "the convention of only quoting in pennies creates what is in effect an underground market where better prices are remitted back to certain firms through payment for order flow relationships but not reflected in any quotation. ${ }^{498}$ Furthermore, INET presented specific examples where, it claimed, moving from penny to sub-penny quoting reduced spreads. ${ }^{499}$

After careful consideration of all comments received, the Commission is adopting Rule 612 as reproposed, with only a few minor amendments for clarity. The Commission notes that a large majority of commenters on both the Reproposing Release ${ }^{500}$ and the initial Proposing Release ${ }^{501}$ supported a sub-penny quoting prohibition. The comments received have reinforced

$496 \quad$ See INET Reproposal Letter at 1.

497 INET observed, for example, that NYSE has less than a 50\% market share in Lucent Technologies and Nortel Networks, two NMS stocks trading below $\$ 5$ per share, even though NYSE's overall market share is approximately $80 \%$. INET attributed this phenomenon to the internalization of orders by other market centers that can readily match the BBO set by NYSE, because vigorous price competition - in the form of subpenny quotations - does not exist. See id. at 6.

Id. at 7.

499 For example, INET observed that, with a penny MPV, JD Uniphase (ticker: JDSU) regularly traded at a penny spread with large size quoted on both the bid and the ask. INET claimed that, immediately after reducing the MPV to $\$ 0.001$ on its system recently, the average spread in JDSU fell to a tenth of a penny and trades occurred "almost uniformly across each sub-penny increment" and were not clustered around the \$0.001 and $\$ 0.009$ price points. $\underline{\text { Id. at } 5 .}$

See supra, note 483.

501 See, e.g., Alliance of Floor Brokers Letter at 12; ACIM Letter at 2; Ameritrade Letter at 10; Archipelago Letter at 14; ATD Letter at 3-4; Bloomberg Tradebook Letter at 2; BNY Letter at 4; BSE Letter at 13-14; CBOE Letter at 7; Citadel Letter at 9; Citigroup Letter at 14-15; CSE Letter at 23; Denizkurt Letter (no page numbers); E*Trade Letter at 11; 
the Commission's preliminary view that there are substantial drawbacks to sub-penny quoting, and the Commission believes that a uniform rule banning this practice (except for quotations priced less than $\$ 1.00$ per share) is appropriate. Several commenters agreed with the Commission's view that sub-penny quotations can increase the incidence of quote flickering, which in turn may have adverse effects such as confusing investors or impeding a broker-dealer's ability to fulfill its duty of best execution. ${ }^{502}$

Moreover, the Commission agrees with the many commenters who believe that Rule 612 will deter the practice of stepping ahead of exposed trading interest by an economically insignificant amount. Limit orders provide liquidity to the market and perform an important price-setting function. The Commission is concerned that, if orders lose execution priority because competing orders step ahead for an economically insignificant amount, liquidity could diminish. As one commenter, the Investment Company Institute, stated, "[t]his potential for the increased stepping-ahead of limit orders would create a significant disincentive for market participants to enter any sizeable volume into the markets and would reduce further the value of displaying limit orders." 503

Financial Information Forum Letter at 2-3; Financial Services Roundtable Letter at 5-6; Goldman Sachs Letter at 10; ICI Letter at 19-20; ISE Letter at 8; JPMSI Letter at 6-7; Knight Letter at 7-8; Lava Letter at 5; Lehman Brothers Letter at 5; Liquidnet Letter at 8; LSC Letter at 11; Morgan Stanley Letter at 3; Nasdaq Letter at 1-2; NYSE Letter at 9-10; NSX Letter at 9; Peake Letter I at 13; Reuters Letter at 4; SBA Letter at 2; Schwab Letter at 17; SIA Letter at 20-21; Specialist Association Letter at 13-15; STA Letter at 7; STANY Letter at 13-14; UBS Letter at 10; Vanguard Letter at 6.

502 See, e.g., Citadel Letter at 9; ICI Letter at 7; Knight Letter at 7; Reuters Letter at 4; SIA Letter at 20-21.

ICI Letter at 20. 
Some commenters argued, however, that investors would suffer harm from the artificially wide spreads resulting from a prohibition on sub-penny quoting. ${ }^{504}$ One commenter stated, for example, that "the primary result of eliminating subpenny trading would be to preserve a minimum profit for market makers, and would result in significantly worse realized prices for the vast majority of market participants not in the business of making markets." ${ }^{505}$ These commenters offered various estimates of the costs of prohibiting sub-penny quoting. ${ }^{506}$ Even assuming that quoting in sub-penny increments would reduce spreads, the Commission continues to believe, on balance, that the costs of sub-penny quoting are not

$504 \quad$ See Chakrabarty and Chung Study at 24; INET Reproposal Letter at 3; Instinet Letter at 51; Mercatus Center Letter at 9; Tower Research Letter at 8.

505 Tower Research Letter at 8. Tower Research also criticized the Nasdaq and OEA studies on which the Commission relied in issuing the sub-penny proposal. Tower Research argued, for example, that the studies did not differentiate between sub-penny trades and sub-penny quotations, and that clustering of sub-penny trades around the $\$ 0.001$ and $\$ 0.009$ price points could result from sub-penny price improvement rather than quotation activity. In response to this comment, OEA reviewed the sources of data used in the original study and found that sub-penny trades cluster at these two price points in markets where trades necessarily result from quotations, such as ECNs, not only in markets where that is not necessarily the case. See Memorandum from Office of Economic Analysis, dated December 15, 2004 (available in Public File No. S7-10-04 and on the Commission's Internet Web site (http://www.sec.gov/rules/proposed/s71004.shtml)) ("OEA December 2004 Sub-Penny Analysis"). Accordingly, the Commission continues to believe that market participants frequently used their ability to quote in sub-pennies to step ahead of competing limit orders by the smallest possible amount.

506 See Chakrabarty and Chung Study at 24 (stating that, for high volume stocks, "the spread reduction in the absence of binding constraints ... translates into savings of millions of dollars"); INET Reproposal Letter at 3 (arguing that allowing sub-penny quoting in "23 of the most appropriate securities" would generate annual savings of anywhere between \$342 million and \$1.9 billion); Instinet Letter at 50 (arguing that, if all markets traded QQQQ solely in sub-pennies, the savings would be approximately $\$ 150$ million per year); Tower Research Letter at 9 (arguing that, just in six high-volume securities, the proposed rule would have would have costs of over $\$ 400$ million due to wider spreads). 
justified by the benefits. ${ }^{507}$ The Commission instead agrees with the commenters who believe that the substantial costs associated with sub-penny quoting - among others, disincentives to liquidity providers whose limit orders are jumped by an economically insignificant amount and the increased incidence of flickering quotes and the resulting regulatory compliance and capacity burdens - make the adoption of Rule 612 appropriate at this time.

Nevertheless, the Commission acknowledges the possibility that the balance of costs and benefits could shift in a limited number of cases or as the markets continue to evolve. Therefore, Rule 612 - as proposed and as adopted - includes a provision setting forth procedures for the Commission, by order, to exempt any person, security, or quotation (or any class or classes or persons, securities, or quotations) from the sub-penny quoting restriction if it determines that such exemption is necessary or appropriate in the public interest, and is consistent with the protection of investors. The Commission could grant such exemption either unconditionally or on specified terms and conditions.

507 The Commission notes that the few commenters who provided detailed, quantitative criticisms of the proposed sub-penny rule relied on a very small number of NMS stocks as examples. These cost estimates appear to assume that all trading in the securities they discuss would occur at narrower quoted spreads if Rule 612 did not exist. The Commission does not believe that the commenters provided any evidence to justify that assumption. Currently, Nasdaq and the national securities exchanges generally do not permit quoting in sub-pennies; this practice exists only a small number of ATSs, and only for a small number of securities. Because spreads on Nasdaq and the exchanges already cannot be smaller than $\$ 0.01$, Rule 612 will not require these markets to take any action that would cause their spreads to widen. Therefore, the Commission believes that the cost to these markets of not having sub-penny spreads should not be considered costs of the rule. Furthermore, the INET methodology for computing the potential savings to investors from quoting in sub-pennies appears to be based on the unjustified assumption that all of selected stocks in their sample would trade with the same price-point distribution as the average of JDSU, SIRI, and QQQQ. With respect to the ATSs that currently do permit some NMS stocks to be quoted in sub-pennies, the Commission staff has estimated that the gross costs of widened spreads in these securities will be approximately $\$ 48$ million annually (or approximately \$33 million if the Commission were to exempt QQQQ from Rule 612). See OEA December 2004 Sub-Penny Analysis. 
In the Proposing Release, the Commission requested comment on whether certain securities should be exempted from Rule $612 .{ }^{508}$ In particular, the Commission asked whether sub-penny quoting of exchange-traded fund shares ("ETFs"), which are derivatively priced, raised the same concerns as with other NMS stocks. ${ }^{509}$ Some commenters that addressed this issue argued that the sub-penny prohibition should apply to all NMS stocks, including ETFs. ${ }^{510}$ These commenters generally believed that sub-penny quoting raises the same type of concerns for ETFs as for other types of securities. ${ }^{511}$ Other commenters provided arguments that exemptions for at least certain securities would be appropriate. One commenter that opposed Rule 612 argued that, if the Commission nevertheless did approve the rule, it should provide an exemption for QQQQ and other ETFs. ${ }^{512}$ This commenter argued that these securities "uniquely lend[] themselves to subpenny quoting and trading" because "the[ir] derivative nature . . . enables investors to determine their true value at any point in time by calculating the aggregate price of the securities constituting a particular ETF." ${ }^{513}$ Other commenters, while not explicitly recommending that the Commission grant particular exemptions, argued that sub-penny quoting was reasonable for certain securities. ${ }^{514}$

\footnotetext{
$508 \quad$ See Proposing Release, 69 FR at 11172.

509 See id.

$510 \quad$ See Ameritrade Reproposal Letter at 10; Amex Letter, Exhibit A, at 29; Citigroup Reproposal Letter at 9; ICI Letter at 20; Knight Letter at 8; Morgan Stanley Letter at 21; NYSE Letter at 10; SIA Letter at 21; Specialist Association Letter at 14.

511 See, e.g., Amex Letter, Exhibit A, at 29; ICI Letter at 20.

$512 \quad$ See Instinet Letter at 51; Instinet Reproposal Letter at 18.

$513 \quad$ Id.

514 See Brut Letter at 25; Mercatus Center Letter at 9-10; Tower Research Letter at 9, 14-15.
} 
As the Commission stated in the Reproposing Release, ${ }^{515}$ a basis may exist to exempt QQQQ and perhaps other actively traded ETFs from Rule 612. The Commission will continue to study this matter during the implementation period for Regulation NMS.

One commenter, although not clearly advocating that the Commission use its authority to exempt certain securities from Rule 612, stated that "the Commission may want to employ objective criteria in determining when it is appropriate to trade in sub-pennies." ${ }^{516}$ In this regard, another commenter stated: "If the Commission wanted to permit only certain stocks to be quoted and traded in sub-penny increments, the main factor that should be considered is the average spread and the quoted size. If a security always trades with a penny spread and there is tremendous liquidity available on both sides of the market, this is a strong indication that the minimum increment is too wide." ${ }^{517}$ The Commission believes that this would be a reasonable consideration in analyzing whether it would be in the public interest and consistent with the protection of investors to grant an exemption pursuant to Rule 612(c). Other factors that the Commission might consider are:

- $\quad$ whether the NMS stock is an ETF or other derivative that can readily be converted into its underlying securities or vice versa, in which case the true value of the security as derived from its underlying components might be at a sub-penny increment;

- $\quad$ large volume of sub-penny executions in that security due to price improvement; and

$515 \quad$ See $69 \mathrm{FR}$ at 77459.

516 Archipelago Reproposal Letter at 15.

517 INET Reproposal Letter at 5. 
- $\quad$ low price of the security.

This list is illustrative, not exclusive. The Commission may consider other factors - noted by a petitioner or in its own analysis - if and when it considers whether to issue an exemption.

The Commission wishes to highlight certain aspects of Rule 612, as adopted, that were raised by commenters on both the Proposing Release and the Reproposing Release.

\section{Restriction Based on Price of the Quotation Not Price of the Stock}

As initially proposed, the restriction on sub-penny quoting would have been triggered if the price of the NMS stock itself were above $\$ 1.00$. One commenter sought clarification of when an NMS stock would become sub-penny eligible, suggesting a threshold of trading below $\$ 1.00$ for 30 consecutive business days. ${ }^{518}$ A second commenter suggested instead that the prohibition should derive from the price of the order, rather than the price of the stock; in other words, the rule should permit any sub-penny quotation below $\$ 1.00$ and prohibit any sub-penny quotation above $\$ 1.00$, regardless of the price where the stock was in fact trading. ${ }^{519}$ The second commenter argued that this approach "does not require countless re-classifications of stocks as 'sub-penny eligible' based on fluctuations in their valuation, stock splits, or other price movements." 520

The Commission agreed with the second commenter and, therefore, revised paragraph (a) of reproposed Rule 612 to prohibit any bid, offer, order, or indication of interest priced equal to or greater than $\$ 1.00$ in an increment smaller than $\$ 0.01$. As the Commission stated in the

$518 \quad$ See Citigroup Letter at 15.

$519 \quad$ See Brut Letter at 25.

520

Id. 
Reproposing Release, ${ }^{521}$ basing the restrictions on the price of the quotation or order rather than the price of the NMS stock itself would spare market participants the need to track the eligibility of stocks priced near the $\$ 1.00$ threshold.

Three commenters on the Reproposing Release noted their approval of basing the subpenny quoting restriction on the price of the quotation rather than the price of the NMS stock itself; ${ }^{522}$ no commenter objected to this approach. The Commission continues to believe in the rationale for this aspect of the proposal as described in the Reproposing Release. Therefore, the Commission is adopting Rule 612(a) substantially in the form reproposed in December 2004. The Commission is making a non-substantive amendment to clarify the rule. Reproposed Rule 612(a) would have stated that no market participant "shall display, rank, or accept from any person a bid or offer, an order, or an indication of interest in any NMS stock equal to or greater than $\$ 1.00$ in an increment smaller than $\$ 0.01$." Rule 612(a) as adopted provides that no market participant "shall display, rank, or accept from any person a bid or offer, an order, or an indication of interest in any NMS stock priced in an increment smaller than \$0.01 if that bid or offer, order, or indication of interest is priced equal to or greater than $\$ 1.00$ per share." The purpose of this revision is to clarify that the qualification "priced equal to or greater than $\$ 1.00$ per share" modifies the phrase "a bid or offer, an order, or an indication of interest" rather than "any NMS stock." The adopted text also makes clear that this proviso applies to bids, offers, orders, and indications of interest priced equal to or greater than $\$ 1.00$ per share. The modifying phrase "per share" was not present in reproposed Rule 612(a).

$521 \quad$ See 69 FR at 77457-58.

522 See BSE Reproposal Letter at 2; Nasdaq Reproposal Letter at 20; SIA Reproposal Letter at 23. 
As a result of Rule 612(a), a broker-dealer may not, for example, accept a sell order in an NMS stock priced at $\$ 1.0025$ per share, even if the NMS stock currently trades below $\$ 1.00$.

\section{Quotations Below \$1.00}

The Commission initially proposed a threshold of $\$ 1.00$ below which the prohibition on sub-penny quoting would not apply and requested comment on whether that threshold was appropriate. The majority of commenters addressing this issue believed that it would be useful for low-priced securities to trade in increments finer than a penny, because a penny would constitute a significant percentage of the overall price. These commenters viewed $\$ 1.00$ as an appropriate threshold. ${ }^{53}$ One commenter stated that there is "real demand for sub-penny trading (and therefore subpenny quoting) in securities trading below $\$ 1.00$, due to the low trading value of the security. ${ }^{524}$ However, another commenter, Ameritrade, argued that Rule 612 should not contain an exception for securities trading under $\$ 1.00 .{ }^{525}$ According to Ameritrade, "[t]he appropriate answer to this issue is for the NYSE, AMEX and NASDAQ markets to uniformly enforce listing standards, which generally require a security to trade above $\$ 1.00 .{ }^{.526}$

The Commission is adopting the $\$ 1.00$ threshold as proposed. The Commission agrees with the commenters who believe that sub-penny quotations for very low-priced securities largely represent genuine trading interest rather than unfair stepping ahead. In such cases, a subpenny increment represents a significant amount of the price of the quotation or order. Accordingly, the prohibition on sub-penny quoting in paragraph (a) of Rule 612 will apply only

$523 \quad$ See Archipelago Letter at 14; BSE Letter at 14; Citigroup Letter at 15; LSC Letter at 11; SIA Letter at 21; STANY Letter at 14.

524 Archipelago Letter at 14.

525 See Ameritrade Reproposal Letter at 10.

$526 \quad$ Id. 
to bids, offers, orders, and indications of interest that are priced $\$ 1.00$ or more per share. With respect to Ameritrade's comment, while the Commission believes that SROs must vigorously enforce their listing standards, there are legitimate circumstances where securities may be trading below \$1.00; therefore, the Commission believes it is appropriate for Rule 612 to address those circumstances.

Before the Reproposing Release, two commenters suggested that the Commission establish an MPV for quotations below \$1.00 per share; both recommended allowing such quotations to extend to four decimal places. ${ }^{527}$ The Commission agreed with these commenters and added a new paragraph (b) to reproposed Rule 612 that would have prohibited a bid, offer, order, or indication of interest priced less than $\$ 1.00$ per share in an increment smaller than $\$ 0.0001$. The Commission believes that, without limiting the number of decimal places used in quotations for very low-priced securities, the problems caused by sub-penny quoting of higherpriced securities, discussed above, could arise. Restricting quotations below $\$ 1.00$ to four decimal places should avoid these problems. The same two commenters reacted favorably to this aspect of the Reproposing Release. ${ }^{528}$

The Commission is adopting, as reproposed, the provision limiting a quotation under $\$ 1.00$ per share to four decimal places. Thus, under new Rule 612, a quotation of $\$ 0.9987 \mathrm{x}$ $\$ 1.00$ is permitted but a quotation of $\$ 0.9987 \times 1.0001$ is not. $^{529}$

$527 \quad$ See Citigroup Letter at 15; SIA Letter at 21.

$528 \quad$ See Citigroup Reproposal Letter at 8-9; SIA Reproposal Letter at 23.

529 One commenter, while supporting the general prohibition on sub-penny quoting, noted that "[t]here are many 'subpenny' stocks on the OTCBB that trade at prices close to or less than \$.0001. Imposing a high minimum tick for stocks in this category may adversely trading in those stocks." Angel Reproposal Letter at 6. The Commission notes that new Rule 612 applies only to NMS stocks, the definition of which generally does not include stocks quoted on the OTCBB. See 17 CFR 242.600(b)(47) (defining "NMS 
The Commission notes that it has made non-substantive revisions to Rule 612(b) in a manner similar to Rule 612(a). Reproposed Rule 612(b) would have stated that no market participant "shall display, rank, or accept from any person a bid or offer, an order, or an indication of interest in any NMS stock less than \$1.00 in an increment smaller than \$0.0001." Rule 612(b) as adopted provides that no market participant "shall display, rank, or accept from any person a bid or offer, an order, or an indication of interest in any NMS stock priced in an increment smaller than $\$ 0.0001$ if that bid or offer, order, or indication of interest is priced less than $\$ 1.00$ per share." The purpose of this revision is to clarify that the qualification "priced less than $\$ 1.00$ per share" modifies the phrase "a bid or offer, an order, or an indication of interest" rather than "any NMS stock." The adopted text also makes clear that this proviso applies to bids, offers, orders, and indications of interest priced less than $\$ 1.00$ per share. The modifying phrase "per share" was not present in reproposed Rule 612(b).

During the Regulation NMS implementation period, the Commission intends to consult with the administrators of the Plans to help ensure that sub-penny quotations permitted by Rule 612 will be widely disseminated to the public. The Commission believes this is necessary so that the problem of hidden markets - where professionals can see and access more competitive subpenny quotations that average investors cannot - is fully addressed.

\section{Revisiting the Penny Increment}

Some commenters, while generally acknowledging problems caused by sub-penny quoting, recommended that the Commission consider increasing the MPV above $\$ 0.01 .^{530}$ One

stock"). Therefore, Rule 612 does not require that quotations below $\$ 1.00$ per share in securities quoted exclusively on the OTCBB be limited to four decimal places.

$530 \quad$ See Amex Letter at 30; Angel Letter at 10; BNY Letter at 4; Citadel Letter at 10; e-mail from LaBranche \& Co. to rule-comments@sec.gov, dated January 26, 2005; McGuire Summary of Intended Testimony (no page numbers); Tullo Letter at 9. 
commenter believed that "[t]he Commission should seriously consider experimenting with different tick sizes to help determine the optimal tick policy." ${ }^{531}$ A second commenter recommended that the Commission establish an MPV of a $\$ 0.01$ for high-volume stocks, $\$ 0.05$ middle-volume stocks, and $\$ 0.10$ for the low-volume stocks. ${ }^{532}$ A third commenter argued that the appropriate MPV in the equities market is at least $\$ 0.05$ "or some reasonable, tiered alternative." ${ }^{533}$ The third commenter previously stated that "sub-penny quoting does little, if anything, to degrade the market from its current state" because "the true damage was done to the market in the shift from a fractionalized environment to a penny spread environment." 534 Rule 612, as adopted, sets a floor for the MPV but does not, and is not designed to, determine the optimal MPV. Penny pricing in NMS stocks was established by rules proposed by NASD and the national securities exchanges and approved by the Commission pursuant to Section 19(b) of the Exchange Act. ${ }^{535}$ While some commenters argue that penny pricing impedes transparency and reduces liquidity, the move to decimals (and specifically the move to a penny quotation increment for NMS stocks) also has significantly reduced spreads and reduced trading costs for investors who enter orders executed at or within the NBBO. As the Commission stated in the Reproposing Release, ${ }^{536}$ it believes that the establishment of a $\$ 0.01$ MPV, on balance, has benefited many investors. Accordingly, the Commission did not propose

\footnotetext{
$531 \quad$ Angel Letter at 10.

$532 \quad$ See Tullo Letter at 9.

$533 \quad$ NextTrade Reproposal Letter at 12.

$534 \quad$ NexTrade Letter at 9.

$535 \quad 15$ U.S.C. 78s(b). See supra, note 470.

$536 \quad$ See $69 \mathrm{FR}$ at 77458.
} 
to raise the MPV in connection with Regulation NMS. The Commission's views on this matter have not changed since issuance of the Reproposing Release, and the Commission is not amending Rule 612 to raise the MPV.

\section{Sub-Penny Trading}

The Commission stated in the Proposing Release that it did not at that time believe that trading in sub-penny increments raised the same concerns as sub-penny quoting. Therefore, the proposed rule would not have prohibited a market center or broker-dealer from executing and printing a trade in sub-penny increments that was, for example, the result of a midpoint or volume-weighted pricing algorithm, as long as it did not otherwise violate the proposed rule. In addition, a broker-dealer could, consistent with the proposed rule, provide price improvement to a customer order that resulted in a sub-penny execution as long as the broker-dealer did not accept an order priced above $\$ 1.00$ per share in a sub-penny increment. The Commission sought specific comment on this aspect of the proposal.

Every commenter that addressed this issue in response to the Proposing Release agreed that Rule 612 should permit sub-penny trades that result from midpoint and average-price algorithms. ${ }^{537}$ While most of these commenters believed that the rule should permit brokerdealers to offer sub-penny price improvement to their customers' orders, ${ }^{538}$ a few commenters urged the Commission to bar this practice. ${ }^{539}$ The Commission did not revise this aspect of the sub-penny rule in the Reproposing Release. Two commenters that addressed this issue in

$537 \quad$ See ACIM Letter at 2; Amex Letter at 12; E*Trade Letter at 11; Liquidnet Letter at 8; SIA Letter at 21; STA Letter at 7; STANY Letter at 14; UBS Letter at 10.

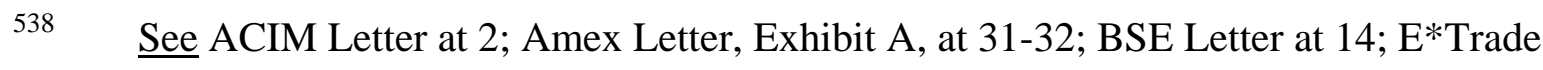
Letter at 11; Liquidnet Letter at 8; Morgan Stanley Letter at 21; SIA Letter at 21; STA Letter at 7; STANY Letter at 14; UBS Letter at 10.

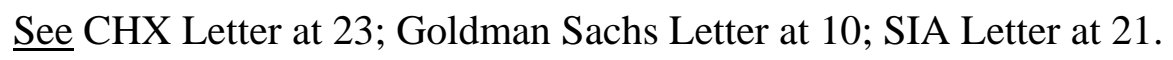


response to the Reproposing Release also believed that the rule should permit sub-penny trades that result from midpoint and average-price algorithms. ${ }^{540}$ One of these commenters added that sub-penny trades resulting from price improvement also should be permitted. ${ }^{541}$

After considering all views expressed on this issue, the Commission is adopting this aspect of Rule 612 as proposed and reproposed. Rule 612 will not prohibit a sub-penny execution resulting from a midpoint or volume-weighted algorithm or from price improvement, so long as the execution did not result from an impermissible sub-penny order or quotation. The Commission believes at this time that trading in sub-penny increments does not raise the same concerns as sub-penny quoting. Sub-penny executions do not cause quote flickering and do not decrease depth at the inside quotation. Nor do they require the same systems capacity as would sub-penny quoting. In addition, sub-penny executions due to price improvement are generally beneficial to retail investors.

\section{Acceptance of Sub-Penny Quotations}

The Commission initially proposed to prohibit national securities exchanges, national securities associations, ATSs, vendors, and broker-dealers from displaying, ranking, or accepting sub-penny orders or quotations in NMS stocks. One commenter argued that Rule 612 should allow a market participant to accept sub-penny quotations if it consistently re-prices such quotations to an acceptable increment and does not give the sub-penny quotations any special priority for ranking or execution purposes. ${ }^{542}$ A second commenter disagreed, arguing that

$540 \quad$ See BSE Reproposal Letter at 2; Citigroup Reproposal Letter at 9.

$541 \quad$ See Citigroup Reproposal Letter at 9.

$542 \quad$ See Brut Letter at 26. 
rounding a sub-penny quotation to the nearest penny may be confusing for investors. ${ }^{543}$ The Commission agreed with the second commenter and reproposed Rule 612 continued to include a prohibition on accepting and rounding a sub-penny order.

In response to the Commission's statements on this matter in the Reproposing Release, one commenter stated that the Commission should "continu[e] to allow (but, of course, not require) market centers to adjust the pricing of disallowed sub-penny quotations, so long as the unadjusted quotations are not displayed or considered for purposes of ranking." ${ }^{544}$ This commenter argued that adjusting such quotations "is a well-established practice" and that prohibiting the practice "has the potential to create needless confusion and impose additional costs." ${ }^{545}$ Another commenter on reproposed Rule 612 argued similarly that keeping the established practice would not present "any real potential for confusion among investors."

Notwithstanding these comments, the Commission is adopting this aspect of Rule 612 as proposed and reproposed. A market participant, therefore, is prohibited from accepting a subpenny order or quotation that is not permitted by the rule, even if it rounds the order or quotation to the nearest permissible pricing increment. While the Commission does not believe that a great deal of customer confusion is likely to arise in either case, it does believe that confusion is more likely to result if a broker-dealer, for example, accepted a customer order to buy at $\$ 20.001$, then rounded and ultimately executed it at $\$ 20.00$. A customer unfamiliar with Rule 612 could conceivably wonder why his or her order did not have priority above orders to buy at $\$ 20.00$. A

$543 \quad$ See CHX Letter at 23.

544 Nasdaq Reproposal Letter at 20.

545 Id.

$546 \quad$ Instinet Reproposal Letter at 18. 
much simpler and more transparent approach is for Rule 612 to prohibit the acceptance of subpenny orders generally (except for orders priced below \$1.00 per share, which may extend to four decimal places), and for the broker-dealer to adhere to the rule by rejecting the customer's sub-penny order to buy at $\$ 20.001$. The Commission sees no purpose that would be served by allowing the broker-dealer to accept this sub-penny order, since Rule 612 would in any case prohibit the full order from being displayed or considered for ranking or execution purposes. ${ }^{547}$

\section{Application to Options Markets}

As initially proposed, Rule 612, by its terms, would have applied only to NMS stocks. The Commission requested comment on whether the rule also should apply to options. ${ }^{548}$ Currently, SRO rules require options to be quoted on the U.S. markets in increments of \$0.05 and $\$ 0.10$. Therefore, the problems that could be created by sub-penny quoting currently do not exist in the options markets.

547 The Commission previously has granted exemptions from Rules 11Ac1-1, 11Ac1-2, and 11Ac1-4 under the Exchange Act, 17 CFR 240.11Ac1-1, 240.11Ac1-2, and 240.11Ac1-4, that permit orders and quotations to be accepted and executed in sub-penny increments but displayed in rounded, penny increments without a rounding identifier. See letter from David S. Shillman, Associate Director, Division, Commission, to Mai S. Shiver, Director of Regulatory Policy, PCX, dated Feb. 10, 2005; letter from David S. Shillman, Associate Director, Division, Commission, to Ellen J. Neely, Senior Vice President and General Counsel, CHX, dated July 15, 2004; letter from David S. Shillman, Associate Director, Division, Commission, to James C. Yong, Senior Vice President, Regulation, and General Counsel, NSX, dated June 30, 2004. See also letter to Ronald Aber, Vice President and General Counsel, Nasdaq, from Richard Lindsey, Director, Division, Commission, dated July 30, 1997 (no-action relief provided by Division similar to three Commission exemptions cited above). These exemptions are inconsistent with new Rule 612 but by their terms expire on June 30, 2005, before the implementation date of Rule 612. Nasdaq's no-action letter does not by its terms include a sunset date. However, Nasdaq may not rely on this letter beyond the implementation date of Rule 612. 
Two commenters believed that the rule should not apply to quoting in options. ${ }^{549}$ One of these commenters, assuming that the rule as proposed would allow options with a premium of less than $\$ 1.00$ to be quoted in sub-pennies and options with a premium over $\$ 1.00$ to be quoted in pennies, argued that this approach "would overwhelm the already taxed capacity of existing options quote processing systems." ${ }^{550}$ The Commission did not believe at the time it issued the Reproposing Release that it was necessary for the sub-penny rule to extend to options, nor does it believe so now. The concerns created by sub-penny quoting - present to some extent in the equities markets - currently do not exist in the options markets, where the smallest quoting increment is $\$ 0.05$. Therefore, Rule 612 will not apply to options. If a national securities exchange seeks to quote options in pennies or sub-pennies in the future, it would first need to propose a rule change to that effect under Section 19(b) of the Exchange Act. ${ }^{551}$ The Commission would have an opportunity to consider such a proposal at that time, after publishing notice and obtaining public comment. ${ }^{552}$

A third commenter, ${ }^{553}$ while agreeing strongly with the proposed sub-penny rule, argued that the Commission should prohibit the Boston Options Exchange ("BOX"), a facility of the Boston Stock Exchange, from using "sub-increment" pricing (i.e., penny prices below the standard \$0.05 and \$0.10 increments used for options) in its "Price Improvement Period"

549 See Amex Letter, Exhibit A, at 32-33; SIA Letter at 21.

$550 \quad$ Amex Letter, Exhibit A, at 32.

$551 \quad 15$ U.S.C. $78 \mathrm{~s}(\mathrm{~b})$.

552 The Commission has previously stated that, "[g]iven the implications of penny quoting for OPRA, penny quoting would require very careful review by the Commission." Securities Exchange Act Release No. 49068 (Jan. 13, 2004), 69 FR 2775, 2789 (Jan. 20, 2004) ("BOX Approval Order").

$553 \quad$ See CBOE Letter at 8. 
("PIP"). ${ }^{554}$ By initiating a PIP auction, a BOX market participant may execute a portion of its agency order as principal in pennies, and BOX market makers can match that price or offer price improvement to those orders in penny increments during the three-second auction. The Commission previously approved the BOX trading rules, including the rules governing the PIP, pursuant to Section 19(b) of the Exchange Act. ${ }^{555}$ The PIP uses pennies in an auction, not in public quotations. Therefore, the Commission does not believe that the PIP raises the same concerns caused by sub-penny quotations of non-option securities and, therefore, that it is not necessary to prohibit the use of pennies in BOX's PIP.

\section{One-to-One Negotiating Systems}

One commenter - Liquidnet, an ATS whose system allows institutional traders to negotiate large-sized orders - argued that Rule 612 should not prohibit orders priced in halfpenny increments for one-to-one negotiating systems. ${ }^{556}$ Liquidnet currently permits a user to submit an order at the mid-point of the spread, which would be at a half-penny increment if the spread were an odd number of cents wide (e.g., \$10.00 x \$10.03). Liquidnet argues that the "sub-penny pricing abuses that the SEC is trying to prevent are not applicable, because any orders are only seen by the two negotiating parties." ${ }^{557}$ Although the Commission does not believe it is necessary or appropriate to include in Rule 612 an exception for one-to-one negotiating systems such as Liquidnet's, it would consider a request for exemptive relief that

554 See BOX Approval Order, 69 FR at 2786-92 (explaining PIP auction).

555 See id.

$556 \quad$ See Liquidnet Reproposal Letter at 4.

$557 \quad$ Id. 
would permit one-to-one negotiations of sub-penny trades through an ATS. The Commission will study this issue further during the Regulation NMS implementation period.

\section{Implementation of Rule 612}

While the majority of commenters supported the sub-penny rule, a few specifically requested that the Commission implement it as quickly as possible. ${ }^{558}$ One of the commenters stated that there are no "significant technological or structural impediments to immediate implementation. ${ }^{559}$ The Commission agrees with this view. Currently, sub-penny quoting that would be prohibited by Rule 612 exists only on a small number of ATSs and in a small number of NMS stocks. Nasdaq and all of the national securities exchanges already have rules that permit quoting only in $\$ 0.01$ increments. No commenter indicated that converting ATS systems to comply with the rule would impose any significant burdens. In light of this, and the small number of impacted NMS stocks, the Commission believes that only minimal systems changes will be necessary for these ATSs to conform to Rule 612 and has determined that the implementation date of Rule 612 will be August 29, 2005.

The Commission notes that it previously has granted exemptions from existing Rules 11Ac1-1, 11Ac1-2, and 11Ac1-4 under the Exchange Act that, among other things, allow certain exchanges to accept sub-penny orders and quotations and to disseminate them in rounded, penny increments without a rounding identifier. ${ }^{560}$ By their terms, these exemptions - which are not consistent with new Rule 612 - expire on June 30, 2005.

$558 \quad$ See ACIM Letter at 2; ATD Reproposal Letter at 4; Charles Schwab Letter at 17; Merrill Lynch Reproposal Letter at 10; Nasdaq Letter at 1.

$559 \quad$ ATD Reproposal Letter at 4.

$560 \quad$ See supra, note 547. 
Rule 612 permits, but does not require, a trading center to offer its users the ability to quote in sub-pennies in a limited number of cases. An exchange or association that wishes to offer this ability to its market participants will likely need to amend its rules before doing so. The Commission expects the SROs to consider this matter during the implementation period. ${ }^{561}$

\section{Market Data Rules and Plan Amendments}

The Exchange Act rules and joint-SRO Plans for disseminating market information to the public are the heart of the NMS. Pursuant to these rules and Plans, investors are able to obtain real-time access to the best current quotes and most recent trades for all NMS stocks. As a result, investors of all types - large and small - have access to a comprehensive, accurate, and reliable source of information for the prices of any NMS stock at any time during the trading day.

The SROs generate consolidated market data by participating in the Plans. ${ }^{562}$ Pursuant to the Plans, three separate networks disseminate consolidated market information for NMS stocks: (1) Network A for securities listed on the NYSE; (2) Network B for securities listed on the Amex and other national securities exchanges; and (3) Network C for securities traded on Nasdaq. For each security, the data includes: (1) an NBBO with prices, sizes, and market center identifications; (2) the best bids and offers from each SRO that includes prices, sizes, and market center identifications; and (3) a consolidated set of trade reports in the security. The Networks

$561 \quad$ One commenter argued that the Commission should allow "sufficient time" for systems development to accommodate sub-penny quoting permitted by Rule 612. See Amex Reproposal Letter at 1, n.1. Because Rule 612 permits but does not require market participants to quote very low-priced NMS stocks in sub-penny increments, the Commission does not believe it is necessary to offer market participants an extended period in which to build the systems capacity to support this activity before making Rule 612 effective.

See supra, note 40 . 
establish fees for this data, which must be filed for Commission approval. ${ }^{563}$ The Networks collect the applicable fees and, after deduction of Network expenses (which do not include the costs incurred by SRO participants to generate market data and supply such data to the Networks), distribute the remaining revenues to their individual SRO participants. As set forth in the following table, the Networks collected \$434.1 million in revenues derived from market data fees in 2004 and distributed \$393.7 million to their individual SRO participants:

2004 Financial Information for Networks A, B, and $C^{564}$

\begin{tabular}{|l|r|r|r|r|}
\hline & Network A & \multicolumn{1}{|c|}{ Network B } & \multicolumn{1}{c|}{ Network C } & \multicolumn{1}{c|}{ Total } \\
\hline Revenues & $\$ 165,588,000$ & $\$ 103,901,000$ & $\$ 164,656,000$ & $\$ 434,145,000$ \\
\hline Expenses & $10,317,000$ & $3,921,000$ & $26,196,000$ & $40,434,000$ \\
\hline Net Income & $155,271,000$ & $99,980,000$ & $138,460,000$ & $393,711,000$ \\
\hline Allocations: & & & & \\
\hline NYSE & $140,661,000$ & $1,296,000$ & 0 & $141,957,000$ \\
\hline NASD/Nasdaq & $8,296,000$ & $8,360,000$ & $61,672,000$ & $78,328,000$ \\
\hline PCX & $2,091,000$ & $43,276,000$ & $30,804,000$ & $76,171,000$ \\
\hline NSX & 694,000 & $14,498,000$ & $36,717,000$ & $51,909,000$ \\
\hline Amex & 0 & $28,301,000$ & 30,000 & $28,331,000$ \\
\hline BSE & $1,345,000$ & 850,000 & $8,757,000$ & $10,952,000$ \\
\hline CHX & $1,995,000$ & $2,946,000$ & 480,000 & $5,421,000$ \\
\hline Phlx & 189,000 & 446,000 & 0 & 635,000 \\
\hline CBOE & 0 & 7,000 & 0 & 7,000 \\
\hline
\end{tabular}

The overriding objective of the Rule and Plan amendments adopted today is to preserve the vital benefits that investors currently enjoy, while addressing those particular problems with the current rules and Plans that are most in need of reform. The changes fall into three categories: (1) modifying the current formulas for allocating market data revenues to the SROs to more appropriately reflect their contributions to public price discovery; (2) establishing nonvoting advisory committees to broaden participation in Plan governance; and (3) updating and See Exchange Act Rule 11Aa3-2(c)(1).

564 The Network financial information for 2004 is preliminary and unaudited. 
streamlining the various Exchange Act rules that govern the distribution and display of market information.

\section{A. Response to Comments and Basis for Adopted Rules}

\section{Alternative Data Dissemination Models}

In addition to proposing specific rules and amendments, the Proposing Release discussed and requested comment on the Commission's decision not to propose an alternative model of data dissemination to replace the current consolidation model. ${ }^{565}$ The great strength of the current model is that it benefits investors, particularly retail investors, by enabling them to assess prices and evaluate the best execution of their orders by obtaining data from a single source that is highly reliable and comprehensive. But, by requiring vendors and broker-dealers to display data to investors that is consolidated from all markets, the current model effectively also requires the purchase of data from all markets. As a result, the most significant drawback of the current model is that it offers little opportunity for market forces to determine a Network's fees, or the allocation of those fees to a Network's SRO participants. Network fees must be closely scrutinized for fairness and reasonableness, and the revenues resulting from those fees must be allocated to the SROs pursuant to a Plan formula. In addition, individual markets have less freedom to innovate in individually providing their quotation and trade data. On the other hand, the consolidated display requirement can promote competition by assuring that markets, particularly smaller or newer ones, can obtain wide distribution of their displayed quotations. ${ }^{566}$

565 Proposing Release, 69 FR at 11176-11179.

566 See Report of the Advisory Committee on Market Information: A Blueprint for Responsible Change (September 14, 2001) (available at http://www.sec.gov) (“Advisory Committee Report”) (recommending retention of the consolidated display requirement because it serves core investor protection and market integrity functions, as well as promoting market competition). 
As noted in section I.A.1 above, vigorous competition among multiple markets trading the same securities is one of the distinctive characteristics of the U.S. equity markets. Thus, the existence of the Networks and the consolidated display requirement has not precluded the NMS from promoting the broad objective of assuring competition among markets.

In the Proposing Release, the Commission specifically considered three alternative models that potentially could introduce greater competition and flexibility into the dissemination of market data: (1) a deconsolidation model, (2) a competing consolidators model, and (3) a hybrid model. It decided not to propose any of these alternative models after consideration of the benefits and drawbacks of each model. The Commission did, however, request comment on whether it should develop an alternative model for disseminating market data to the public, and, in particular, on its evaluation of the strengths and weaknesses of the current model and of the various alternative models for the dissemination of market data.

In response to the Commission's request for comment, a minority of commenters expressed their views regarding the appropriate structure for the dissemination of market information to the public. One group believed that the current model requiring the display of consolidated data in a stock through a Plan processor has produced significant benefits for investors and the markets, although several also strongly recommended that its operation needed to be improved in significant respects. ${ }^{567}$ Another group of commenters, in contrast, asserted that the current system has inhibited competition among markets and that the Plans should be eliminated. ${ }^{568}$ These commenters further suggested deregulation of market data by allowing Letter at 18-20; Financial Information Forum Reproposal Letter at 3; Schwab Letter at 11-13; SIA Letter at 26-28; STANY Letter at 14. 
markets to sell their own data, and by allowing market forces and competition to control the pricing of such data. They advocated a competing consolidators model or a hybrid model.

\section{a. Competing Consolidators Model}

Under a competing consolidators model, the consolidated display requirement would be retained, but the Plans and Networks would no longer be necessary. Each of the nine SROs that participate in the NMS, as well as Nasdaq, would be allowed to establish its own fees, to enter into and administer its own market data contracts, and to provide its own data distribution facility. Any number of data vendors or broker-dealers (‥e., “competing consolidators”) could purchase data from the individual SROs, consolidate the data, and distribute it to investors and other data users. Of the commenters that urged the Commission to adopt a competing consolidators model, ${ }^{569}$ the NYSE, for example, believed that allowing the markets to withdraw from the Plans would "reestablish the link between the value of a market's data... and the fair allocation of costs among...users," thereby ending inter-market subsidies and market-distortive initiatives created by the current system." ${ }^{570}$ Similarly, ArcaEx stated that "the best way to reform the [P]lans is to abolish them altogether and to adopt a competing consolidators model." ${ }^{571}$

Commission, dated June 10, 2004 ("ASA Letter") at 2; ArcaEx Letter at 4, 12, 14; Brut Letter at 22; Financial Services Roundtable Letter at 7; ISE Letter at 8-10; Nasdaq Letter II at 24-26; NYSE Letter, Attachment at 10-11; Reuters Letter at 2; Specialist Assoc. Letter at 17.

569 See, e.g., ArcaEx Letter at 12, 14; ISE Letter at 8-9; NYSE Letter, Attachment at 10-11.

570 NYSE Letter at 7 and Attachment at 10. The NYSE provided several reasons for the elimination of the Plans. 
The Commission has considered the comments advocating a competing consolidators model, but continues to question the extent to which the model would in fact subject the level of market data fees to competitive forces. If the benefits of a fully consolidated data stream are to be preserved for investors, every consolidator would need to purchase the data of each SRO to assure that the consolidator's data stream in fact included the best quotations and most recent trade report in all NMS stocks. Moreover, to comply with the adopted Order Protection Rule, each trading center would need the quotation data from every other trading center in a security. As a practical matter, payment of every SRO's fees would be mandatory, thereby affording little room for competitive forces to influence the level of fees. Consequently, far from freeing the Commission from involvement in market data fee disputes, the multiple consolidator model would require review of at least ten separate fees for individual SROs and Nasdaq. The overall level of fees would not be reduced unless one or more of the SROs or Nasdaq was willing to accept a significantly lower amount of revenues than they currently are allocated by the Plans. It seems unlikely that any SRO or Nasdaq would voluntarily propose to lower just its own fees and reduce its own current revenues, and some might well propose higher fees to increase their revenues, particularly those with dominant market shares whose information is most vital to investors. No commenter offered useful, objective standards for the Commission to use in evaluating the separate fees of SROs and Nasdaq. For this and for data quality concerns, ${ }^{572}$ the Commission remains unconvinced that discarding the current model in favor of a multiple consolidator model would benefit investors and the NMS in general.

\section{b. Hybrid Model}


In its comment on the original proposal, Nasdaq advocated a hybrid model of data dissemination as a compromise if the Commission believes that it is necessary to retain the Plans. ${ }^{573}$ Under a hybrid approach, basic elements of the current model (including the consolidated display requirement and the Plans) would be retained for quotations representing the NBBO, but all trade reports and all quotations other than the NBBO would be deconsolidated. Because much less consolidated data would be disseminated under this model, the fees for consolidated data would be reduced commensurately. The individual SROs would distribute their own trade and quotation information separately and establish fees for such information. To obtain the data eliminated from the consolidated system, investors would need to pay the separate SRO fees.

In its proposal, Nasdaq suggested that consolidated data fees should be reduced, ${ }^{574}$ but only in the context of advocating a hybrid model that would drastically reduce the quantity of consolidated data that would be disseminated to investors (i.e., by eliminating from the consolidated systems all trade reports and all quotations other than the NBBO). Nasdaq stated

$573 \quad$ Nasdaq Letter II at 26-28.

574 At the NMS Hearing, a representative of Nasdaq stated that the current $\$ 20$ fee for professionals to obtain market data in Nasdaq stocks is too high; that the fee, based on a recent analysis of Nasdaq's cost structure, should be around $\$ 5$ to $\$ 7$; and that the $\$ 20$ fee is a monopoly price "set almost twenty years ago without any active review of how that relates." Hearing Tr. at 223-224, 253. These remarks subsequently engendered some confusion among the public, which was reflected in many comments on the market data proposals addressing the level of fees. To put these comments in perspective and dispel any potential misconceptions, the following points should be kept in mind: (1) in 1999, the Commission undertook a comprehensive review of market data fees and revenues, which led to a 75\% reduction in the fees paid by retail investors for market data (Market Information Release, $64 \mathrm{FR}$ at 70614); (2) Nasdaq's suggested \$5 to \$7 monthly fee for professional investors would entitle them to only the NBBO in Nasdaq stocks, which is a fraction of the data that currently is disseminated for the \$20 monthly fee for professional investors for consolidated trades and quotations in Nasdaq stocks; and (3) Nasdaq's $\$ 5$ to $\$ 7$ cost estimate encompassed only its own costs and therefore excluded the costs of other SROs that now represent a large percentage of trading in Nasdaq-listed stocks. 
that the Commission should allow competitive forces to determine the individual SRO fees for deconsolidated data because trade reports and non-NBBO quotations are not "essential to investors." ${ }^{575}$

The Commission believes, however, that comprehensive trade and quotation information, even beyond the NBBO, is vital to investors. The Commission remains concerned that an SRO with a significant share of trading in NMS stocks could exercise market power in setting fees for its data. Few investors could afford to do without the best quotations and trades of such an SRO that is dominant in a significant number of stocks. In the absence of a solid basis to believe that full trade and quotation information would continue to be widely available and affordable to all types of investors under a hybrid model, the Commission has determined that the most responsible course of action is to take such immediate steps are necessary to improve the operation of the current consolidation model. ${ }^{576}$

\section{Level of Fees and Plan Governance}

\section{a. Level of Fees}

In the Proposing Release, the Commission emphasized that one of its primary goals with respect to market data is to assure reasonable fees that promote the wide public availability of consolidated market data. Comment was requested on the extent to which investors and other data users were relatively satisfied with the products and fees offered by the Networks. ${ }^{577}$ At the NMS Hearing, several panelists addressed the current level of fees and questioned whether such

$575 \quad$ Nasdaq Letter II at 27.

576 The Commission also is concerned about the risk of compromising the quality of market information if the hybrid model were adopted. Proposing Release, 69 FR at 11178. Proposing Release, 69 FR at 11179. 
fees remained reasonably related to the cost of market data. ${ }^{578}$ The Supplemental Release therefore noted the panelists' views and welcomed comments on the reasonableness of market data fees and whether the Commission should modify its approach to reviewing such fees. ${ }^{579}$

Many commenters recommended that the level of market data fees should be reviewed and that, in particular, greater transparency concerning the costs of market data and the feesetting process is needed. ${ }^{580}$ The Commission agrees. To respond to commenters' concerns, it has sought comment on market data fees in its concept release relating to SRO structure. ${ }^{581}$ The release discusses and requests comment on a number of issues raised by commenters in the context of SRO revenues and the funding of self-regulation - in particular, whether market data fees are reasonable, whether the Commission should reconsider a flexible cost-based approach as described in the 1999 Market Information Release, and whether market data fees should be used to fund SRO operational or regulatory costs. The Commission also has taken steps to promote more transparency with respect to market data fees and the use of market data revenues through its proposal on SRO transparency. ${ }^{582}$ The proposal would greatly increase SRO transparency by requiring, among other things, that SROs file public reports with the Commission detailing their sources of revenues and their uses of these revenues. Such reports would enhance the public's

578 Hearing Tr. at 223-224, 228-229, 230-231, 233.

579 Supplemental Release, 69 FR at 30148.

$580 \quad$ See, e.g., Ameritrade Reproposal Letter 10; Bloomberg Tradebook Letter at 8-9; Brut Letter at 21-23; Citigroup Letter at 15; Financial Information Forum Letter at 3; Financial Services Roundtable Letter at 6-7; Goldman Sachs Letter at 2, 10; ICI Letter at 21-22; Morgan Stanley Letter at 21-22; Schwab Reproposal Letter at 3-5; SIA Reproposal Letter at 24; STANY Letter at 14; UBS Letter at 10.

SRO Structure Release, supra note 49.

SRO Transparency Release, supra note 50. 
ability to evaluate the role of market data revenues in funding SROs. For example, proposed amendments to Form 1, Exhibit I would require exchange SROs to disclose their revenues earned from market information fees, itemized by product, and proposed new Rule 17a-26 would require SROs to file electronic quarterly and annual reports on particular aspects of their regulatory activities.

Some commenters suggested that, instead of modifying the Plan formulas for allocating market data revenues, the Commission should impose a cost-based limitation on fees. ${ }^{583}$ Most, however, adopted a very restricted view of market data costs - solely the costs of the Networks to collect data from the individual SROs and disseminate it to the public. ${ }^{584}$ Yet nearly the entire financial burden of collecting and producing market data is borne by the individual markets, not by the Networks. If, for example, an SRO's systems break down on a high-volume trading day and it can no longer provide its data to the Networks, investors would suffer the consequences of a defective data stream, regardless of whether the Networks are able to continue operating.

The commenters' suggested approach to market data fees would eliminate any funding for the SROs that supply data to the Networks, which would have reduced SRO funding by $\$ 393.7$ million in 2004. ${ }^{585}$ Before imposing such a significant and sudden reduction in SRO funding, the Commission must carefully consider the consequences this reduction might have on the integrity of the U.S. equity markets. When the Commission last reviewed market data fees and revenues in 1999, it noted the direct connection between an SRO's operational and regulatory functions and the value of its market information:

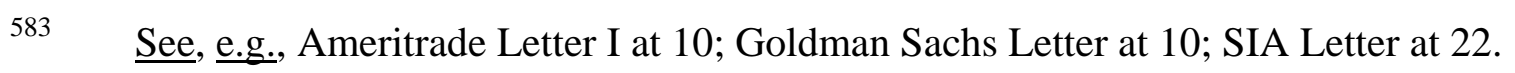

$584 \quad$ See, e.g., ASA Letter at 2; Citigroup Letter at 16; Schwab Letter at 6; SIA Letter at 25.

585 See supra, table accompanying note 564. 
[T]he value of a market's information is dependent on the quality of the market's operation and regulation. Information is worthless if it is cut off during a systems outage (particularly during a volatile, high-volume trading day when reliable access to market information is most critical), tainted by fraud or manipulation, or simply fails to reflect accurately the buying and selling interest in a security. ${ }^{586}$

Moreover, the U.S. equity markets are not alone in their reliance on market data revenues as a substantial source of funding. All of the other major world equity markets currently derive large amounts of revenues from selling market information, despite having significantly less trading volume and less market capitalization than the NYSE and Nasdaq. To illustrate, the following table sets forth the respective market information revenues, dollar value of trading, and market capitalization for the largest world equity markets in $2003:{ }^{587}$

$\begin{array}{lrrr} & \begin{array}{c}\text { Data } \\ \text { Revenues } \\ \text { (millions) }\end{array} & \begin{array}{c}\text { Trading } \\ \text { Volume } \\ \text { (trillions) }\end{array} & \begin{array}{c}\text { Market } \\ \text { Capitalization } \\ \text { (trillions) }\end{array} \\ \text { London } & \$ 180 & \$ 3.6 & \$ 2.5 \\ \text { NYSE } & \$ 172 & \$ 9.7 & \$ 11.3 \\ \text { Nasdaq } & \$ 147 & \$ 7.1 & \$ 2.8 \\ \text { Deutsche Bourse } & \$ 146 & \$ 1.3 & \$ 1.1 \\ \text { Euronext } & \$ 109 & \$ 1.9 & \$ 2.1 \\ \text { Tokyo } & \$ 60 & \$ 2.1 & \$ 3.0\end{array}$

In sum, the Commission is committed to assuring that investors are not required to pay unreasonable or unfair fees for the consolidated market information that they must have to participate in the U.S. equity markets. On the other hand, we must maintain high standards of SRO performance, without which the data they produce would be worth little. Some commenters suggested that SRO funding should be provided through more specifically targeted

586 Market Information Release, 64 FR at 70614-70615.

587 Data for this table is derived from the 2003 annual reports of the various markets and from statistics compiled by the World Federation of Exchanges. The exchange rates are as of August 15, 2004. 
fees, such as an additional regulatory fee to fund market regulation costs. ${ }^{588}$ Given the potential harm if vital SRO functions are not adequately funded, we believe that the level of market data fees is most appropriately addressed in a context that looks at SRO funding as a whole. The Commission's review of SRO structure, governance, and transparency provides a useful context in which these competing policy concerns can be evaluated and balanced appropriately.

The Commission does not believe, however, that reform of the current revenue allocation formulas should be delayed until its review of fees is completed. ${ }^{589}$ The distortions caused by these formulas are substantial and ongoing. In particular, it appears that market participants increasingly are engaging in the practice of trade shredding (i.e., splitting large trades into multiple 100-share trades) as a means to increase their share of market data revenues under the current Plan formulas. As discussed below, the adopted formula would represent a substantial improvement because it is designed to eliminate trade shredding and other gaming of the current formulas and because it would more directly allocate revenues to those markets that contribute data to the consolidated data stream that is most useful to investors.

\section{b. Plan Governance}

The Commission is adopting, as proposed and reproposed, an amendment to the Plans that requires the creation of non-voting advisory committees ("Governance Amendment"). It provides that the members of an advisory committee have the right to submit their views to the Plan operating committees on Plan matters, including any new or modified product, fee, contract,

$588 \quad$ See, e.g., Citigroup Reproposal Letter at 9; Goldman Sachs Letter at 11.

589 See, e.g., SIA Reproposal Letter at 24 (allocation formula should not be revised prior to evaluating the level of market data fees). 
or pilot program. Most commenters supported the Governance Amendment. ${ }^{590}$ They generally believed that expanding the participation of non-SROs parties in Plan governance would be a constructive step. Only a few commenters disagreed, stating that interested parties currently have the ability to communicate their views on Plan matters or questioning the efficacy of the committees. ${ }^{591}$

A number of commenters, however, believed that the proposal did not go far enough to reform the Plans and that even greater participation by interested non-SRO parties in the Plans is needed. ${ }^{592}$ The SIA recommended that the Commission "amend the governance structures of the Plans to incorporate the types of changes that have been implemented recently in corporate governance generally." 593 These commenters also raised concerns regarding several other

$590 \quad$ See, e.g., Amex Letter at 10; Citigroup Letter at 17; Financial Information Forum Letter at 4; SIIA/FISD Reproposal Letter at 2; Financial Services Roundtable Letter at 6-7; ICI Letter at 4 and 21 n. 35; Instinet Letter at 7, 46; Nasdaq Letter II at 33; Reuters Letter at 3; STANY Letter at 15.

591 CBOE Letter at 2, 17; ISE Letter at 2; Specialist Assoc. Letter at 16. Two commenters on the reproposal suggested that the Commission should adopt the advisory committee structure currently in place for the Nasdaq UTP Plan. ArcaEx Reproposal Letter at 14; Letter from Bridget M. Farrell, Co-Chairman, and Michael P. Rountree, Co-Chairman, Operating Committee of the Nasdaq Unlisted Trading Privileges Plan, to Jonathan G. Katz, Secretary, Commission, dated Feb. 2, 2005 ("Nasdaq UTP Plan Reproposal Letter") at 2. The Nasdaq UTP Plan advisory committee meets bi-annually and has the right to present written comments or inquiries to the Plan operating committee. The Commission has retained the reproposed committee structure, primarily because it believes that advisory committee members should have more direct involvement in the deliberations of Plan operating committees. Specifically, the Governance Amendment gives advisory committee members the right to attend meetings of the operating committee and to receive information disseminated to the operating committee.

592 See, e.g., Letter from W. Hardy Callcott, to Jonathan G. Katz, Secretary, Commission, dated Dec. 30, 2004 ("Callcott Reproposal Letter") at 4; Financial Services Roundtable Letter at 6-7; Goldman Sachs Letter at 12-13; Instinet Reproposal Letter at 17; Morgan Stanley Letter at 22; Schwab Reproposal Letter at 5; SIA Reproposal Letter at 27-28; STANY Letter at 15.

SIA Reproposal Letter at 28. 
aspects of Plan governance, including current administrative costs and burden, the unanimous vote requirement for Plan action, and the current process for reviewing SRO fee filings and Plan amendments. For instance, the SIA also believed that inconsistencies among the Networks regarding administrative requirements and burdens (i.e., agreements and contracts, billing policies, data use policies, and annual audit requirements) contribute to high market data fees and should be reduced, streamlined, and made uniform. ${ }^{594}$

In many respects, the Commission agrees with the concerns expressed by commenters regarding administration of the Plans. Nevertheless, it is reluctant at this point to require more intrusive changes to Plan governance that might interfere with effective Plan operations. The Plans fulfill significant operational functions with respect to the systems that deliver consolidated data to the public on a daily basis. Moreover, improved governance structures at the SRO level also should contribute to improved governance of the Plans through their selection and guidance of SRO representatives on the Plan operating committees. The Commission therefore believes that the Governance Amendment represents a useful first step toward improving the responsiveness of Plan participants and the efficiency of Plan operations. Expanding the participation of interested parties other than SROs in Plan governance should increase the transparency of Plan business, as well as provide an established mechanism for alternative views to be heard by the Plans and the Commission. Earlier and more broadly based participation could contribute to the ability of the Plans to achieve consensus on disputed issues. With respect to Plan administration, promising private efforts are underway to improve consistency among data providers and to reduce administrative burdens. ${ }^{595}$ The Commission particularly believes

$594 \quad$ SIA Letter at 27-28.

595 See SIIA/FISD Reproposal Letter at 2-3 (SIIA/FISD developing guidelines to encourage uniformity in exchange and vendor administrative policies and procedures; guidelines 
that the Plans should give full consideration to the views of industry participants on steps that would streamline the administrative procedures and burdens of the three Plans. Enhanced participation of advisory committee members in Plan affairs should help further this process.

The Commission will continue to monitor and evaluate Plan developments to determine whether any further action is warranted.

\section{Revenue Allocation Formula}

As discussed below, the Commission has adopted the Allocation Amendment with some modifications from the proposal and reproposal. ${ }^{596}$ Given the significant changes from the current Plan formulas, the Commission will monitor the operation of the new formula to assess whether it achieves its goals and whether any further modifications are warranted. As with any other aspects of the Plans, the language added to the Plans by the Allocation Amendment can be adjusted in the future pursuant to the normal process of Commission-approved amendments. ${ }^{597}$

The proposal and reproposal included an amendment to the Plans that would modify their formulas for allocating market data revenues to SRO Participants. The current Plan formulas are based solely on the trading activity of an SRO. The proposed and reproposed formulas were intended to address three serious weaknesses in the old formulas: (1) the absence of any allocation of revenues for the quotations contributed by an SRO to the consolidated data stream;

will address exchange data delay intervals, subscriber agreement streamlining, billing and reporting period issues, and unit of count definitions).

596 As set forth in section VII below, the compliance date for the Allocation Amendment is September 1, 2006. Accordingly, Plan revenues for the first eight months of 2006 will be allocated in accordance with the current Plan formulas. Plan revenues for the remaining part of 2006 will be allocated in accordance with the new formula.

597 Cf. Letter from Mary Yeager, Assistant Secretary, NYSE, to Jonathan G. Katz, Secretary, Commission, dated Jan. 26, 2005 ("NYSE Reproposal Letter II") at 5 (suggesting that, given inability to anticipate all issues that may arise, markets should be allowed to make adjustments to market data plans). 
(2) an excessive emphasis on the number of trades reported by an SRO that has led to distortive trading practices, such as wash sales, trade shredding, and print facilities; and (3) a disproportional allocation of revenues for a relatively small number of stocks with extremely high trading volume, with a much smaller allocation to the thousands of other stocks included in a Network, typically issued by smaller companies, with less trading volume.

To address these problems, the proposed formula included a number of elements, including a Quoting Share, an NBBO Improvement Share, a Trading Share, and a Security Income Allocation. The Quoting Share and NBBO Improvement Share would have provided an allocation of revenues for an SRO's quotations. In particular, the Quoting Share would have allocated revenues for all quotes, both automated and manual, according to the dollar size and length of time that such quotes equaled the price of the NBBO. It included an automatic cutoff of credit for manual quotations, however, when they were left alone at the NBBO. This cut-off was intended to preclude SROs from being allocated revenues merely for slowness in updating their manual quotations. The NBBO Improvement Share would have allocated revenues to SROs for the extent to which they displayed quotations that improved the price of the NBBO.

At the NMS Hearing, representatives of floor-based exchanges stated their intention to adopt hybrid trading models that would primarily display automated quotations. ${ }^{598}$ In response, the Commission, in its Supplemental Release, stated that the prospect of hybrid trading models presented an opportunity for simplifying the proposed allocation formula. ${ }^{599}$ It noted that the purpose of the automatic cutoff for manual quotations was to minimize the allocation of revenues for potentially stale quotations and requested comment on whether only automated quotes should

598 Hearing Tr. at 85, 90-92, 94-97, 120-121.

$599 \quad$ Supplemental Release, 69 FR at 30148. 
be entitled to earn an allocation of revenues. The Supplemental Release also noted that the NBBO Improvement Share was significantly more complex than the other aspects of the proposed formula and that it had been proposed largely to counter the potential for an excessive allocation of revenues for manual quotations. As a result, the Reproposing Release included a reproposed allocation formula that eliminated the NBBO Improvement Share and excluded manual quotations from the Quoting Share ${ }^{600}$ It also allocated revenues equally between the trading activity and quoting activity of Plan participants. Based on additional comments received in response to the reproposal, the Commission is adopting the reproposed allocation formula with certain modifications, as discussed below.

The comments on the proposal and reproposal generally addressed four broad categories of issues: (1) whether the current Plan formulas need to be updated; (2) whether quotations should be considered in allocating revenues; (3) whether the size of trades should be considered in allocating revenues; and (4) whether the allocation of revenues should be allocated more evenly across all of a Network's stocks. These comments are discussed below.

\section{a. Need for New Formula}

Many commenters agreed with the Commission that, if the Networks were to continue allocating revenues to the SROs, the current allocation formulas needed to be updated. ${ }^{601}$ Many of these commenters also believed that the proposed and reproposed formulas should be modified in several respects, and their specific suggestions to improve the proposed formula are discussed below. In general, however, they agreed with the objectives of the proposal and

600 Reproposing Release, 69 FR at 77464.

601 See, e.g., Bloomberg Tradebook Letter at 7; BSE Letter at 15; Deutsche Bank Reproposal Letter at 4; Harris Reproposal Letter at 11; ICI Letter at 21; JP Morgan Reproposal Letter at 2; NYSE Reproposal Letter II at 3; STA Letter at 7; UBS Letter at 10; Vanguard Letter at 6 . 
reproposal to eliminate much of the incentive for distortive trade reporting practices and to begin providing some allocation of revenues for the quotations that SROs contribute to the consolidated data stream.

Other commenters, in contrast, opposed changing the current allocation formulas. ${ }^{602}$ Their specific objections to the proposed and reproposed formulas are discussed below, but they also opposed changing the current formulas for more general reasons. First, some believed that, rather than changing the formulas, the Commission simply should prohibit the particular distortive practices caused by the old formulas and enforce the existing prohibitions against such practices. Commenters also opposed the proposed and reproposed formulas because they believed they incorporated arbitrary judgments about the value of quotations and trades. Finally, those opposed to changing the Plan formulas believed that the proposed formula was simply too complex to be implemented effectively and that its costs exceeded any benefits that were likely to be gained.

The Commission has considered the views of these commenters, but does not believe that they warrant leaving the current Plan formulas in place. First, the Commission intends to continue to enforce the existing prohibitions against distortive trade reporting practices. Rather than attempting to devise new prohibitions that address every conceivable harmful practice, however, it has determined to address directly the formula-driven distortions by adopting revisions to the current formulas. As long as the allocation of market data revenues is based primarily on reporting a large number of very small trades, the incentive for distortive trade reporting will continue. Moreover, as discussed below, the current formulas are flawed in

602 See, e.g., Brut Letter at 22; Instinet Reproposal Letter at 13; Letter from David Colker, Chief Executive Officer and President, National Stock Exchange, to Jonathan G. Katz, Secretary, Commission, dated Jan. 26, 2005 ("NSX Reproposal Letter") at 4; Phlx Letter at 4 . 
several important respects beyond the incentives they create for distortive trade reporting practices.

The Commission does not believe that the adopted formula incorporates arbitrary judgments about the value of trades and quotes. In this regard, it is important to recognize that any formula for allocating market data revenues would reflect some judgment regarding the contribution of the various SROs' data to the consolidated data stream; otherwise, the revenues could simply be allocated equally among all Plan participants. The Commission's goal in adopting a new formula is to improve on the judgments incorporated in the old Plan formulas to more fully achieve NMS objectives.

For example, the current formula for Network A and Network B treats a 100-share trade the same as a 20,000 share trade in the same stock, even though their importance for price discovery purposes clearly is not equal. All of the current Plan formulas value only the trades reported by an SRO (for Networks A and B, the number of reported trades; for Network C, the average of number and share volume of reported trades), thus treating a quotation as having no value except to the extent it resulted in a trade. Quotations are accorded no value even if they were fully accessible and established the NBBO for a substantial period of time, thereby providing price discovery for trades occurring at other markets that internalize orders with reference to the NBBO price. Such formulas based solely on an SRO's trading activity may have been adequate many years ago when a single market dominated each group of securities, but are seriously outdated now that trading is split among many different markets whose contributions to the public data stream can vary considerably.

The adopted formula reflects fairly straightforward determinations about the kinds of data that, in general, are likely to be useful to investors. For example, a $\$ 50,000$ quote at the NBBO 
in a stock is likely more useful to investors than a $\$ 2000$ quote in the same stock. Similarly, a $\$ 50,000$ trade in a stock is likely more useful to investors in assessing the trading trend of that stock than a \$2000 trade; again, not necessarily in every case, but in general and on average. By more appropriately weighing data that is useful to investors, the adopted formula represents a substantial improvement on the old formulas. ${ }^{603}$

Commenters on the original proposal generally believed that the originally proposed formula was complex and may have been difficult to implement efficiently. ${ }^{604}$ They particularly noted that the proposed NBBO Improvement Share was difficult to understand and had the potential to be abused through gaming behavior. The Commission agreed with these commenters and has modified the reproposed formula and adopted formula accordingly. Given that only automated quotations will be entitled to earn an allocation under the adopted formula, the originally proposed NBBO Improvement Share, as well as the proposed cutoff of credits for manual quotations left alone at the NBBO, have been deleted from the reproposed formula and remain deleted in the adopted formula. The elimination of these two elements greatly reduces the complexity of the adopted formula and promotes more efficient implementation of the formula. In addition, the $15 \%$ of the Security Income Allocation that was allocated to the NBBO

603 Some commenters were concerned that the formula's use of dollar volume calculations does not sufficiently allocate revenues to markets that trade low-priced stocks. See, e.g., BSE Letter at 18; CHX Letter at 16. The Commission believes that dollar volume is the most appropriate measure, in general, of the importance to investors of trading and quoting information. Per share stock prices, in contrast, are a more arbitrary measure because they are dependent, to a large extent, on the number of shares a company chooses to issue, both originally and through stock splits and reverse stock splits. To the extent the commenters were concerned about the less active stocks of smaller companies, the Security Income Allocation of the adopted formula incorporates the square root function precisely to more appropriately allocate revenues to SROs that provide a venue for price discovery in these stocks. See section V.A.3.d below.

604 See, e.g., Angel Letter I at 11; Financial Information Forum Letter at 3; NYSE Letter, Attachment at 11. 
Improvement Share in the proposed formula now has been shifted to the Quoting Share to assign an even allocation of revenues between trading and quoting.

Other commenters asserted that it would overly costly and complex to calculate the other elements of the proposed formula. ${ }^{605}$ The Commission does not agree with this assertion. An SRO's Trading Share, for example, will not be materially more difficult to calculate than the current Network C formula, which is based on an average of an SRO's proportion of trades and share volume. The Security Income Allocation uses the square root function which is a simple arithmetic calculation. Some commenters believed that the Quoting Share, which incorporates the total dollar size of the NBBO in a stock throughout the trading year, would result in astronomically high numbers that would be extremely difficult to calculate. ${ }^{606}$ In fact, the largest number of Quote Credits in a year for even the highest price stock with the greatest displayed depth at the NBBO is be very unlikely to reach beyond the trillions, a number well within the capabilities of even the most basic spreadsheet program. ${ }^{607}$ Moreover, the allocation is determined by the proportion of an SRO's Quote Credits in relation to other SROs, not the absolute amount of Quote Credits.

\footnotetext{
$605 \quad$ See, e.g., Brut Letter at 22-23; CBOE Letter at 2, 9; NSX Letter at 7.

606 See, e.g., CBOE Letter at 14 (calculation of Quote Credits will "yield astronomical numbers" that "can be expressed only in exponential terms"); NSX Letter at 7 (calculation of large number of Quote Credits is "particularly ludicrous").

607 For example, assume a stock with an average price of $\$ 100$ per share has an unusually large average quoted size of 200,000 shares at both the national best bid and the national best offer throughout every second of the trading year. Over an average 252 trading days during a year, the total Quote Credits in this stock would be 235.9 trillion ( $\$ 100 * 400,000 * 252 * 23,400$ seconds per trading day). Quote Credits are only calculated for individual Network stocks and are not be totaled across all Network stocks.
} 
Some commenters suggested that revenue allocations under the formula should be calculated and paid out on a quarterly basis. ${ }^{608}$ Currently, the Networks make estimated quarterly payments subject to a final annual calculation and payment. Commenters believed quarterly calculations and payments would simplify administration of the formula and reduce the potential for disparities between quarterly estimated and annual final payments. The adopted Allocation Amendment does not alter the current Plan provisions for annual final payments. It is important to retain a final annual calculation and payment to minimize the potential for unusual trading activity, or intentional gaming behavior, to inappropriately distort an allocation within a quarter. The annual calculation will be based on numbers that are four times larger than the numbers for a quarterly calculation. These larger numbers will help smooth out the effect of unusual market activity in a particular quarter, as well as increase the difficulty of any attempt at gaming behavior. Of course, all of the formula's calculations can be updated daily, and quarterly estimated payments based on these calculations can continue to be made to SRO participants.

Finally, a few commenters were concerned about the effect of modifying the current allocation formulas on the existing business models and terms of competition for the various markets. ${ }^{609}$ The Commission recognizes that reforming formulas that have remained unchanged for many years could affect the competitive position of various markets. Given the severe deficiencies of these formulas, however, it does not believe that the interests of any particular business model should preclude updating the formulas to reflect current market conditions. The adopted formula is intended to reflect more appropriately the contributions of the various SROs to the consolidated data stream and thereby better align the interests of individual markets with

\footnotetext{
608 See, e.g., NYSE Reproposal Letter II at 5; Nasdaq UTP Plan Reproposal Letter at 3. 609 See, e.g., Brut Letter at 22; CHX Letter at 21-22; NSX Letter at 6.
} 
the interests of investors. Moreover, by incorporating a much more broad-based measure of an SRO's contribution to the consolidated data stream, the adopted formula should be less subject to any particular type of gaming and distortion than the narrowly-focused current Plan formulas. ${ }^{610}$

\section{b. Quotations that Equal the NBBO}

Many commenters supported the proposal to allocate a portion of market data revenues based on an SRO's quotations, particularly if only automated and accessible quotations would qualify for an allocation. ${ }^{611}$ Some commenters, however, were concerned about the risk of harmful gaming behavior by market participants. ${ }^{612}$ For example, Instinet stated that the "fundamental problem with the Commission's proposed formula stems from the inherently low cost for market participants to generate quotation information and the consequent high potential for gaming behavior in any formula that attempts to reward such behavior." ${ }^{\text {613 }}$ A specific type of gaming that concerned commenters was "flickering quotes" - quotes that are flashed for a short period of time solely to earn market data revenues, but are not truly accessible and therefore do not add any value to the consolidated quote stream. Nasdaq discussed a number of other potential gaming behaviors, including posting quotations in inactive markets or for inactive

610 Two commenters on the reproposal suggested adopting an allocation formula based solely on the dollar volume of trading. ArcaEx Reproposal Letter at 13; Nasdaq Reproposal Letter at 14. Dollar volume alone, however, is not a broad-based measure and would miss important aspects of an SRO's contribution to the public data stream. It would, for example, allocate a disproportionately large amount to block trades. Block trades often are internalized by securities dealers at prices based, at least partly, on current public quotations. A formula based solely on dollar volume would not adequately allocate revenues to the source of quotations relied on in pricing block trades.

611 See, e.g., Bloomberg Tradebook Letter at 7-8; Morgan Stanley Letter at 22-23; NYSE Reproposal Letter II at 3; STA Letter at 7; Vanguard Letter at 6.

612 See, e.g., ArcaEx Reproposal Letter at 13; CHX Letter at 19; Instinet Reproposal Letter at 14; SIA Reproposal Letter at 30.

Instinet Letter at 41. 
securities so that they are less likely to be executed. ${ }^{614}$ Commenters also were concerned that such practices would increase quotation traffic and bandwidth costs, but with little or no benefit for the quality of the consolidated data stream.

The Commission recognizes that abusive quoting behavior is a legitimate concern, particularly given that quotations have not been entitled to an allocation of market data revenues in the past. The adopted formula therefore incorporates a number of modifications to the reproposed formula to minimize the potential for abusive or costly quoting behavior.

First, the adopted formula modifies the language of the reproposed formula to clarify that a quotation must be displayed by the Network processor for a minimum of one full second of time before it is entitled to earn any Quote Credits. This one-second time period is consistent with the one-second time period included in the flickering quotation exception in the Order Protection Rule and is designed to assure that only quotations that are readily accessible can earn Quote Credits. The time stamps assigned to quotations by the Network processors will control this determination. Accordingly, subsecond flickering quotations are excluded from the formula.

Second, the adopted formula modifies the language of the reproposed formula to clarify that, consistent with the approach of the Order Protection Rule, each SRO participant in a Network is entitled to earn Quote Credits only for the SRO's best bid and best offer. Thus, for example, only a single, accessible best bid and best offer for each of the exchange SROs, Nasdaq, and the NASD will be entitled to earn Quote Credits. A best bid and best offer must be accessible by routing an order to a single market destination (i.e., currently, to a single exchange execution system, a single Nasdaq execution system, or a single ADF participant). By limiting the number of separate quotations that are entitled to earn Quote Credits, the adopted formula

$614 \quad$ Nasdaq Reproposal Letter at 12-13. 
both reduces the ability of market participants to "shred" their quotes among many different markets and promotes equal regulation of exchange SROs, Nasdaq, and the NASD.

Third, the adopted formula modifies the language of the reproposed formula to clarify that a quotation cannot earn Quote Credits while it locks or crosses a previously displayed automated quotation. This limitation is needed to remove any potential financial incentive for abusive quoting behavior that would be contrary to the purposes of the provisions on locking and crossing quotations set forth in the Access Rule.

Finally, as discussed further below, ${ }^{615}$ the Security Income Allocation in the adopted formula modifies the reproposed formula by limiting the total revenues allocated to any particular Network security to no more than $\$ 4$ per qualified transaction report. This limitation on each security's revenue allocation therefore will apply to both the Trading Share and Quoting Share. In contrast, the reproposed formula limited the allocation only for the Trading Share of a Network security to $\$ 2$ per qualified transaction report, but shifted the excess balance of revenues to the Quoting Share for such Network security - thereby potentially increasing the risk of abusive quoting behavior in highly inactive Network securities. Under the adopted formula, the excess balance above the limitation will be allocated across all Network securities in direct proportion to their share of dollar volume of trading.

With these clarifications and modifications, the Commission does not believe that the Quoting Share of the adopted formula will be unacceptably vulnerable to gaming, particularly because only automated and fully accessible quotations will be entitled to earn a share of market data revenues. The potential cost of displaying such quotations, in the form of unprofitable trades, should not be underestimated. Quotations would earn significant revenues only if they

615 Infra, section V.A.3.d. 
represent a significant proportion of the total size of quotations displayed at the NBBO for a stock throughout the trading year. The risk of losses that could result from the execution of orders against large quotations would be likely to dwarf any potential allocation of market data revenues. ${ }^{616}$ With the advent of highly sophisticated order-routing algorithms, accessible automated quotations throughout the NMS can be hit at lightning speed. Some of these algorithms are specifically designed to search the market for displayed liquidity and sweep such liquidity immediately when it is displayed. The market discipline imposed by these orderrouting practices should greatly reduce the potential for "low cost" quotations at the NBBO. A market participant would have to be prepared to trade at a price, particularly a price as attractive as the NBBO, before displaying accessible and automated quotations to earn market data revenues. Moreover, any quotations submitted for stocks that are inactively traded (and therefore less likely to attract trading interest) will garner a very small Quoting Share allocation because the size of such allocation will be determined by the proportional dollar volume of trading in a stock.

Finally, commenters were concerned that some quotations might be submitted to "hide in the queue" when a stock already has significant depth displayed at the NBBO.$^{617}$ The strategy is

616 For example, Nasdaq asserted that approximately $\$ 1$ million per month would be distributed among SROs based on quoting in the 2000 least active Nasdaq stocks. Nasdaq Reproposal Letter at 13. In this scenario, an average of $\$ 500$ per month would be allocated to each stock. Given the approximately 491,400 seconds of trading in an average month, the average available Quoting Share in a stock for each second would be approximately $1 / 10$ th of one cent, which would be further divided among bids and offers to approximately $1 / 20$ th of one cent. Moreover, this amount would be shared among all market participants quoting in the stock. Consequently, even the smallest losing trade (i.e., a one-cent loss on an executed 100-share quote) would wipe out 2000 seconds (more than 33 minutes) of the entire Quoting Share allocation for bids or offers in the stock.

617 Nasdaq Reproposal Letter at 13; NYSE Reproposal Letter at 2. 
risky, however, because of the desire for greater liquidity evidenced by the number of marketable limit orders entered but not filled, particularly for Nasdaq stocks, that was discussed above in section II.A.1.b. Typically, the volume of such orders searching for liquidity at the NBBO far exceeds the available liquidity (both displayed size and reserve size). Any quotations attempting to hide in the queue at the NBBO when liquidity seeking orders arrive would necessarily be executed immediately. ${ }^{618}$

A few commenters also opposed the proposed Quoting Share because they believed it represented an inappropriate attempt by the Commission to control the quoting behavior of market participants. ${ }^{619}$ ArcaEx, for example, stated that the "most important question is how paying for top-of-book quotes - on a time- and size-weighted basis or on any other basis encourages beneficial behavior," and questioned whether the Quoting Share would achieve this result. Brut asserted that "[n]ot only would [the proposed formula] increase the potential unnatural trading and quoting behavior, it signifies a desire to use market structure regulation to micro-manage market participant behavior . . . ."620

618 Of course, the Commission and SROs will continue to monitor quoting activity for any conduct that violates the federal securities laws, the rules thereunder, or SRO rules and take appropriate action to address such conduct. For example, one commenter suggested that a market participant might enter a buy order at the national best bid at a time when there already is depth at such bid, but with instructions to "cancel" the order upon execution of orders earlier in the queue. NYSE Reproposal Letter at 2. Such an order type would effectively be impossible to access because it always would be cancelled when at risk of execution. As a result, reflecting these orders in a displayed quotation would be a clear violation of the Rule 602(b) of Regulation NMS, which requires that displayed quotations be firm, as well as constitute a material misstatement to the market and investors concerning trading interest in the stock.

619 ArcaEx Letter at 13; Brut Letter at 22, Phlx Letter at 4.

$620 \quad$ Brut Letter at 22. 
These commenters appear to have misunderstood the Commission's objective in proposing to update the current Plan formulas. As noted above, ${ }^{621}$ it is unlikely that a marginal increase in market data revenues would significantly alter the quoting behavior of market participants, at least for those not already interested in trading a stock for separate reasons. The potential cost of unprofitable trades would be too high. Rather, the Commission's primary objective is to correct an existing flaw in the current formulas by allocating revenues to those SROs that, even now, benefit investors by contributing useful quotations to the consolidated data stream. Currently, such SROs do not receive any allocation for providing a venue for this beneficial quoting activity. Basing an allocation on the extent to which an SRO's quotes equal the NBBO is an appropriate means to correct this flaw, even if the allocation does not always reflect the precise value of quotations. ${ }^{622}$

\section{c. Number and Dollar Volume of Trades}

The current Plan formulas allocate revenues based on the number of trades (Networks A and B) or on the average of number of trades and share volume of trades (Network C) reported by SROs. By focusing solely on trading activity (and particularly by rewarding the reporting of many trades no matter how small their size), these formulas have contributed to a variety of distortive trade reporting practices, including wash sales, shredded trades, and SRO print facilities. To address these practices and to establish a more broad-based measure of an SRO's

621 Supra, note 616 and accompanying text.

622 ArcaEx noted that top-of-book quotes make only a partial contribution to price discovery and that depth-of-book quotes are particularly important since decimalization. ArcaEx Letter at 13. The Commission agrees that depth-of-book quotes are important to investors, and for that reason has adopted amendments to the market data rules to facilitate the independent dissemination of a market's depth of book. The rules will not prevent such a market from charging fees for depth-of-book quotations that are fair and reasonable and not unreasonably discriminatory. 
contribution to the consolidated trade stream, the proposed formula provided that an SRO's Trading Share in a particular stock would be calculated by taking the average of the SRO's percentage of total dollar volume in the stock and the SRO's percentage of qualified trades in the stock. A "qualified trade" was defined as having a dollar volume of $\$ 5000$ or more. The Proposing Release requested comment on whether this amount should be higher or lower, or whether trades with a size of less than $\$ 5000$ should receive credit that was proportional to their size. ${ }^{623}$

Several commenters on the original proposal believed that small trades contribute to price discovery and should be entitled to earn at least some credit in the calculation of the number of qualified trades. ${ }^{624}$ The Commission agreed and included in the reproposed formula a provision that awards a fractional proportion of a qualified report for trades of less than $\$ 5000$. The adopted formula also includes this provision. Thus, a $\$ 2500$ trade will constitute $1 / 2$ of a qualified transaction report. This approach greatly reduces the potential for large allocations attributable to shredded trades, while recognizing the contribution of small trades to price discovery.

Two commenters on the original proposal asserted that the $\$ 5000$ threshold was arbitrary. ${ }^{625}$ As noted in the Proposing Release, an analysis of Network A data indicates that approximately $90 \%$ of dollar volume and $50 \%$ of trades exceed this threshold. The Commission believes that the $\$ 5000$ figure represents a reasonable attempt to address the problem of shredding large trades into 100-share trades. By providing only a proportional allocation for

$623 \quad$ Proposing Release, 69 FR at 11181.

624 See, e.g., BSE Letter at 16; CHX Letter at 19-20; E*Trade Letter at 11.

$625 \quad$ E*Trade Letter at 11; Instinet Letter at 42. 
trades with dollar amounts below this threshold, the ability of market participants to generate large revenue allocations by shredding trades would be greatly reduced. For example, a 2000share trade in a $\$ 25$ stock could be shredded into twenty trades in the absence of a dollar threshold for qualified trades, but could be shredded into only ten qualified trades under the reproposed formula. Moreover, when combined with the allocation of $50 \%$ of revenues to the Quoting Share and the allocation of another 25\% of revenues based on the dollar volume of trades, the $\$ 5000$ threshold for qualified trades will eliminate much of the potential reward for trade shredding under reproposed formula. In the example of the 2000-share trade in a \$25 stock, the incentive for shredding would have been reduced by a total of $87.5 \%(75 \%+(50 \% *$ 25\%). ${ }^{626}$

\section{d. Allocation of Revenues Among Network Stocks}

The proposed formula included a Security Income Allocation, pursuant to which a Network's total distributable revenues would be allocated among each of the Network's stocks based on the square root of dollar volume. The square root function was intended to adjust for the highly disproportionate level of trading in the very top tier of Network stocks. A few hundred stocks (e.g., the top 5\%) are much more heavily traded than the other thousands of Network stocks. The Proposing Release noted that an allocation that simply was directly proportional to trading volume would fail to reflect adequately the importance of price discovery

626 One commenter on the reproposal suggested that the dollar volume allocation for block trades be capped at $\$ 300,000$ to preclude a disproportionate allocation. NYSE Reproposal Letter II at 4-5. The adopted formula does not include a cap on block trades because it would appear to be easily avoidable through trade-shredding. Moreover, the separate allocations for qualified transaction reports and for Quoting Shares serve to limit the extent to which block trades receive a disproportionate allocation under the adopted formula. 
for the vast majority of stocks. ${ }^{627}$ The Reproposing Release retained this provision in the reproposed formula. ${ }^{628}$

Of the commenters that addressed this issue, several supported the use of a square root function to allocate revenues among stocks. ${ }^{629}$ Nasdaq, for example, noted that the "methodology will reduce the disparity between the value of data of the most active and least active securities." ${ }^{630}$ Other commenters, in contrast, opposed the use of the square root function to allocate revenues among Network stocks. ${ }^{631}$ ArcaEx believed that the proposed allocation method "introduces a steeply progressive tax on liquid stocks to subsidize illiquid stocks" and that the allocation of revenues should remain directly proportional to trading volume. ${ }^{632}$

With one modification, the Commission has retained the square root function in the adopted formula to allocate distributable Network revenues more appropriately among all of the stocks included in a Network. Although the extent to which Network stocks are tiered according to trading volume varies among the three Networks, it is quite pronounced in each of them. The use of the square root function reflects the Commission's judgment that, on average and not necessarily in every particular case, information about a $\$ 50,000$ trade in a stock with an average daily trading volume of $\$ 500,000$ is marginally more useful to investors than a $\$ 50,000$ trade in a

$627 \quad$ Proposing Release, 69 FR at 11180.

628 Reproposing Release, 69 FR at 77466.

629 Amex Letter, Exhibit A at 15; Nasdaq Letter II at 32; NYSE Reproposal Letter II at 3; Specialist Assoc. Letter at 16 n. 21.

$630 \quad$ Nasdaq Letter II at 32.

631 ArcaEx Reproposal Letter at 11; CBOE Letter at 11; Instinet Reproposal Letter at 13; Letter from Ronald A. Orguss, President, Xanadu Investment Co., to Jonathan G. Katz, Secretary, Commission, dated Jun. 29, 2004 ("Xanadu Letter") at 2-3.

ArcaEx Letter at 12. 
stock with an average daily trading volume of \$500 million. Markets that provide price discovery in less active stocks serve an extremely important function for investors in those stocks. Price discovery not only benefits those investors who choose to trade on any particular day, but also benefits those who simply need to monitor the status of their investment. Efficient secondary markets support buy-and-hold investors by offering them a ready opportunity to trade at any time at a fair price if they need to buy or sell a stock. Indeed, this enhanced assurance is one of the most important contributions of secondary markets to efficient capital-formation and to reducing the cost of capital for listed companies. The square root function allocates revenues to markets that perform this function for less-active stocks by marginally increasing their percentage of market data revenues, while still allocating a much greater dollar amount to more actively traded stocks.

With respect to very inactively traded stocks, however, the adopted formula modifies the reproposed square root allocation by limiting the revenues that can be allocated to a single Network security to an amount that is no greater than $\$ 4$ per qualified transaction report. The amount that exceeds this $\$ 4$ limitation will be reallocated among all Network securities in direct proportion to their dollar volume of trading (which is heavily weighted toward the most actively traded stocks). The Commission is adopting this $\$ 4$ limitation to respond to commenters' concerns about the potential for abusive quoting behavior in extremely inactive stocks by anyone seeking to game the Quoting Share allocation. ${ }^{633}$

The \$4 limitation is consistent with the \$2 limitation on Trading Share allocations in the proposed formula and reproposed formula. ${ }^{634}$ Whereas the $\$ 2$ reproposed limitation applied only

633 See supra, section V.A.3.b.

$634 \quad$ See Proposing Release, 69 FR at 11181; Reproposing Release, 69 FR at 77467. 
to the 50\% revenue allocation for Trading Share, the $\$ 4$ adopted limitation applies to $100 \%$ of the revenue allocation for a Network security. The $\$ 4$ limitation will prevent extremely high allocations per qualified transaction report for very inactive Network stocks, particularly when compared with the current distributable revenues per trade of the Networks, which ranged from $\$ 0.14$ to $\$ 1.03$ in $2004 .{ }^{635}$ Consequently, the $\$ 4$ limitation is designed to achieve an appropriately balanced allocation among Network stocks by allowing room for a significant increase in the amounts currently allocated for many less active stocks, while also preventing unjustifiably high allocations for the most extremely inactive stocks that might create an inappropriate incentive for abusive quoting behavior.

To illustrate the operation of the $\$ 4$ limitation, assume that the initial square root allocation for a security with 10 qualified transaction reports during the year was $\$ 300$, or an average allocation of $\$ 30$ per qualified transaction report. Rather than allocate the full $\$ 300$ to this extremely inactive security, the adopted formula limits the allocation to $\$ 4$ per qualified transaction report, so that a total of only $\$ 40$ would be allocated to the stock as its Security Income Allocation. The difference of $\$ 260$ (\$300 minus \$40) would be reallocated among all Network securities in direct proportion to their share of dollar volume of trading.

\section{Distribution and Display of Data}

Most commenters supported the provisions, set forth in both the proposal and reproposal, authorizing the independent distribution of market data outside of what is required by the

The distributable revenue per trade for a Network is calculated by dividing the total distributable net income of the Network by the total number of reported trades for the Network's securities. For the Networks in 2004, the distributable revenue per trade was 15.1 cents for Network A, 14.5 cents for Network C, and 103.1 cents for Network B. The foregoing Network financial information is preliminary and unaudited. 
Plans. ${ }^{636}$ They generally agreed that the proposal would allow investors and vendors greater freedom to make their own decisions regarding the data they need. They also believed that the proposed rule amendment's "fair and reasonable" and "not unreasonably discriminatory" standards are appropriate to ensure that the independently distributed market data would be made available to all investors and data users. A few commenters, in contrast, objected to the proposed standards, asserting that the standards would not effectively protect investors and "weaker and newer markets from predatory actions by stronger markets or the potential loss of data integrity." 637

The Commission is adopting Rule 603(a) as proposed and reproposed. ${ }^{638}$ The "fair and reasonable” and "not unreasonably discriminatory” requirements in adopted Rule 603(a) are derived from the language of Section $11 \mathrm{~A}(\mathrm{c})$ of the Exchange Act. Under Section 11A(c)(1)(C), the more stringent "fair and reasonable" requirement is applicable to an "exclusive processor," which is defined in Section 3(a)(22)(B) of the Exchange Act as an SRO or other entity that

$636 \quad$ See, e.g., Brut Letter at 21, 23; CBOE Letter at 2, 17; Citigroup Letter at 16; Financial Information Forum Reproposal Letter at 4; Letter from Coleman Stipanovich, Executive Director, State Board of Administration of Florida, to Jonathan G. Katz, Secretary, Commission, dated June 29, 2004 ("Florida State Board Letter") at 2; Financial Services Roundtable Letter at 6; Goldman Sachs Letter at 12; ICI Letter at 4, 21 n. 35; Instinet Letter at 45; Nasdaq Letter II at 33; NYSE Letter, Attachment at 12; Letter from P. Howard Edelstein, President and CEO, Radianz Americas, Inc., to Jonathan G. Katz, Secretary, Commission, dated Jan. 27, 2005 ("Radianz Reproposal Letter") at 1-2; Reuters Letter at 3.

637 See, e.g., Amex Letter at 10, Exhibit A at 13.

638 The Commission also is adopting the reproposed amendment to current Rule 11Aa3-1 (redesignated as Rule 601 under Regulation NMS), which rescinds the prohibition on SROs and their members from disseminating their trade reports independently. Given that members of an SRO will continue to be required to transmit their trades to the SRO (and SROs will continue to transmit trades to the Networks pursuant to the Plans), the Commission believe that SROs and their members also should be free to distribute their trades independently. 
distributes the market information of an SRO on an exclusive basis. Adopted Rule 603(a)(1) extends this requirement to non-SRO markets when they act in functionally the same manner as exclusive processors and are the exclusive source of their own data. Applying this requirement to non-SROs is consistent with Section $11 \mathrm{~A}(\mathrm{c})(1)(\mathrm{F})$ of the Exchange Act, which grants the Commission rulemaking authority to "assure equal regulation of all markets” for NMS Securities.

Commenters were concerned about the statement in the Proposing Release that the distribution standards would prohibit a market from distributing its data independently on a more timely basis than it makes available the "core data” that is required to be disseminated through a Network processor. ${ }^{639}$ Instinet, for example, requested that the Commission clarify that the proposal would not require a market center to artificially slow the independent delivery of its data in order to synchronize its delivery with the data disseminated by the Network. ${ }^{640}$ Adopted Rule 603(a) will not require a market center to synchronize the delivery of its data to end-users with delivery of data by a Network processor to end-users. Rather, independently distributed data could not be made available on a more timely basis than core data is made available to a Network processor. Stated another way, adopted Rule 603(a) prohibits an SRO or broker-dealer from transmitting data to a vendor or user any sooner than it transmits the data to a Network processor.

A majority of the commenters supported the Commission's proposed reduction of the consolidated display requirements, stating that it should lead to lower costs for investors. ${ }^{641} \mathrm{~A}$

639 Amex Letter, Exhibit A at 12; Instinet Letter at 47; Reuters Letter at 2.

$640 \quad$ Instinet Letter at 47.

641 See, e.g., Brut Letter at 21, 23; Financial Information Forum Letter at 3-4; Instinet Letter at 7, 45; Nasdaq Letter II at 27, 32; Reuters Letter at 2-3. 
few commenters, however, opposed eliminating the requirement to display a full montage of market BBOs. ${ }^{642}$ Amex, for example, believed that elimination of the montage would confuse investors and make it more complicated for vendors and broker-dealers to manage market data. Some commenters believed that, rather than reducing the consolidated display requirement, the Commission should expand the requirement to include additional information on depth-of-book quotations, stating that the NBBO alone has become less informative since decimalization. ${ }^{643}$

The Commission does not believe that streamlining the quotations included in the consolidated display requirement will detract from the quality of information made available to investors. Adopted Rule 603(c), which is adopted today as proposed and reproposed, will continue to require the disclosure of basic quotation information (i.e., prices, sizes and market center identifications of the NBBO). Particularly for retail investors, the NBBO continues to retain a great deal of value in assessing the current market for small trades and the quality of execution of such trades. For example, statistics on order execution quality for small market orders (the order type typically used by retail investors) reveal that their average execution price is very close to, if not better than, the $\mathrm{NBBO}{ }^{644}$ The adopted consolidated display requirement will allow market forces, rather than regulatory requirements, to determine what, if any,

$642 \quad$ See, e.g., Amex Letter at 9 \& Exhibit A at 12; Bloomberg Tradebook Letter at 9; Callcott Letter at 1, 2, 5 .

643 See, e.g., Bloomberg Reproposal Letter at 9; Schwab Reproposal Letter at 5.

644 See, e.g., S\&P Index Study, Table 2 (slippage rates - the extent to which executions occur at prices inferior to the NBBO at time of order receipt - for small market orders range from -2.5 basis points (i.e., price improvement) to 0.5 basis points). The Dash 5 statistics used in the S\&P Index Study were calculated using the NBBO at time of order receipt, whereas trade-through statistics used in the Trade-Through Study were calculated using the market BBOs at the time of order execution. In addition, the Dash 5 statistics reflect the overall average of order executions inside the NBBO, at the NBBO, and outside the NBBO. The trade-through statistics focus solely on trades executed outside the best prices. Consequently, the two sets of statistics are not directly comparable. 
additional quotations outside the NBBO are displayed to investors. Investors who need the BBOs of each SRO, as well as more comprehensive depth-of-book information, will be able to obtain such data from markets or third party vendors.

\section{B. Description of Adopted Rules and Amendments}

\section{Allocation Amendment}

For the reasons just discussed, the Commission is adopting with modifications an amendment to each of the Plans (“Allocation Amendment”) that incorporates a broad based measure of the contribution of an SRO's quotes and trades to the consolidated data stream. ${ }^{645}$ The adopted formula reflects a two-step process. First, a Network's distributable revenues (e.g., $\$ 150$ million) will be allocated among the many individual securities (e.g., 3000) included in the Network's data stream. Second, the revenues that are allocated to an individual security (e.g., $\$ 200,000$ ) will be allocated among the SROs based on measures of the usefulness to investors of the SROs' trades and quotes in the security. The Allocation Amendment provides that, notwithstanding any other provision of a Plan, its SRO participants shall receive an annual payment for each calendar year that is equal to the sum of the SRO's Trading Shares and

645 In 2002, the Commission abrogated several SRO proposals for rebating data revenues to market participants. Securities Exchange Act Release No. 46159 (July 2, 2002), 67 FR 45775 (July 10, 2002). The purpose of the abrogation was to allow more time for the Commission to consider market data issues. Given that the current Plan allocation formulas will be updated to allocate revenues for more beneficial quoting and trading behavior, the Commission will consider whether rebates will be permitted after implementation of the adopted formula, taking into account whether their terms meet applicable Exchange Act standards and SROs are able to meet their regulatory responsibilities. Such SRO rebates would, of course, have to filed with the Commission for notice, comment, and Commission consideration pursuant to Section 19(b) of the Exchange Act. 
Quoting Shares in each Network security for the year. ${ }^{646}$ These two types of Shares are dollar amounts that are calculated based on SRO trading and quoting activity in each Network security.

For the reasons discussed in section V.A.3 above, the Commission finds that the Allocation Amendment is necessary and appropriate in the public interest, for the protection of investors and the maintenance of fair and orderly markets, to remove impediments to, and perfect the mechanisms of, a national market system, and otherwise in furtherance of the purposes of the Exchange Act.

\section{a. Security Income Allocation}

The first step of the adopted formula is to allocate a Network's total distributable revenues among the many different securities that are included in a Network (the "Security Income Allocation”). Paragraph (b) of the adopted Allocation Amendment bases this allocation primarily on the square root of dollar volume of trading in each security. Use of the square root function will more appropriately allocate revenues among stocks with widely differing trading volume. A small number of Network stocks are much more heavily traded than the great majority of Network stocks. By proportionally shifting revenues away from the very top tier of active stocks and increasing the allocation across other stocks, the Security Income Allocation is intended to reflect more adequately the importance of price discovery for all Network stocks.

For the most inactively traded securities, however, the square root function can disproportionately allocate revenues for a small number of trades during the year. For example,

646 Two commenters were concerned that the new formula might prohibit the Network's current practice of making estimated quarterly payments of Network revenues, with a final reconciliation at the end of the year. BSE Letter at 18, 19; CHX Letter at 22. The language of the reproposed formula and adopted formula, however, merely tracks existing Plan language for the calculation of "Annual Shares" or "annual payments." Nothing in the adopted formula prohibits Networks from making estimated quarterly payments. 
the square root allocation for a security with 10 qualified transaction reports during the year might be $\$ 300$. Rather than allocate the full \$300 to such an inactively traded security (for an average allocation per qualified transaction report of \$30), the adopted formula includes a cap of \$4 per qualified transaction report, so that a total of only $\$ 40$ will be allocated to the inactive security pursuant to the square root allocation. The difference of $\$ 260$ (\$300 minus $\$ 40$ ) will be reallocated among all Network securities in direct proportion to the dollar volume of transaction reports in Network securities. A transaction report with a dollar volume of \$5000 or more constitutes one qualified report. A transaction report with a dollar volume of less than $\$ 5000$ constitutes a proportional fraction of a qualified transaction report.

\section{b. Trading Share}

Under paragraph (c) of the adopted Allocation Amendment, an SRO’s Trading Share in a particular Network security will be a dollar amount that is determined by multiplying: (1) an amount equal to $50 \%$ of the Security Income Allocation for the Eligible Security by (2) the SRO’s Trade Rating in the security. A Trade Rating will be a number that represents the SRO's proportion of dollar volume and qualified trades in the security, as compared to the dollar volume and qualified trades of all SROs. The Trade Ratings of all SROs will add up to a total of one. Thus, for example, multiplying $50 \%$ of the Security Income Allocation for a Network security (e.g., \$200,000) by an SRO’s Trade Rating in that security (e.g., 0.2555) would produce a dollar amount (e.g., $50 \%$ x $\$ 200,000$ x $0.2555=\$ 25,550$ ) that is the SRO’s Trading Share for the security for the year.

Applying 50\% of the Security Income Allocation to the Trading Share reflects a judgment that generally trades and quotes are of approximately equal importance for price discovery purposes. An SRO’s Trade Rating will be calculated by taking the average of: (1) the 
SRO's percentage of total dollar volume reported in the Network security during the year and (2) the SRO's percentage of the total number of qualified transaction reports in the Network security for the year. A transaction report with a dollar volume of $\$ 5000$ or more will constitute one qualified report. A transaction report with a dollar volume of less than $\$ 5000$ will constitute a proportional fraction of a qualified transaction report. As a result, all sizes of transaction reports will contribute toward an SRO's Trade Rating.

\section{c. Quoting Share}

Under paragraph (d) of the adopted Allocation Amendment, an SRO’s Quoting Share in a particular Network Security will be a dollar amount that is determined by multiplying (1) an amount equal to $50 \%$ of the Security Income Allocation for the security by (2) the SRO's Quote Rating in the security. A Quote Rating will be a number that represents the SRO's proportion of best bids and best offers that equaled the price of the NBBO during the year ("Quote Credits"), as compared to the Quote Credits of all SRO's during the year. The Quote Ratings of all SROs will add up to a total of one. Multiplying 50\% of the Security Income Allocation for a Network security by an SRO's Quote Rating in that security will produce a dollar amount that is the SRO's Quoting Share for the security for the year.

An SRO will earn one Quote Credit for each second of time and dollar value of size that the SRO's automated best bid or best offer during regular trading hours equals the price of the NBBO and does not lock or cross a previously displayed automated quotation. ${ }^{647}$ To qualify for

647 Regular trading hours are defined in Rule 600(b)(64) of Regulation NMS as between 9:30 a.m. and 4:00 p.m. Eastern Time, unless otherwise specified pursuant to the procedures established in Rule 605(a)(2). One commenter suggested that the reproposal trades also should have limited trades to those reported during regular trading hours. NYSE Reproposal Letter II at 4. The Commission believes that after-hours trades generally have price discovery value and is retaining the current Plan practice of including them in the allocation formula. 
credits, the quoted price must be displayed for at least one full second, and the relevant size will be the minimum size that was displayed during the second. Thus, for example, a bid with a dollar value of $\$ 4000$ (e.g., a bid of $\$ 20$ with a size of 200 shares) that equals the national best bid for three full seconds would be entitled to 12,000 Quote Credits. If an SRO quotes simultaneously at both the national best bid and the national best offer, it would earn Quote Credits for each quote. An automated quotation is defined by reference to adopted Rule 600(b)(3) under Regulation NMS. Thus, an SRO's manual quotations will not be entitled to earn any Quote Credits.

\section{Governance Amendment}

For the reasons discussed above in section V.A.2.b, the Governance Amendment is adopted as proposed and reproposed. Paragraph (a) mandates the formation of a Plan advisory committee. Paragraph (b) of the Governance Amendment sets forth the composition and selection process for such an advisory committee. Members of the advisory committee will be selected by the Plan operating committee, by majority vote, for two-year terms. At least one representative must be selected from each of the following five categories: (1) a broker-dealer with a substantial retail investor customer base; (2) a broker-dealer with a substantial institutional investor customer base; (3) an ATS; (4) a data vendor; and (5) an investor. Each Plan participant also will have the right to select one additional member to the advisory committee that is not employed by or affiliated with any Plan participant or its affiliates or facilities.

Paragraphs (c) and (d) of the Governance Amendment set forth the function of the advisory committee and the requirements for its participation in Plan affairs. Pursuant to paragraph (c), members of an advisory committee have the right to submit their views to the 
operating committee on Plan matters, including, but not limited to, any new or modified product, fee, contract, or pilot program that is offered or used pursuant to the Plan. Paragraph (d) provides that members have the right to attend all operating committee meetings and to receive any information distributed to the operating committee relating to Plan matters, except when the operating committee, by majority vote, decides to meet in executive session after determining that an item of Plan business requires confidential treatment.

For the reasons discussed in section V.A.2.b above, the Commission finds that the Governance Amendment is necessary and appropriate in the public interest, for the protection of investors and the maintenance of fair and orderly markets, to remove impediments to, and perfect the mechanisms of, a national market system, and otherwise in furtherance of the purposes of the Exchange Act.

\section{Consolidation, Distribution, and Display of Data}

\section{a. Independent Distribution of Information}

The Commission is adopting the reproposed amendment to current Rule 11Aa3-1 (redesignated as Rule 601), which rescinds the prohibition on SROs and their members from disseminating their trade reports independently. ${ }^{648}$ Under adopted Rule 601, members of an SRO will continue to be required to transmit their trades to the SRO (and SROs would continue to transmit trades to the Networks pursuant to the Plans), but such members also will be free to distribute their own data independently, with or without fees.

See supra, note 638. Adopted Regulation NMS removes the definitions in former paragraph (a) of Rule 11Aa3-1 and places them in adopted Rule 600(b). Current subparagraphs (c)(2) and (c)(3) of Rule 11Aa3-1 are rescinded. As a result, current subparagraph (c)(4) of current Rule 11Aa3-1 is redesignated as subparagraph (b)(2) of adopted Rule 601. 
For the reasons discussed above in section V.A.4, the Commission also is adopting, as proposed and reproposed, Rule 603(a), which establishes uniform standards for distribution of both quotations and trades that will create an equivalent regulatory regime for all types of markets. First, Rule 603(a)(1) requires that any market information ${ }^{649}$ distributed by an exclusive processor, or by a broker or dealer (including ATSs and market makers) that is the exclusive source of the information, be made available to securities information processors on terms that are fair and reasonable. Rule 603(a)(2) requires that any SRO, broker, or dealer that distributes market information must do so on terms that are not unreasonably discriminatory. These requirements prohibit, for example, a market from making its "core data" (i.e., data that it is required to provide to a Network processor) available to vendors on a more timely basis than it makes available the core data to a Network processor. With respect to non-core data, however, Network processors occupy a unique competitive position. As Network processor, it acts on behalf of all markets in disseminating consolidated information, yet it also may be closely associated with the competitor of a market. The Commission believes that markets should have considerable leeway in determining whether, or on what terms, they provide additional, non-core data to a Network processor.

\section{b. Consolidation of Information}

649 The information covered by the amendment tracks the language of Section 11A(c) of the Exchange Act, which applies to "information with respect to quotations for or transactions in" securities. This statutory language encompasses a broad range of information, including information relating to limit orders held by a market center. See, e.g., S. Report No. 94-75, $94^{\text {th }}$ Cong., $1^{\text {st }}$ Sess. 9 (1975) ("In the securities markets, as in most other active markets, it is critical for those who trade to have access to accurate, upto-the-second information as to the prices at which transactions in particular securities are taking place (i.e., last sale reports) and the prices at which other traders have expressed their willingness to buy or sell (i.e., quotations).”). 
For the reasons discussed above in section V.A.1, the Commission is retaining the current consolidation model and adopting the consolidation requirements of Rule 603(b) as proposed and reproposed. All of the SROs currently participate in Plans that provide for the dissemination of consolidated information for the NMS stocks that they trade. The Plans were adopted in order to enable the SROs to comply with Exchange Act rules regarding the reporting of trades and distribution of quotations. With respect to trades, paragraph (b) of Exchange Act Rule 11Aa3-1 (redesignated as Rule 601(a)) requires each SRO to file transaction reporting plans that specify, among other things, how its transactions are to be consolidated with the transactions of other SROs. With respect to quotations, paragraph (b)(1) of Exchange Act Rule 11Ac1-1 (redesignated as Rule 602(a)(1)) requires an SRO to establish and maintain procedures for making its best quotes available to vendors.

To confirm by Exchange Act rule that both existing and any new SROs will be required to continue to participate in such joint-SRO plans, adopted Rule 603(b) requires SROs to act jointly pursuant to one or more NMS plans to disseminate consolidated information for NMS stocks. Such consolidated information must include an NBBO that is calculated in accordance with the definition set forth in adopted Rule 600(b)(42) ${ }^{650}$ In addition, the NMS plans will be required to provide for the dissemination of all consolidated information for an individual NMS stock through a single processor. Thus, different processors would be permitted to disseminate information for different NMS stocks (e.g., SIAC for Network A stocks, and Nasdaq for Network C stocks), but all quotations and trades in a stock must disseminated through a single processor. As a result, information users, particularly retail investors, will be able to obtain data

650 Adopted Rule 600(b)(42) of Regulation NMS defines "national best bid and national best offer." 
from a single source that reflects the best quotations and most recent trade price for a security, no matter where such quotations and trade are displayed in the NMS.

\section{c. Display of Consolidated Information}

For the reasons discussed above in section V.A.4, the Commission is adopting, as proposed and reproposed, Rule 603(c) (previously Exchange Act Rule 11Ac1-2), which substantially revises the consolidated display requirement. It incorporates a new definition of “consolidated display” (set forth in adopted Rule 600(b)(13)) that is limited to the prices, sizes, and market center identifications of the NBBO and "consolidated last sale information" (which is defined in Rule 600(b)(14)). The consolidated information on quotations and trades must be provided in an equivalent manner to any other information on quotations and trades provided by a securities information processor or broker-dealer. Beyond disclosure of this basic information, market forces, rather than regulatory requirements, will be allowed to determine what, if any, additional data from other market centers is displayed. In particular, investors and other information users ultimately will be able to decide whether they need additional information in their displays.

In addition, adopted Rule 603(c) narrows the contexts in which a consolidated display is required to those when it is most needed - a context in which a trading or order-routing decision could be implemented. For example, the consolidated display requirement will continue to cover broker-dealers who provide on-line data to their customers in software programs from which trading decisions can be implemented. Similarly, the requirement will continue to apply to vendors who provide displays that facilitate order routing by broker-dealers. It will not apply, 
however, when market data is provided on a purely informational website that does not offer any trading or order-routing capability. ${ }^{651}$

\section{Regulation NMS}

To simplify the structure of the rules adopted under Section 11A of the Exchange Act ("NMS rules"), the rules adopted today will designate the NMS rules as Regulation NMS, renumber the NMS rules, and establish a new definitional rule, Rule 600 ("NMS Security Designation and Definitions"). Rule 600(a) replaces Exchange Act Rule 11Aa2-1, which designates "reported securities" as NMS securities. In addition, Rule 600(b) includes, in alphabetical order, all of the defined terms used in Regulation NMS. Regulation NMS includes Rules 610, 611, and 612, which are adopted in this release, in addition to the existing NMS rules. The new rule series is Rule 600 through Rule 612 (17 CFR 242.600 - 612).

Rule 600 provides a single set of definitions that will be used throughout Regulation NMS. To create a single set of definitions, Rule 600 updates or deletes from the existing NMS rules some terms that have become obsolete and eliminates the use of multiple inconsistent definitions for identical terms. In addition, Rule 600 adopts new terms, "NMS security” and “NMS stock,” to replace some terms that have been eliminated. These terms are necessary to maintain distinctions between NMS rules that apply only to equity securities and ETFs (e.g., Exchange Act Rules 11Ac1-4 and 11Ac1-5, redesignated as Rules 604 and 605) and those that apply to equity securities, ETFs, and options (e.g., Exchange Act Rules 11Ac1-1 and 11Ac1-6, redesignated as Rules 602 and 606). Rule 600 retains, unchanged, most definitions used in the

651 The amendment would retain the exemptions currently set forth in Rule 11Ac1-2(f) (redesignated as Rule 603(c)(2)) for exchange and market linkage displays. The current exemption for displays used by SROs for monitoring or surveillance purposes would no longer be necessary because of the limitation of the amendment to trading and orderrouting contexts. 
existing NMS rules and includes definitions used in the new NMS rules adopted today. The definitional changes do not affect the substantive requirements of the existing NMS rules. In addition, the Commission is adopting technical amendments to a number of other Commission rules that cross-reference current NMS rules or that use terms that Regulation NMS amends or eliminates.

The Commission received no comments regarding reproposed Rule 600, the reproposed redesignation of the NMS rules as Regulation NMS, or the reproposed changes to other Commission rules. Accordingly, the Commission is adopting Rule 600 and redesignating the NMS rules as Regulation NMS, and adopting technical amendments to certain other Commission rules that cross-reference current NMS rules or that use terms that Regulation NMS amends or eliminates, substantially as proposed.

\section{A. Description of Regulation NMS}

Regulation NMS renumbers and, in some cases, renames the existing NMS rules, and incorporates Rule 600 and the other NMS rules adopted today. Where applicable, existing NMS rules are being amended to remove the definitions that have been consolidated in Rule 600. The titles and numbering of the rules in Regulation NMS, including the NMS rules adopted today, are as follows:

- Rule 600: NMS Security Designation and Definitions (replaces Exchange Act Rule 11Aa2-1, which the Commission is rescinding, and incorporates definitions from the existing NMS rules and the new rules adopted today); 
- Rule 601: Dissemination of Transaction Reports and Last Sale Data with Respect to Transactions in NMS Stocks (renumbers and renames Exchange Act Rule 11Aa3-1, the substance of which is being modified); ${ }^{652}$

- Rule 602: Dissemination of Quotations in NMS Securities (renumbers and renames Exchange Act Rule 11Ac1-1 (“Quote Rule”), the substance of which remains largely intact);

- Rule 603: Distribution, Consolidation, and Display of Information with Respect to Quotations for and Transactions in NMS Stocks (renumbers and renames Exchange Act Rule 11Ac1-2 ("Vendor Display Rule”), the substance of which is being modified substantially); ${ }^{653}$

- Rule 604: Display of Customer Limit Orders (renumbers Exchange Act Rule 11Ac1-4 (“Limit Order Display Rule”), the substance of which remains largely intact);

- Rule 605: Disclosure of Order Execution Information (renumbers Exchange Act Rule 11Ac1-5, the substance of which remains largely intact);

- Rule 606: Disclosure of Order Routing Information (renumbers Exchange Act Rule 11Ac1-6, the substance of which remains largely intact);

- Rule 607: Customer Account Statements (renumbers Exchange Act Rule 11Ac1-3, the substance of which remains largely intact);

- Rule 608: Filing and Amendment of National Market System Plans (renumbers Exchange Act Rule 11Aa3-2, the substance of which remains largely intact);

652 In the market data rules, discussed in section V, the Commission is adopting substantive amendments to Exchange Act Rule 11Aa3-1 (redesignated as Rule 601).

653 See supra section V for a discussion of the substantive amendments to the Vendor Display Rule. 
- Rule 609: Registration of Securities Information Processors: Form of Application and Amendments (renumbers Exchange Act Rule 11Ab2-1, the substance of which remains largely intact);

- Rule 610: Access to Quotations (adopted in this release);

- Rule 611: Order Protection Rule (adopted in this release); and

- Rule 612: Minimum Pricing Increment (adopted in this release).

\section{B. Rule 600 - NMS Security Designation and Definitions}

\section{NMS Security Designation - Transaction Reporting Requirements for Equities and Listed Options}

Section $11 \mathrm{~A}(\mathrm{a})(2)$ of the Exchange Act directs the Commission to "designate the securities or classes of securities qualified for trading in the national market system." ${ }^{\text {"65 }}$ The 1975 Amendments and the legislative history to the 1975 Amendments were silent as to the particular standards the Commission should employ in designating NMS securities. ${ }^{65}$ Instead, Congress provided the Commission with the flexibility and discretion to base NMS designation standards on the Commission's experience in facilitating the development of an NMS. ${ }^{656}$

To satisfy the requirement that it designate the securities qualified for trading in the NMS, the Commission adopted Exchange Act Rule 11Aa2-1 in 1981. ${ }^{657}$ Exchange Act Rule 11Aa2-1 (redesignated as Rule 600(a)) defined the term "national market system security" to mean "any reported security as defined in Rule 11Aa3-1.” A “reported security” was "any

$654 \quad 15$ U.S.C. $78 \mathrm{k}-1(\mathrm{a})(2)$.

655 See Securities Exchange Act Release No. 23817 (Nov. 17, 1986), 51 FR 42856 (Nov. 26, 1986) (proposing amendments to Exchange Act Rules 11Aa2-1 and 11Aa3-1).

656 See id.

657 See Securities Exchange Act Release No. 17549 (Feb. 17, 1981), 46 FR 13992 (Feb. 25, 1981) (adopting Exchange Act Rule 11Aa2-1). 
security or class of securities for which transaction reports are collected, processed and made available pursuant to an effective transaction reporting plan.”“58 An "effective transaction reporting plan” was “any transaction reporting plan approved by the Commission pursuant to this section.”659 A “transaction reporting plan” was “any plan for collecting, processing, making available or disseminating transaction reports with respect to transactions in reported securities filed with the Commission pursuant to, and meeting the requirements of, this section."660 The effective transaction reporting plans are the CTA Plan and the Nasdaq UTP Plan.

In addition to identifying those securities deemed to be NMS securities, when adopted, the Exchange Act Rule 11Aa2-1 designation also tacitly identified those securities that did not meet that designation (‥e., securities other than those that were so designated as NMS securities). Historically, securities excluded from this designation included standardized options and small capitalization equity securities (a subset of which has been identified as Nasdaq SmallCap securities). Trading in options and Nasdaq SmallCap securities has increased over the past three decades and gradually many of the rules that govern NMS securities have been applied to these securities. As a result, much of the terminology that has been used to distinguish NMS securities from options and Nasdaq SmallCap securities has become obsolete.

For example, the Nasdaq UTP Plan provides for the collection from Plan participants, and the consolidation and dissemination to vendors, subscribers and others, of quotation and transaction information in “eligible securities.” Prior to 2001, the Nasdaq UTP Plan defined an “eligible security” as any Nasdaq National Market security as to which unlisted trading

$658 \quad$ See former Exchange Act Rule 11Aa3-1(a)(4).

659 See former Exchange Act Rule 11Aa3-1(a)(3).

660 See former Exchange Act Rule 11Aa3-1(a)(2). 
privileges have been granted to a national securities exchange pursuant to Section 12(f) of the Exchange Act or that is listed on a national securities exchange. ${ }^{661}$ In 2001, the Nasdaq UTP Plan was amended to include Nasdaq SmallCap securities. ${ }^{662}$ As a result, Nasdaq SmallCap securities became "eligible securities" because they are now reported through an effective transaction reporting plan (i.e., the Nasdaq UTP Plan), bringing them within the purview of the NMS security designation. Several definitions in the existing NMS rules, however, do not reflect the inclusion of Nasdaq SmallCap securities in the Nasdaq UTP Plan and therefore must be updated. Regulation NMS does so.

In addition, transactions in exchange-listed options are reported through the Plan for Reporting of Consolidated Options Last Sale Reports and Quotation Information (“OPRA Plan”). ${ }^{663}$ Unlike the CTA Plan and the Nasdaq UTP Plan -- transaction reporting plans that the Commission approved pursuant to Exchange Act Rules 11Aa3-1 and 11Aa3-2 (redesignated as Rules 601 and 608) -- the Commission approved the OPRA Plan pursuant to Exchange Act Rule 11Aa3-2 (redesignated as Rule 608). ${ }^{64}$ As such, the OPRA Plan is an "effective national market system plan" but not an "effective transaction reporting plan.” While at their core the CTA Plan,

$661 \quad$ See Securities Exchange Act Release No. 28146 (June 26, 1990), 55 FR 27917 (July 6, 1990) (order approving the Nasdaq UTP Plan on a pilot basis

662 In 2001, the Nasdaq UTP Plan was amended to, among other things, revise the definition of “eligible securities” to include Nasdaq SmallCap securities. See Securities Exchange Act Release No. 45081 (Nov. 19, 2001), 66 FR 59273 (Nov. 27, 2001) (order approving Amendment No. 12 to the Nasdaq UTP Plan). See NASD Rule 4200 for the definition of a Nasdaq SmallCap security.

663 The exchanges that are participants to the OPRA Plan are Amex, BSE, CBOE, ISE, PCX, and Phlx.

664 See Securities Exchange Act Release No. 17638 (Mar. 18, 1981), 22 S.E.C. Docket 484 (Mar. 31, 1981). Exchange Act Rule 11Aa3-2 (redesignated as Rule 608) codifies the procedures that SROs must follow to seek approval for or amendment of a national market system plan. 
the Nasdaq UTP Plan, and the OPRA Plan perform essentially the same function (i.e., they govern the consolidated reporting of securities transactions by Plan participants), because the OPRA Plan is not an effective transaction reporting plan, listed options covered by the OPRA Plan are technically not "securities for which transaction reports are collected, processed, and made available pursuant to an effective transaction reporting plan.” Therefore, listed options were not considered NMS securities as defined by Exchange Act Rule 11Aa2-1. While the impact of this distinction may not be readily apparent, the differences in the way the Plans are designated dictates the securities laws and regulations that apply to securities reported pursuant to those Plans.

Further, as discussed below, some terms in the existing NMS rules have become superfluous or outdated, and some NMS rules define identical terms differently. To provide a consolidated set of definitions applicable to all of the NMS rules, Regulation NMS eliminates these inconsistencies. The definitional changes adopted today, however, are not intended to change materially the scope of the existing NMS rules.

\section{NMS Security and NMS Stock}

Some NMS rules, including the Quote Rule (redesignated as Rule 602) and Exchange Act Rule 11Ac1-6 (redesignated as Rule 606), currently apply to both: (1) equities, ETFs and related securities for which transaction reports are made available pursuant to an effective transaction reporting plan; and (2) listed options for which market information is made available pursuant to an effective national market system plan. To provide a single term that will be used in any provision of Regulation NMS that applies to both categories of securities, Regulation NMS adopts a new term, “NMS security.” Specifically, Regulation NMS defines an "NMS security” as “any security or class of securities for which transaction reports are collected, processed, and 
made available pursuant to an effective transaction reporting plan, or an effective national market system plan for reporting transactions in listed options.”665

Because many rules in Regulation NMS, including the Limit Order Display Rule (redesignated as Rule 604) and Exchange Act Rule 11Ac1-5 (redesignated as Rule 605), continue to be inapplicable to listed options, Regulation NMS adopts a new term, "NMS stock" that will be used in those provisions. Regulation NMS defines the term "NMS stock" as "any NMS security other than an option.”666

\section{Changes to Existing Definitions in the NMS Rules}

Rule 600(b) provides a single set of definitions that will be used throughout Regulation

NMS. To create a single set of definitions, Regulation NMS eliminates multiple, inconsistent definitions of identical terms. In addition, Regulation NMS amends some definitions in the NMS rules to reflect changed conditions in the marketplace or to modernize references. ${ }^{667}$ For

Rule 600(b)(46). This definition was used to define a "reported security" in the Quote Rule. See former Exchange Act Rule 11Ac1-1(a)(20). For the reasons described below, the Commission is eliminating the term "reported security" from the Quote Rule and does not include it in Regulation NMS.

Rule 600(b)(47). The term "NMS stock" is defined in part with reference to the term "transaction reporting plan." The definition of the term "transaction reporting plan" as proposed used the term "NMS stocks." Thus, to avoid circularity, the Commission has clarified the definition of "transaction reporting plan" in Rule 600(b)(82) as adopted by replacing the phrase "NMS stocks" with the term "securities."

The term "electronic communications network" was proposed to be defined in the Proposing Release and Reproposing Release to mean "any electronic system that widely disseminates to third parties orders entered therein by an exchange market maker or OTC market maker, and permits such orders to be executed against in whole or in part; except that the term electronic communications network shall not include: (i) Any system that crosses multiple orders at one or more specified times at a single price set by the system (by algorithm or by any derivative pricing mechanism) and does not allow orders to be crossed or executed against directly by participants outside of such times; or (ii) Any system operated by, or on behalf of, an OTC market maker or exchange market maker that executes customer orders primarily against the account of such market maker as principal, other than riskless principal." The Commission has modified this definition to 
example, as discussed above, several definitions in the existing NMS rules have been rendered obsolete by the extension of the Nasdaq UTP Plan to Nasdaq SmallCap securities. ${ }^{668}$ Because the Nasdaq UTP Plan includes Nasdaq SmallCap securities, those securities now are "securities for which transaction reports are collected, processed and made available pursuant to an effective transaction reporting plan" (i.e., they are "reported" securities). ${ }^{669}$ For this reason, it is no longer necessary to distinguish, as several existing NMS rules do, between "reported" securities and equity securities for which market information is made available through Nasdaq. ${ }^{670}$ Accordingly, Regulation NMS eliminates or revises the defined terms in the existing NMS rules that make this distinction.

\section{a. Covered Security}

insert the phrase "for the purposes of § 242.602(b)(5)" at the beginning of the definition to avoid inadvertently narrowing the scope of the term "electronic communications network" as used in the term "vendor" in Rule 600(b)(83) (formerly Exchange Act Rule 11Ac1-2(a)(2)). See also infra, section VI.B.3.g. This modification makes the definition consistent with the definition of "electronic communications network" in former Rule 11Ac1-1(a)(8).

668 See supra, section VI.B.1.

669 The Vendor Display Rule and Exchange Act Rule 11Aa3-1 (redesignated as Rule 601) defined the term "reported security" to mean "any security or class of securities for which transaction reports are collected, processed and made available pursuant to an effective transaction reporting plan.” See former Exchange Act Rules 11Ac1-2(a)(20) and 11Aa31(a)(4). As discussed more fully below, the Quote Rule provides a different definition of "reported security."

670 See e.g., paragraph (a)(4) of the Vendor Display Rule (defining "subject security" to mean "(i) any reported security; and (ii) any other equity security as to which transaction reports, last sale data or quotation information is disseminated through NASDAQ"); and paragraph (a)(6) of the Quote Rule (defining "covered security” to mean "any reported security and any other security for which a transaction report, last sale data or quotation information is disseminated through an automated quotation system as described in Section 3(a)(51)(A)(ii) of the Act (15 U.S.C. 78c(a)(51)(A)(ii))"). 
Different definitions of the term "covered security” appeared in the Quote Rule, the Limit Order Display Rule, and Exchange Act Rule 11Ac1-6 (redesignated as Rule 606). ${ }^{671}$ In addition, as discussed below, the term has become obsolete. Therefore, Regulation NMS eliminates the term "covered security" from the NMS rules and replaces it with the term "NMS security" or “NMS stock,” as applicable, depending upon the scope of the particular rule.

\section{b. Reported Security}

Several NMS rules used the term "reported security." Although the Limit Order Display Rule, the Vendor Display Rule, and Exchange Act Rule 11Aa3-1 (redesignated as Rule 601) contained identical definitions of “reported security,” the Quote Rule provided a different definition. ${ }^{672}$ Because the term "reported security" was defined inconsistently in the NMS rules

671 Although the Quote Rule and the Limit Order Display Rule each defined the term "covered security" as "any reported security and any other security for which a transaction report, last sale data or quotation information is disseminated through an automated quotation system as described in Section 3(a)(51)(A)(ii) of the Act (15 U.S.C. 78c(a)(51)(A)(ii))," the scope of the definitions was not identical because each rule defines the term "reported security" differently. The Quote Rule defined a "reported security" to mean "any security or class of securities for which transaction reports are collected, processed and made available pursuant to an effective transaction reporting plan, or an effective national market system plan for reporting transactions in listed options." See former Exchange Act Rule 11Ac1-1(a)(20). The Limit Order Display Rule defined a "reported security" to mean "any security or class of securities for which transaction reports are collected, processed, and made available pursuant to an effective transaction reporting plan.” See former Exchange Act Rule 11Ac1-4(a)(10).

Exchange Act Rule 11Ac1-6 (redesignated as Rule 606) defined the term "covered security" to mean: "(i) any national market system security and any other security for which a transaction report, last sale data or quotation information is disseminated through an automated quotation system as defined in Section 3(a)(51)(A)(ii) of the Act (15 U.S.C. 78c(a)(51)(A)(ii)); and (ii) any option contract traded on a national securities exchange for which last sale reports and quotation information are made available pursuant to an effective national market system plan." ee former Exchange Act Rule 11Ac1-6(a)(1).

672 The Limit Order Display Rule, the Vendor Display Rule, and Exchange Act Rule 11Aa31 defined a "reported security" to mean "any security or class of securities for which transaction reports are collected, processed and made available pursuant to an effective 
and in light of the changes to related terms, Regulation NMS eliminates the term "reported security” from the NMS rules and replaces it with the term "NMS security” or "NMS stock," depending on the scope of the particular rule.

The Limit Order Display Rule used the term "reported security” solely for the purpose of defining the term “covered security.”673 Because Regulation NMS eliminates the term “covered security,” the term "reported security” also is not needed in the Limit Order Display Rule (redesignated as Rule 604). Therefore, the term “NMS stock” replaces the term “covered security” in the Limit Order Display Rule.

Similarly, the Quote Rule used the term “reported security” primarily to define the term “covered security.”674 Because Regulation NMS eliminates the term “covered security,” the redesignated Quote Rule (redesignated as Rule 602) also will not use the term "reported security. ${ }^{675}$

\section{c. Subject Security}

transaction reporting plan.” See former Exchange Act Rules 11Ac1-4(a)(10), 11Ac12(a)(20), and 11Aa3-1(a)(4). The Quote Rule defined the term "reported security" to mean "any security or class of securities for which transaction reports are collected, processed, and made available pursuant to an effective transaction reporting plan, or an effective national market system plan for reporting transactions in listed options." See former Exchange Act Rule 11Ac1-1(a)(20). As discussed above, this release adopts substantial modifications to the Vendor Display Rule.

673 The Limit Order Display Rule defined a "covered security” to include both reported securities and other securities for which market information is disseminated through Nasdaq. See former Exchange Act Rule 11Ac1-4(a)(5).

674 The Quote Rule defined a “covered security” to include both reported securities and other securities for which market information is disseminated through Nasdaq. See former Exchange Act Rule 11Aa1-1(a)(6).

675 In paragraph (b)(1)(ii) of the Quote Rule (redesignated as Rule 602), which requires a registered national securities association to disseminate quotations at all times when last sale information is available with respect to "reported securities," the reference to "reported security" is being replaced by a reference to "NMS security." 
The Quote Rule and the Vendor Display Rule both used the term “subject security,” although they define the term differently. To eliminate this inconsistency, the amended Vendor Display Rule (redesignated as Rule 603) does not use the term "subject security” and Regulation NMS retains a slightly modified version of the definition of "subject security" currently found in the Quote Rule.

The Vendor Display Rule defined the term "subject security” to mean “(i) any reported security; and (ii) any other equity security as to which transaction reports, last sale data or quotation information is disseminated through NASDAQ." "676 As discussed above, the extension of the Nasdaq UTP Plan to include Nasdaq SmallCap securities rendered obsolete the distinction between a "reported security" and a security for which market information is disseminated through Nasdaq. Accordingly, the amended Vendor Display Rule (redesignated as Rule 603) uses the term "NMS stock” rather than "subject security."

The Quote Rule defined the term “subject security” to mean:

(i) With respect to an exchange: (A) Any exchange-traded security other than a security for which the executed volume of such exchange, during the most recent calendar quarter, comprised one percent or less of the aggregate trading volume for such security as reported in the consolidated system; and (B) Any other covered security for which such exchange has in effect an election, pursuant to paragraph (b)(5)(i) of this section, to collect, process, and make available to quotation vendors bids, offers, quotation sizes, and aggregate quotation sizes communicated on such exchange; and

(ii) With respect to a member of an association: (A) Any exchange-traded security for which such member acts in the capacity of an OTC market maker unless the executed volume of such member, during the most recent calendar quarter, comprised one percent or less of the aggregate trading volume for such security as reported in the consolidated system; and (B) Any other covered security for which such member acts in the capacity of an OTC market maker and has in effect an election, pursuant to paragraph (b)(5)(ii) of this section, to 
communicate to its association bids, offers and quotation sizes for the purpose of making such bids, offers and quotation sizes available to quotation vendors. ${ }^{677}$

Because the Quote Rule (redesignated as Rule 602) will continue to apply to both listed options and equities covered by an effective transaction reporting plan, Regulation NMS's definition of "subject security" revises the Quote Rule’s definition of “subject security” by replacing references to a "covered security" with references to an "NMS security." In addition, for the reasons discussed below, Regulation NMS replaces the phrase "reported in the consolidated system" with the phrase "reported pursuant to an effective transaction reporting plan or effective national market system plan.”

\section{d. Consolidated System}

As noted above, the definition of the term "subject security" in the Quote Rule used the phrase "reported in the consolidated system." ${ }^{678}$ Paragraph (a)(5) of the Quote Rule defines the term "consolidated system" to mean "the consolidated transaction reporting system, including a transaction reporting system operating pursuant to an effective national market system plan.”679 Regulation NMS clarifies the definition of "subject security” by eliminating the phrase "reported in the consolidated system" and replacing it with the phrase "reported pursuant to an effective transaction reporting plan or an effective national market system plan.” Thus, Regulation NMS defines a "subject security" to include, among other things: (1) with respect to a national securities exchange, any exchange-traded security other than a security for which the executed volume of such exchange, during the most recent calendar quarter, comprised one percent or less of the aggregate trading volume for such security as reported pursuant to an

677 See former Exchange Act Rule 11Ac1-1(a)(25) (emphasis added).

678 Id.

679 See former Exchange Act Rule 11Ac1-1(a)(5). 
effective transaction reporting plan or effective national market system plan; and (2) with respect to a member of a national securities association, any exchange-traded security for which such member acts in the capacity of an OTC market maker unless the executed volume of such member, during the most recent calendar quarter, comprised one percent or less of the aggregate trading volume for such security as reported pursuant to an effective transaction reporting plan or effective national market system plan. ${ }^{680}$

This change provides a clearer definition of "subject security" by indicating that the trading volume referred to in the definition is the trading volume in a security that is reported pursuant to an effective transaction reporting plan or an effective national market system plan. Although replacing the phrase "reported in the consolidated system” with the phrase "reported pursuant to an effective transaction reporting plan or an effective national market system plan” produces a clearer definition of "subject security,” it does not alter the scope or the substance of the definition. $^{681}$

\section{e. National Securities Exchange}

Section 3(a)(1) of the Exchange Act defines the term “exchange” to mean "any organization, association, or group of persons... which constitutes, maintains, or provides a market place or facilities for bringing together purchasers and sellers of securities or for otherwise performing with respect to securities the functions commonly performed by a stock

$680 \quad$ Rule 600(b)(73).

681 This change also impacts certain non-NMS rules that define the term "consolidated system." See, e.g., Exchange Act Rule 10b-18(a)(7) ("consolidated system means the consolidated transaction reporting system contemplated by Rule 11Aa3-1"). As discussed below, the Commission also is amending certain non-NMS rules that are affected by the definitional changes adopted today. 
exchange as that term is generally understood...., ${ }^{682}$ Exchange Act Rule 3b-16, ${ }^{683}$ adopted in 1998, interprets the statutory definition of "exchange” broadly to include any organization, association, or group of persons that: (1) brings together the orders for securities of multiple buyers and sellers; and (2) uses established, non-discretionary methods (whether by providing a trading facility or by setting rules) under which such orders interact with each other, and the buyers and sellers entering such orders agree to the terms of a trade. Exchange Act Rule 3b-16 was designed to provide "a more comprehensive and meaningful interpretation of what an exchange is in light of today’s markets." 684

The Quote Rule’s definition of an “exchange market maker” defined the term “national securities exchange" as an "exchange." " 885 To avoid confusion between a "national securities exchange" and the broader interpretation of "exchange" set forth in Exchange Act Rule 3b-16, Regulation NMS uses the term "national securities exchange" rather than "exchange” throughout the Regulation. The national securities exchange definition is intended to capture only those entities that operate as national securities exchanges and that are registered as such with the Commission. It is not intended to capture those entities that meet the "exchange" definition under Regulation ATS but that operate as something other than a national securities exchange. The use of this term is consistent with the use of the term "exchange" in the existing NMS rules.

$682 \quad 15$ U.S.C. 78c(a)(1).

$683 \quad 17$ CFR 240.3b-16.

$684 \quad$ See Securities Exchange Act Release No. 40760 (Dec. 8, 1998), 63 FR 70844 (Dec. 22, 1998) (adopting Regulation ATS).

685 Specifically, the Quote Rule stated that the term “exchange market maker” shall mean "any member of a national securities exchange ('exchange') who is registered as a specialist or market maker pursuant to the rules of such exchange." See former Exchange Act Rule 11Ac1-1(a)(9). The statutory requirements applicable to a national securities exchange are set forth in Section 6 of the Exchange Act, 15 U.S.C. 78f. 


\section{f. OTC Market Maker}

The Quote Rule and Exchange Act Rule 11Ac1-5 (redesignated as Rule 605) defined the

term “OTC market maker” differently. ${ }^{686}$ Unlike the Quote Rule, Exchange Act Rule 11Ac1-5 defined the term "OTC market maker" to include an explicit reference to a securities dealer that holds itself out as being willing to buy from and sell to customers or others in the United States. Regulation NMS retains the reference to transactions with "customers or others in the United States" to indicate clearly that a foreign dealer could be an "OTC market maker" if it acts as a securities dealer with respect to customers or others in the United States.

Accordingly, Regulation NMS defines “OTC market maker” as "any dealer that holds itself out as being willing to buy from and sell to its customers, or others, in the United States, an NMS stock for its own account on a regular or continuous basis otherwise than on a national securities exchange.”687

\section{g. Vendor}

The term "vendor" or "quotation vendor" was defined differently in three NMS rules: the Quote Rule, the Vendor Display Rule, and Exchange Act Rules 11Aa3-1 (redesignated as Rule 601). ${ }^{688}$ Although the definitions are similar, the definition of "vendor" in the Vendor Display

686 Compare former Exchange Act Rules 11Ac1-1(a)(13) and 11Ac1-5(a)(18).

687 The definition of "OTC market maker" uses the term "NMS stock" because there is no OTC market in standardized options.

688 The Quote Rule defined the term "quotation vendor" to mean "any securities information processor engaged in the business of disseminating to brokers, dealers or investors on a real-time basis, bids and offers made available pursuant to this section, whether distributed through an electronic communications network or displayed on a terminal or other display device.” See former Exchange Act Rule 11Ac1-1(a)(19). Former Exchange Act Rule 11Aa3-1(a)(11) defined the term "vendor" to mean "any securities information processor engaged in the business of disseminating transaction reports or last sale data with respect to transactions in reported securities to brokers, dealers or investors on a real-time or other current and continuing basis, whether through an electronic 
Rule was the most comprehensive because it encompasses any SIP that disseminates transaction reports, last sale data, or quotation information, whereas the other definitions were less complete in identifying the types of information that vendors typically make available. To provide a uniform and comprehensive definition of the term "vendor," Regulation NMS includes the definition of "vendor" as it was defined in the Vendor Display Rule. ${ }^{689}$

\section{h. Best Bid, Best Offer, and National Best Bid and National Best Offer}

The Quote Rule and the Vendor Display Rule defined the terms "best bid” and "best offer" differently. The Quote Rule stated that "[t]he terms best bid and best offer shall mean the highest priced bid and the lowest priced offer." ${ }^{\prime 60}$ The Vendor Display Rule defined the terms "best bid" and "best offer" as follows: ${ }^{691}$

(i) With respect to quotations for a reported security, the highest bid or lowest offer for that security made available by any reporting market center pursuant to $\S$ 240.11Ac1-1 (Rule 11Ac1-1 under the Act) (excluding any bid or offer made available by an exchange during any period such exchange is relieved of its obligations under paragraphs (b) (1) and (2) of § 240.11Ac1-1 by virtue of paragraph (b)(3)(i) thereof)); Provided, however, That in the event two or more reporting market centers make available identical bids or offers for a reported security, the best bid or best offer (as the case may be) shall be computed by ranking all such identical bids or offers (as the case may be) first by size (giving

communications network, moving ticker or interrogation device.” The Vendor Display Rule defined the term "vendor" to mean "any securities information processor engaged in the business of disseminating transaction reports, last sale data or quotation information with respect to subject securities to brokers, dealers or investors on a real-time or other current and continuing basis, whether through an electronic communications network, moving ticker or interrogation device.” See former Exchange Act Rule 11Ac1-2(a)(2).

689 See former Exchange Act Rule 11Ac1-2(a)(2). The Commission modified the adopted definition of vendor to conform to a technical change being made to the definition of "quotations" and "quotation information" in Rule 600(b)(62). See infra, note 699 and accompanying text.

690 See former Exchange Act Rule 11Ac1-1(a)(3).

691 See former Exchange Act Rule 11Ac1-2(a)(15). 
the highest ranking to the bid or offer associated with the largest size), then by time (giving the highest ranking to the bid or offer received first in time); and

(ii) With respect to quotations for a subject security other than a reported security, the highest bid or lowest offer (as the case may be) for such security disseminated by an over-the-counter market maker in Level 2 or 3 of NASDAQ.

In addition, Exchange Act Rule 11Ac1-5(a)(7) defined the term “consolidated best bid and offer" to mean "the highest firm bid and the lowest firm offer for a security that is calculated and disseminated on a current and continuous basis pursuant to an effective national market system plan.”

Regulation NMS retains the definitions of "best bid" and "best offer" used in the Quote Rule. A new term called "national best bid and national best offer": (1) replaces the term "best bid and best offer" as that term is used in the Vendor Display Rule; and (2) replaces the term “consolidated best bid and offer” as that term is used in Exchange Act Rule 11Ac1-5 (redesignated as Rule 605). This new term refers to the best quotations that are calculated and disseminated by a plan processor pursuant to an effective national market system plan. ${ }^{692}$ The definition of "national best bid and national best offer" also addresses instances where multiple market centers transmit identical bids and offers to the plan processor pursuant to an NMS plan by establishing the way in which these bids and offers are to be prioritized. ${ }^{693}$

\section{i. Bid, Offer, Customer, Nasdaq Security, Quotations, Quotation Information, and Responsible Broker or Dealer}

692 The definition of "reporting market center" in paragraph (a)(14) of the Vendor Display Rule, which was incorporated into that Rule's definitions of "best bid" and "best offer," is no longer necessary and therefore is being deleted.

See Rule 600(b)(42). 
Regulation NMS also updates or clarifies the following terms in the NMS rules: "bid;” “offer;” "customer;” "Nasdaq security;” "quotations"; "quotation information;" and "responsible broker or dealer.”

The Quote Rule defined the terms "bid" and "offer" to mean "the bid price and the offer price communicated by an exchange member or OTC market maker to any broker or dealer, or to any customer, at which it is willing to buy or sell one or more round lots of a covered security, as either principal or agent, but shall not include indications of interest." ${ }^{\text {694 }}$ Regulation NMS updates this definition by replacing the term "OTC market maker" with the phrase "member of a national securities association" and calls the term "bid or offer" rather than "bid and offer" to reflect the fact that the terms are not always used in the conjunctive. Modifying the definition to apply to any member of a national securities association clarifies that bids and offers include quotations communicated not only by OTC market makers but also by ATSs, ECNs, and order entry firms that are members of the NASD but that are not market makers.

Expanding the definition of "bid" and "offer" could have the unintended consequence of also expanding the scope of the Quote Rule (redesignated as Rule 602) where those terms are used to apply to members of a national securities association that are not OTC market makers (e.g., ECNs and ATSs). To avoid this unintended expansion of the scope of the Quote Rule (redesignated as Rule 602), Regulation NMS proposed a revised version of the Quote Rule's

$694 \quad$ See former Exchange Act Rule 11Ac1-1(a)(4). Paragraph (a)(6) of the Vendor Display Rule used the Quote Rule's definition of "bid" and "offer” for reported securities, but it defined "bid" and "offer" for Nasdaq SmallCap securities as "the most recent bid or offer price of an over-the-counter market maker disseminated through Level 2 or 3 of NASDAQ.” Because Nasdaq SmallCap securities now are reported securities, it is unnecessary to maintain the distinction between reported securities and Nasdaq SmallCap securities. Accordingly, to update and provide a single definition of the terms "bid" and "offer," Regulation NMS eliminates the definitions of "bid" and "offer" used in the Vendor Display Rule and retains modified versions of the terms as they are defined in the Quote Rule. 
definition of "responsible broker or dealer." ${ }^{695}$ In particular, Regulation NMS proposed to amend the portion of the definition of "responsible broker or dealer" found in paragraph (a)(21)(ii) of the Quote Rule ${ }^{696}$ to limit its scope to bids and offers communicated by an OTC market maker. The Commission does not believe, however, that amending the definition of "responsible broker or dealer" is necessary because the definition of the term "subject security" effectively serves to limit the scope of the Quote Rule, with respect to a member of a national securities association, to members acting in the capacity of an OTC market maker. ${ }^{697}$ The Commission therefore is modifying the proposed definition of "responsible broker or dealer" in Rule 600(b)(65)(ii) to replace the term "an OTC marker maker" with the term "a member of an association" and to replace the term "the OTC market maker" with the term "the member."698

695 See former Exchange Act Rule 11Ac1-1(a)(21).

696 See former Exchange Act Rule 11Ac1-1(a)(21)(ii).

697 Rule 600(b)(73)(ii) as adopted defines "subject security" to mean, with respect to a member of a national securities association, (A) any exchange-traded security for which such member acts in the capacity of an OTC market maker unless the executed volume of such member, during the most recent calendar quarter, comprised one percent or less of the aggregate trading volume for such security as reported pursuant to an effective transaction reporting plan or effective national market system plan; and (B) any other NMS security for which such member acts in the capacity of an OTC market maker and has in effect an election, pursuant to $\S 242.602$ (a)(5)(ii), to communicate to its association bids, offers, and quotation sizes for the purpose of making such bids, offers, and quotation sizes available to a vendor

698 As adopted, Rule 600(b)(65)(ii) defines the term "responsible broker or dealer" to mean, when used with respect to bids and offers communicated by a member of an association to a broker or dealer or a customer, the member communicating the bid or offer (regardless of whether such bid or offer is for its own account or on behalf of another person). This modification conforms the definition of "responsible broker or dealer" in Rule 600(b)(65)(ii) as adopted to the definition of "responsible broker or dealer" in former Rule 11Ac1-1(a)(21)(ii) with respect to its application to a member of an association.

The Commission also is making a change to paragraph (b)(3)(i) of Rule 602 from the reproposal to insert the word "size" after the phrase "such revised quotation." This 
The Commission also is making a non-substantive modification to the definition of "quotations" and "quotation information" in Rule 600(b)(62) from the reproposal to delete the term "quotation information" and to delete the phrase "where applicable, quotations sizes and aggregate quotation sizes." The deleted term and phrase are no longer necessary because they were included in a definition used in the Vendor Display Rule, which is being substantially modified and no longer uses the deleted term or phrase. ${ }^{699}$ As adopted, Rule 600(b)(62) simply defines the term "quotation" to mean a bid or an offer.

Regulation NMS also amends the definition of the term "customer.” The Quote Rule defined that term to mean "any person that is not a registered broker-dealer., ${ }^{700}$ To indicate that the scope of the definition includes broker-dealers that are exempt from registration as well as registered broker-dealers, Regulation NMS revises the definition by deleting the term "registered.” Thus, Regulation NMS defines the term “customer” to mean "any person that is not a broker-dealer.”

Exchange Act Rule 11Aa3-1 (redesignated as Rule 601) defined the term "NASDAQ security" to mean "any registered equity security for which quotation information is disseminated in the National Association of Securities Dealers Automated Quotation system (“NASDAQ”).”701 This acronym is now outdated. Therefore, to modernize this definition and

change will correct the inadvertent deletion of "size" in a prior amendment to this rule (the Quote Rule) and will not have any substantive effect.

Conforming modifications are being made to the definition of "dynamic market monitoring device," "interrogation device," and "vendor" in Rules 600(b)(20), 600(b)(31), and 600(b)(83) to replace the term "quotation information" with the term "quotations."

700 See former Exchange Act Rule 11Ac1-1(a)(26).

701 See former Exchange Act Rule 11Aa3-1(a)(6). 
to ensure that any type of registered security that Nasdaq lists is covered by the definition, Regulation NMS defines the term "Nasdaq security” to mean "any registered security listed on The Nasdaq Stock Market, Inc.”

\section{Definitions in the Regulation NMS Rules Adopted Today}

Rule 600(b) includes a number of new definitions used in Regulation NMS Rules 610 through 612, which are adopted in this release. These new terms are discussed in detail in Sections II through V above. Specifically, for the reasons discussed above, Regulation NMS adopts the following terms: automated quotation, automated trading center, consolidated display, consolidated last sale information, intermarket sweep order, manual quotation, protected bid or protected offer, SRO display-only facility, SRO trading facility, trade-through, and trading center.

\section{Changes to Other Rules}

In addition to the changes described above, the rules adopted today amend a number of rules that cross-reference current NMS rules or that use terms that Regulation NMS amends or eliminates. These amendments are intended to be non-substantive. Specifically, the rules 
adopted today make conforming changes to the following rules: ${ }^{702} \S 200.30-3 ;^{703} \S 200.800$, Subpart N: ${ }^{704} \S 201.101 ;{ }^{705}$ Rule $144^{706}$ under the Securities Act of $1933 ;{ }^{707}$ Exchange Act Rule 0-10; ${ }^{708}$ Exchange Act Rule 3a51-1 ${ }^{709}$; Exchange Act Rule 3b-16; ${ }^{710}$ Exchange Act Rules

702 In addition, the Commission voted to approve a conforming amendment to Exchange Act Rule 3a55-1 and Commodity Exchange Act ("CEA") Rule 41.11. These rules were adopted jointly by the Commission and the Commodity Futures Trading Commission ("CFTC") pursuant Section 3(a)(55)(F)(ii) of the Exchange Act and Section 1a(25)(E)(ii) of the CEA and the amendment also must be adopted jointly. Section 3(a)(55)(F)(ii) of the Exchange Act and Section 1a(25)(E)(ii) of the CEA provide that the two Commissions shall, by rule or regulation, jointly specify the method to be used to determine market capitalization and dollar value of average daily trading volume for purposes of definition of "narrow-based security index" (and exclusions from that definition). Exchange Act Rule 3a55-1 and CEA Rule 41.11 refer to "reported securities as defined in $\S 240.11$ Ac1-1." The rules adopted today eliminate the term "reported security" from the NMS rules and replace it with the term "NMS security" or "NMS stock," depending on the scope of the particular rule. To reflect these changes, the joint technical amendment would replace the phrase "reported securities as defined in $\S$ 240.11Ac1-1" with the phrase "NMS securities, as defined in § 242.600 of this chapter" in Exchange Act Rule 3a55-1 and make a corresponding change in CEA Rule 41.11.

70317 CFR 200.30-3. In addition to conforming changes, the Commission is amending this rule to delegate to the Director of the Division of Market Regulation the authority to grant exemptions to Rules 610 through 612.

$704 \quad 17$ CFR 200.800, Subpart N.

$705 \quad 17$ CFR 201.101.

$706 \quad 17$ CFR 230.144.

$707 \quad 15$ U.S.C. 77 a et seq.

70817 CFR 240.0-10.

70917 CFR 240.3a51-1.

$710 \quad 17$ CFR 240.3b-16. 
10a-1; ${ }^{711}$ Exchange Act Rule 10b-10; ${ }^{712}$ Exchange Act Rule 10b-18; ${ }^{713}$ Exchange Act Rule 15b9$1 ;{ }^{714}$ Exchange Act Rule 12a-7; $;{ }^{715}$ Exchange Act Rule 12f-1; ${ }^{716}$ Exchange Act Rule $12 \mathrm{f}-2 ; ;^{717}$ Exchange Act Rule 15c2-11; ${ }^{718}$ Exchange Act Rule 19c-3; ${ }^{719}$ Exchange Act Rule 19c-4; ${ }^{720}$ Exchange Act Rule 31; ${ }^{721}$ Rule 100 of Regulation M under the Exchange Act; ${ }^{722}$ Rule 300 of Regulation ATS under the Exchange Act; ${ }^{723}$ Rule 301 of Regulation ATS under the Exchange Act; ${ }^{724} \S 249.1001 ;{ }^{725}$ and Rule 17a-7 under the Investment Company Act of $1940 .{ }^{726}$

\section{Effective Date and Phased-In Compliance Dates}

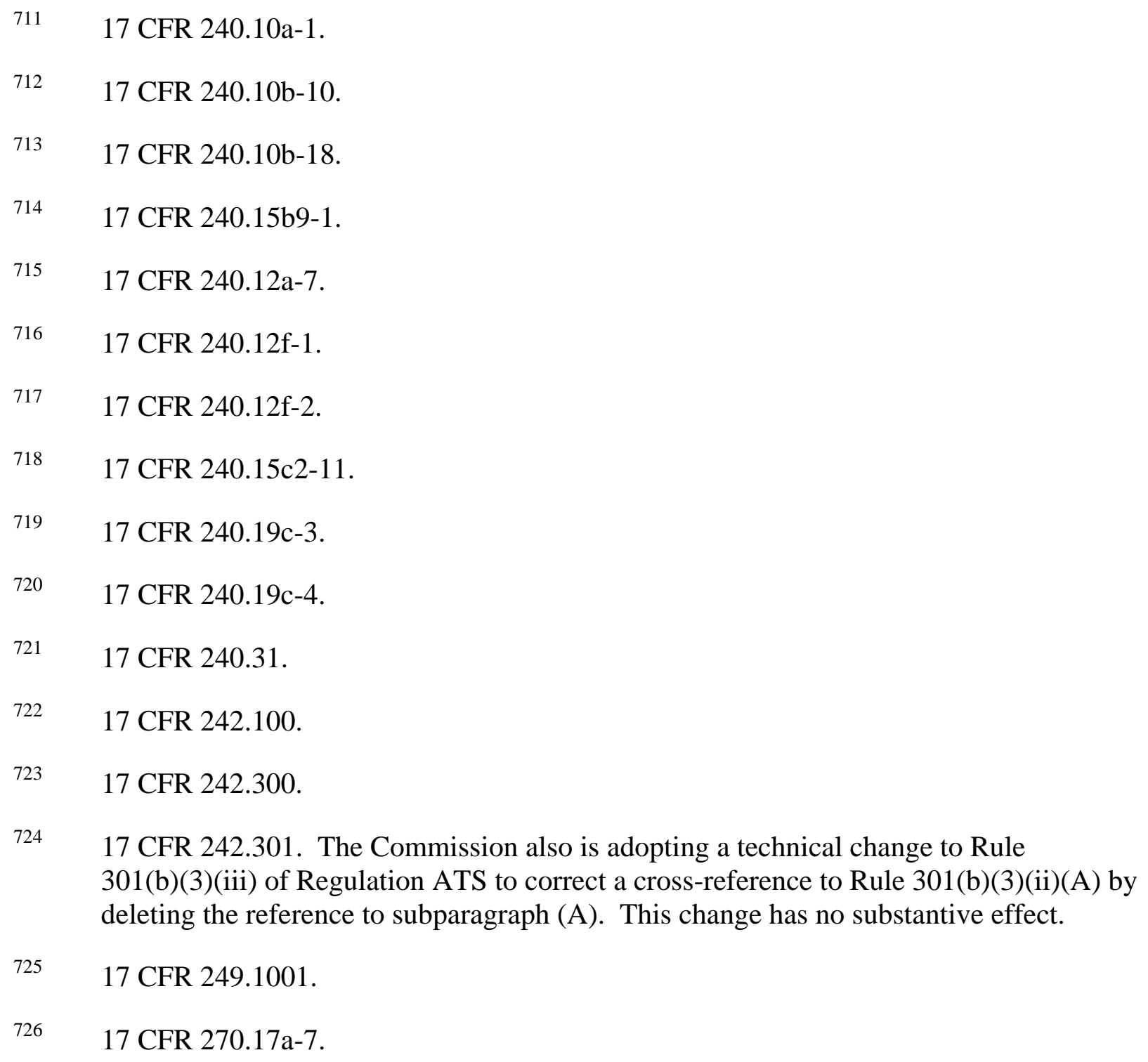
301(b)(3)(iii) of Regulation ATS to correct a cross-reference to Rule 301(b)(3)(ii)(A) by deleting the reference to subparagraph (A). This change has no substantive effect. 17 CFR 249.1001. 17 CFR 270.17a-7. 
Rules 610, 611, 612, the amendment to Rule 301 of Regulation ATS, the amendments to the Market Data Rules and Plans discussed above in Section V, and the Regulation NMS amendments discussed above in Section VI will become effective on August 29, 2005. The compliance date for Rule 612, the amendment to Rule 301 of Regulation ATS, the amendments to the Market Data Rules and Plans discussed above in Section V other than the Allocation Amendment, and the Regulation NMS amendments discussed above in Section VI will be the same date as the effective date. Given the significant systems and other changes necessary to implement the remaining regulatory changes adopted today, the Commission has decided to establish delayed compliance dates for these new regulatory requirements.

Compliance with Rules 610 and Rule 611 will be phased-in as follows:

- Phase I. The first phase-in of NMS stocks subject to Rule 610 and 611will begin on June 29, 2006. Beginning on June 29, 2006 and continuing until the beginning of Phase II, all trading centers must begin trading 100 NMS stocks of each of Networks A and C, and 50 NMS stocks of Network B, pursuant to the requirements of Rules 610 and 611. The particular NMS stocks will be chosen by the primary listing market, in consultation with Commission staff, to be reasonably representative of the range of each Network's securities. The primary purpose of Phase 1 is to allow all market participants to verify the functionality of their systems and procedures necessary to effectively comply with the Rules. 
- $\quad$ Phase II. Phase II will begin on August 31, 2006. As

of that date, trading centers must begin trading all NMS stocks pursuant to the requirements of Rules 610 and 611.

The compliance date for the Allocation Amendment to the Plans will be September 1, 2006.

\section{Paperwork Reduction Act}

\section{A. Order Protection Rule}

The Order Protection Rule contains collection of information requirements within the meaning of the Paperwork Reduction Act of $1995 .{ }^{727}$ The Commission published a notice requesting comment on the collection of information requirements in both the Proposing Release and Reproposing Release, and submitted these requirements to the Office of Management and Budget ("OMB") for review in accordance with 44 U.S.C. 3507(d) and 5 CFR 1320.11. An agency may not conduct or sponsor, and a person is not required to respond to, an information collection unless it displays a currently valid OMB control number. The title of the affected collection is "Order Protection Rule" under OMB control number 3235-0600.

In the Proposing Release, the Commission proposed to create three new information collections. ${ }^{728}$ The first collection of information arose from the proposed requirement that trading centers adopt policies and procedures reasonably designed to prevent the execution of a transaction at prices inferior to prices displayed by other trading centers. The other two collections of information related to requirements in a proposed exception to the Order

72744 U.S.C. 3501 et seq. ("Paperwork Reduction Act").

728 See section III.G.1. of the Proposing Release. 
Protection Rule included in the Proposing Release - the opt-out exception. ${ }^{729}$ The Order Protection Rule as reproposed did not, and as adopted does not, contain an opt-out exception, and therefore, the collections of information associated with the proposed opt-out exception are no longer applicable.

The discussion below reflects the information collection requirements of the Order Protection Rule as adopted.

\section{Summary of Collection of Information}

The Order Protection Rule requires a trading center to establish, maintain, and enforce written policies and procedures reasonably designed to prevent the execution of trades on that trading center at prices inferior to protected quotations displayed by other trading centers, unless a valid exception applies, and, if relying on such an exception, that are reasonably designed to assure compliance with the terms of the exception. The nature and extent of the policies and procedures that a trading center will be required to establish to comply with this requirement will depend upon the type, size, and nature of the trading center.

\section{Proposed Use of Information}

The requirement that each trading center establish, maintain, and enforce written policies and procedures reasonably designed to prevent the execution of trades on that trading center at prices inferior to protected quotations displayed by other trading centers or to assure compliance with the terms of an exception will help ensure that the trading center and its customers, subscribers, members, and employees, as applicable, generally avoid engaging in trade-throughs, unless a valid exception is applicable.

\section{Respondents}

729 See section III.G.1. of the Proposing Release. 
The requirement for each trading center to establish written policies and procedures reasonably designed to prevent the execution of trade-throughs will apply to eight registered national securities exchanges that trade NMS stocks and the NASD, ${ }^{730}$ and approximately 600 broker-dealers registered with the Commission. ${ }^{731}$ The Commission did not receive any comment on these estimates.

The Commission has considered each of these respondents for the purposes of calculating the reporting burden under the Order Protection Rule.

\section{Total Annual Reporting and Recordkeeping Burden}

Trading centers will need to develop written policies and procedures for preventing and monitoring for trade-throughs that do not fall within an enumerated exception, and, if relying on such an exception, that are reasonably designed to assure compliance with the terms of the exception, to assure that they are in compliance with the Rule.

Although the exact nature and extent of the required policies and procedures that a trading center will be required to establish likely will vary depending upon the nature of the trading center (e.g., SRO vs. non-SRO, full service broker-dealer vs. market maker), the Commission broadly estimates that it would take an SRO trading center approximately 270 hours

730 There are eight national securities exchanges (Amex, BSE, CBOE, CHX, NSX, NYSE, Phlx and PCX) and one national securities association (NASD) that trade NMS stocks and thus will be subject to the Rule. The ISE does not trade NMS stocks and thus will not be subject to the Rule.

731 This estimate includes the approximately 585 firms that were registered equity market makers or specialists at year-end 2003 (this number was derived from annual FOCUS reports and discussion with SRO staff), as well as ATSs that operate trading systems that trade NMS stocks. The Commission believes it is reasonable to assume that in general, firms that are block positioners - i.e., firms that are in the business of executing orders internally - are the same firms that are registered market makers (for instance, they may be registered as a market maker in one or more Nasdaq stocks and carry on a block positioner business in exchange-listed stocks), especially given the amount of capital necessary to carry on such a business. 
of legal, ${ }^{732}$ compliance, ${ }^{733}$ information technology ${ }^{734}$ and business operations personnel ${ }^{735}$

time, ${ }^{736}$ and a non-SRO trading center approximately 210 hours of legal, compliance,

732 Based on industry sources, the Commission estimates that the average hourly rate for outsourced legal service in the securities industry is between $\$ 150$ per hour and $\$ 300$ per hour. For purposes of this Release, the Commission will use the highest rate of $\$ 300$ per hour to determine potential outsourced legal costs associated with the proposed rule. For in-house legal services, the Commission estimates that the average hourly rate for an attorney in the securities industry is approximately $\$ 82$ per hour. The $\$ 82$ per hour figure for an attorney is from the Securities Industry Association, Report on Management \& Professional Earnings in the Securities Industry 2003 (Sept. 2003), adjusted by the SEC staff for an 1800-hour work-year with a $35 \%$ upward adjustment for overhead, reflecting the cost of supervision, space, and administrative support.

The Commission estimates that the average hourly rate for an assistant compliance director in the securities industry is approximately $\$ 103$ per hour. The $\$ 103$ per hour figure for an assistant compliance director is from the Securities Industry Association, Report on Management \& Professional Earnings in the Securities Industry 2003 (Sept. 2003), adjusted by the SEC staff for an 1800-hour work-year with a $35 \%$ upward adjustment for overhead, reflecting the cost of supervision, space, and administrative support.

734 The Commission estimates that the average hourly rate for a senior computer programmer in the securities industry is approximately $\$ 67$ per hour. The $\$ 67$ per hour figure for a senior computer programmer is from the Securities Industry Association, Report on Management \& Professional Earnings in the Securities Industry 2003 (Sept. 2003), adjusted by the SEC staff for an 1800-hour work-year with a 35\% upward adjustment for overhead, reflecting the cost of supervision, space, and administrative support.

The Commission estimates that the average hourly rate for an operations manager in the securities industry is approximately $\$ 70$ per hour. The $\$ 70$ per hour figure for an operations manager is from the Securities Industry Association, Report on Management \& Professional Earnings in the Securities Industry 2002 (Sept. 2002), adjusted by the SEC staff for an 1800-hour work-year with a 35\% upward adjustment for overhead, reflecting the cost of supervision, space, and administrative support.

The Commission anticipates that of the 270 hours it estimates will be spent to establish the required policies and procedures, 120 hours will be spent by legal personnel, 105 hours will be spent by compliance personnel, 20 hours will be spent by information technology personnel and 25 hours will be spent by business operations personnel of the SRO trading center. 
information technology and business operations personnel time, ${ }^{737}$ to develop the required policies and procedures.

Included within this estimate, the Commission expects that SRO and non-SRO respondents may incur one-time external costs for out-sourced legal services. While the Commission recognizes that the amount of legal outsourcing utilized to help establish written policies and procedures may vary widely from entity to entity, it estimates that on average, each trading center would outsource 50 hours of legal time in order to establish policies and procedures in accordance with the Rule.

The Commission estimates that there will be an initial one-time burden of 220 burden hours per SRO trading center or 1,980 hours, ${ }^{738}$ and 160 burden hours per non-SRO trading center $^{739}$ or 96,000 hours, for a total of 97,980 burden hours to establish policies and procedures reasonably designed to prevent the execution of a trade-through, for an estimated one-time initial cost of $\$ 8,646,405 .^{740}$ The Commission estimates a capital cost of approximately $\$ 9,135,000$ for

737 The Commission anticipates that of 210 hours it estimates will be spent to establish policies and procedures, 87 hours will be spent by legal personnel, 77 hours will be spent by compliance personnel, 23 hours will be spent by information technology personnel and 23 hours will be spent by business operations personnel of the non-SRO trading center.

738 The estimated 1,980 burden hours necessary for SRO trading centers to establish policies and procedures are calculated by multiplying nine times 220 hours $(9 \times 220$ hours $=$ 1,980 hours).

739 The estimated 96,000 burden hours necessary for non-SRO trading centers to establish policies and procedures are calculated by multiplying 600 times 160 hours (600 x 160 hours $=96,000$ hours).

740 This figure was calculated as follows: (70 legal hours $\mathrm{x} \$ 82)+(105$ compliance hours $\mathrm{x}$ $\$ 103)+(20$ information technology hours $x \$ 67)+(25$ business operation hours $x \$ 70)=$ $\$ 19,645$ per SRO x 9 SROs $=\$ 176,805$ total cost for SROs; (37 legal hours $x$ \$82) + (77 compliance hours $x \$ 103)+(23$ information technology hours $x \$ 67)+(23$ business operation hours x $\$ 70)=\$ 14,116$ per broker-dealer $x 600$ broker-dealers $=\$ 8,469,600$ total cost for broker-dealers; $\$ 176,805+\$ 8,469,600=\$ 8,646,405$. 
both SRO and non-SRO trading centers resulting from outsourced legal work ${ }^{741}$ for a total onetime initial cost of $\$ 17,781,405^{742}$

Once a trading center has established written policies and procedures reasonably designed to prevent trade-throughs in its market, the Commission estimates that it will take the average SRO and non-SRO trading center approximately two hours per month of internal legal time and three hours of internal compliance time to ensure that its written policies and procedures are up-to-date and remain in compliance with Rule 611. The Commission staff estimates that these ongoing costs will be 60 hours annually per respondent, for a total estimated annual cost of $\$ 3,456,684 .^{743}$

The Commission did not receive any comments on its PRA burden estimates.

\section{General Information About Collection of Information}

This collection of information will be mandatory. The Commission expects that the written policies and procedures that will be generated pursuant to Rule 611 will be communicated to the members, subscribers, and employees (as applicable) of all entities covered by the Rule. To the extent that this information is made available to the Commission, it will not be kept confidential. Any records generated in connection with the Rule's requirement to establish written policies and procedures will be required to be preserved in accordance with, and

741 This figure was calculated as follows: (50 legal hours x $\$ 300 \times 9$ SROs) + (50 legal hours x $\$ 300$ x 600 broker-dealers) $=\$ 9,135,000$.

742 This figured was calculated by adding $\$ 8,646,405$ and $\$ 9,135,000$.

743 This figure was calculated as follows: (2 legal hours x 12 months x $\$ 82) \times(9+600)+(3$ compliance hours x 12 months x \$103) x $(9+600))=\$ 3,456,684$. 
for the periods specified in, Exchange Act Rules $17 a-1^{744}$ and 17a-4(e)(7). ${ }^{745}$

\section{B. Access Rule}

In the Proposing Release and Reproposing Release, the Commission requested comment on its preliminary view that proposed Rule 610 and the proposed amendment to Rule 301(b)(5) under Regulation ATS do not contain a collection of information requirement as defined by the Paperwork Reduction Act. ${ }^{746}$ No comments were received that addressed the issue. The Commission continues to believe that Rule 610 and the amendment to Rule 301(b)(5) do not contain a collection of information requirement.

\section{Sub-Penny Rule}

In the Proposing Release and Reproposing Release, the Commission stated its preliminary view that proposed Rule 612 does not contain a collection of information requirement as defined by the Paperwork Reduction Act. ${ }^{747}$ No comments were received that addressed this issue. The Commission continues to believe that Rule 612 does not contain a collection of information requirement.

\section{Market Data Rules and Plan Amendments}

In the Proposing Release and Reproposing Release, the Commission stated its preliminary view that the proposed amendments to the joint-industry plans and to Exchange Act Rules 11Aa3-1 and 11Ac1-2 (redesignated as Rules 601 and 603) do not impose a collection of

\footnotetext{
$744 \quad 17$ CFR 240.17a-1.

$745 \quad 17$ CFR 240.17a-4(e)(7).

746 Proposing Release, 69 FR at 11160; Reproposing Release, 69 FR at 77476.

747 Proposing Release, 69 FR at 11172; Reproposing Release, 69 FR at 77476.
} 
information requirement as defined by the Paperwork Reduction Act. ${ }^{748}$ No comments were received that addressed this issue. The Commission continues to believe that these amendments do not contain a collection of information requirement.

\section{E. Regulation NMS}

In the Proposing Release and Reproposing Release, the Commission stated its preliminary view that proposed Rule 600, the redesignation of the NMS rules, and the conforming amendments to various rules do not impose a collection of information requirement as defined by the Paperwork Reduction Act. ${ }^{749}$ No comments were received that addressed this issue. The Commission continues to believe that these amendments do not contain a collection of information requirement.

\section{Consideration of Costs and Benefits}

In the Proposing Release and Reproposing Release, the Commission identified certain costs and benefits of the Regulation NMS proposals, and, to help evaluate the costs and benefits, requested comment on all aspects of the costs and benefits and encouraged commenters to identify or supply any relevant data concerning the costs or benefits of the proposal. ${ }^{750}$ To the extent commenters discussed costs and benefits, the Commission has considered those comments.

\section{A. Order Protection Rule}

Rule 611 requires a trading center (which includes national securities exchanges and national securities associations that operate SRO trading facilities, ATSs, market makers, and

748 Proposing Release, 69 FR at 11186; Reproposing Release, 69 FR at 77476-77.

749 Proposing Release, 69 FR at 11197; Reproposing Release, 69 FR at 77477.

$750 \quad$ Proposing Release, 69 FR at 11148-11150, 11161, 11172-73, 11186-89, 11197-98;

Reproposing Release, 69 FR at 77441, 77474, 77475, 77477, 77480, 77488, 77489. 
block positioners) to establish, maintain, and enforce written policies and procedures that are reasonably designed to prevent trade-throughs on that trading center of protected quotations, and, if relying on an exception, that are reasonably designed to assure compliance with the terms of the exception. To qualify for protection, a quotation is required to be displayed and immediately accessible through automatic execution. The Rule also requires a trading center to regularly surveil to ascertain the effectiveness of the policies and procedures and to take prompt remedial action to remedy deficiencies in such policies and procedures. As discussed above in Section II.A.5, the Commission has determined to adopt the Market BBO Alternative with respect to the scope of quotations that will be protected under the Rule. The Commission believes that providing enhanced protection for the best bids and offers of each exchange, The NASDAQ Stock Market, and the ADF will represent a major step toward achieving the objectives of intermarket price protection, but with fewer of the costs and potential drawbacks associated with the Voluntary Depth Alternative.

Rule 611 includes a variety of exceptions to make intermarket price protection as efficient and workable as possible. These include an intermarket sweep exception, which allows market participants simultaneously to access multiple price levels at different trading centers - a particularly important function now that trading in penny increments has dispersed liquidity across multiple price levels. The intermarket sweep exception enables trading centers that receive sweep orders to execute those orders immediately, without waiting for better-priced quotations in other markets to be updated. In addition, Rule 611 provides exceptions for the quotations of trading centers experiencing, among other things, a material delay in providing a response to incoming orders, as well as for flickering quotations with prices that have been displayed for less than one second. Both exceptions serve to limit the application of Rule 611 to 
quotations that are truly automated and accessible. In response to commenters, the Commission also is including in the Rule an exception for certain "stopped" orders. ${ }^{751}$

\section{Benefits}

Although commenters were divided on the central issue of whether intermarket protection of displayed quotations is needed to promote the fairest and most efficient markets for investors, many commenters strongly supported the adoption of a rule against trade-throughs without an opt-out for all NMS stocks to promote best execution of market orders, to protect the best displayed prices, and encourage the public display of limit orders. ${ }^{752}$ These commenters noted that such a rule would encourage the use of displayed limit orders, thus increasing depth and liquidity in the market. ${ }^{753}$ Some of these commenters also stated that the trade-through proposal would increase investor confidence by helping to eliminate the impression of unfairness when an investor's order executes at a price that is worse than the best displayed quotation, or when a trade occurs at a price that is inferior to the investor's displayed order. ${ }^{754}$ As discussed above in Section II.A.1, the Commission agrees with these commenters.

The Commission believes that the Order Protection Rule will enhance the overall fairness and efficiency of the NMS and produce significant benefits for investors. The Order Protection Rule will benefit investors by promoting the best execution of customer market orders, promoting the fair treatment of customer limit orders, and strengthening protection of limit orders to promote greater depth and liquidity for NMS stocks and thereby minimize investor

$751 \quad$ See supra, section II.A.4.

752 See supra, section II.A.1.

$753 \quad$ See, e.g., BNY Letter at 2; Consumer Federation Letter at 2; ICI Letter at 7.

$754 \quad$ See, e.g., Consumer Federation Letter at 2; ICI Letter at 7. 
transaction costs. By providing greater protection for displayed prices, the Rule should serve to enhance the depth and liquidity of the NMS, and thus contribute to the maintenance of fair and orderly markets. By better protecting the interests of investors, both those that post limit orders and those that execute against posted limit orders, the Rule will promote investor confidence in the NMS. The Rule will be a significant improvement over the existing ITS trade-through rule, and will level the competitive playing field among markets by eliminating the potential advantage that the ITS rule afforded to manual markets.

By requiring trading centers to establish written policies and procedures reasonably designed to prevent trade-throughs on their markets and to comply with exceptions, and by requiring them to regularly surveil to ascertain the effectiveness of the policies and procedures and to take prompt remedial action to remedy deficiencies in such policies and procedures, the Commission believes that the Rule also will offer greater assurance, on an order-by-order basis, to investors that submit market orders that their orders in fact will be executed at the best readily available prices, which can be difficult for investors, particularly retail investors, to monitor. As noted above, some commenters stated that the trade-through proposal would increase investor confidence by helping to eliminate the impression of unfairness when an investor's order executes at a price that is worse than the best displayed quotation. ${ }^{755}$ Most retail investors justifiably expect that their orders will be executed at the NBBO. Investors generally can know the best quoted prices at the time they place an order by referring to the consolidated quotation stream for a stock. In the interval between order submission and order execution, however, quoted prices can change. If the order execution price differs from the quoted price at order submission, it can be particularly difficult for retail investors to assess whether the difference 
was attributable to changing quoted prices or to an inferior execution by the market. By protecting the BBO of each exchange, The NASDAQ Stock Market, and the NASD, the Rule will further the interests of investors, particularly retail investors, in obtaining - and the ability of broker-dealers to achieve - best execution on an order-by-order basis, because the market to which a broker-dealer routes an order will not execute the order at a price that is inferior to a protected bid or offer displayed on the other market (unless an exception applies). ${ }^{756}$

The Order Protection Rule also will promote the fair and orderly treatment of limit orders for NMS stocks. Many of the limit orders that are bypassed are small orders that often will have been submitted by retail investors. Retail investors will participate directly in the U.S. equity markets only to the extent that they perceive that their orders will be treated fairly and efficiently. The Commission agrees with commenters that the Order Protection Rule will increase investor confidence by helping to eliminate the impression of unfairness when a trade occurs at a price that is inferior to the investor's displayed order. ${ }^{757}$ By better protecting the interests of all investors - both those that execute against posted limit orders and those that post limit orders - the Rule will bolster investor confidence in the integrity of the NMS, which will encourage investors to be more willing to invest in the market, thus adding depth and liquidity to the markets and promoting the ability of listed companies to raise capital.

The Order Protection Rule also is designed to promote greater depth and liquidity for NMS stocks and thereby minimize implicit investor transaction costs. Depth and liquidity will be increased only to the extent that limit order users are given greater incentives than currently exist to display a larger percentage of their trading interest. Investors who post limit orders

756 The Commission emphasizes that adoption of Rule 611 would in no way lessen a brokerdealer's duty of best execution. See supra, section II.B.4. See supra, note 59. 
should not see trades occurring on another market at a price inferior to their orders, except in circumstances where an exception applies. Price protection encourages the display of limit orders by increasing the likelihood that they will realize an execution in a timely manner. Limit orders typically establish the best prices for an NMS stock. Greater use of limit orders will enhance price discovery and increase market depth and liquidity, thereby improving the quality of execution for large orders of institutional investors. The Commission believes that the Order Protection Rule is necessary to, and will serve to, enhance protection of displayed prices. By requiring trading centers to establish written policies and procedures reasonably designed to prevent trade-throughs and to comply with exceptions, and by requiring them to regularly surveil to ascertain the effectiveness of the policies and procedures and to take prompt remedial action to remedy deficiencies in such policies and procedures, the Rule will help ensure that displayed limit orders are not routinely bypassed by transactions occurring in other markets at inferior prices.

Almost all commenters agreed that the current ITS trade-through rule must be fixed to accommodate the realities of today's NMS, in particular the differences in operation among automated and non-automated markets. The Commission believes that Rule 611, by providing protection only for automated quotations displayed by automated trading centers, will significantly update the ITS trade-through rule. Intermarket efficiency and certainty of execution in the NMS will be improved as automated markets will no longer need to wait for responses from non-automated markets and thus will be able to execute trades more quickly without regard for potentially unavailable quotations displayed on non-automated markets. The Rule also will level the playing field by eliminating the potential competitive advantage the existing ITS rule provides to manual markets. In addition, by providing an incentive for non-automated markets 
to automate - because market participants may be less likely to send their order flow to a market center whose orders are not protected by the Order Protection Rule - the Rule generally should improve the accessibility of bids and offers for all investors and increase the efficiency of the NMS.

The Commission believes that the benefits of strengthening price protection for exchange-listed stocks (e.g., by eliminating the gaps in ITS coverage of block positioners and 100-share quotes) and introducing price protection for Nasdaq stocks will be substantial, although the total amount is difficult to quantify. One objective, though quite conservative, estimate of benefits is the dollar amount of quotations that annually are traded through. The Commission staff's analysis of trade-through rates indicates that over 12 billion shares of displayed quotations in Nasdaq and NYSE stocks were traded through in 2003, by an average amount of 2.3 cents for Nasdaq stocks and 2.2 cents for NYSE stocks. ${ }^{758}$ These traded-through quotations represent approximately \$209 million in Nasdaq stocks and \$112 million in NYSE stocks, for a total of $\$ 321$ million in bypassed limit orders and inferior prices for investors in 2003 that could have been addressed by strong trade-through protection. ${ }^{759}$ The Commission believes that this $\$ 321$ million estimated annual benefit, particularly when combined with the benefits of enhanced investor confidence in the fairness and orderliness of the equity markets, justifies the one-time costs of implementation and ongoing annual costs of the Order Protection Rule.

Two commenters on the reproposal asserted that the dollar amount of traded-through quotations overstated the benefits of order protection because "trading is for the most part a zero-

\footnotetext{
$758 \quad$ Trade-Through Study at 3, 5.

$759 \quad$ Id. at 3.
} 
sum game."760 They believed that trades executed at inferior prices were random noise that sometimes benefited and sometimes disadvantaged a particular investor, stating that "[i]t is only if one class of investors systematically loses out to another class as a result of trade-throughs that there is a problem...." ${ }^{761}$

The Commission does not agree that trades executed at inferior prices should be considered merely a transfer of benefits from one group of investors to another equally-situated group of investors. There are at least three parties affected by every trade-through transaction: (1) the party that received an inferior price; (2) the party whose superior-priced limit order was traded-through; and (3) the contra party to the trade-through transaction that received an advantageous price. The redistributions of welfare resulting from trade-through transactions cannot reasonably be expected to occur randomly across these parties. Customers of brokers that are doing a poor job of routing orders are more likely to be harmed than customers of brokers that are doing a better job. ${ }^{762}$ Investors who generally submit limit orders at the best prices are more likely to be harmed than customers who generally submit less aggressively-priced limit orders.

Thus, trade-through transactions can result in direct harm to two parties, as well as more general harm to the efficiency of the markets by dampening the incentive for aggressive quoting. Moreover, even when the party receiving an inferior price does so willingly (such as when an

760 Angel Reproposal Letter at 4; see also Fidelity Reproposal Letter at 8.

761 Angel Reproposal Letter at 4.

762 As discussed above, it can be difficult for retail investors in particular to monitor whether their orders in fact received the best available price at the time of order execution. See supra, note 53 and accompanying text. 
institution accepts a block trade at a price away from the inside quotation) ${ }^{763}$ the party whose quotation was traded through and the efficiency of the markets still are harmed. Finally, many trade-throughs are dealer internalized trades, where the party receiving the advantageous price is not an investor but a market intermediary, and therefore such trades cannot be considered a transfer of benefits from one group of investors to another equally-situated group of investors. This transfer of benefits from investors to market intermediaries cannot be dismissed as mere "random noise."

In addition, economic theory predicts that, in an auction market, buyers who place the highest value on a stock will bid most aggressively. ${ }^{764}$ If an incoming market order is allocated to an investor who is not bidding the best price, this re-allocation is neither zero-sum nor random. It systematically reallocates trades away from those investors for whom the welfare gains would be largest. The argument also can be framed in terms of an investor's preferences with respect to the tradeoff between price and execution speed. Among those investors who

763 Fidelity and the Battalio/Jennings Paper stated that the staff study should not have included block trades in its estimate of the benefits of strengthened trade-through protection. Fidelity Reproposal Letter II at 1; Battalio/Jennings Paper at 2. The Commission does not agree. First, the amount that block trades contributed to the \$321 million estimate is very small. Block trades represented only $1.9 \%$ of total tradethroughs in Nasdaq stocks and $1.1 \%$ of total trade-throughs in NYSE stocks. TradeThrough Study, Tables 6, 13. Most importantly, the staff study used the lesser of the size of the traded-through quotation and the size of the trade-through transaction when calculating the $\$ 321$ million. Id. at 3. Thus, if a 10,000 share transaction traded through a 100-share quotation, only 100 shares counted toward the estimation of benefits. The Battalio/Jennings Paper incorrectly asserted that the staff study did not use this conservative approach. Battalio/Jennings Paper at 2. Finally, block trades are appropriately included in the estimation of benefits because their failure to interact with significant displayed quotations is one of the most serious problems with respect to the protection of limit orders that the Order Protection Rule is designed to address. See supra, section II.A.1.c.

764 See, e.g., B. Hollifield, R. Miller and P. Sandas, "Empirical Analysis of Limit Order Markets," 71 Review of Economic Studies 1027-1063 and n. 4 (2004). 
trade using limit orders, we would expect more aggressive limit orders to be submitted by those investors who place more value on speed or certainty of execution and relatively less value on price. Conversely, we would expect investors who place a lower value on speed and certainty of execution and a higher value on price to submit less aggressive limit orders. When an incoming market order is executed against a limit order with an inferior price, the result is: (1) a faster execution for an investor who does not place as much value on speed of execution; and (2) a lost execution or slower execution for the investor who places a higher value on prompt execution. This is not a zero-sum redistribution.

Moreover, the \$321 million estimate is a conservative measure of the total benefits of the Order Protection Rule. It does not attempt to measure any gains from trading associated with investors’ private values, beyond those expressed in their limit order prices. The Order Protection Rule can be expected to generate other categories of benefits that are not quantified in the $\$ 321$ million estimate, such as the benefits that can be expected to result from increased use of limit orders, increased depth, and increased order interaction.

Thus, the Commission believes that the $\$ 321$ million estimate of benefits is conservative because it is based solely on the size of displayed quotations in the absence of strong price protection. In essence, it measures the problem - a shortage of quoted depth - that the Order Protection Rule is designed to address, rather than the benefits that it could achieve. Every tradethrough transaction potentially sends a message to market participants that their displayed quotations can be and are ignored by other market participants. When the total share volume of trade-through transactions that do not interact with displayed quotations reaches $9 \%$ and above for hundreds of the most actively traded NMS stocks, ${ }^{765}$ this message is unlikely to be missed by 
those who watched their quotations being traded through. Certainly, the common practice of trading through displayed size is most unlikely to prompt market participants to display even greater size.

A primary objective of the Order Protection Rule is to increase displayed depth and liquidity in the NMS and thereby reduce transaction costs for a wide spectrum of investors, particularly institutional investors that must trade in large sizes. Precisely estimating the extent to which strengthened price protection will improve market depth and liquidity, and thereby lower the transaction costs of investors, is very difficult. The difficulty of estimation should not hide from view, however, the enormous potential benefits for investors of improving the depth and efficiency of the NMS. Because of the huge dollar amount of trading volume in NMS stocks - more than $\$ 17$ trillion in $2003^{766}$ - even the most incremental improvement in market depth and liquidity could generate a dollar amount of benefits that annually would dwarf the one-time start-up costs of implementing trade-through protection.

One approach to evaluating the potential benefits of the Order Protection Rule is to examine a category of investors that stand to benefit a great deal from improved depth and liquidity for NMS stocks - the shareholders in U.S. equity mutual funds. In 2003, the total assets of such funds were $\$ 3.68$ trillion. $^{767}$ The average portfolio turnover rate for equity funds was 55\%, meaning that their total purchases and sales of securities amounted to approximately $\$ 4.048$ trillion. $^{768}$ A leading authority on the trading costs of institutional investors has estimated

766 World Federation of Exchanges, Annual Report (2003), at 86.

767 Investment Company Institute, Mutual Fund Fact Book (2004), at 55.

768 Id. at 64. Portfolio turnover is reported as the lesser of portfolio sales or purchases divided by average net assets. Because price impact occurs for both purchases and sales, the turnover rate must be doubled, then multiplied by total fund assets, to estimate the total value of trading that would be affected by an improvement in depth and liquidity. 
that in the second quarter of 2003 the average price impact experienced by investment managers ranged from 17.4 basis points for giant-capitalization stocks, 21.4 basis points for largecapitalization stocks, and up to 35.4 basis points for micro-capitalization stocks. ${ }^{769}$ In addition, it estimated the cost attributable to adverse price movements while searching for liquidity for institutional orders, which often are too large simply to be presented to the market. Its estimate of these liquidity search costs ranged from 13 basis points for giant capitalization stocks, 23 basis points for large capitalization stocks, and up to 119 basis points for micro-capitalization stocks.

To obtain a conservative estimate of price impact costs and liquidity search costs incurred across all stocks, the total market impact and liquidity search costs for giant capitalization stocks (30.4 basis points) and the total market impact and liquidity search costs for large capitalization stocks (44.4 basis points) are averaged together to yield a figure of 37.4 basis points. ${ }^{770}$ The much higher market impact and liquidity search costs of midcap, smallcap, and microcap stocks are not included. Using this estimate of 37.4 basis points, the shareholders in U.S. equity mutual funds incurred implicit transaction costs of $\$ 15.1$ billion in 2003. Based on a hypothetical assumption that, in light of the current share volume of trade-through transactions that does not interact with displayed liquidity, intermarket trade-through protection could improve depth and liquidity for NMS stocks by $5 \%$ (or an average reduction of 1.87 basis points in price impact and liquidity search costs for large investors), the savings in transaction costs for U.S equity funds

769 Plexus Group, Inc., Commentary 80, "Trading Truths: How Mis-Measurement of Trading Costs Is Leading Investors Astray," (April 2004), at 2-3.

770 Cf. supra, note 146 and accompanying text (Plexus estimate of average transaction costs, including commissions, during the fourth quarter of 2003 for Nasdaq and NYSE stocks as, respectively, 83 basis points and 55 basis points; commissions average 12 basis points for large capitalization stocks). 
alone, and the improved returns for their millions of individual shareholders, would have amounted to approximately \$755 million in 2003.

Of course, the benefits of improved depth and liquidity for the equity holdings of other types of investors, including pension funds, insurance companies, and individuals, are not incorporated in the foregoing calculations. In 2003, these other types of investors held $78 \%$ of the value of publicly traded U.S. equity outstanding, with equity mutual funds holding the remaining 22\%. ${ }^{771}$ For example, pension funds alone held $\$ 9$ trillion in assets in 2003, of which an estimated $\$ 4.9$ trillion was held in equity investments other than mutual funds. ${ }^{772}$ Thus, the implicit transaction costs incurred by institutional investors each year is likely at least double the $\$ 15.1$ billion estimated for equity mutual funds, for a total of more than $\$ 30$ billion. Assuming that these other types of investors experienced a reduction in transaction costs that equaled the reduction of trading costs for equity mutual funds, the assumed 5\% improvement in market depth and liquidity could yield total transaction cost savings for all investors of over $\$ 1.5$ billion annually. Such savings would improve the investment returns of equity ownership, thereby promoting the retirement and other long-term financial interests of individual investors and reducing the cost of capital for listed companies.

\section{Costs}

771 Mutual Fund Factbook, supra note 767, at 59.

772 Id. at 91 (employer-sponsored pension market held estimated $\$ 9.0$ trillion in assets in 2003, $\$ 7.7$ trillion of which were not represented by mutual fund assets); Milliman, Inc., Pension Fund Survey (available at www.milliman.com) (consulting firm's survey of 2003 annual reports for 100 of largest U.S. corporations found that the median equity allocation for pension fund assets was 65\%). 
Some commenters expressed concern over the anticipated cost of implementing the original trade-through proposal. ${ }^{73}$ These commenters argued that Rule 611 would be too expensive and that the costs associated with implementing it would outweigh the perceived benefits of the Rule. Some commenters were concerned about the cost of specific requirements in the proposed rule, particularly the procedural requirements associated with the proposed optout exception (e.g., obtaining informed consent from customers and disclosing the NBBO to customers). ${ }^{774}$ As discussed above, however, the Order Protection Rule as reproposed did not (and as adopted does not) contain an opt-out exception, as was originally proposed. ${ }^{775}$ Therefore, the concerns expressed by commenters relating to the costs of implementing an optout exception are not applicable, and were not included in the Reproposing Release. In the Reproposing Release, the Commission also refined its estimate of the number of broker-dealers that would be required to establish, maintain, and enforce written policies and procedures to prevent trade-throughs. ${ }^{776}$ Taken together, these changes substantially reduced the estimated

773 See, e.g., Bloomberg Tradebook Letter at 14; Fidelity Letter I at 12; Instinet Letter at 14, 15; Nasdaq Letter II at 2; Peake Letter I at 2; Reg NMS Study Group Letter at 4; Rosenblatt Securities Letter II at 4; STANY Letter at 3; UBS Letter at 8.

774 See, e.g., Ameritrade Letter I at 8; Brut Letter at 10-12; Citigroup Letter at 8-9; E*TRADE Letter at 7; Financial Information Forum Letter at 2; JP Morgan Letter at 4; SIA Letter at 12-15.

See supra, section II.A.4.

776 As noted in the Reproposing Release, the Commission revised the estimated number of broker-dealers that would be subject to the reproposed Rule from the original proposal. The revised number includes the approximately 585 firms that were registered equity market makers or specialists at year-end 2003 (this number was derived from annual FOCUS reports and discussion with SRO staff), as well as ATSs that operate trading systems that trade NMS stocks. The Commission believes it is reasonable to assume that in general, firms that are block positioners - i.e., firms that are in the business of executing orders internally - are the same firms that are registered market makers (for instance, they may be registered as a market maker in one or more Nasdaq stocks and 
costs associated with the implementation of and ongoing compliance with the reproposed Rule. Commenters also expressed concern that applying the trade-through proposal to the Nasdaq market would harm market efficiency and execution quality. ${ }^{777}$ As discussed above, the Commission believes that a rule that serves to limit the incidence of trade-throughs will improve market efficiency and benefit execution quality. ${ }^{778}$

A number of commenters generally expressed the view that there would be significant costs associated with implementing and complying with the reproposed Rule, ${ }^{779}$ with some commenters stating the belief that the costs would outweigh any potential benefits. ${ }^{780}$ Commenters did not, however, discuss the specific estimated cost figures included in the Reproposing Release or include their own estimates. Many commenters expressed concerns with the costs associated with implementing the Voluntary Depth Alternative, believing that the costs of implementing the Voluntary Depth Alternative would be substantially greater than the Market BBO Alternative. ${ }^{781}$ As discussed above in Section II.A.5, the Commission is adopting the Market BBO Alternative and not the Voluntary Depth Alternative. The Commission does

carry on a block positioner business in exchange-listed stocks), especially given the amount of capital necessary to carry on such a business.

777 See, e.g., Archipelago Reproposal Letter at 5-6; Citadel Letter at 6; Hudson River Trading Letter at 1-2; Instinet Reproposal Letter at 9, 14; Nasdaq Reproposal Letter at 2.

778 See supra, section II.A.1.

779 See, e.g., CIBC Reproposal Letter at 4; Knight Securities Reproposal Letter at 5; Lava Reproposal Letter at 1; Merrill Lynch Reproposal Letter at 5; SIA Reproposal Letter at 11.

780 See, e.g., Angel Reproposal Letter at 2; Instinet Reproposal Letter at 7; Knight Securities Reproposal Letter at 5; MFA Reproposal Letter at 2.

781 See, e.g., Amex Reproposal Letter at 3; ATD Reproposal Letter at 4; BNY Reproposal Letter at 3; CHX Reproposal Letter at 2; NYSE Reproposal Letter I, Detailed Comments at 8; RBC Capital Markets Reproposal Letter at 6; STANY Reproposal Letter at 9. 
not believe that the inclusion of a stopped order exception will materially impact the estimated costs included in the Reproposing Release. ${ }^{782}$ The Commission therefore continues to estimate implementation costs for the Order Protection Rule of approximately \$143.8 million and annual costs of approximately $\$ 21.9$ million, as discussed below.

The Commission recognizes, as noted by commenters, that there will be significant onetime costs to implement the Order Protection Rule. Trading centers will necessarily incur costs associated with establishing written policies and procedures reasonably designed to prevent trade-throughs - in other words, with determining a course of action for how the trading center will comply with the requirements of the Rule, including compliance with the exceptions contained in the Rule. Although the extent of these costs will vary because the exact nature and extent of each trading center's written policies and procedures will depend on the type, size and nature of each entity's business, as discussed above in Section VIII.A., for purposes of the PRA the Commission broadly estimates that SRO trading centers will incur a one-time initial cost for establishing such policies and procedures of approximately $\$ 311,805$ (calculated by multiplying the average cost of $\$ 34,645$ per SRO trading center by the 9 SRO trading centers), and non-SRO trading centers will incur a one-time initial cost for establishing policies and procedures of approximately $\$ 17,469,600$ (calculated by multiplying the average cost of $\$ 29,116$ per non-SRO trading center by the 600 non-SRO trading centers), for a total of $\$ 17,781,405$. $^{783}$

Each trading center also will incur initial up-front costs associated with taking action necessary to implement the written policies and procedures it has developed, which will include necessary modifications to order routing and execution systems to "hard-code" compliance with

782 The estimated cost figures included the Reproposing Release did not include additional costs that would have been associated with the Voluntary Depth Alternative.

See supra, notes 736 to 742 and accompanying text. 
the Rule and the exceptions. For instance, modifications to order routing and execution systems will need to be made to route and execute orders in compliance with the requirements of the Rule to prevent trade-throughs of protected quotations (which include, for instance, the ability to recognize quotations identified in the consolidated quotation system as manual quotations on a quotation-by-quotation basis). Trading centers will need to make sure they have connectivity to other trading centers in the NMS that could post protected quotations, whether through proprietary linkages or through use of third-party services. As noted below, however, the Commission believes that most of this private linkage functionality already exists, particularly in the market for Nasdaq securities. Surveillance systems will need to be modified to assure an effective mechanism for monitoring transactions after-the-fact for ongoing compliance purposes. Also, trading systems will need to be programmed to recognize when exceptions to the operative provisions of Rule 611 are applicable. For example, trading centers will need to be able to identify outgoing and recognize incoming orders as intermarket sweep orders. Data feeds and market vendor systems will need to be modified to accommodate order identifiers for manual quotations and intermarket sweep orders, which costs (to the extent incurred) will likely be passed along to the end users of these systems, the trading centers. These costs are included within the estimates below.

For non-SRO trading centers that rely upon their own internal order routing and execution management systems, of which the Commission estimated in the Reproposing Release that there are approximately 20, the Commission estimates the average cost of necessary systems changes to implement the Rule will be approximately \$3 million per trading center, for a total 
one-time start-up cost of approximately $\$ 60$ million. ${ }^{784}$ The Commission estimates that the remaining non-SRO trading centers that will be subject to the Rule will utilize outside vendors to provide these services, consistent with their current use of such services for order routing and execution management. For these non-SRO trading centers, the Commission estimates the cost of necessary systems modifications that will be passed along to the trading centers to be approximately $\$ 50,000$ per trading center, for a total initial cost of $\$ 21$ million. ${ }^{785}$ The Commission also estimates that the average cost to the nine SROs to make necessary system modifications to implement the Rule will be \$5 million per SRO, for a total of \$45 million. Therefore, estimated overall total one-time implementation costs, added to PRA costs, are approximately \$144 million.

In addition, broker-dealers that do not fall within the definition of a trading center but that employ their own smart-order routing technology to route orders to multiple trading centers could choose to route orders in compliance with the intermarket sweep exception. These brokerdealers would need to make necessary modifications to their order routing practices and proprietary order routing systems to monitor the protected quotations of trading centers and to properly identify such intermarket sweep orders. The Commission does not believe that this category of broker-dealers is very large. The Commission also believes it likely that most if not

784 This number is an average estimated cost; thus, it likely overestimates the costs for some trading centers and underestimates it for others. For instance, it likely overestimates the cost for ATS trading centers, particularly smaller ones, as opposed to full-service brokerdealer trading centers, in part because of the narrower business focus of some ATSs.

Given that floor-based market-makers and specialists utilize exchange execution systems, the Commission believes it is reasonable to assume that such market-makers and specialists will not incur substantial systems-related costs to implement the Rule independent of the costs that will be incurred by the exchange on whose floor they operate to make changes to the exchange's execution systems. Thus, these entities (approximately 160 of the 585) are not directly included within the cost estimates. 
all of these non-trading center broker-dealers that employ their own order-routing technology already have systems in place that monitor best-priced quotations across markets, and thus does not believe that the changes necessary to implement the intermarket sweep order will be substantial.

With respect to maintaining and updating its required written policies and procedures to ensure they continue to be in compliance with the Rule, for purposes of the PRA the Commission estimates that the average annual cost for each trading center will be approximately $\$ 5,676$ per trading center per year, for a total annual cost for all trading centers of $\$ 3,456,684$. $^{786}$ With regard to ongoing monitoring for and enforcement of trading in compliance with the Rule, the Commission believes that, once the tools necessary to carry out on-going monitoring have been put in place (which are included in the above cost estimates), a trading center will be able to incorporate ongoing monitoring and enforcement within the scope of its existing surveillance and enforcement policies and procedures without a substantial additional burden.

The Commission recognizes, however, that this ongoing compliance will not be cost-free, and that trading centers will incur some additional annual costs associated with ongoing compliance, including compliance costs of reviewing transactions. For instance, the Commission recognizes that access to a database of BBO information for each trading center whose quotations will be protected by the Order Protection Rule will be necessary to monitor transactions for compliance with the Rule on an after-the-fact basis. The Commission believes that this information currently is available and understands that such information currently is maintained by at least one industry vendor. The Commission believes that the cost to each trading center to access this database will be incremental in relation to the cost of other services

See supra, note 743 and accompanying text. 
provided by the vendor. The Commission estimates that each trading center will incur an average annual ongoing compliance cost of $\$ 30,144$ for a total annual cost of $\$ 18,357,696$ for all trading centers. ${ }^{787}$

In assessing the costs of systems changes that may be required by the Order Protection Rule, it is important to recognize that much, if not all, of the connectivity among trading centers necessary to implement intermarket price protection has already been put in place. For example, trading centers for exchange-listed securities already are connected through the ITS. The Commission understands that, at least as an interim solution, ITS facilities and rules can be modified relatively easily and at low cost to provide the current ITS participants a means of complying with the provisions of Rule 611. With respect to Nasdaq stocks, connectivity among many trading centers already is established through private linkages. Routing out to other trading centers when necessary to obtain the best prices for Nasdaq stocks is an integral part of the business plan of many trading centers, even when not affirmatively required by best execution responsibilities. Moreover, a variety of private vendors currently offer connectivity to NMS trading centers for both exchange-listed and Nasdaq stocks. Many of the broker-dealers that are non-SRO trading centers that will be subject to the Rule already employ smart order routing technology, either their own systems or those of outside vendors, which should limit the cost of implementing systems changes. The Commission also understands that the cost to the Plan processors to incorporate the Order Protection Rule and its exceptions will be minimal.

787 This estimate was included in the Reproposing Release. The Commission continues to estimate that each trading center will incur an average annual ongoing compliance cost of $\$ 30,144$ for a total annual cost of $\$ 18,357,696$ for all trading centers. This figure was calculated as follows: (16 compliance hours $\mathrm{x} \$ 103)+(8$ information technology hours $\mathrm{x}$ $\$ 67)+(4$ legal hours $\times \$ 82) \times 12$ months $=\$ 30,144$ per trading center $\times 609$ trading centers $=\$ 18,357,696$. See supra, notes 732 to 735 for notation as to hourly rates. 
In determining these estimates the Commission also has considered that many market participants are already making changes to their systems to become more competitive. Many of the changes being made will assist the market participants in preparing for implementation of the Order Protection Rule. For example, Nasdaq, which previously did not have an order routing system, purchased Brut, LLC last year in order to acquire access to such a system. The Commission believes that this acquisition should reduce the costs that will be incurred by Nasdaq to implement the Order Protection Rule. The Commission also notes that the NYSE is in the process of modifying its Direct+ System to make more quotations available on an automated basis. $^{788}$ These changes that the NYSE has undertaken should reduce the cost of additional systems changes needed to implement the Order Protection Rule.

Overall, the Commission believes that the Order Protection Rule will produce significant benefits that justify the costs of implementation of the Rule.

\section{B. Access Rule}

Rule 610 of Regulation NMS sets forth new standards governing means of access to quotations in NMS stocks. These standards will prohibit trading centers from imposing unfairly discriminatory terms that would prevent or inhibit the efficient access of any person through members, subscribers, or customers of such trading center, and enable access to NMS quotations through private linkages, rather than mandating a collective intermarket linkage facility. In addition, the Rule is designed to ensure the fairness and accuracy of displayed quotations by establishing an outer limit on the cost of accessing protected quotations and any other quotations at the best bid and offer of no more than $\$ 0.003$ per share (or $0.3 \%$ of the quotation price per

$788 \quad$ See Securities Exchange Act Release Nos. 50173 (Aug. 10, 2004), 69 FR 50407 (Aug. 16, 2004), 50277 (Aug. 26, 2004), 69 FR 53759 (Sept. 2, 2004) and 50667 (Nov. 15, 2004), 69 FR 67980 (Nov. 22, 2004) (SR-NYSE-2004-05). 
share for quotations priced less than \$1). Rule 610 also requires SROs to establish, maintain, and enforce rules that would, among other things, prohibit their members from engaging in a pattern or practice of displaying quotations that lock or cross the automated quotations of other trading centers. Finally, the adopted amendment to Rule 301 of Regulation ATS lowers the threshold that triggers the Regulation ATS fair access requirements from $20 \%$ to $5 \%$ of average daily volume in a security.

\section{Benefits}

The Commission believes that the adopted Access Rule will help achieve the statutory objectives for the NMS by promoting fair and efficient access to each individual market. By enabling reliance on private linkages, rather than mandating a collective intermarket linkage facility, the access provisions of Rule 610(a) and (b) allow market centers to connect through flexible and cost effective technologies widely used in the markets today, particularly in the market for Nasdaq-listed stocks. This will allow firms to capitalize on the dramatic improvements in communications and processing technologies in recent years, and thereby enhance the linking of all markets for the future NMS. Private linkages also will provide flexibility to meet the needs of different market participants and allow competitive forces to determine the specific nature and cost of connectivity. The access provisions of Rule 610(a) and (b) thus should allow market participants to fairly and efficiently route orders to execute against the best displayed quotations for a stock, wherever such quotations are displayed in the NMS. The Commission believes that fair and efficient access to the best displayed quotations of all trading centers is critical to achieving best execution of those orders.

The access provisions of Rule 610(a) and (b) also will promote fair and efficient means

of access to quotations by prohibiting a trading center from unfairly discriminating against non- 
members or non-subscribers that attempt to access its quotations through a member or subscriber of such trading center. Such fair access to the quotations of other trading centers is critical for access to all displayed quotations and compliance with the adopted Order Protection Rule and broker-dealers' duty of best execution.

The fee limitation of Rule 610(c) will address the potential distortions caused by substantial, disparate fees. The wider the disparity in the level of access fees among different market centers, the less useful and accurate are the prices of displayed quotations. As a result of the adopted fee limitation, displayed prices will more closely reflect actual costs to trade, thereby enhancing the usefulness of market information. The fee limitation also will establish a level playing field across all market participants and trading centers. The rule promotes the NMS objective of equal regulation of markets and broker-dealers by applying equally to all types of trading centers and all types of market participants. ${ }^{789}$ As noted above in Section III.A.2, although ECNs and other types of trading centers, including SROs, may currently charge access fees, market makers have not been permitted to charge any fee for counterparties accessing their quotations. The Commission believes, however, that it is consistent with the Quote Rule for market makers to charge fees for access to their quotations pursuant to Rule 610(c), so long as such fees meet the requirements of Rule 610(c).

The fee limitation also will address "outlier" trading centers that otherwise might charge high fees to other market participants required to access their quotations by the Order Protection Rule. In the absence of a fee limitation, the adoption of the Order Protection Rule and private linkages could significantly boost the viability of the outlier business model. Outlier markets might well try to take advantage of intermarket price protection by acting essentially as a toll 
booth between price levels. Even though high fee markets likely would be the last market to which orders would be routed, prices could not move to the next level until someone routed an order to take out the displayed price at the outlier market. Such a business model would detract from the usefulness of quotation information and impede market efficiency and competition. The fee cap will limit the outlier business model. It will place all markets on a level playing field in terms of the fees they can charge and ultimately the rebates they can pass on to liquidity providers. Some markets might choose to charge lower fees, thereby increasing their ranking in the preferences of order routers. Others might charge the full $\$ 0.003$ and rebate a substantial proportion to liquidity providers. ${ }^{790}$ Competition will determine which strategy is most successful. ${ }^{791}$ The Rule also precludes a trading center from charging high fees selectively to competitors, practices that have occurred in the market for Nasdaq stocks. ${ }^{792}$

Moreover, the fee limitation is necessary to achieve the purposes of the Exchange Act. If outlier markets are allowed to charge high fees and pass most of them through as rebates, the published quotations of such markets would not reliably indicate the true price that is actually available to investors or that would be realized by liquidity providers. Section 11A(c)(1)(B) of the Exchange Act authorizes the Commission to adopt rules assuring the fairness and usefulness of quotation information. For quotations to be fair and useful, there must be some limit on the extent to which the true price for those who access quotations can vary from the displayed price.

790 Nothing in Rule 610(c) will preclude an SRO or other trading center from taking action to limit fees beyond what is required by the rule, and trading centers will have flexibility in establishing their fee schedules to comply with Rule 610(c), consistent with existing requirements of the Exchange Act and the rules and regulations thereunder.

791 The Commission believes that the fee limitation on protected quotations priced less than $\$ 1.00$ will provide the same benefits.

Rule 610(c). 
Consequently, the $\$ 0.003$ fee limitation will further the statutory purposes of the NMS by harmonizing quotation practices and precluding the distortive effects of exorbitant fees. Moreover, the fee limitation is necessary to further the statutory purpose of enabling brokerdealers to route orders in a manner consistent with the operation of the NMS. ${ }^{793}$ To protect limit orders, orders must be routed to those markets displaying the best-priced quotations. This purpose would be thwarted if market participants were allowed to charge exorbitant fees that distort quoted prices.

As discussed above in Section III.A.2, the Commission agrees that the access fee limitation should apply to manual quotations that are best bids and offers to the same extent it applies to protected quotations, to preclude any incentive for trading centers to display manual quotations as a means to charge a higher access fee. In addition, the Commission recognizes that at present a trading center's execution quality statistics will be evaluated against the NBBO, whether that quotation is a manual or automated quotation. The Commission therefore has modified the proposed fee limitation in Rule 610(c) to apply to any quotation that is the best bid or best offer of an exchange, the ADF, or The NASDAQ Market Center, in addition to any protected quotations as defined in Rule 600(b)(57). ${ }^{794}$

The restrictions on locking or crossing quotations in Rule 610(d) will promote fair and orderly markets. Locked and crossed markets can cause confusion among investors concerning trading interest in a stock. Restricting the practice of submitting locking or crossing quotations therefore will enhance the usefulness of quotation information. Consistent with the approach to

793 Section $11 \mathrm{~A}(\mathrm{c})(1)(\mathrm{E})$ of the Exchange Act, 15 U.S.C. 78k-1(c)(1)(E), authorizes the Commission to adopt rules assuring that broker-dealers transmit orders for NMS stocks in a manner consistent with the establishment and operation of a national market system.

794 In addition, the Commission notes that the access standards in Rule 610(a) and (b) apply to all quotations, not just automated quotations. 
trade-through protection, however, Rule 610(d) will allow automated quotations to lock or cross manual quotations. Rule 610(d) thereby addresses the concern that manual quotations may not be fully accessible and recognizes that allowing automated quotations to lock or cross manual quotations may provide useful market information regarding the accessibility of quotations. The Commission believes, however, that an automated quotation is entitled to protection from locking or crossing quotations. When two market participants are willing to trade at the same quoted price, giving priority to the first-displayed automated quotation will encourage posting of quotations and contribute to fair and orderly markets. The basic principle underlying the NMS is to promote fair competition among markets, but within a system that also promotes interaction between all of the buyers and sellers in a particular NMS stock. Allowing market participants simply to ignore accessible quotations in other markets and routinely display locking and crossing quotations is inconsistent with this principle. The restrictions on locking or crossing quotations, in conjunction with the Order Protection Rule, should encourage trading against displayed quotations and enhance the depth and liquidity of the markets.

Finally, lowering of the fair access threshold of Rule 301(b)(5) under Regulation ATS ${ }^{795}$ from $20 \%$ to $5 \%$ of average daily trading volume in a security will further strengthen access to the full range of services of ATSs with significant trading volume in NMS stocks. Such access is particularly important for the success of the private linkage approach adopted for access to quotations. The lowering of the fair access threshold also will make its coverage consistent with the existing 5\% threshold triggering the order display and execution access requirements of Rule 301(b)(3) of Regulation ATS. ${ }^{796}$ As a result, each ATS that is required to disseminate its

17 CFR 242.301(b)(5).

796

17 CFR 242.301(b)(3). 
quotations in the consolidated data stream also will be prohibited from unfairly prohibiting or limiting market participants from becoming a subscriber or customer.

In adopting Rule 610 and the amendment to Rule 301 of Regulation ATS, the Commission seeks to help ensure that securities transactions can be executed efficiently, at prices established by vigorous and fair competition among market centers. By enabling fair access and transparent pricing among diverse marketplaces within a unified national market, the Commission believes that the access provisions will foster efficiency, enhance competition, and contribute to the best execution of orders for NMS securities.

\section{Costs}

The Commission believes that Rule 610 and the amendment to Rule 301 of Regulation ATS will not impose significant costs on most trading centers and market participants. When assessing the costs of access, it is important to recognize that much, if not all, of the connectivity among trading centers has already been put in place. For example, trading centers for exchange-listed securities already are connected through the ITS. The Commission understands that the ITS facilities and rules that currently provide intermarket access for exchange-listed stocks could be modified relatively easily and at low cost to provide the current ITS participants a means of access, at least as an interim measure until private linkages are fully established for exchange-listed stocks. In addition, private linkages already are widely used in the equity markets, particularly for trading in Nasdaq-listed stocks. Moreover, a variety of private vendors currently offer connectivity to NMS trading centers for both exchangelisted and Nasdaq stocks, and many broker-dealers already employ smart order routing technology. The Commission also notes that trading centers already are making changes to their systems to become more competitive. The changes being made will assist those trading centers 
in preparing for implementation of the Access Rule. ${ }^{797}$ The Commission therefore believes that the system changes necessary to meet the new access standards will be minor. ${ }^{798}$

While commenters were generally supportive of the Commission's proposal to employ private linkages to provide access between markets, some commenters (both those supporting and those opposing the reproposed access standards) voiced their concerns about the potential need to develop, and the costs of developing, connections to numerous small trading centers in the ADF. ${ }^{799}$ Several commenters felt that non-SRO trading centers should make their quotations available through the automatic execution facilities of an SRO, thereby requiring other market participants to only have to maintain access to six or seven markets, rather than potentially dozens. ${ }^{800}$ In contrast, one commenter that is an ADF participant stated its belief that the proposal to require ADF participants to establish the necessary connectivity that would facilitate efficient access to their quotations would create a cost barrier that discriminates against smaller firms in the ADF. ${ }^{801}$

797 For example, Nasdaq, which previously did not have an order routing system, purchased Brut, LLC last year in order to acquire access to such a system. The Commission believes that this acquisition should reduce the costs that will be incurred by Nasdaq to implement the Access Rule.

798 One commenter, however, felt that the bilateral links required for private linkages would be particularly burdensome to smaller market centers compared to an ITS-type structure. Letter from Donald E. Weeden to Jonathan G. Katz, Secretary, Commission, dated June 30, 2004, at 9-10.

See supra, section III.A.1.

$800 \quad$ See, e.g., Knight Trading Group Reproposal Letter at 5; Nasdaq Reproposal Letter at 1718 (expressing the view that trading facilities with less than a five percent volume should be required to make their quotations available through an SRO trading facility); STA Reproposal Letter at 6; Type N Reproposal Letter at 1. 
The Commission does not believe that its adopted access approach in Rule 610(b)(1) discriminates against smaller firms or creates a barrier to access for innovative new market entrants. Rather, smaller firms and new entrants have a range of alternatives from which to choose that will allow them to avoid incurring any costs to meet the connectivity requirements of Rule 610(b)(1) if they wish to do so. This approach is fully consistent with Congressional policy set forth in the Regulatory Flexibility Act, which directs the Commission to consider significant alternatives to regulations that accomplish the stated objectives of the Exchange Act and minimize the economic impact on small entities. ${ }^{802}$

Small ATSs are exempt from participation in the consolidated quotation system and, therefore, from the connectivity requirements of Rule 610. Under Rule 301(b)(3) of Regulation ATS, an ATS is required to display its quotations in the consolidated quotation stream only in those securities for which its trading volume reaches $5 \%$ of total trading volume. Consequently, smaller ATSs are not required to provide their quotations to any SRO (whether an SRO trading facility or the NASD's ADF) and thereby trigger the access requirements of Rule 610. Moreover, potential new entrants with innovative trading mechanisms can commence business without having to incur any costs associated with participation in the consolidated quotation system.

Some smaller ATSs, however, may wish to participate voluntarily in the consolidated quotation system. Such participation can benefit smaller firms and promote competition among markets by enabling smaller firms to obtain wide distribution of their quotations among all approximately 600 broker-dealers (including ATSs) that would be subject to Rule 610 are considered small (total capital of less than \$500,000) for purposes of the Regulatory Flexibility Act. $69 \mathrm{FR}$ at 77493 . The adopted access approach provides alternatives that will benefit a wider range of smaller ATSs than the two that are considered small entities. 
market participants. ${ }^{803}$ Here, too, such firms will have alternatives that would not obligate them to comply with the connectivity requirements of Rule 610(b)(1). ATSs and market makers that wish to trade NMS stocks can choose from a number of options for quoting and trading. They can become a member of a national securities exchange and quote and trade through the exchange's trading facilities. They can participate in The NASDAQ Market Center and quote and trade through that facility. By choosing either of these options, an ATS or market maker would not create a new connectivity point that all other market participants must reach and would not be subject to Rule 610(b)(1). Some firms, however, may not want to participate in an SRO trading facility. These ATSs and market makers can quote and trade in the OTC market. The existence of the NASD's ADF makes this third choice possible by providing a facility for displaying quotations and reporting transactions in the consolidated data stream. ${ }^{804}$

As noted above in Section III.A.1, however, the NASD is not statutorily required to provide an order execution functionality in the ADF. The Commission believes that market makers and ECNs should continue to have the option of operating in the OTC market, rather than on an exchange or The NASDAQ Market Center. As noted in the Commission's order approving Nasdaq's SuperMontage trading facility, this ability to operate in the ADF is an important competitive alternative to Nasdaq or exchange affiliation. ${ }^{805}$ Therefore, the Commission has

803 See supra, note 566 (the Commission's Advisory Committee on Market Information recommended retention of the consolidated display requirement because, among other things, it "may promote market competition by assuring that information from newer or smaller exchanges is widely distributed.").

804 Under Rule 301(b)(3) of Regulation ATS, 17 CFR 242.301(b)(3), an ATS is required to display its quotations in the consolidated data stream only in those securities for which its trading volume reaches $5 \%$ of total trading volume.

805 See Securities Exchange Act Release No. 43863 (Jan. 19, 2001), 66 FR 8020 (Jan. 26, 2001). 
determined not to require small trading centers to make their quotations accessible through an SRO trading facility.

Instead, Rule 610(b)(1) requires all trading centers that choose to display quotations in an SRO display-only quotation facility (currently, the ADF) to provide a level and cost of access to such quotations that is substantially equivalent to the level and cost of access to quotations displayed by SRO trading facilities. Rule 610(b)(1) therefore may cause trading centers that display quotations in the ADF to incur additional costs to enhance the level of access to their quotations and to lower the cost of connectivity for market participants seeking to access their quotations. The extent to which these trading centers in fact incur additional costs to comply with the adopted access standard will be largely within the control of the trading center itself. As noted above, ATSs and market makers that wish to trade NMS stocks can choose from a number of options for quoting and trading, including quoting and trading in the OTC market. As a result, the additional connectivity requirements of Rule 610(b) will be triggered only by a trading center that displays its quotations in the consolidated data stream and chooses not to provide access to those quotations through an SRO trading facility.

Currently, nine SROs operate trading facilities in NMS stocks. Market participants throughout the securities industry generally have established connectivity to these nine points of access to quotations in NMS stocks. By choosing to display quotations in the ADF, a trading center effectively could require the entire industry to establish connectivity to an additional point of access. Potentially, many trading centers could choose to display quotations in the ADF, thereby significantly increasing the overall costs of connectivity in the NMS. Such an inefficient outcome would become much more likely if an ADF trading center were not required to assume 
responsibility for the additional costs associated with its decision to display quotations outside of an established SRO trading facility.

Although the Exchange Act envisions an individual broker-dealer having the option of trading in the OTC market, ${ }^{806}$ it does not mandate that the securities industry in general must subsidize the costs of accessing a broker-dealer's quotations in the OTC market if the NASD chooses not to provide connectivity. The Commission believes that it is reasonable and appropriate to require those ATSs and market makers that choose to display quotations in the ADF to bear the responsibility of providing a level and cost of access to their quotations that is substantially equivalent to the level and cost of access to quotations displayed by SRO trading facilities. Under Rule 610(b)(1), therefore, ADF participants will be required to bear the costs of the necessary connectivity to facilitate efficient access to their quotations. ${ }^{807}$ This standard will help ensure that additional connectivity burdens are not imposed on the securities industry each time an additional ADF participant necessitates a new connectivity point by choosing to begin displaying quotations in the consolidated quotation stream. The Commission believes that this requirement will help reduce overall industry costs by more closely aligning the burden of additional connectivity with those entities whose choices have created the need for additional connectivity.

As just discussed, the Commission recognizes that trading centers subject to Rule 610(b)(1) may incur costs associated with providing access to their quotations, although the costs

$806 \quad$ See Sections 11A(c)(3)(A) and (4) of the Exchange Act, 15 U.S.C 78k-1(c)(3)(A) and (4).

807 Thus, although market participants may still be required to access numerous trading centers in the ADF, the Rule should reduce the cost of access to each such trading center by requiring the ADF trading center to provide a cost and level of access substantially equivalent to the level and cost of access to quotations displayed by SRO trading facilities. 
will vary depending upon the manner in which each trading center provides such access. The Commission notes that to meet the standard contained in Rule 610(b)(1), a trading center will be allowed to take advantage of the greatly expanded connectivity options that have been offered by competing access service providers in recent years. ${ }^{808}$ These industry access providers have extensive connections to a wide array of market participants through a variety of direct access options and private networks. A trading center potentially could meet the requirement of Rule 610(b)(1) by establishing connections to and offering access through such vendors. The option of participation in existing market infrastructure and systems should reduce a trading center's cost of compliance. ${ }^{809}$

Two commenters raised concerns about reliance on third party private vendors to provide access, since they may not be regulated by the Commission and thus could deny access to a trading center they viewed as a competitor, or because utilizing their services to link to other trading centers is outside the control of a trading center. ${ }^{810}$ The Commission believes that the requirement in Rule 610(b)(1) that ADF participants provide a substantially equivalent level of access will preclude the ADF participant from providing access only through a narrow range of private access providers. The range of access providers must be sufficient to provide access substantially equivalent to SRO trading facilities. In these circumstances, and given the

808 As noted in the Commission's order approving the pilot program for the ADF, the reduction in communications line costs in recent years and the advent of competing access providers offer the potential for multiple competitive means of access to the various trading centers that trade NMS stocks. Securities Exchange Act Release No. 46249, supra note 390.

809 As the self-regulatory authority responsible for the OTC market, the NASD must act as "gatekeeper" for the ADF, and, as such, will need to closely assess the extent to which ADF participants meet the requirements of Rule 610.

$810 \quad$ NexTrade Reproposal Letter at 6; STANY Reproposal Letter at 4. 
significant number and variety of entities that currently provide access services and the competitive nature of the market for these services, the Commission believes that competition will be sufficient to provide services for any trading center choosing to utilize an outside vendor. ${ }^{811}$

Several commenters, including some that otherwise supported the proposal, expressed concern that requiring non-discriminatory access to markets might undermine the value of SRO membership. ${ }^{812}$ The Commission does not believe that adoption of a private linkage approach will seriously undermine the value of membership in SROs that offer valuable services to their members. First, the fact that markets will not be allowed to impose unfairly discriminatory terms on non-members who obtain indirect access to quotations through members does not mean that non-members will obtain free access to quotations. Members who provide piggyback access will be providing a useful service and presumably will charge a fee for such service. The fee will be subject to competitive forces and likely will reflect the costs of SRO membership, plus some element of profit to the SRO's members. As a result, non-members that frequently make use of indirect access are likely to contribute indirectly to the costs of membership in the SRO market. Moreover, the unfair discrimination standard of Rule 610(a) will apply only to access to quotations, not to the full panoply of services that markets generally provide only to their members. These other services will be subject to the more general fair access provisions applicable to SROs and large ECNs, as well as the statutory provisions that govern SRO rules.

811 For example, one large ECN can be accessed through five extranets and at least 21 other access providers, as well as through direct connections. See supra, note 366 and accompanying text.

812 Alliance of Floor Brokers Letter at 10; Amex Letter, Exhibit A at 25-26; BSE Letter at 12; CHX Letter at 14; Citigroup Letter at 12; Phlx Letter at 2; STANY Letter at 9. 
For the reasons discussed below, the Commission does not believe that the fee limitation of Rule 610(c), including the fee limitation on non-protected quotations at the best bid and offer, will impose significant new costs on most trading centers. First, a few commenters were concerned about the costs to market participants of administering a fee program. ${ }^{813}$ The adopted provision, by imposing a single accumulated fee limitation of $\$ 0.003$ (when the price of the protected quotation is $\$ 1$ or more), greatly simplifies the fee limitation and likely will leave existing fee practices largely intact. For trading centers that currently charge and collect fees and that will continue to do so, the costs of imposing and collecting fees are already incurred. The fee limitation does not require trading centers that do not currently charge fees to begin charging fees. If market makers determine to begin charging fees, they likely will collect fees through an SRO trading facility or ECN through which they display limit orders or quotations, and the administration of such fee program likely will be handled by the SRO or ECN. Therefore, the adopted fee limitation likely will not impose significant new administrative costs.

Two commenters expressed a concern with the ability to determine after-the-fact whether a quotation against which an incoming order executed was subject to an access fee cap, given that under the Rule a market participant could be charged different fees based on whether or not a quotation was protected. ${ }^{814}$ The Commission acknowledges these concerns, but notes that market participants will be able to control the extent to which their orders interact with protected and non-protected quotations. First, under the Order Protection Rule, the definition of intermarket sweep order requires market participants to route orders to interact only with protected quotations. The objective can be achieved by routing an IOC, marketable limit order

$813 \quad$ Brokerage America Letter at 1; NexTrade Reproposal Letter at 8; Oppenheimer Letter at 2; SIA Reproposal Letter at 22; STANY Letter at 11.

814 Bloomberg Reproposal Letter at 8, note 6; SIA Reproposal Letter at 22. 
with a limit price that equals the price of the protected quotation. The extent to which they route to non-protected quotations will be subject to the full range of competitive forces, including the fees that trading centers choose to charge for access to non-protected quotations.

The Commission recognizes, however, the concern that a market participant could intend to interact only with a protected quotation but in fact execute against a non-protected quotation. For example, at the time a market participant routes an order to a trading center, it may be attempting to execute against only that trading center's best bid or offer, which will be subject to the fee cap under adopted Rule 610(c) (for instance, by sending an intermarket sweep order with a limit price equal to the price of the protected quotation). By the time the order arrives at the trading center, the incoming order may, if a better bid or offer has been displayed at the trading center for a size smaller than the size of the incoming order, execute against both the new best bid or offer and the quotation that previously was the trading center's best bid or offer. To meet the requirements of Rule 610(c), however, a trading center must ensure that it never charges a fee in excess of the cap for executions of an order against its quotations that are subject to the fee cap. The operation of this limitation will be based on quotations as they are displayed in the consolidated quotation stream. Thus, the trading center is responsible for ensuring that any time lag between prices in its internal systems and its quotations in the consolidated quotation system do not cause fees to be charged that violate the limitation of Rule 610(c). Compliance with this requirement obviously will not be a problem for trading centers that do not charge any fees in excess of the cap. Given the often rapid updating of quotations in NMS stocks, however, the Commission does not believe a trading center that charges fees above the cap for quotations that are not subject to the fee cap could comply with the Rule unless it provides a functionality that enables market participants to assure that they will never inadvertently be charged a fee in excess 
of the cap. For example, such a trading center could provide a "top-of-book only" or "limited-fee only" order functionality. By using this functionality, market participants themselves could assure that they were never required to pay a fee in excess of the levels set forth in Rule 610(c).

Although the fee limitation is consistent with current business practices, the fee limitation of Rule 610(c) will affect the few markets that currently impose access fees of greater than $\$ 0.003$ per share that apply to a wide range of NMS stocks. ${ }^{815}$ These markets will be required to re-evaluate their business models in light of the adopted fee limitation. In particular, they likely will need to reduce the rebates they currently pay to liquidity providers. The adopted limitation also will affect a few trading centers that charge significant access fees for large transactions in specific types of NMS stocks, such as ETFs. It is unlikely, however, that such fees currently generate a large amount of revenues. ${ }^{816}$

We do not believe that the locked and crossed provisions of Rule 610(d) will impose significant additional costs for the SROs. All SROs currently have rules restricting locking and crossing quotations in exchange-listed stocks to comply with the provisions of the ITS Plan. Such SROs also collect the data and related information required to monitor locked and crossed markets, and the Commission believes that the additional surveillance and enforcement costs related to the provisions will be minor. The Commission recognizes, however, that Rule 610(d), by restricting locked markets with respect to automated quotations, could prohibit the display of an order that would otherwise have been displayed and reduced the quoted spread to zero. Although locked markets do occur a certain percentage of the time, they do not occur all the time, even in extremely active stocks, and thus the average effective spread in these stocks

$815 \quad$ See supra, note 423 and accompanying text.

816 The Commission believes that the same analysis would apply to the fee limitation on protected quotations priced less than $\$ 1.00$. 
typically is between one-half cent and one cent (one cent being the minimum pricing increment for all but a very few stocks). Thus, the Commission believes that any widening of average effective spreads caused solely by the adopted rule will be limited to the difference between a sub-penny and penny spread. In addition, a locked market currently may not actually represent two market participants willing to buy and sell at the same price. Often the locking market participant is not truly willing to trade at the displayed locking price, but instead chooses to lock rather than execute against the already-displayed quotation to receive a liquidity rebate. ${ }^{817}$

Finally, reducing the fair access thresholds of Regulation ATS will require ATSs that exceed the 5\% threshold level to comply with Rule 301(b)(5) under Regulation ATS. Rule 301(b)(5) requires ATSs, among other things, to establish written standards for granting access to trading on its system, to not unreasonably prohibit or limit access to its services, to keep records of all grants or denials of access, and to report such information on Form ATS-R. The Commission believes that the costs to meet these requirements are justified by the need to promote fair and efficient access to trading centers with significant volume.

Overall, the Commission believes that the benefits of Rule 610 and the amendment to Rule 301 of Regulation ATS justify the costs of implementation.

\section{Sub-Penny Rule}

Rule 612 will prohibit market participants from displaying, ranking, or accepting quotations in NMS stocks that are priced in an increment less than $\$ 0.01$ per share, except for quotations priced less than $\$ 1.00$ per share, which may extend to four decimal places.

\section{Benefits}


The Commission believes that the markets' conversion to decimal pricing has benefited investors by, among other things, clarifying and simplifying pricing for investors, making the U.S. securities markets more competitive internationally, and reducing trading costs by narrowing spreads. The Commission is concerned, however, that if the MPV decreases beyond a certain point, some of the benefits of decimals could be lost while some of the negative effects would be exacerbated. The Commission believes that Rule 612, which will prohibit an MPV of less than $\$ 0.01$ for the vast majority of NMS stocks, will have several benefits. The majority of the commenters supported the proposal and noted various benefits of this approach. ${ }^{818}$

The Commission believes that sub-penny quoting impedes transparency by reducing market depth at the NBBO and increasing quote flickering. In an environment where the NBBO can change very quickly, broker-dealers have more difficulty in carrying out their duties of best execution and complying with other regulatory requirements that require them to identify the best bid or offer available at a particular moment (such as the Commission's short sale rule ${ }^{819}$ and NASD's Manning rule ${ }^{820}$ ). Rule 612 should increase market depth at the NBBO and help reduce quote flickering.

In addition, the Commission agrees with the many commenters who believed that prohibiting sub-penny quoting would deter the practice of stepping ahead of exposed trading interest by an economically insignificant amount. Limit orders provide liquidity to the market and perform an important price-setting function. If a quotation or order can lose execution priority because of economically insignificant price improvement from a later-arriving quotation

\footnotetext{
818 See supra, section IV.C.1.

819 Rule 10a-1 under the Exchange Act, 17 CFR 240.10a-1.

$820 \quad$ NASD IM-2110-2.
} 
or order, liquidity could diminish and some market participants could incur greater execution costs. As one commenter, the Investment Company Institute, stated, "[t]his potential for the increased stepping-ahead of limit orders would create a significant disincentive for market participants to enter any sizeable volume into the markets and would reduce further the value of displaying limit orders." ${ }^{821}$ Improved liquidity should decrease the costs of trading, especially for large orders. ${ }^{822}$ Market participants may be more likely to place limit orders if they know that other market participants cannot quote ahead of them by a sub-penny amount.

\section{Costs}

The Commission recognizes that Rule 612 will impose certain costs on the U.S. securities markets. Currently, a few NMS stocks are quoted - and in the absence of the rule, others in the future could be quoted - in sub-penny increments. For these NMS stocks, quoted spreads will be wider than they otherwise would be, because Rule 612 will prohibit market participants from narrowing the spread by a sub-penny amount.

A few commenters argued that investors would incur costs from artificially widened spreads as a result of Rule $612 .{ }^{823}$ One commenter analyzed trading in six high-volume

$821 \quad$ ICI Letter at 20.

822 One commenter argued that a prohibition on sub-penny quoting should not affect institutional investors' trading costs because improvements in trading technology (such as auto-execution and VWAP trading algorithms) allow them to fill large orders at minimal cost. See Tower Research Letter at 9-10. While the Commission agrees that such improvements have been useful, it believes that this commenter did not consider the costs involved in having to develop these technologies in response, at least in part, to insufficient liquidity. Moreover, the Commission believes that this commenter also did not consider the positive externalities that limit orders have on price discovery and price competition; orders that execute without being displayed do not contribute to price discovery and price competition.

823 See Chakrabarty and Chung Study at 24 (stating that, for high volume stocks, "the spread reduction in the absence of binding constraints ... translates into savings of millions of 
securities and concluded that Rule 612 would have costs of over $\$ 400$ million in these securities alone due to wider spreads. ${ }^{824}$ Another commenter stated that, if all markets traded QQQQ solely in sub-pennies, the savings would be approximately $\$ 150$ million per year. ${ }^{825}$ A third commenter argued that allowing sub-penny quoting in "23 of the most appropriate securities" would generate annual savings of anywhere between $\$ 342$ million and $\$ 1.9$ billion. ${ }^{826}$ No other commenters provided any quantitative analysis of the costs that a sub-penny quoting rule would impose by widening spreads to at least a full penny. ${ }^{827}$

The commenters who attempted to quantify the costs appear to assume that all trading activity in the securities they discuss would occur at narrower sub-penny spreads if Rule 612 did not exist. The Commission does not believe that these commenters provided any evidence to justify that assumption. Currently, Nasdaq and the national securities exchanges generally do not permit quoting in sub-pennies; this practice exists on only a small number of ATSs, and only for a small number of securities. Because spreads on Nasdaq and the exchanges already cannot be smaller than $\$ 0.01$, Rule 612 will not require these markets to take any action that would cause spreads to widen. Therefore, the lack of sub-penny spreads on these markets should not be

dollars"); INET Reproposal Letter at 3; Instinet Letter at 50; Mercatus Center Letter at 9; Tower Research Letter at 9.

824 Tower Research Letter at 9.

825 Instinet Letter at 50.

826 INET Reproposal Letter at 3.

827 However, one commenter stated: "When analyzed in terms of costs and benefits, we believe that the costs of sub-penny quoting (i.e., less liquidity at quotes, more transactions required to fill large orders, increased quote flickering, and increased ability to displace orders through minimal price improvement) far exceed any incremental benefits that market participants might enjoy through additional pricing conventions for their limit orders." Deutsche Bank Reproposal Letter at 3. This commenter did not provide empirical evidence to justify that assertion. 
considered costs of Rule 612. With respect to the ATSs that currently do permit some NMS stocks to be quoted in sub-pennies, Commission staff performed a study to better assess and respond to commenters' claims. ${ }^{828}$ Based on that study, Commission staff estimated that the costs of widened spreads in these securities would be approximately \$48 million annually (or approximately \$33 million if the Commission were to exempt QQQQ from Rule 612). ${ }^{829}$

In this study, Commission staff obtained public data from NYSE's "Trade and Quote" files for all NYSE-listed and Amex-listed stocks, and public data from the Nastraq trade file for Nasdaq-listed stocks, for the period June 7-10, 2004. Based on trading activity of the Nasdaqlisted securities, Commission staff estimated that $1.5 \%$ of all trades executed at a per-share price over $\$ 1.00$ were reported in a sub-penny increment. ${ }^{830}$ These trades accounted for $4.7 \%$ of share volume. However, not all trades that were reported as having a sub-penny price resulted from a sub-penny quotation. Commission staff excluded VWAP trades which were marked as such in the Nastraq file. ${ }^{831}$ Based on this screened dataset, Commission staff estimated that $1.4 \%$ of trades were reported in sub-penny increments, accounting for $2.4 \%$ of share volume.

Commission staff then calculated the dollar cost if all such trades executed at the near-side penny

$828 \quad$ See OEA December 2004 Sub-Penny Analysis.

829 The Commission believes that INET overstated the potential costs of Rule 612. INET's methodology for computing the potential savings to investors from quoting in subpennies appears to be based on the incorrect assumption that all of the stocks selected for their sample would trade with the same price-point distribution as the average of JDSU, SIRI, and QQQQ.

830 Trades executed at a per-share price below $\$ 1.00$ were excluded from the sample as Rule 612 will not prohibit sub-penny quotations priced less than $\$ 1.00$.

831 Executions occurring at a sub-penny price resulting from a midpoint, VWAP, or similar volume-weighted pricing algorithm are not prohibited by Rule 612. For purposes of this study, Commission staff excluded all other trades that had a condition code other than "regular way" (e.g., trades reported after normal trading hours, bunched trades, next-day trades, previous reference price trades, and late trades). 
rather than at a sub-penny amount. This price difference, multiplied by the executed volume, produced a dollar cost per trade. ${ }^{832}$ Summed across all sub-penny trades, the average daily cost in this sample was $\$ 80,973$. At 252 trading days per year, this resulted in an estimate of $\$ 20,400,235$ on an annual basis.

Commission staff performed a similar analysis on the trade data for Amex-listed stocks, except that the dataset did not permit VWAP trades to be excluded. Commission staff estimated that, on an annualized basis, the gross costs resulting from slightly wider spreads would be \$16 million (or only \$1.2 million if QQQQ were excluded). Similarly, Commission staff estimated that the gross costs from wider spreads would be approximately \$12 million annually for NYSE-listed stocks.

Another potential cost of Rule 612 is that market participants that have developed systems allowing their users to quote in sub-pennies will, for most NMS stocks, lose the ability to gain any market advantage from such enhancements. In addition, any market participant that currently allows its users to display, rank, or accept orders or quotations in sub-pennies will incur costs in reprogramming its systems to prevent the entry of sub-penny orders or quotations. The Commission believes, however, that these costs are not significant. Currently, only a few ATSs - but not Nasdaq or any of the national securities exchanges - permit sub-penny quoting, and then only in a small number of securities. These ATSs will have to make only minor adjustments to their systems to comply with Rule 612. One commenter, a technology firm that develops software and systems for electronic securities trading, stated, "we do not believe that

832 For example, the cost to a sub-penny trade at price $\$ 25.248$ for 300 shares is as follows. The assumption is that, without sub-penny quotations, this trade would have occurred at $\$ 25.25$ - a difference of $\$ 0.002$ per share. At 300 shares, this trade incurs a cost of $\$ 0.60$ ( $\$ 0.002$ x 300). A sub-penny trade at $\$ 25.242$ would incur a cost of $\$ 0.002$ per share under the assumption that, under Rule 612, it would execute at $\$ 25.24$. 
there are significant technological or structural impediments to immediate implementation" of Rule 612. ${ }^{833}$ No commenter indicated that the compliance costs of ATSs that currently permit sub-penny quoting would be significant.

Finally, the Commission believes that paragraph (b) of Rule 612, which prohibits quotations below $\$ 1.00$ per share from extending beyond four decimal places, will have negligible systems costs. The Commission currently is not aware of any market that quotes and trades NMS stocks in increments beyond four decimal places and believes, therefore, that no market will incur systems costs to limit such quotations to a maximum of four decimal places.

After carefully considering all the comments received, the Commission believes that, on balance, the benefits of Rule 612 will justify the costs.

\section{Market Data Rules and Plan Amendments}

The Commission is adopting amendments to the rules relating to the dissemination of market information to the public. In particular, the Commission is adopting amendments to the Plans to modify the current formulas for allocating market data revenues to the SROs, and to require the establishment of non-voting advisory committees comprised of interested parties other than SROs. In addition, the Commission is rescinding the current prohibition in Exchange Act Rule 11Aa3-1 (redesignated as Rule 601) on SROs and their members from independently distributing their own trade reports, and is adopting an amendment to Exchange Act Rule 11Ac12 (redesignated as Rule 603) to incorporate uniform standards pursuant to which they may independently distribute their own trade reports and quotations (outside of providing the requisite information to Plan processors). The Commission is further amending Exchange Act Rule 11Ac1-2 (redesignated as Rule 603) to make explicit that all SROs must act jointly through the

$833 \quad$ ATD Reproposal Letter at 4. 
Plans and through a single processor per security to disseminate consolidated market information in NMS stocks to the public. Finally, the Commission is adopting amendments to Exchange Act Rule 11Ac1-2 (redesignated as Rule 603) to streamline and simplify the consolidated display requirements by reducing the data required to be displayed under the Rule, and by limiting the range of the Rule to the display of such data in trading and order-routing contexts.

\section{Revenue Allocation Formula}

\section{a. Benefits}

The Commission believes, and a number of commenters agreed, that the adopted amendment to the Plans modifying the current formulas for allocating market data revenues will be beneficial to the marketplace because the new formula will allocate revenues to SROs based on the value of their quotations in addition to their trades. ${ }^{834}$ The current formulas allocate Plan revenues based solely on the number or share volume of an SRO's reported trades, and do not allocate revenues to those market centers that generate quotations with the best prices and the largest sizes that are an important source of public price discovery. The new allocation formula also should help to reduce the economic and regulatory distortions caused by the current formulas, including wash sales, trade shredding, and SRO print facilities. Because the adopted formula will address these distortive practices and would allocate revenues to those market centers that provide the most useful market information, the Commission believes that the NMS will be benefited as a whole.

The adopted new revenue allocation formula will encompass a two-step process. The initial step of the adopted formula, the "Security Income Allocation," allocates a Network's distributable revenues among the many different securities that are included in the Network's

$834 \quad$ See, e.g., Bloomberg Tradebook Letter at 7-8; BSE Reproposal Letter at 8; ICI Letter at 21; STA Reproposal Letter I at 8; Vanguard Letter at 6. 
data stream primarily based on the square root of the dollar volume of trading in each security.

Of those that commented on this aspect of the formula, many generally agreed with the benefits of the Commission's use of square roots. ${ }^{835}$ Some commenters, however, believed that the use of the square root function overly rewards illiquid stocks at the expense of liquid stocks. ${ }^{836}$ To address this concern, the adopted formula modifies the square root allocation with respect to very inactively traded stocks by limiting the revenues that can be allocated to a single Network security to an amount that is no greater than $\$ 4$ per qualified transaction report. ${ }^{837}$ The amount that exceeds this limitation will be reallocated among all Network securities in direct proportion to their dollar volume of trading.

Following this initial distribution of revenues, the next step in the process is to allocate the revenues distributed to an individual security among the various SROs that trade the security based on each SRO's trading and quoting activity. Specifically, under the "Trading Share" criterion, fifty percent of the revenues allocated to a particular security will be allocated to SROs based on their proportion of the total dollar volume and number of qualified trades (transactions that have a dollar volume of $\$ 5,000$ or greater) in that security. A few commenters on the original proposal stated that small trades (transactions that have a dollar value of less than \$5000) should be entitled to partial credit under this criterion because these trades also contribute

835 Amex Letter, Exhibit A at 15; Nasdaq Letter II at 32; NYSE Reproposal Letter II at 3; Specialist Assoc. Letter at 16, note 21.

836 See, e.g., ArcaEx Reproposal Letter at 11; CBOE Letter at 11; Instinet Reproposal Letter at 13 .

837 The limit of $\$ 4$ per qualified transaction report is analogous to the reproposal's limit on Trading Shares to $\$ 2$ per qualified transaction report. Whereas the reproposed limit of \$2 applied to the 50\% Trading Share allocation (described below), the adopted limit of $\$ 4$ applies to the $100 \%$ Security Income Allocation. See supra section V.A.3. 
to public price discovery. ${ }^{838}$ The Commission acknowledged the benefits of small trades and provided for a proportional allocation of revenues for such trades under the reproposed formula. The adopted formula also includes this provision. The Trading Share measure is intended to allocate revenue to those SROs that actively trade in the security, thereby providing liquidity and price discovery, while reducing the potential for the shredding of trade volume.

Under the "Quoting Share" criterion, fifty percent of the revenues allocated to a particular security under the Security Income Allocation measure will be allocated to an SRO based on the SRO's proportion of credits earned for each second of time and dollar value of size that the SRO's automated best bid or offer during regular trading hours equals the price of the NBBO in that security. The Quoting Share criterion of the adopted formula is intended to do what the current formulas do not - allocate revenue to those markets whose quotations frequently equal the best prices and for the largest sizes. Many commenters agreed with the Commission that, if the Networks were to continue allocating revenues to the SROs, the current allocation formulas needed to be updated. ${ }^{839}$ In particular, some of these commenters noted the benefits of adding a quoting component to the new formula, ${ }^{840}$ especially if revenues are allocated only for automated and accessible quotations.

In sum, the Commission believes that the greatest benefit of allocating Plan revenues to the SROs based equally on the Trading Share and Quoting Share measures is that such measures will allocate revenues to an SRO for its overall contribution of both quotations and trades, while

838 See, e.g., BSE Letter at 16; CHX Letter at 19-20; E*Trade Letter at 11-12.

839 See, e.g., Bloomberg Tradebook Letter at 7; BSE Letter at 15; Deutsche Bank Reproposal Letter at 4; Harris Reproposal Letter at 11; ICI Letter at 21; JP Morgan Reproposal Letter at 2; NYSE Reproposal Letter II at 3; STA Letter at 7; UBS Letter at 10; Vanguard Letter at 6.

$840 \quad$ See, e.g., Bloomberg Tradebook Letter at 7-8; Morgan Stanley Letter at 22-23; NYSE Reproposal Letter II at 3; STA Letter at 7; Vanguard Letter at 6. 
reducing the incentive for distortive trade reporting practices caused by the current formulas. Investors will benefit from the adopted new formula because these broad-based measures will allocate revenues to those SROs that provide investors with the most useful market information, and thus that contribute to public price discovery, by allocating them a larger portion of Plan revenues.

\section{b. Costs}

The Commission recognizes that the current allocation formulas have been used since the creation of the Plans and Networks in the 1970s, and that the SROs and the Network processors have become familiar with those formulas for purposes of allocating revenues and structuring their businesses. Because the adopted allocation formula is more detailed than the current formulas, the Network processors will have to learn the particular features of the new formula and will have to consider SRO quotations in addition to reported trades as a measure for allocating Plan revenues. Accordingly, the Network processors, or some other entity retained by the Networks, will be required to develop a program to calculate the Security Income Allocation, Trading Shares, and Quoting Shares of the SRO participants. All of the data necessary for implementation of the formula will be disseminated through the consolidated data stream on a real-time basis. If a single entity were retained to handle the task for all three Networks, the Commission estimates that it will cost approximately $\$ 1$ million annually to make the requisite calculations under the proposed new formula and to disseminate the results to the SRO participants on a daily basis. This estimated cost of implementation and compliance represents only 1/4 of one percent of the total revenues collected and distributed through the Plans for 2004. 
The Commission received a number of comments regarding the potential cost and complexity of the originally proposed revenue allocation formula. ${ }^{841}$ The Commission notes that, consistent with the approach of the Order Protection Rule and the Access Rule, it eliminated in the reproposed formula the most complex elements of the proposed allocation formula that were intended primarily to address the problem of manual quotations - the "NBBO Improvement Share" criterion and the automatic cut-off for manual quotations left at the NBBO under the Quoting Share criterion. The adopted amendment also eliminates these two elements. Because the adopted formula will allocate revenues for only automated quotations, and manual quotations will be excluded from the any revenue allocation, the Commission believes that an NBBO Improvement Share criterion and automatic cut-off for manual quotations are not necessary in the new formula. As a result, the adopted formula is substantially less complex than originally proposed.

Some commenters argued that it would be overly costly and complex to calculate the other elements of the proposed formula. ${ }^{842}$ The Commission does not agree. An SRO's Trading Share, for example, will not be materially more difficult to calculate than the current Network C formula, which is based on an average of an SRO's proportion of trades and share volume. The Security Income Allocation uses the square root function which is a simple arithmetic calculation. In addition, some commenters believed that the Quoting Share, which incorporates the total dollar size of the NBBO in a stock throughout the trading year, would result in

\footnotetext{
841 See, e.g., Angel Letter I at 11; BSE Letter at 15, 18; Brut Letter at 22-23; Callcott Letter at 4; CBOE Letter at 2, 9; Instinet Letter at 42; ISE Letter at 9; Nasdaq Letter II at 31; NSX Letter at 7; NYSE Letter, Attachment at 11; Phlx Letter at 3-4.

$842 \quad$ See, e.g., Brut Letter at 22-23; CBOE Letter at 2, 9; NSX Letter at 7.
} 
astronomically high numbers that would be extremely difficult to calculate. ${ }^{843}$ In fact, the largest number of quote credits in a year for even the highest price stock with the greatest displayed depth at the NBBO is very unlikely to reach beyond the trillions, a number well within the capabilities of even the most basic spreadsheet program. ${ }^{844}$ Moreover, the allocation is determined by the proportion of an SRO's quote credits in relation to other SROs, not the absolute amount of quote credits.

Some commenters were concerned that the inclusion of quotations in the proposed new allocation formula could lead new types of "gaming" of the formula, such as flashing quotations with no real intention to trade at those prices simply to earn more quote credits - and thereby more revenues - under the Quoting Share measure. ${ }^{845}$ Commenters also were concerned that such practices would increase quotation traffic and bandwidth costs, but with little or no benefit for the quality of the consolidated data stream. ${ }^{846}$ Because the Commission recognizes that abusive quoting behavior is a legitimate concern, the adopted formula incorporates a number of modifications to minimize the potential for abusive or costly quoting behavior. First, the adopted formula clarifies that a quotation must be displayed by the Network processor for a minimum of

843 See, e.g., CBOE Letter at 14 (calculation of Quote Credits will "yield astronomical numbers" that "can be expressed only in exponential terms"); NSX Letter at 7 (calculation of large number of Quote Credits is "particularly ludicrous").

844 For example, assume a stock with an average price of $\$ 100$ per share has an unusually large average quoted size of 200,000 shares at both the national best bid and the national best offer throughout every second of the trading year. Over an average 252 trading days during a year, the total Quote Credits in this stock would be 235.9 trillion $(\$ 100 * 400,000 * 252 * 23,400$ seconds per trading day). Quote Credits are only calculated for individual Network stocks and are not be totaled across all Network stocks.

845 See, e.g., ArcaEx Reproposal Letter at 13; CHX Letter at 19; Instinet Reproposal Letter at 14; SIA Reproposal Letter at 30.

846 See, e.g., Financial Information Forum Reproposal Letter at 4; Nasdaq Reproposal Letter at 13; SIA Reproposal Letter at 30. 
one full second of time before it is entitled to earn any quote credits. ${ }^{847}$ Second, the adopted formula clarifies that, consistent with the approach of the Order Protection Rule, each SRO participant in a Network is entitled to earn quote credits only for the SRO's best bid and best offer. $^{848}$ By limiting the number of separate quotations that are entitled to earn quote credits, the adopted formula both reduces the ability of market participants to "shred" their quotes among many different markets and promotes equal regulation of exchange SROs, Nasdaq, and the NASD. Third, the adopted formula modifies the language of the reproposed formula to clarify that a quotation cannot earn Quote Credits while it locks or crosses a previously displayed automated quotation. This limitation is needed to remove any potential financial incentive for abusive quoting behavior that would be contrary to the purposes of the provisions on locking and crossing quotations set forth in the Access Rule. Fourth, the formula limits the revenues that can be allocated to a single Network security to an amount that is no greater than $\$ 4$ per qualified transaction report, in order achieve an appropriately balanced allocation among Network stocks by allowing room for a significant increase in the amounts currently allocated for many less active stocks, while also preventing unjustifiably high allocations for the most extremely inactive stocks that might create an inappropriate incentive for abusive quoting behavior.

In addition, the Commission recognizes that some SROs are likely to be allocated a smaller portion of Plan revenues under the new allocation formula than they would have received under the prior formulas, while other SROs will receive a larger portion of revenues. This will result if certain SROs are currently reporting a large number of trades or share volume of trades, but are not necessarily providing the best quotations or trades with larger sizes. A few

\footnotetext{
$847 \quad$ See supra, section V.A.3.b.

$848 \quad$ See supra, section V.A.3.b.
} 
commenters expressed concern that certain business models would be adversely impacted by the proposed new allocation formula, ${ }^{849}$ particularly for those markets that primarily handle small retail order flow. ${ }^{850}$ The Commission recognizes that reforming formulas that have remained unchanged for many years may affect the competitive position of various markets. Given the severe deficiencies of these formulas, however, it does not believe that the interests of any particular business model should preclude updating the formulas to reflect current market conditions. The adopted formula is designed to reflect more appropriately the contributions of the various SROs to the consolidated data stream and thereby better align the interests of individual markets with the interests of investors. Moreover, by representing a much more broad-based measure of an SROs contribution to the consolidated data stream, the adopted formula will be less subject to any particular type of gaming and distortion than the narrowlyfocused current Plan formulas. ${ }^{851}$ The Commission therefore believes that the benefits of the adopted new allocation formula justify the costs of implementation.

\section{Plan Governance}

\section{a. Benefits}

See, e.g., Brut Letter at 22; CHX Reproposal Letter at 5; CHX Letter at 19, 21-22; NSX Letter at 6-7. See also BSE Reproposal Letter at 2, 3, 8 (suggesting a pilot approval process to address any unintended consequences on individual markets).

$850 \quad$ See, e.g., BSE Letter at 16; CHX Letter at 19, 21-22; E*Trade Letter at 11. The adopted formula will provide a partial allocation of revenues for smaller trades that have a dollar value of less than $\$ 5000$. This provision should lessen impact of the formula on exchanges that handle small retail orders.

851 Two commenters on the reproposal suggested adopting an allocation formula based solely on the dollar volume of trading. ArcaEx Reproposal Letter at 13; Nasdaq Reproposal Letter at 14. Dollar volume alone, however, is not a broad-based measure and would miss important aspects of an SRO's contribution to the public data stream. It would, for example, allocate a disproportionately large amount to block trades. Block trades often are internalized by securities dealers at prices based, at least partly, on current public quotations. A formula based solely on dollar volume would not adequately allocate revenues to the source of quotations relied on in pricing block trades. 
The Commission believes that the adopted amendment to the Plans requiring the creation of Plan advisory committees will improve Plan governance. Most commenters generally supported the adopted amendment to the Plans, generally believing that expanding the participation of non-SROs parties in Plan governance would be a constructive step. ${ }^{852}$ Under the Plans, a representative of each SRO participating in the Plan is a member of the operating committee that governs that Plan. The adopted amendment to the Plans will require the establishment of non-voting advisory committees comprised solely of persons not employed by or affiliated with an SRO participant. This adopted amendment is intended to broaden participation in the governance of the Plans.

The adopted amendment will require the SRO participants to select the members of the advisory committee comprised, at a minimum, of one or more representatives associated with: (1) a broker-dealer with a substantial retail investor base; (2) a broker-dealer with a substantial institutional investor customer base; (3) an ATS; (4) a data vendor; and (5) an investor. In addition, each SRO participant will be entitled to select an additional committee member. The Commission believes that the composition of the advisory committee will give interested parties other than the SROs a voice in matters that affect them.

The members of the advisory committee will have the right to submit their views to the operating committee on Plan business (other than matters determined to be confidential by a majority of Plan participants), prior to any decision made by the operating committee, and will have the right to attend operating committee meetings. Broader participation in the Plans through the creation of Plan advisory committees will be beneficial to the administration of the

$852 \quad$ See, e.g., Amex Letter at 10; Citigroup Letter at 17; Financial Information Forum Letter at 4; Financial Services Roundtable Letter at 6-7; ICI Letter at 4 and 21 n. 35; Nasdaq Letter II at 33; Reuters Letter at 3; SIIA/FISD Reproposal Letter at 2. 
Plans because it will provide transparency to the Plan governance process and can promote the formation of industry consensus on disputed issues.

\section{b. Costs}

The adopted amendment to the Plans requiring the formation of advisory committees can potentially result in costs to the SRO participants who will be required to engage in a selection process for purposes of establishing such committees. A Plan's operating committee as a whole will be required to select a minimum of five committee members, while each SRO participant will also have the right to select an additional committee member. This selection process can potentially result in added costs and administrative burden and expense to the SRO participants.

The adopted Plan amendment also can potentially disrupt of the current governance of the Plans by their participants. Since the creation of the Plans, representatives from the SROs have been the sole participants in the Plans and have been responsible for their administration. A few commenters believed that the additional participation of non-SRO parties could potentially increase the difficulty of reaching a consensus on Plan business, stating that too many members on an advisory committee could complicate and disrupt, rather than assist, Plan operations due to differing party agendas. ${ }^{853}$ Although such a result may occur at times, the Commission believes that this cost would be justified by the benefits that can be gained by increasing the transparency of Plan operations and giving parties other than SROs an opportunity to submit their views. In the past, the Plans may not have adequately considered the viewpoints of non-SRO parties on important issues such as fees and administrative burdens. Establishing advisory committees will address this problem and thereby potentially make the Plans more responsive to the needs of market participants and investors.

$853 \quad$ See, e.g., Amex Letter, Exhibit A at 21-22; Reuters Letter at 3. 


\section{Amendments to Rules 11Aa3-1 and 11Ac1-2 (Redesignated as Rules 601 and 603)}

\section{a. Independent Distribution of Information}

\section{i. Benefits}

The Commission is adopting as proposed the amendment to Rule 11Aa3-1 (redesignated as Rule 601), which rescinds the prohibition on SROs and their members from disseminating

their trade reports independently. ${ }^{854}$ Under adopted Rule 601, members of an SRO will continue to be required to transmit their trades to the SRO (and SROs will continue to transmit trades to the Networks pursuant to the Plans), but such members also will be free to distribute their own data independently, with or without fees. The Commission believes that independently distributed information can be beneficial to investors and other information users because depthof-book quotations have become increasingly important as decimal trading has spread displayed depth across a greater number of price points. Similarly, commenters that discussed this aspect of the proposal generally agreed that the proposal would benefit investors and vendors by giving them greater freedom to make their own decisions regarding the data they need. ${ }^{855}$ Other commenters believed that the proposal would lead to increased competition, the provision of more data products, and/or lower costs, thus benefiting market participants. ${ }^{856}$ In addition, one commenter agreed with the Commission that market centers would benefit from additional

854 Regulation NMS removed the definitions in paragraph (a) of Exchange Act Rule 11Aa31 (redesignated as Rule 601) and placed them in Rule 600. Subparagraphs (c)(2) and (c)(3) of Exchange Act Rule 11Aa3-1 are being rescinded. As a result, subparagraph (c)(4) of Exchange Act Rule 11Aa3-1 is redesignated as subparagraph (b)(2) of Rule 601. $855 \quad$ See, e.g., CBOE Letter at 17; Financial Information Forum Letter at 3-4; Reuters Letter at 3.

$856 \quad$ See, e.g., Brut Letter at 23; Financial Services Roundtable Letter at 6; Nasdaq Reproposal Letter at 15-16. 
revenues and stated that the prospect of additional revenues would encourage markets to provide better markets. $^{857}$

Adopted Rule 603(a) establishes uniform standards for distribution of both quotations and trades. The standards require an exclusive processor, or a broker or dealer with respect to information for which it is the exclusive source, that distributes quotation and transaction information in an NMS stock to a securities information processor ("SIP") to do so on terms that are fair and reasonable. In addition, those SROs, brokers, or dealers that distribute such information to a SIP, broker, dealer, or other persons are required to do so on terms that are not unreasonably discriminatory. Furthermore, these uniform standards are based, in part, on similar requirements found in Sections 3 and 11A of the Exchange $\mathrm{Act}^{858}$ for SROs and entities that distribute SRO information on an exclusive basis. The Commission believes that extending these requirements to non-SRO market centers, including ATSs and market makers, will help assure equal regulation of all markets that trade NMS stocks.

\section{ii. Costs}

The Commission recognizes that the rescission of the prohibition on independent distribution of trade reports under adopted Rule 601 may potentially lead to market centers incurring costs associated with the independent distribution of their market data if they choose to distribute such data without charging a fee. In addition, investors may have to pay for additional data if market centers choose to charge a fee for the additional data. Furthermore, a corollary to one commenter's assertion that market centers could benefit from additional revenues if market centers choose to distribute their own quotation information, ${ }^{859}$ is that the data from one or more

\footnotetext{
$857 \quad$ Specialist Assoc. Letter at 16-17.

85815 U.S.C. $78 \mathrm{c}$ and 15 U.S.C. $78 \mathrm{k}-1$.

859 Specialist Assoc. Letter at 16-17.
} 
other market centers can potentially become more or less valuable than another market center's data, and thereby increase or reduce that market center's overall income. The Commission does not believe that there will be any costs associated with establishment of uniform standards for the distribution of trades and quotations pursuant to adopted Rule 603(a). The Commission did not receive any comments on this issue.

\section{b. Consolidation of Information}

\section{i. Benefits}

All SROs currently participate in Plans that provide for the dissemination of consolidated information for the NMS stocks that they trade. Adopted Rule 603(b) confirms by Exchange Act rule that both existing and any new SROs will be required to continue to participate in jointindustry plans to disseminate consolidated information in NMS stocks to the public. Adopted Rule 603 provides the benefit of clarifying that all SROs - whether existing or new - will be required to participate jointly in one or more Plans to disseminate consolidated information in NMS stocks. Adopted Rule 603 also requires that all quotation and trade information for an individual NMS stock be disseminated through a single processor (currently, SIAC or Nasdaq). The Commission believes that requiring a single processor for a particular security will help to ensure that investors continue to receive the benefits of obtaining consolidated information from a single source.

\section{ii. Costs}

Given that consolidated market information currently is disseminated through a single processor per stock, the Commission does not foresee any new costs associated with adopted Rule 603(b).

\section{c. Display of Consolidated Information}




\section{i. Benefits}

The Commission is adopting as proposed the amendment to Rule 11Ac1-2 (redesignated as Rule 603(c)) that substantially revises the consolidated display requirement by limiting its scope. It incorporates a new definition of "consolidated display" (set forth in adopted Rule 600(b)(13)) that is limited to the prices, sizes, and market center identifications of the NBBO and the "consolidated last sale information." Beyond disclosure of this basic information, market forces, rather than regulatory requirements, will be allowed to determine what, if any, additional data from other market centers is displayed. In particular, investors and other information users ultimately will be able to decide whether they need additional information in their displays.

As amended, Rule 603(c) also eliminates the burden on vendors and broker-dealers to display a complete montage of quotations from all market centers trading a particular security, which would include the price of quotations that may be far away from the current NBBO. Furthermore, vendors and broker-dealers will have the ability to decide what, if any, additional data from other market centers beyond this basic disclosure to display. Vendors, broker-dealers, and investors will benefit from this reduced consolidated display requirement through a more efficient use of system capacity and because the costs of obtaining necessary data may be lowered. The Commission believes that giving investors the ability to choose (and pay for) only the data they need and use will be beneficial.

Rule 603(c) narrows the contexts in which a consolidated display is required to those when it is most needed - a context in which a trading or order-routing decision could be implemented. For example, the consolidated display requirement will continue to cover brokerdealers who provide on-line data to their customers in software programs from which trading decisions can be implemented. Similarly, the requirement will continue to apply to vendors who 
provide displays that facilitate order routing by broker-dealers. It will not apply, however, when market data is provided on a purely informational website that does not offer any trading or order-routing capability. Rule 603(c) also simplifies the rule language to require that consolidated data be made available in an equivalent manner as other data and rescinds unnecessary provisions in order to update the Rule. ${ }^{860}$ We expect Rule 603(c) to benefit brokerdealers and vendors by making compliance with the adopted Rule's more tailored requirements easier and more efficient.

\section{ii. Costs}

A potential cost attributable to Rule 603(c) is that there currently may be individuals who use the displayed montage of quotations from all market centers trading a particular security. If vendors and broker-dealers determined not to display this additional information, these investors would be required to obtain the additional data at additional cost. Rule 603(c) also may potentially result in an administrative cost or burden for vendors and broker-dealers that will be required to assess in what circumstances they are displaying market data information for trading and order-routing purposes and in what circumstances they are displaying such information for other purposes. The Commission believes that such a cost will be minimal.

\section{E. Regulation NMS}

The Commission is redesignating the current NMS rules adopted under Section 11A of the Exchange Act ${ }^{861}$ as Regulation NMS, making non-substantive conforming changes to various rules, and creating a separate definitional rule, Rule 600, which will contain all of the defined terms used in Regulation NMS. Currently, each NMS rule includes its own set of definitions,

860 The provisions being rescinded include requirements relating to moving tickers, categories of market information, and representative bids and offers.

861 15 U.S.C. $78 k-1$. 
and some identical terms, such as "covered security," "reported security," and "subject security," are defined inconsistently. Although Rule 600 retains, unchanged, most of the definitions used in the existing NMS rules, it deletes or revises obsolete definitions and eliminates the use of inconsistent definitions for identical terms. Rule 600 does not alter the requirements or operation of the existing NMS rules.

\section{Benefits}

The Commission believes that Rule 600 and the related amendments to various Commission rules will benefit all entities that are and will be subject to the requirements of the rules contained in Regulation NMS, including brokers, dealers, national securities exchanges, the NASD, ECNs, SIPS, and vendors. By eliminating or revising obsolete and inconsistent definitions and adopting a single set of definitions that will be used throughout Regulation NMS, Rule 600 should make Regulation NMS clearer and easier to understand, thereby facilitating compliance with the Rules' requirements and potentially easing the compliance burden on entities subject to Regulation NMS. Increased compliance with Regulation NMS will, in turn, benefit investors and the public interest. Similarly, the related non-substantive amendments to various Commission rules will ensure that those rules use the definitions provided in Rule 600 and refer accurately to the redesignated NMS rules.

\section{Costs}

Rule 600 will update and clarify the definitions used in existing NMS rules. Neither Rule 600 nor the related conforming amendments to various rules will alter the existing requirements of the NMS rules or other Commission rules. Accordingly, the Commission believes that Rule 600 and the related amendments will impose few additional costs on entities subject to 
Regulation NMS. Although some additional personnel costs may be incurred in reviewing the changes, the Commission believes that these costs will be minimal.

\section{Consideration of Burden on Competition, and Promotion of Efficiency, Competition, and Capital Formation}

Section 3(f) of the Exchange Act ${ }^{862}$ requires the Commission, when engaging in rulemaking that requires the Commission to consider or determine whether an action is necessary or appropriate in the public interest, to consider whether the action will promote efficiency, competition and capital formation. Section 23(a)(2) prohibits the Commission from adopting any rule that would impose a burden on competition not necessary or appropriate in furtherance of the purposes of the Exchange Act. ${ }^{863}$ To assist the Commission in evaluating the costs and benefits of Regulation NMS, the Commission solicited comment in the Proposing Release and the Reproposing Release on whether any of the proposals discussed therein would have an adverse effect on competition that was neither necessary nor appropriate in furtherance of the purposes of the Exchange Act, and whether they would promote efficiency, competition and capital formation. The Commission also requested commenters to provide empirical data and other factual support for their views on these subjects. The Commission has considered comments received and has adopted the rules as discussed above, taking into account these comments.

\section{A. Order Protection Rule}

The Commission agrees with commenters that supported the Reproposed Rule ${ }^{864}$ that the price protection that will be provided by the Order Protection Rule will encourage greater use of

\footnotetext{
$862 \quad 15$ U.S.C. 78c(f).

86315 U.S.C. $78 \mathrm{w}(\mathrm{a})(2)$.

$864 \quad$ See supra, section II.A.1.
} 
limit orders, which will help improve the price discovery process, and contribute to increased liquidity and depth in the markets. The more limit orders available at better prices and greater size, the more liquidity available to fill incoming marketable orders. Greater depth and liquidity will, at a minimum, lower the search costs associated with trying to find liquidity and should lead to improved execution quality, particularly for larger-sized institutional orders. The Commission also believes that the Order Protection Rule, by providing intermarket price protection for accessible, automated orders (but not requiring automated markets to wait for responses from non-automated markets), will help promote efficiency in the markets by more effectively linking markets together and integrating trading centers with different market structures into the NMS, and by providing an incentive for non-automated markets to automate. Rule 611 also will promote investor confidence in the markets by helping to assure, on an order-by-order basis, that customer orders are executed at the best price available and providing protection against limit orders being bypassed by inferior priced executions. In particular, the Commission believes that the providing enhanced protection for the best bids and offers of each exchange, The NASDAQ Stock Market, and the ADF will represent a major step toward achieving the objectives of intermarket price protection. The Order Protection Rule thus will promote best execution for retail investors on an order-by-order basis, given that most retail investors justifiably expect that their orders will be executed at the NBBO.

The Commission believes that Rule 611 will promote intermarket competition by leveling the playing field between automated and non-automated markets and, to the extent that the existing trade-through rule serves to constrain competition, by removing this barrier to competition. The Commission recognizes the vital importance of preserving competition among 
market centers, ${ }^{865}$ but continues to believe that commenters have overstated the risk that such competition will be eliminated by adoption of an order protection rule without an opt-out exception. The Commission believes that markets likely will have strong incentives to compete and innovate to attract both marketable orders and limit orders. Market participants and intermediaries responsible for routing marketable orders, consistent with their desire to achieve the best price and their duty of best execution, will continue to rank trading centers according to the total range of services provided by such markets. The most competitive trading center will be the first choice for routing marketable orders, thereby enhancing the likelihood of execution for limit orders routed to that trading center. Because likelihood of execution is very important to limit orders, routers of limit orders likely will be attracted to this preferred trading center. More limit orders will enhance the depth and liquidity offered by the preferred trading center, thereby increasing its attractiveness for marketable orders, and beginning the cycle over again. In addition, Rule 611 will not require that limit orders be routed to any particular market. Consequently, the Commission believes that competitive forces will be fully operative to discipline markets that offer poor services to limit orders, such as limiting the extent to which limit orders can be cancelled in changing market conditions or providing slow speed of cancellation.

Conversely, trading centers that offer poor services, such as slow response times, will likely rank near the bottom in order-routing preferences of market participants and intermediaries. Whenever a least-preferred trading center is merely posting the same price as other trading centers, orders will be routed to the other trading centers. Competitive forces will

865 Many commenters believed that an opt-out exception would be necessary to promote competition among trading centers, particularly competition based on factors other than price, such as speed of response. See supra, section II.A.4.a. 
continue to dictate that the lowest ranked trading center in order-routing preference will suffer from offering a poor range of services to the routers of marketable orders. The Commission therefore does not believe that Rule 611 will eliminate competition among markets.

Commenters have, however, identified a troubling potential for intermarket price protection to lessen the competitive discipline that market participants now can impose on inefficient trading centers. ${ }^{866}$ The Order Protection Rule generally requires that trading centers match the best quoted prices, cancel orders without an execution, or route orders to the trading centers quoting the best prices. This is good for investors generally, but may not be if the quoting market is inefficient. For example, a market center may have poor systems that do not process orders quickly and reliably. Or a low-volume market may not be nearly as accessible as a high-volume market.

Currently, consistent with their best execution and other agency responsibilities, participants in the market for Nasdaq stocks can choose not to deal with any trading center that they believe provides unsatisfactory services. Under the Order Protection Rule, market participants can limit their involvement with any trading center to routing IOC orders to access only the best bid or best offer of the trading center. Nevertheless, even this limited involvement potentially could lessen the competitive discipline that otherwise will be imposed on an inefficient trading center. The Commission therefore believes that this potentially serious effect must be addressed at multiple levels in addition to the specific exceptions included in the Rule that were discussed above.

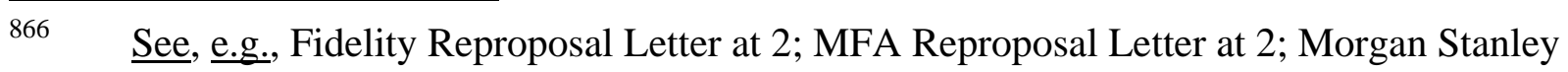
Reproposal Letter at 2; TIAA-CREF Reproposal Letter at 2. 
First, trading centers themselves have a legal obligation to meet their responsibilities under the Exchange Act to provide venues for trading that is orderly and efficient. ${ }^{867}$ Through registration and other requirements, the Exchange Act regulatory regime is designed to preclude entities that are not capable of meeting high standards of conduct from doing business with the public. This critically important function will be undermined by a trading center that displayed quotations in the consolidated data stream, but could not, because of poor systems or otherwise, provide efficient access to market participants and efficient handling of their orders. In addition, a trading center will violate its Exchange Act responsibilities if it failed to comply fully with the requirements set forth in Rule 600(b)(3) and (4) for automated quotations and automated trading centers. In particular, an automated trading center must implement such systems, procedures, and rules as are necessary to render it capable of meeting the requirements for automated quotations and must immediately identify its quotations as manual whenever it has reason to believe that it is not capable of displaying automated quotations. These requirements place an affirmative and vitally important legal duty on trading centers to identify their quotations as manual at the first sign of a problem, not after a problem has fully manifested itself and thereby caused a rippling effect at other trading centers that damages investors and the public interest.

Second, those responsible for the regulatory function at SROs have an affirmative responsibility to examine for and enforce all Exchange Act requirements and the SRO rules that apply to the trading centers that fall within their regulatory authority. One of the key policy justifications for a self-regulatory system is that industry regulators will have close proximity to, and significant expertise concerning, their particular trading centers. In addition, industry Regulation ATS. 
regulators typically have greater flexibility to address problems than governmental authorities. Implementation of the Order Protection Rule will heighten the importance of effective selfregulation. Those responsible for the market operation functions of an SRO may have business incentives that militate against dealing with potential problems in an effective and forthright manner. Regulatory personnel are expected to be independent of such business concerns and have an affirmative responsibility to prevent improper factors from interfering with an SRO's full compliance with regulatory requirements.

Finally, the Commission itself plays a critical role in the Exchange Act regulatory regime. Effective implementation of the Order Protection Rule also will depend on the Commission taking any action that is necessary and appropriate to address problem trading centers that fail to meet fully their regulatory requirements. The Commission and its staff must continue to monitor the markets closely for signs of problems and listen to the concerns of market participants as they arise, especially with regard to the new requirements imposed by the Order Protection Rule. Quick and effective action will be needed to assure that all responsible parties do not feel that inattention to problems is an acceptable course of action.

The Commission therefore believes that Rule 611 will not impose any competitive burden that is not necessary and appropriate in furtherance of the purposes of the Exchange Act. The Commission believes that the Order Protection Rule will help create an NMS that more fully meets the needs of a wide spectrum of investors, particularly long-term investors and publicly traded companies, by providing increased efficiency and improved depth and liquidity to our capital markets. By providing increased efficiency and promoting investor confidence in quality executions, investors may be more willing to invest in our capital markets, thus promoting the ability of listed companies to raise capital at lower cost. 


\section{B. Access Rule}

Rule 610 establishes standards governing access to quotations in NMS stocks that:

(1) prohibit trading centers from unfairly discriminating against non-members members or nonsubscribers that attempt to access their quotations through a member or subscriber of the trading center, and enable access to NMS quotations through private linkages; (2) establish an outer limit on the cost of accessing such quotations of no more than $\$ 0.003$ per share; and (3) require SROs to establish, maintain, and enforce rules that, among other things, prohibit their members from engaging in a pattern or practice of displaying quotations that lock or cross the automated quotations of other trading centers. The amendment to Rule 301(b)(5) under Regulation ATS lowers the threshold that triggers the Regulation ATS fair access requirements from 20\% to 5\% of average daily volume in a security.

The access provisions are intended to bolster investor confidence in the markets by helping to assure investors that their orders will be executed at the best prices and will not subject to hidden fees, regardless of the market on which the execution takes place. By generally imposing a uniform fee limitation of $\$ 0.003$ per share, the Rule will promote equal regulation of different types of trading centers, where currently some are permitted to charge fees and some are not, thereby leveling the playing field among diverse market centers. Moreover, the Commission believes that, by prohibiting a trading center from imposing unfairly discriminatory terms that would prevent or inhibit the efficient access of any person through members, subscribers, or customers of such trading center, the Rule will promote competition among trading centers.

The Commission believes that Rule 610 also will increase transparency and efficiency in the market, thereby enhancing investor confidence, and thus capital formation. Specifically, the 
Rule will permit private linkages between markets, rather than mandating a collective intermarket linkage facility. Private linkages will permit market centers to connect through cost effective and technologically advanced communications networks. Such systems are widely utilized in the market for Nasdaq-listed stocks today and likely will provide speed and flexibility to trading centers and their market participants. The use of private linkages can encourage interaction between the markets and reduce fragmentation by removing impediments to the execution of orders between and among marketplaces, thereby increasing efficiency and competition.

Several commenters expressed concerns regarding the impact that the access fee proposal could have on competition. ${ }^{868}$ As discussed in detail in Section III above, the Commission believes that the flat limitation on access fees of $\$ 0.003$ per share is the fairest and most appropriate solution to what has been a longstanding and contentious issue. A single accumulated fee cap will apply equally to all types of trading centers and all types of market participants, thereby promoting the NMS objective of equal regulation of markets and brokerdealers, and allowing those entities to compete on equal footing. ${ }^{869}$

A fee limitation also is necessary to preclude individual trading centers from raising their fees substantially in an attempt to take improper advantage of strengthened protection against trade-throughs and the adoption of a private linkage regime. In particular, the fee limitation is necessary to address "outlier" trading centers that otherwise might charge high fees to other

$868 \quad$ See, e.g., Amex Letter, Exhibit A at 23-24; ArcaEx Reproposal Letter at 10; BGI Reproposal Letter at 3; Bloomberg Summary of Intended Testimony at 3; BrokerageAmerica Letter at 1; Brut Letter at 14; CHX Letter at 15; Domestic Securities Summary of Intended Testimony; Instinet Reproposal Letter at 10; NexTrade Reproposal Letter at 7-8; Phlx Reproposal Letter at 4 (stating its belief that the proposal is not justified under Section 23(a)(2) of the Exchange Act); TrackECN Letter at 3. Section 11A(c)(1)(F) of the Exchange Act, 15 U.S.C. 78k-1(c)(1)(F). 
market participants required to access their quotations by the Order Protection Rule. It also precludes a trading center from charging high fees selectively to competitors, practices that have occurred in the market for Nasdaq stocks. In the absence of a fee limitation, the adoption of the Order Protection Rule and private linkages could significantly boost the viability of the outlier business model. Outlier markets might well try to take advantage of intermarket price protection by acting essentially as a toll booth between price levels. The high fee market likely would be the last market to which orders would be routed, but prices could not move to the next level until someone routed an order to take out the displayed price at the outlier market. Therefore, the outlier market might see little downside to charging exceptionally high fees, such as $\$ 0.009$, even if it is last in priority. While markets would have significant incentives to compete to be near the top in order-routing priority, ${ }^{870}$ there might be little incentive to avoid being the leastpreferred market if fees were not limited.

The \$0.003 cap will limit the outlier business model. It will place all markets on a level playing field in terms of the fees they can charge and the rebates they can pass on to liquidity providers. Some markets may choose to charge lower fees, thereby increasing their ranking in the preferences of order routers. Others may charge the full \$0.003 and rebate a substantial proportion to liquidity providers. Competition will determine which strategy is most successful.

The Commission notes that the $\$ 0.003$ fee limitation is consistent with current business practices, as very few trading centers currently charge fees that exceed this amount. ${ }^{871}$ It appears

870 See supra, section II.A.4.a (discussion of competitive implications of trade-through protection).

871 Cf. Instinet Letter at 35 ("there is no basis for adopting any limitation other than at the prevailing \$0.003 per share level, which was arrived at through open competition among ATSs, ECNs, and SRO markets in the Nasdaq market") and Instinet Reproposal Letter at 11 ("as for an appropriate amount for such an accumulated fee limitation, the 
that only two ECNs currently charges fees that exceed $\$ 0.003$, charging $\$ 0.005$ for access through the ADF. These ECNs currently do not account for a large percentage of trading volume. In addition, while a few SROs have large fees on their books for transactions in ETFs that exceed a certain size (e.g., 2100 shares), it is unlikely that these fees generate a large amount of revenues. Accordingly, the adopted fee limitation will not impair the agency market business model. The Commission recognizes that agency trading centers perform valuable agency services in bringing buyers and sellers together, and that their business model historically has relied, at least in part, on charging fees for execution of orders against their displayed quotations. Under current conditions, prohibiting access fees entirely would unduly harm this business model.

In addition, the Rule is designed to reduce the instances of locked and crossed quotations, which will promote capital formation by providing market participants a clear picture of the true trading interest in a stock. Moreover, the Commission believes that the access provisions will encourage interaction between the markets and reduce fragmentation by removing impediments to the execution of orders between and among marketplaces, thereby increasing efficiency and competition. Finally, the Commission believes that the access provisions likely will assist broker-dealers in evaluating and complying with their best execution obligations. The Commission therefore believes that Rule 610 will not impose any competitive burden that is not necessary and appropriate in furtherance of the purposes of the Exchange Act.

\section{Sub-Penny Rule}

The Commission has considered Rule 612 in light of Sections 3(f) and 23(a)(2) of the Exchange Act and believes that the Rule will not impose a burden on competition not necessary

Reproposal sets the cap at the prevailing $\$ 0.003$ per share level for stocks priced above $\$ 1.00$, which was arrived at through open competition among marketplaces"). 
or appropriate in furtherance of the purposes of the Exchange Act. To the contrary, by

preserving the benefits of decimalization and guarding against the less desirable effects of further reducing the MPV, Rule 612 should promote fair and vigorous competition. The Commission acknowledges that the rule will, in some circumstances, prevent market participants from offering marginally better prices (through quoting or placing orders in sub-pennies). Some commenters argued that a prohibition on quoting in sub-pennies, at least in some NMS stocks, would inhibit price competition and artificially widen spreads. ${ }^{872}$ Nevertheless, the Commission is concerned that sub-penny quoting may be used by market participants more as a means of stepping ahead of competing limit orders for an economically insignificant amount than of promoting genuine price competition.

The Commission believes that Rule 612 will assist broker-dealers in evaluating and complying with their best execution obligations and other rules premised on identifying the price of a security at a particular moment in time. The Commission also believes that Rule 612 will enhance market depth and improve transparency by preventing trading interest from being spread across an unnecessarily large number of price points. Therefore, we believe Rule 612 will encourage market participants to use limit orders, an important source of liquidity, and thereby promote market efficiency, competition, and capital formation. The Commission also believes that the new Rule will bolster investor confidence by helping ensure that their orders, especially large orders, can be executed without incurring large transaction costs. This increase in investor confidence also will promote market efficiency, competition, and capital formation.

Rule 612 will establish common quoting conventions that will increase transparency in the securities markets. Moreover, the Commission believes that the Rule will encourage

872 See, e.g., Instinet Letter at 47; Mercatus Center Letter at 9-10; Tower Research Letter at 8-11. 
interaction between the markets and reduce fragmentation by removing impediments to the execution of orders between and among markets. The increased transparency in the markets and reduction of fragmentation between the markets will bolster investor confidence, thereby promoting capital formation.

\section{Market Data Rules and Plan Amendments}

The Commission believes that the adopted Plan amendment updating the current revenue allocation formulas will promote efficiency in the marketplace by eliminating incentives for market participants to engage in distortive trading practices such as wash trades, trade shredding, and SRO print facilities to obtain market data revenues. Similarly, commenters supported the need to update the current allocation formulas. ${ }^{873}$ In addition, the Commission believes, and several commenters concurred, that the adopted Plan amendment requiring the creation of nonvoting advisory committees will promote efficiency in the administration of the Plans by allowing interested parties other than SROs to have a voice in Plan matters, ${ }^{874}$ which can, in turn, contribute to the resolution of potential disputes that SRO participants will otherwise bring before the Commission. Furthermore, we expect Rule 603(a) will promote efficiency and competition among market centers by helping to assure that independently reported trade and quotation information is distributed on terms that are fair and reasonable and not unreasonably discriminatory. Commenters that discussed this Rule generally agreed that adopted Rule 603(a) would allow investors and vendors greater freedom to make their own decisions regarding the

873 See, e.g., BGI Reproposal Letter at 3; Citigroup Reproposal Letter at 9; Deutsche Bank Reproposal Letter at 4; Harris Reproposal Letter at 11; JP Morgan Reproposal Letter at 2; STA Letter at 7; UBS Letter at 10; Vanguard Letter at 6.

$874 \quad$ See, e.g., Financial Services Roundtable Letter at 7; Reuters Letter at 3; SIIA/FISD Reproposal Letter at 2. 
data they need and that the proposal should lead to lower costs to investors. ${ }^{875}$ The Commission agrees with these commenters and notes that efficiency is promoted when broker-dealers who do not need the data beyond the prices, sizes, market center identifications of the NBBO and consolidated last sale information are not required to receive (and pay for) such data. The Commission also believes that efficiency is promoted when broker-dealers may choose to receive (and pay for) additional market data based on their own internal analysis of the need for such data. Adopted Rule 603(b) also likely will promote efficiency in the dissemination of consolidated market information by requiring that all SROs act jointly through the Plans to disseminate such information to the public.

The Commission believes that the adopted Plan amendments will assist in capital formation through a more appropriate allocation of the Networks' revenues to those SROs that contribute most to public price discovery. Rule 603(c) also will eliminate the requirement to display a complete montage of quotations from all market centers and will therefore promote capital formation by reducing the costs to vendors and broker-dealers that are currently required to display quotations that may be far away from the NBBO. One commenter stated that brokerdealers currently are discouraged from making quotation and price information on a stock available because, under the current rule, this information must be accompanied by consolidated information for which they must pay market data fees. ${ }^{876}$ Accordingly, the Commission believes that, in certain circumstances, Rule 603(c) will result in additional market data information being provided, which will assist capital formation.

875 See, e.g., Brut Letter at 23; Financial Services Roundtable Letter at 6; Nasdaq Reproposal Letter at 16. In addition, two commenters believed that the proposal would reduce some regulatory burdens imposed on market participants. Financial Information Forum Reproposal Letter at 4-5; Instinet Reproposal Letter at 16.

$876 \quad$ Reuters Letter at 2-3. 
The Commission further believes that the adopted amendments to the Plans and to Rules 601 and 603 will not impose any competitive burden that is not necessary and appropriate in furtherance of the purposes of the Exchange Act. One regional exchange urged the Commission to consider the impact of the formula on competition, because, according to this commenter, most regional market centers rely on market data revenues to fund a significant portion of their budgets and thus a material decrease in such revenues could affect their financial plans, making it infeasible to compete with listing markets, which can survive on listing revenues. ${ }^{877}$ Although any change to the current formulas may result in a competitive advantage for some SROs and in a competitive disadvantage for other SROs, the Commission does not believe that this should preclude the adoption of an allocation formula that would provide a more useful distribution of market data revenues based on the quality of an SROs contribution of quotations and trades to the consolidated data stream. The Commission also believes that the adopted Plan amendment requiring the Plans to form non-voting advisory committees will enhance and promote competition by broadening Plan governance to include non-SRO parties, and thereby provide greater transparency in the administration of such Plans. Furthermore, we expect adopted Rules 601 and 603 to lessen the burden on vendors and broker-dealers from having to comply with certain consolidated display requirements. A few commenters generally noted that allowing market centers to independently disseminate certain market data information could increase competition among markets. ${ }^{878}$ The Commission agrees that the competition among market centers will be enhanced when such markets also choose to independently distribute their own market data. In addition, the amendment providing that all SROs consolidate information in each NMS stock and disseminate such information through a single processor per security will

877 CHX Reproposal Letter at 5.

$878 \quad$ See, e.g., Amex Letter at 10; Specialist Assoc. Letter at 16-17; see also Brut Letter at 23. 
clarify that SROs are on an equal competitive footing with each other. Thus, the Commission believes that the amendments will enhance rather than burden competition by creating a more equal competitive environment for market centers and others.

\section{E. Regulation NMS}

Rule 600, the redesignation of the existing NMS rules as Regulation NMS, and the related conforming changes to other Commission rules will help to promote efficiency and capital formation by making the NMS rules easier to understand, thereby helping to reduce compliance costs for entities subject to the rules. Enhanced clarity in the definitions used in Regulation NMS also will benefit investors and the public interest by facilitating compliance with the requirements of Regulation NMS. Because Rule 600 will clarify the existing definitions used in Regulation NMS without imposing new requirements, and because the redesignation of the NMS rules as Regulation NMS and the conforming changes to other Commission rules will create no new substantive requirements, Rule 600 and the related changes will not impose a burden on competition or alter the competitive standing of entities subject to Regulation NMS.

\section{Regulatory Flexibility Act}

\section{A. Order Protection Rule}

The Commission certified, pursuant to Section 605(b) of the Regulatory Flexibility Act, that the Order Protection Rule will not have a significant economic impact on a substantial number of small entities. ${ }^{879}$ This certification was incorporated into the Reproposing Release. ${ }^{880}$ The Commission did not receive any comments on this certification.

\section{B. Access Rule}

$879 \quad 5$ U.S.C. 605(b).

$880 \quad$ Reproposing Release, 69 FR at 77492. 
The Commission certified, pursuant to Section 605(b) of the Regulatory Flexibility Act, that Rule 610 and the amendments to Rule 301 of Regulation ATS will not have a significant economic impact on a substantial number of small entities. ${ }^{881}$ This certification was incorporated into the Reproposing Release. ${ }^{882}$ The Commission received one comment discussing the certification. The commenter, an ADF participant, believed that the Commission in the certification recognized that Rule 610 could result in a significant economic impact on small firms, just not a substantial number of small firms. ${ }^{883}$ This commenter continued to express its concerns with the proposed access requirements, stating its belief that the proposal to require ADF participants to establish the necessary connectivity that would facilitate efficient access to their quotations would create a cost barrier that discriminates against smaller firms in the ADF. ${ }^{884}$

The Commission does not believe that its adopted access approach in Rule 610(b)(1) discriminates against smaller firms or creates a barrier to access for innovative new market entrants. Rather, smaller firms and new entrants have a range of alternatives from which to choose that will allow them to avoid incurring any costs to meet the connectivity requirements of Rule 610(b)(1) if they wish to do so. This approach is fully consistent with Congressional policy set forth in the Regulatory Flexibility Act, which directs the Commission to consider significant

\footnotetext{
$881 \quad 5$ U.S.C. 605(b).

882 Reproposing Release, 69 FR at 77493.

883 In the Reproposing Release, the Commission noted that only two of the approximately 600 broker-dealers (including ATSs) that would be subject to the Rule are considered small for purposes of the Regulatory Flexibility Act. See Section XII.B of the Reproposing Release, 69 FR at 77493.

$884 \quad$ NexTrade Reproposal Letter at 4-6.
} 
alternatives to regulations that accomplish the stated objectives of the Exchange Act and minimize the economic impact on small entities. ${ }^{885}$

Small ATSs are exempt from participation in the consolidated quotation system and, therefore, from the connectivity requirements of Rule 610. Under Rule 301(b)(3) of Regulation ATS, an ATS is required to display its quotations in the consolidated quotation stream only in those securities for which its trading volume reaches $5 \%$ of total trading volume. Consequently, smaller ATSs are not required to provide their quotations to any SRO (whether an SRO trading facility or the NASD's ADF) and thereby trigger the access requirements of Rule 610.

Moreover, potential new entrants with innovative trading mechanisms can commence business without having to incur any costs associated with participation in the consolidated quotation system.

Some smaller ATSs, however, may wish to participate voluntarily in the consolidated quotation system. Such participation can benefit smaller firms and promote competition among markets by enabling smaller firms to obtain wide distribution of their quotations among all market participants. ${ }^{886}$ Here, too, such firms will have alternatives that would not obligate them to comply with the connectivity requirements of Rule 610(b)(1). ATSs and market makers that wish to trade NMS stocks can choose from a number of options for quoting and trading. They can become a member of a national securities exchange and quote and trade through the exchange's trading facilities. They can participate in The NASDAQ Market Center and quote

$885 \quad 5$ U.S.C. 603(c). The adopted access approach provides alternatives that will benefit a wider range of smaller ATSs than the two that are considered small entities. See supra note 385 .

886 See supra, note 566 (the Commission's Advisory Committee on Market Information recommended retention of the consolidated display requirement because, among other things, it "may promote market competition by assuring that information from newer or smaller exchanges is widely distributed."). 
and trade through that facility. By choosing either of these options, an ATS or market maker would not create a new connectivity point that all other market participants must reach and would not be subject to Rule 610(b)(1). Some firms, however, may not want to participate in an SRO trading facility. These ATSs and market makers can quote and trade in the OTC market. The existence of the NASD's ADF makes this third choice possible by providing a facility for displaying quotations and reporting transactions in the consolidated data stream. ${ }^{887}$

As noted above in Section III.A.1, however, the NASD is not statutorily required to provide an order execution functionality in the ADF. The Commission believes that market makers and ECNs should continue to have the option of operating in the OTC market, rather than on an exchange or The NASDAQ Market Center. As noted in the Commission's order approving Nasdaq's SuperMontage trading facility, this ability to operate in the ADF is an important competitive alternative to Nasdaq or exchange affiliation. ${ }^{888}$ Therefore, the Commission has determined not to require small trading centers to make their quotations accessible through an SRO trading facility.

Instead, Rule 610(b)(1) requires all trading centers that choose to display quotations in an SRO display-only quotation facility (currently, the ADF) to provide a level and cost of access to such quotations that is substantially equivalent to the level and cost of access to quotations displayed by SRO trading facilities. Rule 610(b)(1) therefore may cause trading centers that display quotations in the ADF to incur additional costs to enhance the level of access to their quotations and to lower the cost of connectivity for market participants seeking to access their

887 Under Rule 301(b)(3) of Regulation ATS, 17 CFR 242.301(b)(3), an ATS is required to display its quotations in the consolidated data stream only in those securities for which its trading volume reaches $5 \%$ of total trading volume.

888 See Securities Exchange Act Release No. 43863 (Jan. 19, 2001), 66 FR 8020 (Jan. 26, 2001). 
quotations. The extent to which these trading centers in fact incur additional costs to comply with the adopted access standard will be largely within the control of the trading center itself. As noted above, ATSs and market makers that wish to trade NMS stocks can choose from a number of options for quoting and trading, including quoting and trading in the OTC market. As a result, the additional connectivity requirements of Rule 610(b) will be triggered only by a trading center that displays its quotations in the consolidated data stream and chooses not to provide access to those quotations through an SRO trading facility.

Currently, nine SROs operate trading facilities in NMS stocks. Market participants throughout the securities industry generally have established connectivity to these nine points of access to quotations in NMS stocks. By choosing to display quotations in the ADF, a trading center effectively could require the entire industry to establish connectivity to an additional point of access. Potentially, many trading centers could choose to display quotations in the ADF, thereby significantly increasing the overall costs of connectivity in the NMS. Such an inefficient outcome would become much more likely if an ADF trading center were not required to assume responsibility for the additional costs associated with its decision to display quotations outside of an established SRO trading facility.

Although the Exchange Act envisions an individual broker-dealer having the option of trading in the OTC market, ${ }^{889}$ it does not mandate that the securities industry in general must subsidize the costs of accessing a broker-dealer's quotations in the OTC market if the NASD chooses not to provide connectivity. The Commission believes that it is reasonable and appropriate to require those ATSs and market makers that choose to display quotations in the ADF to bear the responsibility of providing a level and cost of access to their quotations that is

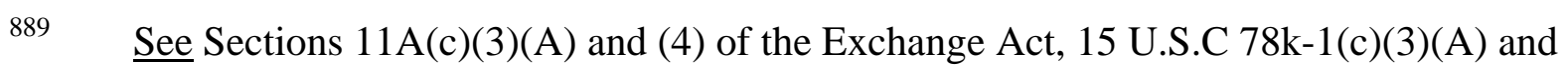
(4). 
substantially equivalent to the level and cost of access to quotations displayed by SRO trading facilities. Under Rule 610(b)(1), therefore, ADF participants will be required to bear the costs of the necessary connectivity to facilitate efficient access to their quotations. ${ }^{890}$ This standard will help ensure that additional connectivity burdens are not imposed on the securities industry each time an additional ADF participant necessitates a new connectivity point by choosing to begin displaying quotations in the consolidated quotation stream. The Commission believes that this requirement will help reduce overall industry costs by more closely aligning the burden of additional connectivity with those entities whose choices have created the need for additional connectivity.

As just discussed, the Commission recognizes that trading centers subject to Rule 610(b)(1) may incur costs associated with providing access to their quotations, although the costs will vary depending upon the manner in which each trading center provides such access. The Commission notes that to meet the standard contained in Rule 610(b)(1), a trading center will be allowed to take advantage of the greatly expanded connectivity options that have been offered by competing access service providers in recent years. ${ }^{891}$ These industry access providers have extensive connections to a wide array of market participants through a variety of direct access options and private networks. A trading center potentially could meet the requirement of

890 Thus, although market participants may still be required to access numerous trading centers in the ADF, the Rule should reduce the cost of access to each such trading center by requiring the ADF trading center to provide a cost and level of access substantially equivalent to the level and cost of access to quotations displayed by SRO trading facilities.

891 As noted in the Commission's order approving the pilot program for the ADF, the reduction in communications line costs in recent years and the advent of competing access providers offer the potential for multiple competitive means of access to the various trading centers that trade NMS stocks. Securities Exchange Act Release No. 46249, supra note 390. 
Rule 610(b)(1) by establishing connections to and offering access through such vendors. The option of participation in existing market infrastructure and systems should reduce a trading center's cost of compliance. ${ }^{892}$

Section 3(a) of the Regulatory Flexibility Act ${ }^{893}$ requires the Commission to undertake an Initial Regulatory Flexibility Analysis of proposed rules on small entities unless the Commission certifies that the proposed rules, if adopted, would not have a significant economic impact on a substantial number of small entities. The Commission continues to believe that the Access Rule will not have a significant economic impact on a substantial number of small entities.

\section{Sub-Penny Rule}

This Final Regulatory Flexibility Act Analysis ("FRFA") relating to Rule 612 of Regulation NMS has been prepared in accordance with the Regulatory Flexibility Act. ${ }^{894}$

\section{1. $\quad$ Need for and Objective of Rule $\mathbf{6 1 2}$}

Although the conversion from fractional to decimal trading benefited investors by clarifying and simplifying prices, making our markets more competitive internationally, and reducing trading costs by narrowing spreads, these benefits could be diluted if market participants could quote NMS stocks in increments less than a penny. The Commission is particularly concerned that sub-penny orders may be used to step ahead of competing limit orders for an economically insignificant amount.

892 As the self-regulatory authority responsible for the OTC market, the NASD must act as "gatekeeper" for the ADF, and, as such, will need to closely assess the extent to which ADF participants meet the requirements of Rule 610.

893

5 U.S.C. 603(a).

$894 \quad 5$ U.S.C. 604. 
New Rule 612 prohibits an exchange, association, vendor, ATS, or broker-dealer from accepting, ranking, or displaying an order, quotation, or indication of interest in an NMS stock priced in a sub-penny increment (except for an order, quotation, or indication of interest priced less than $\$ 1.00$ per share, in which case the price may not extend beyond four decimal places). The rule is designed to improve market depth by preventing quotations from spreading across an unduly large number of price points, while also encouraging the use of limit orders - an important source of liquidity - by preventing competing market participants from stepping ahead of a limit order by an economically insignificant amount. We expect the rule to reduce the instances of quote flickering and to facilitate broker-dealers' efforts to meet their best execution and other regulatory duties premised on identifying a security's prevailing market price.

\section{Significant Issues Raised by Public Comment}

The IRFA appeared in the Proposing Release and in the Reproposing Release. ${ }^{895}$ The Commission requested comment in the IRFA on the impact the proposals would have on small entities and how to quantify the impact. The Commission did not receive any comment letters addressing the IRFA.

\section{Small Entities Subject to the Rule}

Rule 612 applies to every national securities exchange, national securities association, ATS, vendor, and broker-dealer. Each type of market participant that will be affected by the new Rule 612 is discussed below.

\section{a. National Securities Exchanges and National Securities Associations}

895 Proposing Release, 69 FR at 11174-75; Reproposing Release, 69 FR 77493-94. 
Rule 0-10(e) under the Exchange Act ${ }^{896}$ provides that the term "small business" or "small organization," when referring to an exchange, means any exchange that: (1) has been exempted from the reporting requirements of Rule 601 under the Exchange Act; and (2) is not affiliated with any person (other than a natural person) that is not a small business or small organization, as defined by Rule 0-10. No national securities exchange meets these criteria; therefore, no national securities exchange is a small entity. Currently, there is one national securities association (NASD) that is subject to Rule 612. NASD is not a small entity as defined by 13 CFR 121.201.

\section{b. Broker-Dealers}

Commission rules generally define a broker-dealer as a small entity for purposes of the Exchange Act and the Regulatory Flexibility Act if the broker-dealer had total capital (net worth plus subordinated liabilities) of less than $\$ 500,000$ on the date in the prior fiscal year as of which its audited financial statements were prepared, and the broker-dealer is not affiliated with any person (other than a natural person) that is not a small entity. ${ }^{897}$ The Commission estimates that, as of the end of 2003, there were approximately 6,565 Commission-registered broker-dealers, ${ }^{898}$ of which approximately 905 are considered small entities pursuant to Rule 0-10(c) under the Exchange Act. ${ }^{899}$

\section{c. Vendors}

$896 \quad 17$ CFR 240.0-10(e).

897 See 17 CFR 240.0-10(c).

898 This number reflects the number of FOCUS filings. ATSs that are not registered as exchanges are required to register as broker-dealers. Accordingly, an ATS would be considered a small entity if it fell within the definition of "small entity" as it applies to broker-dealers.

17 CFR 240.0-10(c). 
A vendor is any securities information processor engaged in the business of disseminating transaction reports or last sale data with respect to transactions in reported securities to brokers, dealers, or investors on a real-time or other current and continuing basis, whether through an ECN, moving ticker, or interrogation device. ${ }^{900}$ Rule 0-10(g) ${ }^{901}$ provides that the term "small business" or "small organization," when referring to a securities information processor, means any securities information processor that: (1) had gross revenues of less than \$10 million during the preceding fiscal year (or in the time it has been in business, if shorter); (2) provided service to fewer than 100 interrogation devices or moving tickers at all times during the preceding fiscal year (or in the time that it has been in business, if shorter); and (3) is not affiliated with any person (other than a natural person) that is not a small business or small organization under this section. The Commission estimates that there are approximately 80 vendors, 16 of which are considered small entities.

\section{Reporting, Recordkeeping, and Other Compliance Requirements}

Rule 612 will not impose any new reporting, recordkeeping, or other compliance requirements on any entities subject to the rule, including small entities.

\section{Agency Action to Minimize Effect on Small Entities}

Rule 612 establishes a uniform pricing increment for NMS stocks. All entities subject to the rule generally are prohibited from displaying, ranking, or accepting an order, quotation, or indication of interest priced in a sub-penny increment. Imposing different compliance requirements for small entities would be impractical and undermine the goal of uniformity. Furthermore, the Commission does not believe it necessary or appropriate to consider whether

$900 \quad$ See 17 CFR 11Aa3-1(a)(11).

$901 \quad 17$ CFR 240.0-10(g). 
small entities should be permitted to use performance rather than design standards to comply with Rule 612. The rule already establishes performance standards and does not dictate any particular design standard that must be employed to achieve the rule's objectives.

\section{Market Data Rules and Plan Amendments}

\section{Regulatory Flexibility Act Certification for the Plan Amendments}

The Commission certified, pursuant to Section 605(b) of the Regulatory Flexibility Act, that amending the Plans to: (1) modify the current formulas for allocating market data revenues, and; (2) require the establishment of non-voting advisory committees will not have a significant

economic impact on a substantial number of small entities. ${ }^{902}$ This certification was incorporated into the Proposing Release and Reproposing Release. ${ }^{903}$ The Commission did not receive any comments on this certification.

\section{Final Regulatory Flexibility Analysis for Amendments to Rules 11Aa3-1 and 11Ac1-2 (Redesignated as Rules 601 and 603)}

This FRFA has been prepared in accordance with the Regulatory Flexibility Act. ${ }^{904}$ This FRFA relates to Exchange Act Rules 11Aa3-1 and 11Ac1-2 (redesignated as Rules 601 and $603)$.

\section{a. Need for and Objectives of Rules 601 and 603}

The Commission believes that an overall modernization of the rules for disseminating market data to the public is necessary to address problems posed by the current market data rules. In adopting Rules 601 and 603 as reproposed, the Commission retains the core elements of the existing rules - price discovery and mandatory consolidation - which provide important

\footnotetext{
$902 \quad 5$ U.S.C. 605(b).

903 Proposing Release, 69 FR at 11190-91; Reproposing Release, 69 FR at 77495-96.

9045 U.S.C. 604.
} 
benefits to investors and to others who use market information, but amends other parts of the existing rules that have resulted in serious economic and regulatory distortions. More specifically, adopted Rules 601 and 603 reduce the burden on, and provide simplification and uniformity for, those market centers, broker-dealers, and data vendors that have to comply with requirements under the Rules.

Adopted Rules 601 and 603 are designed to fulfill several objectives, including: (1) providing market centers, including ATSs and market makers, with flexibility to independently distribute their own trade reports, aside from their obligation to provide their trade reports and best quotations to an SRO or to the Networks (depending on the type of market center); (2) providing uniform standards for all market centers, including non-SRO market centers and entities that are exclusive processors of SRO market data, for the independent distribution of market data; (3) providing that all SROs act jointly through the Plans and disseminate their consolidated information through a single processor, to clarify the practice among the SROs and to require continued participation in the Plans and dissemination through one processor per security; (4) reducing consolidated display requirements on broker-dealers and vendors and limiting their consolidated display obligations to the disclosure of the NBBO and consolidated last sale information and to the display of market information in a trading or order-routing context; and (5) easing the burden of compliance by simplifying the current consolidated display requirements under the Rule and by rescinding old provisions in the Rule that are outdated and no longer necessary.

\section{b. Significant Issues Raised by Public Comment}


The IRFA appeared in the Proposing Release and in the Reproposing Release. ${ }^{905}$ The Commission requested comment in the IRFA on the impact the proposals would have on small entities and how to quantify the impact. The Commission did not receive any comment letters addressing the IRFA.

\section{c. Small Entities Subject to the Rule}

Adopted Rules 601 and 603 affect ATSs, market makers, broker-dealers, and SIPs that could potentially be small entities. Paragraph (c) of Rule 0-10 under the Exchange Act ${ }^{906}$ defines $^{2}$ the term "small business" or "small organization," when referring to a broker-dealer, to mean a broker or dealer that had total capital of less than $\$ 500,000$ on the date in the prior fiscal year as of which its audited financial statements were prepared, or, if not required to file such statements, that had total capital of less than $\$ 500,000$ on the last business day of the preceding fiscal year; and is not affiliated with any person (other than a natural person) that is not a small business or small organization. ATSs and market makers would be considered broker-dealers for purposes of this definition. Paragraph (g) of Rule $0-10^{907}$ defines the term "small business" or "small organization," when referring to a SIP, to mean a SIP that had gross revenues of less than \$10 million during the preceding fiscal year and provided service to fewer than 100 interrogation devices or moving tickers at all times during the preceding fiscal year; and is not affiliated with any person (other than a natural person) that is not a small business or small organization.

In the IRFA included in the Reproposing Release, the Commission estimated that, as of December 31, 2003, there were approximately 905 registered broker-dealers, including ATSs and market makers that would be considered small entities. In addition, approximately 16 SIPs

905 Proposing Release, 69 FR at 11190-91; Reproposing Release, 69 FR 77495-96.

90617 CFR 240.0-10(c).

$907 \quad 17$ CFR 240.0-10(g). 
would be considered small entities. In the Proposing Release and in the Reproposing Release, the Commission requested comment on the number of small entities that would be impacted by adopted Rules 601 and 603, including any available empirical data. No commenters responded with cost estimates pertaining to the requested data listed above. Adopted Rule 601 enables small market centers, including ATSs and market makers, that contribute to consolidated information, if they so choose, to also independently distribute their own trade reports. Adopted Rule 603 reduces the compliance burden on small broker-dealers and SIPs by limiting the data required to be displayed under the Rule. ${ }^{908}$

\section{d. Reporting, Recordkeeping and Other Compliance Requirements}

Adopted Rules 601 and 603 do not impose any new reporting, recordkeeping or other compliance requirements on ATSs, market makers, broker-dealers, and SIPs that are small entities. SROs that would be subject to these proposed amendments are not considered small entities. $^{909}$

\section{e. Agency Action to Minimize Effects on Small Entities}

As required by the Regulatory Flexibility Act, the Commission has considered alternatives that would accomplish the stated objective, while minimizing any significant adverse impact on small entities. As discussed in the Proposing Release and in the Reproposing Release, the Commission has considered the following alternative models for disseminating market data to the public: (1) a competing consolidators model under which each SRO would be allowed to sell its market data separately to any number of consolidators; (2) a rescission of the consolidated

\footnotetext{
908 Adopted Rule 603, providing that all SROs act jointly through the Plans and disseminate their consolidated information through a single processor, would only apply to the SROs, which are not "small entities" for purposes of the Regulatory Flexibility Act. See supra, section XI.C.3.a.
} 
display requirement and allowing all SROs and other market centers to distribute their market data individually; and (3) a hybrid model that would retain the consolidated display requirement and existing Networks solely for the dissemination of the NBBO, but allow the SROs to distribute their own quotations and trades independently and without a consolidated display requirement.

The primary goal of the adopted amendments to Rules 11Aa3-1 and 11Ac1-2 (redesignated as Rules 601 and 603) is to retain the benefits of the consolidated display requirement, which provides a uniform, consolidated stream of data and is the single most important tool for unifying all of the market centers trading NMS Stocks, while providing market centers that contribute to consolidated information with the ability to independently distribute their own market data and reducing the consolidated display requirements on broker-dealers and SIPs. As stated in the Proposing Release and in the Reproposing Release and in Section V.A.1 above, the Commission believes that these potential alternative models pose an unacceptable risk of losing important benefits that investors and other information users receive under the current system - an affordable and highly reliable stream of quotations and trades that is consolidated from all significant market centers trading an NMS Stock.

The Commission believes that different compliance or reporting requirements for small entities, and further clarification, consolidation, or simplification of Rules 601 and 603, is not necessary because adopted Rules 601 and 603 do not establish any new reporting, recordkeeping or other compliance requirements for small entities and, in fact, adopted Rule 603 should reduce the compliance burden on small broker-dealers and SIPs by limiting the data required to be consolidated and displayed under the Rule. The Commission also notes that the amendments contain performance standards and do not dictate for entities of any size any particular design 
standards (e.g., technology) that must be employed to achieve the objectives of the adopted amendments.

\section{E. Regulation NMS}

The Commission certified, pursuant to Section 605(b) of the Regulatory Flexibility Act, that Rule 600 and the redesignation of the NMS rules as Regulation NMS will not have a significant economic impact on a substantial number of small entities. ${ }^{910}$ This certification was incorporated into the Reproposing Release. ${ }^{911}$ The Commission did not receive any comments on this certification.

\section{Response to Dissent}

The Commission has added this section to its release to respond directly to the dissent's claims that the Commission's "statutory interpretations and policy changes are arbitrary, unreasonable and anticompetitive" and that they are "not supported by substantial evidence that, notwithstanding their anti-competitive effect, they are necessary or appropriate to further the

purposes of the Exchange Act." ${ }^{912}$ Previous sections of this release discuss in greater detail the basis of the Commission's decision to adopt Regulation NMS. By modernizing and strengthening the regulatory structure of the U.S. equity markets, Regulation NMS will protect investors, promote fair competition, and enhance market efficiency. Because the dissent appears to have misconstrued a number of the Commission's policy positions and the reasoning underlying them, we are including this section to clarify the record.

\footnotetext{
$910 \quad 5$ U.S.C. 605(b).

$911 \quad$ Reproposing Release, 69 FR at 77496.

912 Dissent of Commissioners Cynthia A. Glassman and Paul S. Atkins to the Adoption of Regulation NMS ("Dissent"), Introduction.
} 
We understand that reasonable minds can disagree with the policy decisions reflected in Regulation NMS. In light of the substantial record, however, the Commission rejects any assertion that this rulemaking is arbitrary, unreasonable, anticompetitive, or otherwise outside the agency's authority. In making this claim, the dissent appears to ignore the clear statutory authority for the Commission's action, the many public comments strongly supporting the adoption of Regulation NMS, and the extensive and comprehensive rulemaking process undertaken by the Commission. As discussed below, the drafters of the Exchange Act itself repeatedly affirmed the basic principles that underlie Regulation NMS. In particular, they specifically contemplated and endorsed the Commission's authority to adopt an intermarket price protection rule. ${ }^{913}$ In addition, the comments supporting Regulation NMS were submitted by a broad spectrum of investors, listed companies, academics, market centers, and other market participants, many of which have extensive experience and expertise regarding the inner workings of the equity markets. ${ }^{914}$

Moreover, Regulation NMS is the culmination of a long and open process that included the original proposals, a public hearing, a supplemental request for comment, the reproposals, eight in-depth analyses of relevant trading data, and more than 2000 public comments. The issues raised by Regulation NMS undoubtedly are multifaceted. Reaching decisions in this complex area requires an understanding of the relevant facts and of the often subtle ways in which the markets work, and the balancing of policy objectives that sometimes may not point in precisely the same direction. Perhaps not surprisingly, there continue to be differences of opinion, even after this long process, among Commissioners, investors, market participants, and

913 See infra, notes 920-922 and accompanying text.

914 See supra, notes 56-59 and accompanying text; infra, notes 939-941, 957-960, and accompanying text. 
the public in general concerning the most appropriate future regulatory structure for the U.S. equity markets.

In sum, the Regulation NMS rulemaking process has required the Commission to grapple with many difficult and contentious issues that have lingered unresolved for many years. The Commission has devoted a great deal of effort to studying these issues, assessing the views of all commenters, and modifying its proposals to respond appropriately to their comments. Indeed, this release discusses at length our response to commenters, particularly those that disagree with the proposals. However, decisions must be made and contentious issues must be resolved so that the markets can move forward with certainty concerning their future regulatory environment and appropriately respond to fundamental economic and competitive forces. The Commission always seeks to achieve a consensus, but when positions have become entrenched after many years of study and debate, waiting for consensus can mean indefinite gridlock that ultimately could damage the competitiveness of the U.S. equity markets, both at home and internationally. The Commission believes that further delay is not warranted and that the time has come to make the difficult decisions necessary to modernize and strengthen the national market system.

\section{A. Statutory Authority for Order Protection Rule}

The dissent suggests that the Commission is exceeding its authority by attempting to impose an "optimal market structure." ${ }^{915}$ This claim misconstrues the nature and impact of the Order Protection Rule and ignores the clear mandate provided to the Commission by Congress in Section 11A(a)(2) of the Exchange Act to facilitate the establishment of a national market system. Regulation NMS does not dictate any particular structure for the markets; rather, it establishes basic "rules-of-the-road" for all markets that will promote competition on terms that

Dissent, text accompanying note 27. 
benefit investors. In particular, competition will be guided by three basic principles - price transparency, open access, and best price. As a result, all investors will be able to ascertain the best prices for NMS stocks, obtain fair and non-discriminatory access to the markets displaying such prices, and have assurance that their orders will be executed at the best prices that are immediately and automatically accessible. Within this regulatory framework of transparency, access, and best price, competitive forces will determine the optimal market structure.

\section{Intermarket Price Protection Rule}

The dissent cites a selected few passages from the legislative history of the 1975 Amendments ${ }^{916}$ to the Exchange Act as support for the claim that an intermarket price protection rule is inconsistent with the Exchange Act. ${ }^{917}$ A more complete review of the legislative history, however, makes it clear that the Order Protection Rule is squarely consistent with the policy determinations made by Congress in 1975 - indeed, it may be the dissent's disagreement with those Congressional policy determinations that explains its opposition to the Order Protection Rule. In particular, the national market system is premised on promoting fair competition among individual markets, while at the same time assuring that these markets are linked together in a unified system that promotes competition among the orders of buyers and sellers in individual NMS stocks. The most succinct statement of order competition is found in the House Report on the 1975 Amendments: "Investors must be assured that they are participants in a system which maximizes the opportunities for the most willing seller to meet the most willing buyer."1918 This

$916 \quad$ Pub. L. No. 94-29, 89 Stat. 97 (1975).

$917 \quad$ See, e.g., Dissent, notes 3-5, 51-52.

918 H.R. Rep. 94-123, 94th Cong., 1st Sess. 50 (1975) ("House Report"). 
Congressional mandate for the national market system is not achieved when trades occur at prices inferior to the best quotations that are immediately and automatically accessible.

The dissent appears to focus on the NMS objective of fair competition among markets, without giving appropriate weight to the important Congressional objective of integrating markets into a system that promotes order interaction and the best execution of investor orders. ${ }^{919}$ The House Report gives the following overview of the "goals and principles to serve as a guide" to the Commission that specifically endorses price protection for investor orders:

Briefly stated, these embrace the principles of competition in which all buying and selling interests are able to participate and be represented. The objective is to enhance competition and to allow economic forces, interacting within a fair regulatory field, to arrive at appropriate variations of practices and services. Neither the markets themselves nor the broker-dealer participant in these markets should be forced into a single mold. Market centers should compete and evolve according to their own natural genius and all actions to compel uniformity must be measured and justified as necessary to accomplish the salient purposes of the Securities Exchange Act, assure the maintenance of fair and orderly markets and to provide price protection for the orders of investors. ${ }^{920}$

The establishment of a "fair regulatory field" that will "provide price protection for the orders of investors" is precisely what the Order Protection Rule is designed to do.

Similarly, the Senate Report on the 1975 Amendments emphasizes both competition among markets and integration of those markets into a unified system:

S. 249 would lay the foundation for a new and more competitive market system, vesting in the SEC power to eliminate all unnecessary or inappropriate burdens on competition while at the same time granting to that agency complete and effective powers to pursue the goal to centralized trading of securities in the interest of both efficiency and investor protection. ${ }^{921}$

919 See supra, section I.B (discussion of NMS principles and objectives).

$920 \quad$ House Report at 51.

921 S. Rep. No. 94-75, 94th Cong., 1st Sess. 2 (1975) ("Senate Report"). 
By "centralized trading," the Senate Report did not mean a single market, but rather NMS rules and facilities that link the markets into a unified system to assure best execution of investor orders - the approach incorporated in Regulation NMS. For example, the Senate Report specifically addresses the importance of intermarket price protection:

[A] limited price order is presently "protected" as to price priority on the exchange on which it is held but it is not protected in any way [with] respect to trading on another exchange or in the third market. As a consequence, a limit order for a listed security held in only one of several markets for that security need not be executed before a transaction is effected at the same price or at a price less favorable to the other party in another market. In the Committee's view this is the basic problem caused by fragmentation of the securities markets: the lack of a mechanism by which all buying and selling interest in a given security can be centralized and thus assure public investors best execution. ${ }^{922}$

Consequently, the Commission's challenge in meeting its NMS responsibilities is to

promote both competition among markets and competition among orders, as well as to assure a regulatory structure that is workable and minimizes regulatory costs. Notably, Congress chose not to mandate any particular NMS rules in order to give the Commission greater flexibility to use its expertise in achieving NMS objectives:

The Committee considered mandating certain minimum components of the national market system but rejected this approach. The nation's securities markets are in dynamic change and in some respects are delicate mechanisms; the sounder approach appeared to the Committee, therefore, to be to establish a statutory scheme clearly granting the Commission broad authority to oversee the implementation, operation, and regulation of the national market system and at the same time to charging it with the clear responsibility to assure that the system develops and operates in accordance with Congressionally determined goals and objectives. Section $11 \mathrm{~A}(\mathrm{a})$ and $11 \mathrm{~A}(\mathrm{c})$, taken together, would establish such an arrangement. ${ }^{923}$

$922 \quad$ Senate Report at 17.

923 Senate Report at 8-9. See also H.R. Rep. No. 94-229, 94th Cong., 1st Sess. 92 (1975) ("Conference Report") (adopting Senate approach to "provide maximum flexibility to the Commission and the securities industry in giving specific content to the general concept of the national market system"). 
Although the dissent may disagree with the policy of an intermarket price protection rule, there is no basis for the claim that Regulation NMS is at odds with the Commission's statutory mandate to facilitate the establishment of a national market system.

\section{Long-Term Investors}

The dissent questions the Commission's authority to give precedence to the interests of long-term investors in those limited contexts where their interests conflict with the interests of short-term traders. ${ }^{924}$ As is discussed elsewhere in this release, ${ }^{925}$ the interests of long-term investors and short-term traders in fair and efficient markets coincide most of the time. In those few contexts where the interests of long-term investors directly conflict with short-term trading strategies, we believe that, in implementing regulatory structure reform, the Commission has both the authority and the responsibility to further the interests of long-term investors, and that the record provides substantial support for the Commission's determination to further their interests.

As discussed above, intermarket price protection will significantly benefit the more than 84 million individual investors in the U.S. equity markets by reducing their transaction costs and thereby enhancing their long-term investment returns. ${ }^{926}$ Price protection may, however,

Dissent, section IV. Many short-term trading strategies are conducted by registered broker-dealers, such as specialists and market makers. Despite the dissent's repeated references in section IV to both short-term investors and market intermediaries, we do not believe the dissent means to suggest that the Commission lacks authority under the Exchange Act to give precedence to the interests of long-term investors over market intermediaries.

926 See supra, text accompanying notes 25-26 (survey finding that more than 84 million individuals representing more than $50 \%$ of American households own equity securities, directly or indirectly, and that nearly all view their equity investments as savings for the long-term). 
interfere to some extent with the extremely short-term trading strategies that can depend on millisecond response times from markets for orders taking displayed liquidity. It also may interfere with short-term trading strategies that benefit from volatile and illiquid markets. The dissent claims that the "length of time an individual owns a stock is not a relevant factor in distinguishing among groups of investors" and that the distinction between long-term investors and short-term traders is arbitrary and unreasonable. ${ }^{927}$ But in those limited contexts where the interests of long-term investors conflict with short-term trading strategies, the conflict cannot be reconciled by stating that the NMS should benefit all investors. In particular, failing to adopt a price protection rule because short-term trading strategies can be dependent on millisecond response times would be unreasonable in that it would elevate such strategies over the interests of millions of long-term investors - a result that would be directly contrary to the purposes of the Exchange Act. ${ }^{928}$

As discussed earlier in this release, ${ }^{929}$ the legislative history of the Exchange Act from its adoption in 1934 emphasizes the Congressional concern to protect the interests of the many average investors who are not active traders or market intermediaries, but who depend on their equity investments, whether directly in corporate stocks or indirectly through their investment in mutual funds and retirement accounts, to meet their long-term financial goals. The dissent suggests that these statements of Congressional concern for millions of average investors were

$927 \quad$ Dissent, section IV.

928 See, e.g., Exchange Act Section 11A(a)(1)(C) ("It is in the public interest and appropriate for the protection of investors and the maintenance of fair and orderly markets to assure," among other things, "the economically efficient execution of securities transactions" and "the practicability of brokers executing investors' orders in the best market.").

Supra, section I.B.2. 
no longer relevant when Congress adopted the 1975 Amendments, but the legislative history of the 1975 Amendments does not support this proposition. ${ }^{930}$

The dissent also argues that short-term traders often provide liquidity to the market and thereby benefit long-term investors. The Commission certainly agrees with this statement as a general matter, but believes that, in the specific context of an intermarket price protection rule, directly promoting the display of limit orders, which directly provide liquidity to the market, rather than promoting short-term trading strategies that require millisecond response times for orders that take displayed liquidity, is the most appropriate approach to protect investors and enhance market efficiency. Many commenters agreed with this policy decision. For example, T. Rowe Price stated that "we do not believe that speed of access considerations should drive market structure issues if to do so would jeopardize legitimate market linkage initiatives. Connected markets provide the opportunity for information gathering, block trading, and improved price discovery, as well as the legitimacy of the 'last-sale' price. While speed of access and execution are crucial, there is a limit to how fast such linkages need to be in order to protect and enhance our markets." 931 Similarly, the Committee on Investment of Employee Benefit Assets, which represents 110 of the nation's largest corporate retirement funds managing \$1.1 trillion on behalf of 15 million plan participants and beneficiaries, stated that "it is unclear with the advance of automation why we would need or should allow anything other than the best price requirement for investors. Our constituency is concerned with long-term growth and market

930 See, e.g., Conference Report at 91 ("The securities markets of the United States are an important national asset. Under the system of Federal regulation established in the 1930's, these markets have flourished. They have provided a means for millions of Americans to share in the profits of our free enterprise system and have facilitated the raising of capital by new and growing businesses.").

T. Rowe Price Reproposal Letter at 2. 
stability and the ability to opt-out [of the best price requirement] could place long-term investors at a disadvantage." ${ }^{932}$ Finally, the National Association of Investors Corporation emphasized that "[m]ake no mistake, the best price best serves investors. It is part of the value equation when buying and selling stock. Please keep in mind that individual investors are long-term investors and price is of utmost importance to them." ${ }^{933}$ Although the dissent may disagree with the policy views of these commenters on the best means to protect investors and to promote market integrity and liquidity, it does not provide a basis for concluding that the commenters' views, which the Commission shares, are arbitrary or unreasonable.

\section{B. Basis for Adoption of Order Protection Rule}

A prior section of this release discusses at length the Commission's basis for adopting the Order Protection Rule. ${ }^{934}$ This section responds to certain specific claims made in the dissent where the dissent appears to have misconstrued the Commission's decision-making process and conclusions, and highlights the critical policy issues on which the views expressed in the dissent simply conflict with the considered views of the Commission and many commenters.

The dissent asserts that the Commission's objectives for the Order Protection Rule have been "a moving target, morphing from the protection of limit orders, to the need to increase market depth and liquidity, to the reduction of transaction costs for long-term investors and

932 Letter from Gary A. Glynn, Chairman, Committee on Investment of Employee Benefit Assets, to Jonathan G. Katz, Secretary, Commission, dated Jun. 24, 2004 ("CIEBA Letter") at 1.

933 Letter from Kenneth S. Janke, Chairman, National Association of Investors Corporation, to Jonathan G. Katz, Secretary, Commission, dated Jun. 24, 2004 ("NAIC Letter") at 1. Supra, section II.A. 
issuers." ${ }^{935}$ In fact, the Commission's objectives have remained consistent throughout the NMS rulemaking. ${ }^{936}$ While certain details in the original proposal have been modified to respond appropriately to public comment, the policies underlying the Rule as proposed, reproposed, and adopted have remained the same. Indeed, the dissent seems not to appreciate that the "moving targets" it identifies - the objectives of protecting limit orders, increasing market depth and liquidity, and reducing investor transaction costs - are all quite closely inter-related. As the Commission has explained quite consistently in this release and in the proposing releases, protecting limit orders contributes to market depth, which in turn reduces investor transaction costs. In addition, the Commission has consistently emphasized that intermarket price protection will promote the best execution of investor orders and fair and orderly markets. ${ }^{937}$

\section{Investor Protection}

As discussed previously in this release ${ }^{938}$ the Commission believes that the Order Protection Rule is needed to strengthen the protection of investors in the U.S. equity markets. Many commenters agreed with the Commission on the need for strengthened price protection to protect investors. For example, the Consumer Federation of America believed that "the brokers' duty of best execution is simply too vague to serve as an effective deterrent to abuse. It is too

935 Dissent, section I. The dissent asserts that the Commission has sought to reduce transaction costs for issuers. Stated more accurately, the Commission has sought to reduce transaction costs for investors, which would thereby help reduce the cost of capital for the listed companies in which they invest. See supra, note 15 and accompanying text.

936 For example, the Proposing Release emphasized that one of the three overarching objectives of the proposals was to "promote greater order interaction and displayed depth," thereby reducing the price impact costs of large, institutional investors. Proposing Release, 69 FR at 11129.

Id. at 11132 .

938 See supra, section II.A.1. 
vague for the broker to know with certainty that it has satisfied its best execution obligation and too vague to be enforced consistently and effectively. In fact, one of the real benefits of the proposed trade-through rule is that it has the potential to simplify compliance with best execution rules." ${ }^{1939}$ The Committee on Investment of Employee Benefit Assets also recognized the vital importance of maintaining equity markets in which all investors can participate with confidence: "[I]n light of the scandals in the securities and mutual fund industries, our first priority should be to restore investor confidence in our capital markets. To allow trading to take place outside of the best price will continue to raise questions of fairness and could diminish investor confidence."1940 Other commenters shared these concerns about the impact of trade-throughs on investor confidence in the fairness of the U.S. equity markets. ${ }^{941}$

\section{$939 \quad$ Consumer Federation Letter at 4.}

$940 \quad$ CIEBA Letter at 2.

941 See, e.g., BSE Reproposal Letter at 2 ("The Exchange believes that the reproposed TradeThrough Rule is critical to the protection of customer limit orders through 'protected quotes' for all securities. . . . Minimum investor protection principles should not be bifurcated on the basis of whether a security trades in either a listed or NASDAQ environment."); Letter from James W. Vitalone, Chair, U.S. Advocacy Committee, and Linda L. Rittenhouse, CFA Institute - Advocacy, to Jonathan G. Katz, Secretary, Commission, dated Sep. 22, 2004 ("CFA Institute Letter") at 1 ("We believe that the current way of doing business has become a system permeated with trading practices that often obfuscate the manner in which best price is determined or how some limit orders are filled. Thus, we strongly support and urge reforms that will bring uniformity and transparency to the current system, ultimately leveling the playing field as much as possible among market participants. To this end, we support a trade-through rule that applies to all securities."); Letter from Lawrence E. Harris, Marshall School of Business, University of Southern California, to Jonathan G. Katz, Secretary, Commission, dated Feb. 5, 2005 ("Harris Reproposal Letter") at 7 ("The proposed trade-through rule would prevent exchanges from trading through exposed electronically accessible orders at another exchange. In principle, such rules should not be necessary because traders generally will access liquidity wherever it is cheapest. In practice, dealers, brokers, and exchanges sometimes do trade through other orders since it is generally in their selfinterest to control an execution rather than share it. Accordingly, the primary benefit of the proposed trade-through regulation will be to promote investor protection."); NAIC Letter at 1 ("Having confidence that one is receiving the best price in stock transactions 
The dissent, however asserts that the Trade-Through Study prepared by Commission staff to estimate trade-through rates does not substantiate investor protection concerns. ${ }^{942}$ The dissent further suggests that the Commission has "cherry-picked" statistics that support its position, while ignoring, or even failing to disclose, statistics that do not support its position. ${ }^{943}$ While the Commission believes that the total number of trade-throughs should not be the sole consideration in making its policy choices, an earlier section of this release discusses in detail the data demonstrating the significance of trade-through rates found in the Study, ${ }^{944}$ and that discussion makes clear that the Commission has not ignored or failed to disclose the findings of the TradeThrough Study. Indeed, at the time the Reproposing Release was published, the Study was placed in the public file specifically to assure that all commenters had a full opportunity to evaluate its data and methodologies.

The Study used a variety of calculation methodologies that generated many different statistics on trade-through rates, but summarized its findings as follows: "Depending on the methodology applied, the overall trade-through rate ranged from $2 \%$ to $10 \%$ of trades and from $2 \%$ to $13 \%$ of share volume. Using the more conservative of these methods, we estimate that $2 \%$

contributes greatly to the confidence that investors have in the fairness and integrity of the marketplace."); Phlx Reproposal Letter at 1 ("Phlx believes that intermarket protection of firm and accessible quotes is not only necessary, but should foster a more efficient marketplace, which is consistent with protecting investors and the public interest.").

942 The Trade-Through Study is described in note 66 above.

943 Dissent, section II.A.

944 Supra, section II.A.1.a.ii. As discussed above, different measures of trade-through rates are relevant for assessing the extent to which the Order Protection Rule is needed to achieve the objectives of best execution of market orders, fair and orderly treatment of limit orders, and greater depth and liquidity for NMS stocks, respectively. 
to $3 \%$ of all trades and $2 \%$ to $8 \%$ of all share volume are trade-throughs." 945 The Reproposing Release explained why the Commission believed that the most relevant measure is $2.5 \%$ of total trades, representing more than $7 \%$ of total share volume, that trade through the best displayed prices. The Reproposing Release also explained the deficiency of the dissent's preferred measure - the displayed size of quotations that are traded through. This measure primarily reflects the current shortage of displayed size, which is a symptom of one of the primary problems that the Order Protection Rule is designed to address. ${ }^{946}$ It therefore is not a useful means to assess the potential upside of strengthened price protection.

The dissent also asserts that the Trade-Through Study did not indicate "that investors are not obtaining best execution, that their orders are being unfairly treated, or that investors are otherwise suffering economic harm." ${ }^{947}$ The Study, however, found that $2.5 \%$ of trades in Nasdaq stocks do not receive the best prices that are immediately and electronically accessible and that the average amount by which such trades miss the best prices is 2.3 cents per share. ${ }^{948}$ In addition, Nasdaq submitted statistics with its comment letter on the reproposal indicating that the trade-through rate for dealers that internalize customer orders in Nasdaq stocks was 3.2\% in 2003. The dissent attempts to minimize the seriousness of these statistics on a variety of grounds, but it concedes that the trade-through rate for customers in Nasdaq stocks was between

945 Trade-Through Study at 1 (emphasis in original).

$946 \quad$ Reproposing Release, 69 FR at 77443.

947 Dissent, section II.A.

$948 \quad$ Trade-Through Study at 3. 
$1 \%$ and 2\% in 2004 and states that "these numbers speak for themselves" that customers are not being treated unfairly. ${ }^{949}$

Even if the Commission accepted the dissent's focus on a limited portion of the rulemaking record, we strongly believe that the evidence contained in this record would raise serious investor protection concerns. Because of the enormous volume of trading in the U.S. equity markets, even small percentages can translate into significant harm to investors. For example, even a 1.5\% trade-through rate for customers in Nasdaq stocks in 2004 would mean that 14.3 million customer orders received a price that was inferior to an immediately and automatically accessible quotation. ${ }^{950}$ Because of the difficulties faced by retail investors in monitoring whether their orders receive the best prices, it is likely that a great many of these customers were not aware that they in fact received an inferior price for their order. ${ }^{951}$ We suspect that the millions of customers who received inferior prices, had they known, would believe that they had been treated unfairly.

Moreover, the dissent does not appear to take into account the practical difficulties faced by retail customers in monitoring and obtaining best execution of their orders. Such difficulties vary depending on the type of order. As discussed previously in this release, ${ }^{952}$ retail customers

949 Dissent, text following note 47.

950 More than 955 million trades were reported in 2004 by the consolidated market data network for Nasdaq stocks.

951 The difficulties faced by retail investors in monitoring the execution quality of their market orders are discussed further above in the text accompanying note 53.

952 See supra, text accompanying note 53. See also J.P. Morgan Reproposal Letter at 3 ("[P]rincipal agent conflicts can lead to less than best execution, particularly for retail investors who may not have the sophistication or resources to assess the quality of the trades provided by their agents. By prohibiting the execution of orders at prices inferior to those displayed, a trade-through rule can therefore help provide protection to limit orders and further encourage their use.") 
who submit market and marketable limit orders seeking the best available market price generally can ascertain the best quotations at the time they submit their orders, but quotations can change rapidly, thereby making it quite difficult for customers to know whether their orders were in fact executed at the best quotations at the time of order execution. ${ }^{953}$ In contrast, retail customers who display non-marketable limit orders at the best prices can readily see when their orders are traded through - the inferior trade prices will be disseminated in the consolidated trade stream. ${ }^{954}$ These customers legitimately may feel that their orders have not been treated in a fair and orderly fashion. By establishing strong intermarket price protection, the Order Protection Rule will benefit investors who use both types of orders. It will promote the execution of investor market orders at the best prices on an order-by-order basis, ${ }^{955}$ as well as protect displayed limit orders, no matter how small or large their displayed size, from trade throughs. In both contexts, the Rule will significantly enhance the protection of investors in all NMS stocks.

\section{Improved Depth and Liquidity in Nasdaq Stocks}

The dissent asserts that there is no evidence of a need for greater depth in Nasdaq stocks that would warrant application of the Order Protection Rule. ${ }^{956}$ In making this assertion, the

$953 \quad$ Cf. Dissent, note 42 ("the majority fails to acknowledge that retail investors have access to consolidated information that allows them to monitor their executions").

$954 \quad$ Cf. Dissent, note 44 (questioning the basis for the Commission's assertion that retail investors are not given a level playing field when their displayed limit orders are bypassed by large, block trades and stating that the assertion is "also inconsistent with the majority's previous assertion that investors have difficulty monitoring execution quality").

955 See supra, notes 341-344 and accompanying text (duty of best execution not interpreted as requiring order-by-order routing by brokers with large volume of customer orders).

956 Dissent, section II.B. The dissenters imply that a need for greater depth was the only basis relied on by the Commission for applying the Order Protection Rule to Nasdaq stocks. Dissent, text accompanying note 52. As discussed in the preceding section, the Commission believes that enhancing investor protection, particularly for retail investors, 
dissent does not address the views of many commenters that intermarket price protection is needed to improve depth and liquidity in all NMS stocks, including those listed on Nasdaq. For example, the Investment Company Institute, whose members account for more than 95\% of all U.S. mutual fund assets, noted that "[b]y affirming the principle of price priority, a trade-through rule should encourage the display of limit orders, which in turn would improve the price discovery process and contribute to increased market depth and liquidity." ${ }^{157}$ It therefore "strongly recommend[ed] that the Commission adopt a uniform trade-through rule that applies across all market centers and to all types of securities, including Nasdaq-listed securities."958 Similarly, the Bank of New York stated that "[w]e agree with the Commission that a uniform trade-through rule would encourage the use of displayed limit orders and aggressive quotation. In the market for Nasdaq securities, for example, many investors are reluctant to show their full trading interest for fear of having others use that information to their detriment. A uniform trade-through rule would incentivize these investors to display their interest, knowing their order must be filled before the next-priced order. Accordingly, a well-formulated trade-through rule will promote transparency and liquidity in the national market system." ${ }^{159}$ Many other commenters similarly believed that an intermarket price protection rule is needed to promote market depth and liquidity in all NMS stocks. ${ }^{960}$

is a compelling reason to apply the Order Protection Rule consistently across all NMS stocks.

957 ICI Reproposal Letter at 2.

$958 \quad$ Id. at 3.

$959 \quad$ BNY Letter at 2.

960 See, e.g., American Century Letter at 2 ("[W]e support the establishment of a uniform trade-through rule for all securities across all market centers within the National Market System."); Letter from Yakov Amihud, New York University, and Haim Mendelson, 
In addition to not addressing the views of commenters, the dissent does not refute the significance of data analyses prepared by Commission staff to assess the views of commenters that intermarket price protection is needed to promote depth and liquidity in Nasdaq stocks. First, the dissent does not mention the staff studies that found that short-term price volatility is

Stanford University, to Jonathan G. Katz, Secretary, Commission, dated Jan. 25, 2005 ("Amihud/Mendelson Reproposal Letter"), Attachment at 14 ("The BBO Alternative is most potent in protecting the interests of small, uninformed investors. This will induce their participation in the stock market and thus will make the market more liquid."); Capital Research Letter at 2 ("We believe providing price protection will create an incentive for buyers and sellers to display their intentions. This will generate a more accurate reflection of true supply and demand, which will enhance price discovery. We also believe that this will lead to an increased use of limit orders outside the best bid and offer which will increase depth in the market and dampen volatility. For this reason we favor a trade-through rule."); Consumer Federation Letter at 2 ("The lack of a tradethrough rule in the Nasdaq market has unquestionably contributed significantly to fragmentation in that market, by allowing practices such as internalization and payment for order flow that prevent substantial pockets of orders from interacting with the broader market while leaving limit orders that set the best price unfilled. ... [W]e believe a universal trade-through rule will not only benefit the investors who have their limit orders filled as a result, but also will benefit the market as a whole, through increased liquidity, improved price discovery, and tighter spreads."); Deutsche Bank Reproposal Letter at 1-2 ("DBSI agrees with the Commission that limit orders are critically important to our markets, and we believe that readily accessible limit orders should be protected. In our view, protection means that the first mover who commits to offer liquidity at a particular price point should be rewarded with the assurance that others in the marketplace cannot overlook that price and trade at an inferior price."); Global Electronic Trading Company Reproposal Letter at 2 ("The BBO Alternative and electronic efficiencies will have a positive impact on the economy by increasing market efficiency and, thereby, GDP."); Interactive Brokers Group Reproposal Letter at 1 ("We strongly support adoption of proposed Regulation NMS, which is a common sense and long-overdue update of the national market system rules in light of the major technological changes that have taken place in the equity markets in the last three decades."); Vanguard Reproposal Letter ("We agree with the Commission that an intermarket trade-through rule should be applied to Nasdaq stocks to strengthen price protection."); Weaver Reproposal Letter ("I also urge the commission to extend the rule to NASDAQ stocks. Clearly establishing price as the primary priority rule in markets will encourage the submission of limit orders, leading to lower execution costs for investors, and consequently lowering the cost of capital for traded firms."). 
significantly higher in Nasdaq stocks than in NYSE stocks. ${ }^{961}$ Excessive short-term price volatility indicates a need for greater depth and liquidity to dampen price fluctuations. Although acknowledging that the drafters of the 1975 Amendments identified "the maintenance of stable and orderly markets with maximum capacity for absorbing trading imbalances without undue price movements" as one of the "paramount" objectives for the NMS, ${ }^{962}$ the dissent does not address the staff volatility analyses indicating the need to address price volatility in Nasdaq stocks. ${ }^{963}$

Second, the dissent fails to appreciate the significance of staff studies examining fill rates and other order execution quality statistics for marketable limit orders in Nasdaq stocks. ${ }^{964}$ The

961 The relevant studies are the Volatility Study and the Supplemental Volatility Study prepared by the Commission's Office of Economic Analysis, described in notes 143-144 above. Dissent, note 30 (quoting Senate Report on 1975 Amendments).

963 Dissent, section II.B. The dissenters also imply that minimizing price volatility and enhancing depth and liquidity are not encompassed within the five broad objectives for the NMS specified in Exchange Act Section 11A(a)(1)(C). Dissent, text accompanying notes $30,50-52$. In fact, both minimizing price volatility and enhancing depth and liquidity are essential elements for achieving the broad objective of assuring the "economically efficient execution of securities transactions." Section 11A(a)(1)(C)(i). Both elements help reduce investor transaction costs and thereby promote efficient trading. See Conference Report at 91-92 ("The basic goals of the Exchange Act remain salutatory and unchallenged: To provide fair and honest mechanisms for the pricing of securities, to assure that dealing in securities is fair and without under preferences or advantages among investors, to ensure that securities can be purchased and sold at economically efficient transaction costs, and to provide, to the maximum degree practicable, markets that are open and orderly.") (emphasis added). The implicit costs associated with the prices at which transactions are executed represent one of the most significant elements of investor transaction costs. See supra, text accompanying notes 300-302.

964 The relevant studies are the Matched Pairs Study, prepared by the Commission's Office of Economic Analysis, and the S\&P Index Study and the Nasdaq-100 Index Supplemental Study, prepared by the Commission's Division of Market Regulation, described in notes 114 and 137 above. The significance of marketable limit orders in the 
dissent incorrectly interprets the Commission's evaluation of these studies as critical of the trading strategy of submitting "pinging" orders - orders with sizes greater than the displayed size of quotations. ${ }^{965}$ The Commission's evaluation of low fill rates in Nasdaq stocks is not a criticism of pinging orders. The use of pinging orders is a valid strategy for trading stocks on electronic markets and certainly will continue after implementation of the Order Protection Rule. Indeed, an important goal of the Rule is to improve the execution quality for such orders by increasing their fill rates and, thereby, the ability of investors to trade Nasdaq stocks in larger sizes. As discussed earlier in this release, ${ }^{966}$ the important consideration is not that fill rates in Nasdaq stocks are lower than fill rates in NYSE stocks. This difference likely is explained by broad structural differences unrelated to market efficiency. Rather, the problem is that fill rates, as well as the executed share volume, in Nasdaq stocks for orders with sizes ranging from 2,000 to 9,999 shares are very low in absolute terms (falling as low as $12 \%$ to $27 \%$ ), even for many active stocks included in the Nasdaq-100 Index. ${ }^{967}$ The Commission believes that this data supports the views of commenters that intermarket price protection is needed to promote greater depth and liquidity across the whole range of Nasdaq stocks.

\section{Effectiveness of Order Protection Rule}

The dissent suggests that the Order Protection Rule will not meet its goals because some trade-throughs will continue even after implementation of the Rule. The dissent notes that the Rule contains exceptions for intermarket sweep orders, flickering quotations, trading centers that

market for Nasdaq stocks is addressed at length elsewhere and will not be repeated here. See supra, text accompanying notes 121-123.

965 Dissent, text accompanying notes 57-58.

966 Supra, text accompanying notes 132-136.

967 See supra, text accompanying notes 138-139. 
are experiencing a material delay, volume weighted average price ("VWAP") orders, and stopped orders, and questions whether, given these exceptions, the Rule will lead to a significant reduction in trade-through rates. ${ }^{968}$

The dissent fails to appreciate both the methodology of the staff study of trade-through rates and the operation of the Order Protection Rule. As explained at length earlier in this release, ${ }^{969}$ the staff used a conservative methodology in the Trade-Through Study that did not include trade-throughs attributable to intermarket sweep orders, flickering quotations, and VWAP trades in its calculation of trade-through rates. Thus, given the consistency between the Study's methodology and the Rule's exceptions, the Commission believes that implementation of the Rule will lead to the elimination of the great majority of the types of trade-throughs found in the Trade-Through Study. ${ }^{970}$

Moreover, the exceptions in the Order Protection Rule are fully consistent with the principle of price protection. For example, to comply with the exemptions for intermarket sweep orders, VWAP orders, and stopped orders as a practical matter, market participants must trade with, rather than trade through, the displayed size of protected quotations. ${ }^{971}$ Intermarket sweep orders must, by definition, be routed to execute against the full displayed size of protected quotations, while the dealers that execute VWAP and stopped orders typically will execute trades in the public markets to establish the positions necessary to fill the orders. In addition, the exceptions for flickering quotations and trading centers experiencing a material delay are

968 Dissent, section III.A.

969 Supra, section II.A.1.a.

$970 \quad$ See supra, notes 61-63 and accompanying text.

971 See supra, notes 220-221, 249-257, and accompanying text. 
consistent with intermarket price protection because they are designed to exclude quotations that are not truly accessible. The existence of these exceptions, therefore, will not detract from the effectiveness of the Rule in strengthening price protection.

The dissent also states that the Order Protection Rule will not increase market depth and liquidity because the Rule does not provide what the dissent views as complete protection of limit orders. ${ }^{972}$ In particular, it points to the Commission's decision to protect only quotations that are the best bids and offers ("BBOs") of markets, and to the ability of markets to match the best prices displayed in other markets. The Commission's reasons for protecting market BBOs are discussed in detail earlier in this release. ${ }^{973}$ The practice of price matching, by definition, does not cause investors to receive inferior prices or result in trade-throughs of displayed quotations. Most importantly, the dissent's assertion that the other approaches might have given greater protection to limit orders does not dispose of the relevant question, which is whether strengthening the current level of price protection for market BBOs will lead to greater depth and liquidity. $^{974}$

\section{Promoting Competition}

The dissent claims that the Order Protection Rule will limit competition, stifle innovation, and create regulatory barriers to entry. The dissent argues that intermarket protection of the best accessible prices will "reduce markets to the lowest common denominator." 975 As discussed in an earlier section of this release, the Commission believes that markets will continue to have

\footnotetext{
972 Dissent, section III.C.

973 Supra, section II.A.5.

974 See, e.g., supra, notes 56-59, 957-960, and accompanying text (commenters supporting adoption of Order Protection Rule to promote depth and liquidity).

975 Dissent, section V.A.1.
} 
strong incentives to compete and innovate, particularly to be the first preference of order routers at any given price and thereby maximize their share of trading volume. ${ }^{976}$ Liquidity providers will be able to compete on both price and size through use of the intermarket sweep order exception, which will allow them to execute immediately a large transaction at prices outside the best prices by routing orders to execute against the displayed size of better-priced quotations. ${ }^{977}$ Finally, the Order Protection Rule will promote competition among markets by assuring new or smaller markets that, if they display the best prices, they will attract order flow, because larger, dominant markets will not be allowed to ignore their quotations. New or smaller markets also will benefit from the price transparency and open access elements of Regulation NMS, which preclude dominant markets from unreasonably restricting the availability of their market information or unfairly discriminating against competing markets by denying access to their displayed quotations.

The dissent also claims that the Order Protection Rule will create barriers to competition and regulatory barriers to entry, largely because the Rule protects quotations that are displayed by SROs registered under the Exchange Act. ${ }^{978}$ Here, however, the dissent appears to take issue with one of the most basic elements of the Exchange Act regulatory scheme - the equity market

976 Supra, section II.A.4.a. See also Bear Stearns Reproposal Letter at 2 (Market BBO alternative "accomplishes the right balance for trade-through protection because it encourages competitive quoting behavior both within and among markets, without imposing excessive routing obligations and related costs on receiving trading centers."); CHX Reproposal Letter at 3 ("[T]he Market BBO Alternative provides an ideal balance; it recognizes the importance of preserving essential price protections, while permitting market centers to control costs and to preserve intermarket competition."); Letter Type J (Letter submitted by 548 commenters stating that protecting the best bid and offer in each market center preserves both competition among markets and competition among quotations "in a way that benefits all securities industry participants."). See supra, text accompanying notes 249-250.

Dissent, sections V.A.3 and V.A.4. 
registration requirement. Congress enacted this registration requirement in 1934 to assure that all significant equity markets have the capacity and integrity to meet their responsibilities to protect investors and promote the public interest. The Commission strongly believes that this basic registration requirement is an essential element of any effective scheme of securities regulation. Consistent with this requirement, the SROs for many years have been responsible for collecting quotations and disseminating them to the public in the consolidated quotation stream. Broker-dealers and ATSs can participate in the consolidated quotation stream by providing their quotations to an SRO. They will continue to be able to do so after implementation of the Order Protection Rule and, to the extent their quotations constitute the best bids or offers of the SRO, such quotations will be protected. Moreover, small ATSs with less than $5 \%$ of trading volume are exempted from participation in the consolidated quotation stream, thereby reducing barriers to entry for new markets. ${ }^{979}$ But these aspects of the U.S. regulatory scheme all flow from the basic Exchange Act registration requirement for significant equity markets, not Regulation NMS.

\section{Scope of Order Protection Rule}

The dissent argues that the scope of the Order Protection Rule has been substantially expanded beyond the reproposal without the benefit of the normal notice and comment process, and further states that the "practical effect is that market participants must exhaust liquidity in reserve prior to moving to the next price level." ${ }^{980}$ Both of these assertions are incorrect. The scope of the Order Protection Rule has not been expanded from the reproposal, nor does the Rule, as reproposed or adopted, require market participants to route orders to execute against reserve size or any other liquidity that is not displayed. As reproposed and adopted, the Rule

979 See supra, text accompanying notes 385-386.

980 Dissent, text following note 63. 
protects the best displayed prices of protected quotations, without regard to their sizes, ${ }^{981}$ but provides an exception for transactions at inferior prices if intermarket sweep orders simultaneously are routed to execute against the "full displayed size" of the protected quotations. $^{982}$ Therefore, the removal of references to size in the definition of quotation has no effect on the operation of the Rule as adopted.

Market participants will not be required to route oversized orders in an attempt to execute against reserve size, as the dissenters claim. While a technical correction to a reproposed Regulation NMS definition has been made, it does not raise a notice and comment issue. A clause was deleted from the definition of "quotation" in reproposed Rule 600(b)(63), but this clause was not relevant to the Order Protection Rule or to any other rule in Regulation NMS, as reproposed or adopted. ${ }^{983}$

981 For example, "trade-through" is defined in adopted Rule 600(b)(77), as it was in the reproposal, solely with respect to price - "the purchase or sale of an NMS stock during regular trading hours, either as principal or agent, at a price that is lower than a protected bid or higher than a protected offer." This definition is unchanged from the reproposal.

982 Rule 600(b)(30) defines an "intermarket sweep order" as requiring, among other things, that limit orders be "routed to execute against the full displayed size of any protected bid, in the case of a limit order to sell, or the full displayed size of any protected offer, in the case of a limit order to buy, for the NMS stock with a price that is superior to the limit price of the limit order identified as an intermarket sweep order." This definition is unchanged from the reproposal.

983 Reproposed Rule 600(b)(63) provided that "quotations and quotation information means bids, offers and, where applicable, quotation sizes and aggregate quotation sizes." As adopted, Rule 600(b)(62) simply defines "quotation" as "a bid or an offer." The deleted language currently is found only in a definition from Exchange Act Rule 11Ac1-2(a)(5), which Rule has been entirely rewritten and redesignated as Rule 603 in Regulation NMS. See supra, section V.B.3.c. The new Rule does not use the terms "quotation information," "quotation sizes," or "aggregate quotation sizes," and therefore the deleted language now is obsolete. The language was inadvertently left in the definition of "quotation" in the reproposal and has been deleted as a technical correction. Its deletion does not change the substantive operation of the reproposed or adopted Order Protection Rule. 
The dissent minimizes the role of the intermarket sweep order exception in the operation of the adopted Order Protection Rule. It states that, under the Rule as reproposed, "trading centers could route an order to a protected quotation's full displayed size and simultaneously execute an order at an inferior price," and then implies that this practice is no longer allowed under the adopted Rule. ${ }^{984}$ But simultaneously executing orders at multiple price levels is precisely what the intermarket sweep order exception allows under the reproposed and adopted Rule. Regardless of the dissent's position, there is no indication that commenters were confused concerning the importance of the exception or operation of the Rule. ${ }^{985}$

\section{Benefits and Costs of Order Protection Rule}

The dissent states that the Commission's estimate of \$321 million in annual benefits to investors from the Order Protection Rule constitutes a "mere rounding error" compared to the \$18.7 trillion in total dollar value of trading in $2003 .{ }^{986}$ However, the dissent also states that \$143.8 million in one-time start-up costs and \$22 million in annual costs to comply with the Rule, which ultimately will be paid by investors, are "very high." ${ }^{987}$ These statements appear to

$984 \quad$ Dissent, text following note 63.

985 See, e.g., Letter from Adam Cooper, Senior Managing Director and General Counsel, Citadel Investment Group, L.L.C., to Jonathan G. Katz, Secretary, Commission, dated Jan. 26, 2005 ("Citadel Reproposal Letter") at 2-3 ("The proposed intermarket sweep exception addresses most of Citadel's concerns about the Commission's initial tradethrough proposal, and would have many benefits.... [T]his exception would increase execution speed and reliability because it would allow market participants to simultaneously and immediately sweep through multiple price levels."); SIA Reproposal Letter at 20 ("We continue to believe that an exception for intermarket sweep orders is imperative for the proper functioning of the trade-through rule and for the facilitation of various beneficial trading strategies, including smart routing and block trading. Therefore, we applaud the SEC's decision to include such an exception in its Reproposal.").

Dissent, text accompanying note 41 .

987 Dissent, section V.C. 
be inconsistent. If more than $\$ 300$ million in net annual benefits is an inconsequential amount to investors, why is less than one-half of that amount in one-time start-up costs a significant burden for investors?

In fact, of course, both of the amounts are substantial, and the dissent has used an "apples-to-oranges" comparison. The \$321 million amount measures the estimated reduction in investor transaction costs. Even the total amount of transaction costs will always be a fraction of the total dollar volume of trading in the U.S. equity markets. Indeed, if transaction costs were ever to represent a large proportion of the total dollar volume of trading, investors would cease to trade, liquidity would dry up, and the cost of capital for listed companies would be prohibitive. All transaction costs, however, eat away at the long-term returns of investors. One of the keys to successful long-term investing is to minimize, wherever possible, transaction costs of all kinds. Even under the conservative estimate used in the Commission's cost-benefit analysis, which is based on the dissent's preferred trade-through measure - the share volume of quotations that are traded through ${ }^{988}$ - investors would benefit over a five-year period by a total of more than $\$ 1.3$ billion. ${ }^{989}$ Moreover, this estimate is conservative because it does not include any benefits for investors that would result from improved market depth and liquidity, ${ }^{990}$ nor does it reflect the

$988 \quad$ See Dissent, text accompanying note 33; Trade-Through Study at 3 (\$321 million "includes only share volume that traded through depth displayed on market center's top of book").

989 The estimated net benefits of more than $\$ 1.3$ billion over a five-year period are calculated by deducting the estimated annual costs of compliance of $\$ 22$ million from the estimated annual benefits of $\$ 321$ million, multiplying by five, and then deducting the estimated one-time start-up costs of $\$ 143.8$ million.

990 As discussed in section II.A.6 above, even small percentage improvements in depth and liquidity can generate enormous dollar benefits for investors in the form of reduced transaction costs because the total amount of transaction costs incurred each year by investors is so large. Such costs were conservatively estimated earlier in this release at more than $\$ 30$ billion annually. Supra, text accompanying notes 300-305. Others have 
non-monetary benefits associated with enhanced investor confidence in the fairness and orderliness of the equity markets. The Commission believes that all of these benefits amply justify the costs of the Order Protection Rule.

\section{Alternatives to Order Protection Rule}

The dissent states that the Commission did not seriously consider alternatives to the Order Protection Rule. ${ }^{991}$ It suggests that the Commission first could have adopted only access standards, and then adopted a price protection rule later if deemed necessary, or, alternatively, that the Commission could have adopted a price protection rule in stages for some markets, while waiting to evaluate its effect before applying the rule to other markets. Both of these alternatives were considered, and the Commission believed that they would have led to continued uncertainty concerning the future regulatory structure of the U.S. equity markets, and that the second alternative would have perpetuated inconsistent regulatory requirements for different NMS markets and stocks. At bottom, these alternatives simply reflect the dissenters' policy view that a price protection rule is not needed and will not be effective. Indeed, it is not clear why the dissent believes that the alternatives should have been seriously considered when they also believe that intermarket price protection in general will not be effective. It is even more difficult to understand how these alternatives could be suggested by the dissenters if they believe that the

estimated such costs as being much higher. See, e.g., Instinet Group Incorporated, Eliminating Unnecessary Cost: Reducing Transaction Costs and Recapturing Value for Your Portfolio 2 (2004) (available at www.instinetgroup.com) ("Transaction costs can have a significant effect on returns. Implementation shortfall in U.S. equity markets has been estimated to range from 20 basis points to as much as $2 \%$ of the principal value of transactions and orders. Taking the mid-point of this range, however, even an average of $1 \%$ per year in lost performance, before inflation and taxes, compounded over the average life of a pension liability, represents substantial foregone value. If we apply it to the $\$ 12$ trillion U.S. equity market, we get approximately $\$ 120$ billion lost to transaction costs every year.").

Dissent, note 6. 
very basis of intermarket price protection is "arbitrary, unreasonable and anticompetitive." The Commission disagrees and believes that further delay in reaching final decisions on vital NMS issues could have caused significant harm to the U.S. markets.

The dissent also states that the Commission failed to consider the alternative of prohibiting only those trade-throughs that are more than three cents inferior to the best prices. A three-cent trade-through threshold is analogous to the temporary exemption from the ITS tradethrough provisions that was originally granted in 2002 for trading in three exchange-traded funds. ${ }^{992}$ These derivative securities, one of which tracks the Nasdaq-100 Index (then referred to as the "QQQ"), are highly liquid and their value is readily derived from the values of their underlying stocks. The deficiencies of the ITS trade-through provisions, which protect both automated and manual quotations, were most evident in these securities. The Commission granted the exemption to address the pressing need for regulatory action in these securities, while it continued to evaluate a more comprehensive resolution of NMS issues.

The dissent argues that the exemption led to increased competition, narrowing of spreads, and a significant reduction in trade-through rates, citing an October 2002 study of trading in the QQQs by the Commission's Office of Economic Analysis that was referenced in the Proposing Release. ${ }^{993}$ This study, however, found that trade-through rates were extremely high both before and after the exemption was granted $-48 \%$ before and $47 \%$ after. The exemption therefore essentially ratified trading activity that already was occurring. ${ }^{994}$ Consequently, data on trading

992 Securities Exchange Act Release No. 46428 (Aug. 28, 2002), 67 FR 56607 (Sep. 14, 2002).

993 Dissent, note 6 (citing Proposing Release, 69 FR at 11134 n. 50).

994 Unlike the more recent Trade-Through Study, the October 2002 study did not incorporate a three-second quotation window to address timing latency issues. The earlier study also included manual quotations disseminated by Amex and the NYSE in the QQQs. The 
before and after the exemption provides little basis for drawing conclusions on the effect of the exemption.

Most importantly, the Commission considered and rejected a rule with a three-cent tradethrough threshold because it so clearly would fail to achieve any of the primary objectives of the Order Protection Rule, including investor protection, fair and orderly markets, and increased depth and liquidity. Such a rule would allow intermediaries and markets to execute investor orders at prices significantly inferior to the best prices that are immediately and automatically accessible. In many NMS stocks, quoted spreads are as low as one penny. A three-cent tradethrough on a single trade would represent a $300 \%$ increase in investor transaction costs in these stocks. In addition, allowing three-cent trade-throughs would seriously undercut the objectives of encouraging the display of limit orders. The average trade-through amount is 2.3 cents per share in Nasdaq stocks and 2.2 cents per share in NYSE stocks. ${ }^{995}$ Consequently, a rule with a three-cent threshold would not affect the majority of trade-throughs and thereby have little beneficial effect on the incentives to display limit orders.

\section{Market Data}

The dissent addresses issues relating to the level of market data fees and the single consolidator model for disseminating market data. As discussed above, ${ }^{996}$ the Commission has

respective findings of the two studies therefore are not comparable. The October 2002 study did not examine the effect of the exemption on the spreads paid by investors. The dissent also cites a comment letter stating that spreads narrowed in the QQQ's when they became a Nasdaq-listed security in December 2004. Dissent, note 6. Given that the three-cent trade-through threshold already allowed an extremely high percentage of tradethroughs even prior to the switch from Amex to Nasdaq listing, there is no basis to believe that the effect of the switch on spreads, if accurately stated, is related to any change in trade-through protection.

995 Trade-Through Study, Tables 3, 10.

996 Supra, section V.A. 
determined that the most appropriate forum in which to address the level of market data fees is its review of SRO structure, and it has retained the single consolidator model primarily because of its significant role in protecting investors.

\section{Conclusion}

The dissent concludes by stating that Regulation NMS is "far from final" and that it fears that "inevitable delays in obtaining guidance, the attendant regulatory uncertainty, and concomitant costs will harm a competitive marketplace." ${ }^{997}$ In fact, the Commission has taken great care to craft clear and workable rules for market participants to follow. Indeed, as discussed throughout this release, a variety of changes to the rules as originally proposed have been made specifically to respond to the comments of market participants. ${ }^{998}$ Given the wide range of participants in the securities markets, the particular means chosen by different entities to comply with the NMS rules may vary. The staff, under the purview of the Commission, will be available to work with the securities industry and the public to provide any desired guidance on implementation questions. In this regard, the NMS rules are no different from other rules that the Commission adopts, including previously-adopted NMS rules, such as those relating to limit order display and execution quality disclosure, which were widely cited by commenters as effective regulation. The Commission's experience with these other rules has demonstrated the wisdom of this approach.

$997 \quad$ Dissent, Conclusion.

998 See, e.g., supra, text accompanying notes 191-196 (discussing rule provisions that respond to commenters' suggestions on ways to make rules workable and implementable in a fair and orderly fashion). 


\section{Statutory Authority}

Pursuant to the Exchange Act and particularly, Sections 2, 3(b), 5, 6, 11, 11A, 15, 15A, 17(a) and (b), 19, 23(a), and 36 thereof, 15 U.S.C. 78b, 78c(b), 78e, 78f, 78k-1, 78o, 78o-3, 78q(a) and (b), 78s; 78w(a), and 78mm, and Rules 11Aa3-2(b)(2) and 11Aa3-2(c)(1) thereunder, 17 CFR 240.11Aa3-2(b)(2) and 17 CFR 240.11Aa3-2(c)(1), the Commission: (1) redesignates the NMS rules under Section 11A of the Exchange Act as Regulation NMS rules; (2) adopts Rules 600, 610, 611, and 612 of Regulation NMS; (3) amends current Rules 11Aa3-1 and 11Ac1-2 under the Exchange Act and redesignates them as Rules 601 and 603 of Regulation NMS; (4) amends the CTA Plan, the CQ Plan, and the Nasdaq UTP Plan; and (5) amends various other rules to reflect the adoption of Regulation NMS, as set forth below.

\section{Text of Adopted Amendments to the CTA Plan, the CQ Plan, and the Nasdaq UTP Plan}

The Commission hereby amends the CTA Plan, the CQ Plan, and the Nasdaq UTP Plan to incorporate the new net income allocation formula into each Plan, which supersedes the existing allocation formulas in those Plans, and to incorporate the new Plan governance language into each Plan.

Set forth below is the text of (1) the new allocation formula to be incorporated into each of the Plans, and (2) the new Plan governance language to be incorporated into each of the Plans.

\section{Allocation Amendment}

(\#) $\quad$ Allocation of Net Income.

(a) Annual Payment. Notwithstanding any other provision of this Plan, each Participant eligible to receive distributable net income under the Plan shall receive an annual payment for each calendar year that is equal to the sum of the Participant's Trading Shares and Quoting Shares, as defined below, in each Eligible Security for the calendar year. 
(b) Security Income Allocation. The Security Income Allocation for an Eligible Security shall be determined by multiplying (i) the distributable net income of the Plan for the calendar year by (ii) the Volume Percentage for such Eligible Security (the "initial allocation"), and then adding or subtracting any amounts specified in the reallocation set forth below. The Volume Percentage for an Eligible Security shall be determined by dividing (i) the square root of the dollar volume of transaction reports disseminated by the Processor in such Eligible Security during the calendar year by (ii) the sum of the square roots of the dollar volume of transaction reports disseminated by the Processor in each Eligible Security during the calendar year. If the initial allocation of distributable net income in accordance with the Volume Percentage of an Eligible Security equals an amount greater than $\$ 4.00$ multiplied by the total number of qualified transaction reports in such Eligible Security during the calendar year, the excess amount shall be subtracted from the initial allocation for such Eligible Security and reallocated among all Eligible Securities in direct proportion to the dollar volume of transaction reports disseminated by the Processor in Eligible Securities during the calendar year. A transaction report with a dollar volume of $\$ 5000$ or more shall constitute one qualified transaction report. A transaction report with a dollar volume of less than $\$ 5000$ shall constitute a fraction of a qualified transaction report that equals the dollar volume of the transaction report divided by $\$ 5000$.

(c) Trading Share. The Trading Share of a Participant in an Eligible Security shall be determined by multiplying (i) an amount equal to fifty percent of the Security Income Allocation for the Eligible Security by (ii) the Participant’s Trade Rating in the Eligible Security. A Participant's Trade Rating in an Eligible Security shall be determined by taking the average of (i) the Participant's percentage of the total dollar volume of transaction reports disseminated by the Processor in the Eligible Security during the calendar year, and (ii) the Participant's percentage 
of the total number of qualified transaction reports disseminated by the Processor in the Eligible Security during the calendar year.

(d) Quoting Share. The Quoting Share of a Participant in an Eligible Security shall be determined by multiplying (i) an amount equal to fifty percent of the Security Income Allocation for the Eligible Security by (ii) the Participant's Quote Rating in the Eligible Security. A Participant's Quote Rating in an Eligible Security shall be determined by dividing (i) the sum of the Quote Credits earned by the Participant in such Eligible Security during the calendar year by (ii) the sum of the Quote Credits earned by all Participants in such Eligible Security during the calendar year. A Participant shall earn one Quote Credit for each second of time (with a minimum of one full second) multiplied by dollar value of size that an automated best bid (offer) transmitted by the Participant to the Processor during regular trading hours is equal to the price of the national best bid (offer) in the Eligible Security and does not lock or cross a previously displayed automated quotation. An automated bid (offer) shall have the meaning specified in Rule 600 of Regulation NMS of the Exchange Act for an "automated quotation." The dollar value of size of a quote shall be determined by multiplying the price of a quote by its size.

\section{Governance Amendment}

(\#) $\quad$ Advisory Committee.

(a) Formation. Notwithstanding any other provision of this Plan, an Advisory Committee to the Plan shall be formed and shall function in accordance with the provisions set forth in this section.

(b) Composition. Members of the Advisory Committee shall be selected for two-year terms as follows: 
(1) Operating Committee Selections. By affirmative vote of a majority of the Participants entitled to vote, the Operating Committee shall select at least one representative from each of the following categories to be members of the Advisory Committee: (i) a brokerdealer with a substantial retail investor customer base, (ii) a broker-dealer with a substantial institutional investor customer base, (iii) an alternative trading system, (iv) a data vendor, and (v) an investor.

(2) Participant Selections. Each Participant shall have the right to select one member of the Advisory Committee. A Participant shall not select any person employed by or affiliated with any Participant or its affiliates or facilities.

(c) Function. Members of the Advisory Committee shall have the right to submit their views to the Operating Committee on Plan matters, prior to a decision by the Operating Committee on such matters. Such matters shall include, but not be limited to, any new or modified product, fee, contract, or pilot program that is offered or used pursuant to the Plan.

(d) Meetings and Information. Members of the Advisory Committee shall have the right to attend all meetings of the Operating Committee and to receive any information concerning Plan matters that is distributed to the Operating Committee; provided, however, that the Operating Committee may meet in executive session if, by affirmative vote of a majority of the Participants entitled to vote, the Operating Committee determines that an item of Plan business requires confidential treatment.

\section{Text of Adopted Rules}

\section{List of Subjects}

\section{CFR Part 200}


Administrative practice and procedure, Authority delegations (Government agencies),

Organization and functions (Government agencies).

\section{CFR Part 201}

Administrative practice and procedure, Securities.

\section{CFR Parts 230 and 270}

Reporting and recordkeeping requirements, Securities.

\section{CFR Parts 240, 242, and 249}

Brokers, Reporting and recordkeeping requirements, Securities.

For the reasons set out in the preamble, Title 17, Chapter II of the Code of the Federal Regulations is amended as follows:

\section{PART 200-ORGANIZATION; CONDUCT AND ETHICS; AND INFORMATION AND REQUESTS}

1. The authority citation for part 200 continues to read in part as follows:

Authority: 15 U.S.C. 77s, 77o, 77sss, 78d, 78d-1, 78d-2, 78w, 78ll(d), 78mm, 79t, 80a37, 80b-11, and 7202, unless otherwise noted.

2. Section 200.30-3 is amended by:

a. $\quad$ Removing paragraphs (a)(62) and (a)(71);

b. Redesignating paragraphs (a)(63) through (a)(82) as paragraphs (a)(62) through (a)(80);

c. Revising paragraphs (a)(27), (a)(28), (a)(36), (a)(37), (a)(42), (a)(49), (a)(61), and newly redesignated paragraphs (a)(68), and (a)(69); and

d. $\quad$ Adding new paragraphs (a)(81), (a)(82), and (a)(83).

The revisions and additions read as follows: 


\section{§ 200.30-3 Delegation of authority to Director of Division of Market Regulation.}

(a) $* * *$

(27) To approve amendments to the joint industry plan governing consolidated transaction reporting declared effective by the Commission pursuant to Rule 601 (17 CFR 242.601) or its predecessors, Rule 11Aa3-1 and Rule 17a-15, and to grant exemptions from Rule 601 pursuant to Rule 601(f) (17 CFR 242.601(f)) to exchanges trading listed securities that are designated as national market system securities until such times as a Joint Reporting Plan for such securities is filed and approved by the Commission.

(28) To grant exemptions from Rule 602 (17 CFR 242.602), pursuant to Rule 602(d) (17 CFR 242.602(d)).

(36) To grant exemptions from Rule 603 (17 CFR 242.603), pursuant to Rule 603(d) (17 CFR 242.603(d)).

(37) Pursuant to Rule 600 (17 CFR 242.600), to publish notice of the filing of a designation plan with respect to national market system securities, or any proposed amendment thereto, and to approve such plan or amendment.

(42) Under 17 CFR 242.608(e), to grant or deny exemptions from 17 CFR 242.608.

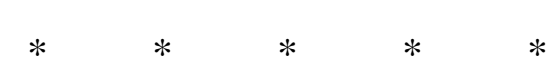

(49) Pursuant to section $11 \mathrm{~A}(\mathrm{~b})$ of the Act (15 U.S.C. 78k-1(b)) and Rule 609 thereunder (17 CFR 242.609), to publish notice of and, by order, grant under section 11A(b) of the Act and Rule 609 thereunder: Applications for registration as a securities information 
processor; and exemptions from that section and any rules or regulations promulgated thereunder, either conditionally or unconditionally.

(61) To grant exemptions from Rule 604 (17 CFR 242.604), pursuant to Rule 604(c) (17 CFR 242.604(c)).

(68) Pursuant to Rule 605(b) (17 CFR 242.605(b)), to grant or deny exemptions, conditionally or unconditionally, from any provision or provisions of Rule 605 (17 CFR 242.605).

(69) Pursuant to Rule 606(c) (17 CFR 242.606(c)), to grant or deny exemptions, conditionally or unconditionally, from any provision or provisions of Rule 606 (17 CFR 242.606).

(81) To grant or deny exemptions from Rule 610 (17 CFR 242.610), pursuant to Rule 610(e) (17 CFR 242.610(e)).

(82) To grant or deny exemptions from Rule 611 (17 CFR 242.611), pursuant to Rule 611(d) (17 CFR 242.611(d)).

(83) To grant or deny exemptions from Rule 612 (17 CFR 242.612), pursuant to Rule 612(c) (17 CFR 242.612(c)).

Subpart N - Commission Information Collection Requirements Under the Paperwork Reduction Act: OMB Control Numbers

3. The authority citation for Subpart N continues to read as follows: 
Authority: 44 U.S.C. 3506; 44 U.S.C. 3507.

4. Section 200.800 is amended by revising paragraph (b) to read as follows:

$\S 200.800$ OMB control numbers assigned pursuant to the Paperwork Reduction Act.

(a) $* * *$

(b) Display.

\begin{tabular}{|l|l|l|}
\hline \multicolumn{1}{|c|}{$\begin{array}{c}\text { Information } \\
\text { collection } \\
\text { requirement }\end{array}$} & $\begin{array}{c}\text { 17 CFR Part or } \\
\text { Section } \\
\text { where identified } \\
\text { and described }\end{array}$ & $\begin{array}{c}\text { Current } \\
\text { OMB } \\
\text { Control } \\
\text { No. }\end{array}$ \\
\hline Regulation S-X & PART 210 & $3235-0009$ \\
\hline Regulation S-B & PART 228 & $3235-0417$ \\
\hline Regulation S-K & PART 229 & $3235-0071$ \\
\hline Rule 154 & 230.154 & $3235-0495$ \\
\hline Rule 155 & 230.155 & $3235-0549$ \\
\hline Rule 236 & 230.236 & $3235-0095$ \\
\hline Rule 237 & 230.237 & $3235-0528$ \\
\hline Regulation A & 230.251 thru & $3235-0286$ \\
\hline Regulation C & 230.263 & $3235-0074$ \\
\hline Rule 425 & 230.400 thru \\
\hline Rule 477 & 230.494 & $3235-0521$ \\
\hline Rule 489 & 230.425 & $3235-0550$ \\
\hline Rule 498 & 230.477 & $3235-0411$ \\
\hline Regulation D & 230.489 & $3235-0488$ \\
\hline Regulation E & 230.498 & $3235-0076$ \\
\hline & 230.501 thru & 230.506 \\
\hline
\end{tabular}




\begin{tabular}{|c|c|c|}
\hline Rule 604 & 230.604 & $3235-0232$ \\
\hline Rule 605 & 230.605 & 3235-0232 \\
\hline Rule 609 & 230.609 & $3235-0233$ \\
\hline Rule 701 & 230.701 & 3235-0522 \\
\hline Regulation S & $\begin{array}{l}230.901 \text { thru } \\
230.905\end{array}$ & $3235-0357$ \\
\hline Regulation S-T & Part 232 & $3235-0424$ \\
\hline Form SB-1 & 239.9 & $3235-0423$ \\
\hline Form SB-2 & 239.10 & $3235-0418$ \\
\hline Form S-1 & 239.11 & $3235-0065$ \\
\hline Form S-2 & 239.12 & $3235-0072$ \\
\hline Form S-3 & 239.13 & $3235-0073$ \\
\hline Form N-2 & 239.14 & $3235-0026$ \\
\hline Form N-1A & 239.15A & 3235-0307 \\
\hline Form S-6 & 239.16 & 3235-0184 \\
\hline Form S-8 & 239.16b & 3235-0066 \\
\hline Form N-3 & 239.17a & $3235-0316$ \\
\hline Form N-4 & 239.17b & $3235-0318$ \\
\hline Form S-11 & 239.18 & $3235-0067$ \\
\hline Form N-14 & 239.23 & 3235-0336 \\
\hline Form N-5 & 239.24 & 3235-0169 \\
\hline Form S-4 & 239.25 & 3235-0324 \\
\hline Form F-1 & 239.31 & $3235-0258$ \\
\hline Form F-2 & 239.32 & 3235-0257 \\
\hline Form F-3 & 239.33 & $3235-0256$ \\
\hline Form F-4 & 239.34 & $3235-0325$ \\
\hline Form F-6 & 239.36 & 3235-0292 \\
\hline Form F-7 & 239.37 & 3235-0383 \\
\hline
\end{tabular}




\begin{tabular}{|l|l|l|}
\hline Form F-8 & 239.38 & $3235-0378$ \\
\hline Form F-9 & 239.39 & $3235-0377$ \\
\hline Form F-10 & 239.40 & $3235-0380$ \\
\hline Form F-80 & 239.41 & $3235-0404$ \\
\hline Form F-X & 239.42 & $3235-0379$ \\
\hline Form F-N & 239.43 & $3235-0411$ \\
\hline Form ET & 239.62 & $3235-0329$ \\
\hline Form ID & 239.63 & $3235-0328$ \\
\hline Form SE & 239.64 & $3235-0327$ \\
\hline Form TH & 239.65 & $3235-0425$ \\
\hline Form 1-A & 239.90 & $3235-0286$ \\
\hline Form 2-A & 239.91 & $3235-0286$ \\
\hline Form 144 & 239.144 & $3235-0101$ \\
\hline Form 1-E & 239.200 & $3235-0232$ \\
\hline Form CB & 239.800 & $3235-0518$ \\
\hline Rule 6a-1 & $240.6 \mathrm{a}-1$ & $3235-0017$ \\
\hline Rule 6a-3 & $240.6 \mathrm{a}-3$ & $3235-0021$ \\
\hline Rule 6a-4 & $240.6 \mathrm{a}-4$ & $3235-0554$ \\
\hline Rule 6h-1 & $240.6 \mathrm{~h}-1$ & $3235-0555$ \\
\hline Rule 8c-1 & $240.8 \mathrm{c}-1$ & $3235-0514$ \\
\hline Rule 9b-1 & $240.9 \mathrm{~b}-1$ & $3235-0480$ \\
\hline Rule 10a-1 & $240.10 \mathrm{a}-1$ & $3235-0475$ \\
\hline Rule 10b-10 & $240.10 \mathrm{~b}-10$ & $3235-0444$ \\
\hline Rule 10b-17 & $240.10 \mathrm{~b}-17$ & $3235-0476$ \\
\hline Rule 10b-18 & $240.10 \mathrm{~b}-18$ & $3235-0474$ \\
\hline Rule 10A-1 & $240.10 \mathrm{~A}-1$ & $3235-0468$ \\
\hline Rule 11a1-1(T) & 20478 \\
\hline Rule 12a-5 & $240-11-1$ (T) & 32379 \\
\hline
\end{tabular}




\begin{tabular}{|c|c|c|}
\hline Regulation 12B & $\begin{array}{l}\text { 240.12b-1 thru } \\
240.12 b-36\end{array}$ & $3235-0062$ \\
\hline Rule 12d1-3 & 240.12d1-3 & 3235-0109 \\
\hline Rule 12d2-1 & 240.12d2-1 & 3235-0081 \\
\hline Rule $12 \mathrm{~d} 2-2$ & 240.12d2-2 & $3235-0080$ \\
\hline Rule 12f-1 & 240.12f-1 & $3235-0128$ \\
\hline Rule 13a-16 & 240.13a-16 & 3235-0116 \\
\hline Regulation 13D/G & $\begin{array}{l}\text { 240.13d-1 thru } \\
240.13 d-7\end{array}$ & 3235-0145 \\
\hline Schedule 13D & 240.13d-101 & 3235-0145 \\
\hline Schedule 13G & 240.13d-102 & 3235-0145 \\
\hline Rule 13e-1 & 240.13e-1 & 3235-0305 \\
\hline Rule 13e-3 & 240.13e-3 & $3235-0007$ \\
\hline Schedule 13E-3 & 240.13e-100 & 3235-0007 \\
\hline Schedule 13e-4F & 240.13e-101 & 3235-0375 \\
\hline Regulation 14A & $\begin{array}{l}\text { 240.14a-1 thru } \\
\text { 240.14a-12 }\end{array}$ & 3235-0059 \\
\hline Schedule 14A & 240.14a-101 & $3235-0059$ \\
\hline Regulation 14C & 240.14c-1 & 3235-0057 \\
\hline Schedule $14 \mathrm{C}$ & 240.14c-101 & 3235-0057 \\
\hline Regulation 14D & $\begin{array}{l}\text { 240.14d-1 thru } \\
240.14 d-9\end{array}$ & 3235-0102 \\
\hline Schedule TO & 240.14d-100 & 3235-0515 \\
\hline Schedule 14D-1 & 240.14d-101 & 3235-0102 \\
\hline Schedule 14D-9 & 240.14d-101 & 3235-0102 \\
\hline Schedule 14D-1F & 240.14d-102 & $3235-0376$ \\
\hline Schedule 14D-9F & 240.14d-103 & 3235-0382 \\
\hline Regulation 14E & $\begin{array}{l}\text { 240.14e-1 thru } \\
240.14 \mathrm{e}-2\end{array}$ & 3235-0102 \\
\hline Rule 14f-1 & $240.14 f-1$ & 3235-0108 \\
\hline
\end{tabular}




\begin{tabular}{|l|l|l|}
\hline Rule 15a-4 & $240.15 \mathrm{a}-4$ & $3235-0010$ \\
\hline Rule 15a-6 & $240.15 \mathrm{a}-6$ & $3235-0371$ \\
\hline Rule 15b1-1 & $240.15 \mathrm{~b} 1-1$ & $3235-0012$ \\
\hline Rule 15b6-1(a) & $240.15 \mathrm{~b} 6-1(\mathrm{a})$ & $3235-0018$ \\
\hline Rule 15c1-5 & $240.15 \mathrm{c} 1-5$ & $3235-0471$ \\
\hline Rule 15c1-6 & $240.15 \mathrm{c} 1-6$ & $3235-0472$ \\
\hline Rule 15c1-7 & $240.15 \mathrm{c} 1-7$ & $3235-0134$ \\
\hline Rule 15c2-1 & $240.15 \mathrm{c}-1$ & $3235-0485$ \\
\hline Rule 15c2-5 & $240.15 \mathrm{c} 2-5$ & $3235-0198$ \\
\hline Rule 15c2-7 & $240.15 \mathrm{c}-7$ & $3235-0479$ \\
\hline Rule 15c2-8 & $240.15 \mathrm{c} 2-8$ & $3235-0481$ \\
\hline Rule 15c2-11 & $240.15 \mathrm{c} 2-11$ & $3235-0202$ \\
\hline Rule 15c2-12 & $240.15 \mathrm{c} 2-12$ & $3235-0372$ \\
\hline Rule 15c3-1 & $240.15 \mathrm{c} 3-1$ & $3235-0200$ \\
\hline Rule 15c3-1(c)(13) & $240.15 \mathrm{c} 3-1(\mathrm{c})(13)$ & $3235-0499$ \\
\hline Appendix F to Rule 15c3-1 & $240.15 \mathrm{c} 3-1 \mathrm{f}$ & $3235-0496$ \\
\hline Rule 15c3-3 & $240.15 \mathrm{c} 3-3$ & $3235-0078$ \\
\hline Rule 15c3-4 & $240.15 \mathrm{c} 3-4$ & $3235-0497$ \\
\hline Rule 15d-16 & $240.15 \mathrm{~d}-16$ & $3235-0116$ \\
\hline Rule 15g-2 & $240.15 \mathrm{~g}-2$ & $3235-0434$ \\
\hline Rule 15g-3 & $240.15 \mathrm{~g}-3$ & $3235-0392$ \\
\hline Rule 15g-4 & $240.15 \mathrm{~g}-4$ & $3235-0393$ \\
\hline Rule 15g-5 & $240.15 \mathrm{~g}-5$ & $3235-0394$ \\
\hline Rule 15g-6 & $240.15 \mathrm{~g}-6$ & $3235-0395$ \\
\hline Rule 15g-9 & $240.15 \mathrm{~g}-9$ & $3235-0385$ \\
\hline Rule 15Aj-1 & $240.15 \mathrm{Aj}-1$ & $3235-0044$ \\
\hline Rule 15Ba2-1 & $240.15 \mathrm{Ba} 2-1$ & $3235-0083$ \\
\hline Rule 15Ba2-5 & $3235-0088$ \\
\hline
\end{tabular}




\begin{tabular}{|l|l|l|}
\hline Rule 15Bc3-1 & 240.15 Bc3-1 & $3235-0087$ \\
\hline Rule 17a-1 & $240.17 \mathrm{a}-1$ & $3235-0208$ \\
\hline Rule 17a-2 & $240.17 \mathrm{a}-2$ & $3235-0201$ \\
\hline Rule 17a-3 & $240.17 \mathrm{a}-3$ & $3235-0033$ \\
\hline Rule 17a-3(a)(16) & $240.17 \mathrm{a}-3(\mathrm{a})(16)$ & $3235-0508$ \\
\hline Rule 17a-4 & $240.17 \mathrm{a}-4$ & $3235-0279$ \\
\hline Rule 17a-4(b)(10) & $240.17 \mathrm{a}-4(\mathrm{~b})(10)$ & $3235-0506$ \\
\hline Rule 17a-5 & $240.17 \mathrm{a}-5$ & $3235-0123$ \\
\hline Rule 17a-5(c) & $240.17 \mathrm{a}-5(\mathrm{c})$ & $3235-0199$ \\
\hline Rule 17a-6 & $240.17 \mathrm{a}-6$ & $3235-0489$ \\
\hline Rule 17a-7 & $240.17 \mathrm{a}-7$ & $3235-0131$ \\
\hline Rule 17a-8 & $240.17 \mathrm{a}-8$ & $3235-0092$ \\
\hline Rule 17a-9T & $240.17 \mathrm{a}-9 \mathrm{~T}$ & $3235-0524$ \\
\hline Rule 17a-10 & $240.17 \mathrm{a}-10$ & $3235-0122$ \\
\hline Rule 17a-11 & $240.17 \mathrm{a}-11$ & $3235-0085$ \\
\hline Rule 17a-12 & $240.17 \mathrm{a}-12$ & $3235-0498$ \\
\hline Rule 17a-13 & $240.17 \mathrm{a}-13$ & $3235-0035$ \\
\hline Rule 17a-19 & $240.17 \mathrm{a}-19$ & $3235-0133$ \\
\hline Rule 17a-22 & $240.17 \mathrm{a}-22$ & $3235-0196$ \\
\hline Rule 17a-25 & $240.17 \mathrm{a}-25$ & $3235-0540$ \\
\hline Rule 17f-1(b) & $240.17 f-1(\mathrm{~b})$ & $3235-0032$ \\
\hline Rule 17f-1(c) & $240.17 \mathrm{f}-1(\mathrm{c})$ & $3235-0037$ \\
\hline Rule 17f-1(g) & $240.17 \mathrm{f}-1(\mathrm{~g})$ & $3235-0290$ \\
\hline Rule 17f-2(a) & $240.17 \mathrm{f}-2(\mathrm{a})$ & $3235-0034$ \\
\hline Rule 17f-2(c) & $240.17 \mathrm{f}-2(\mathrm{c})$ & $3235-0029$ \\
\hline Rule 17f-2(d) & $240.17 \mathrm{f}-2(\mathrm{~d})$ & $3235-0028$ \\
\hline Rule 17f-2(e) & $240.17 \mathrm{f}-2(\mathrm{e})$ & $3235-0031$ \\
\hline Rule 17f-5 & $240.17-5$ & $3235-0269$ \\
\hline
\end{tabular}




\begin{tabular}{|c|c|c|}
\hline Rule 17h-1T & 240.17h-1T & $3235-0410$ \\
\hline Rule $17 \mathrm{~h}-2 \mathrm{~T}$ & 240.17h-2T & $3235-0410$ \\
\hline Rule 17Ab2-1 & 240.17Ab2-1 (a) & 3235-0195 \\
\hline Rule 17Ac2-1 & 240.17Ac2-1 & $3235-0084$ \\
\hline Rule 17Ad-2(c), (d), and (h) & $\begin{array}{l}\text { 240.17Ad-2(c), (d) } \\
\text { and (h) }\end{array}$ & $3235-0130$ \\
\hline Rule 17Ad-3(b) & 240.17Ad-3(b) & $3235-0473$ \\
\hline Rule 17Ad-4 (b) and (c) & $\begin{array}{l}\text { 240.17Ad-4(b) and } \\
\text { (c) }\end{array}$ & $3235-0341$ \\
\hline Rule 17Ad-6 & 240.17Ad-6 & 3235-0291 \\
\hline Rule 17Ad-7 & 240.17Ad-7 & 3235-0291 \\
\hline Rule 17Ad-10 & 240.17Ad-10 & $3235-0273$ \\
\hline Rule 17Ad-11 & 240.17Ad-11 & $3235-0274$ \\
\hline Rule 17Ad-13 & 240.17Ad-13 & $3235-0275$ \\
\hline Rule 17Ad-15 & 240.17Ad-15 & 3235-0409 \\
\hline Rule 17Ad-16 & 240.17Ad-16 & $3235-0413$ \\
\hline Rule 17Ad-17 & 240.17Ad-17 & $3235-0469$ \\
\hline Rule 19b-1 & 240.19b-1 & $3235-0354$ \\
\hline Rule 19b-4 & 240.19b-4 & $3235-0045$ \\
\hline Rule 19b-4(e) & 240.19b-4(e) & 3235-0504 \\
\hline Rule 19b-5 & 240.19b-5 & $3235-0507$ \\
\hline Rule 19b-7 & 240.19b-7 & $3235-0553$ \\
\hline Rule 19d-1 & $\begin{array}{l}\text { 240.19d-1(b) thru } \\
\text { 240.19d-1(i) }\end{array}$ & 3235-0206 \\
\hline Rule 19d-2 & 240.19d-2 & 3235-0205 \\
\hline Rule 19d-3 & 240.19d-3 & 3235-0204 \\
\hline Rule 19h-1 & $\begin{array}{l}\text { 240.19h-1(a), (c) } \\
\text { thru (e), and (g) }\end{array}$ & $3235-0259$ \\
\hline Rule 24b-1 & $240.24 b-1$ & 3235-0194 \\
\hline
\end{tabular}




\begin{tabular}{|c|c|c|}
\hline Rule 101 & 242.101 & $3235-0464$ \\
\hline Rule 102 & 242.102 & 3235-0467 \\
\hline Rule 103 & 242.103 & $3235-0466$ \\
\hline Rule 104 & 242.104 & $3235-0465$ \\
\hline Rule 301 & 242.301 & 3235-0509 \\
\hline Rule 302 & 242.302 & $3235-0510$ \\
\hline Rule 303 & 242.303 & 3235-0505 \\
\hline Rule 604 & 242.604 & $3235-0462$ \\
\hline Rule 605 & 242.605 & $3235-0542$ \\
\hline Rule 606 & 242.606 & $3235-0541$ \\
\hline Rule 607 & 242.607 & 3235-0435 \\
\hline Rule 608 & 242.608 & $3235-0500$ \\
\hline Rule 609 & 242.609 & $3235-0043$ \\
\hline Rule 611 & 242.611 & $3235-0600$ \\
\hline Regulation S-P & Part 248 & 3235-0537 \\
\hline Form 1 & 249.1 & 3235-0017 \\
\hline Form 1-N & 249.10 & $3235-0554$ \\
\hline Form 25 & 249.25 & $3235-0080$ \\
\hline Form 26 & 249.26 & $3235-0079$ \\
\hline Form 3 & 249.103 & 3235-0104 \\
\hline Form 4 & 249.104 & $3235-0287$ \\
\hline Form 5 & 249.105 & $3235-0362$ \\
\hline Form 8-A & 249.208a & $3235-0056$ \\
\hline Form 10 & 249.210 & 3235-0064 \\
\hline Form 10-SB & 249.210b & $3235-0419$ \\
\hline Form 18 & 249.218 & $3235-0121$ \\
\hline Form $20-\mathrm{F}$ & 249.220f & $3235-0288$ \\
\hline
\end{tabular}




\begin{tabular}{|l|l|l|}
\hline Form $40-\mathrm{F}$ & $249.240 \mathrm{f}$ & $3235-0381$ \\
\hline Form 6-K & 249.306 & $3235-0116$ \\
\hline Form 8-K & 249.308 & $3235-0060$ \\
\hline Form 10-Q & $249.308 \mathrm{a}$ & $3235-0070$ \\
\hline Form 10-QSB & $249.308 \mathrm{~b}$ & $3235-0416$ \\
\hline Form 10-K & 249.310 & $3235-0063$ \\
\hline Form 10-KSB & $249.310 \mathrm{~b}$ & $3235-0420$ \\
\hline Form 11-K & 249.311 & $3235-0082$ \\
\hline Form 18-K & 249.318 & $3235-0120$ \\
\hline Form 12B-25 & 249.322 & $3235-0058$ \\
\hline Form 15 & 249.323 & $3235-0167$ \\
\hline Form 13F & 249.325 & $3235-0006$ \\
\hline Form SE & 249.444 & $3235-0327$ \\
\hline Form ET & 249.445 & $3235-0329$ \\
\hline Form ID & 249.446 & $3235-0328$ \\
\hline Form DF & 249.448 & $3235-0482$ \\
\hline Form BD & 249.501 & $3235-0012$ \\
\hline Form BDW & $249.501 \mathrm{a}$ & $3235-0018$ \\
\hline Form BD-N & $249.501 \mathrm{~b}$ & $3235-0556$ \\
\hline Form X-17A-5 & 249.617 & $3235-0123$ \\
\hline Form X-17A-19 & 249.635 & $3235-0133$ \\
\hline Form ATS & 249.637 & $3235-0509$ \\
\hline Form ATS-R & 249.638 & $3235-0509$ \\
\hline Form X-15AJ-1 & 249.802 & $3235-0044$ \\
\hline Form X-15AJ-2 & 249.803 & $3235-0044$ \\
\hline Form 19b-4 & 249.819 & $3235-0045$ \\
\hline Form 19b-4(e) & 249504 \\
\hline Form Pilot & & \\
\hline
\end{tabular}




\begin{tabular}{|l|l|l|}
\hline Form SIP & 249.1001 & $3235-0043$ \\
\hline Form MSD & 249.1100 & $3235-0083$ \\
\hline Form MSDW & 249.1110 & $3235-0087$ \\
\hline Form X-17F-1A & 249.1200 & $3235-0037$ \\
\hline Form TA-1 & $249 \mathrm{~b} .100$ & $3235-0084$ \\
\hline Form TA-W & $249 \mathrm{~b} .101$ & $3235-0151$ \\
\hline Form TA-2 & $249 \mathrm{~b} .102$ & $3235-0337$ \\
\hline Form CA-1 & $249 \mathrm{~b} .200$ & $3235-0195$ \\
\hline Rule 1(a) & $250.1(\mathrm{a})$ & $3235-0170$ \\
\hline Rule 1(b) & $250.1(\mathrm{~b})$ & $3235-0170$ \\
\hline Rule 1(c) & $250.1(\mathrm{c})$ & $3235-0164$ \\
\hline Rule 2 & 250.2 & $3235-0161$ \\
\hline Rule 3 & 250.3 & $3235-0160$ \\
\hline Rule 7 & 250.7 & $3235-0165$ \\
\hline Rule 7(d) & $250.7(\mathrm{~d})$ & $3235-0165$ \\
\hline Rule 20(b) & $250.20(\mathrm{~b})$ & $3235-0125$ \\
\hline Rule 20(c) & $250.20(\mathrm{c})$ & $3235-0125$ \\
\hline Rule 20(d) & $250.20(\mathrm{~d})$ & $3235-0163$ \\
\hline Rule 23 & 250.23 & $3235-0125$ \\
\hline Rule 24 & 250.24 & $3235-0126$ \\
\hline Rule 26 & 250.26 & $3235-0183$ \\
\hline Rule 29 & 250.29 & $3235-0149$ \\
\hline Rule 44 & 250.44 & $3235-0147$ \\
\hline Rule 45 & 250.45 & $250.53-0154$ \\
\hline Rule 47(b) & $250.47(\mathrm{~b})$ \\
\hline Rule 52 & 250.52 & \\
\hline Form 53 & & $3235-0369$ \\
\hline Rule 54 & 2536 \\
\hline
\end{tabular}




\begin{tabular}{|c|c|c|}
\hline Rule 57(a) & 250.57(a) & $3235-0428$ \\
\hline Rule 57(b) & 250.57(b) & 3235-0429 \\
\hline Rule 58 & 250.58 & $3235-0457$ \\
\hline Rule 62 & 250.62 & 3235-0152 \\
\hline Rule 71(a) & 250.71(a) & 3235-0173 \\
\hline Rule 72 & 250.72 & 3235-0149 \\
\hline Rule 83 & 250.83 & 3235-0181 \\
\hline Rule 87 & 250.87 & $3235-0552$ \\
\hline Rule 88 & 250.88 & 3235-0182 \\
\hline Rule 93 & 250.93 & $3235-0153$ \\
\hline Rule 94 & 250.94 & $3235-0153$ \\
\hline Rule 95 & 250.95 & 3235-0162 \\
\hline Rule 100(a) & 250.100(a) & 3235-0125 \\
\hline $\begin{array}{l}\text { Uniform System of Accounts for Mutual Service Companies } \\
\text { and Subsidiary Service Companies, Public Utility Holding } \\
\text { Company Act of } 1935\end{array}$ & Part 256 & 3235-0153 \\
\hline $\begin{array}{l}\text { Preservation and Destruction of Records of Registered Public } \\
\text { Utility Holding Companies and of Mutual and Subsidiary } \\
\text { Service Companies }\end{array}$ & Part 257 & 3235-0306 \\
\hline Form U5A & 259.5a & $3235-0170$ \\
\hline Form U5B & $259.5 b$ & $3235-0170$ \\
\hline Form U5S & $259.5 \mathrm{~s}$ & 3235-0164 \\
\hline Form U-1 & 259.101 & 3235-0125 \\
\hline Form U-13-1 & 259.113 & $3235-0182$ \\
\hline Form U-6B-2 & 259.206 & 3235-0163 \\
\hline Form U-57 & 259.207 & $3235-0428$ \\
\hline Form U-9C-3 & 259.208 & $3235-0457$ \\
\hline Form U-12(I)-A & 259.212a & $3235-0173$ \\
\hline Form U-12(I)-B & 259.212b & $3235-0173$ \\
\hline
\end{tabular}




\begin{tabular}{|c|c|c|}
\hline Form U-13E-1 & 259.213 & 3235-0162 \\
\hline Form U-R-1 & 259.221 & 3235-0152 \\
\hline Form U-13-60 & 259.313 & $3235-0153$ \\
\hline Form U-3A-2 & 259.402 & 3235-0161 \\
\hline Form U-3A3-1 & 259.403 & $3235-0160$ \\
\hline Form U-7D & 259.404 & 3235-0165 \\
\hline Form U-33-S & 259.405 & $3235-0429$ \\
\hline Form ET & 259.601 & 3235-0329 \\
\hline Form ID & 259.602 & 3235-0328 \\
\hline Form SE & 259.603 & $3235-0327$ \\
\hline Rule 7a-15 thru 7a-37 & $\begin{array}{l}\text { 260.7a-15 thru } \\
260.7 a-37\end{array}$ & 3235-0132 \\
\hline Form T-1 & 269.1 & $3235-0110$ \\
\hline Form T-2 & 269.2 & 3235-0111 \\
\hline Form T-3 & 269.3 & 3235-0105 \\
\hline Form T-4 & 269.4 & 3235-0107 \\
\hline Form ET & 269.6 & $3235-0329$ \\
\hline Form ID & 269.7 & $3235-0328$ \\
\hline Form SE & 269.8 & $3235-0327$ \\
\hline Form T-6 & 269.9 & 3235-0391 \\
\hline Rule $0-1$ & $270.0-1$ & 3235-0531 \\
\hline Rule 2a-7 & 270.2a-7 & 3235-0268 \\
\hline Rule 2a19-1 & 270.2a19-1 & $3235-0332$ \\
\hline Rule 3a-4 & 270.3a-4 & 3235-0459 \\
\hline Rule 6c-7 & $270.6 c-7$ & $3235-0276$ \\
\hline Rule 6e-2 & 270.6e-2 & 3235-0177 \\
\hline Rule 7d-1 & 270.7d-1 & 3235-0311 \\
\hline Rule 7d-2 & $270.7 d-2$ & $3235-0527$ \\
\hline
\end{tabular}




\begin{tabular}{|l|l|l|}
\hline Section 8(b) of the Investment Company Act of 1940 & $270.8 \mathrm{~b}-1$ thru & $3235-0176$ \\
\hline Rule 10f-3 & $270.10 \mathrm{~b}-32$ & $3235-0226$ \\
\hline Rule 11a-2 & $270.11 \mathrm{a}-2$ & $3235-0272$ \\
\hline Rule 11a-3 & $270.11 \mathrm{a}-3$ & $3235-0358$ \\
\hline Rule 12b-1 & $270-12 \mathrm{~b}-1$ & $3235-0212$ \\
\hline Rule 17a-7 & $270.17 \mathrm{a}-7$ & $3235-0214$ \\
\hline Rule 17a-8 & $270.17 \mathrm{a}-8$ & $3235-0235$ \\
\hline Rule 17e-1 & $270.17 \mathrm{e}-1$ & $3235-0217$ \\
\hline Rule 17f-1 & $270.17 \mathrm{f}-1$ & $3235-0222$ \\
\hline Rule 17f-2 & $270.17 \mathrm{f}-2$ & $3235-0223$ \\
\hline Rule 17f-4 & $270.17 \mathrm{f}-4$ & $3235-0225$ \\
\hline Rule 17f-6 & $270.17 \mathrm{f}-6$ & $3235-0447$ \\
\hline Rule 17f-7 & $270-17 \mathrm{f}-7$ & $3235-0529$ \\
\hline Rule 17g-1(g) & $270.17 \mathrm{~g}-1(\mathrm{~g})$ & $3235-0213$ \\
\hline Rule 17j-1 & $270.17 \mathrm{j}-1$ & $3235-0224$ \\
\hline Rule 18f-1 & $270.18 \mathrm{f}-1$ & $3235-0211$ \\
\hline Rule 18f-3 & $270.18 \mathrm{f}-3$ & $3235-0441$ \\
\hline Rule 19a-1 & $270.19 \mathrm{a}-1$ & $3235-0216$ \\
\hline Rule 20a-1 & $270-20 \mathrm{a}-1$ & $3235-0158$ \\
\hline Rule 22d-1 & $270-22 \mathrm{~d}-1$ & $3235-0310$ \\
\hline Rule 23c-1 & $270.23 \mathrm{c}-1$ & $3235-0260$ \\
\hline Rule 23c-3 & $270.23 \mathrm{c}-3$ & $3235-0422$ \\
\hline Rule 27e-1 & $270.27 \mathrm{e}-1$ & $3235-0545$ \\
\hline Rule 30b2-1 & $270.30 \mathrm{~b} 2-1$ & $3235-0220$ \\
\hline Rule 30d-2 & $270.30 \mathrm{~d}-2$ & $3235-0494$ \\
\hline Rule 30e-1 & $270.30 \mathrm{e}-1$ & $3235-0025$ \\
\hline Rule 31a-1 & $3235-0178$ \\
\hline
\end{tabular}




\begin{tabular}{|c|c|c|}
\hline Rule 31a-2 & 270.31a-2 & 3235-0179 \\
\hline Rule 32a-4 & 270.32a-4 & $3235-0530$ \\
\hline Rule 34b-1 & 270.34b-1 & $3235-0346$ \\
\hline Rule 35d-1 & $270-35 d-1$ & $3235-0548$ \\
\hline Form N-5 & 274.5 & $3235-0169$ \\
\hline Form N-8A & 274.10 & $3235-0175$ \\
\hline Form N-2 & 274.11a-1 & $3235-0026$ \\
\hline Form N-3 & $274.11 \mathrm{~b}$ & 3235-0316 \\
\hline Form N-4 & 274.11c & $3235-0318$ \\
\hline Form N-8B-2 & 274.12 & 3235-0186 \\
\hline Form N-6F & 274.15 & $3235-0238$ \\
\hline Form 24F-2 & 274.24 & $3235-0456$ \\
\hline Form N-18F-1 & 274.51 & $3235-0211$ \\
\hline Form N-54A & 274.53 & 3235-0237 \\
\hline Form N-54C & 274.54 & $3235-0236$ \\
\hline Form N-SAR & 274.101 & $3235-0330$ \\
\hline Form N-27E-1 & 274.127e-1 & $3235-0545$ \\
\hline Form N-27F-1 & 274.127f-1 & $3235-0546$ \\
\hline Form N-17D-1 & 274.200 & $3235-0229$ \\
\hline Form N-23C-1 & 274.201 & $3235-0230$ \\
\hline Form N-8F & 274.218 & $3235-0157$ \\
\hline Form N-17F-1 & 274.219 & 3235-0359 \\
\hline Form N-17F-2 & 274.220 & $3235-0360$ \\
\hline Form N-23c-3 & 274.221 & $3235-0422$ \\
\hline Form ET & 274.401 & $3235-0329$ \\
\hline Form ID & 274.402 & $3235-0328$ \\
\hline Form SE & 274.403 & $3235-0327$ \\
\hline Rule $0-2$ & $275.0-2$ & $3235-0240$ \\
\hline
\end{tabular}




\begin{tabular}{|l|l|l|}
\hline Rule 203-3 & $275.203-3$ & $3235-0538$ \\
\hline Rule 204-2 & $275.204-2$ & $3235-0278$ \\
\hline Rule 204-3 & $275.204-3$ & $3235-0047$ \\
\hline Rule 206(3)-2 & $275.206(3)-2$ & $3235-0243$ \\
\hline Rule 206(4)-2 & $275.206(4)-2$ & $3235-0241$ \\
\hline Rule 206(4)-3 & $275.206(4)-3$ & $3235-0242$ \\
\hline Rule 206(4)-4 & $275.206(4)-4$ & $3235-0345$ \\
\hline Form ADV & 279.1 & $3235-0049$ \\
\hline Schedule I to Form ADV & 279.1 & $3235-0490$ \\
\hline Form ADV-W & 279.2 & $3235-0313$ \\
\hline Form ADV-H & 379.3 & $3235-0538$ \\
\hline Form 4-R & 279.4 & $3235-0240$ \\
\hline Form 5-R & 279.5 & $3235-0240$ \\
\hline Form 6-R & 279.6 & $3235-0240$ \\
\hline Form 7-R & 279.7 & $3235-0240$ \\
\hline Form ADV-E & 279.8 & $3235-0361$ \\
\hline
\end{tabular}

\section{PART 201 - RULES OF PRACTICE}

5. The authority citation for part 201, subpart D, continues to read as follows:

Authority: $\quad 15$ U.S.C. 77f, 77g, 77h, , 77h-1, 77j, 77s, 77u, 78c(b), 78d-1, 78d-2, 781, 78m, 78n, 78ㅁ⒟, 78o-3, 78s, 78u-2, 78u-3, 78v, 78w, 79c, 79s, 79t, 79z-5a, 77sss, 77ttt, 80a-8, 80a-9, 80a-37, 80a-38, 80a-39, 80a-40, 80a-41, 80a-44, 80b-3, 80b-9, 80b-11, 80b-12, 7202, 7215, and 7217.

6. Section 201.101 is amended by revising paragraphs (a)(9)(vi) and (a)(9)(vii) to read as follows:

Subpart D - Rules of Practice 


\section{$\S$ 201.101 Definitions.}

(a) $* * *$
(9) $* * *$

(vi) By the filing, pursuant to $\S 242.601$ of this chapter, of an application for review of an action or failure to act in connection with the implementation or operation of any effective transaction reporting plan; or

(vii) By the filing, pursuant to $\S 242.608$ of this chapter, of an application for review of an action taken or failure to act in connection with the implementation or operation of any effective national market system plan; or

\section{PART 230-GENERAL RULES AND REGULATIONS, SECURITIES ACT OF 1933}

7. The authority citation for part 230 continues to read in part as follows:

Authority: 15 U.S.C. 77b, 77c, 77d, 77f, 77g, 77h, 77j, 77r, 77s, 77z-3, 77sss, 78c, 78d, 78j, 78l, 78m, 78n, 78o, 78t, 78w, 78l⒟, 78mm, 79t, 80a-8, 80a-24, 80a-28, 80a-29, 80a-30, and $80 \mathrm{a}-37$, unless otherwise noted.

8. Section 230.144 is amended by:

a. $\quad$ Removing the authority citation following $§ 230.144$; and

b. $\quad$ Revising paragraph (e)(1)(iii).

The revision reads as follows:

\section{$\S 230.144$ Persons deemed not to be engaged in a distribution and therefore not} underwriters. 
(e) $* * *$

(1) $* * *$

(iii) The average weekly volume of trading in such securities reported pursuant to an

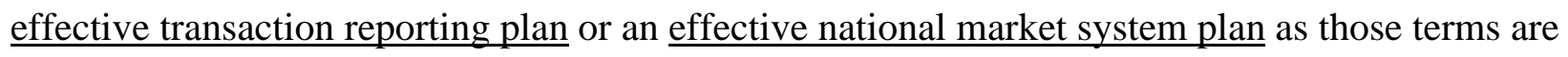
defined in $\S 242.600$ of this chapter during the four-week period specified in paragraph (e)(1)(ii) of this section.

\section{PART 240-GENERAL RULES AND REGULATIONS, SECURITIES EXCHANGE}

\section{ACT OF 1934}

9. The authority citation for part 240 continues to read as follows:

Authority: 15 U.S.C. 77c, 77d, 77g, 77j, 77s, 77z-2, 77z-3, 77eee, 77ggg, 77nnn, 77sss, 77ttt, 78c, 78d, 78e, 78f, 78g, 78i, 78j, 78j-1, 78k, 78k-1, 78l, 78m, 78n, 78o, 78p, 78q, 78s, 78u-5, 78w, 78x, 78ll, 78mm, 79q, 79t, 80a-20, 80a-23, 80a-29, 80a-37, 80b-3, 80b-4, 80b11, and 7201 et seq.; and 18 U.S.C. 1350, unless otherwise noted.

10. Section 240.0-10 is amended by revising paragraph (e)(1) to read as follows:

\section{$\S$ 240.0-10 Small entities under the Securities Exchange Act for purposes of the Regulatory} Flexibility Act.

(e) $\quad * * *$

(1) Has been exempted from the reporting requirements of $\S 242.601$ of this chapter; and 
11. Section 240.3a51-1 is amended by revising the introductory text of paragraphs (a) and (e) to read as follows:

\section{$\S$ 240.3a51-1 Definition of "penny stock”.}

(a) That is an NMS stock, as defined in $\S 242.600$ of this chapter:

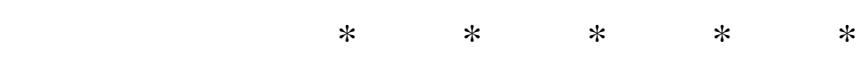

(e) That is registered, or approved for registration upon notice of issuance, on a national securities exchange that makes transaction reports available pursuant to $§ 242.601$ of this chapter, provided that:

12. Section $240.3 \mathrm{~b}-16$ is amended by revising paragraph (d) to read as follows:

\section{$\S 240.3 b-16$ Definitions of terms used in Section 3(a)(1) of the Act.}

(d) For the purposes of this section, the terms bid and offer shall have the same meaning as under $\S 242.600$ of this chapter.

13. Section 240.10a-1 is amended by revising paragraphs (a)(1), (e)(5)(ii) and (e)(11) to read as follows:

\section{§ 240.10a-1 Short sales.}

(a)(1)(i) No person shall, for his own account or for the account of any other person, effect a short sale of any security registered on, or admitted to unlisted trading privileges on, a national securities exchange, if trades in such securities are reported pursuant to an "effective 
transaction reporting plan" as defined in $§ 242.600$ of this chapter and information as to such trades is made available in accordance with such plan on a real-time basis to vendors of market transaction information:

(A) Below the price at which the last sale thereof, regular way, was reported pursuant to an effective transaction reporting plan; or

(B) At such price unless such price is above the next proceeding different price at which a sale of such security, regular way, was reported pursuant to an effective transaction reporting plan.

(ii) The provisions of paragraph (a)(1)(i) of this section hereof shall not apply to transactions by any person in Nasdaq securities as defined in $\S 242.600$ of this chapter, except for those Nasdaq securities for which transaction reports are collected, processed, and made available pursuant to the plan originally submitted to the Commission pursuant to $§ 240.17 a-15$ (subsequently amended and redesignated as $\S 240.11$ Aa3-1 and subsequently redesignated as $\S$ 242.601 of this chapter), which plan was declared effective as of May 17, 1974.

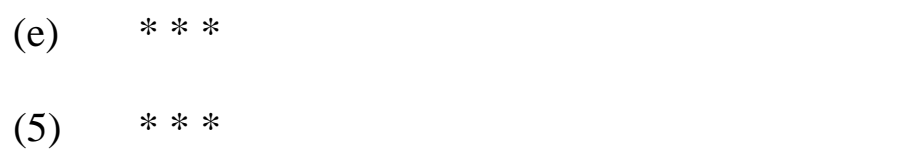

(ii) Effected at a price equal to the most recent offer communicated for the security by such registered specialist, registered exchange market maker or third market maker to an exchange or a national securities association ("association") pursuant to $§ 242.602$ of this chapter, if such offer, when communicated, was equal to or above the last sale, regular way, reported for such security pursuant to an effective transaction reporting plan: 
Provided, however, That any exchange, by rule, may prohibit its registered specialist and registered exchange market makers from availing themselves of the exemption afforded by this paragraph (e)(5) if that exchange determines that such action is necessary or appropriate in its market in the public interest or for the protection of investors;

(11) Any sale of a security covered by paragraph (a) of this section (except a sale to a stabilizing bid complying with $\S 242.104$ of this chapter) by any broker or dealer, for his own account or for the account of any other person, effected at a price equal to the most recent offer communicated by such broker or dealer to an exchange or association pursuant to $\S 242.602$ of this chapter in an amount less than or equal to the quotation size associated with such offer, if such offer, when communicated, was:

(i) Above the price at which the last sale, regular way, for such security was reported pursuant to an effective transaction reporting plan; or

(ii) At such last sale price, if such last sale price is above the next preceding different price at which a sale of such security, regular way, was reported pursuant to an effective transaction reporting plan.

14. Section $240.10 b-10$ is amended by:

a. $\quad$ Revising paragraphs (a)(2)(i)(C), (a)(2)(ii)(B) and (d)(7);

b. $\quad$ Removing paragraph (d)(8); and

c. Redesignating paragraphs (d)(9) and (d)(10) as paragraphs (d)(8) and (d)(9).

The revisions read as follows:

\section{§ 240.10b-10 Confirmation of transactions.}




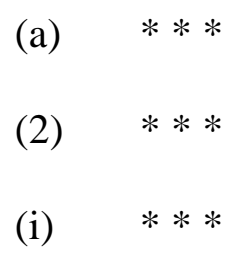

(C) For a transaction in any NMS stock as defined in $\S 242.600$ of this chapter or a security authorized for quotation on an automated interdealer quotation system that has the characteristics set forth in section 17B of the Act (15 U.S.C. 78q-2), a statement whether payment for order flow is received by the broker or dealer for transactions in such securities and the fact that the source and nature of the compensation received in connection with the particular transaction will be furnished upon written request of the customer; provided, however, that brokers or dealers that do not receive payment for order flow in connection with any transaction have no disclosure obligations under this paragraph; and

(ii) $* * *$

(B) In the case of any other transaction in an NMS stock as defined by $\S 242.600$ of this chapter, or an equity security that is traded on a national securities exchange and that is subject to last sale reporting, the reported trade price, the price to the customer in the transaction, and the difference, if any, between the reported trade price and the price to the customer.

(d) $* * *$

(7) NMS stock shall have the meaning provided in $\S 242.600$ of this chapter. 
15. Section $240.10 \mathrm{~b}-18$ is amended by revising paragraph (a)(6) to read as follows: $\S 240.10 b-18$ - Purchases of certain equity securities by the issuer and others.

(a) $* * *$

(6) Consolidated system means a consolidated transaction or quotation reporting system that collects and publicly disseminates on a current and continuous basis transaction or quotation information in common equity securities pursuant to an effective transaction reporting plan or an effective national market system plan (as those terms are defined in $\S 242.600$ of this chapter).

\section{§ 240.11Aa2-1 through 240.11Ac1-6 [Removed]}

16. The undesignated center heading preceding § 240.11Aa2-1 and §§ 240.11Aa2-1 through 240.11Ac1-6 are removed.

17. Section 240.12a-7 is amended by revising the introductory text of paragraph (a)(2) to read as follows:

\section{§ 240.12a-7 Exemption of stock contained in standardized market baskets from section} 12(a) of the Act.

(a) $* * *$

(2) The stock is an NMS stock as defined in $\S 242.600$ of this chapter and is either:

18. Section $240.12 \mathrm{f}-1$ is amended by:

a. Removing the authority citation following the section;

b. Removing “and” at the end of paragraph (a)(3); and 
c. Revising paragraph (a)(4).

The revision reads as follows:

\section{§ 240.12f-1 Applications for permission to reinstate unlisted trading privileges.}

(a)

(4) Whether transaction information concerning such security is reported pursuant to an effective transaction reporting plan contemplated by $\S 242.601$ of this chapter;

19. Section $240.12 \mathrm{f}-2$ is amended by revising paragraph (a) to read as follows:

\section{$\S$ 240.12f-2 Extending unlisted trading privileges to a security that is the subject of an initial public offering.}

(a) General provision. A national securities exchange may extend unlisted trading privileges to a subject security when at least one transaction in the subject security has been effected on the national securities exchange upon which the security is listed and the transaction has been reported pursuant to an effective transaction reporting plan, as defined in $\S 242.600$ of this chapter.

20. Section $240.15 b 9-1$ is amended by:

a. Removing the authority citation following the section; and

b. $\quad$ Revising paragraph (c).

The revision reads as follows:

\section{§ 240.15b9-1 Exemption for certain exchange members.}


(c) For purposes of this section, the term Intermarket Trading System shall mean the intermarket communications linkage operated jointly by certain self-regulatory organizations pursuant to a plan filed with, and approved by, the Commission pursuant to $\S 242.608$ of this chapter.

21. Section 240.15c2-11 is amended by revising paragraph (f)(5) to read as follows:

\section{$\S \mathbf{2 4 0 . 1 5 c 2 - 1 1}$ Initiation or resumption of quotations without specified information.}

(f) $\quad * * *$

(5) The publication or submission of a quotation respecting a Nasdaq security (as defined in $\S 242.600$ of this chapter), and such security's listing is not suspended, terminated, or prohibited.

22. Section 240.19c-3 is amended by revising paragraph (b)(6) to read as follows: § 240.19c-3 Governing off-board trading by members of national securities exchanges.

(b) $* * *$

(6) The term effective transaction reporting plan shall mean any plan approved by the Commission pursuant to $\S 242.601$ of this chapter for collecting, processing, and making available transaction reports with respect to transactions in an equity security or class of equity securities.

23. Section 240.19c-4 is amended by revising paragraph (e)(6) to read as follows: § 240.19c-4 Governing certain listing or authorization determinations by national securities exchanges and associations. 
(e) $\quad * * *$

(6) The term exchange shall mean a national securities exchange, registered as such with the Securities and Exchange Commission pursuant to section 6 of the Act (15 U.S.C. 78f), which makes transaction reports available pursuant to $\S 242.601$ of this chapter; and

24. Section 240.31 is amended by revising paragraph (a)(11)(v) to read as follows:

\section{$\S 240.31$ Section 31 transaction fees.}

(a) $* * *$
(11) $* * *$

(v) Any sale of a security that is executed outside the United States and is not reported, or required to be reported, to a transaction reporting association as defined in $\S 242.600$ of this chapter and any approved plan filed thereunder;

\section{PART 242-REGULATIONS M, SHO, ATS, AC, AND NMS AND CUSTOMER MARGIN REQUIREMENTS FOR SECURITY FUTURES}

25. The authority citation for part 242 continues to read as follow:

Authority: 15 U.S.C. 77g, 77q(a), 77s(a), 78b, 78c, 78g(c)(2), 78i(a), 78j, 78k-1(c), 78l, 78m, 78n, 78o(b), 78o(c), 78o(g), 78q(a), 78q(b), 78q(h), 78w(a), 78dd-1, 78mm, 80a-23, 80a29, and $80 \mathrm{a}-37$.

26. The part heading for part 242 is revised as set forth above.

27. Section 242.100 is amended by revising the definition for "electronic communications network" and "Nasdaq" found in paragraph (b) to read as follows:

\section{$\S$ 242.100 Preliminary note; definitions.}


(b) $* * *$

Electronic communications network has the meaning provided in $\S 242.600$.

Nasdaq means the electronic dealer quotation system owned and operated by The Nasdaq Stock Market, Inc.

28. Section 242.300 is amended by:

a. $\quad$ Revising paragraphs (g) and (h);

b. Removing paragraphs (i) and (j); and

c. $\quad$ Redesignating paragraphs (k), (l), and (m) as paragraphs (i), (j), and (k).

The revisions read as follows:

\section{$\S$ 242.300 Definitions.}

(g) NMS stock shall have the meaning provided in § 242.600; provided, however, that a debt or convertible debt security shall not be deemed an NMS stock for purposes of this Regulation ATS.

(h) $\quad$ Effective transaction reporting plan shall have the meaning provided in $\S 242.600$.

29. Section 242.301 is amended by revising paragraphs (b)(3), (b)(5), and (b)(6) to read as follows:

$\S$ 242.301 Requirements for alternative trading systems. 
(b) $* * *$

(3) $\quad$ Order display and execution access.

(i) An alternative trading system shall comply with the requirements set forth in paragraph (b)(3)(ii) of this section, with respect to any NMS stock in which the alternative trading system:

(A) Displays subscriber orders to any person (other than alternative trading system employees); and

(B) During at least 4 of the preceding 6 calendar months, had an average daily trading volume of 5 percent or more of the aggregate average daily share volume for such NMS stock as reported by an effective transaction reporting plan.

(ii) Such alternative trading system shall provide to a national securities exchange or national securities association the prices and sizes of the orders at the highest buy price and the lowest sell price for such NMS stock, displayed to more than one person in the alternative trading system, for inclusion in the quotation data made available by the national securities exchange or national securities association to vendors pursuant to $\S 242.602$.

(iii) With respect to any order displayed pursuant to paragraph (b)(3)(ii) of this section, an alternative trading system shall provide to any broker-dealer that has access to the national securities exchange or national securities association to which the alternative trading system provides the prices and sizes of displayed orders pursuant to paragraph (b)(3)(ii) of this section, the ability to effect a transaction with such orders that is:

(A) Equivalent to the ability of such broker-dealer to effect a transaction with other orders displayed on the exchange or by the association; and 
(B) At the price of the highest priced buy order or lowest priced sell order displayed for the lesser of the cumulative size of such priced orders entered therein at such price, or the size of the execution sought by such broker-dealer.

(5) $\quad$ Fair access.

(i) An alternative trading system shall comply with the requirements in paragraph (b)(5)(ii) of this section, if during at least 4 of the preceding 6 calendar months, such alternative trading system had:

(A) With respect to any NMS stock, 5 percent or more of the average daily volume in that security reported by an effective transaction reporting plan;

(B) With respect to an equity security that is not an NMS stock and for which transactions are reported to a self-regulatory organization, 5 percent or more of the average daily trading volume in that security as calculated by the self-regulatory organization to which such transactions are reported;

(C) With respect to municipal securities, 5 percent or more of the average daily volume traded in the United States;

(D) With respect to investment grade corporate debt, 5 percent or more of the average daily volume traded in the United States; or

(E) With respect to non-investment grade corporate debt, 5 percent or more of the average daily volume traded in the United States.

(ii) An alternative trading system shall:

(A) Establish written standards for granting access to trading on its system; 
(B) Not unreasonably prohibit or limit any person in respect to access to services offered by such alternative trading system by applying the standards established under paragraph (b)(5)(ii)(A) of this section in an unfair or discriminatory manner;

(C) Make and keep records of:

(1) All grants of access including, for all subscribers, the reasons for granting such access; and

(2) All denials or limitations of access and reasons, for each applicant, for denying or limiting access; and

(D) Report the information required on Form ATS-R (§ 249.638 of this chapter) regarding grants, denials, and limitations of access.

(iii) Notwithstanding paragraph (b)(5)(i) of this section, an alternative trading system shall not be required to comply with the requirements in paragraph (b)(5)(ii) of this section, if such alternative trading system:

(A) Matches customer orders for a security with other customer orders;

(B) Such customers' orders are not displayed to any person, other than employees of the alternative trading system; and

(C) Such orders are executed at a price for such security disseminated by an effective transaction reporting plan, or derived from such prices.

(6) Capacity, integrity, and security of automated systems.

(i) The alternative trading system shall comply with the requirements in paragraph (b)(6)(ii) of this section, if during at least 4 of the preceding 6 calendar months, such alternative trading system had: 
(A) With respect to any NMS stock, 20 percent or more of the average daily volume reported by an effective transaction reporting plan;

(B) With respect to equity securities that are not NMS stocks and for which transactions are reported to a self-regulatory organization, 20 percent or more of the average daily volume as calculated by the self-regulatory organization to which such transactions are reported;

(C) With respect to municipal securities, 20 percent or more of the average daily volume traded in the United States;

(D) With respect to investment grade corporate debt, 20 percent or more of the average daily volume traded in the United States; or

(E) With respect to non-investment grade corporate debt, 20 percent or more of the average daily volume traded in the United States.

(ii) With respect to those systems that support order entry, order routing, order execution, transaction reporting, and trade comparison, the alternative trading system shall:

(A) Establish reasonable current and future capacity estimates;

(B) Conduct periodic capacity stress tests of critical systems to determine such system’s ability to process transactions in an accurate, timely, and efficient manner;

(C) Develop and implement reasonable procedures to review and keep current its system development and testing methodology;

(D) Review the vulnerability of its systems and data center computer operations to internal and external threats, physical hazards, and natural disasters;

(E) Establish adequate contingency and disaster recovery plans; 
(F) On an annual basis, perform an independent review, in accordance with established audit procedures and standards, of such alternative trading system's controls for ensuring that paragraphs (b)(6)(ii)(A) through (E) of this section are met, and conduct a review by senior management of a report containing the recommendations and conclusions of the independent review; and

(G) Promptly notify the Commission staff of material systems outages and significant systems changes.

(iii) Notwithstanding paragraph (b)(6)(i) of this section, an alternative trading system shall not be required to comply with the requirements in paragraph (b)(6)(ii) of this section, if such alternative trading system:

(A) Matches customer orders for a security with other customer orders;

(B) Such customers' orders are not displayed to any person, other than employees of the alternative trading system; and

(C) Such orders are executed at a price for such security disseminated by an effective transaction reporting plan, or derived from such prices.

30. Part 242 is amended by adding Regulation NMS, $\S \S 242.600$ through 242.612 to read as follows:

\section{REGULATION NMS - REGULATION OF THE NATIONAL MARKET SYSTEM} Sec.

242.600 NMS security designation and definitions.

242.601 Dissemination of transaction reports and last sale data with respect to transactions in NMS stocks. 
242.602 Dissemination of quotations in NMS securities.

242.603 Distribution, consolidation, and display of information with respect to quotations for and transactions in NMS stocks.

242.604 Display of customer limit orders.

242.605 Disclosure of order execution information.

242.606 Disclosure of order routing information.

242.607 Customer account statements.

242.608 Filing and amendment of national market system plans.

242.609 Registration of securities information processors: form of application and amendments.

242.610 Access to quotations.

242.611 Order protection rule.

242.612 Minimum pricing increment.

\section{REGULATION NMS - REGULATION OF THE NATIONAL MARKET SYSTEM}

\section{$\S 242.600$ NMS security designation and definitions.}

(a) The term national market system security as used in section 11A(a)(2) of the Act (15 U.S.C. 78k-1(a)(2)) shall mean any NMS security as defined in paragraph (b) of this section.

(b) For purposes of Regulation NMS (§§ 242.600 through 242.612), the following definitions shall apply:

(1) Aggregate quotation size means the sum of the quotation sizes of all responsible brokers or dealers who have communicated on any national securities exchange bids or offers for an NMS security at the same price.

(2) Alternative trading system has the meaning provided in $\S 242.300(a)$.

(3) Automated quotation means a quotation displayed by a trading center that: 
(i) Permits an incoming order to be marked as immediate-or-cancel;

(ii) Immediately and automatically executes an order marked as immediate-or-cancel against the displayed quotation up to its full size;

(iii) Immediately and automatically cancels any unexecuted portion of an order marked as immediate-or-cancel without routing the order elsewhere;

(iv) Immediately and automatically transmits a response to the sender of an order marked as immediate-or-cancel indicating the action taken with respect to such order; and

(v) Immediately and automatically displays information that updates the displayed quotation to reflect any change to its material terms.

(4) Automated trading center means a trading center that:

(i) Has implemented such systems, procedures, and rules as are necessary to render it capable of displaying quotations that meet the requirements for an automated quotation set forth in paragraph (b)(3) of this section;

(ii) Identifies all quotations other than automated quotations as manual quotations;

(iii) Immediately identifies its quotations as manual quotations whenever it has reason to believe that it is not capable of displaying automated quotations; and

(iv) Has adopted reasonable standards limiting when its quotations change from automated quotations to manual quotations, and vice versa, to specifically defined circumstances that promote fair and efficient access to its automated quotations and are consistent with the maintenance of fair and orderly markets.

(5) Average effective spread means the share-weighted average of effective spreads for order executions calculated, for buy orders, as double the amount of difference between the execution price and the midpoint of the national best bid and national best offer at the time of 
order receipt and, for sell orders, as double the amount of difference between the midpoint of the national best bid and national best offer at the time of order receipt and the execution price.

(6) Average realized spread means the share-weighted average of realized spreads for order executions calculated, for buy orders, as double the amount of difference between the execution price and the midpoint of the national best bid and national best offer five minutes after the time of order execution and, for sell orders, as double the amount of difference between the midpoint of the national best bid and national best offer five minutes after the time of order execution and the execution price; provided, however, that the midpoint of the final national best bid and national best offer disseminated for regular trading hours shall be used to calculate a realized spread if it is disseminated less than five minutes after the time of order execution.

(7) Best bid and best offer mean the highest priced bid and the lowest priced offer.

(8) Bid or offer means the bid price or the offer price communicated by a member of a national securities exchange or member of a national securities association to any broker or dealer, or to any customer, at which it is willing to buy or sell one or more round lots of an NMS security, as either principal or agent, but shall not include indications of interest.

(9) Block size with respect to an order means it is:

(i) Of at least 10,000 shares; or

(ii) For a quantity of stock having a market value of at least $\$ 200,000$.

(10) Categorized by order size means dividing orders into separate categories for sizes from 100 to 499 shares, from 500 to 1999 shares, from 2000 to 4999 shares, and 5000 or greater shares. 
(11) Categorized by order type means dividing orders into separate categories for market orders, marketable limit orders, inside-the-quote limit orders, at-the-quote limit orders, and near-the-quote limit orders.

(12) Categorized by security means dividing orders into separate categories for each NMS stock that is included in a report.

(13) Consolidated display means:

(i) The prices, sizes, and market identifications of the national best bid and national best offer for a security; and

(ii) Consolidated last sale information for a security.

(14) Consolidated last sale information means the price, volume, and market identification of the most recent transaction report for a security that is disseminated pursuant to an effective national market system plan.

(15) Covered order means any market order or any limit order (including immediateor-cancel orders) received by a market center during regular trading hours at a time when a national best bid and national best offer is being disseminated, and, if executed, is executed during regular trading hours, but shall exclude any order for which the customer requests special handling for execution, including, but not limited to, orders to be executed at a market opening price or a market closing price, orders submitted with stop prices, orders to be executed only at their full size, orders to be executed on a particular type of tick or bid, orders submitted on a "not held” basis, orders for other than regular settlement, and orders to be executed at prices unrelated to the market price of the security at the time of execution.

(16) Customer means any person that is not a broker or dealer. 
(17) Customer limit order means an order to buy or sell an NMS stock at a specified price that is not for the account of either a broker or dealer; provided, however, that the term customer limit order shall include an order transmitted by a broker or dealer on behalf of a customer.

(18) Customer order means an order to buy or sell an NMS security that is not for the account of a broker or dealer, but shall not include any order for a quantity of a security having a market value of at least $\$ 50,000$ for an NMS security that is an option contract and a market value of at least $\$ 200,000$ for any other NMS security.

(19) Directed order means a customer order that the customer specifically instructed the broker or dealer to route to a particular venue for execution.

(20) Dynamic market monitoring device means any service provided by a vendor on an interrogation device or other display that:

(i) Permits real-time monitoring, on a dynamic basis, of transaction reports, last sale data, or quotations with respect to a particular security; and

(ii) Displays the most recent transaction report, last sale data, or quotation with respect to that security until such report, data, or quotation has been superseded or supplemented by the display of a new transaction report, last sale data, or quotation reflecting the next reported transaction or quotation in that security.

(21) Effective national market system plan means any national market system plan approved by the Commission (either temporarily or on a permanent basis) pursuant to $§ 242.608$.

(22) Effective transaction reporting plan means any transaction reporting plan approved by the Commission pursuant to $\S 242.601$. 
(23) Electronic communications network means, for the purposes of $\S 242.602(b)(5)$, any electronic system that widely disseminates to third parties orders entered therein by an exchange market maker or OTC market maker, and permits such orders to be executed against in whole or in part; except that the term electronic communications network shall not include:

(i) Any system that crosses multiple orders at one or more specified times at a single price set by the system (by algorithm or by any derivative pricing mechanism) and does not allow orders to be crossed or executed against directly by participants outside of such times; or

(ii) Any system operated by, or on behalf of, an OTC market maker or exchange market maker that executes customer orders primarily against the account of such market maker as principal, other than riskless principal.

(24) Exchange market maker means any member of a national securities exchange that is registered as a specialist or market maker pursuant to the rules of such exchange.

(25) Exchange-traded security means any NMS security or class of NMS securities listed and registered, or admitted to unlisted trading privileges, on a national securities exchange; provided, however, that securities not listed on any national securities exchange that are traded pursuant to unlisted trading privileges are excluded.

(26) Executed at the quote means, for buy orders, execution at a price equal to the national best offer at the time of order receipt and, for sell orders, execution at a price equal to the national best bid at the time of order receipt.

(27) Executed outside the quote means, for buy orders, execution at a price higher than the national best offer at the time of order receipt and, for sell orders, execution at a price lower than the national best bid at the time of order receipt. 
(28) Executed with price improvement means, for buy orders, execution at a price lower than the national best offer at the time of order receipt and, for sell orders, execution at a price higher than the national best bid at the time of order receipt.

(29) Inside-the-quote limit order, at-the-quote limit order, and near-the-quote limit order mean non-marketable buy orders with limit prices that are, respectively, higher than, equal to, and lower by $\$ 0.10$ or less than the national best bid at the time of order receipt, and nonmarketable sell orders with limit prices that are, respectively, lower than, equal to, and higher by $\$ 0.10$ or less than the national best offer at the time of order receipt.

(30) Intermarket sweep order means a limit order for an NMS stock that meets the following requirements:

(i) When routed to a trading center, the limit order is identified as an intermarket sweep order; and

(ii) Simultaneously with the routing of the limit order identified as an intermarket sweep order, one or more additional limit orders, as necessary, are routed to execute against the full displayed size of any protected bid, in the case of a limit order to sell, or the full displayed size of any protected offer, in the case of a limit order to buy, for the NMS stock with a price that is superior to the limit price of the limit order identified as an intermarket sweep order. These additional routed orders also must be marked as intermarket sweep orders.

(31) Interrogation device means any securities information retrieval system capable of displaying transaction reports, last sale data, or quotations upon inquiry, on a current basis on a terminal or other device.

(32) Joint self-regulatory organization plan means a plan as to which two or more selfregulatory organizations, acting jointly, are sponsors. 
(33) Last sale data means any price or volume data associated with a transaction.

(34) Listed equity security means any equity security listed and registered, or admitted to unlisted trading privileges, on a national securities exchange.

(35) Listed option means any option traded on a registered national securities exchange or automated facility of a national securities association.

(36) Make publicly available means posting on an Internet Web site that is free and readily accessible to the public, furnishing a written copy to customers on request without charge, and notifying customers at least annually in writing that a written copy will be furnished on request.

(37) Manual quotation means any quotation other than an automated quotation.

(38) Market center means any exchange market maker, OTC market maker, alternative trading system, national securities exchange, or national securities association.

(39) Marketable limit order means any buy order with a limit price equal to or greater than the national best offer at the time of order receipt, or any sell order with a limit price equal to or less than the national best bid at the time of order receipt.

(40) Moving ticker means any continuous real-time moving display of transaction reports or last sale data (other than a dynamic market monitoring device) provided on an interrogation or other display device.

(41) Nasdaq security means any registered security listed on The Nasdaq Stock Market, Inc.

(42) National best bid and national best offer means, with respect to quotations for an NMS security, the best bid and best offer for such security that are calculated and disseminated on a current and continuing basis by a plan processor pursuant to an effective national market 
system plan; provided, that in the event two or more market centers transmit to the plan processor pursuant to such plan identical bids or offers for an NMS security, the best bid or best offer (as the case may be) shall be determined by ranking all such identical bids or offers (as the case may be) first by size (giving the highest ranking to the bid or offer associated with the largest size), and then by time (giving the highest ranking to the bid or offer received first in time).

(43) National market system plan means any joint self-regulatory organization plan in connection with:

(i) The planning, development, operation or regulation of a national market system (or a subsystem thereof) or one or more facilities thereof; or

(ii) The development and implementation of procedures and/or facilities designed to achieve compliance by self-regulatory organizations and their members with any section of this Regulation NMS and part 240, subpart A of this chapter promulgated pursuant to section 11A of the Act (15 U.S.C. 78k-1).

(44) National securities association means any association of brokers and dealers registered pursuant to section 15A of the Act (15 U.S.C. 78o-3).

(45) National securities exchange means any exchange registered pursuant to section 6 of the Act (15 U.S.C. 78f).

(46) NMS security means any security or class of securities for which transaction reports are collected, processed, and made available pursuant to an effective transaction reporting plan, or an effective national market system plan for reporting transactions in listed options.

(47) NMS stock means any NMS security other than an option.

(48) Non-directed order means any customer order other than a directed order. 
(49) Odd-lot means an order for the purchase or sale of an NMS stock in an amount less than a round lot.

(50) Options class means all of the put option or call option series overlying a security, as defined in section 3(a)(10) of the Act (15 U.S.C. 78c(a)(10)).

(51) Options series means the contracts in an options class that have the same unit of trade, expiration date, and exercise price, and other terms or conditions.

(52) OTC market maker means any dealer that holds itself out as being willing to buy from and sell to its customers, or others, in the United States, an NMS stock for its own account on a regular or continuous basis otherwise than on a national securities exchange in amounts of less than block size.

(53) Participants, when used in connection with a national market system plan, means any self-regulatory organization which has agreed to act in accordance with the terms of the plan but which is not a signatory of such plan.

(54) Payment for order flow has the meaning provided in $\S 240.10 \mathrm{~b}-10$ of this chapter.

(55) Plan processor means any self-regulatory organization or securities information processor acting as an exclusive processor in connection with the development, implementation and/or operation of any facility contemplated by an effective national market system plan.

(56) Profit-sharing relationship means any ownership or other type of affiliation under which the broker or dealer, directly or indirectly, may share in any profits that may be derived from the execution of non-directed orders.

(57) Protected bid or protected offer means a quotation in an NMS stock that:

(i) Is displayed by an automated trading center;

(ii) Is disseminated pursuant to an effective national market system plan; and 
(iii) Is an automated quotation that is the best bid or best offer of a national securities exchange, the best bid or best offer of The Nasdaq Stock Market, Inc., or the best bid or best offer of a national securities association other than the best bid or best offer of The Nasdaq Stock Market, Inc.

(58) Protected quotation means a protected bid or a protected offer.

(59) Published aggregate quotation size means the aggregate quotation size calculated by a national securities exchange and displayed by a vendor on a terminal or other display device at the time an order is presented for execution to a responsible broker or dealer.

(60) Published bid and published offer means the bid or offer of a responsible broker or dealer for an NMS security communicated by it to its national securities exchange or association pursuant to § 242.602 and displayed by a vendor on a terminal or other display device at the time an order is presented for execution to such responsible broker or dealer.

(61) Published quotation size means the quotation size of a responsible broker or dealer communicated by it to its national securities exchange or association pursuant to $\S$ 242.602 and displayed by a vendor on a terminal or other display device at the time an order is presented for execution to such responsible broker or dealer.

(62) Quotation means a bid or an offer.

(63) Quotation size, when used with respect to a responsible broker's or dealer's bid or offer for an NMS security, means:

(i) The number of shares (or units of trading) of that security which such responsible broker or dealer has specified, for purposes of dissemination to vendors, that it is willing to buy at the bid price or sell at the offer price comprising its bid or offer, as either principal or agent; or 
(ii) In the event such responsible broker or dealer has not so specified, a normal unit of trading for that NMS security.

(64) Regular trading hours means the time between 9:30 a.m. and 4:00 p.m. Eastern Time, or such other time as is set forth in the procedures established pursuant to § 242.605(a)(2).

(65) Responsible broker or dealer means:

(i) When used with respect to bids or offers communicated on a national securities exchange, any member of such national securities exchange who communicates to another member on such national securities exchange, at the location (or locations) or through the facility or facilities designated by such national securities exchange for trading in an NMS security a bid or offer for such NMS security, as either principal or agent; provided, however, that, in the event two or more members of a national securities exchange have communicated on or through such national securities exchange bids or offers for an NMS security at the same price, each such member shall be considered a responsible broker or dealer for that bid or offer, subject to the rules of priority and precedence then in effect on that national securities exchange; and further provided, that for a bid or offer which is transmitted from one member of a national securities exchange to another member who undertakes to represent such bid or offer on such national securities exchange as agent, only the last member who undertakes to represent such bid or offer as agent shall be considered the responsible broker or dealer for that bid or offer; and

(ii) When used with respect to bids and offers communicated by a member of an association to a broker or dealer or a customer, the member communicating the bid or offer (regardless of whether such bid or offer is for its own account or on behalf of another person).

(66) Revised bid or offer means a market maker's bid or offer which supersedes its published bid or published offer. 
(67) Revised quotation size means a market maker's quotation size which supersedes its published quotation size.

(68) Self-regulatory organization means any national securities exchange or national securities association.

(69) Specified persons, when used in connection with any notification required to be provided pursuant to $\S 242.602(a)(3)$ and any election (or withdrawal thereof) permitted under $\S$ 242.602(a)(5), means:

(i) Each vendor;

(ii) Each plan processor; and

(iii) The processor for the Options Price Reporting Authority (in the case of a notification for a subject security which is a class of securities underlying options admitted to trading on any national securities exchange).

(70) Sponsor, when used in connection with a national market system plan, means any self-regulatory organization which is a signatory to such plan and has agreed to act in accordance with the terms of the plan.

(71) SRO display-only facility means a facility operated by or on behalf of a national securities exchange or national securities association that displays quotations in a security, but does not execute orders against such quotations or present orders to members for execution.

(72) SRO trading facility means a facility operated by or on behalf of a national securities exchange or a national securities association that executes orders in a security or presents orders to members for execution.

(73) Subject security means:

(i) With respect to a national securities exchange: 
(A) Any exchange-traded security other than a security for which the executed volume of such exchange, during the most recent calendar quarter, comprised one percent or less of the aggregate trading volume for such security as reported pursuant to an effective transaction reporting plan or effective national market system plan; and

(B) Any other NMS security for which such exchange has in effect an election, pursuant to $\S 242.602(a)(5)(i)$, to collect, process, and make available to a vendor bids, offers, quotation sizes, and aggregate quotation sizes communicated on such exchange; and

(ii) With respect to a member of a national securities association:

(A) Any exchange-traded security for which such member acts in the capacity of an OTC market maker unless the executed volume of such member, during the most recent calendar quarter, comprised one percent or less of the aggregate trading volume for such security as reported pursuant to an effective transaction reporting plan or effective national market system plan; and

(B) Any other NMS security for which such member acts in the capacity of an OTC market maker and has in effect an election, pursuant to § 242.602(a)(5)(ii), to communicate to its association bids, offers, and quotation sizes for the purpose of making such bids, offers, and quotation sizes available to a vendor.

(74) Time of order execution means the time (to the second) that an order was executed at any venue.

(75) Time of order receipt means the time (to the second) that an order was received by a market center for execution.

(76) Time of the transaction has the meaning provided in $\S 240.10 \mathrm{~b}-10$ of this chapter. 
(77) Trade-through means the purchase or sale of an NMS stock during regular trading hours, either as principal or agent, at a price that is lower than a protected bid or higher than a protected offer.

(78) Trading center means a national securities exchange or national securities association that operates an SRO trading facility, an alternative trading system, an exchange market maker, an OTC market maker, or any other broker or dealer that executes orders internally by trading as principal or crossing orders as agent.

(79) Trading rotation means, with respect to an options class, the time period on a national securities exchange during which:

(i) Opening, re-opening, or closing transactions in options series in such options class are not yet completed; and

(ii) Continuous trading has not yet commenced or has not yet ended for the day in options series in such options class.

(80) Transaction report means a report containing the price and volume associated with a transaction involving the purchase or sale of one or more round lots of a security.

(81) Transaction reporting association means any person authorized to implement or administer any transaction reporting plan on behalf of persons acting jointly under § 242.601(a).

(82) Transaction reporting plan means any plan for collecting, processing, making available or disseminating transaction reports with respect to transactions in securities filed with the Commission pursuant to, and meeting the requirements of, § 242.601.

(83) Vendor means any securities information processor engaged in the business of disseminating transaction reports, last sale data, or quotations with respect to NMS securities to 
brokers, dealers, or investors on a real-time or other current and continuing basis, whether through an electronic communications network, moving ticker, or interrogation device.

\section{$\S$ 242.601 Dissemination of transaction reports and last sale data with respect to transactions in NMS stocks.}

(a) Filing and effectiveness of transaction reporting plans.

(1) Every national securities exchange shall file a transaction reporting plan regarding transactions in listed equity and Nasdaq securities executed through its facilities, and every national securities association shall file a transaction reporting plan regarding transactions in listed equity and Nasdaq securities executed by its members otherwise than on a national securities exchange.

(2) Any transaction reporting plan, or any amendment thereto, filed pursuant to this section shall be filed with the Commission, and considered for approval, in accordance with the procedures set forth in $\S 242.608$ (a) and (b). Any such plan, or amendment thereto, shall specify, at a minimum:

(i) The listed equity and Nasdaq securities or classes of such securities for which transaction reports shall be required by the plan;

(ii) Reporting requirements with respect to transactions in listed equity securities and Nasdaq securities, for any broker or dealer subject to the plan;

(iii) The manner of collecting, processing, sequencing, making available and disseminating transaction reports and last sale data reported pursuant to such plan;

(iv) The manner in which such transaction reports reported pursuant to such plan are to be consolidated with transaction reports from national securities exchanges and national securities associations reported pursuant to any other effective transaction reporting plan; 
(v) The applicable standards and methods which will be utilized to ensure promptness of reporting, and accuracy and completeness of transaction reports;

(vi) Any rules or procedures which may be adopted to ensure that transaction reports or last sale data will not be disseminated in a fraudulent or manipulative manner;

(vii) Specific terms of access to transaction reports made available or disseminated pursuant to the plan; and

(viii) That transaction reports or last sale data made available to any vendor for display on an interrogation device identify the marketplace where each transaction was executed.

(3) No transaction reporting plan filed pursuant to this section, or any amendment to an effective transaction reporting plan, shall become effective unless approved by the Commission or otherwise permitted in accordance with the procedures set forth in § 242.608.

(b) Prohibitions and reporting requirements.

(1) No broker or dealer may execute any transaction in, or induce or attempt to induce the purchase or sale of, any NMS stock:

(i) On or through the facilities of a national securities exchange unless there is an effective transaction reporting plan with respect to transactions in such security executed on or through such exchange facilities; or

(ii) Otherwise than on a national securities exchange unless there is an effective transaction reporting plan with respect to transactions in such security executed otherwise than on a national securities exchange by such broker or dealer.

(2) Every broker or dealer who is a member of a national securities exchange or national securities association shall promptly transmit to the exchange or association of which it 
is a member all information required by any effective transaction reporting plan filed by such exchange or association (either individually or jointly with other exchanges and/or associations).

(c) Retransmission of transaction reports or last sale data. Notwithstanding any provision of any effective transaction reporting plan, no national securities exchange or national securities association may, either individually or jointly, by rule, stated policy or practice, transaction reporting plan or otherwise, prohibit, condition or otherwise limit, directly or indirectly, the ability of any vendor to retransmit, for display in moving tickers, transaction reports or last sale data made available pursuant to any effective transaction reporting plan; provided, however, that a national securities exchange or national securities association may, by means of an effective transaction reporting plan, condition such retransmission upon appropriate undertakings to ensure that any charges for the distribution of transaction reports or last sale data in moving tickers permitted by paragraph (d) of this section are collected.

(d) Charges. Nothing in this section shall preclude any national securities exchange or national securities association, separately or jointly, pursuant to the terms of an effective transaction reporting plan, from imposing reasonable, uniform charges (irrespective of geographic location) for distribution of transaction reports or last sale data.

(e) Appeals. The Commission may, in its discretion, entertain appeals in connection with the implementation or operation of any effective transaction reporting plan in accordance with the provisions of § 242.608(d).

(f) Exemptions. The Commission may exempt from the provisions of this section, either unconditionally or on specified terms and conditions, any national securities exchange, national securities association, broker, dealer, or specified security if the Commission determines 
that such exemption is consistent with the public interest, the protection of investors and the removal of impediments to, and perfection of the mechanisms of, a national market system.

\section{§ 242.602 Dissemination of quotations in NMS securities.}

(a) Dissemination requirements for national securities exchanges and national securities associations.

(1) Every national securities exchange and national securities association shall establish and maintain procedures and mechanisms for collecting bids, offers, quotation sizes, and aggregate quotation sizes from responsible brokers or dealers who are members of such exchange or association, processing such bids, offers, and sizes, and making such bids, offers, and sizes available to vendors, as follows:

(i) Each national securities exchange shall at all times such exchange is open for trading, collect, process, and make available to vendors the best bid, the best offer, and aggregate quotation sizes for each subject security listed or admitted to unlisted trading privileges which is communicated on any national securities exchange by any responsible broker or dealer, but shall not include:

(A) Any bid or offer executed immediately after communication and any bid or offer communicated by a responsible broker or dealer other than an exchange market maker which is cancelled or withdrawn if not executed immediately after communication; and

(B) Any bid or offer communicated during a period when trading in that security has been suspended or halted, or prior to the commencement of trading in that security on any trading day, on that exchange.

(ii) Each national securities association shall, at all times that last sale information with respect to NMS securities is reported pursuant to an effective transaction reporting plan, 
collect, process, and make available to vendors the best bid, best offer, and quotation sizes communicated otherwise than on an exchange by each member of such association acting in the capacity of an OTC market maker for each subject security and the identity of that member (excluding any bid or offer executed immediately after communication), except during any period when over-the-counter trading in that security has been suspended.

(2) Each national securities exchange shall, with respect to each published bid and published offer representing a bid or offer of a member for a subject security, establish and maintain procedures for ascertaining and disclosing to other members of that exchange, upon presentation of orders sought to be executed by them in reliance upon paragraph (b)(2) of this section, the identity of the responsible broker or dealer who made such bid or offer and the quotation size associated with it.

(3)(i) If, at any time a national securities exchange is open for trading, such exchange determines, pursuant to rules approved by the Commission pursuant to section 19(b)(2) of the Act (15 U.S.C. 78s(b)(2)), that the level of trading activities or the existence of unusual market conditions is such that the exchange is incapable of collecting, processing, and making available to vendors the data for a subject security required to be made available pursuant to paragraph (a)(1) of this section in a manner that accurately reflects the current state of the market on such exchange, such exchange shall immediately notify all specified persons of that determination. Upon such notification, responsible brokers or dealers that are members of that exchange shall be relieved of their obligation under paragraphs (b)(2) and (c)(3) of this section and such exchange shall be relieved of its obligations under paragraphs (a)(1) and (2) of this section for that security; provided, however, that such exchange will continue, to the maximum extent 
practicable under the circumstances, to collect, process, and make available to vendors data for that security in accordance with paragraph (a)(1) of this section.

(ii) During any period a national securities exchange, or any responsible broker or dealer that is a member of that exchange, is relieved of any obligation imposed by this section for any subject security by virtue of a notification made pursuant to paragraph (a)(3)(i) of this section, such exchange shall monitor the activity or conditions which formed the basis for such notification and shall immediately renotify all specified persons when that exchange is once again capable of collecting, processing, and making available to vendors the data for that security required to be made available pursuant to paragraph (a)(1) of this section in a manner that accurately reflects the current state of the market on such exchange. Upon such renotification, any exchange or responsible broker or dealer which had been relieved of any obligation imposed by this section as a consequence of the prior notification shall again be subject to such obligation.

(4) Nothing in this section shall preclude any national securities exchange or national securities association from making available to vendors indications of interest or bids and offers for a subject security at any time such exchange or association is not required to do so pursuant to paragraph (a)(1) of this section.

(5)(i) Any national securities exchange may make an election for purposes of the definition of subject security in $\S 242.600(b)(73)$ for any NMS security, by collecting, processing, and making available bids, offers, quotation sizes, and aggregate quotation sizes in that security; except that for any NMS security previously listed or admitted to unlisted trading privileges on only one exchange and not traded by any OTC market maker, such election shall be 
made by notifying all specified persons, and shall be effective at the opening of trading on the business day following notification.

(ii) Any member of a national securities association acting in the capacity of an OTC market maker may make an election for purposes of the definition of subject security in $\S$ 242.600(b)(73) for any NMS security, by communicating to its association bids, offers, and quotation sizes in that security; except that for any other NMS security listed or admitted to unlisted trading privileges on only one exchange and not traded by any other OTC market maker, such election shall be made by notifying its association and all specified persons, and shall be effective at the opening of trading on the business day following notification.

(iii) The election of a national securities exchange or member of a national securities association for any NMS security pursuant to this paragraph (a)(5) shall cease to be in effect if such exchange or member ceases to make available or communicate bids, offers, and quotation sizes in such security.

(b) Obligations of responsible brokers and dealers.

(1) Each responsible broker or dealer shall promptly communicate to its national securities exchange or national securities association, pursuant to the procedures established by that exchange or association, its best bids, best offers, and quotation sizes for any subject security.

(2) Subject to the provisions of paragraph (b)(3) of this section, each responsible broker or dealer shall be obligated to execute any order to buy or sell a subject security, other than an odd-lot order, presented to it by another broker or dealer, or any other person belonging to a category of persons with whom such responsible broker or dealer customarily deals, at a price at least as favorable to such buyer or seller as the responsible broker's or dealer's published 
bid or published offer (exclusive of any commission, commission equivalent or differential customarily charged by such responsible broker or dealer in connection with execution of any such order) in any amount up to its published quotation size.

(3)(i) No responsible broker or dealer shall be obligated to execute a transaction for any subject security as provided in paragraph (b)(2) of this section to purchase or sell that subject security in an amount greater than such revised quotation size if:

(A) Prior to the presentation of an order for the purchase or sale of a subject security, a responsible broker or dealer has communicated to its exchange or association, pursuant to paragraph (b)(1) of this section, a revised quotation size; or

(B) At the time an order for the purchase or sale of a subject security is presented, a responsible broker or dealer is in the process of effecting a transaction in such subject security, and immediately after the completion of such transaction, it communicates to its exchange or association a revised quotation size, such responsible broker or dealer shall not be obligated by paragraph (b)(2) of this section to purchase or sell that subject security in an amount greater than such revised quotation size.

(ii) No responsible broker or dealer shall be obligated to execute a transaction for any subject security as provided in paragraph (b)(2) of this section if:

(A) Before the order sought to be executed is presented, such responsible broker or dealer has communicated to its exchange or association pursuant to paragraph (b)(1) of this section, a revised bid or offer; or

(B) At the time the order sought to be executed is presented, such responsible broker or dealer is in the process of effecting a transaction in such subject security, and, immediately after the completion of such transaction, such responsible broker or dealer communicates to its 
exchange or association pursuant to paragraph (b)(1) of this section, a revised bid or offer; provided, however, that such responsible broker or dealer shall nonetheless be obligated to execute any such order in such subject security as provided in paragraph (b)(2) of this section at its revised bid or offer in any amount up to its published quotation size or revised quotation size.

(4) Subject to the provisions of paragraph (a)(4) of this section:

(i) No national securities exchange or OTC market maker may make available, disseminate or otherwise communicate to any vendor, directly or indirectly, for display on a terminal or other display device any bid, offer, quotation size, or aggregate quotation size for any NMS security which is not a subject security with respect to such exchange or OTC market maker; and

(ii) No vendor may disseminate or display on a terminal or other display device any bid, offer, quotation size, or aggregate quotation size from any national securities exchange or OTC market maker for any NMS security which is not a subject security with respect to such exchange or OTC market maker.

(5)(i) Entry of any priced order for an NMS security by an exchange market maker or OTC market maker in that security into an electronic communications network that widely disseminates such order shall be deemed to be:

(A) A bid or offer under this section, to be communicated to the market maker's exchange or association pursuant to this paragraph (b) for at least the minimum quotation size that is required by the rules of the market maker's exchange or association if the priced order is for the account of a market maker, or the actual size of the order up to the minimum quotation size required if the priced order is for the account of a customer; and 
(B) A communication of a bid or offer to a vendor for display on a display device for purposes of paragraph (b)(4) of this section.

(ii) An exchange market maker or OTC market maker that has entered a priced order for an NMS security into an electronic communications network that widely disseminates such order shall be deemed to be in compliance with paragraph (b)(5)(i)(A) of this section if the electronic communications network:

(A)(1) Provides to a national securities exchange or national securities association (or an exclusive processor acting on behalf of one or more exchanges or associations) the prices and sizes of the orders at the highest buy price and the lowest sell price for such security entered in, and widely disseminated by, the electronic communications network by exchange market makers and OTC market makers for the NMS security, and such prices and sizes are included in the quotation data made available by such exchange, association, or exclusive processor to vendors pursuant to this section; and

(2) Provides, to any broker or dealer, the ability to effect a transaction with a priced order widely disseminated by the electronic communications network entered therein by an exchange market maker or OTC market maker that is:

(i) Equivalent to the ability of any broker or dealer to effect a transaction with an exchange market maker or OTC market maker pursuant to the rules of the national securities exchange or national securities association to which the electronic communications network supplies such bids and offers; and

(ii) At the price of the highest priced buy order or lowest priced sell order, or better, for the lesser of the cumulative size of such priced orders entered therein by exchange market 
makers or OTC market makers at such price, or the size of the execution sought by the broker or dealer, for such security; or

(B) Is an alternative trading system that:

(1) Displays orders and provides the ability to effect transactions with such orders under $\S 242.301(\mathrm{~b})(3)$; and

(2) Otherwise is in compliance with Regulation ATS (§ 242.300 through $\S 242.303$ ).

(c) Transactions in listed options.

(1) A national securities exchange or national securities association:

(i) Shall not be required, under paragraph (a) of this section, to collect from responsible brokers or dealers who are members of such exchange or association, or to make available to vendors, the quotation sizes and aggregate quotation sizes for listed options, if such exchange or association establishes by rule and periodically publishes the quotation size for which such responsible brokers or dealers are obligated to execute an order to buy or sell an options series that is a subject security at its published bid or offer under paragraph (b)(2) of this section;

(ii) May establish by rule and periodically publish a quotation size, which shall not be for less than one contract, for which responsible brokers or dealers who are members of such exchange or association are obligated under paragraph (b)(2) of this section to execute an order to buy or sell a listed option for the account of a broker or dealer that is in an amount different from the quotation size for which it is obligated to execute an order for the account of a customer; and

(iii) May establish and maintain procedures and mechanisms for collecting from responsible brokers and dealers who are members of such exchange or association, and making 
available to vendors, the quotation sizes and aggregate quotation sizes in listed options for which such responsible broker or dealer will be obligated under paragraph (b)(2) of this section to execute an order from a customer to buy or sell a listed option and establish by rule and periodically publish the size, which shall not be less than one contract, for which such responsible brokers or dealers are obligated to execute an order for the account of a broker or dealer.

(2) If, pursuant to paragraph (c)(1) of this section, the rules of a national securities exchange or national securities association do not require its members to communicate to it their quotation sizes for listed options, a responsible broker or dealer that is a member of such exchange or association shall:

(i) Be relieved of its obligations under paragraph (b)(1) of this section to communicate to such exchange or association its quotation sizes for any listed option; and

(ii) Comply with its obligations under paragraph (b)(2) of this section by executing any order to buy or sell a listed option, in an amount up to the size established by such exchange's or association's rules under paragraph (c)(1) of this section.

(3) Thirty second response. Each responsible broker or dealer, within thirty seconds of receiving an order to buy or sell a listed option in an amount greater than the quotation size established by a national securities exchange's or national securities association's rules pursuant to paragraph (c)(1) of this section, or its published quotation size must:

(i) Execute the entire order; or

(ii)(A) Execute that portion of the order equal to at least:

(1) The quotation size established by a national securities exchange's or national securities association's rules, pursuant to paragraph (c)(1) of this section, to the extent that such 
exchange or association does not collect and make available to vendors quotation size and aggregate quotation size under paragraph (a) of this section; or

(2) Its published quotation size; and

(B) Revise its bid or offer.

(4) Notwithstanding paragraph (c)(3) of this section, no responsible broker or dealer shall be obligated to execute a transaction for any listed option as provided in paragraph (b)(2) of this section if:

(i) Any of the circumstances in paragraph (b)(3) of this section exist; or

(ii) The order for the purchase or sale of a listed option is presented during a trading rotation in that listed option.

(d) Exemptions. The Commission may exempt from the provisions of this section, either unconditionally or on specified terms and conditions, any responsible broker or dealer, electronic communications network, national securities exchange, or national securities association if the Commission determines that such exemption is consistent with the public interest, the protection of investors and the removal of impediments to and perfection of the mechanism of a national market system.

\section{§ 242.603 Distribution, consolidation, and display of information with respect to quotations for and transactions in NMS stocks.}

(a) Distribution of information.

(1) Any exclusive processor, or any broker or dealer with respect to information for which it is the exclusive source, that distributes information with respect to quotations for or transactions in an NMS stock to a securities information processor shall do so on terms that are fair and reasonable. 
(2) Any national securities exchange, national securities association, broker, or dealer that distributes information with respect to quotations for or transactions in an NMS stock to a securities information processor, broker, dealer, or other persons shall do so on terms that are not unreasonably discriminatory.

(b) Consolidation of information. Every national securities exchange on which an NMS stock is traded and national securities association shall act jointly pursuant to one or more effective national market system plans to disseminate consolidated information, including a national best bid and national best offer, on quotations for and transactions in NMS stocks. Such plan or plans shall provide for the dissemination of all consolidated information for an individual NMS stock through a single plan processor.

(c) Display of information.

(1) No securities information processor, broker, or dealer shall provide, in a context in which a trading or order-routing decision can be implemented, a display of any information with respect to quotations for or transactions in an NMS stock without also providing, in an equivalent manner, a consolidated display for such stock.

(2) The provisions of paragraph (c)(1) of this section shall not apply to a display of information on the trading floor or through the facilities of a national securities exchange or to a display in connection with the operation of a market linkage system implemented in accordance with an effective national market system plan.

(d) Exemptions. The Commission, by order, may exempt from the provisions of this section, either unconditionally or on specified terms and conditions, any person, security, or item of information, or any class or classes of persons, securities, or items of information, if the 
Commission determines that such exemption is necessary or appropriate in the public interest, and is consistent with the protection of investors.

\section{§ 242.604 Display of customer limit orders.}

(a) Specialists and OTC market makers. For all NMS stocks:

(1) Each member of a national securities exchange that is registered by that exchange as a specialist, or is authorized by that exchange to perform functions substantially similar to that of a specialist, shall publish immediately a bid or offer that reflects:

(i) The price and the full size of each customer limit order held by the specialist that is at a price that would improve the bid or offer of such specialist in such security; and

(ii) The full size of each customer limit order held by the specialist that:

(A) Is priced equal to the bid or offer of such specialist for such security;

(B) Is priced equal to the national best bid or national best offer; and

(C) Represents more than a de minimis change in relation to the size associated with the specialist's bid or offer.

(2) Each registered broker or dealer that acts as an OTC market maker shall publish immediately a bid or offer that reflects:

(i) The price and the full size of each customer limit order held by the OTC market maker that is at a price that would improve the bid or offer of such OTC market maker in such security; and

(ii) The full size of each customer limit order held by the OTC market maker that:

(A) Is priced equal to the bid or offer of such OTC market maker for such security;

(B) Is priced equal to the national best bid or national best offer; and 
(C) Represents more than a de minimis change in relation to the size associated with the OTC market maker's bid or offer.

(b) Exceptions. The requirements in paragraph (a) of this section shall not apply to any customer limit order:

(1) That is executed upon receipt of the order.

(2) That is placed by a customer who expressly requests, either at the time that the order is placed or prior thereto pursuant to an individually negotiated agreement with respect to such customer's orders, that the order not be displayed.

(3) That is an odd-lot order.

(4) That is a block size order, unless a customer placing such order requests that the order be displayed.

(5) That is delivered immediately upon receipt to a national securities exchange or national securities association-sponsored system, or an electronic communications network that complies with the requirements of $\S 242.602$ (b)(5)(ii) with respect to that order.

(6) That is delivered immediately upon receipt to another exchange member or OTC market maker that complies with the requirements of this section with respect to that order.

(7) That is an "all or none" order.

(c) Exemptions. The Commission may exempt from the provisions of this section, either unconditionally or on specified terms and conditions, any responsible broker or dealer, electronic communications network, national securities exchange, or national securities association if the Commission determines that such exemption is consistent with the public interest, the protection of investors and the removal of impediments to and perfection of the mechanism of a national market system. 


\section{§ 242.605 Disclosure of order execution information.}

Preliminary Note: Section 242.605 requires market centers to make available standardized, monthly reports of statistical information concerning their order executions. This information is presented in accordance with uniform standards that are based on broad assumptions about order execution and routing practices. The information will provide a starting point to promote visibility and competition on the part of market centers and broker-dealers, particularly on the factors of execution price and speed. The disclosures required by this section do not encompass all of the factors that may be important to investors in evaluating the order routing services of a broker-dealer. In addition, any particular market center's statistics will encompass varying types of orders routed by different broker-dealers on behalf of customers with a wide range of objectives. Accordingly, the statistical information required by this section alone does not create a reliable basis to address whether any particular broker-dealer failed to obtain the most favorable terms reasonably available under the circumstances for customer orders.

(a) Monthly electronic reports by market centers.

(1) Every market center shall make available for each calendar month, in accordance with the procedures established pursuant to paragraph (a)(2) of this section, a report on the covered orders in NMS stocks that it received for execution from any person. Such report shall be in electronic form; shall be categorized by security, order type, and order size; and shall include the following columns of information:

(i) For market orders, marketable limit orders, inside-the-quote limit orders, at-thequote limit orders, and near-the-quote limit orders:

(A) The number of covered orders; 
(B) The cumulative number of shares of covered orders;

(C) The cumulative number of shares of covered orders cancelled prior to execution;

(D) The cumulative number of shares of covered orders executed at the receiving market center;

(E) The cumulative number of shares of covered orders executed at any other venue;

(F) The cumulative number of shares of covered orders executed from 0 to 9 seconds after the time of order receipt;

(G) The cumulative number of shares of covered orders executed from 10 to 29 seconds after the time of order receipt;

(H) The cumulative number of shares of covered orders executed from 30 seconds to 59 seconds after the time of order receipt;

(I) The cumulative number of shares of covered orders executed from 60 seconds to 299 seconds after the time of order receipt;

(J) The cumulative number of shares of covered orders executed from 5 minutes to 30 minutes after the time of order receipt; and

(K) The average realized spread for executions of covered orders; and

(ii) For market orders and marketable limit orders:

(A) The average effective spread for executions of covered orders;

(B) The cumulative number of shares of covered orders executed with price improvement;

(C) For shares executed with price improvement, the share-weighted average amount per share that prices were improved; 
(D) For shares executed with price improvement, the share-weighted average period from the time of order receipt to the time of order execution;

(E) The cumulative number of shares of covered orders executed at the quote;

(F) For shares executed at the quote, the share-weighted average period from the time of order receipt to the time of order execution;

(G) The cumulative number of shares of covered orders executed outside the quote;

(H) For shares executed outside the quote, the share-weighted average amount per share that prices were outside the quote; and

(I) For shares executed outside the quote, the share-weighted average period from the time of order receipt to the time of order execution.

(2) Every national securities exchange on which NMS stocks are traded and each national securities association shall act jointly in establishing procedures for market centers to follow in making available to the public the reports required by paragraph (a)(1) of this section in a uniform, readily accessible, and usable electronic form. In the event there is no effective national market system plan establishing such procedures, market centers shall prepare their reports in a consistent, usable, and machine-readable electronic format, and make such reports available for downloading from an Internet Web site that is free and readily accessible to the public.

(3) A market center shall make available the report required by paragraph (a)(1) of this section within one month after the end of the month addressed in the report.

(b) Exemptions. The Commission may, by order upon application, conditionally or unconditionally exempt any person, security, or transaction, or any class or classes of persons, securities, or transactions, from any provision or provisions of this section, if the Commission 
determines that such exemption is necessary or appropriate in the public interest, and is consistent with the protection of investors.

\section{$\S$ 242.606 Disclosure of order routing information.}

(a) Quarterly report on order routing.

(1) Every broker or dealer shall make publicly available for each calendar quarter a report on its routing of non-directed orders in NMS securities during that quarter. For NMS stocks, such report shall be divided into three separate sections for securities that are listed on the New York Stock Exchange, Inc., securities that are qualified for inclusion in The Nasdaq Stock Market, Inc., and securities that are listed on the American Stock Exchange LLC or any other national securities exchange. Such report also shall include a separate section for NMS securities that are option contracts. Each of the four sections in a report shall include the following information:

(i) The percentage of total customer orders for the section that were non-directed orders, and the percentages of total non-directed orders for the section that were market orders, limit orders, and other orders;

(ii) The identity of the ten venues to which the largest number of total non-directed orders for the section were routed for execution and of any venue to which five percent or more of non-directed orders were routed for execution, the percentage of total non-directed orders for the section routed to the venue, and the percentages of total non-directed market orders, total non-directed limit orders, and total non-directed other orders for the section that were routed to the venue; and 
(iii) A discussion of the material aspects of the broker's or dealer's relationship with each venue identified pursuant to paragraph (a)(1)(ii) of this section, including a description of any arrangement for payment for order flow and any profit-sharing relationship.

(2) A broker or dealer shall make the report required by paragraph (a)(1) of this section publicly available within one month after the end of the quarter addressed in the report.

(b) Customer requests for information on order routing.

(1) Every broker or dealer shall, on request of a customer, disclose to its customer the identity of the venue to which the customer's orders were routed for execution in the six months prior to the request, whether the orders were directed orders or non-directed orders, and the time of the transactions, if any, that resulted from such orders.

(2) A broker or dealer shall notify customers in writing at least annually of the availability on request of the information specified in paragraph (b)(1) of this section.

(c) Exemptions. The Commission may, by order upon application, conditionally or unconditionally exempt any person, security, or transaction, or any class or classes of persons, securities, or transactions, from any provision or provisions of this section, if the Commission determines that such exemption is necessary or appropriate in the public interest, and is consistent with the protection of investors.

\section{$\S$ 242.607 Customer account statements.}

(a) No broker or dealer acting as agent for a customer may effect any transaction in, induce or attempt to induce the purchase or sale of, or direct orders for purchase or sale of, any NMS stock or a security authorized for quotation on an automated inter-dealer quotation system that has the characteristics set forth in section 17B of the Act (15 U.S.C. 78q-2), unless such 
broker or dealer informs such customer, in writing, upon opening a new account and on an annual basis thereafter, of the following:

(1) The broker's or dealer's policies regarding receipt of payment for order flow from any broker or dealer, national securities exchange, national securities association, or exchange member to which it routes customers' orders for execution, including a statement as to whether any payment for order flow is received for routing customer orders and a detailed description of the nature of the compensation received; and

(2) The broker's or dealer's policies for determining where to route customer orders that are the subject of payment for order flow absent specific instructions from customers, including a description of the extent to which orders can be executed at prices superior to the national best bid and national best offer.

(b) Exemptions. The Commission, upon request or upon its own motion, may exempt by rule or by order, any broker or dealer or any class of brokers or dealers, security or class of securities from the requirements of paragraph (a) of this section with respect to any transaction or class of transactions, either unconditionally or on specified terms and conditions, if the Commission determines that such exemption is consistent with the pubic interest and the protection of investors.

\section{$\S 242.608$ Filing and amendment of national market system plans.}

(a) Filing of national market system plans and amendments thereto.

(1) Any two or more self-regulatory organizations, acting jointly, may file a national market system plan or may propose an amendment to an effective national market system plan ("proposed amendment") by submitting the text of the plan or amendment to the Secretary of the Commission, together with a statement of the purpose of such plan or amendment and, to the 
extent applicable, the documents and information required by paragraphs (a)(4) and (5) of this section.

(2) The Commission may propose amendments to any effective national market system plan by publishing the text thereof, together with a statement of the purpose of such amendment, in accordance with the provisions of paragraph (b) of this section.

(3) Self-regulatory organizations are authorized to act jointly in:

(i) Planning, developing, and operating any national market subsystem or facility contemplated by a national market system plan;

(ii) Preparing and filing a national market system plan or any amendment thereto; or

(iii) Implementing or administering an effective national market system plan.

(4) Every national market system plan filed pursuant to this section, or any amendment thereto, shall be accompanied by:

(i) Copies of all governing or constituent documents relating to any person (other than a self-regulatory organization) authorized to implement or administer such plan on behalf of its sponsors; and

(ii) To the extent applicable:

(A) A detailed description of the manner in which the plan or amendment, and any facility or procedure contemplated by the plan or amendment, will be implemented;

(B) A listing of all significant phases of development and implementation (including any pilot phase) contemplated by the plan or amendment, together with the projected date of completion of each phase;

(C) An analysis of the impact on competition of implementation of the plan or amendment or of any facility contemplated by the plan or amendment; 
(D) A description of any written understandings or agreements between or among plan sponsors or participants relating to interpretations of the plan or conditions for becoming a sponsor or participant in the plan; and

(E) In the case of a proposed amendment, a statement that such amendment has been approved by the sponsors in accordance with the terms of the plan.

(5) Every national market system plan, or any amendment thereto, filed pursuant to this section shall include a description of the manner in which any facility contemplated by the plan or amendment will be operated. Such description shall include, to the extent applicable:

(i) The terms and conditions under which brokers, dealers, and/or self-regulatory organizations will be granted or denied access (including specific procedures and standards governing the granting or denial of access);

(ii) The method by which any fees or charges collected on behalf of all of the sponsors and/or participants in connection with access to, or use of, any facility contemplated by the plan or amendment will be determined and imposed (including any provision for distribution of any net proceeds from such fees or charges to the sponsors and/or participants) and the amount of such fees or charges;

(iii) The method by which, and the frequency with which, the performance of any person acting as plan processor with respect to the implementation and/or operation of the plan will be evaluated; and

(iv) The method by which disputes arising in connection with the operation of the plan will be resolved.

(6) In connection with the selection of any person to act as plan processor with respect to any facility contemplated by a national market system plan (including renewal of any 
contract for any person to so act), the sponsors shall file with the Commission a statement identifying the person selected, describing the material terms under which such person is to serve as plan processor, and indicating the solicitation efforts, if any, for alternative plan processors, the alternatives considered and the reasons for selection of such person.

(7) Any national market system plan (or any amendment thereto) which is intended by the sponsors to satisfy a plan filing requirement contained in any other section of this Regulation NMS and part 240, subpart A of this chapter shall, in addition to compliance with this section, also comply with the requirements of such other section.

(b) Effectiveness of national market system plans.

(1) The Commission shall publish notice of the filing of any national market system plan, or any proposed amendment to any effective national market system plan (including any amendment initiated by the Commission), together with the terms of substance of the filing or a description of the subjects and issues involved, and shall provide interested persons an opportunity to submit written comments. No national market system plan, or any amendment thereto, shall become effective unless approved by the Commission or otherwise permitted in accordance with paragraph (b)(3) of this section.

(2) Within 120 days of the date of publication of notice of filing of a national market system plan or an amendment to an effective national market system plan, or within such longer period as the Commission may designate up to 180 days of such date if it finds such longer period to be appropriate and publishes its reasons for so finding or as to which the sponsors consent, the Commission shall approve such plan or amendment, with such changes or subject to such conditions as the Commission may deem necessary or appropriate, if it finds that such plan or amendment is necessary or appropriate in the public interest, for the protection of investors 
and the maintenance of fair and orderly markets, to remove impediments to, and perfect the mechanisms of, a national market system, or otherwise in furtherance of the purposes of the Act. Approval of a national market system plan, or an amendment to an effective national market system plan (other than an amendment initiated by the Commission), shall be by order. Promulgation of an amendment to an effective national market system plan initiated by the Commission shall be by rule.

(3) A proposed amendment may be put into effect upon filing with the Commission if designated by the sponsors as:

(i) Establishing or changing a fee or other charge collected on behalf of all of the sponsors and/or participants in connection with access to, or use of, any facility contemplated by the plan or amendment (including changes in any provision with respect to distribution of any net proceeds from such fees or other charges to the sponsors and/or participants);

(ii) Concerned solely with the administration of the plan, or involving the governing or constituent documents relating to any person (other than a self-regulatory organization) authorized to implement or administer such plan on behalf of its sponsors; or

(iii) Involving solely technical or ministerial matters. At any time within 60 days of the filing of any such amendment, the Commission may summarily abrogate the amendment and require that such amendment be refiled in accordance with paragraph (a)(1) of this section and reviewed in accordance with paragraph (b)(2) of this section, if it appears to the Commission that such action is necessary or appropriate in the public interest, for the protection of investors, or the maintenance of fair and orderly markets, to remove impediments to, and perfect the mechanisms of, a national market system or otherwise in furtherance of the purposes of the Act. 
(4) Notwithstanding the provisions of paragraph (b)(1) of this section, a proposed amendment may be put into effect summarily upon publication of notice of such amendment, on a temporary basis not to exceed 120 days, if the Commission finds that such action is necessary or appropriate in the public interest, for the protection of investors or the maintenance of fair and orderly markets, to remove impediments to, and perfect the mechanisms of, a national market system or otherwise in furtherance of the purposes of the Act.

(5) Any plan (or amendment thereto) in connection with:

(i) The planning, development, operation, or regulation of a national market system (or a subsystem thereof) or one or more facilities thereof; or

(ii) The development and implementation of procedures and/or facilities designed to achieve compliance by self-regulatory organizations and/or their members of any section of this Regulation NMS and part 240, subpart A of this chapter promulgated pursuant to section 11A of the Act (15 U.S.C. 78k-1), approved by the Commission pursuant to section 11A of the Act (or pursuant to any rule or regulation thereunder) prior to the effective date of this section (either temporarily or permanently) shall be deemed to have been filed and approved pursuant to this section and no additional filing need be made by the sponsors with respect to such plan or amendment; provided, however, that all terms and conditions associated with any such approval (including time limitations) shall continue to be applicable; provided, further, that any amendment to such plan filed with or approved by the Commission on or after the effective date of this section shall be subject to the provisions of, and considered in accordance with the procedures specified in, this section.

(c) Compliance with terms of national market system plans. Each self-regulatory organization shall comply with the terms of any effective national market system plan of which it 
is a sponsor or a participant. Each self-regulatory organization also shall, absent reasonable justification or excuse, enforce compliance with any such plan by its members and persons associated with its members.

(d) Appeals. The Commission may, in its discretion, entertain appeals in connection with the implementation or operation of any effective national market system plan as follows:

(1) Any action taken or failure to act by any person in connection with an effective national market system plan (other than a prohibition or limitation of access reviewable by the Commission pursuant to section 11A(b)(5) or section 19(d) of the Act (15 U.S.C. 78k-1(b)(5) or 78s(d))) shall be subject to review by the Commission, on its own motion or upon application by any person aggrieved thereby (including, but not limited to, self-regulatory organizations, brokers, dealers, issuers, and vendors), filed not later than 30 days after notice of such action or failure to act or within such longer period as the Commission may determine.

(2) Application to the Commission for review, or the institution of review by the Commission on its own motion, shall not operate as a stay of any such action unless the Commission determines otherwise, after notice and opportunity for hearing on the question of a stay (which hearing may consist only of affidavits or oral arguments).

(3) In any proceedings for review, if the Commission, after appropriate notice and opportunity for hearing (which hearing may consist solely of consideration of the record of any proceedings conducted in connection with such action or failure to act and an opportunity for the presentation of reasons supporting or opposing such action or failure to act) and upon consideration of such other data, views, and arguments as it deems relevant, finds that the action or failure to act is in accordance with the applicable provisions of such plan and that the applicable provisions are, and were, applied in a manner consistent with the public interest, the 
protection of investors, the maintenance of fair and orderly markets, and the removal of impediments to, and the perfection of the mechanisms of a national market system, the Commission, by order, shall dismiss the proceeding. If the Commission does not make any such finding, or if it finds that such action or failure to act imposes any burden on competition not necessary or appropriate in furtherance of the purposes of the Act, the Commission, by order, shall set aside such action and/or require such action with respect to the matter reviewed as the Commission deems necessary or appropriate in the public interest, for the protection of investors, and the maintenance of fair and orderly markets, or to remove impediments to, and perfect the mechanisms of, a national market system.

(e) Exemptions. The Commission may exempt from the provisions of this section, either unconditionally or on specified terms and conditions, any self-regulatory organization, member thereof, or specified security, if the Commission determines that such exemption is consistent with the public interest, the protection of investors, the maintenance of fair and orderly markets and the removal of impediments to, and perfection of the mechanisms of, a national market system.

\section{$\S$ 242.609 Registration of securities information processors: form of application and amendments.}

(a) An application for the registration of a securities information processor shall be filed on Form SIP (§ 249.1001 of this chapter) in accordance with the instructions contained therein.

(b) If any information reported in items 1-13 or item 21 of Form SIP or in any amendment thereto is or becomes inaccurate for any reason, whether before or after the 
registration has been granted, the securities information processor shall promptly file an amendment on Form SIP correcting such information.

(c) The Commission, upon its own motion or upon application by any securities information processor, may conditionally or unconditionally exempt any securities information processor from any provision of the rules or regulations adopted under section $11 \mathrm{~A}(\mathrm{~b})$ of the Act (15 U.S.C. 78k-1(b)).

(d) Every amendment filed pursuant to this section shall constitute a "report" within the meaning of sections 17(a), 18(a) and 32(a) of the Act (15 U.S.C. 78q(a), 78r(a), and 78ff(a)).

\section{$\S 242.610$ Access to quotations.}

(a) Quotations of SRO trading facility. A national securities exchange or national securities association shall not impose unfairly discriminatory terms that prevent or inhibit any person from obtaining efficient access through a member of the national securities exchange or national securities association to the quotations in an NMS stock displayed through its SRO trading facility.

(b) Quotations of SRO display-only facility.

(1) Any trading center that displays quotations in an NMS stock through an SRO display-only facility shall provide a level and cost of access to such quotations that is substantially equivalent to the level and cost of access to quotations displayed by SRO trading facilities in that stock.

(2) Any trading center that displays quotations in an NMS stock through an SRO display-only facility shall not impose unfairly discriminatory terms that prevent or inhibit any person from obtaining efficient access to such quotations through a member, subscriber, or customer of the trading center. 
(c) Fees for access to quotations. A trading center shall not impose, nor permit to be imposed, any fee or fees for the execution of an order against a protected quotation of the trading center or against any other quotation of the trading center that is the best bid or best offer of a national securities exchange, the best bid or best offer of The Nasdaq Stock Market, Inc., or the best bid or best offer of a national securities association other than the best bid or best offer of The Nasdaq Stock Market, Inc. in an NMS stock that exceed or accumulate to more than the following limits:

(1) If the price of a protected quotation or other quotation is $\$ 1.00$ or more, the fee or fees cannot exceed or accumulate to more than $\$ 0.003$ per share; or

(2) If the price of a protected quotation or other quotation is less than $\$ 1.00$, the fee or fees cannot exceed or accumulate to more than $0.3 \%$ of the quotation price per share.

(d) Locking or crossing quotations. Each national securities exchange and national securities association shall establish, maintain, and enforce written rules that:

(1) Require its members reasonably to avoid:

(i) Displaying quotations that lock or cross any protected quotation in an NMS stock; and

(ii) Displaying manual quotations that lock or cross any quotation in an NMS stock disseminated pursuant to an effective national market system plan;

(2) Are reasonably designed to assure the reconciliation of locked or crossed quotations in an NMS stock; and

(3) Prohibit its members from engaging in a pattern or practice of displaying quotations that lock or cross any protected quotation in an NMS stock, or of displaying manual quotations that lock or cross any quotation in an NMS stock disseminated pursuant to an 
effective national market system plan, other than displaying quotations that lock or cross any protected or other quotation as permitted by an exception contained in its rules established pursuant to paragraph (d)(1) of this section.

(e) Exemptions. The Commission, by order, may exempt from the provisions of this section, either unconditionally or on specified terms and conditions, any person, security, quotations, orders, or fees, or any class or classes of persons, securities, quotations, orders, or fees, if the Commission determines that such exemption is necessary or appropriate in the public interest, and is consistent with the protection of investors.

\section{§ 242.611 Order protection rule.}

(a) Reasonable policies and procedures.

(1) A trading center shall establish, maintain, and enforce written policies and procedures that are reasonably designed to prevent trade-throughs on that trading center of protected quotations in NMS stocks that do not fall within an exception set forth in paragraph (b) of this section and, if relying on such an exception, that are reasonably designed to assure compliance with the terms of the exception.

(2) A trading center shall regularly surveil to ascertain the effectiveness of the policies and procedures required by paragraph (a)(1) of this section and shall take prompt action to remedy deficiencies in such policies and procedures.

(b) Exceptions.

(1) The transaction that constituted the trade-through was effected when the trading center displaying the protected quotation that was traded through was experiencing a failure, material delay, or malfunction of its systems or equipment. 
(2) The transaction that constituted the trade-through was not a "regular way" contract.

(3) The transaction that constituted the trade-through was a single-priced opening, reopening, or closing transaction by the trading center.

(4) The transaction that constituted the trade-through was executed at a time when a protected bid was priced higher than a protected offer in the NMS stock.

(5) The transaction that constituted the trade-through was the execution of an order identified as an intermarket sweep order.

(6) The transaction that constituted the trade-through was effected by a trading center that simultaneously routed an intermarket sweep order to execute against the full displayed size of any protected quotation in the NMS stock that was traded through.

(7) The transaction that constituted the trade-through was the execution of an order at a price that was not based, directly or indirectly, on the quoted price of the NMS stock at the time of execution and for which the material terms were not reasonably determinable at the time the commitment to execute the order was made.

(8) The trading center displaying the protected quotation that was traded through had displayed, within one second prior to execution of the transaction that constituted the tradethrough, a best bid or best offer, as applicable, for the NMS stock with a price that was equal or inferior to the price of the trade-through transaction.

(9) The transaction that constituted the trade-through was the execution by a trading center of an order for which, at the time of receipt of the order, the trading center had guaranteed an execution at no worse than a specified price (a "stopped order"), where:

(i) The stopped order was for the account of a customer; 
(ii) The customer agreed to the specified price on an order-by-order basis; and

(iii) The price of the trade-through transaction was, for a stopped buy order, lower than the national best bid in the NMS stock at the time of execution or, for a stopped sell order, higher than the national best offer in the NMS stock at the time of execution.

(c) Intermarket sweep orders. The trading center, broker, or dealer responsible for the routing of an intermarket sweep order shall take reasonable steps to establish that such order meets the requirements set forth in $\S 242.600(b)(30)$.

(d) Exemptions. The Commission, by order, may exempt from the provisions of this section, either unconditionally or on specified terms and conditions, any person, security, transaction, quotation, or order, or any class or classes of persons, securities, quotations, or orders, if the Commission determines that such exemption is necessary or appropriate in the public interest, and is consistent with the protection of investors.

\section{§ 242.612 Minimum pricing increment.}

(a) No national securities exchange, national securities association, alternative trading system, vendor, or broker or dealer shall display, rank, or accept from any person a bid or offer, an order, or an indication of interest in any NMS stock priced in an increment smaller than $\$ 0.01$ if that bid or offer, order, or indication of interest is priced equal to or greater than $\$ 1.00$ per share.

(b) No national securities exchange, national securities association, alternative trading system, vendor, or broker or dealer shall display, rank, or accept from any person a bid or offer, an order, or an indication of interest in any NMS stock priced in an increment smaller than $\$ 0.0001$ if that bid or offer, order, or indication of interest is priced less than $\$ 1.00$ per share. 
(c) The Commission, by order, may exempt from the provisions of this section, either unconditionally or on specified terms and conditions, any person, security, quotation, or order, or any class or classes of persons, securities, quotations, or orders, if the Commission determines that such exemption is necessary or appropriate in the public interest, and is consistent with the protection of investors.

\section{PART 249—FORMS, SECURITIES EXCHANGE ACT OF 1934}

31. The authority citation for part 249 continues to read in part as follows:

Authority: 15 U.S.C. 78 a et seq. and 7201 et seq.; and 18 U.S.C. 1350, unless otherwise noted.

32. Section 249.1001 is revised to read as follows:

\section{$\S$ 249.1001 Form SIP, for application for registration as a securities information processor or to amend such an application or registration.}

This form shall be used for application for registration as a securities information processor, pursuant to section 11A(b) of the Securities Exchange Act of 1934 (15 U.S.C. 78k1(b)) and $\S 242.609$ of this chapter, or to amend such an application or registration.

33. Form SIP (referenced in $\S 249.1001$ ) is amended by revising Instruction 6 of General Instructions for Preparing and Filing Form SIP to read as follows:

Note: The text of Form SIP does not and this amendment will not appear in the Code of Federal Regulations.

\section{FORM SIP}




\section{GENERAL INSTRUCTIONS FOR PREPARING AND FILING FORM SIP}

6. Rule 609(b) of Regulation NMS requires that if any information contained in items 1 through 13 or item 21 of this application, or any supplement or amendment thereto, is or becomes inaccurate for any reason, an amendment must be filed promptly on Form SIP correcting such information.

\section{PART 270 -- RULES AND REGULATIONS, INVESTMENT COMPANY ACT OF}

1940

34. The authority citation for part 270 continues to read in part as follows:

Authority: 15 U.S.C. 80a-1 et seq., 80a-34(d), 80a-37, and 80a-39, unless otherwise noted.

35. Section 270.17a-7 is amended by revising paragraph (b)(1) to read as follows: $\S$ 270.17a-7 Exemption of certain purchase or sale transactions between an investment company and certain affiliated persons thereof.

(b) $* * *$

(1) If the security is an "NMS stock" as that term is defined in 17 CFR 242.600, the last sale price with respect to such security reported in the consolidated transaction reporting system ("consolidated system") or the average of the highest current independent bid and lowest 
current independent offer for such security (reported pursuant to 17 CFR 242.602) if there are no reported transactions in the consolidated system that day; or

By the Commission.

Margaret H. McFarland

Deputy Secretary

Dated: June 9, 2005 